\author{
UNIVERSIDADE DE SÃO PAULO \\ ESCOLA DE ENGENHARIA DE SÃO CARLOS \\ DEPARTAMENTO DE ENGENHARIA DE ESTRUTURAS
}

VINICIUS SLOMPO PINTO

Dimensionamento de pilares de concreto com seção transversal retangular usando envoltórias de momentos 

VINICIUS SLOMPO PINTO

\title{
Dimensionamento de pilares de concreto com seção transversal retangular usando envoltórias de momentos
}

\author{
VERSÃO CORRIGIDA
}

A versão original encontra-se na Escola de Engenharia de São Carlos

Dissertação apresentada ao Departamento de Engenharia de Estruturas da Escola de Engenharia de São Carlos, Universidade de São Paulo, como parte dos quesitos necessários para obtenção do título de Mestre em Engenharia Civil (Estruturas).

Orientador: Prof. Dr. Libânio Miranda Pinheiro

SÃO CARLOS 
AUTORIZO A REPRODUÇÃO TOTAL OU PARCIAL DESTE TRABALHO, POR QUALQUER MEIO CONVENCIONAL OU ELETRÔNICO, PARA FINS DE ESTUDO E PESQUISA, DESDE QUE CITADA A FONTE.

P659d transversal retangular usando envoltórias de momentos
/ Vinicius Slompo Pinto; orientador Libânio Miranda

Pinheiro. São Carlos, 2017.

Dissertação (Mestrado) - Programa de Pós-Graduação em Engenharia Civil(Engenharia de Estruturas) e Área de Concentração em Estruturas - - Escola de Engenharia de São Carlos da Universidade de São Paulo, 2017.

1. Pilares de concreto. 2. Dimensionamento. 3. Flexão composta oblíqua. 4. Envoltórias de momentos. 5. Não linearidades. I. Título. 


\section{POLHA DE JULGAMENTO}

Candidato: Engenheiro VINICIUS SLOMPO PINTO.

Título da dissertação: "Dimensionamento de pilares de concreto com seção transversal retangular usando envoltórias de momentos".

Data da defesa: 29/05/2017.

Comissão Julgadora:

Resultado:

Prof. Dr. Libânio Miranda Pinheiro (Orientador)

APROVADO

(Escola de Engenharia de São Carlos/EESC)

Prof. Dr. Paulo Sérgio dos Santos Basios

Aprovado

(Universidade Estadual Paulista "Júlio de Mesquita Filho"/(UNESP - Bauru)

Prof. Dr. Roberto Chust Carvalho

(Universidade Federal de São Carlos/UFSCar - São Carlos)

Coordenador do Programa de Pós-Graduação em Engenheira Civil (Engenharia de Estruturas):

Prof. Titular Humberio Breves Coda

Presidente da Comissão de Pós-Graduação:

Prof. Associado Luís Fernando Cosła Alberło 

Aos meus pais, João e Isabel, e à minha família, dedico este trabalho. 



\section{AGRADECIMENTOS}

A Deus por ter me dado sabedoria, oportunidade e perseverança para que pudesse realizar este trabalho.

À Universidade de São Paulo por ter me formado Engenheiro Civil e por ter me oferecido a oportunidade de ampliar meus conhecimentos.

Ao prof. Libânio Miranda Pinheiro pela ótima orientação, dedicação, compreensão, respeito, amizade e confiança depositada em mim desde a graduação até o fim do mestrado.

Aos meus pais, João Luís Pinto e Isabel Cristina Slompo Pinto, pelo incentivo ao estudo, trabalho, esforço, preocupação, suporte emocional e financeiro e, por fim, pelo mais importante, o amor.

À minha namorada Ana Maria Marson Bonatti pelo apoio para que realizasse o mestrado, amor, carinho, e acima de tudo preocupação e paciência.

Às amigas do Departamento: Karolinne Coelho, Mariana Posterlli, Mariana Paiva, Marina Graci e Margot Pereira e a todos os outros que me deram apoio em vários momentos durante o mestrado.

Ao Departamento de Engenharia de Estruturas da Escola de Engenharia de São Carlos pela infraestrutura disponibilizada para a realização do mestrado.

Aos funcionários e professores do Departamento de Engenharia de Estruturas, em especial ao Dorival Piedade Neto, que me ensinou a linguagem Python, e ao Francisco Carlos Guete de Brito, pelo auxílio com algumas figuras.

Aos meus amigos Marcelo Monari e Renan Victor Donalonso Siqueira pelo companheirismo, apoio e amizade enquanto morávamos juntos.

Aos meus amigos de Bariri que me ajudaram nos momentos de lazer e descontração, em especial ao meu amigo João Pedro Bricce pela tradução do Abstract.

À Coordenação de Aperfeiçoamento de Pessoal de Nível Superior - CAPES pela bolsa de estudo concedida. 



\section{RESUMO}

PINTO, V. S. Dimensionamento de pilares de concreto com seção transversal retangular usando envoltórias de momentos. 2017. 312 p. Dissertação (Mestrado em Engenharia Civil (Estruturas)) - Escola de Engenharia de São Carlos, Universidade de São Paulo, São Carlos, 2017.

A ABNT NBR 6118:2014 - Projeto de Estruturas de Concreto apresenta quatro métodos para dimensionamento de pilares, sendo necessário o uso de envoltórias de momentos quando houver flexão composta oblíqua. Devido à complexidade, não se considera de forma adequada a não linearidade física, a verificação de flexão composta oblíqua e as imperfeições geométricas locais. Este trabalho apresenta diretrizes para o dimensionamento de pilares retangulares de concreto com armadura simétrica, submetidos à flexão composta oblíqua, empregando-se as envoltórias mínimas e resistentes para verificação da armadura. São feitas análises de como as não linearidades influem no estado-limite último de instabilidade e como elas devem ser consideradas nos métodos de dimensionamento. São indicadas duas situações que podem ser críticas para o pré-dimensionamento. São elaborados roteiros para determinação das envoltórias solicitantes, para cada método de dimensionamento, e das envoltórias resistentes, por meio do cálculo direto ou com o uso de ábacos para flexão composta normal. Há, também, dois apêndices, um sobre a determinação dos diagramas momento fletor - força normal - curvatura para qualquer tipo de seção, e outro sobre obtenção dos diagramas de interação $\left(N_{u}, M_{u}\right)$, construção de ábacos para flexão composta normal e definição da taxa mecânica de armadura $\omega$, sem o uso de ábacos para concretos de classe até C50. Concluindo, este trabalho constitui uma bibliografia atualizada para o projeto de pilares seguros e economicamente viáveis, esclarecendo conceitos tais como momento fletor resistente, envoltórias solicitantes e resistentes e utilização das não linearidades nos métodos de dimensionamento.

Palavras-chave: Pilares de concreto. Dimensionamento. Flexão composta oblíqua. Envoltórias de momentos. Não linearidades. 



\section{ABSTRACT}

PINTO, V. S. Concrete columns design with rectangular cross section using envelopment of moments. 2017. 312 p. Dissertation (M. Sc. in Civil Engineering (Structures)) - São Carlos School of Engineering, University of São Paulo, São Carlos, 2017.

The Brazilian Code ABNT NBR 6118:2014 - Design of concrete structures presents four methods for columns dimensioning, requiring the use of envelopment of moments when there is biaxial bending. Due to complexity, do not accurately consider physical nonlinearity, biaxial bending and local geometric imperfections. This work presents guidelines for the design of concrete rectangular columns with symmetrical reinforcement, subjected to biaxial bending, employing the minimum and resisting envelopment curves for the verification of the reinforcement. Analysis are made of how nonlinearities influence in the ultimate limit state of instability and how they should be considered in design methods. Two situations are indicated that can be critical for the pre-dimensioning of the reinforcement. Procedures are developed to determine the envelopment of acting moments, for each design method, as well as the envelopment of resisting moments by means of either direct method or use of abacuses for eccentrical compression. There is also two appendixes, one about the determination of the diagrams bending moment - normal force - curvature for any kind of section, and another one about getting interaction diagrams $\left(N_{u}, M_{u}\right)$, construction of abacuses for eccentrical compression and definition of $\omega$, the reinforcement mechanical rate, without the use of abacuses for C50 concrete class or below. In conclusion, this constitutes an updated bibliography for the safe and economically viable columns project, clarifying concepts such as resistant moment, envelopments of acting and resisting moments, and the use of nonlinearities in the design methods.

Keywords: Concrete columns. Design. Biaxial bending. Envelopments of moments. Nonlinearities. 



\section{SUMÁRIO}

1 INTRODUÇÃO

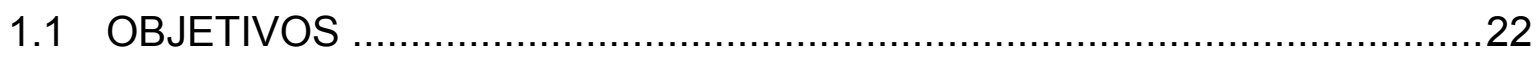

1.2 JUSTIFICATIVA

1.3 METODOLOGIA

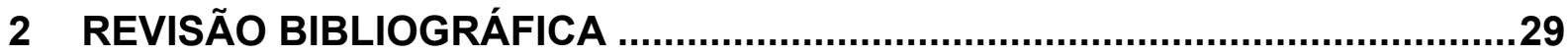

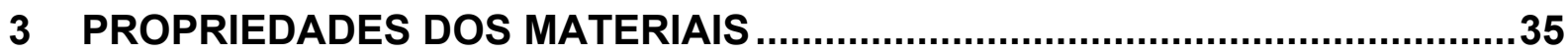

3.1 CONCRETO

3.1.1 Resistências de cálculo à compressão e tração ..................................35

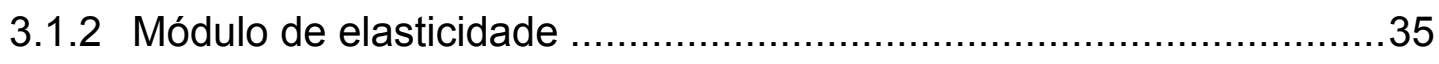

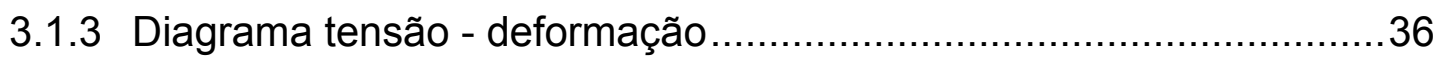

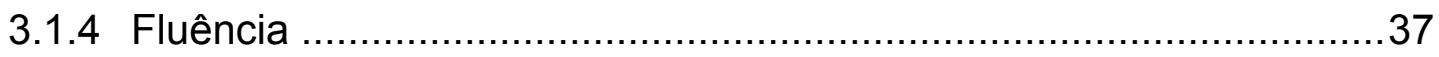

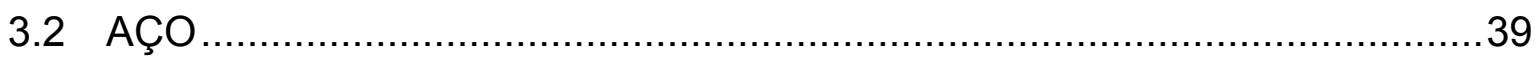

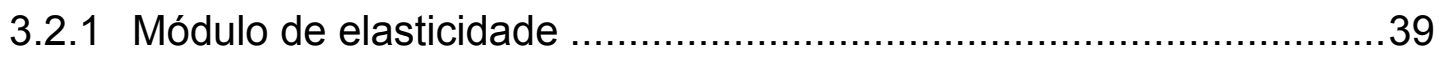

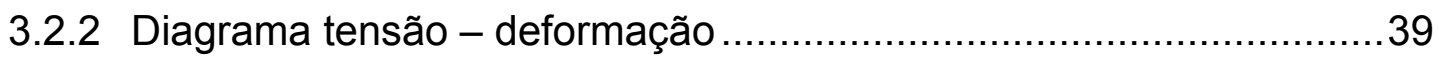

4 HIPÓTESES FUNDAMENTAIS DO ESTADO-LIMITE ÚLTIMO .........................41

4.1 TIPOS DE RUÍNAS NO ESTADO-LIMITE ÚLTIMO ..................................43

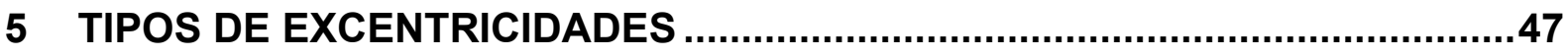

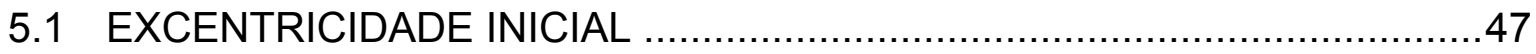

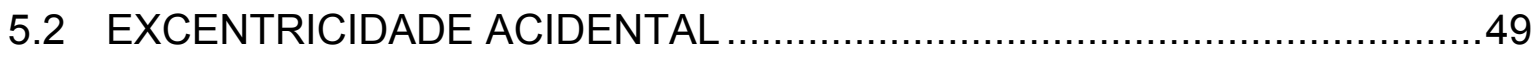

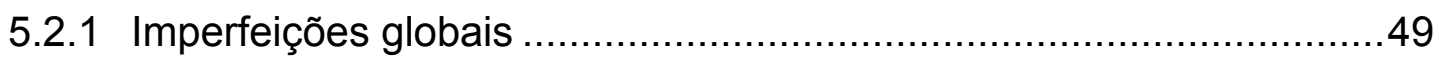

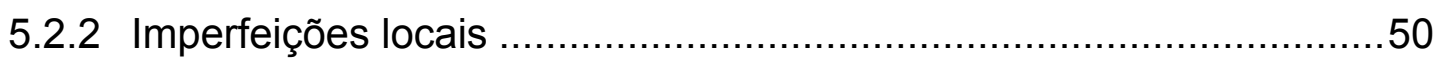

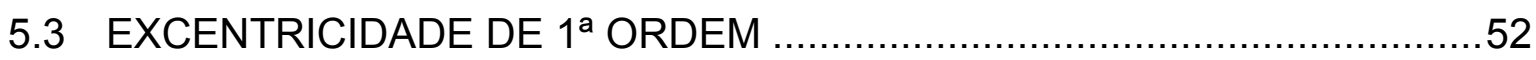

5.4 EXCENTRICIDADE MÍNIMA E MOMENTO MÍNIMO ...............................52

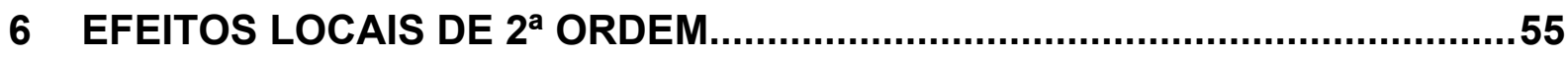

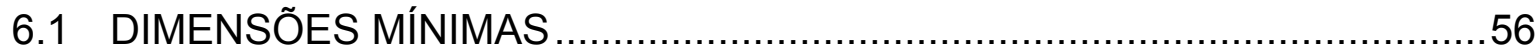

6.2 DISPENSA DOS EFEITOS LOCAIS DE 2 ${ }^{\mathrm{a}}$ ORDEM ……........................56 


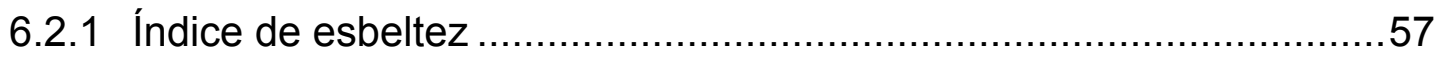

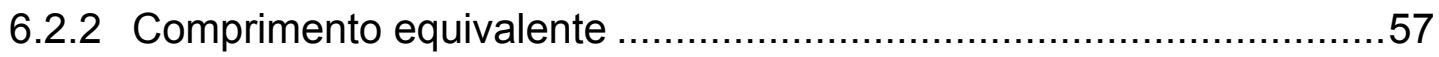

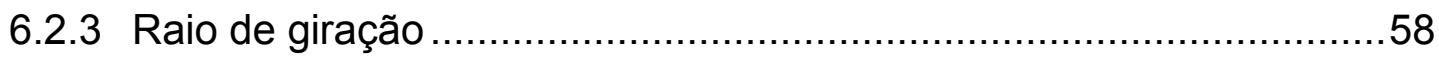

6.2.4 Índice de esbeltez para seção retangular .........................................58

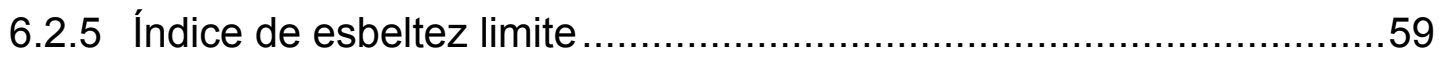

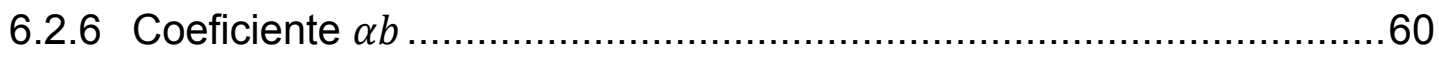

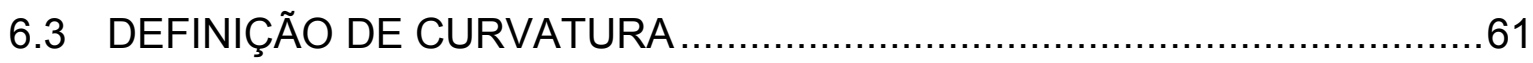

6.3.1 Expressão diferencial da linha elástica ...........................................64

6.4 DIAGRAMA MOMENTO FLETOR - FORÇA NORMAL - CURVATURA.....66

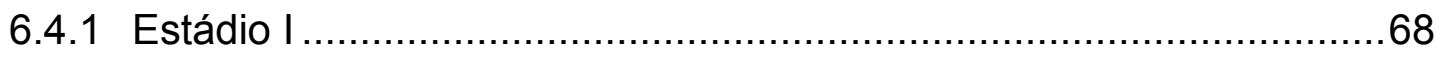

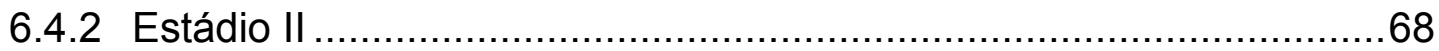

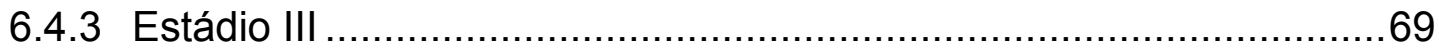

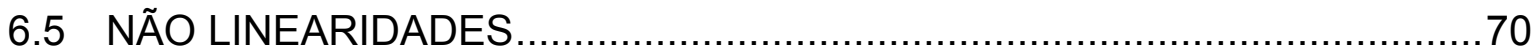

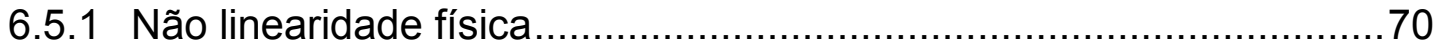

6.5.2 Não linearidade geométrica ..........................................................

6.6 MÉTODO DO PILAR-PADRÃO COM CURVATURA APROXIMADA............72

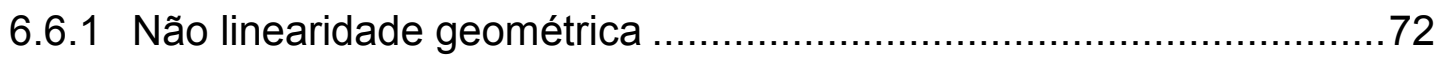

6.6.2 Não linearidade física.................................................................

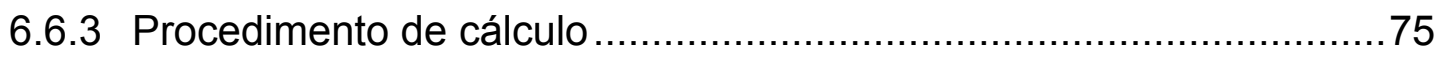

6.6.4 Origem da expressão da curvatura da seção crítica ..........................76

6.7 RELAÇÕES MOMENTO FLETOR - RIGIDEZ SECANTE …………..........79

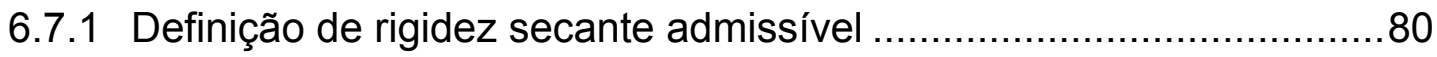

6.7.2 Pilar-padrão melhorado e relações momento fletor - rigidez secante81

6.8 PILAR-PADRÃO E DIAGRAMAS MOMENTO FLETOR - FORÇA NORMAL -

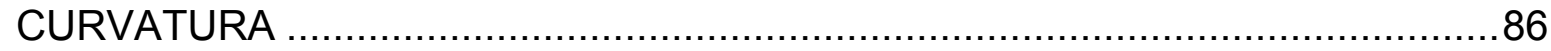

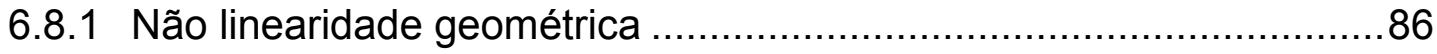

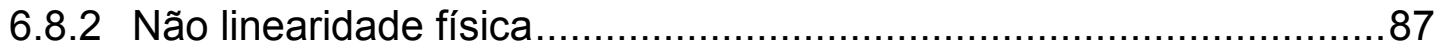


6.8.3 Apresentação do método

6.9 MÉTODO DO PILAR-PADRÃO COM RIGIDEZ $\kappa$ APROXIMADA ...............89

6.9.1 Não linearidade geométrica .........................................................90

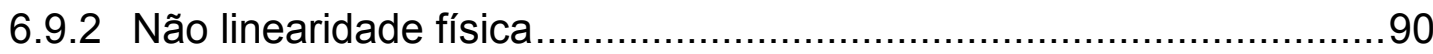

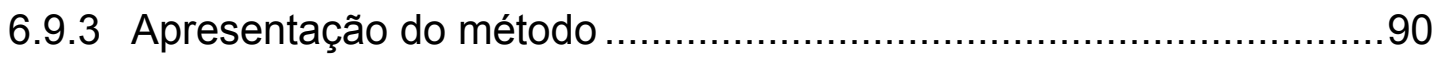

6.9.4 Origem da expressão da rigidez $\kappa$ aproximada.............................92

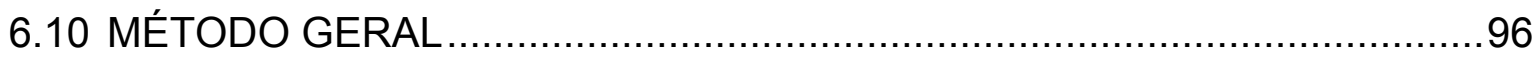

6.10.1 Processo do carregamento progressivo proporcional ........................97

6.10.2 Processo das excentricidades progressivas ...................................98

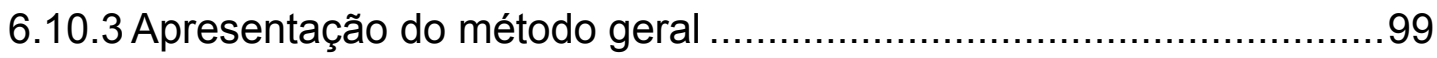

6.10.4 Processo das diferenças finitas....................................................100

6.10.5 Processo de Engesser-Vianello ..................................................104

7 DIMENSIONAMENTO DE PILARES .........................................................111

7.1 CONVENÇÃO DE EIXOS E DE DIMENSÕES DA SEÇÃO .......................111

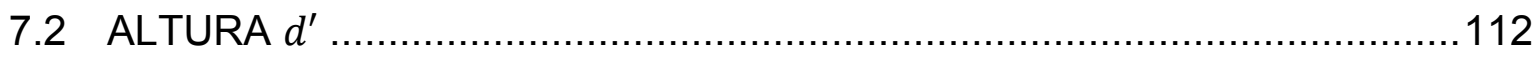

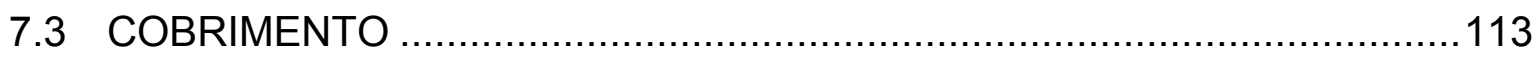

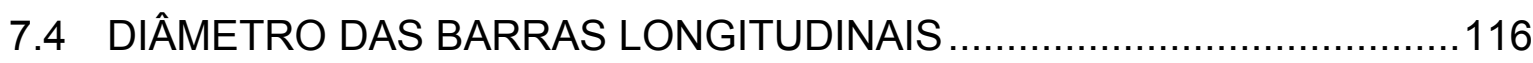

7.5 DIÂMETRO DA ARMADURA TRANSVERSAL ………….....................116

7.6 PRÉ-DIMENSIONAMENTO DA ARMADURA LONGITUDINAL .................116

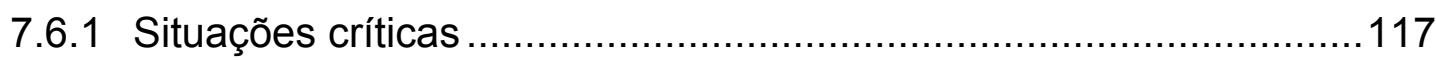

7.6.2 Ábaco para a situação crítica I.....................................................118

7.6.3 Ábacos para a situação crítica II ..................................................118

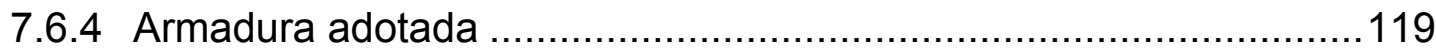

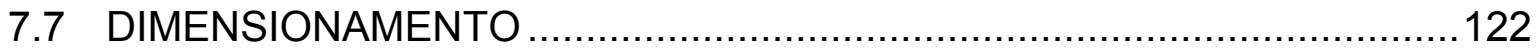

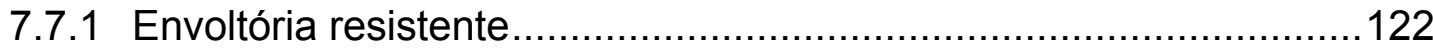

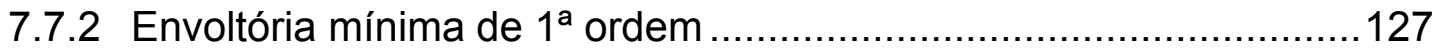

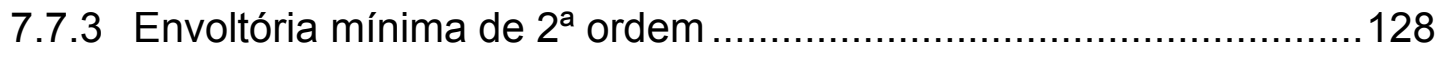


7.7.4 Verificação dos momentos fletores solicitantes 129

7.7.5 Excentricidade acidental versus momento mínimo .........................132

7.7.6 Verificação da segurança ou providências......................................132

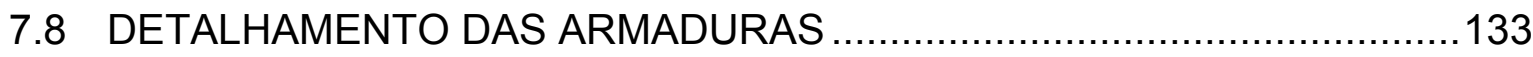

7.8.1 Espaçamento para armadura transversal ......................................134

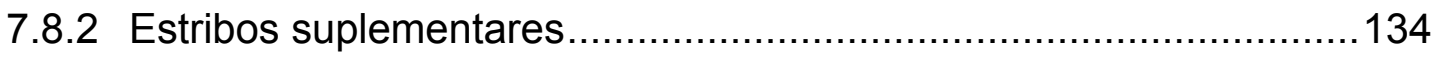

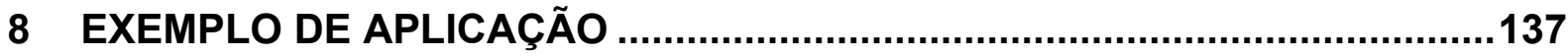

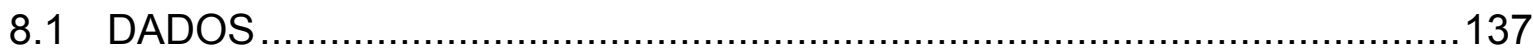

8.2 COMPRIMENTOS EQUIVALENTES DO PILAR …...............................138

8.2.1 Comprimentos equivalentes entre o térreo e o primeiro andar tipo.. 138

8.2.2 Comprimentos equivalentes entre os andares tipos …...................138

8.3 VÃOS EFETIVOS DAS VIGAS .........................................................142

8.4 MOMENTOS FLETORES NA LIGAÇÃO VIGA-PILAR - DIREÇÃO x........143

8.4.1 Comprimentos equivalentes - direção $x$........................................143

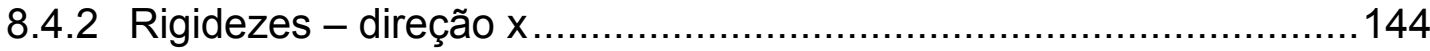

8.4.3 Momentos fletores na ligação - direção x ......................................144

8.4.4 Momentos fletores no pilar inferior - direção x.................................145

8.5 MOMENTOS FLETORES NA LIGAÇÃO VIGA-PILAR - DIREÇÃO y........146

8.5.1 Comprimentos equivalentes dos pilares - direção y ........................147

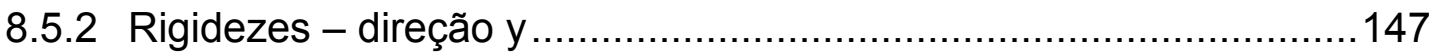

8.5.3 Momentos fletores na ligação - direção y ........................................148

8.5.4 Momentos fletores no pilar inferior - direção y.................................149

8.6 MOMENTOS FLETORES INICIAIS NO PILAR ……..............................150

8.7 MOMENTOS FLETORES NA LIGAÇÃO DE UM PILAR QUALQUER ........150

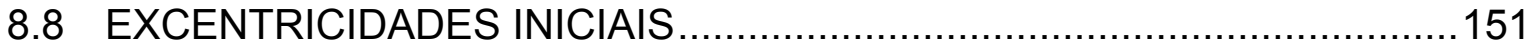

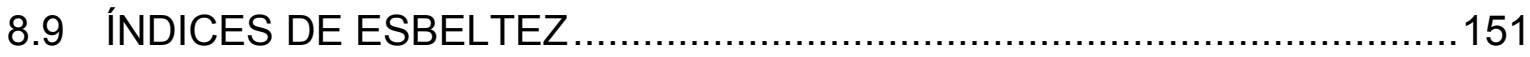

8.10 EXCENTRICIDADE ACIDENTAL VERSUS MOMENTO MÍNIMO .............151 


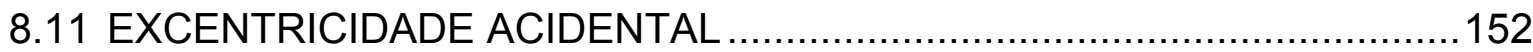

8.12 MOMENTO MÍNIMO E EXCENTRICIDADES MÍNIMAS ….......................152

8.13 VERIFICAÇÃO DA DISPENSA DOS EFEITOS DE 2 ${ }^{\mathrm{a}}$ ORDEM ..................153

8.14 MÉTODO DO PILAR-PADRÃO COM CURVATURA APROXIMADA..........154

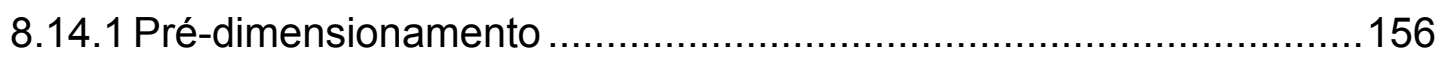

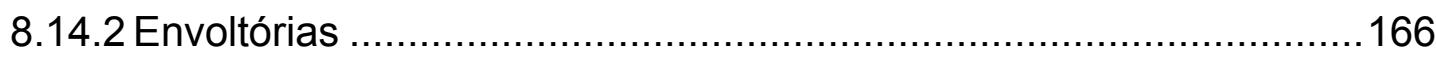

8.14.3 Verificação da excentricidade acidental .........................................178

8.15 MÉTODO DO PILAR-PADRÃO COM RIGIDEZ $\kappa$ APROXIMADA ..............184

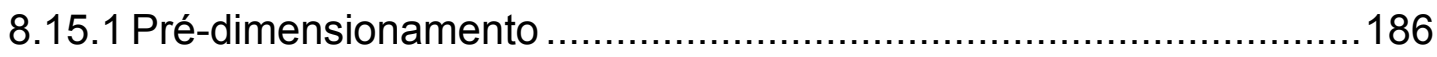

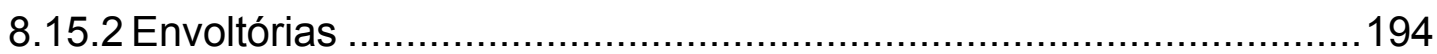

8.15.3 Verificação da excentricidade acidental ..........................................199

8.16 MÉTODO DO PILAR-PADRÃO ACOPLADO A DIAGRAMAS MOMENTO FLETOR - FORÇA NORMAL - CURVATURA ..............................................202

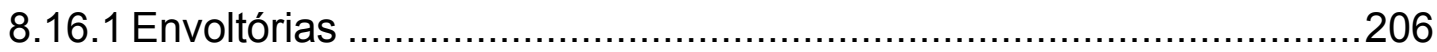

8.16.2 Nova armadura (dez barras de $20 \mathrm{~mm}$ ) ……….........................208

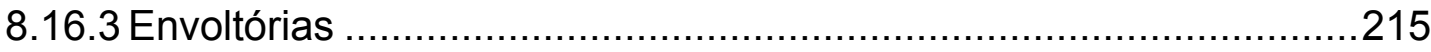

8.16.4 Nova armadura (oito barras de $20 \mathrm{~mm}$ ) ……...............................217

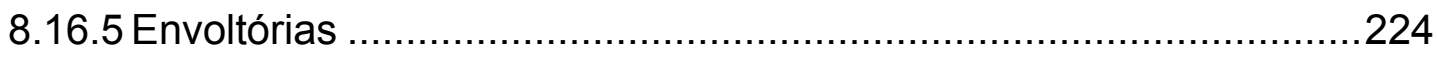

8.16.6 Verificação da excentricidade acidental ........................................226

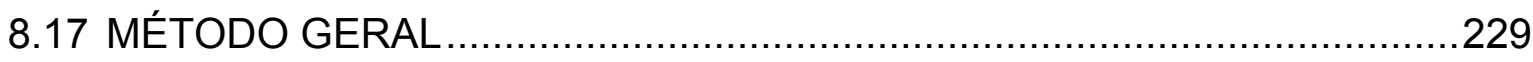

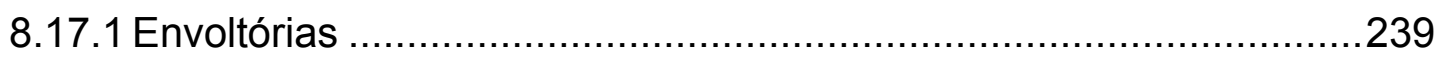

8.17.2 Verificação da excentricidade acidental ........................................243

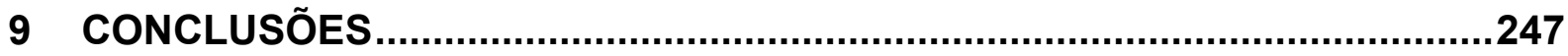

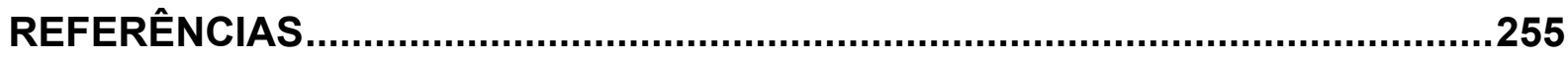

APÊNDICE A

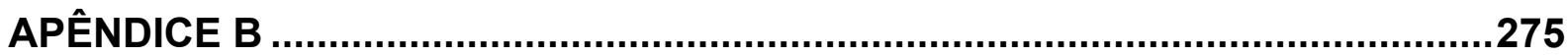

ANEXO A 



\section{Introdução}

Com a evolução da construção civil, houve a necessidade da criação de estruturas mais seguras, porém economicamente viáveis. Devido a essa realidade, estudos apurados sobre o comportamento estrutural possibilitaram o advento de novos métodos, que tornaram possível o surgimento de novas tecnologias. Inseremse nesse contexto os elementos estruturais como os pilares.

Os estudos dos efeitos de $2^{\mathrm{a}}$ ordem, aliados ao avanço da tecnologia do concreto, viabilizaram a construção de pilares cada vez mais esbeltos, como os indicados na figura 1.1, de um edifício localizado em Porto Alegre, no Brasil.

Figura 1.1 - Edifício com pilares esbeltos

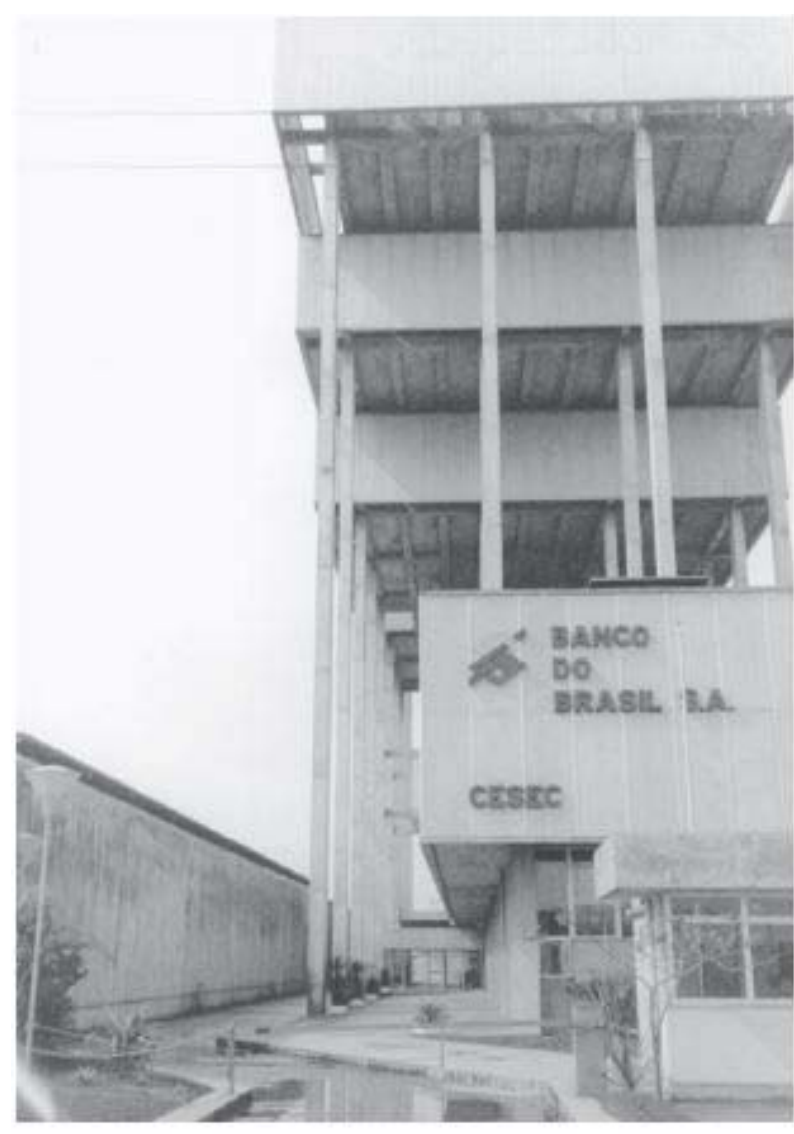

Fonte: WIGHT; MACGREGOR, 2012, p. 566.

O índice de esbeltez $(\lambda)$ de um pilar depende da geometria de sua seção transversal e das condições de vínculo nas extremidades. Os pilares podem ser classificados de acordo com seu índice de esbeltez (KIMURA, 2010): 
a) $0 \leq \lambda \leq 40$ - Pilar pouco esbelto;

b) $40<\lambda \leq 90$ - Pilar esbelto;

C) $90<\lambda \leq 140$ - Pilar muito esbelto;

d) $140<\lambda \leq 200$ - Pilar excessivamente esbelto;

e) $\lambda>200$ - Não pode ser considerado um pilar.

Efeitos de $2^{\mathrm{a}}$ ordem são computados quando a análise do equilíbrio é efetuada considerando a configuração deformada da estrutura. São somados àqueles obtidos em uma análise de primeira ordem, na qual o equilíbrio da estrutura é estudado na configuração geométrica inicial (ABNT NBR 6118:2014). Para pilares esbeltos os efeitos de $2^{\mathrm{a}}$ ordem são cruciais. É necessária uma análise rigorosa da não linearidade física, decorrente do comportamento do material, e geométrica do elemento em estudo (ARAÚJO, 2010).

É costumeiro no ramo do projeto estrutural evitar os pilares esbeltos, pois nesse caso o estado-limite último pode ser a instabilidade, ou seja, a falta de equilíbrio da posição deformada da barra, antes da ruína tradicional por ruptura do concreto ou por deformação plástica excessiva da armadura.

A análise estrutural com efeitos de $2^{a}$ ordem deve assegurar que, para as combinações mais desfavoráveis das ações, não ocorra perda de estabilidade nem esgotamento da capacidade resistente do material. A não linearidade física, que está presente nas estruturas de concreto armado, deve ser obrigatoriamente considerada (ABNT NBR 6118:2014).

A não linearidade física é caracterizada pela não proporcionalidade entre causa e efeito; o concreto é um material não linear, ou seja, a tensão não é proporcional à deformação (SANTOS, 1987).

Sob a ação das cargas verticais e horizontais, os nós da estrutura deslocam-se horizontalmente, de forma que os esforços de $2^{\mathrm{a}}$ ordem decorrentes desses deslocamentos são chamados de efeitos globais de $2^{a}$ ordem (ABNT NBR 6118:2014).

A análise global de $2^{a}$ ordem fornece os esforços na extremidade dos pilares. Em seguida, deve ser realizada a análise dos efeitos locais de $2^{\mathrm{a}}$ ordem ao longo do eixo dos pilares (ABNT NBR 6118:2014). 
A ABNT NBR 6118:2014 apresenta quatro métodos para a análise dos efeitos locais de $2^{\mathrm{a}}$ ordem e dimensionamento de pilares:

a) Método do pilar-padrão com curvatura aproximada;

b) Método do pilar-padrão com rigidez $\kappa$ aproximada;

c) Método do pilar-padrão acoplado a diagramas momento fletor - força normal - curvatura;

d) Método geral.

Os três primeiros métodos citados são aproximados e apresentam como não linearidade geométrica o pilar-padrão. Trata-se de uma simplificação que admite, aproximadamente, que a forma final da posição de equilíbrio do elemento em estudo seja uma curva senoidal (SANTOS, 1987).

O método do pilar-padrão com curvatura aproximada considera a não linearidade física através de uma expressão aproximada da curvatura da seção crítica. Em contrapartida o método do pilar-padrão com rigidez $\kappa$ aproximada considera a não linearidade física através de uma expressão aproximada da rigidez (ABNT NBR 6118:2014).

O método do pilar-padrão acoplado a diagramas momento fletor - força normal - curvatura apresenta a modulação da não linearidade física de forma mais precisa que o método do pilar-padrão com curvatura aproximada e o método do pilar padrão com rigidez $\kappa$ aproximada (KIMURA, 2010). Utiliza-se como não linearidade física a curvatura da seção crítica retirada diretamente dos diagramas momento fletor - força normal - curvatura (ABNT NBR 6118:2014).

O método geral consiste em uma análise efetuada com discretização adequada da barra, no qual há a consideração das relações momento fletor - curvatura real em cada seção e a consideração da não linearidade geométrica é feita de maneira não aproximada (ABNT NBR 6118:2014).

A análise global dos edifícios, que gera as solicitações iniciais a serem acrescidas dos efeitos locais de $2^{a}$ ordem, pode ser realizada com os modelos de grelha e de pórticos espaciais. Devido à consideração de ações horizontais, como o vento, a maioria dos pilares está submetida à flexão composta oblíqua. 
Na prática, todo pilar, seja ele de canto, de extremidade ou intermediário, está submetido a uma força normal de compressão e a momentos fletores concomitantes nas duas direções, ou seja, a uma flexão composta oblíqua, mesmo que os momentos fletores, em uma ou ambas as direções, sejam pequenos (KIMURA, 2010).

O dimensionamento de pilares submetidos à flexão composta oblíqua é realizado por meio das análises de pontos solicitantes, de envoltórias mínimas e de envoltórias resistentes.

O trabalho tem como público-alvo os projetistas de estruturas, além de alunos de graduação e de pós-graduação.

\subsection{OBJETIVOS}

O objetivo principal deste trabalho é fornecer as diretrizes para o dimensionamento de pilares submetidos à flexão composta oblíqua, de acordo com as prescrições da ABNT NBR 6118:2014, utilizando comparações de diferentes métodos de dimensionamento de pilares retangulares de concreto armado e consideração das imperfeições geométricas locais.

São objetivos específicos deste trabalho:

- Apresentar e definir o conceito de estado-limite último de instabilidade e seus desdobramentos na determinação dos efeitos locais de $2^{\mathrm{a}}$ ordem;

- Considerar a teoria de todos os métodos de dimensionamento de pilares retangulares de concreto armado;

- Mostrar a verificação de pilares submetidos à flexão composta oblíqua por envoltórias, como proposto na ABNT NBR 6118:2014;

- Elaborar um exemplo de dimensionamento de um pilar submetido à flexão composta oblíqua, por todos os métodos de dimensionamento, e mostrar as diferenças da consideração das imperfeições geométricas locais;

- Desenvolver o equacionamento que permite obter o momento fletor resistente de uma seção em função de sua curvatura adimensional, e utilizar esse 
equacionamento para a obtenção dos diagramas momento fletor - força normal curvatura;

- Considerar as hipóteses e o equacionamento que permite obter o momento fletor resistente de uma seção em função da posição da linha neutra, e utilizar esse equacionamento para obtenção das curvas de interação $\left(N_{u}, M_{u}\right)$;

- Elaborar um algoritmo que possibilite a obtenção da taxa mecânica de armadura sem a necessidade de ábacos de flexão composta normal.

\subsection{JUSTIFICATIVA}

O advento dos concretos de alta resistência possibilitou a construção de edifícios altos, devido à alta velocidade de construção, além de ser alternativa econômica para pilares maciços de concreto convencional, gerando estruturas esbeltas (MEHTA; MONTEIRO, 2008).

Com o aumento da resistência do concreto e com as exigências arquitetônicas atuais, é possível a idealização de estruturas cada vez mais esbeltas, tornando necessária uma análise minuciosa dessas estruturas. Os métodos aproximados são limitados e geram armaduras exageradas quando utilizados acima dos limites de esbeltez especificados, sendo evitados por projetistas do ramo.

Em contrapartida, métodos antigos, como o "processo $\omega$ ", geram armaduras significativamente menores que as obtidas pelos métodos atuais. Estruturas dimensionadas pelo "processo $\omega$ " encontram-se superdimensionadas ou podem estar com probabilidade de ruína acima dos valores desejáveis (SANTOS, 1987).

Portanto o entendimento de métodos mais precisos visa ajudar projetistas e construtoras, já que possibilitam o cálculo de armaduras condizentes com os esforços, e são menores do que aquelas obtidas por outros métodos. Dessa forma, com taxas de armadura menores, há redução dos custos relativos à execução da obra sem comprometer a segurança da estrutura. 
Devido ao surgimento de programas computacionais que efetuam a análise global de edifícios, a obtenção dos efeitos globais de $2^{\mathrm{a}}$ ordem é feita mediante modelagem dos elementos (vigas, lajes e pilares) com grelha ou pórticos espaciais.

Esse tipo de análise facilita a consideração de ações horizontais, como o vento, de forma que a maioria dos pilares de um edifício apresente esforços em ambos os eixos de análise. Assim, todos os pilares de um edifício estão submetidos a uma flexão composta oblíqua, ou seja, a seção está submetida a uma força normal de compressão agindo concomitantemente com momentos fletores em ambos os eixos de análise (KIMURA, 2010).

Com o surgimento da ABNT NBR 6118:2003, introduziu-se o conceito de momento mínimo de $1^{a}$ ordem, que pode substituir o ângulo $\theta_{1}$ para determinação das imperfeições geométricas locais. Nos casos de flexão oblíqua, a verificação dessas imperfeições deve ser efetuada por meio de envoltórias solicitantes, no primeiro caso, e por meio da adição de uma excentricidade acidental nas solicitações totais, no segundo. Ambas as solicitações e envoltórias devem ser englobadas por uma envoltória resistente.

Portanto, o dimensionamento de pilares submetidos à flexão oblíqua é um processo de verificações de envoltórias mínimas, que representam as imperfeições geométricas locais; pontos solicitantes, que representam as solicitações críticas a que o pilar esteja submetido (adicionadas ou não à excentricidade acidental); e envoltórias resistentes, obtidas por meio da contribuição da seção bruta de concreto e da armadura pré-definida.

A determinação da envoltória resistente bem como o uso de alguns métodos de dimensionamento são complexos se efetuados manualmente, sendo necessário o auxílio de ferramentas computacionais. Os programas comerciais atuais resolvem a maioria dos problemas relacionados ao dimensionamento de estruturas submetidas à flexão composta oblíqua, porém não fornecem a linguagem computacional e a teoria que embasa esse dimensionamento.

O entendimento dos métodos de dimensionamento é uma arma poderosa e essencial aos projetistas e estudantes da área, uma vez que possibilita a compreensão do que está sendo feito pelos programas computacionais comerciais. Além disso, o projetista pode criar técnicas de verificação do dimensionamento, assim 
como desenvolver habilidade para aplicação de soluções estruturais mais econômicas, justificando-se este trabalho realizado.

\subsection{METODOLOGIA}

Inicialmente é realizada uma revisão bibliográfica sobre a análise de segunda ordem local de pilares esbeltos de concreto armado, considerando os métodos: pilarpadrão com curvatura aproximada, pilar-padrão com rigidez $\kappa$ aproximada, pilarpadrão acoplado aos diagramas momento fletor - forçar normal - curvatura e método geral.

Apresenta-se o embasamento teórico para todos os métodos de dimensionamento de pilares, para obtenção das taxas mecânicas de armadura sem a necessidade do uso de ábacos, para a obtenção dos diagramas momento fletor força normal - curvatura e dos diagramas de interação $\left(N_{u}, M_{u}\right)$, e para a geração das envoltórias solicitantes e resistentes.

O foco do trabalho é apresentar o equacionamento do problema, contemplando as exigências normativas, explicando-se a origem de equações utilizadas nos métodos de dimensionamento, a obtenção das envoltórias e dos pontos solicitantes (envoltórias mínimas de $1^{\mathrm{a}}$ ordem e $2^{\mathrm{a}}$ ordem, pontos de solicitações críticas e pontos de solicitação crítica considerando a excentricidade acidental) e envoltórias resistentes, por meio do cálculo direto dos momentos fletores resistentes da seção ou por meio de ábacos para flexão composta normal.

As equações que representam a não linearidade física de todos os métodos derivam das relações momento fletor - curvatura. Dessa forma, também é feita uma revisão bibliográfica sobre algoritmos para obtenção das relações momento fletorcurvatura, como os sugeridos por: Fusco (1981), França (1984), Araújo (1984), Süssekind (1987), Santos (1987), Ribeiro (2011), entre outros. Maior ênfase será dada ao algoritmo de Ribeiro (2011).

Utilizando o trabalho de Santos (1987), realiza-se inicialmente um estudo sobre a instabilidade de pilares, focando no assunto do trabalho que é a flexo-compressão de pilares com material elástico não linear, conceituando-se o estado-limite último de 
instabilidade. Verifica-se a influência das não linearidades e suas implicações na determinação dos efeitos de segunda ordem.

Com base nos trabalhos de Fusco (1981), França (1987), França (1991), Oliveira (2004) e Santos (1987), verifica-se a origem das equações utilizadas em todos os métodos de dimensionamento propostos pela ABNT NBR 6118:2014.

Será realizado um estudo da ABNT NBR 6118:2014 frente ao dimensionamento de pilares submetidos à flexão composta oblíqua, de forma a se obterem as hipóteses, o equacionamento e as diretrizes para a determinação das envoltórias.

Inicialmente, como sugestão, define-se uma nova convenção de eixos e dimensões utilizada para o cálculo das envoltórias. Propõem-se também duas situações críticas para o pré-dimensionamento da seção, já que a obtenção das envoltórias resistentes é dependente dessa escolha.

Destaca-se também que a obtenção das envoltórias resistentes pode ser efetuada por cálculo direto (integração das tensões resistentes da seção) ou, como opção simplificada, por meio de ábacos de flexão composta normal, como os construídos por Venturini (1987).

Aprofundamentos sobre obtenção dos diagramas momento fletor - força normal - curvatura estão presentes no apêndice $A$, no qual se desenvolve o equacionamento das forças resistentes da armadura e do concreto em função da curvatura adimensional $\theta$, conforme prescrito por Santos (1994), de forma a se obter o momento fletor resistente da seção em função desse parâmetro. Apresenta-se também um algoritmo de obtenção desses diagramas, proposto por Ribeiro (2011).

Aprofundamentos sobre a obtenção das curvas de interação $\left(N_{u}, M_{u}\right)$ estão presentes no apêndice $B$, no qual se desenvolve o equacionamento das forças resistentes da armadura e do concreto em função da posição da linha neutra, conforme prescrito por Venturini (1987). Apresenta-se um algoritmo para obtenção dessas curvas, assim como um algoritmo alternativo para obtenção da taxa mecânica de armadura, sem a necessidade do uso de ábacos de dimensionamento.

Por meio dos conceitos expostos, será analisado um exemplo de pilar de concreto armado submetido à flexão composta oblíqua. Será realizado o dimensionamento utilizando todos os métodos expostos no texto, mostrando as 
particularidades de cada um frente à obtenção dos esforços resistentes e à construção das envoltórias. Os resultados serão comparados avaliando-se a influência de cada método no dimensionamento. Apresentam-se também as diferenças na consideração das imperfeições geométricas locais, utilizando momento mínimo ou excentricidade acidental. 
28 | Pá g in a 


\section{Revisão Bibliográfica}

A normalização sobre o cálculo de pilares sujeitos aos efeitos de flambagem ocorreu com a NB1/60, na qual o cálculo da instabilidade era efetuado de acordo com a Teoria da Flambagem. A carga de trabalho, suposta axial, era multiplicada pelo coeficiente de segurança $\gamma$ e por um coeficiente de majoração $\omega$, cujo valor dependia do índice de esbeltez da peça $(\lambda)$, de forma simplória (SANTOS, 1987; SCADELAI, 2004).

O fenômeno de estado-limite último de instabilidade substituiu a teoria da flambagem em pilares, já que esta só ocorre em peças de materiais elástico-lineares sujeitas a carga centrada. Mesmo que se possa considerar o concreto um material elástico-linear, há a impossibilidade da carga centrada devida à imposição das imperfeições geométricas ocorridas em projeto (AUFIERO, 1977; SANTOS, 1987).

Após a revisão na NB1 em 1978, ela passou a ser chamada também de NBR $6118 / 78$. Com o advento dessa versão, surgiram novos métodos para caracterizar os efeitos de segunda ordem, de forma que, dependendo do índice de esbeltez da peça, utilizava-se o processo simplificado ou o processo exato, no qual se considerava a relação momento fletor-curvatura. Esse procedimento foi mantido nas versões posteriores da norma (KETTERMANN, 2001).

O momento mínimo de $1^{\text {a }}$ ordem, que entrou em vigor na ABNT NBR 6118:2003, tem origem na norma americana $(\mathrm{ACl})$ e pode substituir o ângulo $\theta_{1}$ na definição das imperfeições geométricas locais, enquanto o primeiro é um valor mínimo, o segundo gera a excentricidade acidental $e_{a}$ que é sempre aditiva (KIMURA, 2010).

Devido a essa mudança, a ABNT NBR 6118:2003 definiu como proposta de dimensionamento a flexão oblíqua o conceito de envoltória mínima de $1^{\text {a }}$ ordem e envoltória de $2^{\mathrm{a}}$ ordem.

Assim, com a evolução do estudo do concreto, houve a possibilidade da criação de novos métodos que caracterizassem o comportamento não linear e os efeitos de segunda ordem que ocorrem em peças esbeltas, sob a atuação da flexão composta oblíqua, e, portanto, dando origem a dimensionamentos mais eficazes. 
Estudos sobre relações momento fletor-curvatura, imperfeições geométricas locais e flexão composta oblíqua foram determinantes para a evolução da ABNT NBR 6118:2014, e para o desenvolvimento dos métodos de dimensionamento. Porém, cada trabalho difere por seus enfoques teóricos. Citam-se os trabalhos que contribuíram para a elucidação do dimensionamento de pilares esbeltos submetidos à flexão composta oblíqua.

Aufiero (1977), baseando-se no Boletim de Informação n 103 do CEB e antecipando a NB1/78, verificou as considerações sobre o efeito da esbeltez no dimensionamento de colunas isostáticas de concreto armado, verificando também a capacidade de barras esbeltas sujeitas à flexão composta (excentricidade em uma única direção), e à flexão oblíqua (excentricidade biaxial). Há no trabalho um algoritmo para determinação da relação momento fletor-curvatura.

Araújo (1984) apresenta uma rotina para o dimensionamento de pilares esbeltos de concreto armado, considerando cargas de curta e de longa duração (consideração da fluência). Há também três algoritmos numéricos para o cálculo das relações momento fletor - força normal - curvatura em seções com um eixo de simetria. Há uma comparação entre a solução numérica e pilares experimentais para verificar a precisão dessa solução numérica.

Em França (1984) encontra-se um estudo sobre as relações momento fletorcurvatura e força normal - deformação longitudinal em barras de qualquer seção submetida à flexão composta oblíqua. Há o desenvolvimento da formulação geral e integrada das relações momento fletor-curvatura. Apresentam-se várias formas de representação das curvas momento fletor-curvatura e sua relação com o estado-limite último do concreto. É feito um estudo comparativo entre o comportamento momento fletor-curvatura dos materiais elásticos lineares e dos materiais não elásticos.

Schirmbeck (1988) desenvolve computacionalmente um procedimento numérico para a determinação do diagrama momento fletor-curvatura, aplicado inicialmente a vigas de concreto armado e, em seguida, a um ponto genérico da superfície média de placas de concreto armado, ambos submetidos a carga de curta duração. Há comparação do modelo teórico com o experimental.

Paula (1988) apresenta um estudo da estabilidade de pilares esbeltos submetidos à flexão composta normal. Apresenta comparações do método geral e do 
método do pilar-padrão em relação a: obtenção da carga crítica, dimensionamento e elaboração de diagramas. Há um algoritmo para obtenção de diagramas momento fletor - força normal - curvatura e sua implementação em linguagem PASCAL.

França (1991) tem papel fundamental no método do pilar-padrão acoplado a diagramas momento fletor - força normal - curvatura e do pilar-padrão com rigidez $\kappa$ aproximada, pois propôs a substituição das relações momento fletor - normal curvatura por relações momento fletor - normal - rigidez. A proposta é a da linearização das relações momento fletor-curvatura por meio de valores de rigidez secante. E com essa definição, é possível a construção de ábacos para dimensionamento e verificação de pilares.

Bacarji (1993) e Aufieri (1997) tentam unificar os procedimentos de cálculo de pilares quanto à estabilidade global e ao projeto de pilares (estabilidade local), dando uma visão geral e eliminando lacunas na análise. Para tanto, estudam o fenômeno da instabilidade de peças comprimidas e os métodos de verificação da estabilidade, global e local. Apresentam também um guia para localização dos pilares no sistema estrutural e pré-dimensionamento de seções transversais. Há um algoritmo para determinação das relações momento fletor-curvatura.

Cadamuro (1997) apresenta um estudo geral sobre dimensionamento e verificação de pilares esbeltos solicitados por flexão composta oblíqua. As seções analisadas são poligonais quaisquer, e apresentam distribuição e armadura arbitrária. A fluência é considerada por meio da correção do diagrama tensão-deformação do concreto. Nesse trabalho apresentam-se vários algoritmos e rotinas computacionais que foram implementadas no programa SISTEMA FLEXOR, escrito em linguagem FORTRAN.

Malakoski (1998) apresenta o dimensionamento e a verificação da estabilidade de pilares esbeltos de concreto armado com seção variável submetidos à flexão composta normal, pelo método geral. O foco do trabalho é o equacionamento dos métodos "refinados", dando destaque para seções de pilares com armaduras não simétricas. Desenvolveu-se o equacionamento necessário gerando ábacos, além de uma rotina computacional em linguagem PASCAL. Há um algoritmo para determinação do diagrama momento fletor - força normal - curvatura. 
Em Amaral (2000) apresenta-se estudo da instabilidade dos pilares, objetivando encontrar caminhos alternativos aos programas computacionais, e que permitam avaliar com certa precisão a estabilidade de uma barra. Dessa forma, desenvolveram-se formulários, ábacos e tabelas de dimensionamento. $O$ trabalho complementa o estudo de Paula (1988), com adaptações nos algoritmos com o intuito de facilitar o uso por engenheiros do ramo.

Kettermann (2001) apresenta um estudo sobre os efeitos que o diagrama momento fletor - força normal - curvatura causa no estado-limite último de instabilidade. Há também uma análise sobre as mudanças propostas pela NB1/78 na construção do diagrama momento fletor - força normal - curvatura, comparando com os diagramais usuais. Há também a obtenção de diagramas adimensionais de interação, para o dimensionamento de pilares esbeltos.

Em Scadelai (2004) há uma revisão do dimensionamento de pilares de concreto armado submetidos à flexão composta, de acordo com a ABNT NBR 6118:2003, analisando os métodos presentes nessa versão da norma. Há a preocupação de criar um conteúdo de "Prática Recomendada", com exemplos práticos de dimensionamento.

Oliveira (2004) dá continuidade ao trabalho de França (1991) em relação à rigidez de pilares em análises de segunda ordem. Há a construção de ábacos para seção retangular, retangular vazada, circular e circular vazada, devido a sua grande demanda em projetos. Complementando o trabalho, há novos ábacos, com mais valores de cobrimento e com outras disposições de armadura. Para a construção dos ábacos, explica-se a origem da expressão da rigidez $\kappa$ aproximada, presente na ABNT NBR 6118:2014.

Em Pires (2006) há procedimentos de análise da estabilidade e do dimensionamento de pilares de concreto armado submetidos à flexão normal composta pelo método geral. É feita uma comparação dos resultados com os obtidos experimentalmente e com os relativos ao programa comercial CAD/TQS.

Em Ribeiro (2011) há o desenvolvimento de rotinas de programação para a execução de processos iterativos que possibilitam a construção dos diagramas momento fletor - força normal - curvatura e a determinação dos efeitos de segunda ordem. Há uma análise minuciosa dos diagramas de interação, verificando tendências 
e alternativas de extrapolação, propondo o ajuste de uma expressão polinomial à curva de momento fletor - curvatura.

Chaves et al. (2015) determinam a capacidade resistente de pilares de concreto armado pelo método geral. Para tanto, apresentam um processo iterativo no qual integram as curvaturas ao longo do pilar com base em um modelo discreto de fibras. Para obtenção das curvaturas, utiliza-se uma nova forma de determinação das relações momento fletor - curvatura por meio do método Newton - Raphson. A barra é discretizada em certo número de elementos finitos, na qual é realizado o equilíbrio de cada nó, determinando a rotação e, assim, a curvatura.

Do ponto de vista da análise da estabilidade de pilares esbeltos de concreto armado e dos efeitos que causam no dimensionamento, podem-se citar as publicações de: Fusco (1981), Süssekind (1987), Santos (1983,1987 e 1994), Kimura (2010) e Araújo (2010).

Do ponto de vista da criação de ábacos e tabelas de dimensionamento, citamse os trabalhos de Venturini (1987), Pinheiro (2003), França (1991) e Oliveira (2004).

Do ponto de vista da análise dos pilares submetidos à flexão composta oblíqua de acordo com a ABNT NBR 6118:2014, citam-se os trabalhos de Kimura (2010) e os do IBRACON (2006). 
34 | P á g i n a 


\section{Propriedades dos materiais}

\subsection{CONCRETO}

\subsubsection{Resistências de cálculo à compressão e tração}

A resistência de cálculo à compressão do concreto é definida no item 12.3 .3 da ABNT NBR 6118:2014 sendo:

$$
f_{c d}=\frac{f_{c k}}{\gamma_{c}}
$$

Essa resistência, conforme prescrito no mesmo item, é adotada quando a verificação se faz em data igual ou superior aos 28 dias, de forma a confirmar o valor de $f_{c k}$ adotado.

O coeficiente de ponderação das resistências no estado-limite último $\gamma_{c}$ é dependente do tipo de combinação utilizada para verificação do estado-limite último. Nesse trabalho a combinação adotada será a normal, e, portanto, o coeficiente $\gamma_{c}$ assume o valor de 1,4.

A resistência de cálculo à tração do concreto será desprezada, de forma que, não se considere a resistência à tração do concreto na determinação da capacidade resistente da seção.

\subsubsection{Módulo de elasticidade}

O módulo de elasticidade é obtido conforme item 8.2.8 da ABNT NBR 6118:2014, assim, quando não forem realizados ensaios o valor do módulo de elasticidade inicial é dado pelas equações 3.2, em concretos com $f_{c k}$ de $20 \mathrm{MPa}$ a $50 \mathrm{MPa}$, e 3.3, em concretos de $f_{c k}$ de $55 \mathrm{MPa}$ a $90 \mathrm{MPa}$.

$$
E_{c i}=\alpha_{E} \cdot 5600 \cdot \sqrt{f_{c k}}
$$




$$
E_{c i}=21,5 \cdot 10^{3} \cdot \alpha_{E} \cdot\left(\frac{f_{c k}}{10}+1,25\right)^{\frac{1}{3}}
$$

Nessas equações, os valores possíveis de $\alpha_{E}$ são:

- $\alpha_{E}=1,2$ para basalto e diabásio;

- $\alpha_{E}=1,0$ para granito e gnaisse;

- $\alpha_{E}=0,9$ para calcário;

- $\alpha_{E}=0,7$ para arenito.

\subsubsection{Diagrama tensão - deformação}

O diagrama tensão-deformação utilizado no trabalho é o proposto no item 8.2.10.1 da ABNT NBR 6118:2014 e presente na figura 3.1, sendo que o diagrama utilizado versa apenas sobre a região de compressão do concreto, já que a tração é desprezada.

Figura 3.1 - Diagrama tensão - deformação idealizado

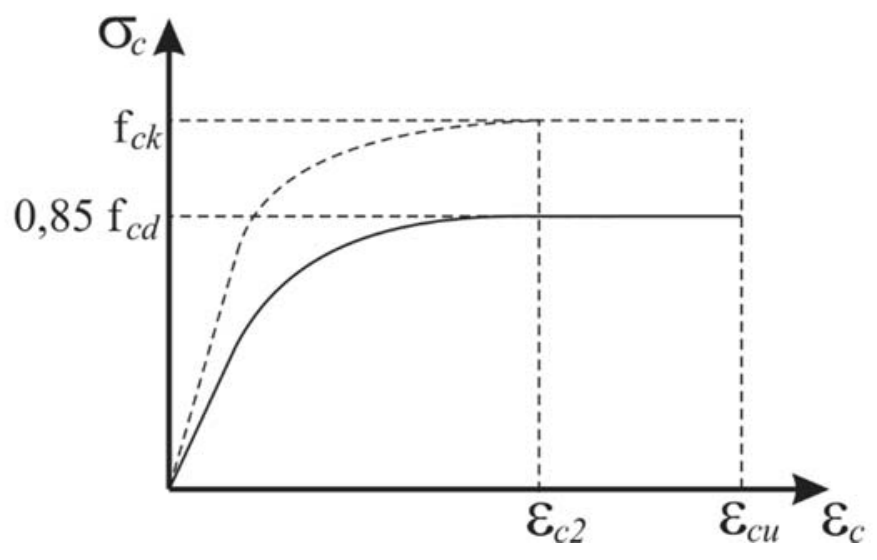

Fonte: Adaptado da ABNT NBR 6118:2014, item 8.2.10.1.

De acordo com a figura 3.1 verifica-se que a tensão de pico utilizada no diagrama é a de $0,85 \cdot f_{c d}$, esse valor é devido a três fatores:

a) Efeito Rüsch: Consideração da variação da resistência do concreto em função das velocidades de carregamento (efeito da fluência); 
b) Ganho de resistência do concreto aos 28 dias;

c) Efeito escala: Influência da forma do corpo de prova.

Ainda verifica-se que o formato do diagrama apresenta duas techos, de forma que:

$$
\begin{gathered}
0 \leq \sigma_{c} \leq \varepsilon_{c 2} \rightarrow \sigma_{c}=0,85 \cdot f_{c d} \cdot\left[1-\left(1-\frac{\varepsilon_{c}}{\varepsilon_{c 2}}\right)^{n}\right] \\
\sigma_{c}>\varepsilon_{c 2} \rightarrow \sigma_{c}=0,85 \cdot f_{c d}
\end{gathered}
$$

O fator $n$ da expressão 3.4, bem como os parâmetros $\varepsilon_{c 2}$ e $\varepsilon_{c u}$ presentes na figura 3.1, são dependentes do $f_{c k}$ da peça, assim sendo, a ABNT NBR 6118:2014 insere o comportamento dos concretos de alta resistência (Classes superiores a C50) modificando o diagrama tensão-deformação do concreto. Assim:

- Para concretos de classes até C50:

$$
\begin{aligned}
& n=2 \\
& \varepsilon_{c 2}=2,0 \% 0 \\
& \varepsilon_{c u}=3,5 \% 0
\end{aligned}
$$

- Para concretos de classes C55 até C90:

$$
\begin{gathered}
n=1,4+23,4 \cdot\left[\frac{\left(90-f_{c k}\right)}{100}\right]^{4} \\
\varepsilon_{c 2}=2,0 \% 0+0,085 \% 0 \cdot\left(f_{c k}-50\right)^{0,53} \\
\varepsilon_{c u}=2,6 \% 0+35 \% 0 \cdot\left[\frac{\left(90-f_{c k}\right)}{100}\right]^{4}
\end{gathered}
$$

\subsubsection{Fluência}

A fluência é um fenômeno que ocorre no concreto quando submetido a cargas de compressão de longa duração; seu efeito é uma gradual deformação do elemento com o tempo (PINHEIRO, 2016). A ABNT NBR 6118:2014 apresenta em seu item 
15.8.3.1: "A consideração da fluência é obrigatória para $\lambda>90$ ". Isto posto, a consideração da fluência é efetuada de maneira aproximada com a inserção de uma excentricidade adicional ao cálculo $\left(e_{c c}\right)$, como exposto no item 15.8.4 da ABNT NBR 6118:2014, assim a excentricidade acidental é dada pela expressão 3.12:

$$
e_{c c}=\left(\frac{M_{s g}}{N_{s g}}+e_{a}\right) \cdot\left(2,718^{\frac{\varphi N_{s g}}{N_{e}-N_{s g}}}-1\right)
$$

Sendo:

a) $e_{a}$ a excentricidade devida às imperfeições locais;

b) $M_{s g}$ e $N_{s g}$ os esforços solicitantes devidos à combinação quase permanente;

c) $\varphi$ o coeficiente de fluência dado pela tabela 8.2 do item 8.2.11 da ABNT NBR 6118:2014;

O parâmetro $N_{e}$ é dado pela expressão 3.13:

$$
N_{e}=\frac{10 \cdot E_{c i} \cdot I_{c}}{l e^{2}}
$$

De forma que:

d) $E_{c i}$ o módulo de elasticidade tangente do concreto, dado pelo item 3.1.2 desse trabalho;

e) $I_{c}$ a inércia bruta da seção de concreto;

f) $l_{e}$ o comprimento equivalente na análise local.

As demais considerações sobre a determinação da fluência serão abordadas em itens futuros. 


\subsection{AÇO}

\subsubsection{Módulo de elasticidade}

Conforme prescrito no item 8.3.5 da ABNT NBR 6118:2014: "na falta de ensaios ou valores fornecidos pelo fabricante, o módulo de elasticidade do aço pode ser admitido igual a $210 \mathrm{GPa}$.

\subsubsection{Diagrama tensão - deformação}

O diagrama tensão-deformação do aço utilizado para análises de estado-limite de serviço e último é o preconizado pelo item 8.3.6 da ABNT NBR 6118:2014 e presente na figura 3.2. Em oposição ao caso do concreto, o diagrama tensãodeformação do aço é utilizado para as regiões de compressão e tração da peça. Dessa forma, pode-se dizer que toda a tração que a peça em análise está submetida é absorvida pelo aço da armadura.

Figura 3.2 - Diagrama tensão - deformação do aço

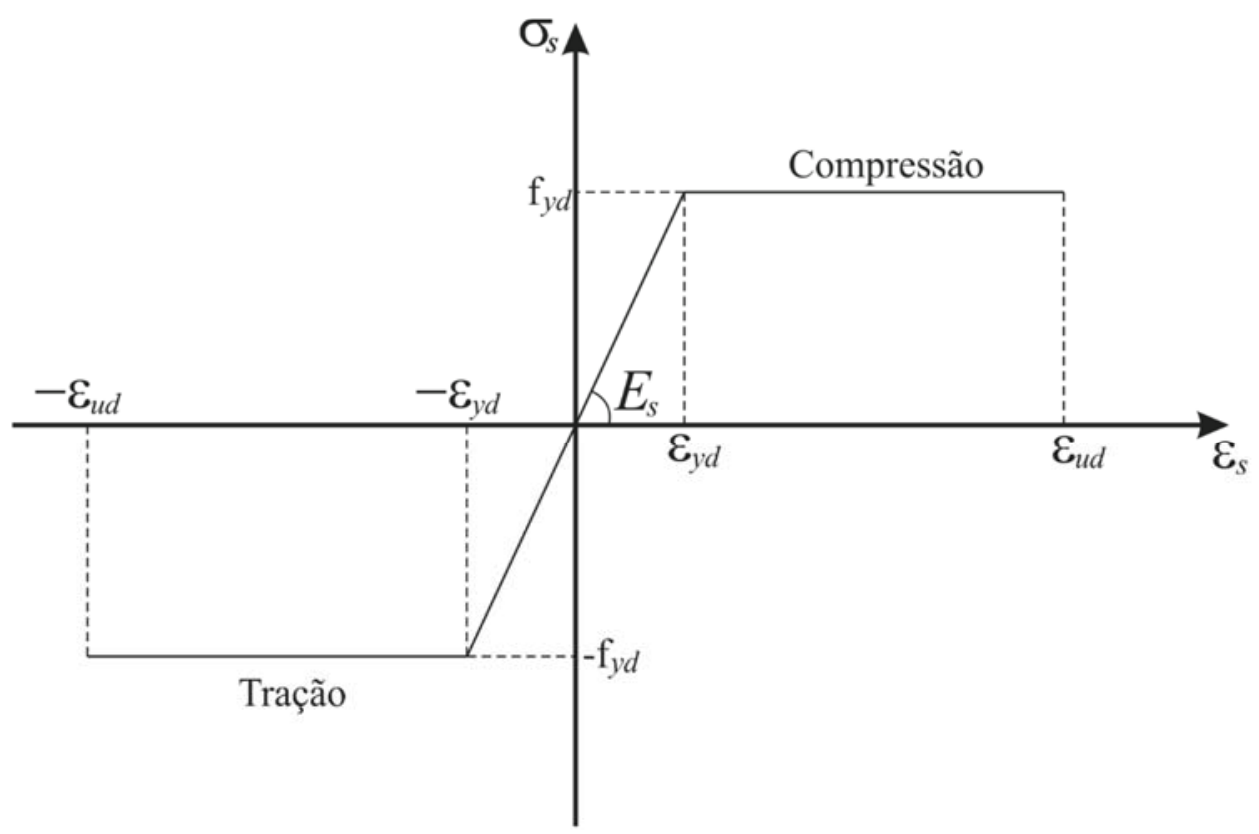

Fonte: Adaptado da ABNT NBR 6118:2014, item 8.3.6. 
A tensão de pico do diagrama é dada pela tensão de escoamento $f_{y d}$, sendo calculada pela expressão 3.14, conforme prescrito no item 12.3.1 da ABNT NBR 6118:2014:

$$
f_{y d}=\frac{f_{y k}}{\gamma_{s}}
$$

O valor característico da resistência de escoamento $f_{y k}$ e da deformação última $\varepsilon_{u d}$ deve ser obtido mediante ensaios de tração. O valor de $\varepsilon_{u d}$ adotado nesse trabalho é o definido na figura 17.1 do item 17.2.2 da ABNT NBR 6118:2014. Dessa forma, o valor é dado na expressão 3.15 :

$$
\varepsilon_{u d}=10 \%
$$

O valor da deformação de escoamento $\varepsilon_{y d}$ é uma relação entre a tensão de escoamento $f_{y d}$ e o módulo de elasticidade do aço, dessa forma percebe-se que é dependente do tipo de aço adotado, é calculada pela expressão 3.16:

$$
\varepsilon_{y d}=\frac{f_{y d}}{E_{s}}
$$

O coeficiente de ponderação das resistências no estado-limite último $\gamma_{s}$ é dependente do tipo de combinação utilizada para verificação do estado-limite último. Nesse trabalho a combinação adotada será a normal, e, portanto, o coeficiente $\gamma_{s}$ assume o valor de 1,15.

O diagrama é valido para intervalos de temperatura entre $-20^{\circ} \mathrm{C}$ e $150^{\circ} \mathrm{C}$.

Da figura 3.2 verifica-se que o diagrama possui duas regiões definidas:

a) Comportamento linear para $\left|\varepsilon_{s}\right| \leq\left|\varepsilon_{y d}\right|$ :

$$
\sigma_{s d}=f_{y d} \cdot \frac{\varepsilon_{s}}{\left|\varepsilon_{y d}\right|}
$$

b) Patamar de escoamento para $\left|\varepsilon_{s}\right|>\left|\varepsilon_{y d}\right|$ :

$$
\begin{aligned}
& \text { Se } \varepsilon_{s}>\varepsilon_{y d} \rightarrow \sigma_{s d}=f_{y d} \\
& \text { Se } \varepsilon_{s}<-\varepsilon_{y d} \rightarrow \sigma_{s d}=-f_{y d}
\end{aligned}
$$




\section{$4 \quad$ Hipóteses fundamentais do estado-limite último}

O item 17.2 da ABNT NBR 6118:2014 fundamenta-se nas diretrizes da determinação dos esforços resistentes de elementos lineares sujeitos a solicitações normais. Assim, insere-se nesse caso os pilares submetidos a força normal e momentos fletores.

A determinação dos esforços resistentes $N_{R d}$ e $M_{R d}$ será analisada em itens futuros. No entanto, adianta-se que os esforços resistentes determinados deverão ser maiores que os esforços solicitantes, constituindo assim a condição de segurança para flexão composta oblíqua, expressa em 4.1, 4.2 e 4.3:

$$
\begin{aligned}
M_{S d, x} & \leq M_{R d, x} \\
M_{S d, y} & \leq M_{R d, y} \\
N_{S d} & \leq N_{R d}
\end{aligned}
$$

As seguintes hipóteses básicas devem ser adotadas para a determinação dos esforços resistentes:

- Seções planas: As seções transversais permanecem planas após a deformação até a ruptura do elemento;

- $\quad$ Aderência perfeita entre aço e concreto: Considera-se que a deformação das barras passivas aderentes em tração ou compressão seja o mesmo do concreto que a envolve;

- Esforço de tração nulo no concreto: As tensões de tração do concreto, normais à seção transversal, são desprezadas.

O estado-limite último é definido quando as deformações $\left(\varepsilon_{c u}\right.$ no concreto ou $10 \%$ no aço) calculadas na seção transversal pertença a um dos domínios definidos na figura 17.1 do item 17.2.2 da ABNT NBR 6118:2014 e presente na figura 4.1 do presente trabalho: 
Com as considerações, quando houver ruptura por deformação plástica excessiva da armadura:

a) Reta a: Tração uniforme;

b) Domínio 1: Tração não uniforme, sem compressão;

c) Domínio 2: Flexão simples ou composta sem ruptura à compressão do concreto e máximo alongamento da armadura;

Figura 4.1 - Domínios de deformação para estado-limite último

Alongamento

Encurtamento

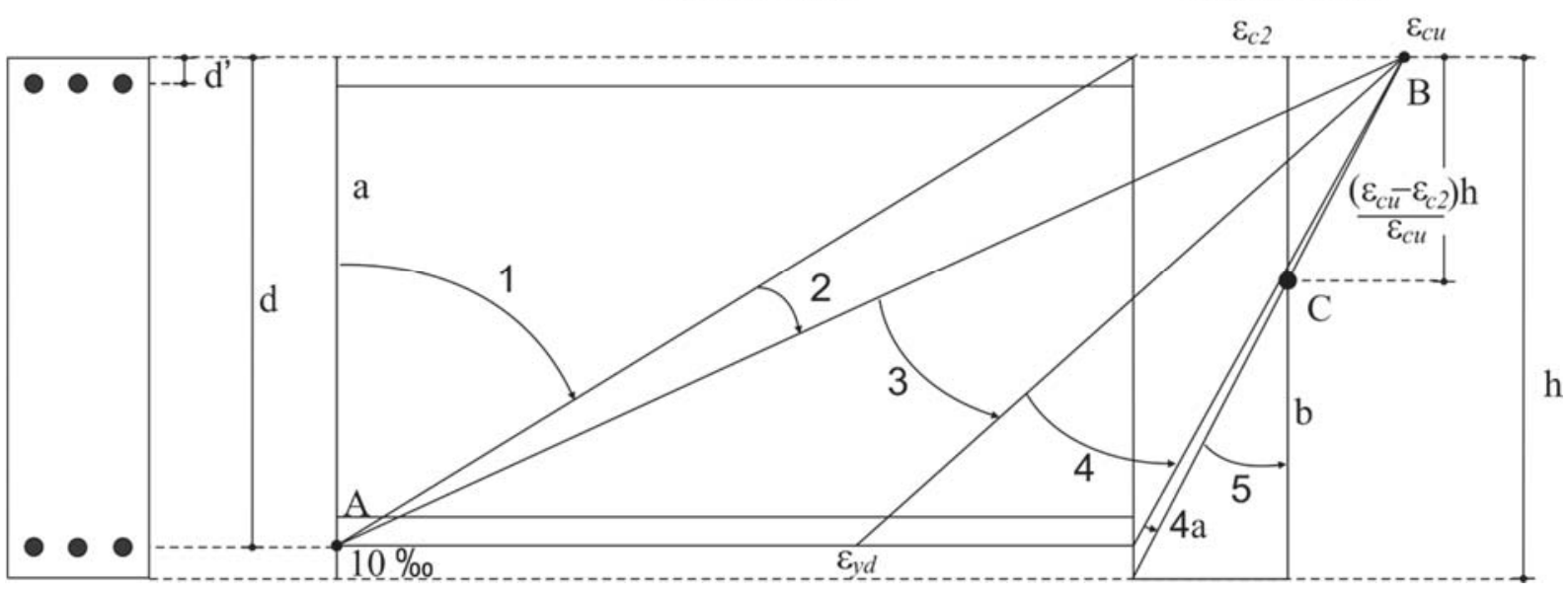

Fonte: Adaptado da ABNT NBR 6118:2014, item 17.2.2.

E com as considerações, quando houver ruptura por encurtamento-limite do concreto:

d) Domínio 3: Flexão simples ou composta com ruptura à compressão do concreto e com escoamento das armaduras;

e) Domínio 4: Flexão simples ou composta com ruptura à compressão do concreto e armadura tracionada sem escoamento;

f) Domínio 4a: Flexão composta com armaduras comprimidas;

g) Domínio 5: Compressão não uniforme, sem tração;

h) Reta $b$ : Compressão uniforme.

Durante o trabalho, a convenção de sinal para força e tensão adotada é a de que o sinal positivo seja para a compressão e o negativo para a tração. Apesar de a 
convenção adotada ser contrária à convenção internacional, ela é adequada, já que o trabalho trata de pilares, elementos que sofrem esforços de compressão.

\subsection{TIPOS DE RUÍNAS NO ESTADO-LIMITE ÚLTIMO}

Os pilares de concreto armado podem atingir a ruína de duas maneiras diferentes, dependendo da geometria e do carregamento aplicado. A ruína pode se dar por esgotamento da capacidade resistente ou por instabilidade do equilíbrio (ARAÚJO, 1984).

A ruína por esgotamento da capacidade resistente da seção é típica de estruturas pouco esbeltas, enquanto que a instabilidade do equilíbrio é mais comum em elementos de maior esbeltez (RIBEIRO, 2010).

Essa ruína por esgotamento da capacidade resistente é obtida quando uma determinada solicitação (momento fletor e força normal) gera uma distribuição de tensões solicitantes que ultrapasse as tensões resistentes do material que compõe a seção. Dessa forma, há dois possíveis casos de esgotamento da capacidade resistente, ambos relacionados ao material que compõe o concreto armado: esmagamento do concreto ou deformação excessiva da armadura.

A ruína por instabilidade do equilíbrio foi definida no Anexo A deste texto. Esse fenômeno pode ser entendido analisando a curva da figura 4.2, na qual o aumento da força até um limite crítico faz com que os deslocamentos resultantes passem de uma configuração estável para uma configuração instável. 
Figura 4.2 - Equilíbrio estável e instável para diferentes excentricidades

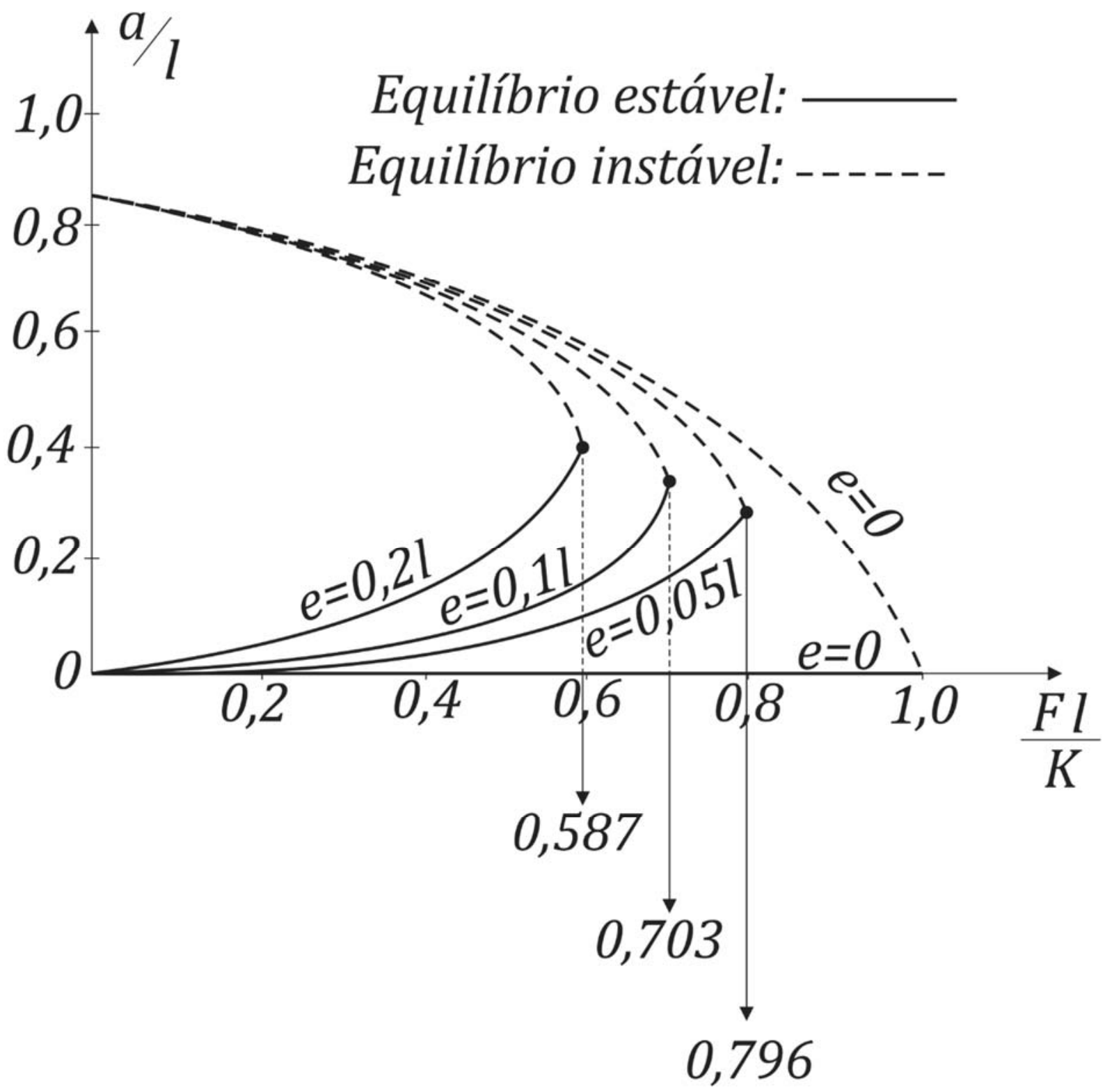

Fonte: Adaptado de SANTOS, 1987, p. 26.

Destaca-se que nesse caso a instabilidade pode ser alcançada sem que necessariamente haja esgotamento da capacidade resistente da seção, ou seja, a seção ainda é capaz de absorver esforços, porém, o aumento dos esforços devidos aos efeitos de $2^{\mathrm{a}}$ ordem faz com que a seção atinja seu estado-limite último.

Efeitos de $2^{a}$ ordem são computados quando a análise do equilíbrio é efetuada considerando a configuração deformada da estrutura. São somados àqueles obtidos em uma análise de primeira ordem, na qual o equilíbrio da estrutura é estudado na configuração geométrica inicial (ABNT NBR 6118:2014). Após ser atingida essa 
condição ocorre um fenômeno irreversível, pois os deslocamentos transversais do eixo aumentam e, consequentemente, os momentos fletores de segunda ordem também crescem, ocorrendo ruptura da seção.

Assim, o estudo dos efeitos locais de $2^{a}$ ordem é essencial para o dimensionamento de pilares de concreto armado, já que eles definem qual o tipo de ruína que a peça em análise atinge no estado-limite último.

Esse fenômeno é mais bem entendido considerando a análise de três pilares de mesma seção transversal, mesma distribuição e taxa de armadura, mesma classe de concreto e tipo de aço, conforme indicado na figura 4.3, de forma que o pilar 1 seja pouco esbelto, o pilar 2, moderadamente esbelto, e o pilar 3, muito esbelto.

Figura 4.3 - Casos de pilares e tipos de ruínas
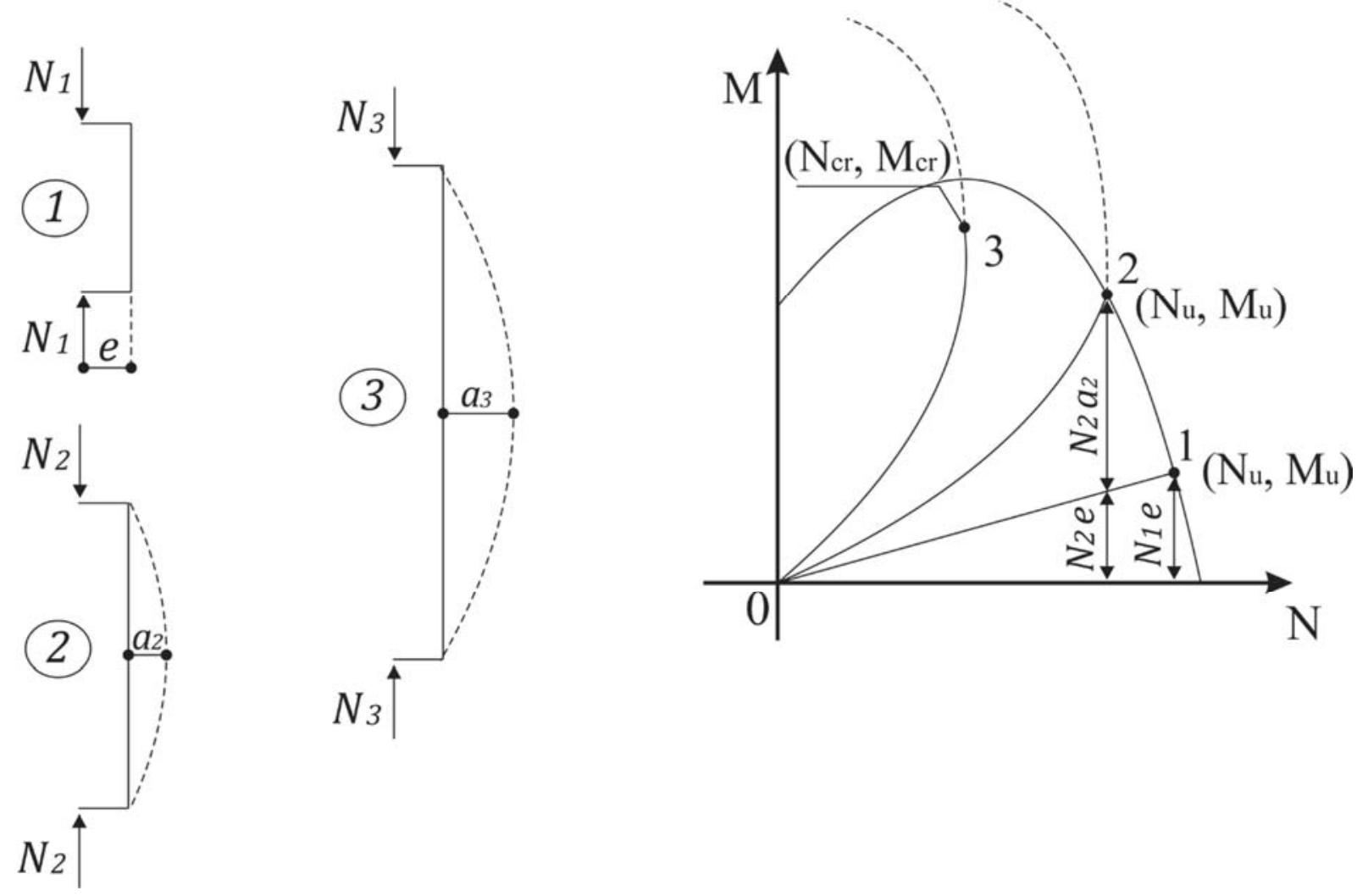

Fonte: Adaptado de SANTOS, 1987, p. 36.

Nesse exemplo, a excentricidade e é a mesma para todos os pilares, e aumenta-se a força de compressão $N$ até o estado-limite último de cada pilar. $O$ diagrama da figura 4.3 demonstra a capacidade resistente da seção, ou seja, o par de força normal e momento fletor que gera deformações de estado-limite último, como definido no item 4 deste texto. 
O pilar 1 é pouco esbelto, logo os efeitos de $2^{\mathrm{a}}$ ordem podem ser desprezados, de forma que apenas se considere o momento fletor $N_{1} \cdot e$. Assim, os pares $(N, M)$ solicitantes configuram uma reta, com $N$ crescente e $e$ fixo. $O$ ponto 1 indica que a reta alcançou o diagrama de interação $N-M$, mostrando que houve esgotamento da resistência da seção, ou seja, os esforços atingem valores últimos. Assim, o par $\left(N_{U}, M_{U}\right)$ representa a capacidade resistente do pilar 1.

O pilar 2 é moderadamente esbelto, e assim os efeitos de $2^{a}$ ordem não podem ser desprezados. Dessa forma, o momento fletor solicitante da seção é a soma da parcela de $1^{a}$ ordem com a de $2^{a}$ ordem, que surge devida à formação do deslocamento $a_{2}$, configurando uma curva. O ponto 2 indica que a curva também alcançou o diagrama de interação e a ruína se dá por esgotamento da seção.

O pilar 3 é muito esbelto e, portanto, os efeitos de $2^{a}$ ordem não podem ser desprezados. Porém, verifica-se que a curva de solicitações gera um estado-limite último antes da curva de interação, representado pelo ponto 3. Ou seja, ocorre um ponto limite em que a força normal $N_{3}$ atinge um valor crítico $N_{c r}$, gerando um momento fletor crítico $M_{c r}$. Assim, o pilar atinge a ruína por instabilidade. 


\section{$5 \quad$ Tipos de excentricidades}

\subsection{EXCENTRICIDADE INICIAL}

Os pilares, dependendo de sua classificação quanto à posição em planta, podem estar submetidos, predominantemente, a determinados tipos de esforços. Esses esforços são oriundos de uma análise global da estrutura submetida aos esforços do vento e outras ações, ou de uma análise simplificada com a consideração do modelo clássico de viga contínua, simplesmente apoiada nos pilares. A análise global de $2^{\mathrm{a}}$ ordem fornece os esforços na extremidade dos pilares (ABNT NBR 6118:2014).

A análise global da estrutura é efetuada através de uma modelagem numérica (elementos finitos, grelhas e pórticos espaciais). Hoje, costumeiramente utiliza-se o pórtico espacial para esse tipo de análise, no qual cada lance de pilar fica representado por uma única barra, e ao final do processamento obtêm-se as solicitações iniciais e de $2^{\mathrm{a}}$ ordem global (KIMURA, 2010).

Porém, a NBR 6118:2014 apresenta um processo aproximado para obtenção das solicitações iniciais, sem a necessidade da utilização de uma modelagem numérica. Trata-se do modelo clássico de viga contínua, simplesmente apoiada nos pilares, em que a ação do vento não é considerada (estudo das cargas verticais), e ele pode ser utilizado mediante algumas correções, entre as quais:

- $\quad$ Não podem ser considerados momentos fletores positivos menores que os que se obteriam se houvesse engastamento perfeito da viga nos apoios internos;

- Quando a viga for solidária com o pilar intermediário e a largura do apoio, medida na direção do eixo da viga, for maior que a quarta parte da altura do pilar, não pode ser considerado o momento fletor negativo de valor absoluto menor que o de engastamento perfeito nesse apoio;

- $\quad$ Quando não for realizado o cálculo exato da influência da solidariedade dos pilares com a viga, deve ser considerado, nos apoios extremos, 
momento fletor igual ao momento fletor de engastamento perfeito multiplicado pelos coeficientes estabelecidos nas seguintes relações:

- na viga:

$$
\frac{r_{\text {inf }}+r_{\text {sup }}}{r_{v i g}+r_{\text {inf }}+r_{\text {sup }}}
$$

- no tramo superior do pilar:

$$
\frac{r_{\text {sup }}}{r_{\text {vig }}+r_{\text {inf }}+r_{\text {sup }}}
$$

- no tramo inferior do pilar:

$$
\frac{r_{\text {inf }}}{r_{\text {vig }}+r_{\text {inf }}+r_{\text {sup }}}
$$

A rigidez do elemento $i$ no nó considerado, avaliada conforme a figura 5.1, é dada por:

$$
r_{i}=\frac{I_{i}}{l_{i}}
$$

Figura 5.1 - Esquema estático em apoios extremos

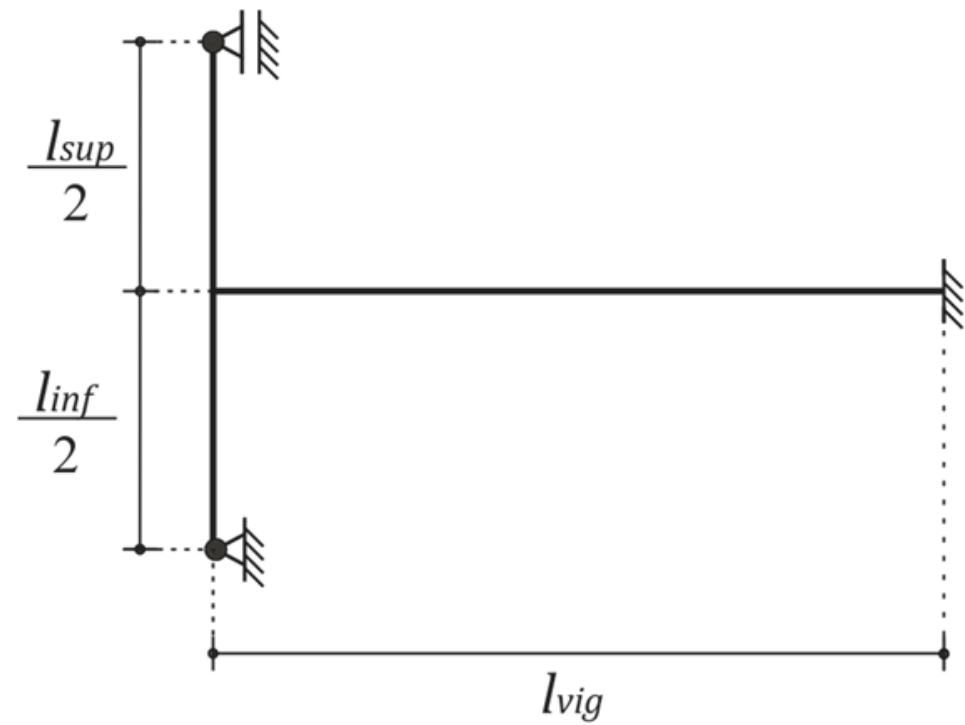

Fonte: Adaptado da NBR 6118:2014, item 14.6.6.1. 
Utilizando-se qualquer um dos processos, é possível obter a distribuição de momentos fletores atuantes no lance do pilar, e assim definir as excentricidades iniciais, obtidas pela relação entre o momento fletor em cada direção e a força normal atuante na peça.

$$
e_{i}=\frac{M_{S d}}{N_{S d}}
$$

Para o pré-dimensionamento do pilar, e para determinação de alguns parâmetros (como o índice de esbeltez limite, item 6.2.1) é necessário definir uma excentricidade máxima. Assim, define-se $e_{i A}$ como sendo uma excentricidade inicial relativa ao maior momento fletor (de maior valor absoluto) que atua em uma das extremidades da peça. Dessa forma, considerando $M_{A d}$ o maior momento fletor (em valor absoluto) atuante em uma das extremidades:

$$
e_{i A}=\frac{M_{A d}}{N_{d}}
$$

\subsection{EXCENTRICIDADE ACIDENTAL}

A excentricidade acidental é decorrente das imperfeições de construção em estruturas de concreto, responsáveis por gerar desvios dos eixos e afetar significativamente a estabilidade da estrutura. Podem ser divididas em imperfeições globais e locais.

\subsubsection{Imperfeições globais}

Imperfeições globais são consideradas no cálculo global da estrutura, por meio de parâmetros globais juntamente com os efeitos de segunda ordem, e são avaliadas na modelagem global. Elas são causadas pela ação do vento e pelo desaprumo do edifício, e são calculadas como indicado na figura 5.2, nas equações 5.7 e 5.8 e nos valores indicados em seguida. 
Figura 5.2 - Imperfeições geométricas globais

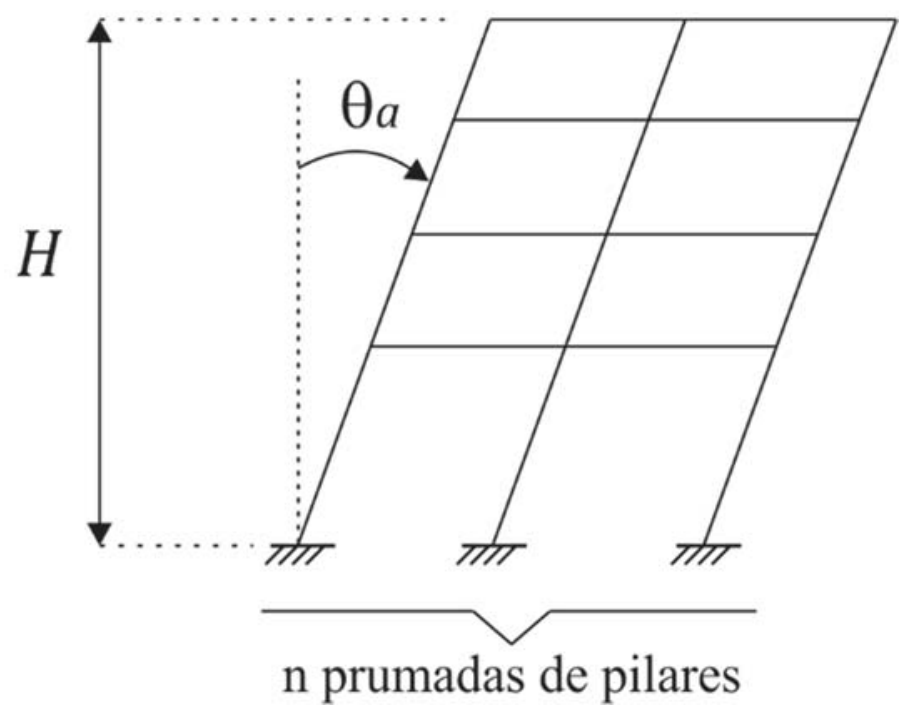

Fonte: Adaptado da NBR 6118:2014, item 11.3.3.4.1.

$$
\begin{gathered}
\theta_{a}=\theta_{1} \cdot \sqrt{\frac{1+\frac{1}{n}}{2}} \\
\theta_{1}=\frac{1}{100 \cdot \sqrt{H}}
\end{gathered}
$$

- $\quad \theta_{1 m i n}=\frac{1}{300}:$ para estruturas reticuladas e imperfeições locais;

- $\quad \theta_{1 \text { máx }}=\frac{1}{200}$;

- $\quad H$ : altura total da edificação em metros;

- $\quad n$ : número de prumadas de pilares no pórtico plano.

\subsubsection{Imperfeições locais}

As imperfeições locais podem ser consideradas pela falta de retilineidade ou desaprumo do eixo do pilar, sendo calculadas conforme a figura 5.3. Admite-se que, nos casos usuais de estruturas reticuladas, a consideração apenas da falta de retilineidade ao longo do pilar seja suficiente (ABNT NBR 6118:2014). 
Figura 5.3 - Imperfeições geométricas locais

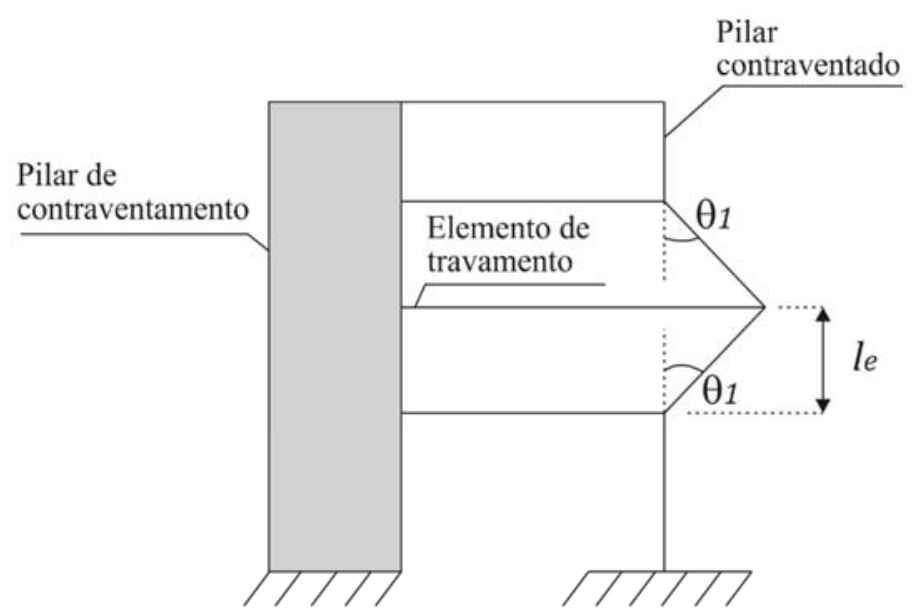

a) Elementos de travamento (tracionado ou comprimido)

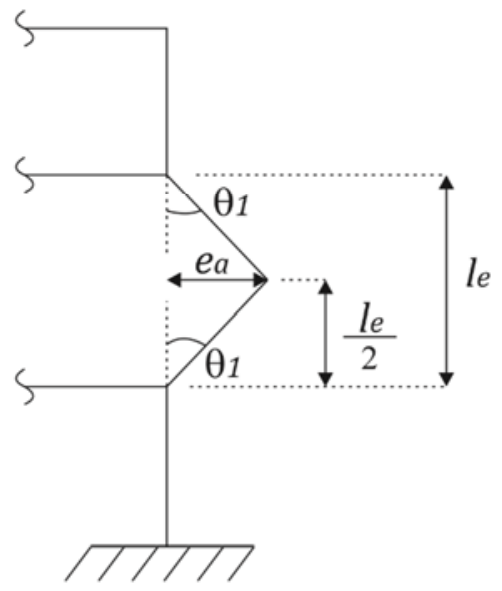

b) Falta de retilineidade do pilar

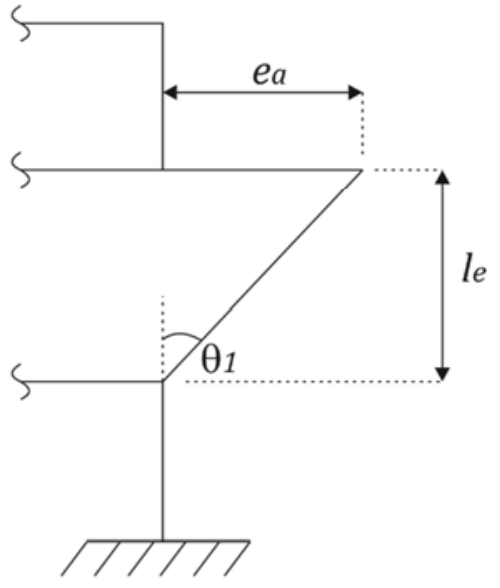

c) Desaprumo do pilar

Fonte: Adaptado da NBR 6118:2014, item 11.3.3.4.2.

$\mathrm{Na}$ figura 5.3, percebe-se que a excentricidade acidental pode assumir dois valores, dependente se a análise é feita no centro (falta de retilineidade no pilar) ou no topo e base (desaprumo do pilar) do lance do pilar. Dessa forma, obtém-se a excentricidade acidental pelas expressões 5.9 e 5.10 :

- Excentricidade acidental no topo e na base:

$$
e_{a}=\theta_{1} \cdot l_{e}
$$

- Excentricidade acidental no centro:

$$
e_{a}=\theta_{1}\left(\frac{l_{e}}{2}\right)
$$


- $\quad l_{e}$ : comprimento equivalente do pilar na direção analisada (item 6.2.2);

- $\theta_{1}$ : desaprumo do elemento vertical, dado por:

$$
\theta_{1}=\frac{1}{100 \sqrt{l_{e}}}
$$

De forma que:

$$
\theta_{1 m i n} \leq \theta_{1} \leq \theta_{1 m a ́ x}
$$

Os valores mínimo e máximo são dados por:

$$
\begin{aligned}
& \theta_{1 \text { mín }}=\frac{1}{300} \\
& \theta_{1 \text { máx }}=\frac{1}{200}
\end{aligned}
$$

Caso o pilar analisado esteja em balanço, deve-se adotar $\theta_{1}=\frac{1}{200}$.

\subsection{EXCENTRICIDADE DE $1^{\text {a }}$ ORDEM}

As excentricidades de $1^{\text {a }}$ ordem são a soma das excentricidades iniciais e acidentais. Têm-se, para a direção x e direção y, respectivamente:

$$
\begin{gathered}
e_{1 x}=e_{i A x}+e_{a x} \\
e_{1 y}=e_{i A y}+e_{a y}
\end{gathered}
$$

\subsection{EXCENTRICIDADE MÍNIMA E MOMENTO MÍNIMO}

O efeito das imperfeições locais nos pilares pode ser substituído pela consideração do momento mínimo de $1^{\text {a }}$ ordem dado a seguir:

$$
M_{1 d, \min }=N_{d} \cdot(0,015+0,03 h)
$$

- $\quad N_{d}$ é a força normal de cálculo; 
- $\quad h$ é a altura total da seção transversal na direção considerada, em metros.

Com a determinação do momento mínimo, pode-se determinar uma excentricidade mínima, dada por:

$$
e_{1, \text { min }}=\frac{M_{1 d, \text { mín }}}{N_{d}}
$$


54 | P á g i n a 


\section{$6 \quad$ Efeitos locais de $2^{\mathrm{a}}$ ordem}

Efeitos de $2^{a}$ ordem são computados quando a análise do equilíbrio é efetuada considerando a configuração deformada da estrutura. São somados àqueles obtidos em uma análise de primeira ordem, na qual o equilíbrio da estrutura é estudado na configuração geométrica inicial (ABNT NBR 6118:2014).

Quando solicitados por ações verticais e horizontais, os nós da estrutura deslocam-se horizontalmente. Os esforços de $2^{\mathrm{a}}$ ordem oriundos desses deslocamentos são chamados de efeitos globais de $2^{a}$ ordem. Nos lances de pilares, os respectivos eixos não se mantêm retilíneos, surgindo os efeitos locais de $2^{a}$ ordem, que afetam os esforços solicitantes ao longo dos eixos dos pilares (ABNT NBR 6118:2014).

A análise global de $2^{a}$ ordem fornece os esforços na extremidade dos pilares. Em seguida, deve ser realizada a análise dos efeitos locais de $2^{\mathrm{a}}$ ordem ao longo do eixo dos pilares (ABNT NBR 6118:2014).

A ABNT NBR 6118:2014 apresenta quatro métodos para determinação dos efeitos locais de $2^{\mathrm{a}}$ ordem:

a) Método do pilar-padrão com curvatura aproximada;

b) Método do pilar-padrão com rigidez $\kappa$ aproximada;

c) Método do pilar-padrão acoplado a diagramas momento fletor - força normal - curvatura;

d) Método geral.

O método geral é considerado o mais refinado dos métodos citados, pois é considerado "exato", já que considera a não linearidade geométrica de maneira não aproximada e a não linearidade física é obtida através das relações momento fletorcurvatura real de cada seção da barra discretizada.

O método do pilar-padrão com curvatura aproximada, o do pilar-padrão com rigidez $\kappa$ aproximada e o do pilar-padrão acoplado a diagramas momento fletor - força normal - curvatura são considerados métodos aproximados, já que utilizam expressões que aproximam a não linearidade física e a não linearidade geométrica. 


\subsection{DIMENSÕES MÍNIMAS}

A seção transversal de pilares, qualquer que seja sua forma, não deve apresentar como dimensão mínima um valor inferior a 19 cm (ABNT NBR 6118:2014).

Em casos especiais, permite-se a consideração de dimensões entre $19 \mathrm{~cm}$ e $14 \mathrm{~cm}$, desde que as ações, no dimensionamento, sejam multiplicadas por um coeficiente adicional $\gamma_{n}$ (ABNT NBR 6118:2014):

$$
\gamma_{n}=1,95-0,05 \cdot b
$$

Nessa expressão, $b$ é a menor dimensão da seção transversal do pilar, em centímetros.

Portanto, o coeficiente $\gamma_{n}$ deve majorar os esforços solicitantes finais de cálculo dos pilares quando de seu dimensionamento.

De qualquer maneira, em qualquer caso, não se permitem pilares com seção transversal de área inferior a $360 \mathrm{~cm}^{2}$. Alguns exemplos de seções transversais mínimas são: quadrada com $19 \mathrm{~cm}$ x $19 \mathrm{~cm}\left(361 \mathrm{~cm}^{2}\right)$ e circular com diâmetro $21,4 \mathrm{~cm}\left(360 \mathrm{~cm}^{2}\right)$. Com $\gamma_{n}=1,25$, pode ser adotada seção retangular com $14 \mathrm{~cm} \times 26 \mathrm{~cm}\left(364 \mathrm{~cm}^{2}\right)$.

Denomina-se pilar-parede ao elemento estrutural em que a maior dimensão da seção transversal é superior a cinco vezes a menor dimensão. Exemplos de seções transversais de pilares-parede: $19 \mathrm{~cm}$ x $96 \mathrm{~cm}, 25 \mathrm{~cm}$ x $126 \mathrm{~cm}$ e $14 \mathrm{~cm} \times 71 \mathrm{~cm}$ $\left(\gamma_{n}=1,25\right)$. Nesses exemplos, a maior dimensão supera em apenas $1 \mathrm{~cm}$ aquela correspondente a um pilar comum.

\subsection{DISPENSA DOS EFEITOS LOCAIS DE $2^{\mathrm{a}}$ ORDEM}

Os efeitos de $2^{a}$ ordem podem ser desprezados quando o índice de esbeltez $(\lambda)$ for menor que o valor limite $\left(\lambda_{1}\right)$ calculado como se indica no item 6.2.5. 


\subsection{1 Índice de esbeltez}

O índice de esbeltez é calculado como (ABNT NBR 6118:2014):

$$
\lambda=\frac{l_{e}}{i}
$$

\subsubsection{Comprimento equivalente}

O parâmetro $l_{e}$ é o comprimento equivalente, sendo igual a $2 l$ no caso de pilar engastado na base e livre no topo; nos demais casos, adota-se o menor entre os dois valores demonstrados na figura 6.1 e na expressão 6.3.

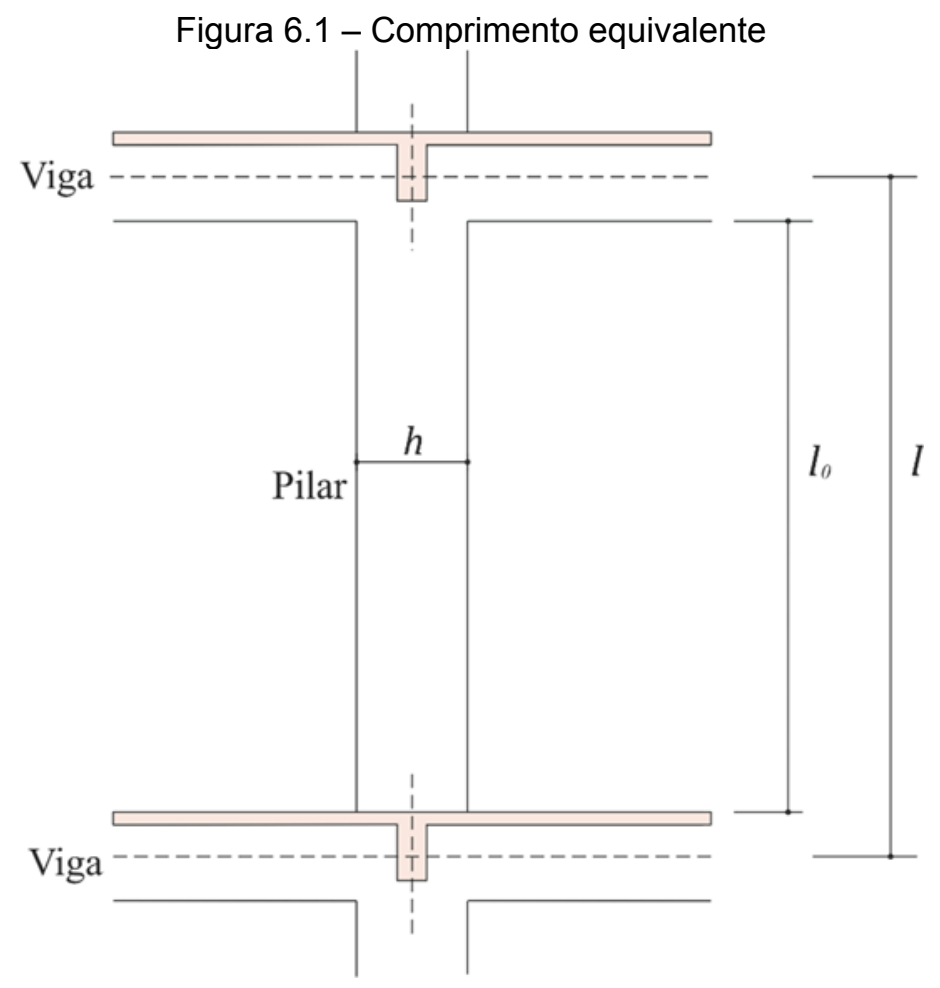

Fonte: Elaborado pelo Autor.

$$
\mathrm{l}_{\mathrm{e}} \leq\left\{\begin{array}{c}
l_{0}+h \\
l
\end{array}\right.
$$


- $\quad l_{0}$ é a distância entre faces internas dos elementos estruturais, supostos horizontais, que vinculam o pilar, ou seja, distância do topo da viga inferior à base da viga superior;

- $\quad h$ é a dimensão da seção transversal do pilar, medida no plano da estrutura em estudo;

- $\quad l$ é a distância entre os eixos dos elementos estruturais aos quais o pilar está vinculado (distância do eixo da viga inferior ao eixo da viga superior).

\subsubsection{Raio de giração}

O valor do raio de giração da seção transversal de concreto é dado pela expressão 6.4:

$$
\mathrm{i}=\sqrt{\frac{I}{A}}
$$

- $\quad I$ é o momento de inércia na direção analisada;

- $\quad A$ é a área da seção transversal.

\subsection{4 Índice de esbeltez para seção retangular}

Este trabalho analisa apenas pilares com seção transversal retangular. Assim, a expressão 6.4 pode ser simplificada para:

$$
\lambda=\frac{l_{e}}{i}=\frac{l_{e}}{\sqrt{\frac{b \cdot h^{3}}{12 \cdot b \cdot h}}}=\frac{l_{e} \cdot \sqrt{12}}{h}
$$




\subsection{5 Índice de esbeltez limite}

O valor limite $\left(\lambda_{1}\right)$ é calculado (ABNT NBR 6118:2014):

$$
\lambda_{1}=\frac{25+12,5 \cdot \frac{e_{1}}{h}}{\alpha_{b}}
$$

Com $h$ definido no item 6.2.2, deve ser adotado:

- $\quad 35 \leq \lambda_{1} \leq 90$;

- $\quad e_{1}$ igual à excentricidade de $1^{\mathrm{a}}$ ordem na extremidade do pilar onde ocorre o momento fletor de $1^{\text {a }}$ ordem de maior valor absoluto, excluindo a excentricidade acidental (ABNT NBR 6118:2014). Como definido nos itens 5.1 e 5.3 deste texto, se a excentricidade acidental é excluída, resulta $e_{1}=e_{i A}=M_{A d} / N_{d}$, com $M_{A d}$ definido na sequência deste item. Dessa forma, recomenda-se o uso de $e_{i A}$ em substituição a $e_{1}$ na expressão 6.6.

O parâmetro $\alpha_{b}$ é obtido conforme estabelecido nos itens indicados a seguir:

a) Para pilares biapoiados sem cargas transversais:

$$
\alpha_{b}=0,60+0,40 \cdot \frac{M_{B d}}{M_{A d}}
$$

- $\quad 0,4 \leq \alpha_{b} \leq 1,0$

- $\quad M_{A d}$ e $M_{B d}$ são os momentos fletores de cálculo de $1^{\text {a }}$ ordem nas extremidades do pilar, obtidos na análise de $1^{\text {a }}$ ordem no caso de estruturas de nós fixos, e os momentos fletores totais $\left(1^{\mathrm{a}}\right.$ ordem $+2^{\mathrm{a}}$ ordem global) no caso de estruturas de nós móveis. Deve ser adotado para $M_{A d}$ o maior valor absoluto presente no eixo do pilar, e para $M_{B d} \circ$ sinal positivo, se tracionar a mesma face que $M_{A d}$, e negativo, em caso contrário. 
b) Para pilares biapoiados com cargas transversais significativas ao longo da altura:

$$
\alpha_{b}=1,0
$$

c) Para pilares em balanço:

$$
\alpha_{b}=0,80+0,20 \cdot \frac{M_{C}}{M_{A}}
$$

- $\quad 0,85 \leq \alpha_{b} \leq 1,0$

- $\quad M_{A}$ seja o momento fletor de $1^{\text {a }}$ ordem no engaste e $M_{C}$, o momento fletor de $1^{\text {a }}$ ordem no meio do pilar em balanço.

d) Para pilares biapoiados ou em balanço com momentos fletores menores que o momento mínimo:

$$
\alpha_{b}=1,0
$$

Segundo a NBR 6118:2014 (item 15.8.2), os efeitos de 2a ordem em elementos isolados podem ser desprezados quando o índice de esbeltez $(\lambda)$ for menor que o valor limite $\left(\lambda_{1}\right)$.

\subsubsection{Coeficiente $\alpha_{b}$}

Scadelai (2004, apud SOUZA, 2003) define que nos pilares considerados isoladamente a excentricidade de $2^{\mathrm{a}}$ ordem varia ao longo do eixo do pilar, anulandose nos extremos destes. O fenômeno é representado na figura 6.2 para pilares com curvatura única e curvatura reversa. 
Figura 6.2 - Efeitos de $2^{\mathrm{a}}$ ordem em pilares com curvatura única (Caso 1) e curvatura reversa (Caso 2)

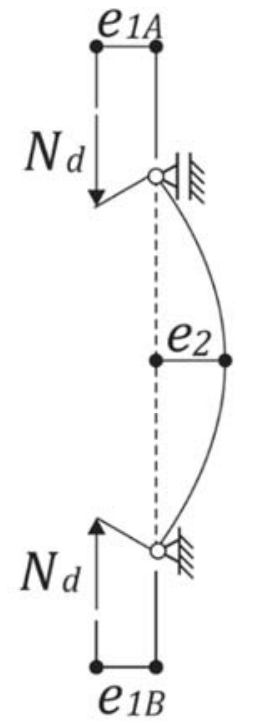

Caso 1

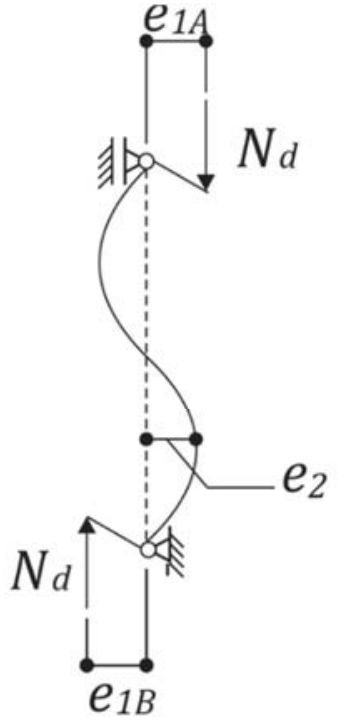

Caso 2

Fonte: Adaptado de SCADELAI, 2004, p. 31.

Pela figura 6.2 verifica-se que para pilares com curvatura única (Caso 1) e excentricidades de $1^{\text {a }}$ ordem nos extremos iguais $\left(e_{1 A}=e_{1 B}\right)$, a excentricidade de $1^{\mathrm{a}}$ ordem $\left(e_{1}\right)$ e a excentricidade de $2^{\mathrm{a}}$ ordem $\left(e_{2}\right)$ são aditivas em todos os pontos ao longo do pilar. A determinação da situação crítica é imediata e corresponde à seção do meio do vão (SCADELAI, 2004).

Porém quando as excentricidades são desiguais nas duas extremidades, a curvatura da peça é diferente e a determinação da seção crítica não é imediata. Para estes casos, a ABNT NBR 6118:2014 utiliza a equação 6.9 (item 6.2 .5 deste texto).

\subsection{DEFINIÇÃO DE CURVATURA}

A determinação das não linearidades física e geométrica é dependente do conceito de curvatura da seção. Dessa forma, é necessária a definição de curvatura.

Fusco (1981) apresenta como definição de curvatura a formulação a seguir. Considerando a figura 6.3, tem-se que:

$$
\widehat{A B}=r \cdot d \varphi=d s
$$


Figura 6.3 - Curvatura na Flexão Simples

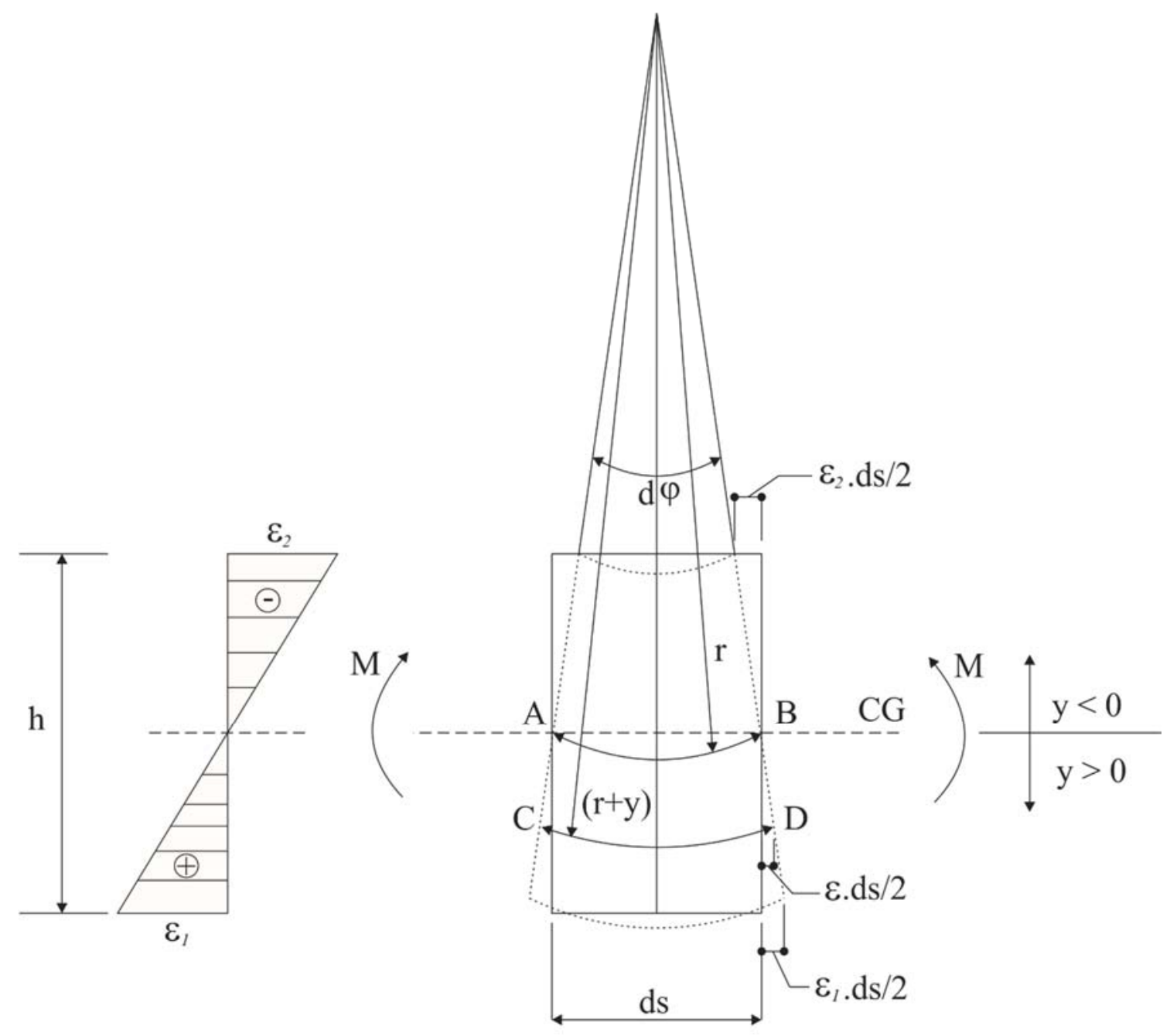

$\varepsilon>0 \quad$ ALONGAMENTO

FLEXÃO SIMPLES

Fonte: Adaptado de FUSCO, 1981, p. 168.

Da figura 6.3 e da relação 6.11 :

$$
\widehat{C D}=(r+y) \cdot d \varphi=r \cdot d \varphi+y \cdot d \varphi=d s+y \cdot d \varphi
$$

Por outro lado, considerando o alongamento da fibra CD, tem-se:

$$
\widehat{C D}=d s \cdot(1+\varepsilon)=d s+d s \cdot \varepsilon
$$

Igualando 6.12 e 6.13 :

$$
y \cdot d \varphi=\varepsilon \cdot d s
$$


Logo:

$$
\frac{1}{r}=\frac{d \varphi}{d s}=\frac{\varepsilon}{y}
$$

Aplicando a expressão 6.15 às fibras extremas, tem-se:

$$
\frac{1}{r}=\frac{\varepsilon_{1}}{y_{1}}=\frac{\varepsilon_{2}}{y_{2}}>0
$$

Da determinação dos sinais da figura 6.3 , têm-se que $\varepsilon_{1}>0$ e $y_{1}>0$ bem como $\varepsilon_{2}<0$ e $y_{2}<0$. Desse modo, resulta:

$$
\frac{1}{r}=\frac{\varepsilon_{2}-\varepsilon_{1}}{y_{2}-y_{1}}=\frac{\varepsilon_{2}+\left|\varepsilon_{1}\right|}{y_{2}+\left|y_{1}\right|}=\frac{\varepsilon_{2}+\left|\varepsilon_{1}\right|}{h}
$$

Assim, generalizando para o caso de uma viga qualquer, tem-se:

$$
\frac{1}{r}=\frac{\varepsilon_{c 1}-\varepsilon_{c 2}}{c}
$$

Nesta expressão $\varepsilon_{c 1}-\varepsilon_{c 2}$ é a diferença entre as deformações em duas fibras quaisquer da seção, e $c$ é a distância entre elas.

Caso haja linearidade física do material, têm-se que:

$$
\begin{aligned}
& \varepsilon=\frac{\sigma}{E} \\
& \sigma=\frac{M}{I} \cdot y
\end{aligned}
$$

Substituindo 6.20 em 6.19:

$$
\frac{1}{r}=\frac{\varepsilon}{y}=\frac{M}{E I}
$$


Pela expressão 6.21 verifica-se que há uma relação entre a curvatura $\frac{1}{r}$, o momento fletor interno $M$, e a rigidez $E I$, que é explorada nos métodos de dimensionamento. Verifica-se também que foi admitida a linearidade física do material, o que não ocorre em peças de concreto armado. Dessa forma, a relação entre curvatura, momento interno e rigidez não é linear.

\subsubsection{Expressão diferencial da linha elástica}

Seja a viga da figura 6.4 submetida a uma solicitação de forma que seu eixo se deforme até atingir uma situação de equilíbrio. Essa configuração deformada é denominada linha elástica, ou seja, linha elástica é uma função $y=f(x)$ que exprime a curva deformada da estrutura em relação ao eixo da viga.

Figura 6.4 - Linha elástica de uma viga submetida a uma solicitação

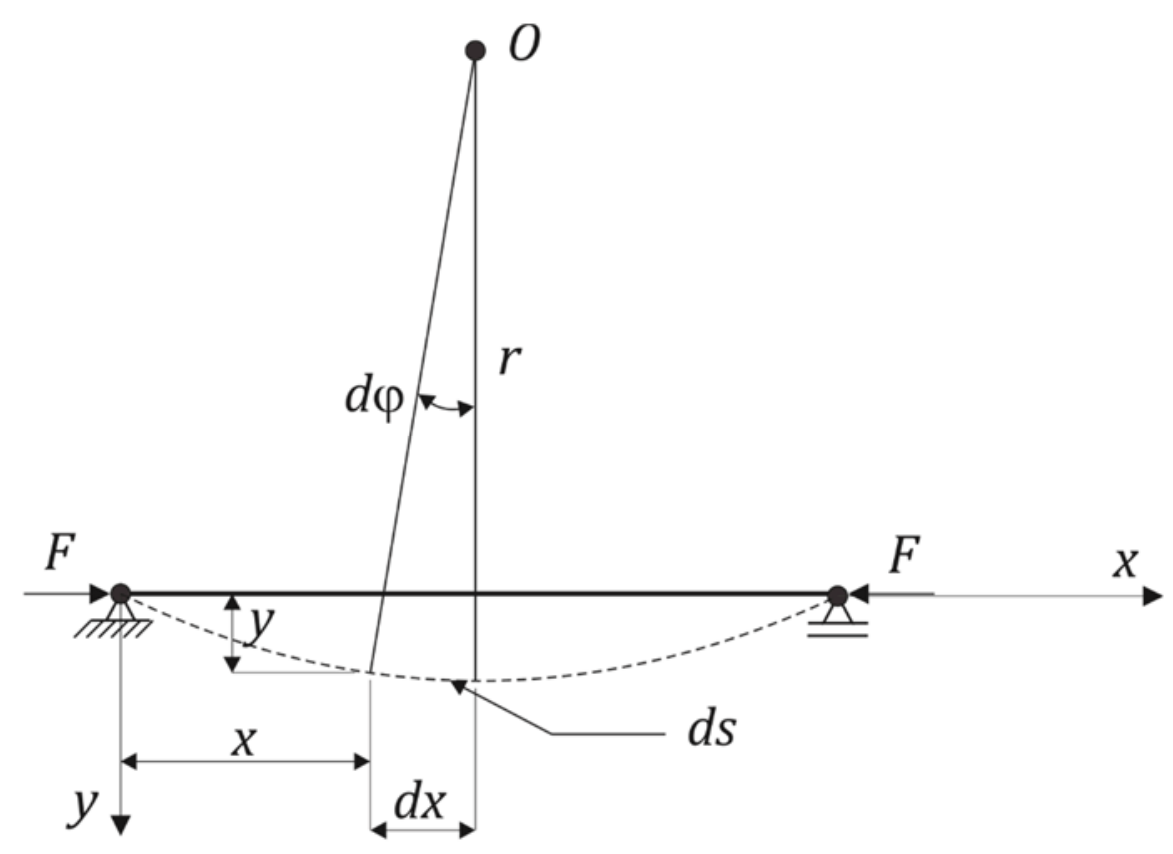

Fonte: Adaptado de SCADELAI, 2004, p. 14.

Como visto anteriormente, caso haja linearidade física do material, é possível concluir que (o sinal negativo é devido ao fato da curvatura e o momento fletor terem sinais contrários): 


$$
\frac{1}{r}=-\frac{M}{E I}
$$

Assim, será estabelecida uma relação entre os deslocamentos na direção y e o valor do momento fletor $M$, através da curvatura $1 / r$.

Da análise da figura 6.4 tem-se que:

$$
d s=r \cdot d \varphi
$$

Rearranjando 6.23:

$$
\frac{1}{r}=\frac{d \varphi}{d s}=\frac{d \varphi}{d x} \cdot \frac{d x}{d s}
$$

Mas:

$$
\operatorname{tg} \varphi=\frac{d y}{d x} \rightarrow \varphi=\operatorname{arctg}\left(\frac{d y}{d x}\right)
$$

Derivando 6.25, pela regra da cadeia, tem-se:

$$
\frac{d \varphi}{d x}=\frac{1}{1+\left(\frac{d y}{d x}\right)^{2}} \cdot \frac{d^{2} y}{d x^{2}}
$$

Considerando $d s$ muito pequeno, pode-se confundir o arco com uma reta. Assim, pode-se concluir que:

$$
d s^{2}=d x^{2}+d y^{2}
$$

Resultando em: 


$$
\frac{d s}{d x}=\left[1+\left(\frac{d y}{d x}\right)^{2}\right]^{1 / 2}
$$

Substituindo 6.26 e 6.28 em 6.24 :

$$
\frac{1}{r}=\frac{\frac{d^{2} y}{d x^{2}}}{\left[1+\left(\frac{d y}{d x}\right)^{2}\right]^{3 / 2}}=-\frac{M}{E I}
$$

A expressão 6.29 é a expressão diferencial completa da linha elástica.

Algumas simplificações podem ser realizadas, já que a parcela $(d y / d x)^{2}$ é muito pequena, resultando na expressão simplificada da linha elástica:

$$
\frac{1}{r}=\frac{d^{2} y}{d x^{2}}=y^{\prime \prime}=-\frac{M}{E I}
$$

\subsection{DIAGRAMA MOMENTO FLETOR - FORÇA NORMAL - CURVATURA}

Nos problemas de instabilidade, devem ser utilizadas equações de equilíbrio e de compatibilidade. Essas equações referem-se a deformações em serviço, ou seja, deformações inicialmente baixas que, progressivamente, tornam-se deformações últimas e ocorre ruína da peça, seja por esgotamento da resistência ou deformação excessiva, seja por perda de estabilidade (SANTOS, 1987).

A relação entre equações de equilíbrio e compatibilidade é conseguida através da grandeza curvatura, que relaciona diretamente deformações como definido na expressão 6.18. Com as deformações, utilizando-se de equações constitutivas, é possível determinar a tensão atuante na seção, e, integrando essa tensão, obter as forças resistivas do concreto e das linhas de armadura. Essas forças resistivas devem 
se igualar à força normal solicitante. Para tanto, é necessário variar a posição da linha neutra.

Com as forças resistivas, é possível efetuar o equilíbrio da seção e, assim, obter o momento fletor interno referente a uma determinada curvatura. A ruína é atingida quando alguma das deformações da seção atingir o estado-limite último definido no item 4 deste texto.

É perceptível que os diagramas são particulares e dependentes das características da seção, tais como: dimensões, arranjo e taxa de armadura, cobrimento, tipo de aço e tipo de concreto.

Como visto no item 6.3, a relação entre a curvatura, o momento fletor interno e a rigidez não é linear no concreto armado devido à não linearidade física do material. Esse fato é comprovado na figura 6.5, que analisa as fases de um diagrama momento fletor - curvatura, explicitando as fases do estado-limite de serviço.

Figura 6.5 - Diagrama momento fletor - curvatura

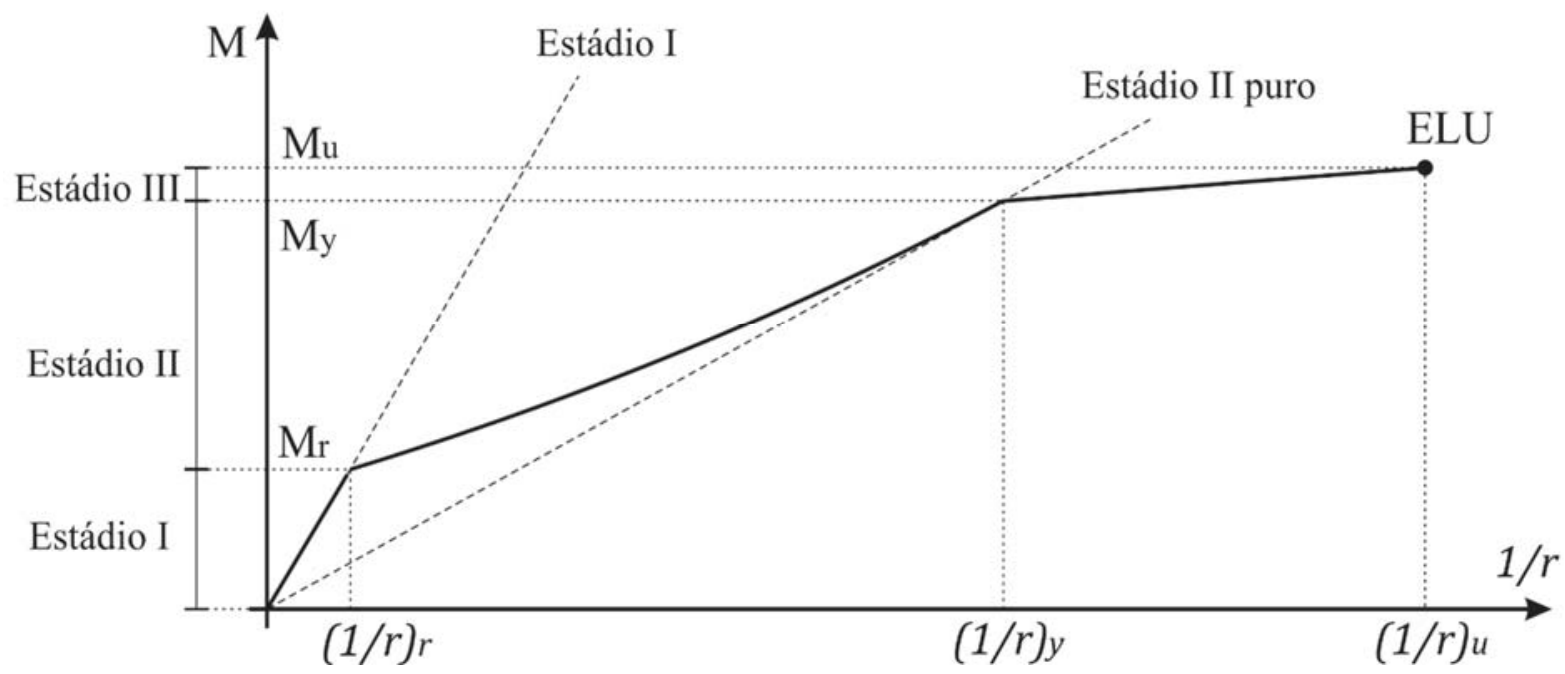

Fonte: Adaptado de KIMURA, 2010, p. 60.

Nessa figura:

a) $\quad M_{r}$ é o momento fletor de fissuração;

b) $\quad M_{y}$ é o momento fletor de escoamento;

c) $\quad M_{u}$ é o momento fletor último. 
Para melhor compreensão da figura 6.5 define-se o conceito de estádios, que correspondem às fases do diagrama de tensões do concreto em uma seção transversal submetida a flexão, desde o início do carregamento até a ruptura da seção (PINHEIRO et al., 2016).

\subsubsection{Estádio I}

O estádio I corresponde ao início do carregamento, de forma que as tensões atuantes são menores que a resistência do concreto à tração, ou seja, o concreto resiste à tração. As tensões são de baixa intensidade e o diagrama de tensões é linear, valendo, portanto, a lei de Hooke.

Figura 6.6 - Estádio I

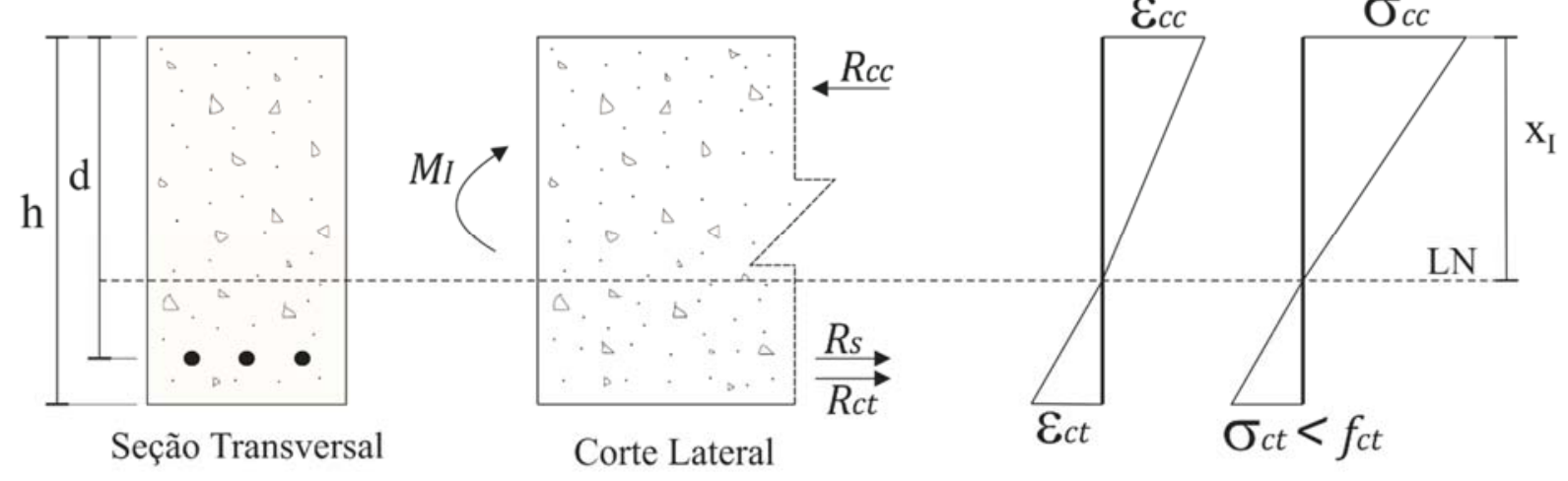

Fonte: Adaptado de PINHEIRO et al., 2016, p. 4.12.

\subsubsection{Estádio II}

No estádio II a seção já se encontra fissurada na região de tração, portanto o concreto não resiste mais a esse esforço, sendo desprezada a contribuição do concreto à tração. $O$ concreto comprimido apresenta deformações abaixo de $\varepsilon_{c 2}$, de forma que o diagrama ainda seja linear, ou seja, ainda é válida a lei de Hooke. 
Figura 6.7 - Estádio II

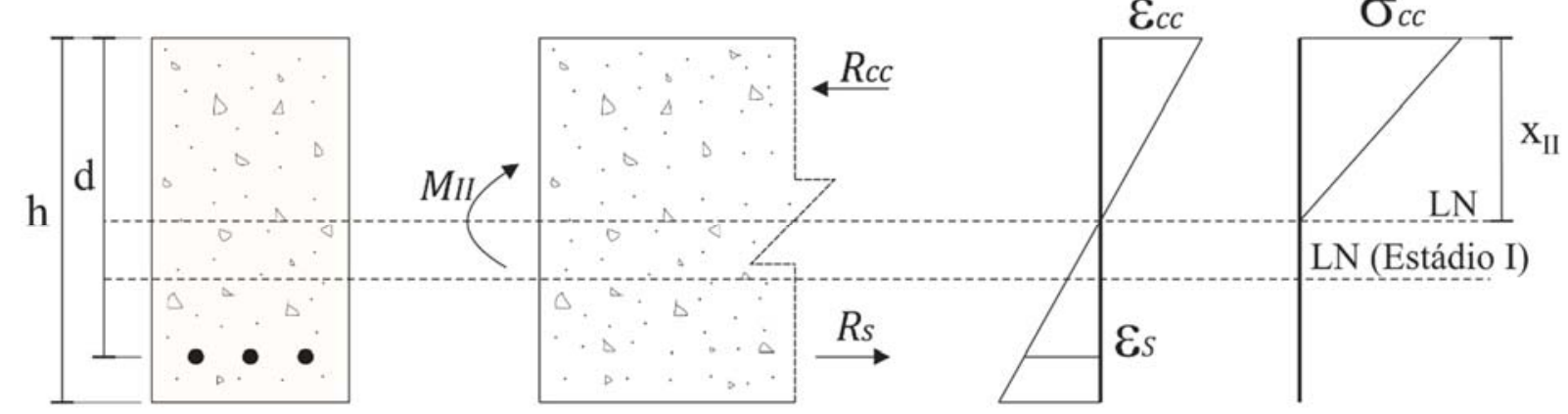

Seção Transversal Corte Lateral

Fonte: Adaptado de PINHEIRO et al., 2016, p. 4.13.

\subsubsection{Estádio III}

No estádio III a região comprimida da seção encontra-se plastificada e o concreto está em fase de ruptura. O diagrama deixa de ser linear e toma a forma parabólica-retangular, ou parábola-retângulo como definido no item 3.1.3 deste texto.

Figura 6.8 - Estádio III

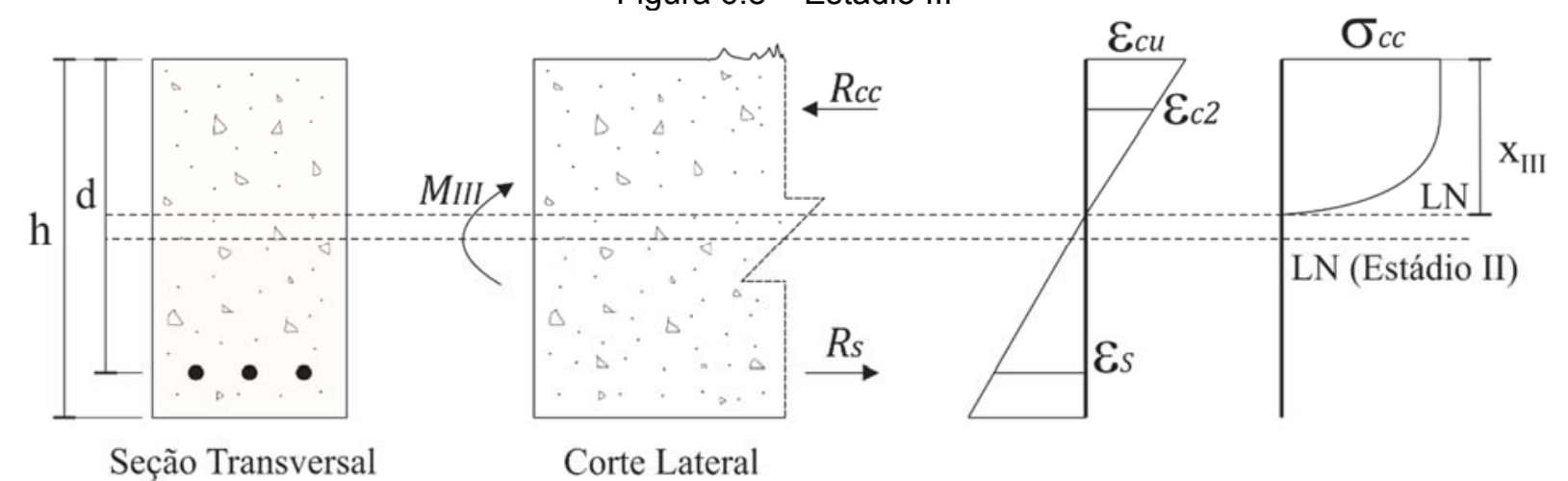

Fonte: Adaptado de PINHEIRO et al., 2016, p. 4.14.

Através da análise dos estádios e do diagrama momento fletor - curvatura, é perceptível que a rigidez $E I$ do elemento diminui progressivamente com o aumento da solicitação. Esse fenômeno é indicado pela tangente da curva momento fletor curvatura, e pela intensa fissuração a que a peça está submetida quando o carregamento é levado até a ruptura.

A determinação dos diagramas momento fletor - força normal - curvatura é de alta complexidade se efetuada manualmente, sendo necessário o auxílio de 
ferramentas computacionais. O algoritmo e a obtenção do equacionamento para a determinação dos diagramas estão presentes no apêndice A deste texto.

\subsection{NÃO LINEARIDADES}

Ao se pensar em não linearidade, deve-se imaginar uma relação entre duas variáveis em que não haja proporcionalidade. No estudo das estruturas, em sua maioria, a relação entre variáveis considera causa e efeito. Dessa forma, encontramse vários diagramas que relacionam: força (causa) e deslocamento (efeito), tensão (causa) e deformação (efeito), e em muitos casos a relação entre essas variáveis é não linear.

Sendo assim, no estudo das estruturas, definem-se duas não linearidades: não linearidade física e não linearidade geométrica.

\subsubsection{Não linearidade física}

A não linearidade física é uma propriedade intrínseca do comportamento de certos materiais quando submetidos a solicitações.

A não proporcionalidade entre causa e efeito é vista na não proporcionalidade entre a tensão e a deformação no diagrama tensão - deformação de certos materiais (SANTOS, 1987).

A figura 6.9 mostra o diagrama tensão - deformação de dois materiais genéricos: o material 1 é linear e segue a Lei de Hooke, ou seja, há proporcionalidade entre a tensão e a deformação; o material 2 é não linear, não havendo a proporcionalidade. 
Figura 6.9 - Diagrama tensão - deformação de material linear (1) e não linear (2)

1

$\sigma$

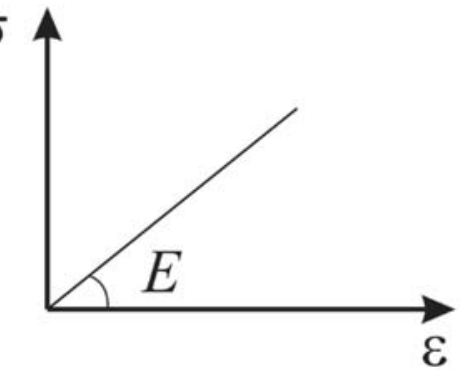

2

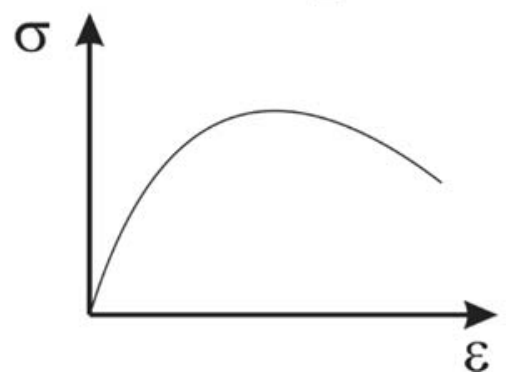

Fonte: Elaborado pelo Autor.

O concreto armado apresenta comportamento não linear, já que é resultado da associação de dois materiais não lineares: o concreto e o aço.

A não linearidade física é decorrente do comportamento do concreto armado não ser linear, devido aos efeitos da fissuração, fluência e escoamento das armaduras (PINTO; RAMALHO, 2002).

Assim, é obrigatória a consideração da não linearidade física em dimensionamento de peças de concreto armado.

\subsubsection{Não linearidade geométrica}

Os efeitos da não linearidade geométrica são aqueles advindos de uma análise do equilíbrio da estrutura em sua posição deslocada (PINTO; RAMALHO, 2002). O estudo de estruturas com sua posição deslocada é chamado de teoria de $2^{\mathrm{a}}$ ordem. Em alguns casos, como a análise de vigas, os esforços advindos de uma análise com teoria de $2^{a}$ ordem são tão pequenos que podem ser desprezados.

Porém, em casos como a instabilidade de pilares, a análise da estrutura em sua posição deformada torna-se crucial. Nesse caso, quando a força aplicada é menor que a carga crítica $\left(F_{a p l}<F_{c r}\right)$, o deslocamento resultante no meio do lance do pilar é nulo. Porém, quando $F_{a p l}>F_{c r}$, o deslocamento começa a existir.

Esse deslocamento no meio do lance do pilar é função de $F_{a p l}$, mas ele aumenta mais rapidamente que o crescimento dessa força. Assim, verifica-se a não 
proporcionalidade entre a força aplicada e o deslocamento resultante no meio do lance do pilar. O fenômeno está representado na figura 6.10 .

Figura 6.10 - Fenômeno da instabilidade
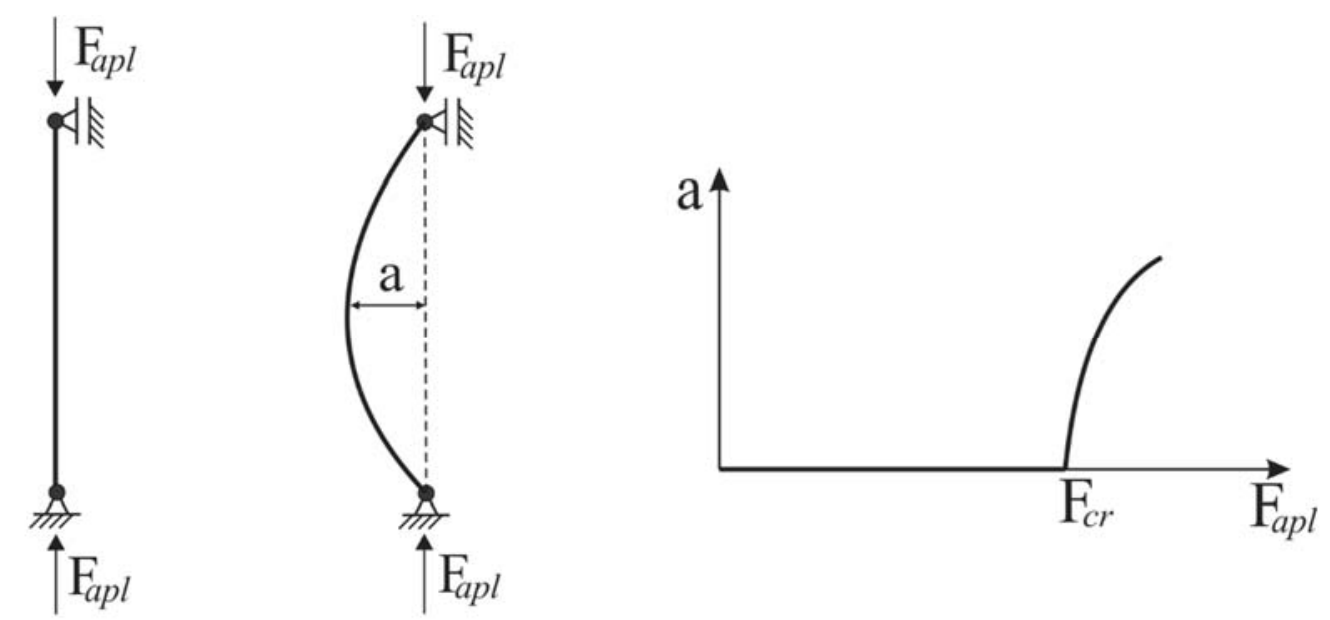

Fonte: Adaptado de SANTOS, 1987, p. 4.

\subsection{MÉTODO DO PILAR-PADRÃO COM CURVATURA APROXIMADA}

Apresentam-se neste item: como se consideram as não linearidades geométrica e física, o procedimento de cálculo e a origem da expressão da curvatura da seção crítica.

\subsubsection{Não linearidade geométrica}

A não linearidade geométrica é considerada de forma aproximada pelo conceito de pilar-padrão.

Trata-se de uma simplificação que admite que a posição de equilíbrio de um pilar em balanço, representado na figura 6.11 , seja uma curva cuja flecha $a$ no topo seja proporcional à curvatura na base, sendo essa flecha dada pela expressão 6.31:

$$
a=0,4 \cdot l^{2} \cdot\left(\frac{1}{r}\right)_{b a s e}=\frac{l_{e}^{2}}{10} \cdot\left(\frac{1}{r}\right)_{b a s e}
$$


Figura 6.11 - Pilar-Padrão

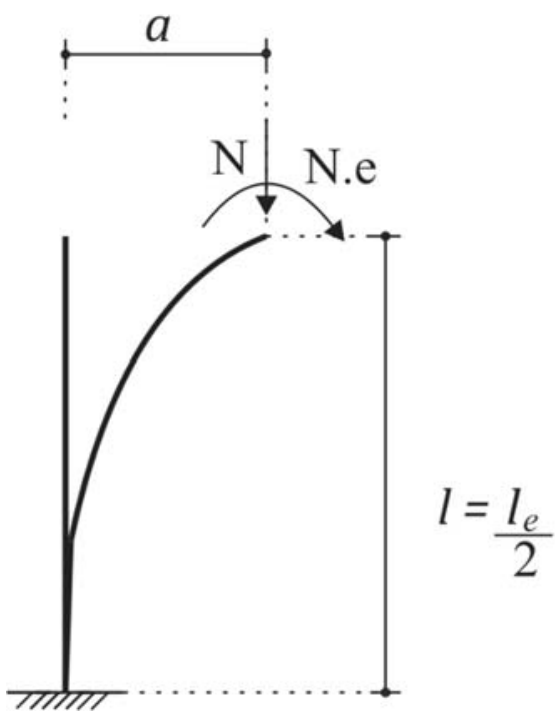

Fonte: Adaptado de FUSCO, 1981, p. 181.

Várias curvas $\mathrm{y}=\mathrm{f}(\mathrm{x})$ satisfazem a relação 6.31. A curva senoidal é uma delas. Admitindo que a deformada do pilar seja uma curva com forma senoidal, tem-se que:

$$
y=a \cdot \operatorname{sen} \frac{\pi \cdot x}{2 \cdot l}
$$

Quando $x=0 \rightarrow y=0 / x=l \rightarrow y=a$, verificando-se a validade da curva.

Derivando duas vezes a expressão 6.32, obtêm-se:

$$
\begin{aligned}
& y^{\prime}=\frac{a \cdot \pi}{2 \cdot l} \cdot \cos \frac{\pi \cdot x}{2 \cdot l} \\
& y^{\prime \prime}=-\frac{a \cdot \pi^{2}}{4 \cdot l^{2}} \cdot \operatorname{sen} \frac{\pi \cdot x}{2 \cdot l}
\end{aligned}
$$

A expressão para a curvatura da base resulta:

$$
\left(y^{\prime \prime}\right)_{x=l}=-\left(\frac{1}{r}\right)_{b a s e}=-\frac{a \cdot \pi^{2}}{4 \cdot l^{2}}
$$


Isolando o termo $a$ :

$$
a=\left(\frac{1}{r}\right)_{b a s e} \cdot \frac{4 \cdot l^{2}}{\pi^{2}}
$$

Como $\pi^{2} \approx 10$, obtém-se:

$$
a=0,4 \cdot l^{2} \cdot\left(\frac{1}{r}\right)_{b a s e}
$$

Como se tem um pilar em balanço, $l_{e}=2 l$ ou $l=l_{e} / 2$. Resulta:

$$
a=\frac{l_{e}^{2}}{10} \cdot\left(\frac{1}{r}\right)_{b a s e}
$$

Sendo assim, o método do pilar-padrão determina, aproximadamente, que a forma final da posição de equilíbrio do elemento em estudo seja uma curva senoidal (SANTOS, 1987).

\subsubsection{Não linearidade física}

Analisando a figura 6.11 verifica-se que a seção do engastamento é a seção crítica da peça, ou seja, a seção que terá o maior momento fletor dentre as seções da barra, pois:

$$
M_{\text {eng }}=N \cdot e+N \cdot a
$$

Como a análise da barra é feita em sua configuração de equilíbrio deformada, pode-se dizer que a flecha $a$ tem origem nos efeitos de $2^{a}$ ordem, ou, em outras palavras, ela é a excentricidade de $2^{\mathrm{a}}$ ordem.

Assim, a parcela do momento fletor de segunda ordem é:

$$
M_{2}=N \cdot a
$$


Ou ainda, substituindo 6.38 em 6.40 :

$$
M_{2}=N \cdot \frac{l_{e}^{2}}{10} \cdot\left(\frac{1}{r}\right)_{b a s e}
$$

Da relação 6.41 pode-se concluir que o momento fletor de $2^{\mathrm{a}}$ ordem na seção crítica é diretamente proporcional à curvatura dessa seção.

Esse conceito pode ser extrapolado para outros tipos de vinculação de pilares, e, com uma expressão aproximada da curvatura da seção crítica, pode-se obter o momento fletor total ( $1^{\mathrm{a}}$ ordem $+2^{\mathrm{a}}$ ordem) da seção crítica de qualquer pilar.

Assim, a não linearidade física do método é obtida, de maneira aproximada, através de uma expressão da curvatura da seção crítica.

\subsubsection{Procedimento de cálculo}

O método do pilar-padrão com curvatura aproximada pode ser empregado apenas em pilares com $\lambda \leq 90$, com seção constante e armadura simétrica e constante ao longo do seu eixo (ABNT NBR 6118:2014).

O momento fletor total máximo da seção crítica é calculado pela expressão 6.42:

$$
M_{d, t o t}=\alpha_{b} M_{1 d, A}+N_{d} \cdot \frac{l_{e}^{2}}{10} \cdot \frac{1}{r} \geq M_{1 d, A}
$$

A curvatura da seção crítica pode ser avaliada pela expressão 6.43:

$$
\frac{1}{r}=\frac{0,005}{h(v+0,5)} \leq \frac{0,005}{h}
$$

- $\quad \alpha_{b}$ é definido no item 6.2.5 deste texto;

- $\quad M_{1 d, A}$ é o valor de cálculo do momento fletor de $1 \stackrel{\text { a }}{\text { ordem }} M_{A d}$, definido no item 6.2.5 deste texto, sendo $M_{1 d, A} \geq M_{1 d, m i n}$; 
- $\quad N_{d}$ é a força normal solicitante de cálculo;

- $\quad l_{e}$ é o comprimento equivalente do pilar na direção analisada;

- $\quad h$ é a dimensão da seção na direção considerada;

- $\quad v=\frac{N_{d}}{A_{c} \cdot f_{c d}}$ é a força normal adimensional;

- $\quad A_{c}$ é a área da seção bruta de concreto;

- $\quad f_{c d}$ é a resistência de cálculo do concreto à compressão.

A expressão 6.42 apresenta duas parcelas: a primeira é advinda do momento fletor de primeira ordem na seção crítica, ou seja, do momento fletor máximo que atua no lance do pilar, como explicitado no item 6.2.6 deste texto; a segunda refere-se aos efeitos de segunda ordem, como explicitado no item 6.6.2.

\subsubsection{Origem da expressão da curvatura da seção crítica}

No item 6.6.2 determinou-se que a parcela do momento fletor na base (conceito que pode ser extrapolado para a seção crítica de pilares com outros tipos de vinculação) é dada por:

$$
M_{2}=N \cdot a \rightarrow M_{2}=N \cdot \frac{l_{e}^{2}}{10} \cdot\left(\frac{1}{r}\right)_{b a s e}
$$

Dessa forma, conclui-se que o momento fletor de $2^{a}$ ordem é uma função linear da curvatura $\left(\frac{1}{r}\right)_{\text {base }}$.

Considerando que a seção transversal da base seja conhecida, assim como a força normal solicitante, é possível traçar o diagrama momento fletor - força normal curvatura, que nada mais é que a curva do momento fletor interno da peça (equilíbrio das forças resistentes da seção no ELU).

$$
M_{i n t}=f\left(\frac{1}{r}\right)
$$


O momento fletor externo (solicitante) é a composição do momento fletor de $1^{\mathrm{a}}$ ordem com o momento fletor de $2^{\mathrm{a}}$ ordem:

$$
M_{\text {ext }}=M_{1}+M_{2}
$$

Substituindo o valor de $M_{2}$ dado pela expressão 6.44:

$$
M_{e x t}=M_{1}+N \cdot \frac{l_{e}^{2}}{10} \cdot\left(\frac{1}{r}\right)_{b a s e}
$$

Com base na expressão 6.47 conclui-se que o momento fletor externo também é uma função da curvatura.

Com isso, para o momento fletor externo, pode-se plotar ao diagrama momento fletor - força normal - curvatura da seção referente à base, conforme indicado na figura 6.12 .

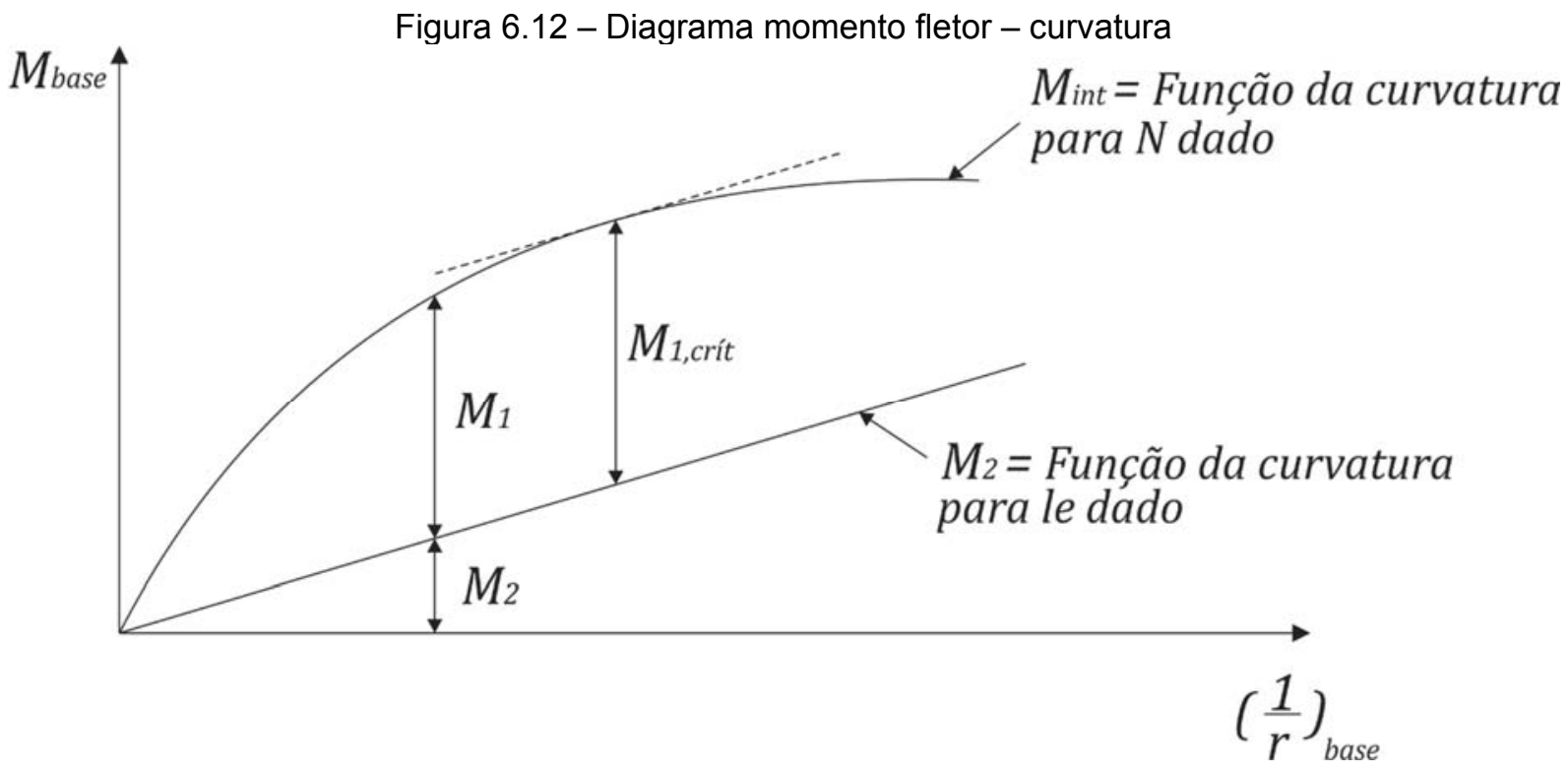

Fonte: Adaptado de FUSCO, 1981, p. 183.

Uma estrutura bem dimensionada é aquela em que há proximidade do esforço crítico com o esforço resistente. Assim, para $N_{d}=N_{u}$, a composição de esforços $M_{1}+$ $M_{2}$ deve ser próxima a $M_{R d}$. Para tanto, é necessário o conhecimento da curvatura crítica, que em alguns casos é de difícil determinação. 
Porém, no caso de pilares não muito esbeltos, a curvatura crítica é evitada escolhendo-se curvaturas próximas às últimas. Esse fato é devido à reta do momento fletor $M_{2}$ apresentar baixo coeficiente angular, e assim a curvatura crítica fica próxima à última. Esse fato é comprovado na figura 6.13.

Figura 6.13 - Curvaturas críticas

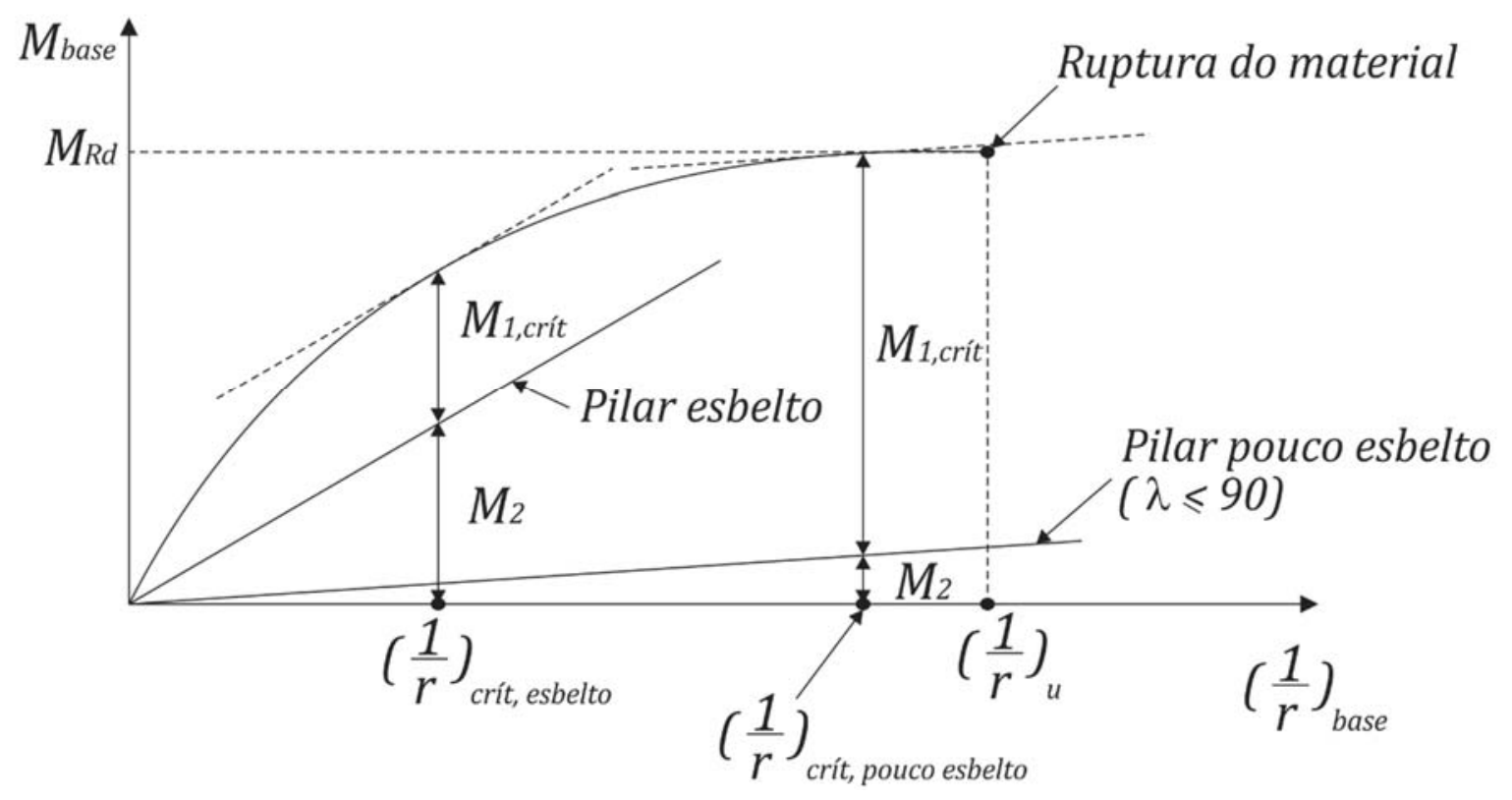

FONTE: Adaptado de FUSCO, 1981, p. 195.

Dessa forma, a antiga NB-1/78 adotava como curvatura crítica aproximada a expressão 6.48, que nada mais é a expressão da curvatura última com algumas correções.

$$
(1 / r)_{c r^{\prime} t}=\frac{0,0035+\frac{f_{y d}}{E_{s}}}{(v+0,5) \cdot h}
$$

Nesta expressão 6.48 deve-se adotar $(v+0,5) \geq 1$.

Na construção civil, é usual utilizar o aço CA-50. Dessa forma, o valor de $\frac{f_{y d}}{E_{s}}$ resulta: 


$$
\frac{f_{y d}}{E_{s}}=\frac{\frac{500}{1,15}}{210 \cdot 10^{3}}=0,00207
$$

Assim, a ABNT NBR 6118:2014 adota valor aproximado ao dado pela expressão 6.48 , considerando a curvatura crítica dada por:

$$
(1 / r)_{c r i t}=\frac{0,0035+0,002}{(v+0,5) \cdot h} \cong \frac{0,005}{(v+0,5) \cdot h}
$$

Percebe-se que a ABNT NBR 6118:2014 limita a curvatura crítica como indicado na expressão 6.51 .

$$
\frac{1}{r}=\frac{0,005}{h(v+0,5)} \leq \frac{0,005}{h}
$$

Esse fato é decorrente da NB-1/78, na qual havia um limite de $v$ de tal forma que resultasse $(v+0,5) \geq 1$. Analisando a figura 6.13, percebe-se que a curvatura crítica é menor que a última. Porém, caso o limite $(v+0,5)$ fosse menor que 1 , seriam obtidos valores de curvaturas críticas superiores à última, o que não condiz com a realidade estrutural.

O método do pilar-padrão com curvatura aproximada só é válido para peças com índice de esbeltez menor que 90, já que este limite apresenta curvaturas críticas próximas à curvatura última.

\subsection{RELAÇÕES MOMENTO FLETOR - RIGIDEZ SECANTE}

Para definição da não linearidade física, França (1991) propôs a substituição do uso das relações momento fletor - força normal - curvatura pelo emprego das relações momento fletor - força normal - rigidez secante. Essa substituição ajuda no fornecimento direto de valores que são utilizados em etapas de análises lineares nas 
quais são decompostas as análises não lineares e simplifica o processo do pilarpadrão melhorado, facilitando a obtenção dos esforços de segunda ordem.

Os processos simplificados da ABNT NBR 6118:2014 utilizam para aproximação da não linearidade geométrica o processo do pilar-padrão. Porém, para a dedução das expressões, será utilizado o processo do pilar-padrão melhorado, e quando for pertinente, serão introduzidas as peculiaridades do pilar-padrão.

\subsubsection{Definição de rigidez secante admissível}

Para utilização das relações momento fletor - rigidez secante em conjunto com o processo do pilar-padrão melhorado, é necessária a adoção de uma rigidez secante adimensional, que para seções retangulares é dada pelas expressões 6.52 e 6.53 .

$$
\begin{gathered}
\kappa_{i}=\frac{E I_{i, s e c}}{b \cdot h^{3} \cdot f_{c d}} \\
E I_{i, \text { sec }}=\frac{M_{i}}{\left(\frac{1}{r}\right)_{i}}
\end{gathered}
$$

- $\quad M_{i}$ é o valor do momento fletor para o qual a rigidez está sendo definida;

- $\left(\frac{1}{r}\right)_{i}$ é a curvatura correspondente ao momento fletor $M_{i}$;

- $\quad E I_{i, s e c}$ é a rigidez secante relativa ao momento fletor $M_{i}$ e à força normal $N_{i}$;

- $\quad h$ é a altura da seção na direção do plano de atuação do momento fletor $M_{i}$;

- $\quad f_{c d}$ é o valor de cálculo da resistência do concreto à compressão;

- $\quad b$ é a dimensão da seção na direção perpendicular à do plano de atuação do momento fletor $M_{i}$.

Percebe-se que esta definição de rigidez secante gera resultados para qualquer valor de momento fletor analisado, levando a dúvidas de qual rigidez deve ser considerada. Nos próximos itens, França (1991) apresenta um processo que define um valor único da rigidez secante para a análise da peça. 


\subsubsection{Pilar-padrão melhorado e relações momento fletor - rigidez secante}

O processo do pilar-padrão melhorado pode ser utilizado em pilares com seção e armadura constantes, e que tenham uma distribuição de momentos fletores na qual o momento fletor máximo, incluindo segunda ordem, ocorra na base da coluna. A dedução das expressões será conforme prescrito por França (1991), com base na figura 6.14 .

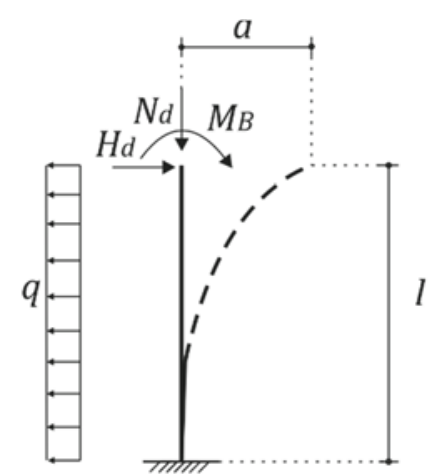

Pilar-padrão

Figura 6.14 - Pilar-padrão melhorado

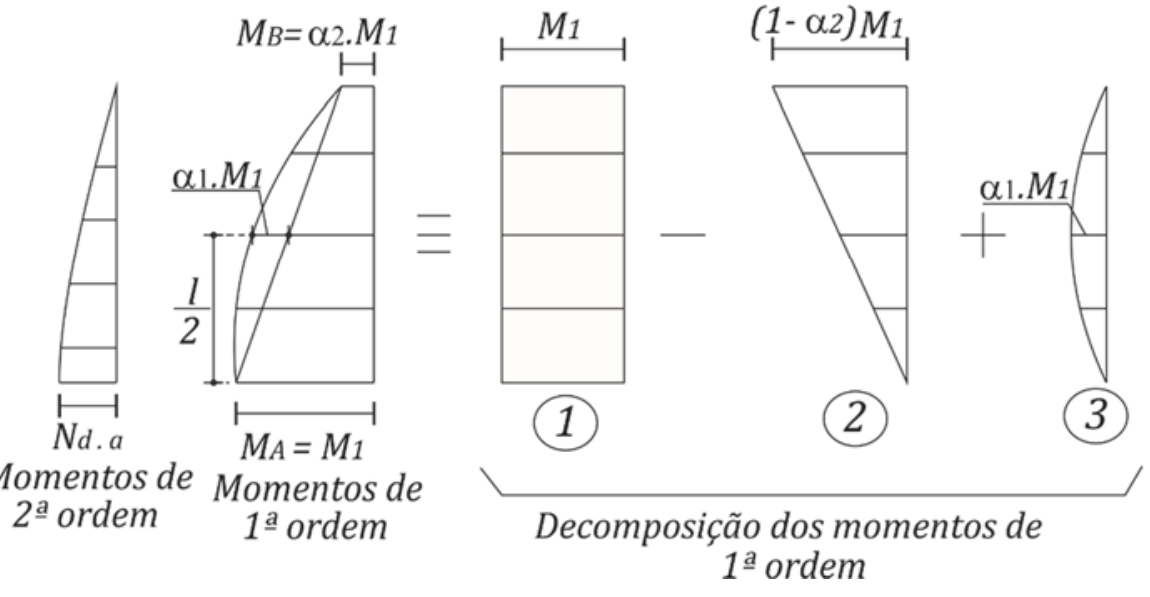

FONTE: Adaptado de FRANÇA, 1991, p. 4.6.

O pilar-padrão melhorado tem como fundamento as seguintes hipóteses:

a) A curvatura na base do pilar é decomposta em duas parcelas: uma referente aos momentos fletores de primeira ordem $\left(1 / r_{1}\right)$ e outra devida aos momentos fletores de segunda ordem $\left(1 / r_{2}\right)$, de forma que seja admitida a mesma rigidez para ambas as parcelas, dada pela reta OD (figura 6.15), ou seja, os deslocamentos de primeira e de segunda ordem são calculados com a mesma rigidez, e a curvatura da base seja a soma das duas parcelas, como indicado na expressão 6.54:

$$
1 / r_{\text {base }}=1 / r_{1}+1 / r_{2}
$$

b) Somente a parcela de deslocamento de segunda ordem $\left(a_{2}\right)$ é uma curva senoidal, e assim é dada por: 


$$
a_{2}=\frac{1}{10} \cdot l_{e}^{2} \cdot \frac{1}{r_{2}}=\frac{1}{10} \cdot l_{e}^{2} \cdot \frac{M_{2}}{E I_{i, s e c}}
$$

Figura 6.15 - Diagrama momento fletor - força normal - curvatura do pilar-padrão melhorado

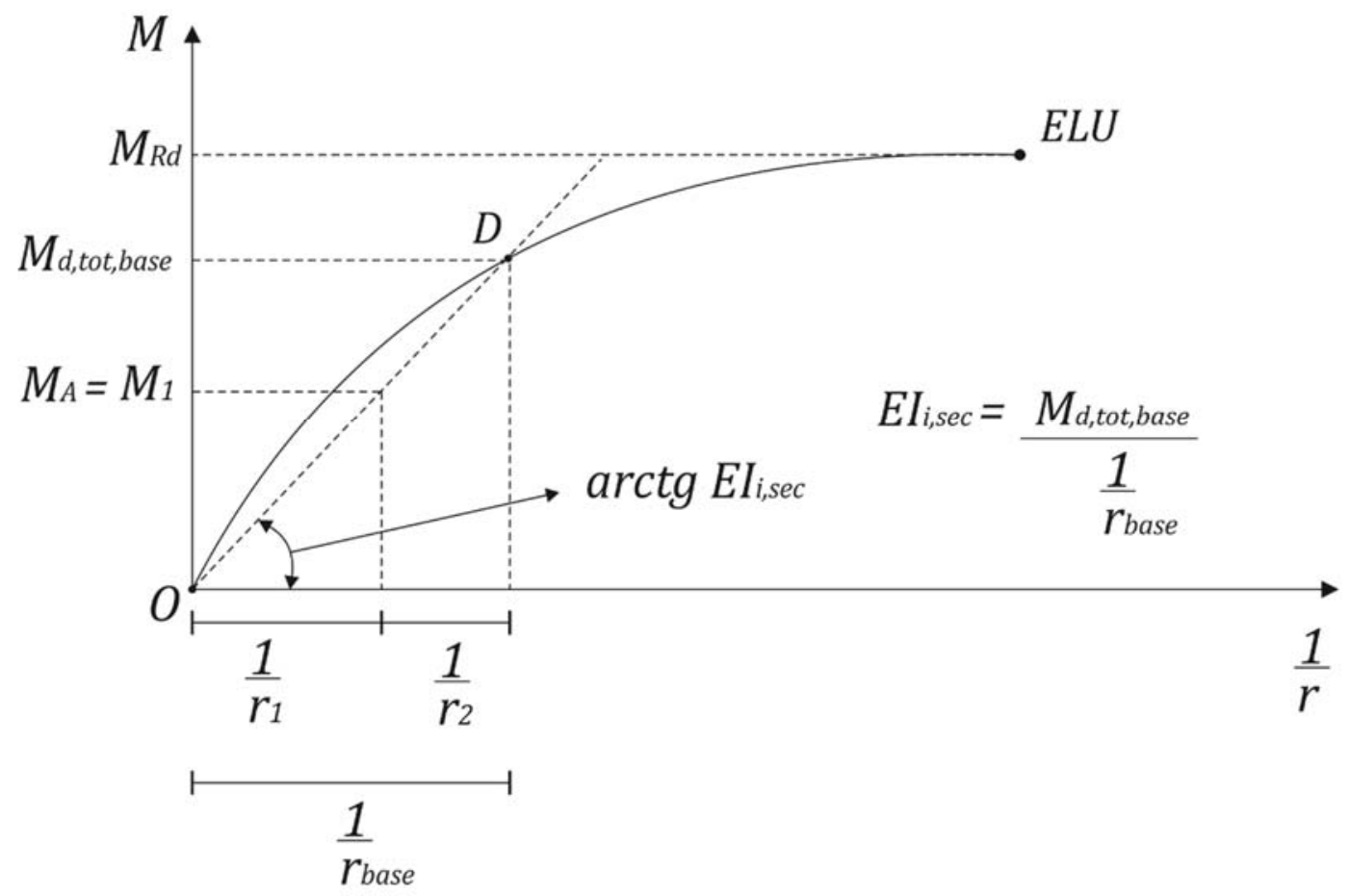

Fonte: Adaptado de FRANÇA, 1991, p. 4.8.

O deslocamento total do topo do pilar é dado pela soma das parcelas de primeira e de segunda ordem:

$$
a_{t o t}=a_{1}+a_{2}
$$

O deslocamento de primeira ordem será computado por meio da decomposição do diagrama de momentos fletores de primeira ordem (1, 2 e 3), conforme indicado na figura 6.14. O deslocamento no topo do pilar será determinado de acordo com o princípio dos trabalhos virtuais.

Dessa forma, será aplicada no topo do pilar uma força virtual unitária, conforme indicado na figura 6.16 . 
Figura 6.16 - Diagrama de momentos fletores virtuais

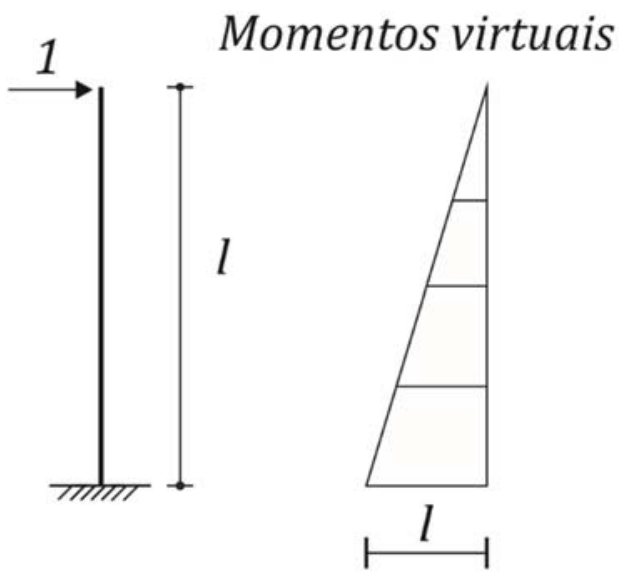

Fonte: Elaborado pelo autor.

Pelo método da carga unitária, o deslocamento no topo do pilar será dado por:

$$
a_{\text {topo }}=\int \frac{M_{\text {real }} \cdot M_{\text {virtual }}}{E I} d x
$$

Utilizando uma tabela de integração e sabendo que para pilar engastado $l=l_{e} / 2$, têm-se:

a) Parcela 1:

$$
a_{1,1}=\frac{M_{1}}{E I_{i, \mathrm{sec}}} \cdot \frac{l^{2}}{2}=0,125 \cdot l_{e}^{2} \cdot \frac{M_{1}}{E I_{i, \mathrm{sec}}}=1,25 \cdot \frac{l_{e}{ }^{2}}{10} \cdot \frac{M_{1}}{E I_{i, \mathrm{sec}}}
$$

b) Parcela 2 (Esta parcela é subtraída da decomposição):

$$
a_{1,2}=\left(1-\alpha_{2}\right) \cdot \frac{M_{1}}{E I_{i, s e c}} \cdot \frac{l^{2}}{6}=-\left(1-\alpha_{2}\right) \cdot \frac{l_{e}^{2}}{24} \cdot \frac{M_{1}}{E I_{i, s e c}}
$$

c) Parcela 3:

$$
a_{1,3}=\alpha_{1} \cdot \frac{M_{1}}{E I_{i, \sec }} \cdot \frac{l^{2}}{3}=\alpha_{1} \cdot \frac{l_{e}^{2}}{12} \cdot \frac{M_{1}}{E I_{i, \sec }}
$$

Assim, o deslocamento total de primeira ordem é dado por: 


$$
a_{1}=\left(1-\alpha_{C}\right) \cdot \frac{l_{e}{ }^{2}}{10} \cdot \frac{M_{1}}{E I_{i, \text { sec }}}
$$

Sendo:

$$
\alpha_{C}=1-\left(1,25-\frac{1-\alpha_{2}}{2,4}+\frac{\alpha_{1}}{1,2}\right)
$$

E o valor de deslocamento total será:

$$
a_{t o t}=a_{1}+a_{2}=\left[\left(1-\alpha_{C}\right) \cdot M_{1}+M_{2}\right] \cdot \frac{l_{e}{ }^{2}}{10 \cdot E I_{i, s e c}}
$$

Mas o valor do momento fletor de segunda ordem é dado por:

$$
M_{2}=N_{d} \cdot a_{t o t}
$$

Substituindo 6.63 em 6.64:

$$
\begin{gathered}
\frac{M_{2}}{N_{d}}=\left[\left(1-\alpha_{C}\right) \cdot M_{1}+M_{2}\right] \cdot \frac{l_{e}{ }^{2}}{10 \cdot E I_{i, \text { sec }}} \\
M_{2}=\left[\left(1-\alpha_{C}\right) \cdot M_{1}+M_{2}\right] \cdot \frac{N_{d}}{\frac{10 \cdot E I_{i, s e c}}{l_{e}{ }^{2}}}=\left[\left(1-\alpha_{C}\right) \cdot M_{1}+M_{2}\right] \cdot \alpha_{E}
\end{gathered}
$$

Portanto:

$$
M_{2}=\frac{\left(1-\alpha_{C}\right) \cdot \alpha_{E} \cdot M_{1}}{1-\alpha_{E}}
$$

Com:

$$
\alpha_{E}=\frac{N_{d} \cdot l_{e}^{2}}{10 \cdot E I_{i, s e c}}
$$


O momento fletor total na base é dado por:

$$
M_{d, t o t, b a s e}=M_{1}+M_{2}=M_{1} \cdot\left[1+\frac{\left(1-\alpha_{C}\right) \cdot \alpha_{E}}{1-\alpha_{E}}\right]
$$

Que resulta em:

$$
M_{d, t o t, \text { base }}=M_{1} \cdot\left[1+\frac{\left(1-\alpha_{C}\right) \cdot \alpha_{E}}{1-\alpha_{E}}\right]=M_{1 d, \text { base }} \frac{1-\alpha_{C} \cdot \alpha_{E}}{1-\alpha_{E}}
$$

Com:

$$
\alpha_{E}=\frac{N_{d} \cdot l_{e}{ }^{2}}{10 \cdot E I_{i, s e c}}=\frac{v \cdot\left(\frac{l_{e}}{h}\right)^{2}}{10 \cdot \kappa_{i}}
$$

A expressão 6.70 com $\alpha_{C}=0$ representa o resultado fornecido pelo pilarpadrão sem refinamento. Assim:

$$
M_{d, t o t, b a s e}=M_{1 d, \text { base }} \cdot \frac{1}{1-\alpha_{E}}
$$

O índice de esbeltez para peças com seção retangular é dado pela expressão 6.5 , e assim:

$$
\frac{l_{e}}{h}=\frac{\lambda}{\sqrt{12}}
$$

Utilizando 6.73 em 6.71, têm-se:

$$
\alpha_{E}=\frac{v \cdot \frac{\lambda^{2}}{12}}{10 \cdot \kappa_{i}}=\frac{\lambda^{2}}{120 \cdot \frac{\kappa_{i}}{v}}
$$


Substituindo 6.74 em 6.72 e considerando a teoria explanada no item 6.2.6, em que se pode substituir o momento fletor da seção crítica $M_{1 d \text {,base }}$ por $\alpha_{b} \cdot M_{1 d, A}$, pois trata-se de um caso de generalização da seção crítica para qualquer tipo de vinculação do pilar, resulta:

$$
M_{S d, t o t, c r i t}=\frac{\alpha_{b} \cdot M_{1 d, A}}{1-\frac{\lambda^{2}}{120 \cdot \frac{\kappa_{i}}{v}}}
$$

A expressão 6.75 está presente no item 15.8.3.3.3 da ABNT NBR 6118:2014, sendo que o parâmetro $\kappa_{i}$ pode ser admitido de duas formas: por uma expressão aproximada da rigidez ou pela linearização do diagrama momento fletor - força normal - curvatura.

\subsection{PILAR-PADRÃO E DIAGRAMAS MOMENTO FLETOR - FORÇA NORMAL - CURVATURA}

Neste item, após indicação das aproximações relativas às não linearidades geométrica e física, apresenta-se o método do pilar-padrão acoplado a diagramas momento fletor - força normal - curvatura.

\subsubsection{Não linearidade geométrica}

A não linearidade geométrica é considerada com base no conceito de pilarpadrão, ou seja, considera-se que a posição de equilíbrio deformada seja uma curva senoidal, como explicitado no item 6.6.1, sendo que a expressão do momento fletor total da seção crítica é conforme prescrito em 6.7.2. 


\subsubsection{Não linearidade física}

A não linearidade física é levada em conta por meio da linearização do diagrama momento fletor - força normal - curvatura da peça estudada. Com esse procedimento, calcula-se o parâmetro $E I_{i, s e c}$ e, utilizando a expressão 6.52, obtém-se o parâmetro $\kappa$ utilizado no dimensionamento.

\subsubsection{Apresentação do método}

O método do pilar-padrão acoplado a diagramas momento fletor - força normal - curvatura pode ser empregado apenas no cálculo de pilares com $\lambda \leq 140$. Pode ser empregado o método do pilar-padrão ou o do pilar-padrão melhorado. Se $\lambda>90$, é obrigatória a consideração dos efeitos da fluência (ABNT NBR 6118:2014).

Como explicitado no item 6.7, a substituição das relações momento fletor curvatura pelas relações momento fletor - rigidez visam simplificar a obtenção dos efeitos de segunda ordem.

No item 6.7.1, na busca de parâmetros para possibilitar essa substituição, há a definição de uma rigidez secante adimensional, em que o parâmetro $E I_{i, s e c}$ é a rigidez secante correspondente ao momento fletor $M_{i}$ e à força normal $N_{i}$. Porém, o cálculo da rigidez secante, assim posto, considera que para cada ponto do diagrama momento fletor - força normal - curvatura há uma rigidez secante correspondente.

França (1991) propõe uma linearização do diagrama momento fletor - força normal - curvatura, conforme apresentado na figura 6.17, de forma que o parâmetro rigidez secante seja único e a favor da segurança, para simplificar análises em que seja necessário o uso das relações momento fletor - rigidez. 
Figura 6.17 - Linearização do diagrama momento fletor - força normal - curvatura

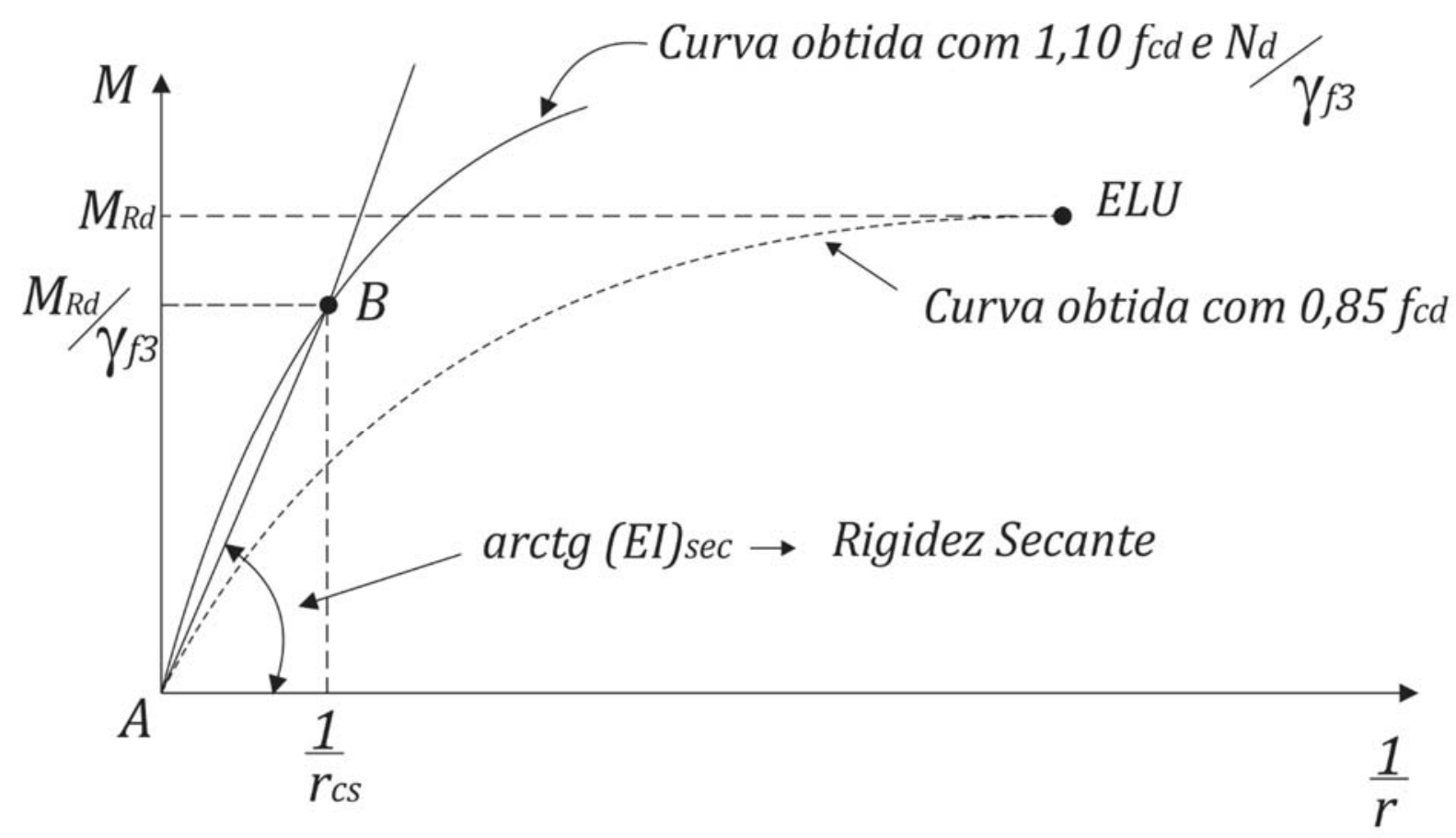

Fonte: Adaptado da ABNT NBR 6118:2014, item 15.3.1.

A curva tracejada da figura 6.17 é construída com os valores de cálculo das resistências do concreto, do aço e da força normal. Ela é utilizada para definir o esforço resistente último $M_{R d}$, ou seja, para obter a capacidade resistente da seção. As diretrizes, equacionamento e algoritmo para obtenção dessa curva estão presentes no apêndice A deste texto.

É necessária a construção de outra curva, obtida com $1,10 \cdot f_{c d}$ e $N_{R d} / \gamma_{f 3}$, de forma que se siga o mesmo algoritmo proposto no apêndice $A$ para obtenção dos diagramas momento fletor - força normal - curvatura.

A linearização proposta consiste em substituir a relação momento fletor - força normal - curvatura (calculada com $1,10 \cdot f_{c d}$ e $N_{R d} / \gamma_{f 3}$ ) pela reta que liga a origem (Ponto A) ao ponto (Ponto B) correspondente ao momento fletor resistente dividido por $\gamma_{f 3}\left(M_{R d} / \gamma_{f 3}\right)$ (FRANÇA, 1991).

A rigidez secante $\left(E I_{s e c}\right)$ é obtida através da tangente da reta $A B$, ou seja:

$$
E I_{s e c}=\frac{M_{R d} / \gamma_{f 3}}{1 / r_{c s}}
$$


Nesta expressão, $1 / r_{c S}$ é a rigidez correspondente a $M_{R d} / \gamma_{f 3}$ (Figura 6.17).

A forma adimensional da rigidez secante é dada pela expressão 6.77 (FRANÇA, 1991):

$$
\kappa_{s e c}=\frac{E I_{s e c}}{b \cdot h^{3} \cdot f_{c d}}=\frac{M_{R d} / \gamma_{f 3}}{1 / r_{c s}} \cdot \frac{1}{b \cdot h^{3} \cdot f_{c d}}
$$

- $\quad h$ é a dimensão da seção na direção analisada;

- $\quad b$ é a largura da seção na direção analisada;

- $f_{c d}$ é a resistência de cálculo do concreto à compressão.

De posse do parâmetro $\kappa_{s e c}$, é possível calcular o momento fletor total da seção crítica utilizando a expressão 6.78, cuja origem está explicada no item 6.7.2.

$$
M_{S d, t o t}=\frac{\alpha_{b} \cdot M_{1 d, A}}{1-\frac{\lambda^{2}}{120 \cdot \gamma_{f 3} \cdot \kappa_{s e c} / v}}
$$

- $\quad \alpha_{b}$ é definido no item 6.2 .5 deste texto;

- $\quad M_{1 d, A}$ é o valor de cálculo do momento fletor de 1a ordem $M_{A}$, também definido no item 6.2 .5 deste texto;

- $\quad \lambda$ é definido no item 6.2.1;

- $\quad v=\frac{N_{d}}{A_{c} \cdot f_{c d}}$ é a força normal adimensional.

- $\quad \gamma_{f 3}$ é o coeficiente de majoração que leva em conta imperfeições do modelo de cálculo, e que pode assumir o valor 1,1 ou 1,0.

\subsection{MÉTODO DO PILAR-PADRÃO COM RIGIDEZ $\kappa$ APROXIMADA}

O método do pilar-padrão com rigidez $\kappa$ (kapa) aproximada é apresentado após indicação de como são consideradas as não linearidades geométrica e física. 


\subsubsection{Não linearidade geométrica}

A não linearidade geométrica do método é baseada no conceito de pilarpadrão, ou seja, considera-se que a posição de equilíbrio deformada seja uma curva senoidal, como explicitado no item 6.6.1, sendo que a expressão do momento fletor total da seção crítica é conforme prescrito em 6.7.2.

\subsubsection{Não linearidade física}

A não linearidade física é considerada por meio de uma expressão aproximada da rigidez secante.

\subsubsection{Apresentação do método}

O método do pilar-padrão com rigidez $\kappa$ aproximada pode ser empregado apenas no cálculo de pilares $\operatorname{com} \lambda \leq 90$, com seção retangular constante e armadura simétrica e constante ao longo de seu eixo (ABNT NBR 6118:2014).

O valor de cálculo do momento fletor total máximo no pilar $\left(M_{S d, t o t}\right)$, que abrange o momento fletor de $1 \stackrel{\text { a }}{ }$ ordem e o de $2^{a}$ ordem, deve ser calculado a partir da majoração do momento fletor de 1 a ordem pela expressão:

$$
M_{S d, t o t}=\frac{\alpha_{b} \cdot M_{1 d, A}}{1-\frac{\lambda^{2}}{120\left(\frac{\kappa_{\text {aprox }}}{v}\right)}} \geq M_{1 d, A}
$$

A desigualdade $M_{S d, t o t} \geq M_{1 d, A}$ é por causa da procura pelo momento fletor máximo no pilar. Assim a expressão de majoração do momento fletor de $1^{\text {a }}$ ordem resulta no momento fletor total da seção crítica, que pode ser menor ou maior que o momento fletor máximo de $1^{\mathrm{a}}$ ordem que o pilar está submetido.

Para o valor da rigidez adimensional $\kappa$ é utilizada a expressão aproximada: 


$$
\kappa_{\text {aprox }}=32\left(1+5 \frac{M_{R d, t o t}}{h N_{S d}}\right) v
$$

Em um processo de dimensionamento, toma-se $M_{R d, t o t}=M_{S d, t o t}$. Em um processo de verificação, no qual a armadura é conhecida, $M_{R d, t o t}$ é o momento fletor resistente calculado com essa armadura e com $N_{S d}=N_{R d}$.

Nas expressões 6.79 e 6.80 têm-se que:

- $\quad \alpha_{b}$ é definido no item 6.2.5 deste texto;

- $\quad M_{1 d, A}$ é o valor de cálculo do momento fletor de 1ạ ordem $M_{A}$, também definido no item 6.2 .5 deste texto;

- $\quad N_{S d}$ é a força normal solicitante de cálculo;

- $\quad \lambda$ é o índice de esbeltez do pilar na direção considerada;

- $\quad h$ é a dimensão da seção na direção considerada;

- $\quad v=\frac{N_{d}}{A_{c} \cdot f_{c d}}$ é o valor de cálculo da força normal adimensional.

O cálculo é iterativo de forma a obter a convergência dos parâmetros $\kappa_{\text {aprox }}$ e $M_{S d, t o t}$. Porém, em um caso de dimensionamento, é possível obter uma formulação sem a necessidade do cálculo iterativo.

Rearranjando a expressão 6.80, tem-se:

$$
\frac{\kappa_{\text {aprox }}}{v}=32\left(1+5 \frac{M_{R d, t o t}}{h N_{S d}}\right)
$$

Substituindo 6.81 em 6.79 obtém-se uma expressão de segundo grau em $M_{S d, t o t}$, de forma que já se considere a igualdade $M_{R d, t o t}=M_{S d, t o t}$.

$$
a \cdot M_{S d, t o t}^{2}+b \cdot M_{S d, t o t}+c=0
$$

- $\quad a=5 \cdot h$

- $\quad b=h^{2} \cdot N_{S d}-\frac{N_{S d} \cdot l_{e}^{2}}{320}-5 \cdot h \cdot \alpha_{b} \cdot M_{1 d, A}$

- $\quad c=-N_{S d} \cdot h^{2} \cdot \alpha_{b} \cdot M_{1 d, A}$ 


$$
M_{S d, t o t}=\frac{-b+\sqrt{b^{2}-4 \cdot a \cdot c}}{2 \cdot a}
$$

As variáveis $h, N_{S d}, l_{\mathrm{e}}, \alpha_{b}$ e $M_{1 d, A}$ são as mesmas definidas anteriormente.

\subsubsection{Origem da expressão da rigidez $\kappa$ aproximada}

França (1991) propôs a construção de ábacos de iteração força normal momento fletor para obtenção do valor da rigidez secante adimensional $\left(\kappa_{\text {sec }}\right)$, utilizando-se do processo de linearização explicitado no item 6.8.3, sem a necessidade da construção dos diagramas momento fletor - força normal - curvatura da seção em análise, por meio dos procedimentos descritos a seguir.

Dada uma seção retangular com arranjo de armadura definido, são construídas curvas de iteração dos valores últimos $\left(M_{u d}, N_{u d}\right)$ para várias taxas de armadura. O algoritmo para obtenção das curvas de iteração dos valores últimos $\left(M_{u d}, N_{u d}\right)$ está indicado no apêndice B.

Para cada conjunto de valores $\left(A_{s, t o t}, N_{u d}, M_{u d}\right)$ é construído o diagrama momento fletor - força normal - curvatura linearizado (com $N=N_{d} / \gamma_{f 3}, 1,10 \cdot f_{c d}$, e $f_{y d}$ ) e calculado o valor de $1 / r_{c s}$ correspondente a $M_{u d} / \gamma_{f 3}$ e $N_{d} / \gamma_{f 3}$. O valor da rigidez secante adimensional $\kappa_{\text {sec }}$ é calculado conforme a expressão 6.77.

Dessa forma obtêm-se, para o conjunto de pontos escolhidos, os valores: $A_{s, t o t}$, $N_{u d}, M_{u d}, \kappa_{s e c}$. Utilizando-se de interpolações obtêm-se os pares $\left(N_{u d}, M_{u d}\right)$ que correspondem a valores inteiros de $\kappa_{\text {sec }}$. Unindo os pontos de mesmos valores de rigidez secante, obtêm-se as curvas de $\kappa_{\sec }$ em função de $N_{d}, M_{d}$.

Para exemplificar o problema, será utilizado o exemplo apresentado por Oliveira (2004). Assim, considere-se o diagrama de iteração $\left(N_{u d}, M_{u d}\right)$, indicado na figura 6.19 do arranjo de armadura mostrado na figura 6.18 de forma que seja utilizado aço CA-50 e $d^{\prime} / h_{x}=0,25$. 
Figura 6.18 - Esquema do arranjo de armadura

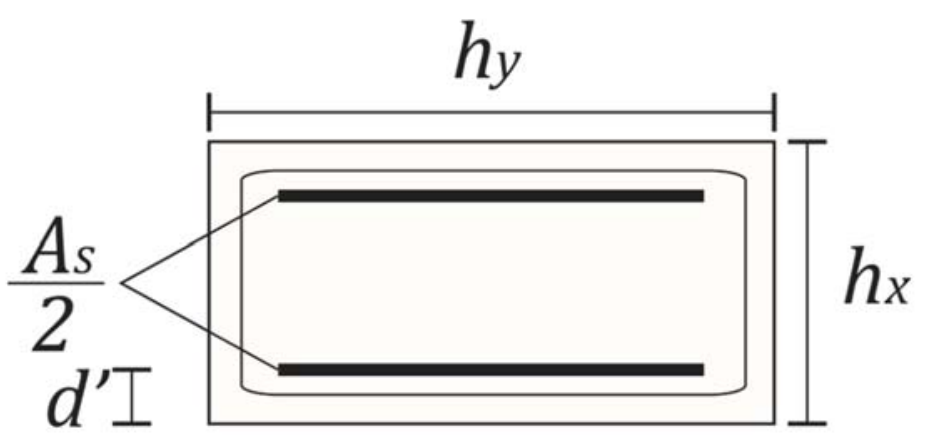

Fonte: Elaborado pelo Autor.

Figura 6.19 - Diagrama de iteração dos valores últimos para várias taxas de armadura

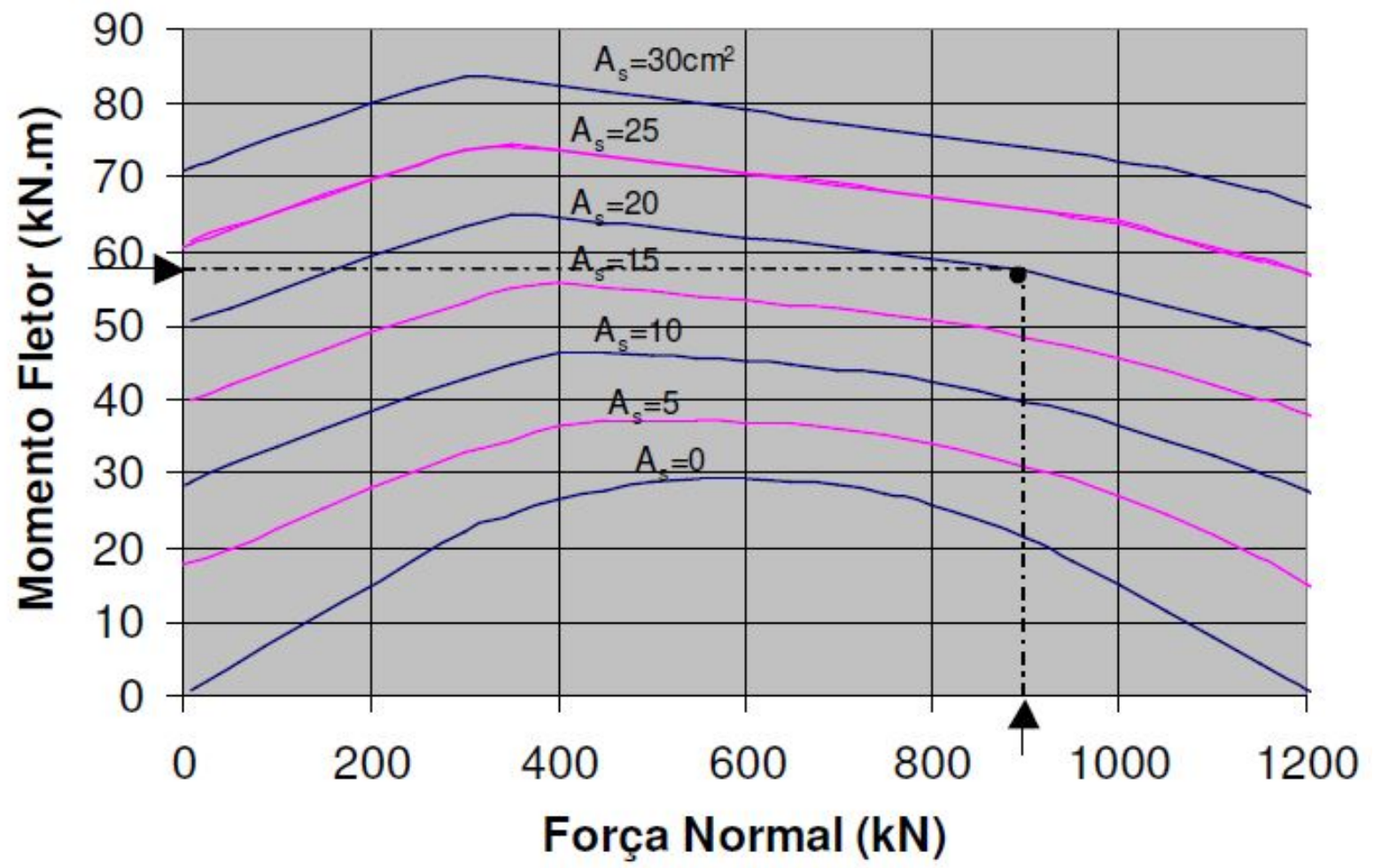

Fonte: OLIVEIRA, 2004, p. 28.

Tomando como exemplo $N_{d}=900 \mathrm{kN}$ e $M_{d}=57,5 \mathrm{kN} . \mathrm{m}$, obtém-se do diagrama da figura 6.19 a taxa de armadura $A_{s}=20 \mathrm{~cm}^{2}$. Calculando o diagrama momento fletor - força normal - curvatura com os dados da figura 6.20 (utilizando concreto (25), de forma que se obedeça o arranjo de armadura da figura 6.18, e aplicando a linearização, obtém-se o diagrama da figura 6.21. 
Figura 6.20 - Dados de armadura

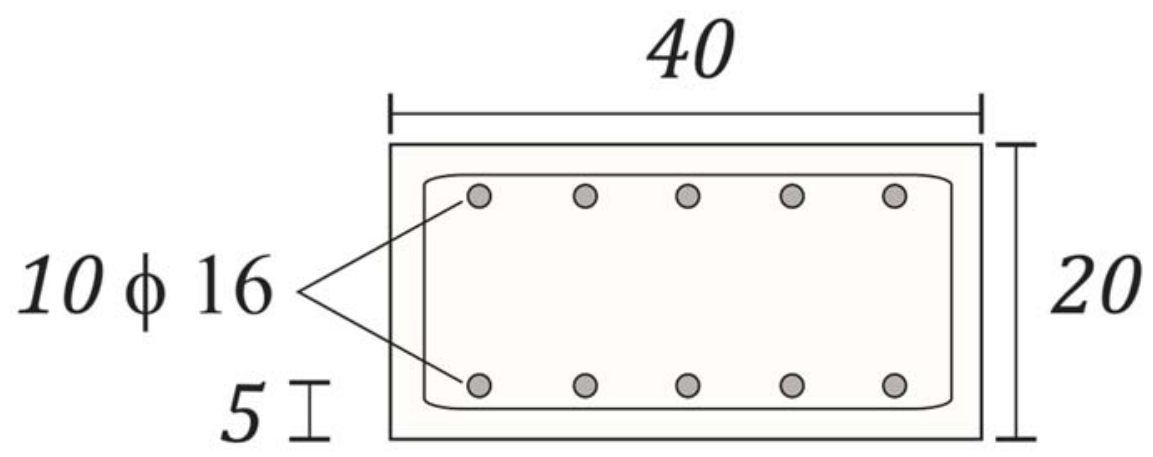

Fonte: Elaborado pelo Autor.

Figura 6.21 - Diagrama momento fletor - força normal - curvatura e linearização correspondente

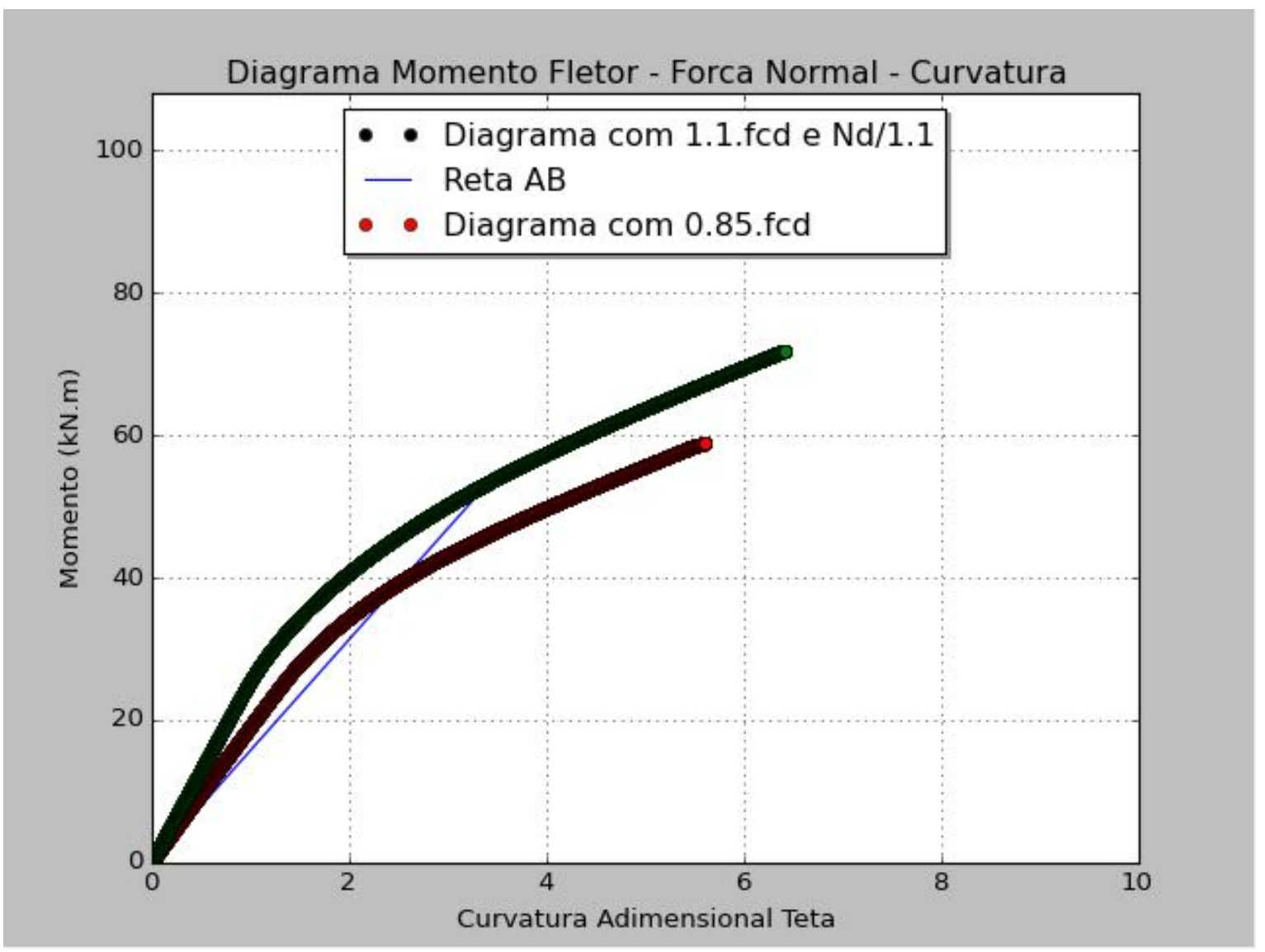

Fonte: Elaborado pelo Autor.

A armadura de $10 \phi 16 \mathrm{~mm}$ resulta em uma área de aço $A_{s}=20,11 \mathrm{~cm}^{2}$. Algumas discrepâncias devem ser encontradas nos resultados devido à imprecisão da leitura do diagrama de iteração $\left(N_{u d}, M_{u d}\right)$. 
Da linearização do diagrama é possível retirar a rigidez secante adimensional que, no exemplo, assume o valor de $\kappa_{\text {sec }} \cong 54$.

Assim, plota-se o valor da rigidez secante calculada no diagrama de iteração dos valores últimos, como mostrado na figura 6.22.

Agindo de maneira análoga para outras taxas de armadura, obtém-se o diagrama de iteração completo da figura 6.22.

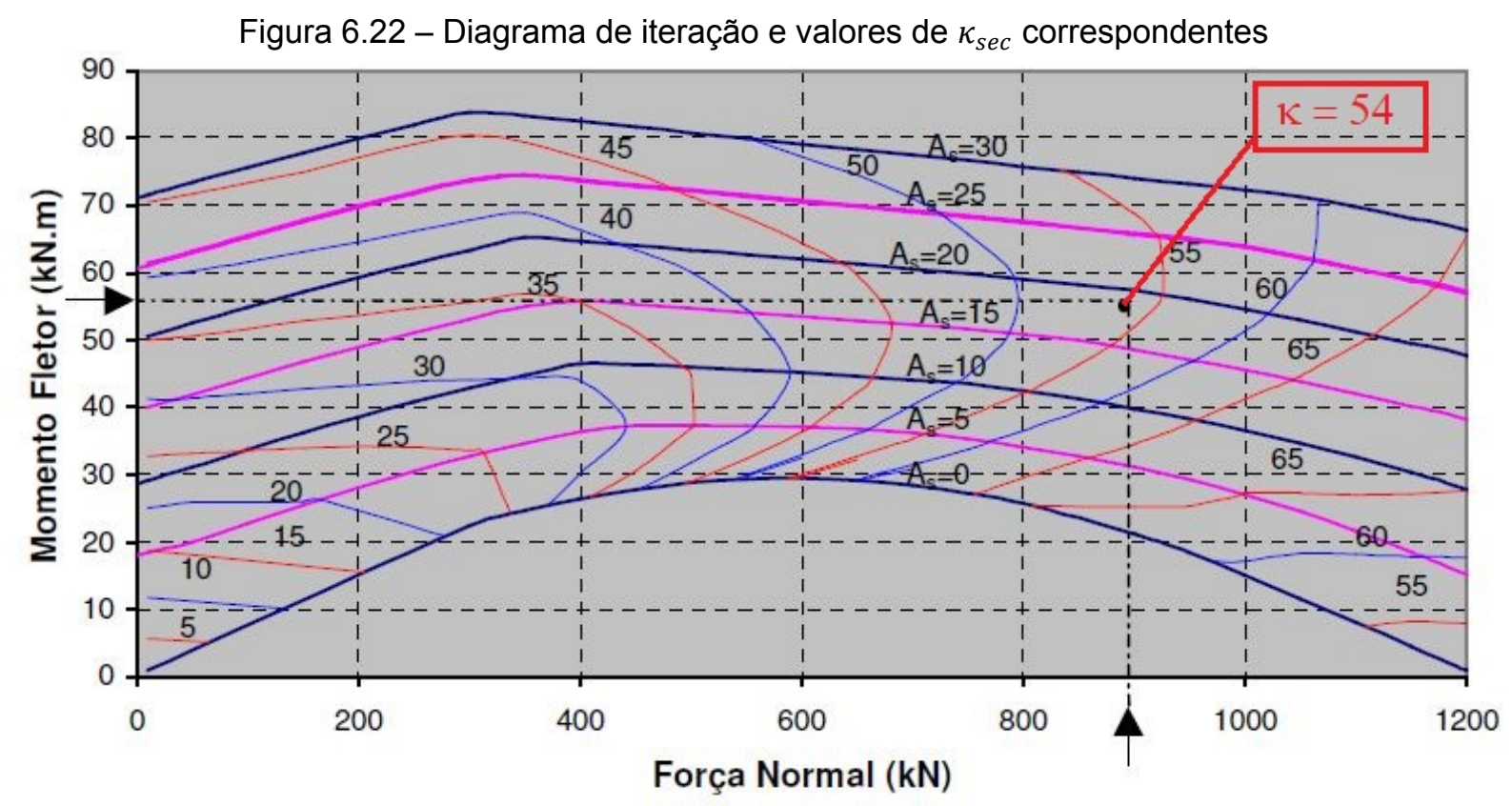

Fonte: Adaptado de OLIVEIRA, 2004, p. 29.

A expressão da rigidez aproximada presente na ABNT NBR 6118:2014 é retirada desses diagramas de iteração adimensionais momento fletor - normal rigidez secante. Através dos ábacos monta-se um gráfico de $\mu / v$ em função de $\kappa / v$ dos valores encontrados nos ábacos, e ao construir uma reta que se adeque a esses valores, nota-se que a expressão $\kappa / v=32 \cdot(1+5 \cdot \mu / v)$ é a reta que melhor se adequa aos dados (OLIVEIRA, 2004).

Assim, considerando o arranjo apresentado na figura 6.18 e com $d^{\prime} / h_{x}=0,10$ apresenta-se o gráfico dos valores plotados e da expressão de aproximação (Figura $6.23)$. 
Figura 6.23 - Gráfico de $\mu / v$ por $\kappa / v$

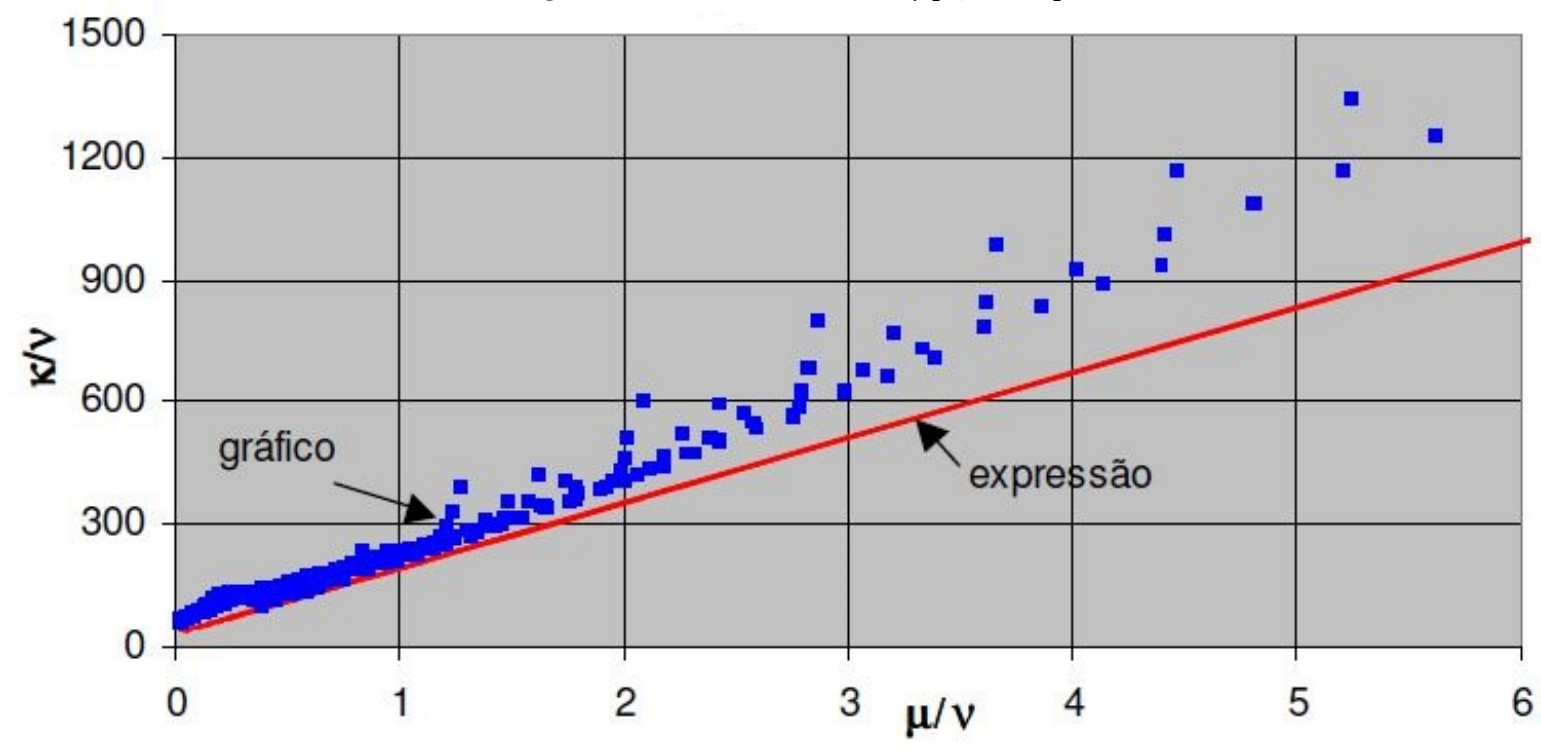

Fonte: OLIVEIRA, 2004, p. 33.

\subsection{MÉTODO GERAL}

O método geral consiste em estudar o comportamento das estruturas de concreto armado, à medida que se dá o aumento do carregamento ou da excentricidade do carregamento na peça em análise (SCADELAI, 2004). Com isso, é possível verificar se a estrutura possui configuração deformada de equilíbrio estável, de forma que em nenhuma das seções transversais haja ruptura.

Trata-se de um processo de verificação, ou seja, com o método geral é possível verificar a distribuição de momentos fletores ( $1^{\mathrm{a}}$ ordem $+2^{\mathrm{a}}$ ordem) em cada seção da peça, já que é possível obter a configuração fletida final (caso haja). Assim, para aplicação do método, é necessário o conhecimento prévio das dimensões da peça e a taxa de armadura correspondente a cada seção analisada.

O método geral só faz duas concessões: admite que a curvatura $1 / r$ seja dada por $y^{\prime \prime}$ (como explanado no item 6.3.1 deste texto) e a outra aproximação é efetuada quando são utilizados processos numéricos que dividem a barra em um determinado número de elementos. Apesar dessas duas aproximações, o método geral é muito preciso, e, portanto, pode ser considerado "exato" (SANTOS, 1987). 
A utilização de processos numéricos para divisão da barra dispensa a consideração do conceito de pilar-padrão utilizado nos métodos aproximados, ou seja, a deformada calculada pelo método geral não necessariamente é uma curva senoidal, de forma que se pode dizer que a deformada calculada é a mais próxima da realidade estrutural. Logo, a não linearidade geométrica é considerada de maneira bastante precisa.

O cálculo da deformada do pilar envolve o uso de equações diferenciais que não possuem soluções diretas, sendo necessária a utilização de aproximações por meio de cálculo iterativo. Esse cálculo iterativo, dependendo do número de subdivisões da peça, pode ser extremamente trabalhoso, sendo, portanto, necessário o uso de alguma ferramenta computacional.

Por ser um processo de verificação, o principal objetivo do método geral é a determinação da carga crítica que a peça suporta. Para essa determinação, podemse utilizar dois processos iterativos: processo do carregamento progressivo proporcional ou processo das excentricidades progressivas.

\subsubsection{Processo do carregamento progressivo proporcional}

Para determinação da carga crítica pelo método geral utilizando o processo do carregamento progressivo proporcional, devem-se efetuar incrementos progressivos de carga $\Delta F_{i}$, calculando para cada etapa o deslocamento $y_{r e f}$ de uma seção de referência. $O$ deslocamento calculado, além de considerar os efeitos de $1^{\text {a }}$ ordem, deve considerar os efeitos de $2^{\mathrm{a}}$ ordem decorrentes das deformações devidas ao carregamento da seção anterior. O valor da carga crítica é obtido quando a carga $F$ tender assintoticamente no diagrama carga-deslocamento, como mostrado na figura 6.24 . 
Figura 6.24 - Processo do carregamento progressivo proporcional no método geral

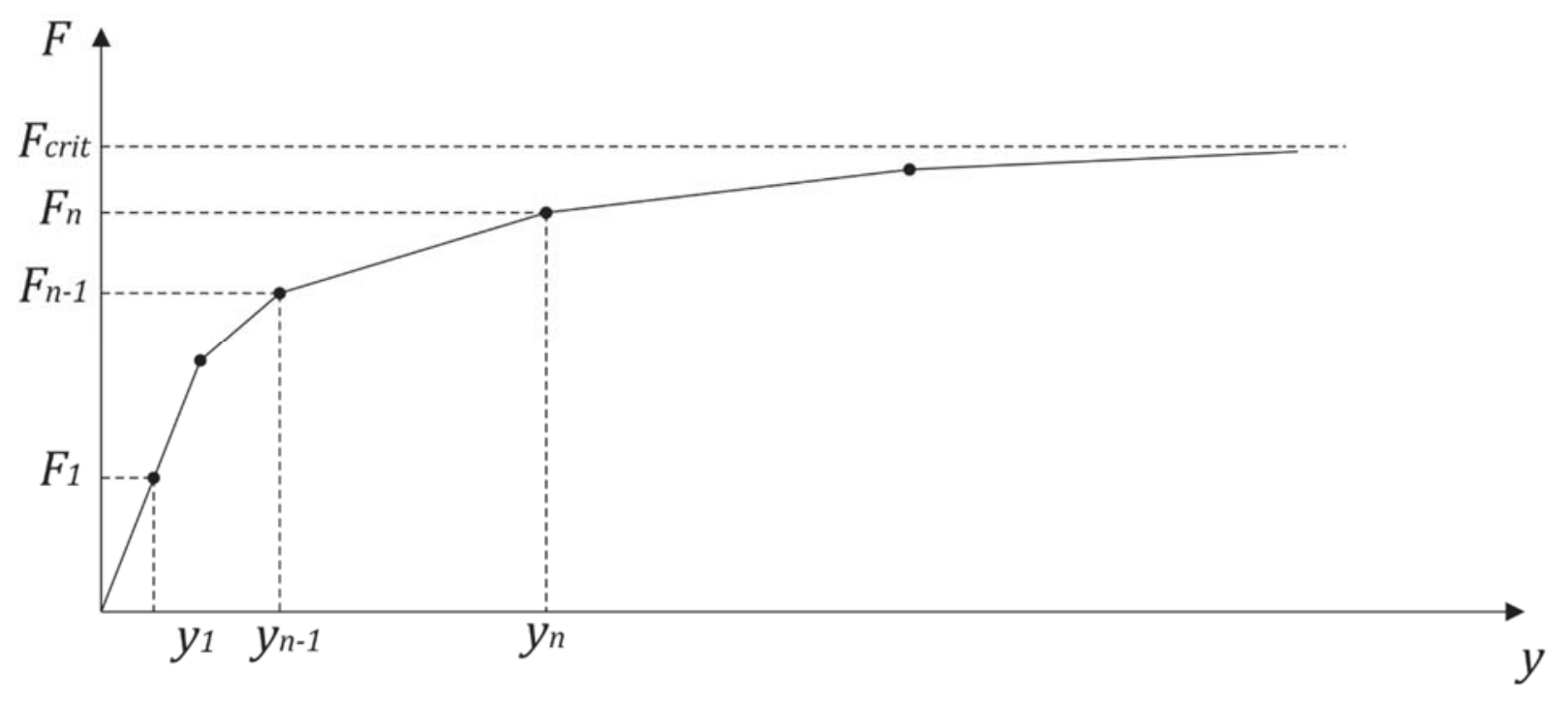

Fonte: Adaptado de FUSCO, 1981, p. 179.

Para o cálculo dos deslocamentos de referência $\left(y_{n}\right)$, basta o conhecimento do diagrama momento fletor - força normal - curvatura da seção da peça.

O processo do carregamento progressivo proporcional, por relacionar a carga axial (comumente chamada de $P$ ) com o deslocamento horizontal $(\Delta)$ ), é chamado de processo $P-\Delta$, utilizado em análises globais de $2^{\mathrm{a}}$ ordem.

\subsubsection{Processo das excentricidades progressivas}

No processo anterior, as excentricidades das cargas são constantes, variandose apenas as forças aplicadas. Já no processo das excentricidades progressivas, mantêm-se as cargas constantes, variando-se progressivamente as excentricidades de $1^{\text {a }}$ ordem, até serem atingidos os valores críticos, agindo-se de forma análoga ao que foi feito no processo anterior. O valor crítico da excentricidade é obtido com o valor assintótico do diagrama excentricidade versus deslocamento, como mostrado na figura 6.25 . 
Figura 6.25 - Processo das excentricidades progressivas

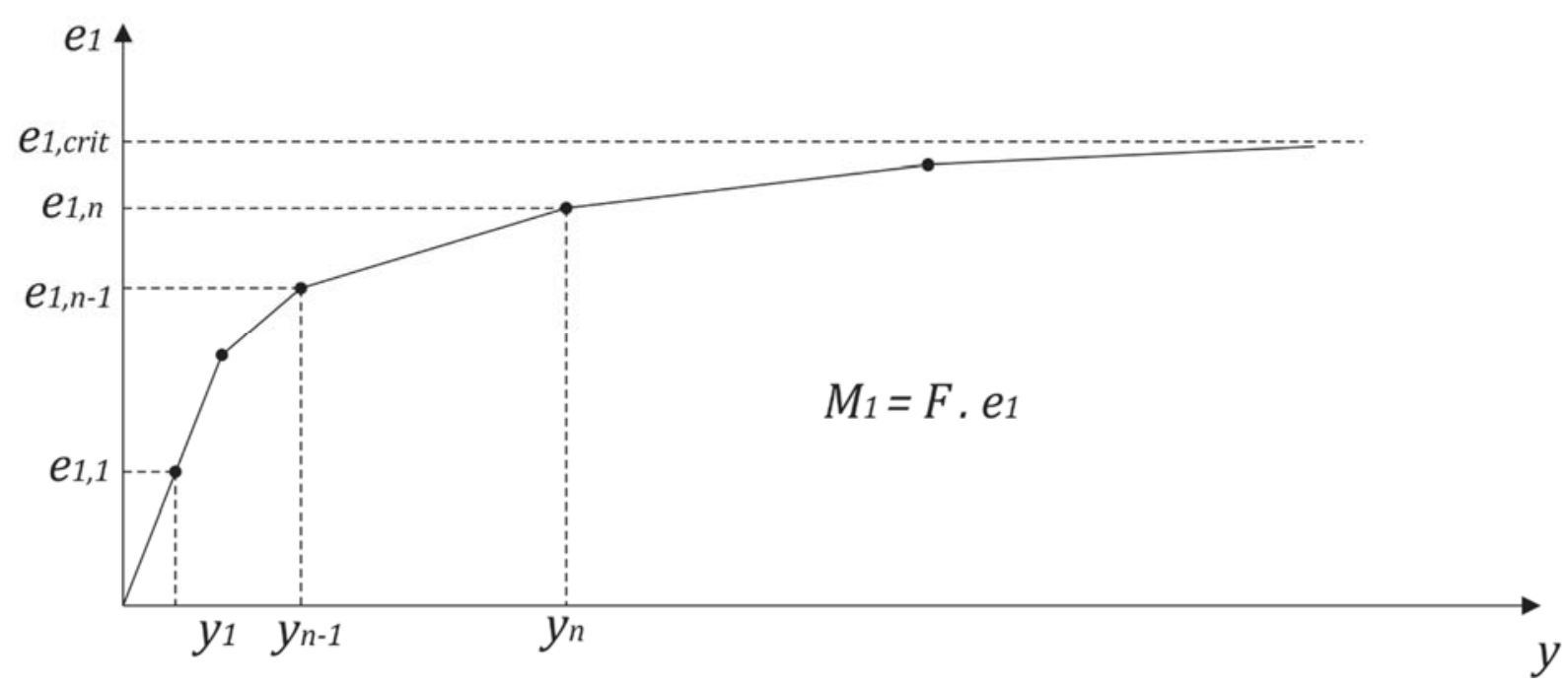

Fonte: Adaptado de FUSCO, 1981, p. 180.

\subsubsection{Apresentação do método geral}

O método geral consiste na análise não linear de $2^{a}$ ordem efetuada com discretização adequada da barra, considerando a relação momento fletor-curvatura real em cada seção e considerando a não linearidade geométrica de maneira não aproximada, sendo obrigatório para pilares com $\lambda>140$ (ABNT NBR 6118:2014).

Em contraponto com os métodos aproximados, no quais a não linearidade física é considerada por meio de expressões para a curvatura da seção crítica ou por expressões para a rigidez aproximada da peça, o método geral utiliza a curvatura real de cada seção do lance, já que é possível obter qual a solicitação que atua em cada seção.

Assim, com o auxílio de um diagrama momento fletor - força normal curvatura, é possível obter a curvatura correspondente a cada solicitação a que o pilar está submetido. Pode-se dizer, portanto, que se trata do modelo mais refinado para consideração da não linearidade física.

A não linearidade geométrica é considerada por meio da curva deformada real da peça em análise. Para obter essa curva, é necessária a utilização de métodos iterativos, efetuando uma discretização adequada da barra. Na literatura, encontram- 
se alguns métodos iterativos que satisfazem o problema. Neste texto, será dado enfoque ao processo das diferenças finitas e ao de Engesser-Vianello.

\subsubsection{Processo das diferenças finitas}

Considere-se o pilar excêntrico (excentricidade de $1^{\text {a }}$ ordem $e$ ) da figura 6.26, engastado na base e livre no topo, submetido a uma força de compressão $N_{d}$.

Figura 6.26 - Pilar submetido a uma compressão excêntrica

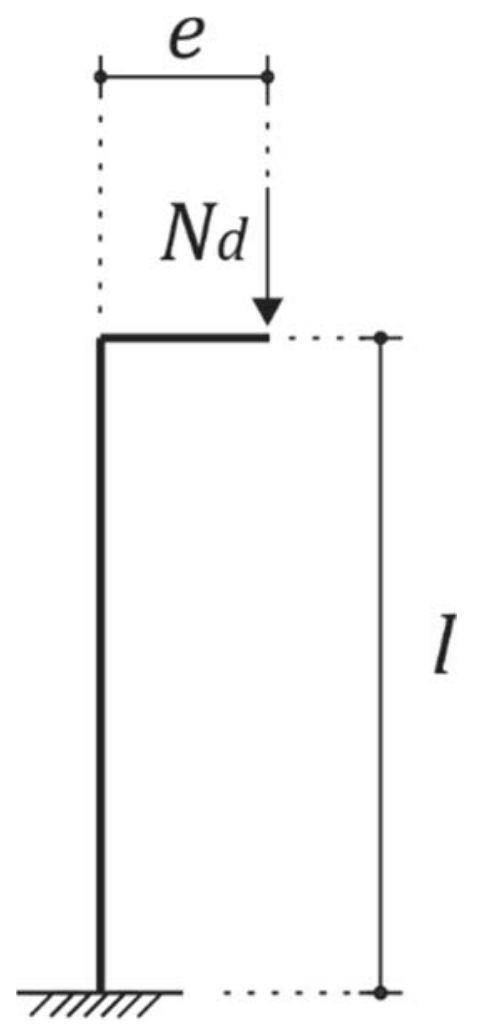

Fonte: Adaptado de SANTOS, 1987, p. 52.

Devido à solicitação, o pilar se deforma, dando origem às excentricidades de segunda ordem $e_{2}$, que variam de uma seção para outra. Devido ao surgimento dessas excentricidades, aparecem novos momentos fletores $N \cdot y$ nas seções, que geram mais deformações, e assim sucessivamente (SANTOS, 1987). Assim, têm-se dois casos possíveis: ou a série de momentos fletores é divergente, indicando a instabilidade do pilar, ou a série é convergente e, portanto, o pilar adquire uma forma curva de equilíbrio estável, como indicado na figura 6.27. 
Figura 6.27 - Configurações fletidas
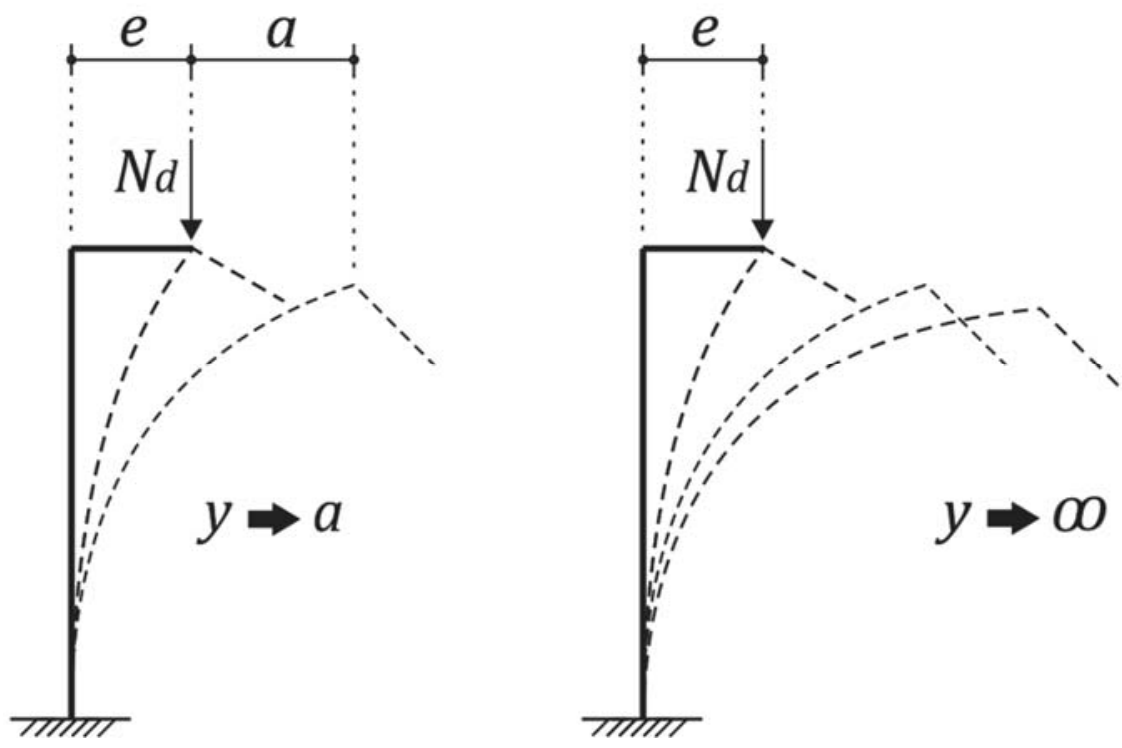

Fonte: Adaptado de SCADELAI, 2004, p. 44.

Seja o pilar da figura 6.26 submetido a uma força $N_{d}$ de compressão. Conhecidas as dimensões da seção transversal do pilar e a disposição da armadura, é possível construir o diagrama momento fletor - força normal - curvatura (ver apêndice A) que considera as equações de equilíbrio, a compatibilidade de deformações e as equações constitutivas dos materiais.

Cada valor de momento fletor resistido pela seção corresponde a uma única curvatura. Para que haja forma fletida estável, basta encontrar uma deformada tal que a curvatura em qualquer seção corresponda a um momento fletor interno igual ao momento fletor externo total calculado com a deformada (SANTOS, 1987). Assim, tem-se uma compatibilização geral.

Para determinar a curva deformada $y=f(x)$ do pilar, deve-se dividir o pilar em $n$ elementos, como mostrado na figura 6.28. 
Figura 6.28 - Discretização da deformada estável

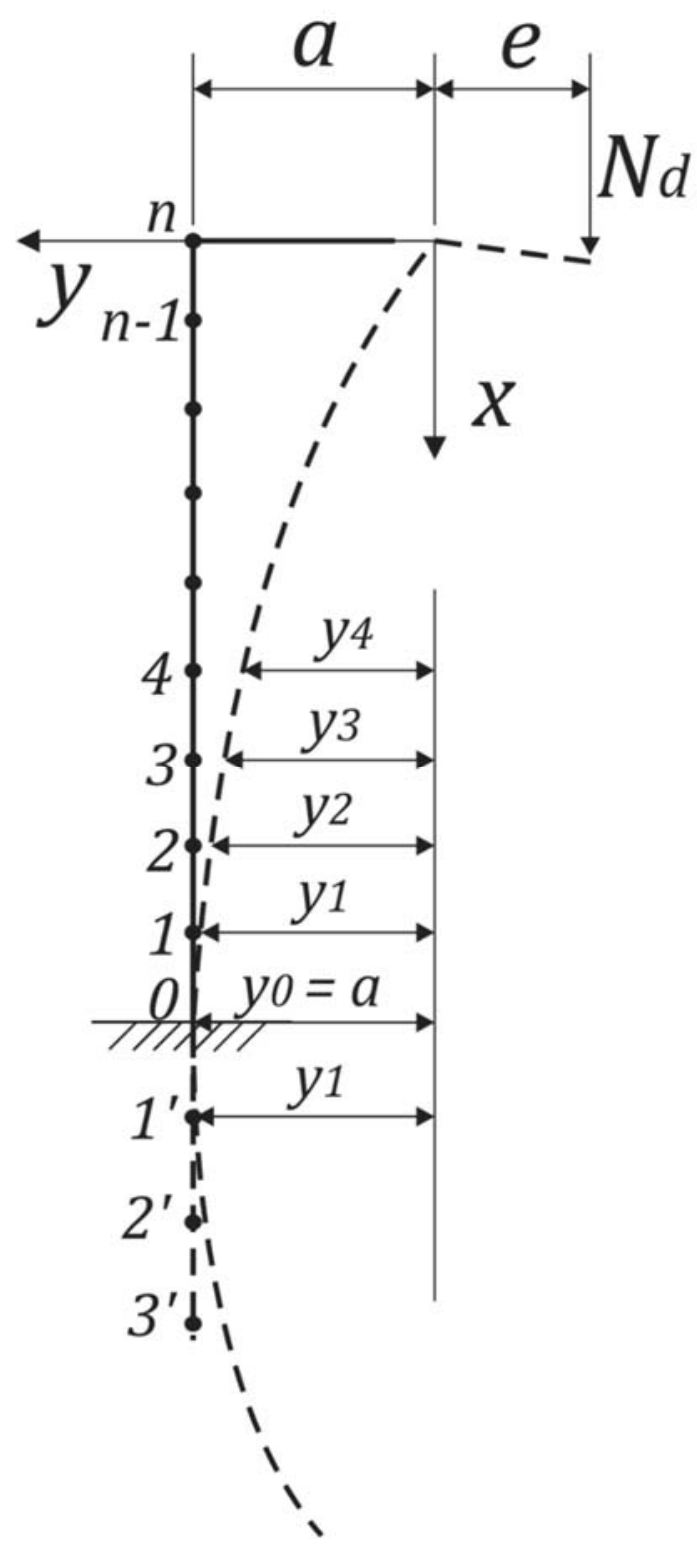

FONTE: Adaptado de SANTOS, 1987, p. 54.

Santos (1987) apresenta as seguintes etapas para a determinação da expressão $y=f(x)$ da deformada do pilar, que será realizada por tentativas:

a) Dividir o pilar em $n$ trechos de comprimento:

$$
\Delta x=\frac{l}{n}
$$

b) Adotar um valor inicial para a flecha $a$ :

$$
y_{0}=a
$$


c) Calcular o momento fletor de $2^{\mathrm{a}}$ ordem no engastamento (Seção 0 ):

$$
\left(M_{2 d}\right)_{0}=N_{d} \cdot a
$$

d) Como a excentricidade de $1^{\text {a }}$ ordem é conhecida $\left(e_{1}=e\right)$, pode-se determinar o momento fletor total no engastamento:

$$
M_{o}=\left(M_{1 d}\right)_{0}+\left(M_{2 d}\right)_{0}
$$

e) Usa-se o diagrama momento fletor - força normal - curvatura, construído com o conhecimento da taxa e da disposição de armadura e da força normal atuante. Com o momento fletor atuante na seção de engastamento $\left(M_{o}\right)$, é possível obter no diagrama a curvatura correspondente.

$$
M_{0} \rightarrow\left(\frac{1}{r}\right)_{0}=-\left(y^{\prime \prime}\right)_{0}
$$

Na expressão 6.88, $y^{\prime \prime}$ assume valor negativo, devido à escolha dos eixos da figura 6.28 .

f) Com emprego das diferenças finitas, calcula-se numericamente $\left(y^{\prime \prime}\right)_{0}$ :

$$
\left(y^{\prime \prime}\right)_{0}=\frac{y_{1}-2 \cdot y_{0}+y_{1}}{\Delta x^{2}}=-\left(\frac{1}{r}\right)_{0} \rightarrow y_{1}=-\frac{\Delta x^{2}}{2} \cdot\left(\frac{1}{r}\right)_{0}+y_{0}
$$

g) De posse de $y_{1}$, o processo se repete, assim:

$$
\left(M_{2 d}\right)_{1}=N_{d} \cdot y_{1} \rightarrow M_{1} \rightarrow\left(\frac{1}{r}\right)_{1}=-\left(y^{\prime \prime}\right)_{1}
$$

h) Calcula-se $y_{2}$ por diferenças finitas:

$$
\left(y^{\prime \prime}\right)_{1}=\frac{y_{0}-2 \cdot y_{1}+y_{2}}{\Delta x^{2}}=-\left(\frac{1}{r}\right)_{1} \rightarrow y_{2}=-\frac{\Delta x^{2}}{2} \cdot\left(\frac{1}{r}\right)_{1}-y_{0}+2 \cdot y_{1}
$$


i) Repete-se o processo para as demais seções, com a seguinte expressão genérica:

$$
y_{i+1}=2 \cdot y_{i}-y_{i-1}-\Delta x^{2} \cdot\left(\frac{1}{r}\right)_{i}
$$

j) Ao chegar à seção n (topo do pilar), deve-se obter $y_{n}=0$. Caso contrário, recomeçam-se novas tentativas com novo valor de $a$ escolhido.

Quando resultar $y_{n}=0$, obtém-se a forma fletida do pilar.

\subsubsection{Processo de Engesser-Vianello}

O processo de Engesser-Vianello é a adaptação do processo da analogia de Mohr ao concreto armado, já que se utiliza a ideia de uma carga fictícia em um sistema equivalente que produza momentos fletores que constituem a deformada do sistema real (SANTOS, 1987).

\section{- Analogia de Mohr}

A dedução das equações encontra-se em Santos (1987). Seja a viga indicada na figura 6.29 que está submetida a um carregamento $q$ qualquer. A viga se deforma com ordenadas $y$ e giros $\phi$. 
Figura 6.29 - Viga submetida a carregamento $q$
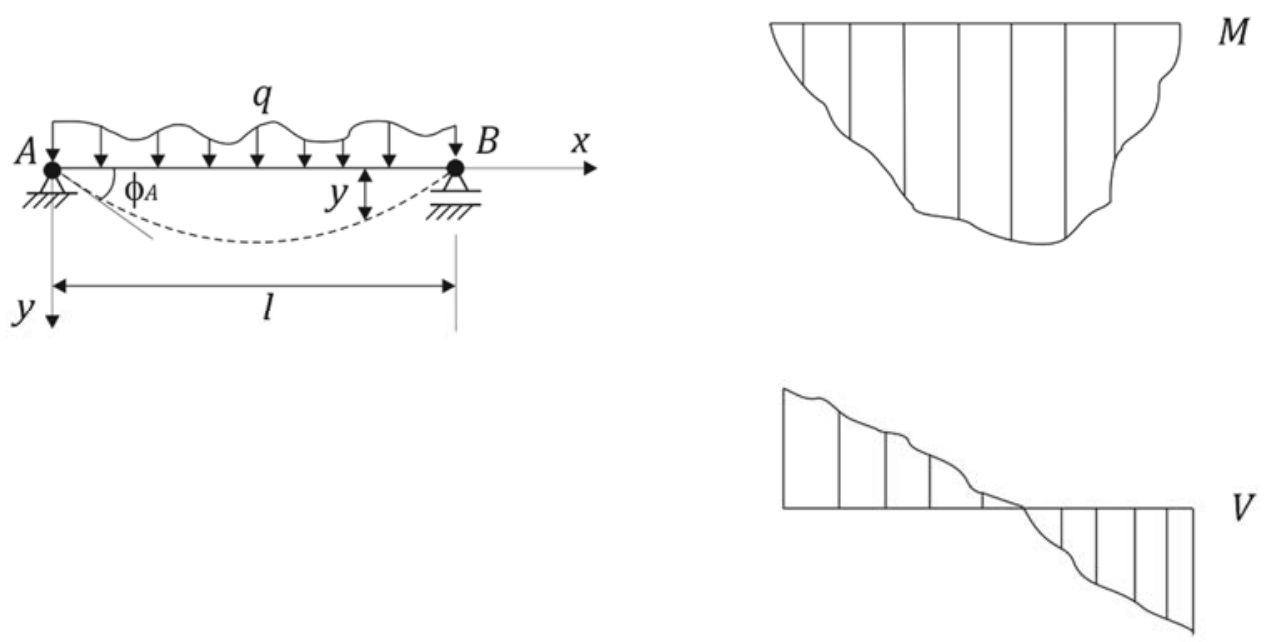

Fonte: Adaptado de SANTOS, 1987, p. 66.

Sabe-se que:

$$
\begin{gathered}
\frac{d y}{d x}=\phi \\
\frac{d M}{d x}=V \\
\frac{d \phi}{d x}=\frac{d^{2} y}{d x^{2}}=-\frac{1}{r}=-\frac{M}{E I} \\
\frac{d V}{d x}=\frac{d^{2} M}{d x^{2}}=-q
\end{gathered}
$$

Conclui-se que há uma relação entre as grandezas: $V$ e $\phi, M$ e $y, q$ e $1 / r$. Assim, caso a viga da figura 6.29 seja carregada por uma carga fictícia, de forma que $M$ seja o momento fletor gerado pela carga $q$ :

$$
q^{\prime}=\frac{M}{E I}
$$

Das equações 6.95 e 6.96, conclui-se que:

$$
q^{\prime}=\frac{M}{E I} \rightarrow \frac{d^{2} M^{\prime}}{d x^{2}}=\frac{d^{2} y}{d x^{2}}
$$


Como as funções $M^{\prime}(x)$ e $y(x)$ têm derivadas segundas iguais, elas só podem divergir em duas constantes (coeficiente de $\mathrm{x}$ e termo independente). Porém, caso se crie um sistema equivalente (viga análoga) no qual as condições 6.99 e 6.100 sejam satisfeitas, haverá igualdade entre as funções y e $M^{\prime}$, e por consequência, igualdade entre $\phi$ e $V^{\prime}$.

$$
\begin{gathered}
\text { Se } x=0 \rightarrow y=M^{\prime} \\
\text { Se } x=x_{1} \rightarrow\left\{\begin{array}{c}
y=y_{\text {máx }} \text { na viga real }(\phi=0) \\
M^{\prime}=M_{\text {máx }} \text { na viga análoga }\left(V^{\prime}=0\right)
\end{array}\right.
\end{gathered}
$$

Assim, o diagrama de momentos fletores $M^{\prime}$ obtido na viga análoga com a carga fictícia $q^{\prime}$ é a linha elástica $y=y(x)$ da viga real, e o diagrama de forças cortantes $V^{\prime}$ é o diagrama de $\phi$ da viga real. Dois exemplos de vigas reais e vigas análogas estão indicados na figura 6.30 .

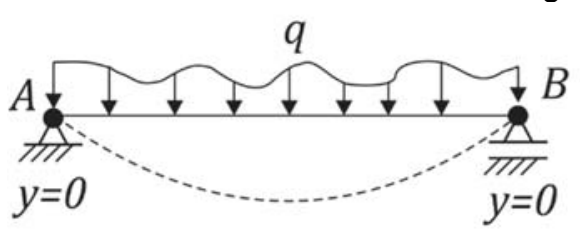

Viga Real

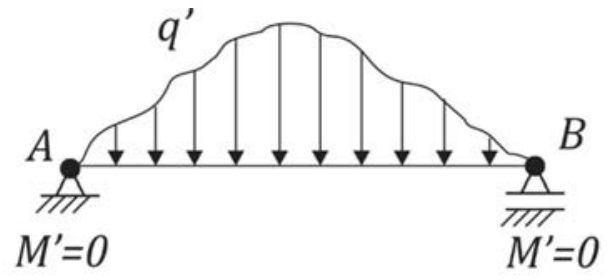

Viga Análoga

Figura 6.30 - Vigas reais e análogas

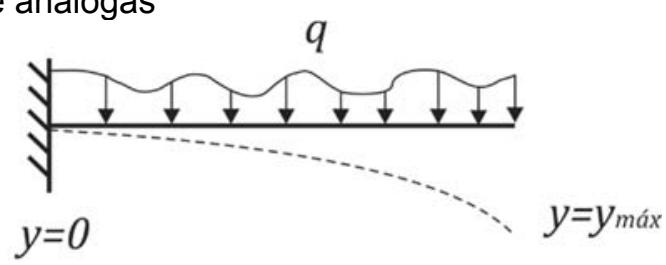

Viga Real

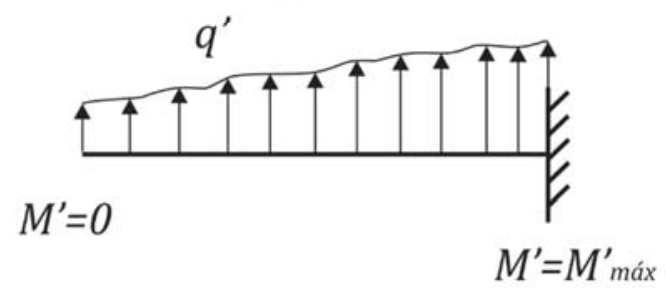

Viga Análoga

Fonte: Adaptado de SANTOS, 1987, p. 67.

A analogia de Mohr pode ser utilizada em peças de concreto armado desde que o carregamento fictício aplicado na viga análoga seja como indicado na expressão 6.101.

$$
q^{\prime}=\frac{1}{r}
$$


Também é necessário que a curvatura seja obtida através da relação entre o momento real e os diagramas momento fletor - força normal - curvatura.

Considere-se o pilar biarticulado da figura 6.31, com força de compressão $N_{d} \mathrm{e}$ excentricidade $e$ em ambas as extremidades.

Figura 6.31 - Pilar biarticulado excêntrico

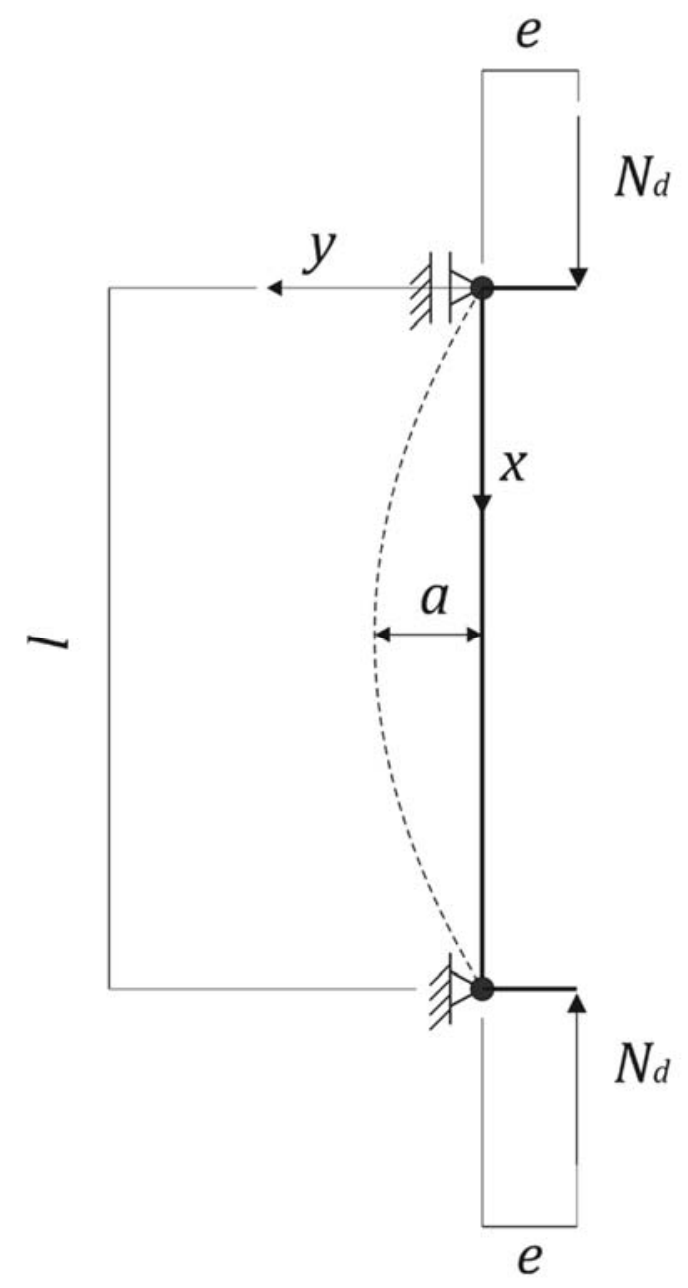

Fonte: Adaptado de SANTOS, 1987, p. 68.

Caso a deformação do pilar fosse desprezada, apareceria apenas o momento fletor de $1^{\text {a }}$ ordem $M_{1 d}$ constante ao longo da peça. Carregando o pilar da figura 6.31 com a carga fictícia $q^{\prime}=1 / r$ (que será constante devido ao diagrama de momento fletores ser constante e ser retirado do diagrama de momento fletor - força normal curvatura de qualquer seção da peça), os diagramas de força cortante e de momento fletor fornecem, respectivamente, o diagrama de curvatura e a deformada da estrutura. 
Para a análise em segunda ordem, é necessário que se divida o pilar da figura 6.31 em n segmentos de igual comprimento:

$$
\Delta x=\frac{l}{n}
$$

Numerando-se as seções de zero a $n$ ( quando se tratar de pilar biarticulado com carregamento simétrico, recomenda-se $n$ ímpar), a carga fictícia $q^{\prime}$ pode ser substituída por um carregamento discretizado equivalente constituído por $(n+1)$ cargas concentradas aplicadas nas seções genéricas $i$ ( $i$ variando de zero a $n$ ), como indicado na figura 6.32 .

Essas cargas concentradas são chamadas de "pesos elásticos", e são dadas pelas expressões:

$$
\begin{gathered}
W_{0}=W_{n}=\frac{1}{r} \cdot \frac{\Delta x}{2} \\
W_{i}=\frac{1}{r} \cdot \Delta x \quad \text { para } i \neq 0 \text { e } i \neq n
\end{gathered}
$$




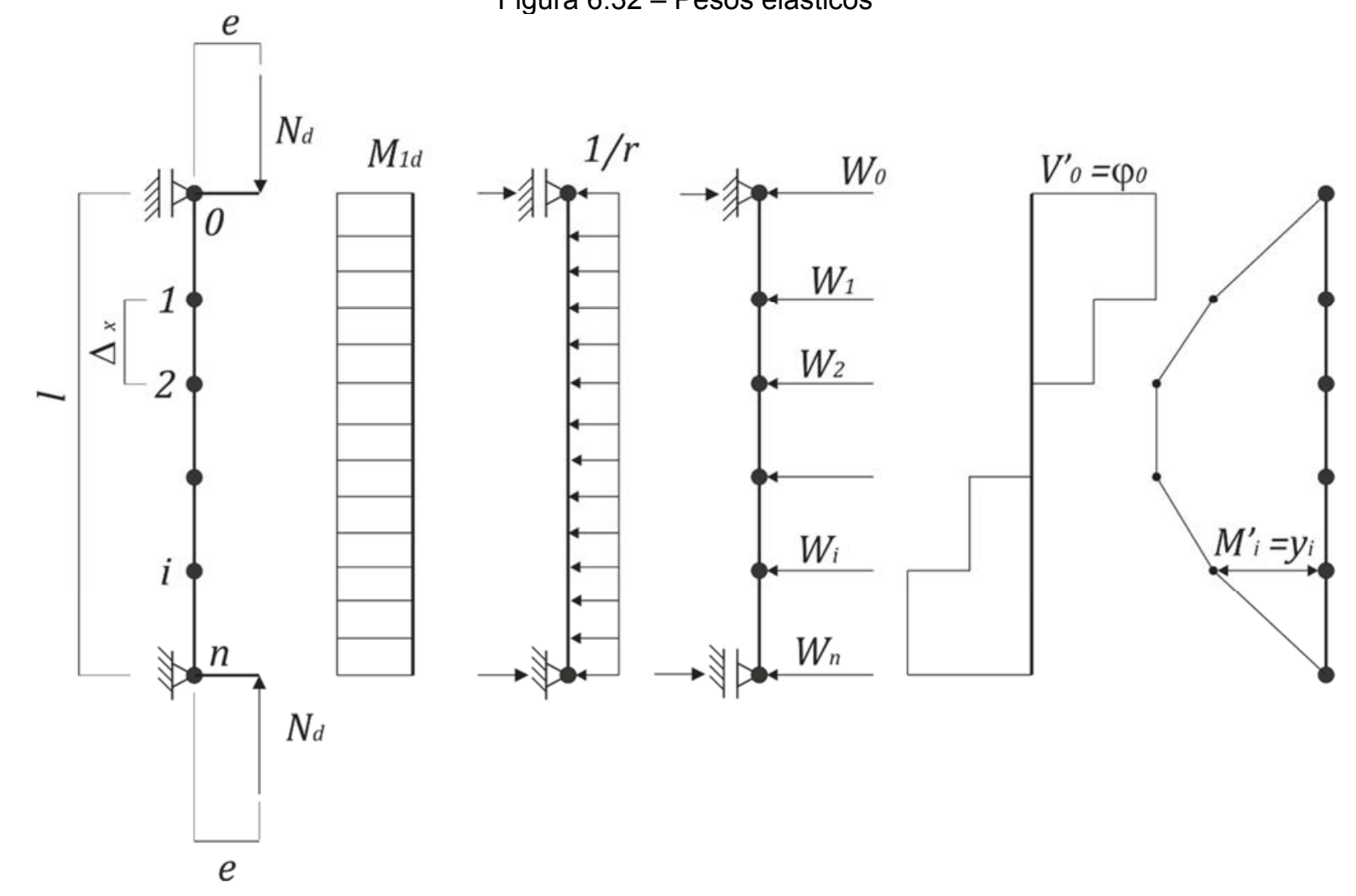

Figura 6.32 - Pesos elásticos

Fonte: Adaptado de SANTOS, 1987, p. 69.

Caso $\Delta x$ seja suficientemente pequeno, o sistema de cargas $W_{i}$ fornecerá com uma razoável aproximação os mesmos valores $V^{\prime}$ e $M^{\prime}$ obtidos com o carregamento $1 / r$.

O diagrama de momentos fletores indicado na figura 6.32 apresenta apenas a teoria de $1^{\text {a }}$ ordem, e assim a linha quebrada do diagrama de $M^{\prime}$ representa a curva final apresentada pela deformada. Porém, considerando a teoria de $2^{\mathrm{a}}$ ordem (consideração da deformação do pilar), o pilar apresentará novos momentos fletores:

$$
\left(M_{2 d}\right)_{i}=N_{d} \cdot y_{i}
$$

$\left(M_{2 d}\right)_{i}$ é o momento fletor de $2^{\mathrm{a}}$ ordem na seção genérica $i$. Assim, deve-se realizar novo cálculo da deformada.

Na segunda iteração, o diagrama de momentos fletores apresenta a forma curva indicada na figura 6.32, aproximando-se da realidade, de forma que: 


$$
M_{d i}=M_{1 d}+N_{d} \cdot y_{i}
$$

Figura 6.33 - Momentos fletores de $2^{\mathrm{a}}$ ordem e pesos elásticos
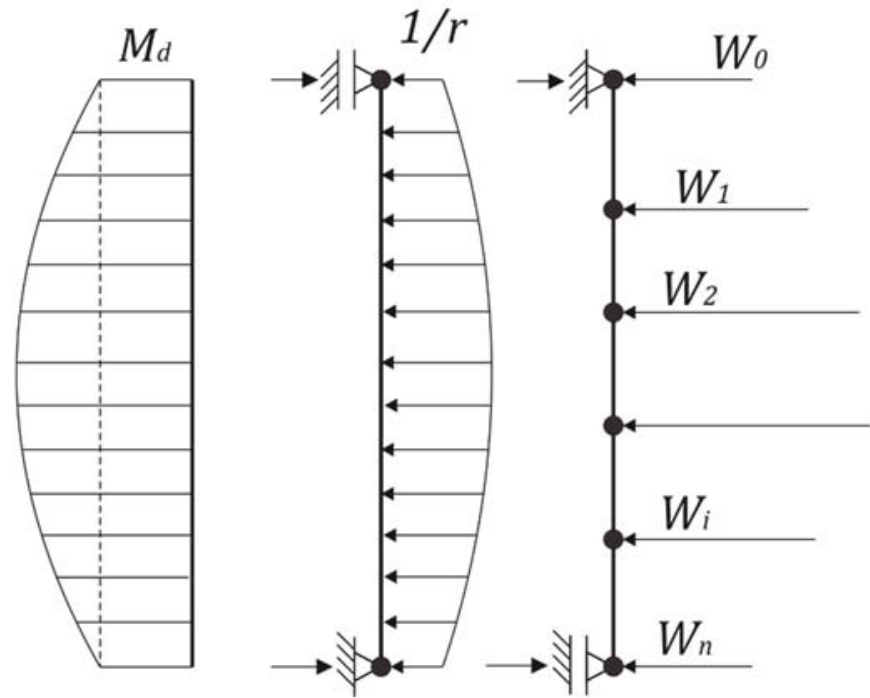

Fonte: Adaptado de SANTOS, 1987, p. 70.

Em cada seção existe um momento fletor total $M_{d i}$ diferente, correspondendo a uma curvatura $1 / r$ (retirada do diagrama momento fletor - força normal - curvatura) diferente. Assim, com a discretização das seções, é possível obter um número limitado de curvaturas $\left(1 / r_{0}, 1 / r_{1}, \ldots 1 / r_{n}\right)$, com auxílio dos diagramas momento fletor - força normal - curvatura.

Com os novos pesos elásticos $W_{i}$, determina-se o novo diagrama de momentos fletores $M^{\prime}$, obtendo-se a deformada da segunda iteração.

Caso haja novos valores de $y_{i}$, os momentos fletores de $2^{\mathrm{a}}$ ordem aumentam e todo o processo se repete. As iterações terminam quando a deformada da enésima iteração coincidir com a precedente, com uma determinada tolerância. O pilar terá conseguido, assim, uma forma fletida de equilíbrio estável.

Se não houver convergência, ou seja, se a deformada do pilar crescer continuamente, haverá ruptura, obtendo-se os valores de momento fletor resistente e de curvatura correspondentes a ela. 


\section{$7 \quad$ Dimensionamento de pilares}

Neste capítulo serão considerados: a convenção de eixos e das dimensões da seção transversal do pilar, o cálculo do parâmetro d', o cobrimento da armadura, os diâmetros das barras longitudinais e transversais, os critérios para prédimensionamento das seções, a determinação das envoltórias resistentes dos momentos fletores e o detalhamento das armaduras do pilar.

\subsection{CONVENÇÃO DE EIXOS E DE DIMENSÕES DA SEÇÃO}

A ABNT NBR 6118:2014 (item 11.3.3.4.3) apresenta a convenção de eixos e de dimensões o conforme a figura 7.1. Percebe-se que pode haver dúvidas quanto à nomenclatura das dimensões da seção transversal quando for considerada uma rotação de $90^{\circ}$.

Figura 7.1 - Convenção de eixos e de dimensões segundo a ABNT NBR 6118:2014
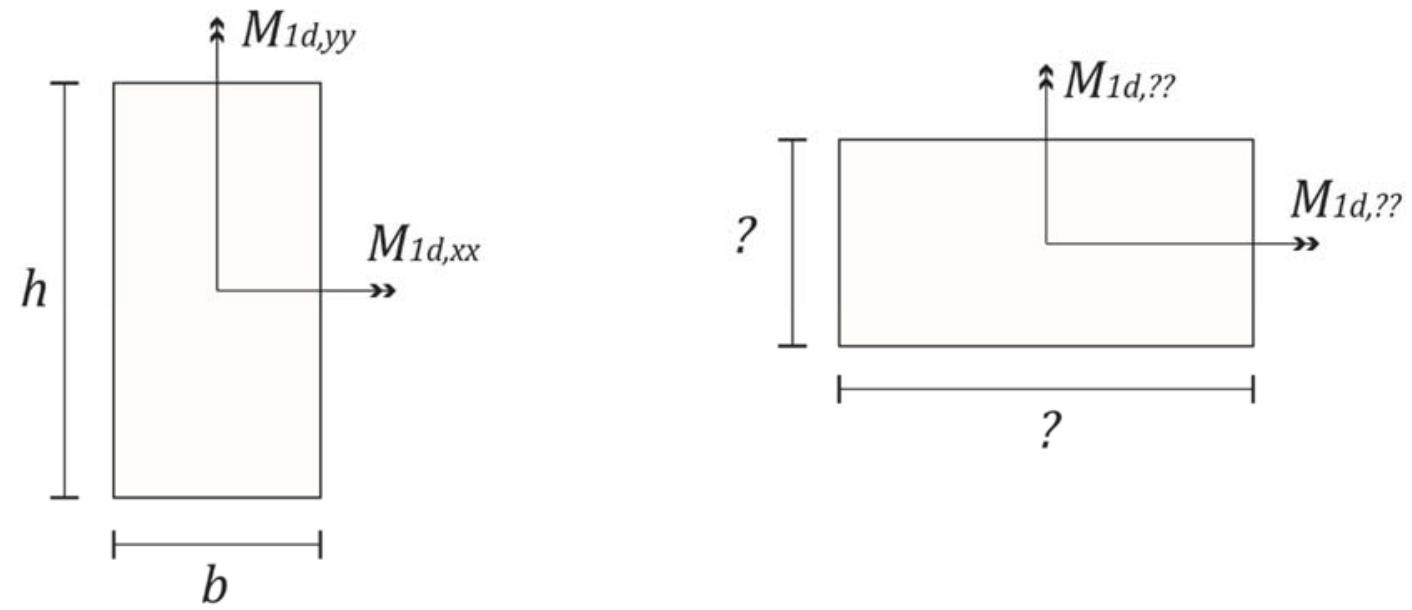

Fonte: Adaptado de ABNT NBR 6118:2014, item 11.3.3.4.3.

Assim, para evitar esse tipo de dúvida, neste trabalho considera-se que:

k) $\quad h_{x}$ é a menor dimensão da seção transversal;

I) $h_{y}$ é a maior dimensão da seção transversal. 
Fixadas as dimensões, fica fácil determinar os eixos e os momentos fletores referentes a eles, já que:

$$
\begin{aligned}
& \text { eixo // dimensão } \\
& \text { eixo ь vetor momento }
\end{aligned}
$$

Assim, define-se o sistema de eixos e as dimensões adotadas neste trabalho, de acordo com a figura 7.2.
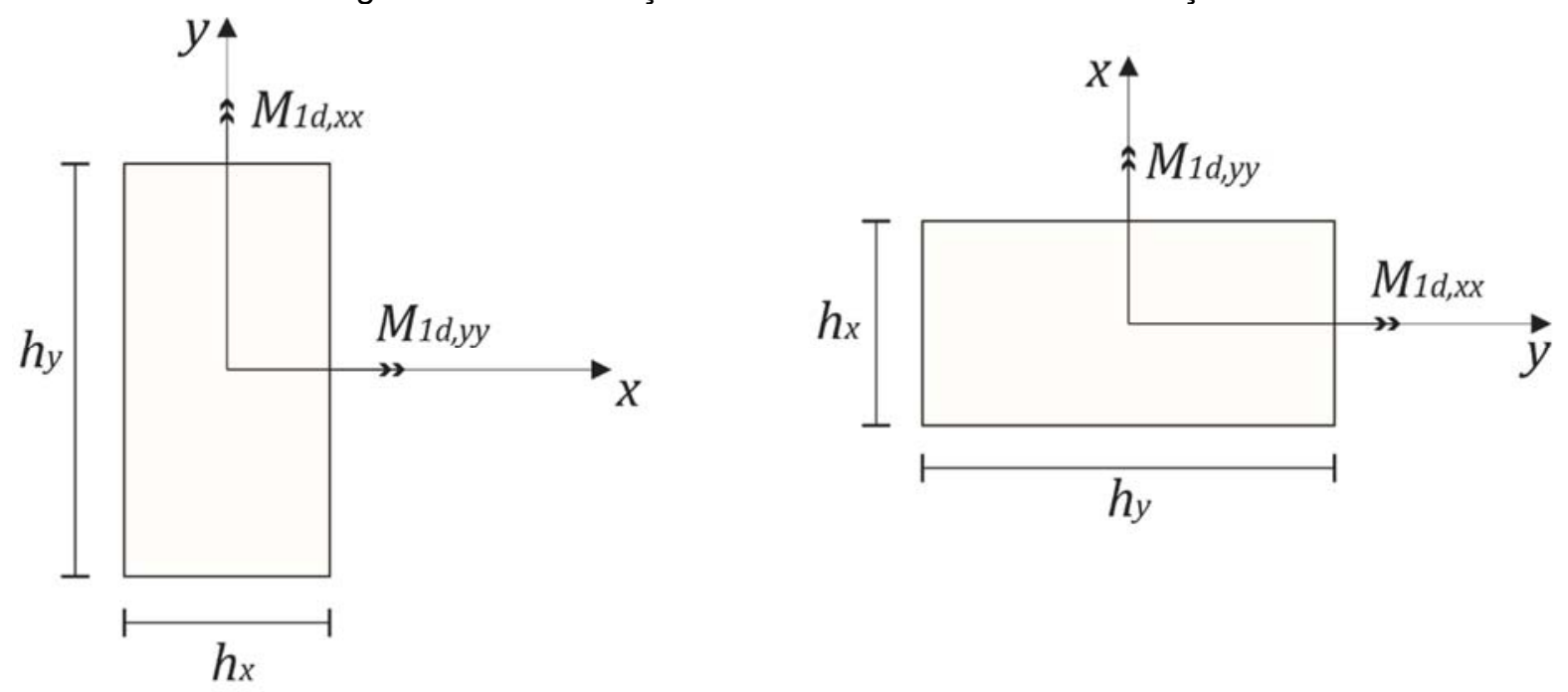

Fonte: Elaborado pelo Autor.

Com os eixos definidos, reforça-se o fato de que o momento fletor resistente (vetor momento fletor), calculado para cada eixo, é perpendicular ao eixo em análise, conforme indicado na figura 7.2.

\subsection{ALTURA $d^{\prime}$}

Na seção transversal de uma peça de concreto, a altura $d^{\prime}$ é definida para a armadura longitudinal ao longo de uma borda. O valor $d^{\prime}$ corresponde à distância entre o centro de gravidade dessa armadura longitudinal e a respectiva borda. 
Trata-se de um parâmetro importante para o pré-dimensionamento da seção, inclusive na geração de ábacos de flexão composta e no cálculo por meio deles (Apêndice B).

Para barras longitudinais dispostas em uma só camada, seu valor é dado por:

$$
d^{\prime}=c+\phi_{t}+\frac{\phi_{l}}{2}
$$

- $\quad c$ é o cobrimento da armadura;

- $\phi_{t}$ é o diâmetro do estribo;

- $\quad \phi_{l}$ é o diâmetro das barras longitudinais.

\subsection{COBRIMENTO}

O cobrimento da armadura é definido de acordo com a agressividade ambiental.

Segundo o item 6.4.2 da ABNT NBR 6118:2014, a agressividade ambiental deve ser classificada de acordo com o apresentado na Tabela 7.1 e pode ser avaliada, simplificadamente, segundo as condições de exposição da estrutura ou de suas partes.

O cobrimento mínimo da armadura é o menor valor que deve ser respeitado ao longo de todo o elemento considerado. Para garantir esse cobrimento mínimo $\left(c_{m i ́ n}\right)$, deve-se considerar o cobrimento nominal $\left(c_{n o m}\right)$ que é o cobrimento mínimo acrescido da tolerância de execução $(\Delta c)$ (ABNT NBR 6118:2014). Ou seja:

$$
c_{\text {nom }}=c_{\text {min }}+\Delta c
$$

Dessa forma, as dimensões das armaduras e os espaçadores devem respeitar os cobrimentos nominais, presentes na tabela 7.2 , que está em função da agressividade ambiental, $\operatorname{com} \Delta c=10 \mathrm{~mm}$ 
Tabela 7.1 - Classes de agressividade ambiental (CAA)

\begin{tabular}{|c|c|c|c|}
\hline $\begin{array}{l}\text { Classe de } \\
\text { agressividade } \\
\text { ambiental (CAA) }\end{array}$ & Agressividade & $\begin{array}{l}\text { Classificação geral do tipo de } \\
\text { ambiente para efeito de projeto }\end{array}$ & $\begin{array}{l}\text { Risco de } \\
\text { deterioração da } \\
\text { estrutura }\end{array}$ \\
\hline $\mathrm{I}$ & Fraca & $\begin{array}{c}\text { Rural } \\
\text { Submersa }\end{array}$ & Insignificante \\
\hline II & Moderada & Urbana a b & Pequeno \\
\hline III & Forte & $\begin{array}{c}\text { Marinha a } \\
\text { Industrial a b }\end{array}$ & Grande \\
\hline IV & Muito Forte & $\begin{array}{c}\text { Industrial a c } \\
\text { Respingos de maré }\end{array}$ & Elevado \\
\hline \multicolumn{4}{|c|}{$\begin{array}{l}\text { a Pode-se admitir um microclima com uma classe de agressividade mais branda (um nível acima) } \\
\text { para ambientes internos secos (salas, dormitórios, banheiros, cozinhas e áreas de serviço de } \\
\text { apartamentos residenciais e conjuntos comerciais ou ambientes com concreto revestido com } \\
\text { argamassa e pintura). }\end{array}$} \\
\hline \multicolumn{4}{|c|}{$\begin{array}{l}\text { b Pode-se admitir uma classe de agressividade mais branda (um nível acima) em: obras em regiões } \\
\text { de clima seco, com umidade relativa do ar menor ou igual a } 65 \% \text {, partes da estrutura protegidas de } \\
\text { chuva em ambientes predominantemente secos ou regiões onde chove raramente. }\end{array}$} \\
\hline
\end{tabular}

Fonte: Adaptado da ABNT NBR 6118:2014, item 6.4.2. 
Tabela 7.2 - Correspondência entre a classe de agressividade ambiental e o cobrimento nominal, para $\Delta \mathrm{c}=10 \mathrm{~mm}$

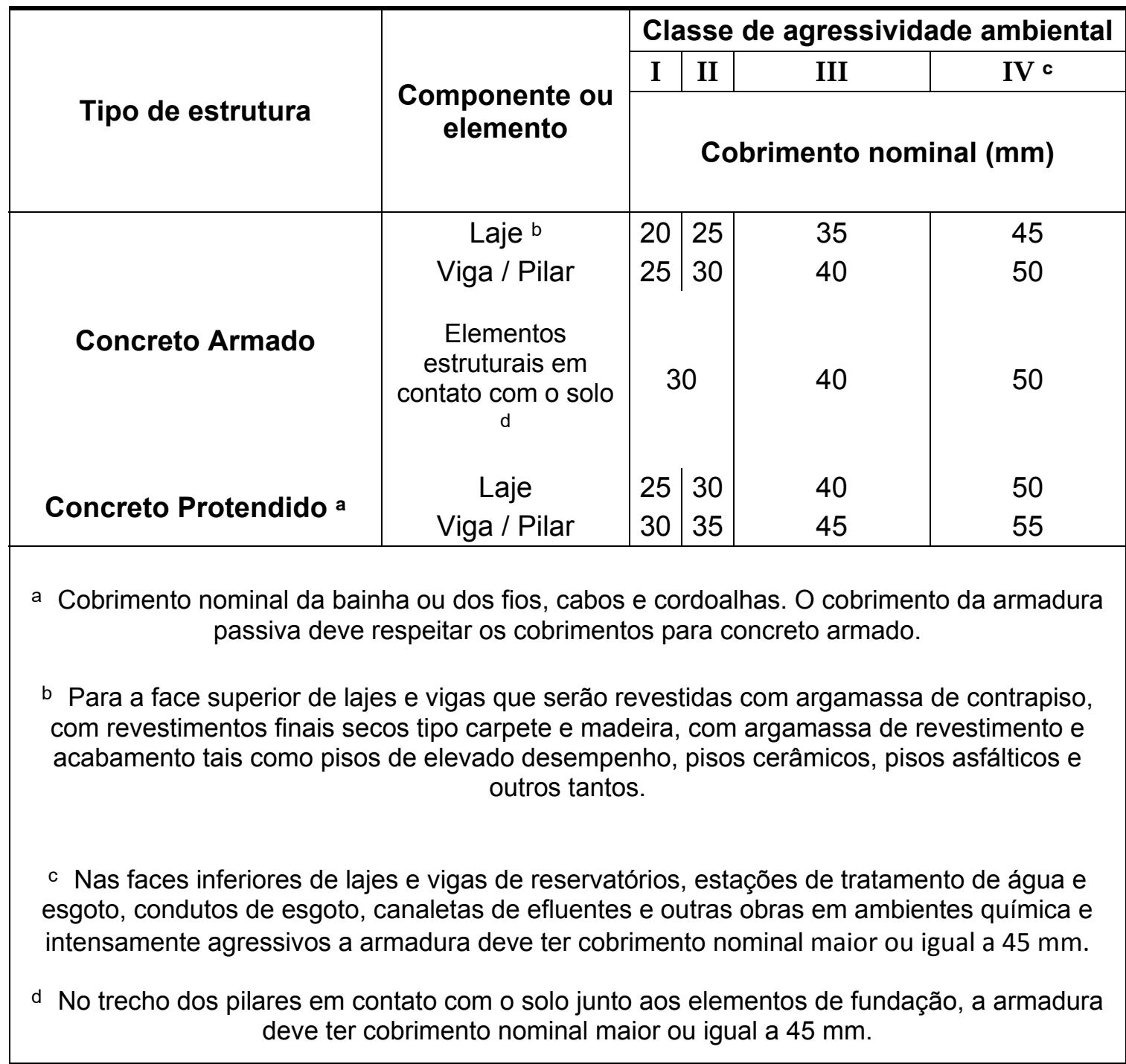

Fonte: Adaptado da ABNT NBR 6118:2014, item 7.4.7.6.

Nas obras correntes, o valor de $\Delta c$ deve ser maior ou igual a $10 \mathrm{~mm}$. Porém, quando houver um controle adequado de qualidade e limites rígidos de tolerância da variabilidade das medidas durante a execução, pode ser adotado $\Delta c=5 \mathrm{~mm}$. Permitese, então, a redução dos cobrimentos nominais da tabela $7.2 \mathrm{em} 5 \mathrm{~mm}$ (ABNT NBR 6118:2014). 


\subsection{DIÂMETRO DAS BARRAS LONGITUDINAIS}

O diâmetro das barras longitudinais dos pilares não pode ser inferior a $10 \mathrm{~mm}$ nem superior a $1 / 8$ da menor dimensão transversal $\left(h_{x}\right)$. Ou seja:

$$
10 m m \leq \phi_{l} \leq \frac{h_{x}}{8}
$$

\subsection{DIÂMETRO DA ARMADURA TRANSVERSAL}

O diâmetro dos estribos $\left(\phi_{\mathrm{t}}\right)$ em pilares não pode ser inferior a $5 \mathrm{~mm}$ nem a $1 / 4$ do diâmetro da barra isolada ou do diâmetro equivalente do feixe que constituirá a armadura longitudinal. Portanto:

$$
\phi_{t} \geq\left\{\begin{array}{c}
5 \mathrm{~mm} \\
\frac{1}{4} \cdot \phi_{\text {longitudinal }}
\end{array}\right.
$$

\subsection{PRÉ-DIMENSIONAMENTO DA ARMADURA LONGITUDINAL}

Como em outros elementos estruturais, o pré-dimensionamento é uma etapa corriqueira e necessária no projeto de pilares. A armadura necessária para o lance do pilar é obtida por meio de ábacos de dimensionamento. Para tanto, é necessário adotar um arranjo prévio de armadura e a altura $d^{\prime}$.

Porém, apesar do arranjo prévio de armadura ser uma escolha do projetista, a altura $d^{\prime}$ é adotada por meio de uma suposição de valores de cobrimento e de diâmetros das armaduras longitudinal e transversal. Assim, após o prédimensionamento, é necessário verificar se a armadura obtida é condizente com os valores supostos inicialmente. Caso não seja, é necessária uma nova suposição de valores e novo pré-dimensionamento. 


\subsubsection{Situações críticas}

A definição de situações críticas na flexão composta oblíqua pode exigir alguma habilidade por parte do engenheiro estrutural, já que há vários tipos de composição de esforços (direção x e direção y) que podem figurar como situações críticas, e cabe ao engenheiro considerar todas elas.

Mas, como inicialmente precisa ser realizado um pré-dimensionamento, sugere-se neste trabalho a verificação de duas situações críticas que podem ser suficientes para atender todos os casos de solicitação a que o pilar possa estar submetido. Se no final as condições de segurança não forem atendidas, nova armadura deverá ser verificada.

Dessa forma, para o pré-dimensionamento de um lance de pilar, podem ser consideradas as duas situações críticas indicadas a seguir.

\section{a) Situação crítica I}

Pode ser adotada como situação crítica I o caso de flexão composta oblíqua com atuação do momento fletor considerando efeito de $2^{\mathrm{a}}$ ordem na direção $\mathrm{x}$, obtido utilizando alguns dos métodos expostos no item 7 deste texto, e momento mínimo na direção y, como indicado no item 6.4, também deste trabalho. Esta situação é representada pelas equações 7.7 e 7.8 :

$$
\begin{gathered}
M_{c r, x}=\alpha_{b} \cdot M_{1 d A, x}+M_{2 x} \\
M_{c r, y}=M_{1 d \min , y}
\end{gathered}
$$

\section{b) Situação crítica II}

Como situação crítica II, pode ser admitido o caso de flexão composta normal com atuação do momento mínimo com $2^{\mathrm{a}}$ ordem na direção x. Para determinação dos efeitos de segunda ordem, como na situação anterior, pode-se adotar algum dos 
métodos expostos no item 7 deste texto. Esta situação crítica é representada pela expressão 7.9:

$$
M_{c r, x}=\alpha_{b} \cdot M_{1 d \min , x}+M_{2 x}
$$

\subsection{2 Ábaco para a situação crítica I}

A situação crítica I é uma flexão composta oblíqua. Portanto, podem ser utilizados os ábacos de Pinheiro et al. (2014). Para seções transversais retangulares, como primeira tentativa, é costumeiro admitir arranjo de barras relativo a armadura bilateral simétrica com um número grande de barras, por exemplo, cinco ou mais barras em cada face. Para estimar a altura $d^{\prime}$, pode ser adotado cobrimento de $3 \mathrm{~cm}$ ou outro valor mais adequado, diâmetro das barras longitudinais $20 \mathrm{~mm}$ e dos estribos $6,3 \mathrm{~mm}$, valores que deverão ser verificados posteriormente.

Com os parâmetros definidos, é possível obter nos ábacos a taxa mecânica de armadura $(\omega)$, e com ela calcular a área de armadura correspondente:

$$
A_{s}=\frac{\omega \cdot A_{c} \cdot f_{c d}}{f_{y d}}
$$

Pode-se, então, adotar a quantidade de barras de $20 \mathrm{~mm}$.

Se esta não for a solução adequada, é necessário aumentar ou diminuir o diâmetro das barras longitudinais, adotar nova distribuição de barras ou outro diâmetro para os estribos. Recorre-se novamente aos ábacos e determina-se novo $\omega$ e a nova quantidade de barras, com o diâmetro escolhido. Em geral, não é necessária outra tentativa.

\subsection{3 Ábacos para a situação crítica II}

A situação crítica II é uma flexão composta normal. Com o arranjo de armadura e parâmetros utilizados para a situação anterior (estimativa da altura $d^{\prime}$ ), é necessário 
utilizar os ábacos de Venturini (1987). O procedimento para obtenção desses ábacos está indicado no apêndice B.

Com os parâmetros definidos, é possível obter a taxa mecânica de armadura $(\omega)$. Se ela for menor que a obtida no caso anterior, adota-se a armadura já obtida. Caso contrário, nova armadura deve ser calculada.

\subsubsection{Armadura adotada}

A armadura longitudinal escolhida deve satisfazer as condições de armadura mínima e de armadura máxima:

a) A armadura mínima deve atender as indicações do item 17.3.5.3.1 da ABNT NBR 6118:2014:

$$
A_{s, \min }=\frac{0,15 \cdot N_{d}}{f_{y d}} \geq 0,004 \cdot A_{c}
$$

- $\quad N_{d}$ é a força normal de cálculo;

- $\quad f_{y d}$ é a resistência de cálculo do aço ao escoamento.

b) A máxima armadura permitida em pilares é dada por (item 17.3.5.3.2 da ABNT NBR 6118:2014):

$$
A_{s, \text { máx }}=0,08 A_{c}
$$

Essa armadura deve considerar inclusive a sobreposição de barras nas regiões de emenda. Assim, é prudente tomar como área máxima de armadura um valor da ordem de $4 \%$ da área bruta de concreto $\left(A_{s, \text { máx }}=0,04 A_{c}\right)$, de modo que na região de emenda a soma não ultrapasse $0,08 A_{c}$. Outras condições devem ser respeitadas, indicadas a seguir.

c) Número mínimo de barras:

Em seções poligonais, deve existir pelo menos uma barra em cada vértice; em seções circulares, no mínimo seis barras distribuídas ao longo do perímetro. 
Alguns exemplos de número mínimo de barras para alguns tipos de seção estão presentes na Figura 7.3.

Figura 7.3 - Número mínimo de barras
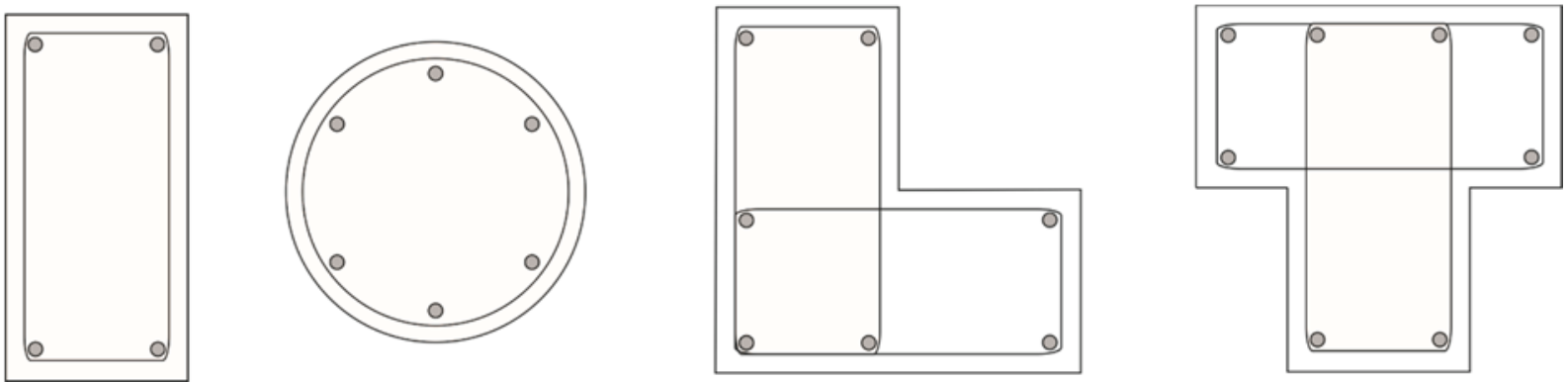

Fonte: Adaptado de Pinheiro, L. M - Estruturas de concreto - Capítulo 16, 2005.

d) Espaçamento mínimo das barras longitudinais (item 18.4.2.2 da ABNT NBR 6118:2014):

O espaçamento mínimo (a) livre entre as faces das barras longitudinais, medido no plano da seção transversal, fora da região de emendas, deve ser igual ou superior ao maior dos seguintes valores (Figura 7.4):

- $20 \mathrm{~mm}$;

- diâmetro da barra, do feixe ou da luva;

- 1,2 vez a dimensão máxima característica do agregado graúdo.

Esses valores se aplicam também às regiões de emenda por traspasse das barras. 
Figura 7.4 - Espaçamento entre as barras longitudinais

\section{Sem emendas} por traspasse

\section{Com emendas por traspasse}

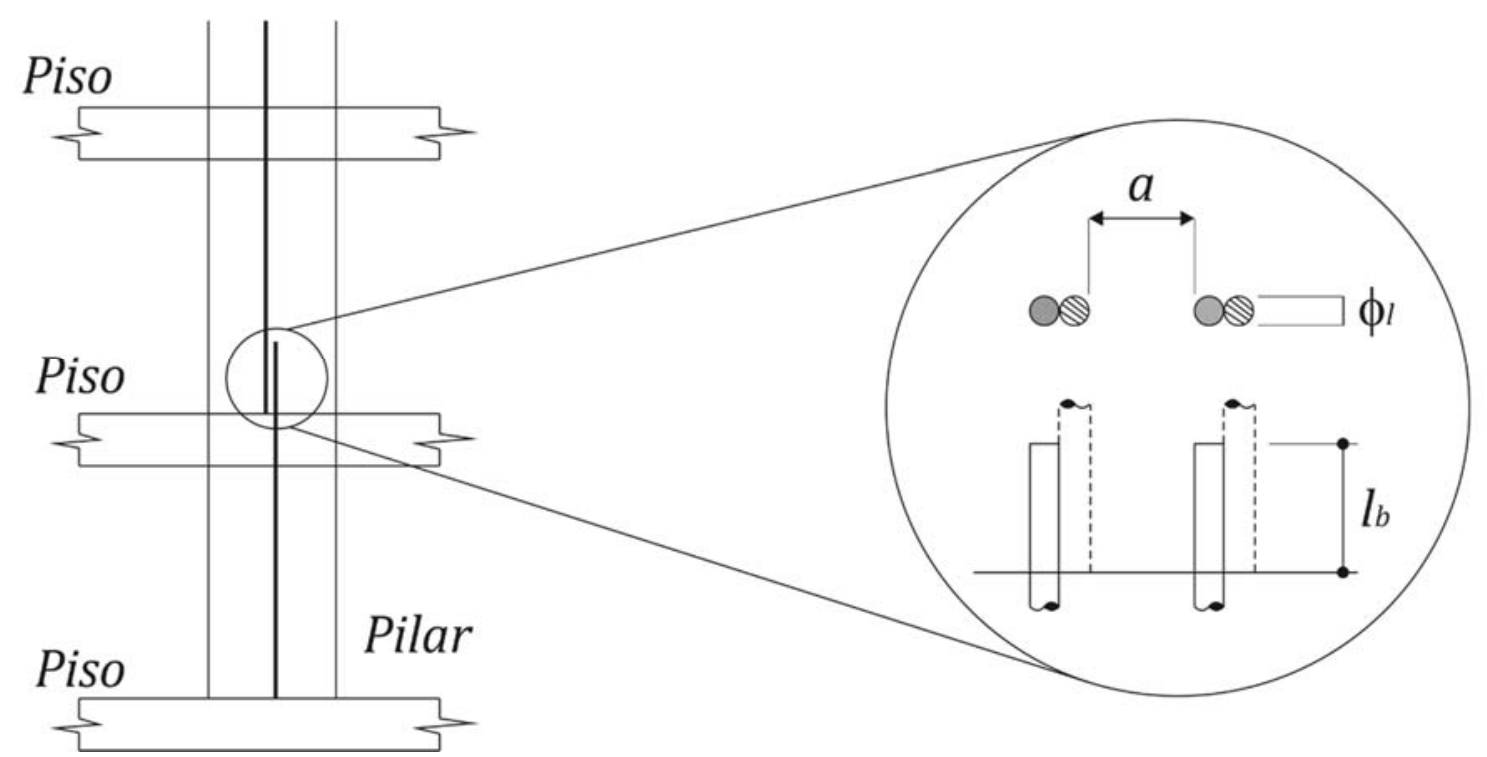

Fonte: Adaptado de Pinheiro, L. M. - Estruturas de concreto - Capítulo 16, 2005.

Para feixes de barras, deve-se considerar o diâmetro do feixe: $\phi_{n}=\phi$. $\sqrt{n}$.

e) Espaçamento máximo das barras longitudinais:

O espaçamento máximo entre eixos das barras, ou de centros de feixes de barras, deve ser menor ou igual a duas vezes a menor dimensão da seção no trecho considerado, sem exceder $400 \mathrm{~mm}$. 
Caso uma ou mais das condições deste item não sejam adotadas, é necessário modificar os parâmetros iniciais (diâmetro da armadura longitudinal e da armadura transversal) e realizar novo pré-dimensionamento.

\subsection{DIMENSIONAMENTO}

O pré-dimensionamento da seção leva ao conhecimento da taxa mecânica de armadura $(\omega)$. No dimensionamento, verifica-se se a armadura obtida com essa taxa resiste às solicitações críticas impostas ao pilar.

Dessa forma, com o intuito de facilitar o dimensionamento de peças submetidas a flexão oblíqua, a ABNT NBR 6118:2014 define o conceito de envoltórias solicitantes (envoltória mínima de $1^{\mathrm{a}}$ ordem, envoltória mínima de $2^{\mathrm{a}}$ ordem e pontos de solicitação) que deverão ser contornadas por uma envoltória resistente (relativa aos momentos fletores resistentes em cada eixo da seção), para um dimensionamento seguro.

\subsubsection{Envoltória resistente}

Segundo o item 17.2.5 da ABNT NBR 6118:2014, nas situações de flexão oblíqua, simples ou composta, pode ser adotada a aproximação dada pela expressão de interação:

$$
\left(\frac{M_{R d, x}}{M_{R d, x x}}\right)^{\alpha}+\left(\frac{M_{R d, y}}{M_{R d, y y}}\right)^{\alpha}=1
$$

- $\quad M_{R d, x}$ e $M_{R d, y}$ são as componentes do momento fletor resistente de cálculo em flexão oblíqua composta, segundo os dois eixos principais de inércia x e y, da seção bruta, com um esforço normal resistente de cálculo $N_{R d}$ igual à normal solicitante $N_{S d}$. Esses são os valores que se deseja obter;

- $\quad M_{R d, x x}$ e $M_{R d, y y}$ são os momentos fletores resistentes de cálculo segundo cada um dos referidos eixos em flexão composta normal, com o mesmo 
valor de $N_{R d}$. Esses valores são calculados a partir do arranjo e da quantidade de armadura em estudo;

- $\quad \alpha$ é um expoente cujo valor depende de vários fatores, entre eles o valor da força normal, a forma da seção, o arranjo da armadura e de suas porcentagens. Em geral pode ser adotado $\alpha=1$, a favor da segurança. No caso de seções retangulares, pode-se adotar $\alpha=1,2$, valores que se aproximam aos obtidos por Venturini (1987).

A envoltória resistente é a criação, por meio da expressão 7.13, de uma curva que represente o esforço máximo suportado por certa seção do pilar. Basicamente, o cálculo envolve a contribuição de cada elemento da seção (área de concreto comprimido e linhas de armadura, em tração ou compressão) até que alguma deformação desses elementos corresponda ao estado-limite último (domínios de deformação definidos no item 4 deste texto). Assim, é necessário o conhecimento da distribuição e da taxa de armadura da seção para a construção dessa envoltória.

Nos apêndices $A$ e $B$ deste texto estão presentes o equacionamento e o algoritmo para obtenção desses momentos fletores resistentes, por dois métodos diferentes. O cálculo desses momentos fletores em cada um dos eixos em flexão composta normal é dispendioso, porém, em alguns casos, a obtenção dos momentos fletores resistentes pode ser facilitada pela utilização de ábacos.

Os ábacos de flexão composta normal gerados por Venturini (1987) são curvas $\left(v_{u}, \mu_{u}\right)$ de esforços resistentes adimensionais para uma seção retangular de concreto armado construídas para variadas taxas mecânica de armadura $(\omega)$ e para uma disposição de barras previamente fixada (mais informações encontram-se no apêndice B).

Portanto, considerando que o esforço normal resistente de cálculo $N_{R d}$ seja igual à normal solicitante $N_{S d}$, é possível retirar o momento fletor resistente $M_{R d}$ para determinada disposição e taxa mecânica de armadura.

Para demonstrar como é feita a obtenção dos momentos fletores resistentes utilizando ábacos, considere-se a figura 7.5. 
Figura 7.5 - Seção exemplo

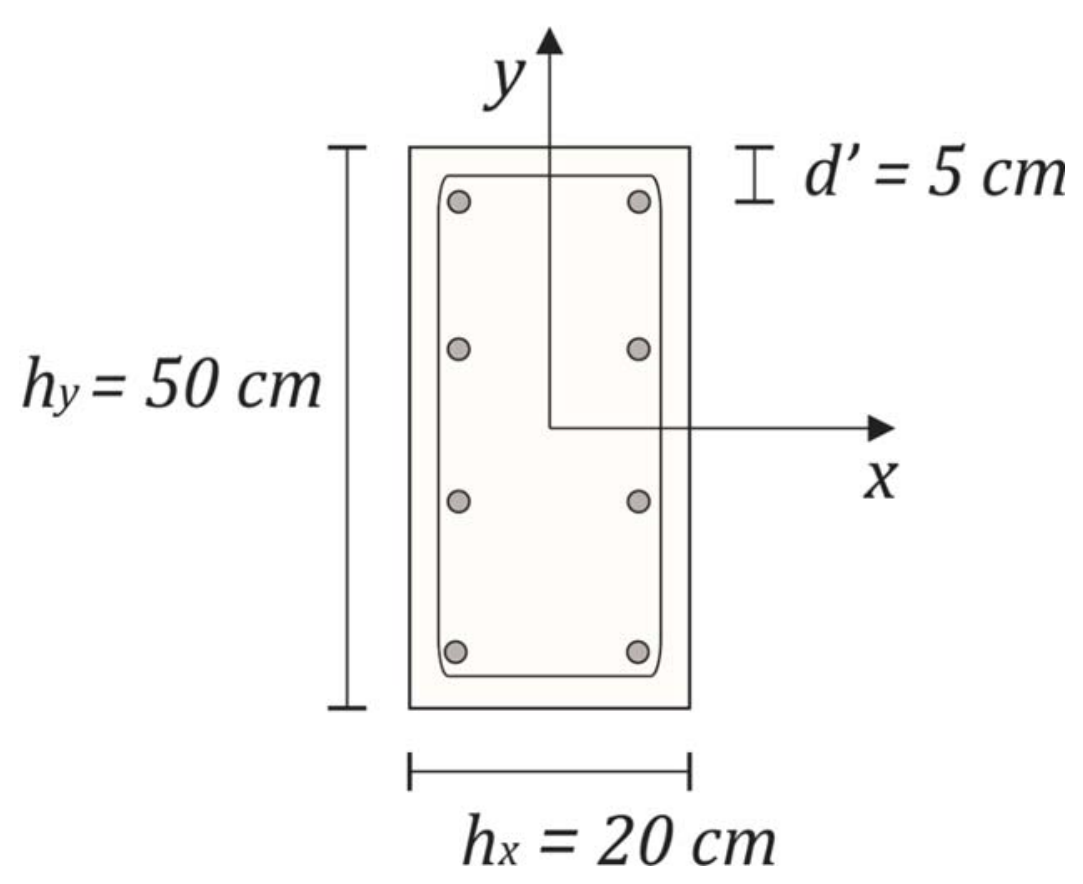

Fonte: Elaborado pelo Autor.

Nessa figura, admite-se que os eixos respeitem o proposto no item 7 , o aço seja CA-50, o concreto do tipo C25, a normal solicitante $N_{S d}=1072 \mathrm{kN}$ e a bitola de armadura longitudinal $\phi_{l}=20 \mathrm{~mm}$ de forma que a armadura da seção seja de 8 barras de $20 \mathrm{~mm}$. Da figura 7.5, pode-se retirar:

$$
\begin{aligned}
& \frac{d^{\prime}}{h_{x}}=\frac{5}{20}=0,25 \\
& \frac{d^{\prime}}{h_{y}}=\frac{5}{50}=0,10
\end{aligned}
$$

Para poder obter os momentos fletores resistentes referentes a cada eixo nos ábacos de flexão composta, deve-se ter, inicialmente, o conhecimento da força normal solicitante adimensional (que será igualada à força normal resistente adimensional) e a distribuição de armadura referente ao momento fletor resistente de cada eixo. Assim, considerem-se a expressão 7.16 e a figura 7.6.

$$
v=\frac{N_{S d}}{A_{c} \cdot f_{c d}}=\frac{1072}{20 \cdot 50 \cdot 2,5 / 1,4}=0,60
$$


Figura 7.6 - Determinação do momento fletor resistente
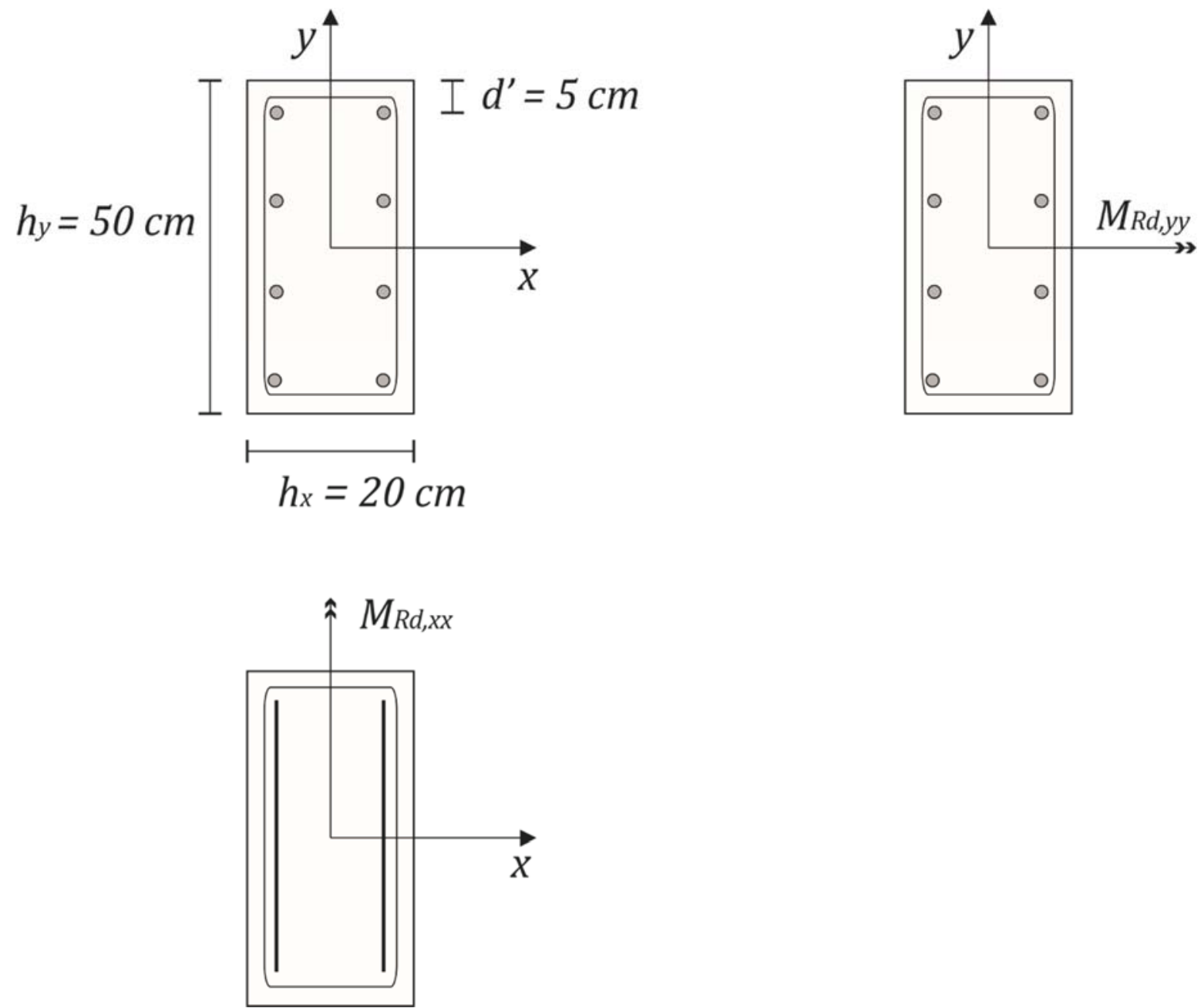

Fonte: Elaborado pelo Autor.

Analisando a figura 7.6 verifica-se que o momento fletor resistente no eixo y $\left(M_{R d, y y}\right)$ apresenta distribuição de armadura referente a 8 barras de $20 \mathrm{~mm}$, com $d^{\prime} / h_{y}=0,10$. O momento fletor resistente no eixo $\times\left(M_{R d, x x}\right)$ apresenta distribuição bilateral simétrica de armadura, com $d^{\prime} / h_{x}=0,25$.

Os ábacos de Venturini (1987) estão em função de três parâmetros: força normal adimensional $\nu$, momento fletor adimensional $\mu$ e taxa mecânica de armadura $\omega$. A força normal adimensional foi determinada com a expressão 7.16. A taxa mecânica de armadura é obtida com a expressão 7.17, sabendo que 8 barras de $20 \mathrm{~mm}$ correspondem à área de armadura $A_{s}=25,13 \mathrm{~cm}^{2}$ : 


$$
\omega=\frac{A_{s} \cdot f_{y d}}{A_{c} \cdot f_{c d}}=\frac{25,13 \cdot \frac{50}{1,15}}{20 \cdot 50 \cdot \frac{2,5}{1,4}}=0,61
$$

Assim, para obtenção do momento fletor resistente no eixo y, deve-se inicialmente escolher o ábaco pertinente ao arranjo de armadura (demonstrado na figura 7.6) e a $d^{\prime} / h_{y}=0,10$. Escolhe-se, portanto, o ábaco A-11. Com os parâmetros $v=0,60$ e $\omega=0,61$, obtém-se no ábaco o momento fletor adimensional $\mu=0,22$ e, assim:

$$
\begin{gathered}
M_{R d, y y}=A_{c} \cdot h_{y} \cdot f_{c d} \cdot \mu=20 \cdot 50 \cdot 50 \cdot \frac{2,5}{1,4} \cdot 0,22=19643 \mathrm{kN} . \mathrm{cm} \\
\therefore M_{R d, y y}=196,43 \mathrm{kN} . \mathrm{m}
\end{gathered}
$$

Agindo de maneira análoga, o momento fletor resistente no eixo x é obtido com a escolha do ábaco pertinente ao arranjo de armadura (indicado na figura 7.6) e a $d^{\prime} / h_{x}=0,25$, escolhendo-se, portanto, o ábaco A-5. Com os parâmetros $v=0,60$ e $\omega=0,61$ obtém-se no ábaco o momento fletor adimensional $\mu=0,205 \mathrm{e}$, assim:

$$
\begin{gathered}
M_{R d, x x}=A_{c} \cdot h_{x} \cdot f_{c d} \cdot \mu=20 \cdot 50 \cdot 20 \cdot \frac{2,5}{1,4} \cdot 0,205=7321 \mathrm{kN} . \mathrm{cm} \\
\therefore M_{R d, x x}=73,21 \mathrm{kN} . \mathrm{m}
\end{gathered}
$$

Percebe-se que o método indicado é extremamente simples e, portanto, passível de alguns erros. Assim, quando do uso do ábaco para determinar o momento fletor adimensional, o usuário pode cometer erros de aproximação devido à leitura imprecisa do ábaco.

Cita-se também o fato de os ábacos não serem completos, considerando apenas algumas distribuições de armaduras e determinados valores $d^{\prime} / h$. Portanto, recomenda-se, para obtenção mais precisa dos momentos fletores resistentes, 0 procedimento proposto nos apêndices A e B. 


\subsubsection{Envoltória mínima de $1^{\text {a }}$ ordem}

Para pilares de seção retangular submetidos a flexão composta oblíqua, podese definir uma envoltória mínima de 1 a ordem, adotada, a favor da segurança, de acordo com a Figura 7.7.

Figura 7.7 - Envoltória mínima de $1^{\text {a }}$ ordem

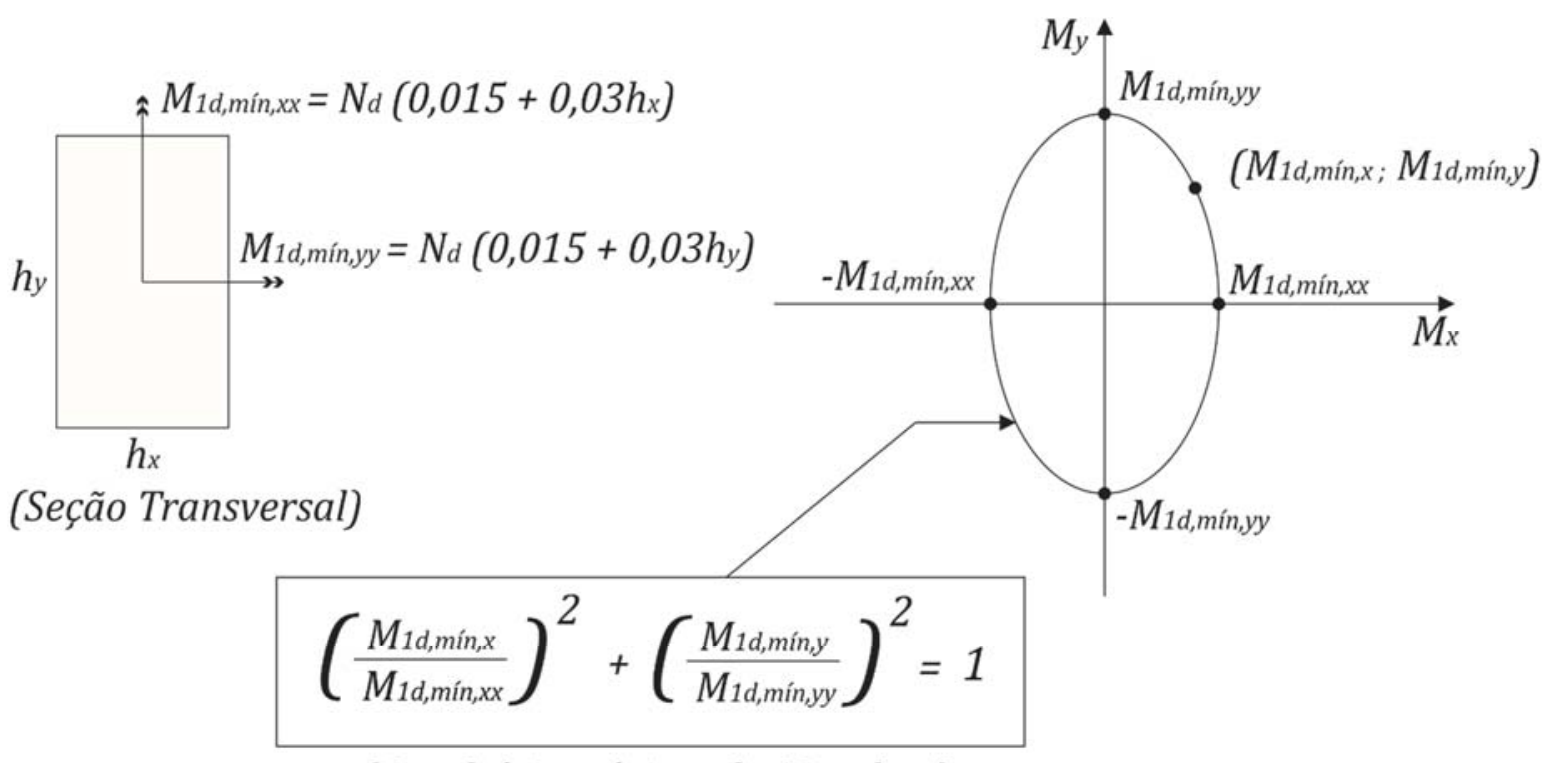

(Envoltória mínima de 1ํㅡordem)

Sendo: M1d,min,xx e M1d,mín,yy as componentes em flexão composta normal e M1d,mín,x e M1d,mín,y as componentes em flexão composta oblíqua

Fonte: Adaptado da ABNT NBR 6118:2014, item 11.3.3.4.3.

Analisando a Figura 7.7, verifica-se que a envoltória mínima é composta de duas componentes principais: $M_{1 d, \min , x x}$ que é o momento mínimo definido por uma flexão composta normal no eixo x, e $M_{1 d, m i ́ n, y y}$, que é relativo a uma flexão composta normal no eixo y.

Nas estruturas reticuladas usuais, admite-se que o efeito das imperfeições locais esteja atendido se forem respeitados esses valores de momento mínimo. Portanto, adota-se o maior valor entre $M_{1 d \text {,mín }}$ e o efeito das imperfeições locais (item 6.2.2 deste texto). A verificação do momento mínimo é considerada atendida quando se obtém uma envoltória resistente que englobe a envoltória mínima de 1a ordem. 


\subsubsection{Envoltória mínima de $2^{\mathrm{a}}$ ordem}

A envoltória mínima com 2ª ordem está indicada na Figura 7.8. Quando houver a necessidade de calcular os efeitos locais de segunda ordem, a verificação do momento mínimo pode ser considerada atendida quando, no dimensionamento adotado, obtém-se uma envoltória resistente que englobe a envoltória mínima com 2aㅡ ordem.

Os momentos fletores totais $\left(M_{S d y, t o t}\right.$ e $\left.M_{S d x, t o t}\right)$ são calculados a partir dos momentos mínimos de $1^{a}$ ordem, com o emprego de algum dos métodos de análise dos efeitos locais de 2 a ordem apresentados no item 7 deste texto. $\mathrm{O}$ cálculo dos momentos fletores totais é feito com base em duas análises à flexão composta, uma em cada direção, separadamente.

Figura 7.8 - Envoltória mínima com $2^{\mathrm{a}}$ ordem

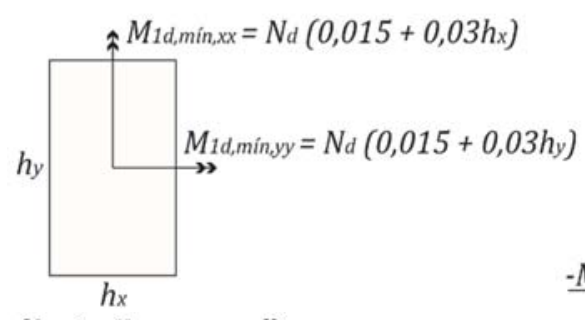

(Seção Transversal)

$\left(\frac{M_{d, t o t, \min , x}}{M_{d, t o t, \min , x x}}\right)^{2}+\left(\frac{M_{d, t o t, \min , y}}{M_{d, t o t, m i n}, y y}\right)^{2}=1$

(Envoltória mínima de 2aㅡordem)

Flexão composta normal em torno de

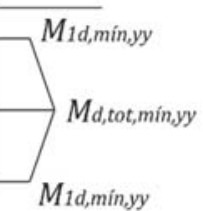

Sendo: Md,tot,min,xx e Md,tot,min,yy as componentes em flexão composta normal e $M_{d, t o t, m i n, x}$ e Md,tot,miny as componentes em flexão composta oblíqua

Fonte: Adaptado da ABNT NBR 6118:2014, item 15.3.2. 


\subsubsection{Verificação dos momentos fletores solicitantes}

Como apresentado no item anterior, "se houver a necessidade de calcular os efeitos locais de segunda ordem, a verificação do momento mínimo pode ser considerada atendida quando, no dimensionamento adotado, for obtida uma envoltória resistente que englobe a envoltória mínima com 2a ordem”. Dessa forma, a prática indica que se deve escolher um arranjo de armadura conveniente para a solicitação, e assim verificar, por meio do desenho aproximado das envoltórias mínimas de $1^{\mathrm{a}}$ e $2^{\mathrm{a}}$ ordem, se a taxa mecânica de armadura obtida é conveniente para o dimensionamento da peça, como indicado na Figura 7.9.

Figura 7.9 - Verificação do momento mínimo

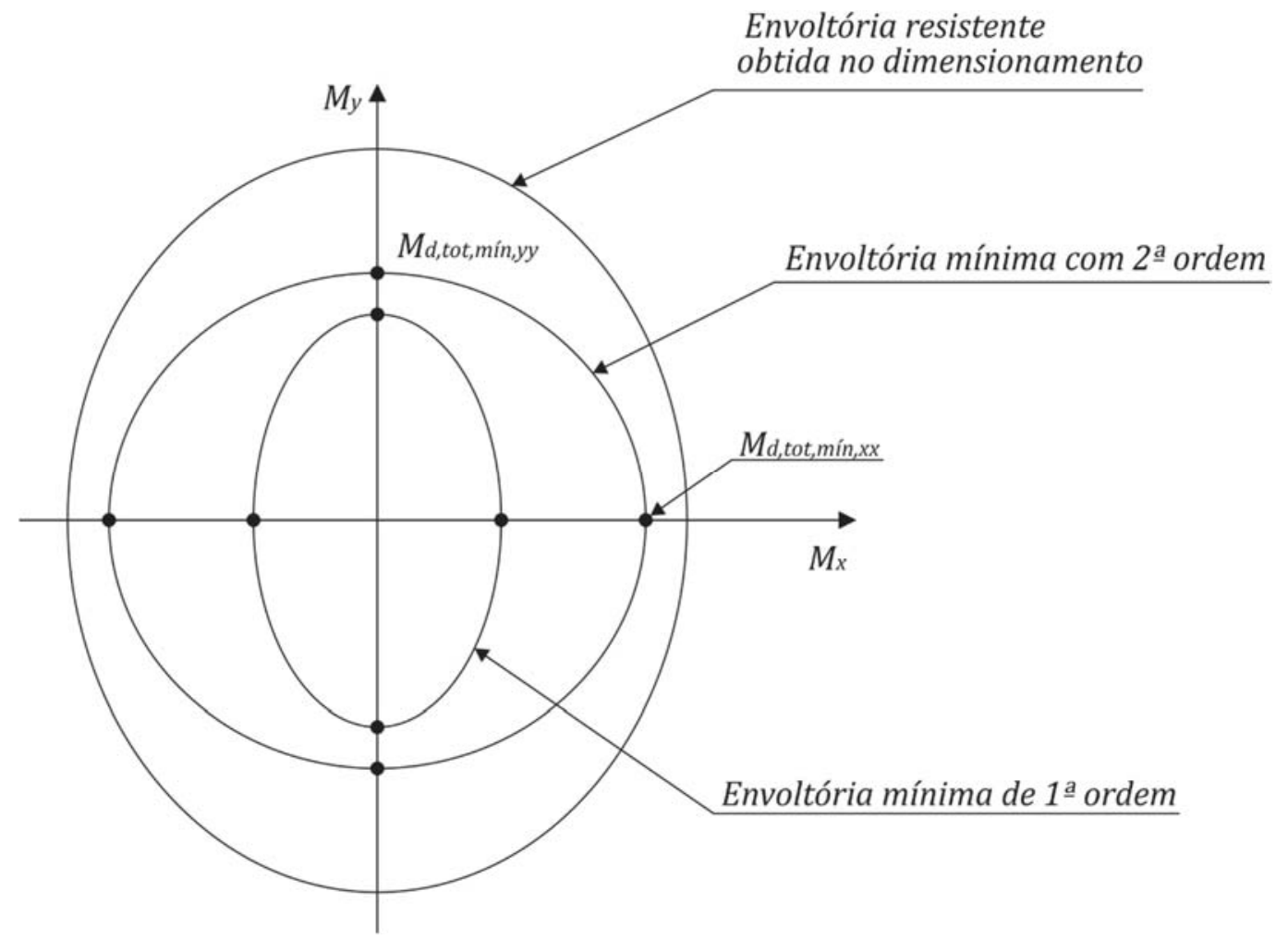

Fonte: Adaptado de Comentários Técnicos e Exemplos de Aplicação da NB-1 (IBRACON), p. 161.

Além das envoltórias mínimas, deve-se verificar a segurança dos pontos críticos do lance do pilar. Para isso, podem-se utilizar os métodos de determinação dos efeitos de segunda ordem apresentados no item 6 deste texto.

Porém, dentre os métodos apresentados, os três primeiros (pilar-padrão com curvatura aproximada, pilar-padrão com rigidez $\kappa$ aproximada e pilar-padrão acoplado 
a diagramas momento fletor - força normal - curvatura) analisam apenas uma seção crítica do pilar (adotada como sendo a seção intermediária), diferente do método geral, que analisa todas as seções pré-selecionadas para dividir o lance do pilar.

Dessa forma, para os três primeiros métodos, devem-se inserir os momentos fletores do topo, da base e da seção intermediária (considerada crítica) do lance do pilar, e verificar se esses pontos encontram-se dentro da envoltória resistente adotada. A Figura 7.10 mostra um exemplo dessa verificação, no qual os esforços no topo, na base e na seção intermediária são representados pelos pontos $T, B$ e $M$, respectivamente.

Figura 7.10 - Verificação dos momentos fletores solicitantes

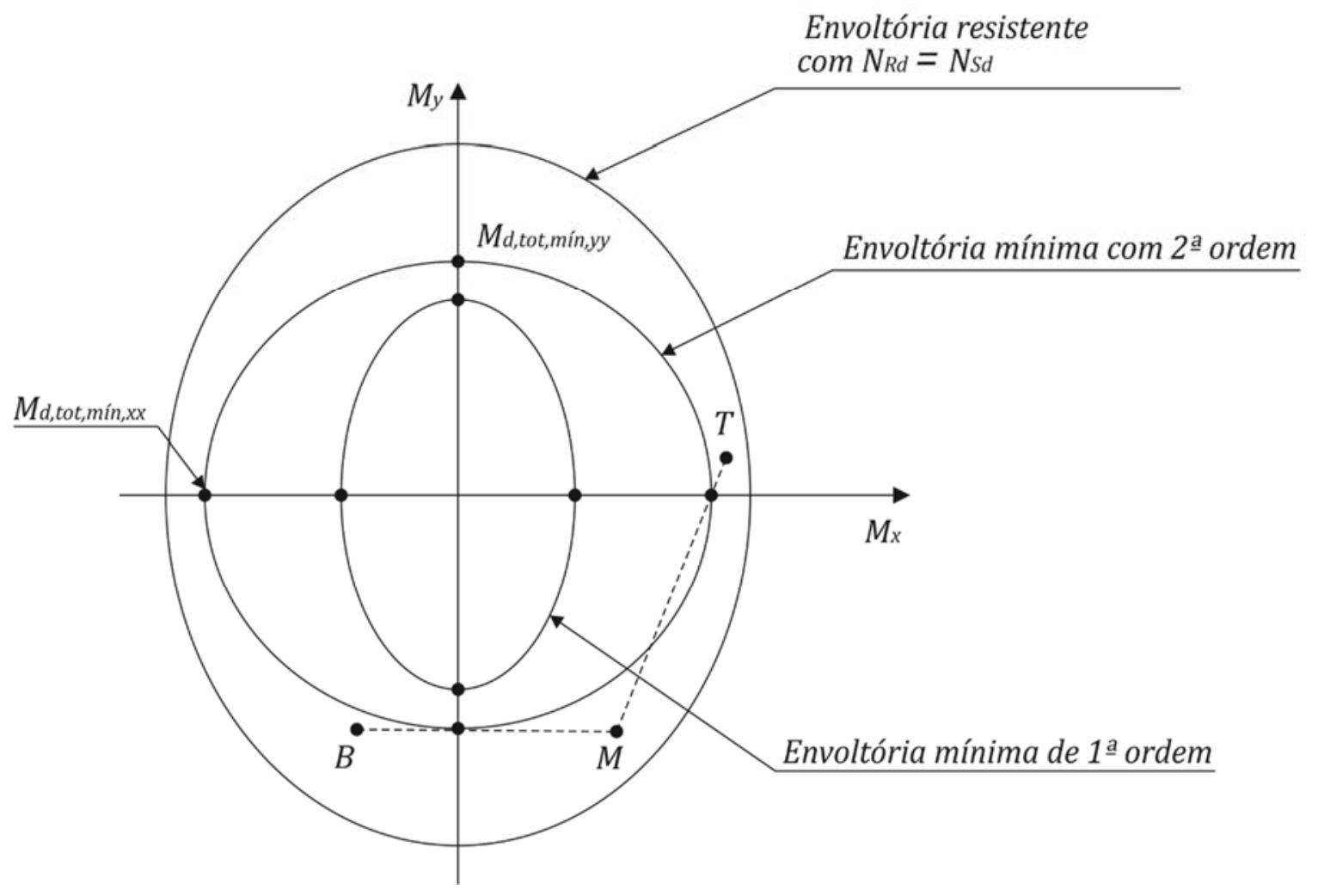

Fonte: Elaborado pelo Autor.

Já para o método geral, devem-se inserir os momentos fletores do topo, da base e de todas as seções que dividiram o lance do pilar, e verificar se esses pontos encontram-se dentro da envoltória resistente adotada. A Figura 7.11 mostra um exemplo dessa verificação, em que o pilar em análise foi dividido em 13 elementos, no qual os esforços no topo e na base são representados pelos pontos $T$ e $B$, respectivamente. 
Diferentemente dos métodos aproximados (pilar-padrão com curvatura aproximada, com rigidez $\kappa$ aproximada e pilar-padrão acoplado a diagramas momento fletor - força normal - curvatura), nos quais era possível computar os efeitos de $2^{\mathrm{a}}$ ordem diretamente no momento mínimo (quando fosse necessário), no método geral a análise é feita seção por seção. Assim, é intuitivo perceber que não há envoltória mínima de $2^{\mathrm{a}}$ ordem, e a consideração do momento mínimo será feita seção por seção.

Pela definição, o momento mínimo é o mínimo valor de momento fletor que deve ser considerado no dimensionamento de uma peça. Dessa forma, na distribuição de momentos fletores de $1^{\text {a }}$ ordem da peça, quando houver momentos fletores menores que o momento mínimo, esse momento mínimo deve substituir os momentos fletores e ser acrescido dos momentos fletores de $2^{\mathrm{a}}$ ordem.

Figura 7.11 - Verificação dos momentos fletores solicitantes utilizando o método geral

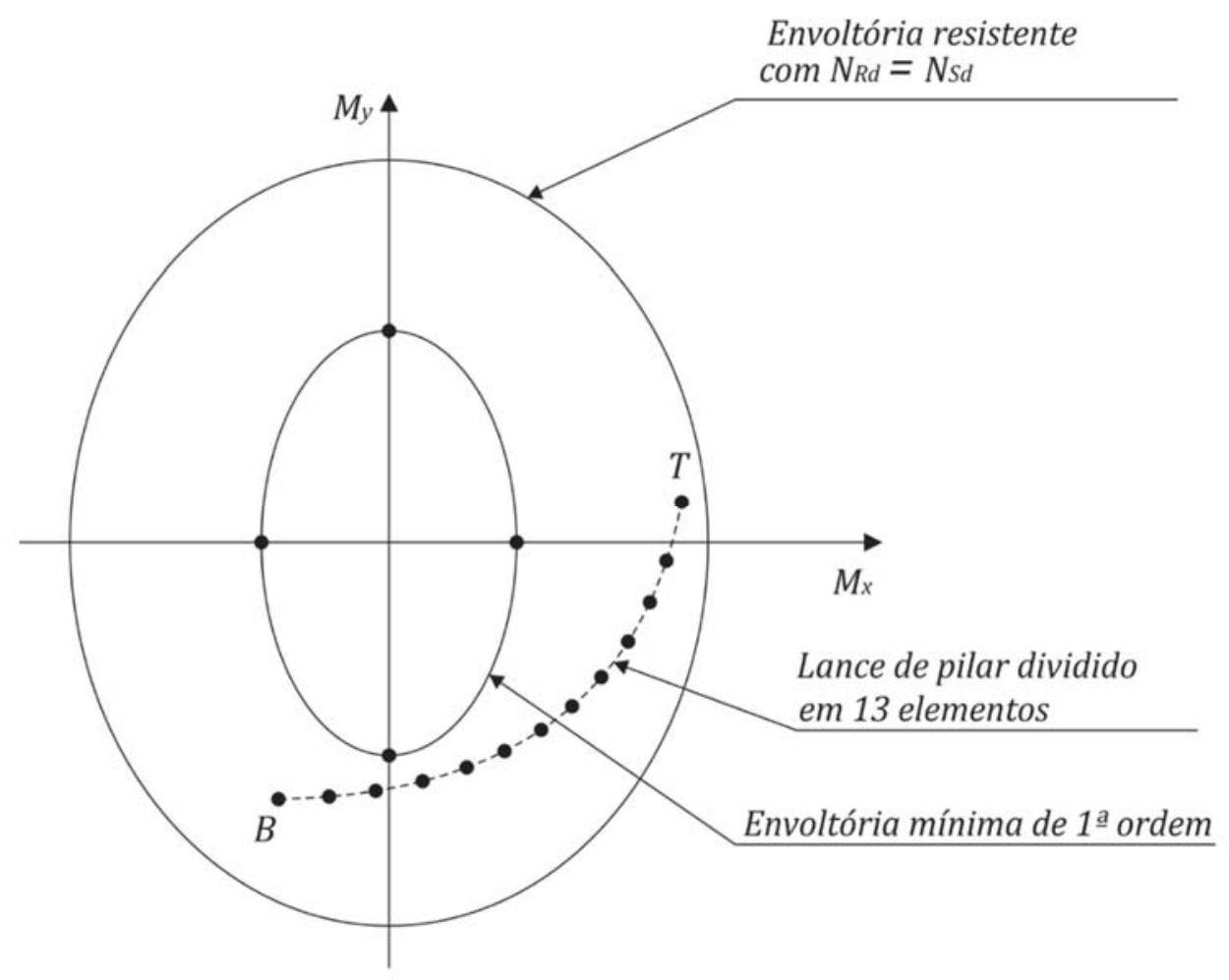

Fonte: Elaborado pelo Autor. 


\subsubsection{Excentricidade acidental versus momento mínimo}

A ABNT NBR 6118:2014 define um ângulo de inclinação $\theta_{1}$ para modelar os efeitos das imperfeições geométricas locais (item 6.2.2) e permite que esses efeitos sejam substituídos pela consideração do momento mínimo.

Esse momento fletor é um valor mínimo e não um valor aditivo como a excentricidade acidental gerada por $\theta_{1}$. Assim, têm-se duas vertentes totalmente distintas que se propõem a solucionar o mesmo problema. Por enquanto não há razões que mostram o favorecimento de uma proposta em relação à outra (KIMURA, 2010).

Assim, recomenda-se que o dimensionamento seja realizado para uma das vertentes: excentricidade acidental ou momento mínimo. Neste trabalho o dimensionamento será realizado para ambas as vertentes para efeito de comparação.

Para a consideração da excentricidade acidental, não há os conceitos de envoltórias mínimas e de momento mínimo. Como a ABNT NBR 6118:2014 não apresenta diretrizes para a utilização da excentricidade acidental, a consideração das imperfeições geométricas locais será feita com a adição de uma excentricidade acidental às excentricidades solicitantes do pilar.

\subsubsection{Verificação da segurança ou providências}

A verificação de segurança é atendida se todas as solicitações (envoltórias mínimas de $1^{\mathrm{a}}$ e $2^{\mathrm{a}}$ ordem, e solicitações no topo, na base, na seção intermediária ou em todas as seções analisadas pelo método geral, acrescidas, ou não, da excentricidade acidental) estiverem na região interna à envoltória resistente.

Pode-se verificar esse fato analiticamente pela expressão indicada a seguir, que delimita a região de segurança, com os mesmos parâmetros definidos no item 7.7.1 deste texto:

$$
\left(\frac{M_{S d, x}}{M_{R d, x x}}\right)^{\alpha}+\left(\frac{M_{S d, y}}{M_{R d, y y}}\right)^{\alpha} \leq 1
$$


Portanto, conhecidos os momentos fletores resistentes da seção $\left(M_{R d, x x} \mathrm{e}\right.$ $\left.M_{R d, y y}\right)$, basta efetuar um simples cálculo com os momentos fletores solicitantes $\left(M_{S d, x}\right.$ e $M_{S d, y}$ ) e verificar se a desigualdade é atendida.

Neste trabalho analisam-se somente pilares de seção retangular, portanto $\alpha=1,2$.

Caso alguma das solicitações esteja fora da envoltória resistente, é necessário tomar algumas providências. Assim, a primeira seria procurar no ábaco uma taxa de armadura que atenda todas as solicitações. Caso o ábaco não apresente mais taxas de armadura para o momento fletor necessário, deve-se tomar uma segunda providência, que seria efetuar novo pré-dimensionamento, conforme explicitado no item 7.6 deste texto, aumentando o diâmetro da armadura longitudinal. Se mesmo com o aumento da armadura longitudinal a verificação não for satisfeita, deve-se aumentar a seção transversal da seção e efetuar novamente o pré-dimensionamento.

\subsection{DETALHAMENTO DAS ARMADURAS}

Para poder efetuar o pré-dimensionamento, foi necessário arbitrar a altura $d^{\prime}$ (item 7.2 deste texto), que é dependente de parâmetros tais como cobrimento e diâmetros das barras longitudinais e transversais, de forma que esses parâmetros, após o dimensionamento, devem ser confirmados.

Quando realizado o pré-dimensionamento também foi necessário verificar se a armadura obtida atendia os requisitos de armadura mínima, armadura máxima, número mínimo de barras e espaçamento máximo e mínimo de barras longitudinais. Assim, após o dimensionamento, esses parâmetros também devem ser confirmados.

Resta, portanto, a definição do espaçamento permitido para a armadura transversal e a verificação da necessidade de estribos suplementares. 


\subsubsection{Espaçamento para armadura transversal}

A armadura transversal de pilares, constituída por estribos, deve ser colocada em toda a altura do pilar, sendo obrigatória sua colocação na região de cruzamento com vigas e lajes (ABNT NBR 6118:2014).

O espaçamento longitudinal entre estribos, medido na direção do eixo do pilar, conforme prescrito no item 18.4.3 da ABNT NBR 6118:2014, deve ser igual ou inferior ao menor dos seguintes valores:

- $200 \mathrm{~mm}$;

- $\quad$ menor dimensão da seção $\left(h_{x}\right)$;

- $\quad 24 \cdot \phi_{l}$ para CA-25 e $12 \cdot \phi_{l}$ para CA-50.

Caso o diâmetro dos estribos adotado seja menor que $1 / 4$ da dimensão da barra longitudinal, deve-se impor que as armaduras sejam constituídas do mesmo tipo de aço e o espaçamento respeite a limitação:

$$
S_{\text {máx }}=90000 \cdot\left(\frac{\phi_{t}{ }^{2}}{\phi_{l}}\right) \cdot \frac{1}{f_{y k}}
$$

Caso se utilize concretos de classe C55 a C90, recomenda-se que os espaçamento máximos entre os estribos sejam reduzidos em $50 \%$, com inclinação dos ganchos de pelo menos $135^{\circ}$.

\subsubsection{Estribos suplementares}

Sempre que houver possibilidade de flambagem das barras da armadura, situadas junto à superfície do elemento estrutural, devem ser tomadas precauções para evitá-la.

Os estribos poligonais garantem contra a flambagem as barras longitudinais situadas em seus cantos e as por eles abrangidas, situadas no máximo à distância de 
$20 \phi_{t}$ do canto, se nesse trecho de comprimento $\left(20 \phi_{t}\right)$ não houver mais de duas barras, não contando a de canto. Quando houver mais de duas barras nesse trecho ou barra fora dele, deve haver estribos suplementares (ABNT NBR 6118:2014, item 18.2.4).

Se o estribo suplementar for constituído por uma barra reta, terminada em ganchos $\left(90^{\circ}\right.$ a $\left.180^{\circ}\right)$, ele deve atravessar a seção do elemento estrutural, e os seus ganchos devem envolver a barra longitudinal (ABNT NBR 6118:2014).

As duas situações estão apresentadas na figura 7.12.

Figura 7.12 - Estribos suplementares

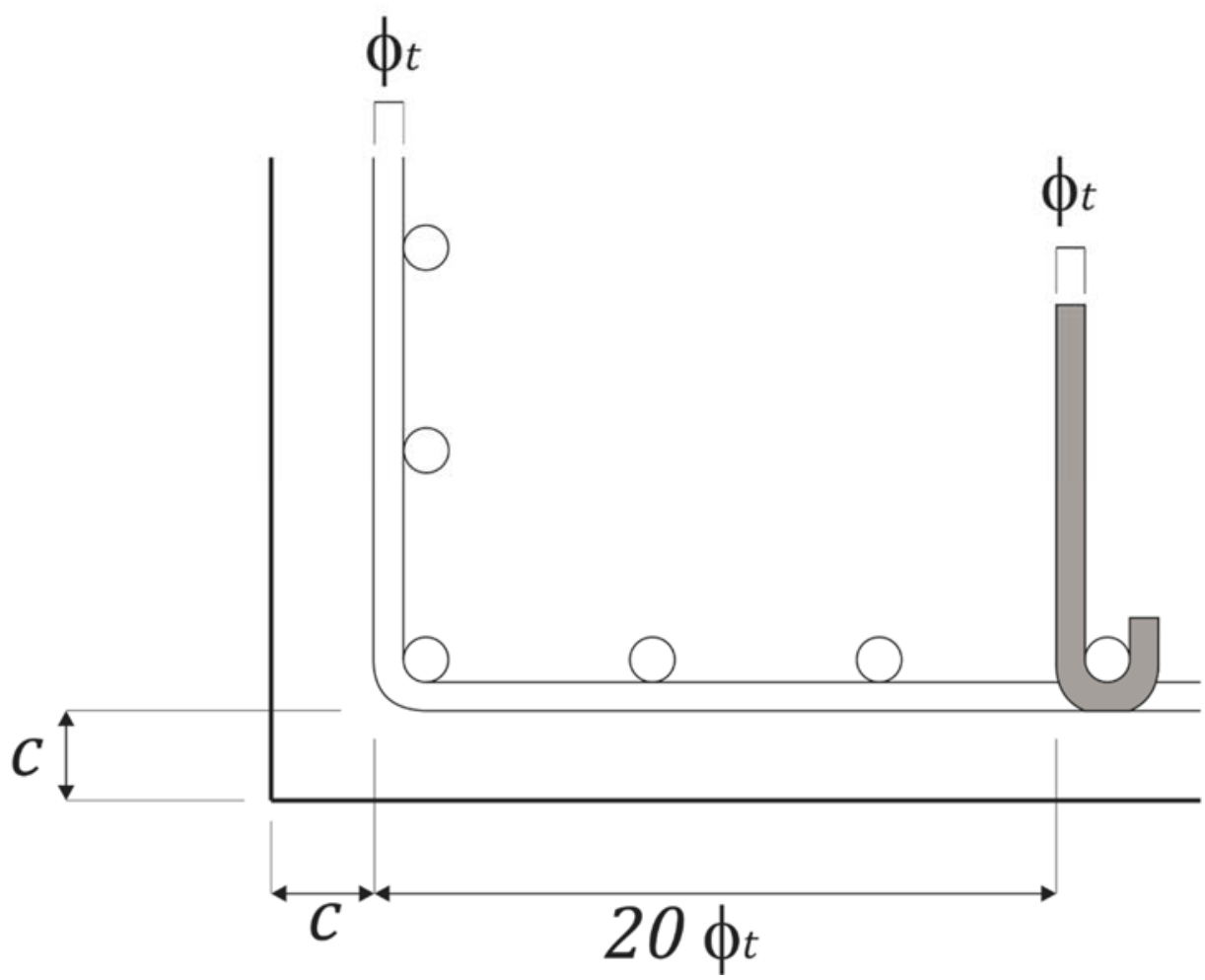

Fonte: Adaptado da ABNT NBR 6118:2014, item 18.2.4.

Ressalta-se que, na figura 7.12, a distância máxima $20 \phi_{t}$ também pode ser medida entre o eixo da barra longitudinal de canto e o eixo da respectiva barra longitudinal interna. 
136 | P á g i n a 


\section{Exemplo de aplicação}

Como exemplo de aplicação será considerado o pilar P1 do primeiro andar tipo, ou seja, entre o térreo e o primeiro andar do edifício cuja forma estrutural é indicada na Figura 8.1. Também será admitido que o andar térreo corresponde à fundação do edifício, e que o pilar está engastado nesse nível. A determinação do comprimento de flambagem do pilar será efetuada a favor da segurança, já que não há conhecimento do grau de engastamento desse pilar com a fundação.

Serão utilizados todos os métodos de dimensionamento expostos no item 6 . De acordo com a ABNT NBR 6118:2014, serão empregados os conceitos de envoltórias solicitantes e resistentes.

Quando os eixos baricêntricos das vigas não passam pelo centro de gravidade da seção transversal do pilar, as reações da viga apresentam excentricidades que são denominadas excentricidades de forma, caso do pilar P1 em análise. As excentricidades de forma serão desprezadas neste exemplo de aplicação.

A obtenção dos momentos fletores iniciais será conforme proposto no item 5.1, ou seja, utilizando o modelo clássico de viga contínua. Porém poderiam ser usados outros procedimentos, como, por exemplo, os que consideram a análise global do edifício por meio do modelo de pórtico espacial.

\subsection{DADOS}

Serão admitidos os seguintes dados:

- $\quad$ Concreto C25, aço CA-50;

- $\quad$ Seção transversal: $19 \mathrm{~cm}$ x $50 \mathrm{~cm}$;

- $\quad$ Cobrimento $\mathrm{c}=3 \mathrm{~cm}$ (classe de agressividade II - Moderada);

- $\quad$ Comprimento do pilar do primeiro andar tipo (entre o piso do térreo e o piso do primeiro andar): $480 \mathrm{~cm}$ (Figura 8.2);

- $\quad$ Comprimento do pilar de piso a piso dos andares tipos (entre os pisos): $450 \mathrm{~cm}$ (Figura 8.2);

- $\quad N_{k}=860 \mathrm{kN} ; N_{d}=1203 \mathrm{kN}$;

- $\quad$ Carga total na V201 e na V208 $p_{k}=20 \mathrm{kN} / \mathrm{m}$ (inclui peso próprio). 


\subsection{COMPRIMENTOS EQUIVALENTES DO PILAR}

Os comprimentos equivalentes $\ell_{\mathrm{ex}} \quad \mathrm{e} \ell_{\mathrm{ey}}$ dos pilares são calculados considerando $h_{x}$ a menor dimensão da seção transversal e $h_{y}$ a maior.

\subsubsection{Comprimentos equivalentes entre o térreo e o primeiro andar tipo}

Os comprimentos equivalentes $\ell_{\text {ex,inf }}$ e $\ell_{\text {ey,inf }}$ do primeiro andar tipo são os menores dos seguintes valores:

- $\quad$ Direção da V208 (direção x):

$$
\ell_{\mathrm{ex}, \mathrm{inf}} \leq\left\{\begin{array}{c}
\ell_{0 x}+h_{x} \\
\ell_{\mathrm{x}}
\end{array} \rightarrow \ell_{\mathrm{ex}, \mathrm{inf}} \leq\left\{\begin{array}{c}
420+19=439 \mathrm{~cm} \\
480 \mathrm{~cm}
\end{array} \rightarrow \ell_{\mathrm{ex}, \mathrm{inf}}=439 \mathrm{~cm}\right.\right.
$$

- $\quad$ Direção da V201 (direção y):

$$
\ell_{\text {ey,inf }} \leq\left\{\begin{array}{c}
\ell_{0 y}+h_{y} \\
\ell_{\mathrm{y}}
\end{array} \rightarrow \ell_{\text {ey,inf }} \leq\left\{\begin{array}{c}
420+50=470 \mathrm{~cm} \\
480 \mathrm{~cm}
\end{array} \rightarrow \ell_{\text {ey,inf }}=470 \mathrm{~cm}\right.\right.
$$

\subsubsection{Comprimentos equivalentes entre os andares tipos}

Entre o primeiro e o segundo andar tipo, os comprimentos equivalentes $\ell_{\text {ex,sup }}$ e $\ell_{\text {ey,sup }}$ são os menores dos seguintes valores:

- $\quad$ Direção da V208 (direção x):

$$
\ell_{\text {ex }, \text { sup }} \leq\left\{\begin{array}{c}
\ell_{0 x}+h_{x} \\
\ell_{\mathrm{x}}
\end{array} \rightarrow \ell_{\text {ex,sup }} \leq\left\{\begin{array}{c}
390+19=409 \mathrm{~cm} \\
450 \mathrm{~cm}
\end{array} \rightarrow \ell_{\text {ex,sup }}=409 \mathrm{~cm}\right.\right.
$$

- $\quad$ Direção da V201 (direção y):

$$
\ell_{\text {ey,sup }} \leq\left\{\begin{array}{c}
\ell_{0 y}+h_{y} \\
\ell_{\mathrm{y}}
\end{array} \rightarrow \ell_{\text {ey,sup }} \leq\left\{\begin{array}{c}
390+50=440 \mathrm{~cm} \\
450 \mathrm{~cm}
\end{array} \rightarrow \ell_{\text {ey,sup }}=440 \mathrm{~cm}(8.4)\right.\right.
$$


Figura 8.1 - Forma estrutural do edifício

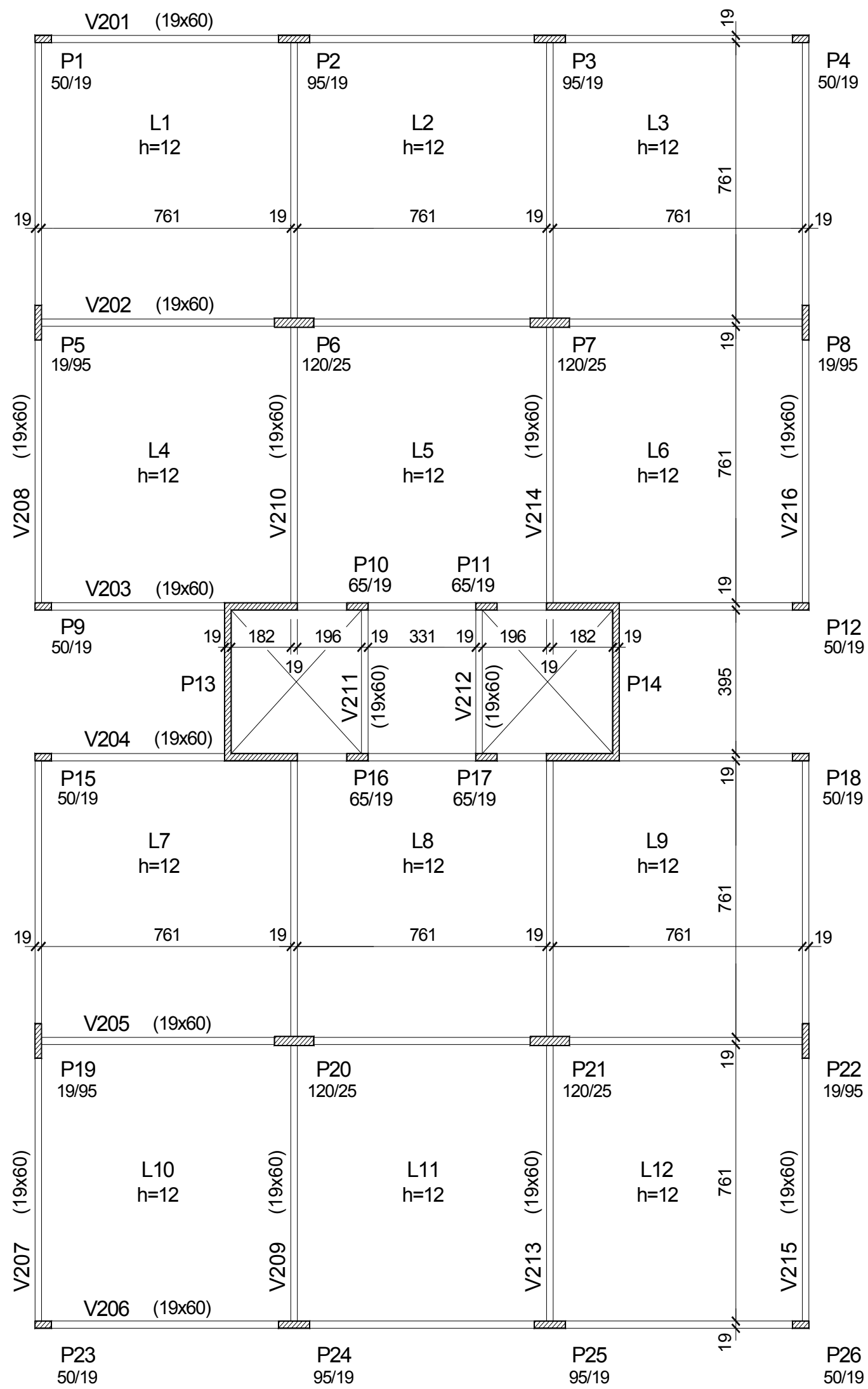

Fonte: Elaborado pelo Autor. 
Figura 8.2 - Corte lateral do edifício e eixos da seção transversal
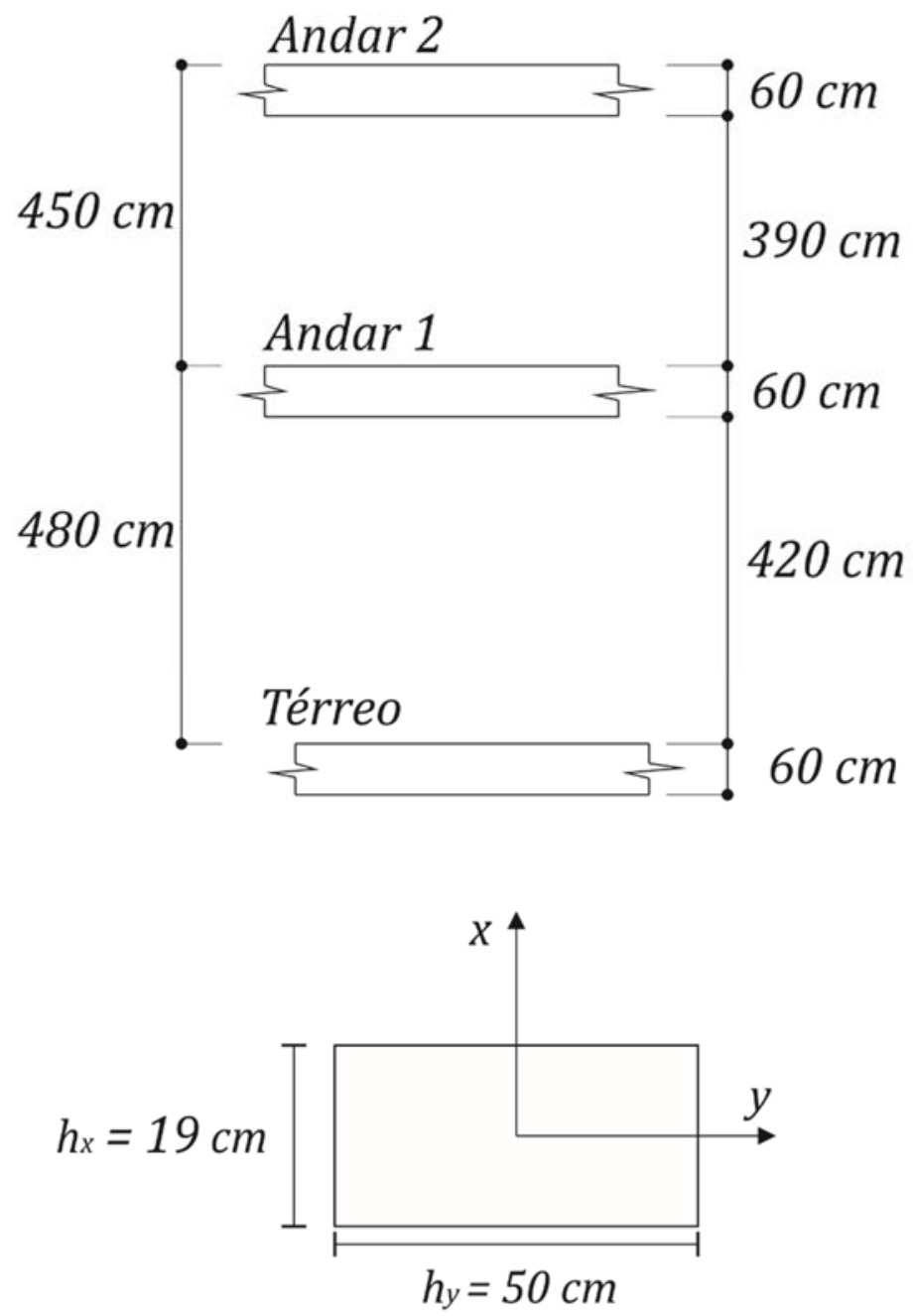

Fonte: Elaborado pelo Autor. 
Figura 8.3 - Vistas laterais do pilar P1
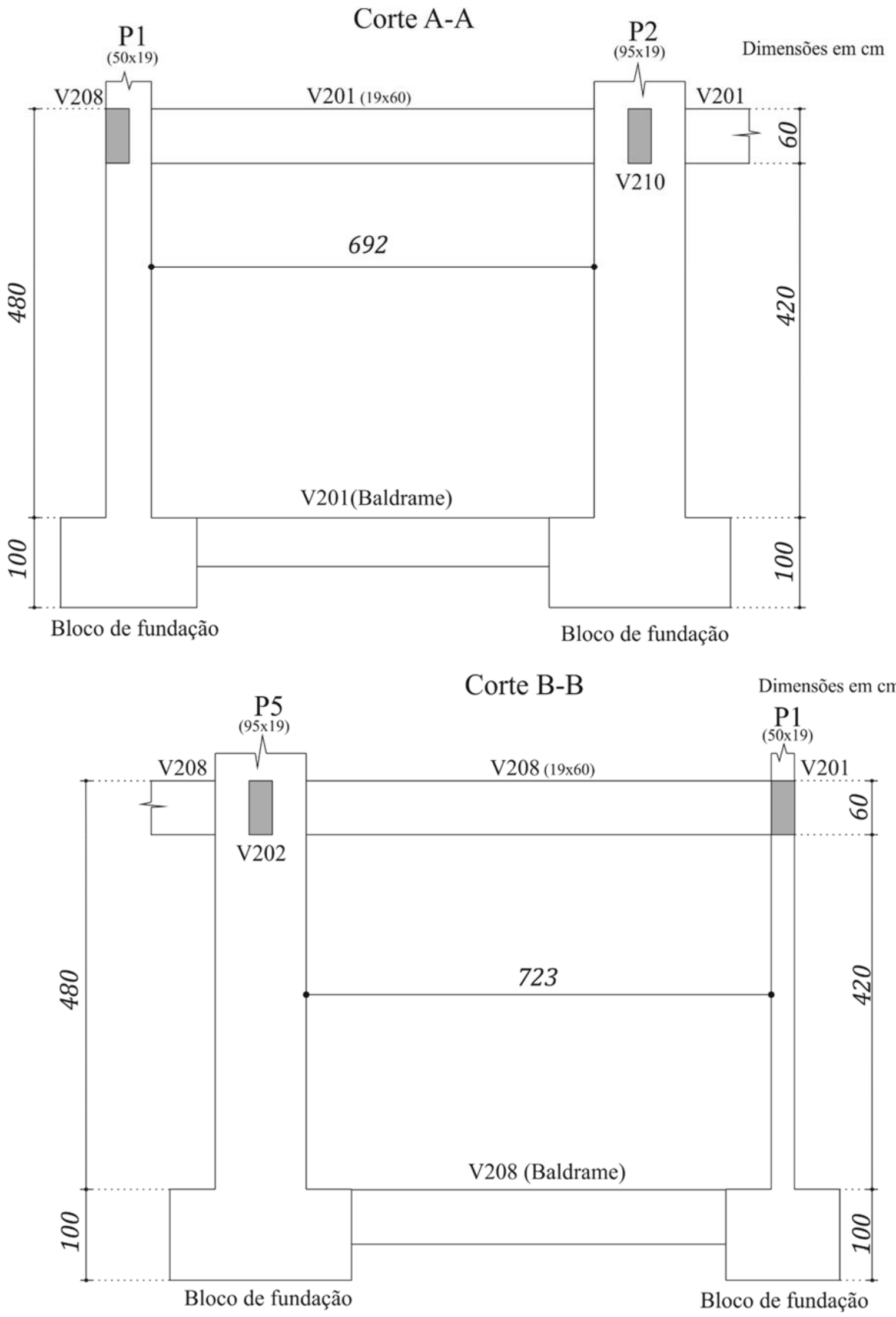

Fonte: Elaborado pelo Autor. 


\subsection{VÃOS EFETIVOS DAS VIGAS}

Os vãos efetivos das vigas são calculados conforme a Figura 8.4. Ressalta-se que, neste caso, h é a altura da viga e que $\ell_{0}$ é a distância entre as faces dos pilares.

Figura 8.4 - Vão efetivo

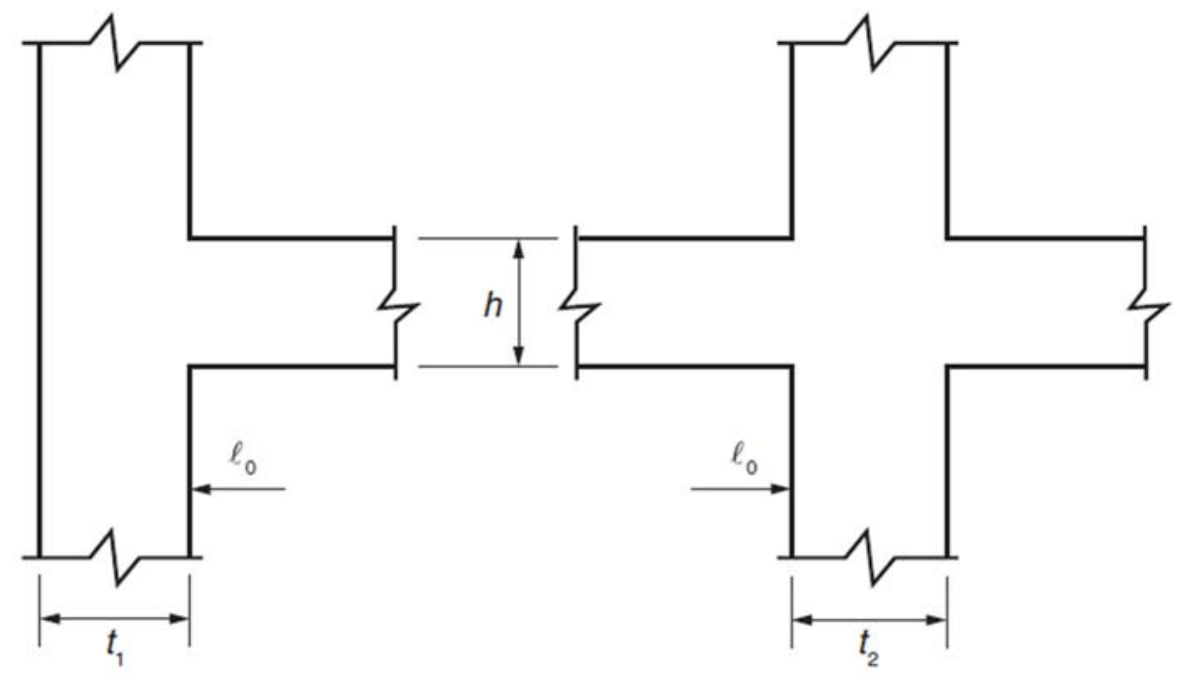

Fonte: ABNT NBR 6118:2014, Figura 14.5.

$$
\ell_{\text {evig }}=\ell_{0}+\mathrm{a}_{1}+\mathrm{a}_{2}
$$

- $\quad$ Direção da V208 (direção x):

$$
\begin{gathered}
a_{1} \leq\left\{\begin{array}{c}
t_{1} / 2=95 / 2=47,5 \mathrm{~cm} \\
0,3 \cdot h=0,3 \cdot 60=18 \mathrm{~cm}
\end{array} \rightarrow a_{1 \mathrm{y}}=18 \mathrm{~cm}\right. \\
a_{2} \leq\left\{\begin{array}{r}
t_{2} / 2=19 / 2=9,5 \mathrm{~cm} \\
0,3 \cdot h=0,3 \cdot 60=18 \mathrm{~cm}
\end{array} \rightarrow a_{2 \mathrm{y}}=9,5 \mathrm{~cm}\right. \\
\ell_{0 \mathrm{x}}=761+9,5-47,5=723 \mathrm{~cm} \\
\ell_{\mathrm{e}, \mathrm{V} 208}=\ell_{\mathrm{ex}, \mathrm{vig}}=\ell_{0 \mathrm{x}}+a_{1}+a_{2}=723+18+9,5=750,5 \mathrm{~cm}
\end{gathered}
$$

- $\quad$ Direção da V201 (direção y):

$$
a_{1} \leq\left\{\begin{array}{c}
t_{1} / 2=50 / 2=25 \mathrm{~cm} \\
0,3 \cdot h=0,3 \cdot 60=18 \mathrm{~cm}
\end{array} \rightarrow \quad a_{1 \mathrm{y}}=18 \mathrm{~cm}\right.
$$




$$
\begin{gathered}
a_{2} \leq\left\{\begin{array}{c}
t_{2} / 2=95 / 2=47,5 \mathrm{~cm} \\
0,3 \cdot h=0,3 \cdot 60=18 \mathrm{~cm}
\end{array} \rightarrow a_{2 \mathrm{y}}=18 \mathrm{~cm}\right. \\
\ell_{0 \mathrm{y}}=761+19-50+9,5-47,5=692 \mathrm{~cm} \\
\ell_{\mathrm{e}, \mathrm{V} 201}=\ell_{\mathrm{ey}, \mathrm{vig}}=\ell_{0 \mathrm{y}}+a_{1}+a_{2}=692+18+18=728 \mathrm{~cm}
\end{gathered}
$$

\subsection{MOMENTOS FLETORES NA LIGAÇÃO VIGA-PILAR - DIREÇÃO X}

Para o cálculo dos momentos fletores nas ligações das vigas com o pilar P1, será considerado o esquema estático apresentado na Figura 8.5. Ressalta-se que na direção x, da viga V208, a ligação considerada encontra-se à direita.

Figura 8.5 - Esquema estático para cálculo dos momentos fletores nas ligações viga-pilar

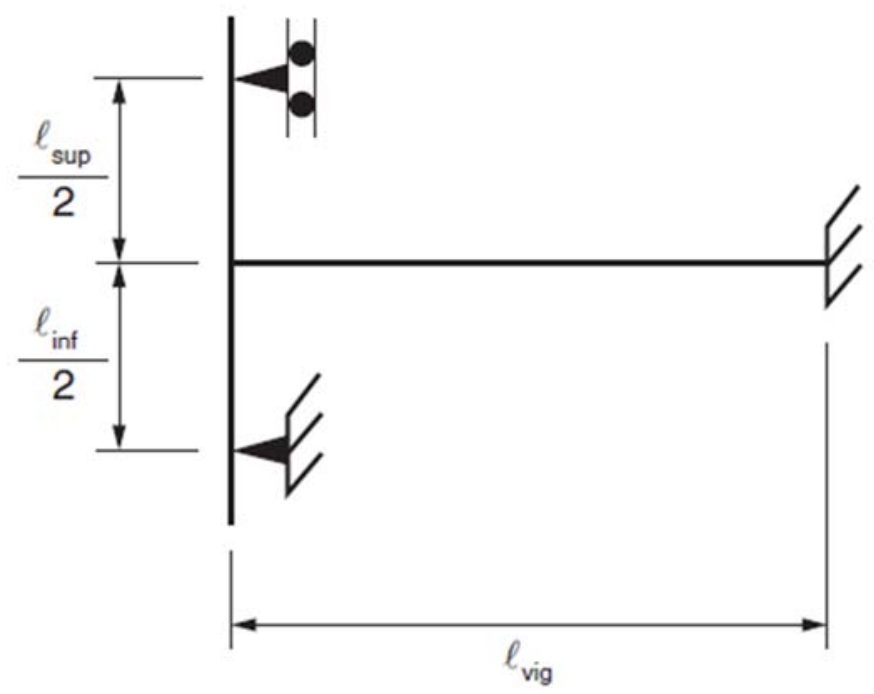

Fonte: ABNT NBR 6118:2014, item 14.6.6.1.

\subsubsection{Comprimentos equivalentes - direção $x$}

Como indicado na figura $8.2, \ell_{\text {sup }} \neq \ell_{\text {inf }}$. Nesses casos, ou naqueles em que as vigas dos andares subsequentes tiverem carga ou vão diferentes, há necessidade de cálculo separado para o nó inferior e para o superior. 
No item 8.2 foram calculados os valores de $\ell_{\text {ex,inf }}$ e $\ell_{\text {ex,sup }}$, na direção da V208, cujos valores são indicados a seguir.

$$
\begin{aligned}
& \ell_{\text {ex,inf }}=439 \mathrm{~cm} \\
& \ell_{\text {ex sup }}=409 \mathrm{~cm}
\end{aligned}
$$

O comprimento efetivo da V208 foi calculado no item 8.3, resultando:

$$
\ell_{\mathrm{e}, \mathrm{V} 208}=\ell_{\mathrm{ex}, \mathrm{vig}}=750,5 \mathrm{~cm}
$$

\subsubsection{Rigidezes - direção $x$}

Para a ligação viga-pilar na direção da V208 (direção x), os cálculos das rigidezes do pilar inferior, do pilar superior e da viga estão indicados a seguir. Destacase que a dimensão da seção do pilar que é elevada ao cubo encontra-se na direção do eixo da viga.

$$
\begin{aligned}
& r_{x, \text { inf }}=\frac{I}{\frac{\ell_{\text {ex }, \text { inf }}}{2}}=\frac{\frac{50 \cdot 19^{3}}{12}}{\frac{439}{2}} \rightarrow r_{x, \text { inf }}=130,20 \mathrm{~cm}^{3} \\
& r_{x, \text { sup }}=\frac{I}{\frac{\ell_{\text {ex,sup }}}{2}}=\frac{\frac{50 \cdot 19^{3}}{12}}{\frac{409}{2}} \rightarrow r_{x, \text { sup }}=139,75 \mathrm{~cm}^{3} \\
& r_{x, \text { vig }}=\frac{I_{\text {viga }}}{\ell_{\text {ex,vig }}}=\frac{\frac{19 \cdot 60^{3}}{12}}{750,5} \rightarrow r_{x, \text { vig }}=455,70 \mathrm{~cm}^{3}
\end{aligned}
$$

\subsubsection{Momentos fletores na ligação - direção x}

As cargas nas vigas V208 e V201 têm o mesmo valor:

$$
p_{k}=20 \mathrm{kN} / \mathrm{m}
$$


Na direção x (da V208), o esquema estático está representado na figura 8.6. Os cálculos dos momentos fletores na ligação encontram-se indicados na sequência.

Figura 8.6 - Esquema estático da viga V208 (Direção x)

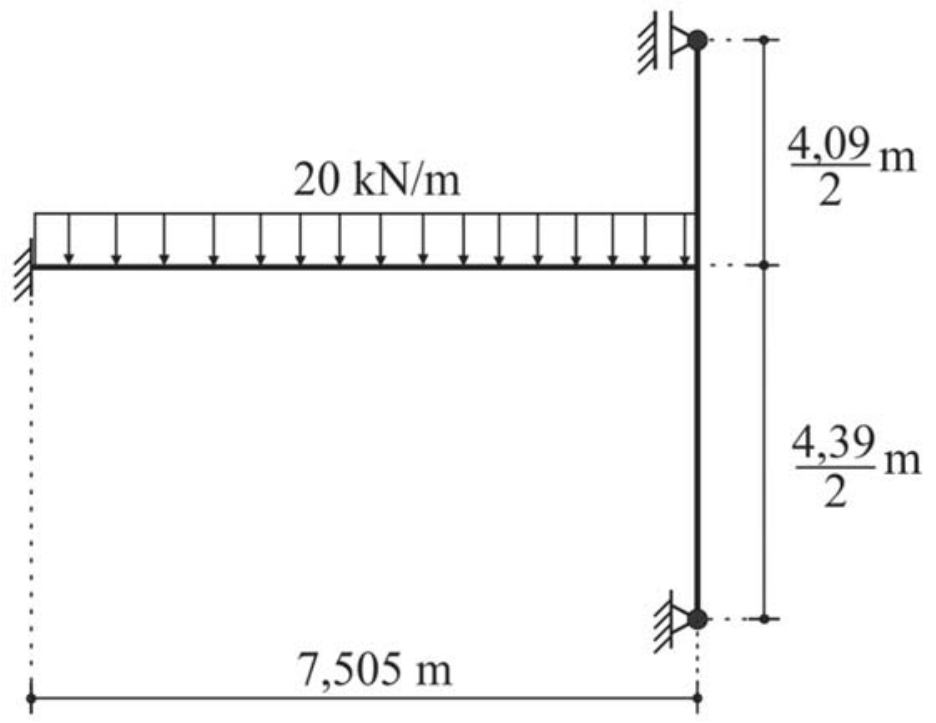

Fonte: Elaborado pelo Autor.

$$
\begin{gathered}
M_{x, \text { eng }}=\frac{p \cdot l^{2}}{12}=\frac{20 \cdot 7,505^{2}}{12} \rightarrow M_{x, \text { eng }}=93,88 \mathrm{kN} \cdot \mathrm{m} \\
M_{x, \text { inf }}=M_{x, \text { eng }} \cdot \frac{r_{\text {inf }}}{r_{v i g}+r_{\text {inf }}+r_{\text {sup }}}=93,88 \cdot \frac{130,20}{455,70+130,20+139,75} \\
\therefore M_{x, \text { inf }}=16,84 \mathrm{kN} \cdot \mathrm{m} \\
M_{x, \text { sup }}=M_{x, \text { eng }} \cdot \frac{r_{\text {sup }}}{r_{\text {vig }}+r_{\text {inf }}+r_{\text {sup }}}=93,88 \cdot \frac{139,75}{455,70+130,20+139,75} \\
\therefore M_{x, \text { sup }}=18,08 \mathrm{kN} \cdot \mathrm{m} \\
M_{x, \text { vig }}=M_{x, \text { inf }}+M_{x, \text { sup }}
\end{gathered}
$$

\subsubsection{Momentos fletores no pilar inferior - direção $x$}

Para o pilar inferior, tem-se que o momento fletor no topo é igual ao momento fletor inferior do nó, ou seja:

$$
M_{x, \text { topo }}=M_{x, \text { inf }}=16,84 \mathrm{kN} \cdot \mathrm{m}
$$


De modo semelhante, no pilar superior tem-se que o momento fletor na base é igual ao momento fletor superior do nó:

$$
M_{x, \text { base }}=M_{x, \text { sup }}=18,08 \mathrm{kN} \cdot \mathrm{m}
$$

Como neste exemplo será dimensionado somente o tramo inferior do pilar, ou seja, entre o térreo e o primeiro andar tipo, esse momento fletor na base do tramo superior não será considerado.

Portanto, interessa, apenas, o momento fletor:

$$
M_{x, \text { topo }}=16,84 \mathrm{kN} \cdot \mathrm{m}
$$

Será admitido que esse tramo inferior é engastado no nível do térreo, consideração que conduz ao momento fletor do topo multiplicado por 0,5 , resultando:

$$
M_{x, \text { base }}=8,42 \mathrm{kN} \cdot \mathrm{m}
$$

Como $M_{\text {topo }}$ e $M_{\text {base }}$ tracionam faces opostas, eles serão considerados com sinais também opostos, de forma que o momento fletor de maior valor absoluto será considerado positivo.

Portanto, neste exemplo, podem-se considerar os valores característicos:

$$
\begin{aligned}
& M_{k x, \text { topo }}=16,84 \mathrm{kN} \cdot \mathrm{m} \\
& M_{k x, \text { base }}=-8,42 \mathrm{kN} \cdot \mathrm{m}
\end{aligned}
$$

\subsection{MOMENTOS FLETORES NA LIGAÇÃO VIGA-PILAR - DIREÇÃO Y}

Para o cálculo dos momentos fletores na ligação da V201 com o pilar P1, será considerado o esquema estático apresentado na Figura 8.7. 


\subsubsection{Comprimentos equivalentes dos pilares - direção y}

Já foi salientado que $\ell_{\text {sup }} \neq \ell_{\text {inf }}$. No item 8.2 foram calculados os valores de $\ell_{\text {ey,inf }}$ e $\ell_{\text {ey,sup }}$, cujos valores são indicados a seguir.

$$
\begin{aligned}
& \ell_{\text {ey,inf }}=470 \mathrm{~cm} \\
& \ell_{\text {ey,sup }}=440 \mathrm{~cm}
\end{aligned}
$$

O comprimento efetivo da V201 foi calculado no item 8.3, resultando:

$$
\ell_{\mathrm{e}, \mathrm{V} 201}=\ell_{\mathrm{ey}, \mathrm{vig}}=728 \mathrm{~cm}
$$

\subsubsection{Rigidezes - direção y}

Para a ligação viga-pilar na direção da V201, direção y, os cálculos das rigidezes do pilar inferior, do pilar superior e da viga são indicados a seguir. Destacase novamente que a dimensão da seção do pilar que é elevada ao cubo encontra-se na direção do eixo da viga.

$$
\begin{aligned}
& r_{y, \text { inf }}=\frac{I}{\frac{\ell_{\text {ey,inf }}}{2}}=\frac{\frac{19 \cdot 50^{3}}{12}}{\frac{470}{2}} \rightarrow r_{y, \text { inf }}=842,20 \mathrm{~cm}^{3} \\
& r_{y, \text { sup }}=\frac{I}{\frac{\ell_{\text {ey,sup }}}{2}}=\frac{\frac{19 \cdot 50^{3}}{12}}{\frac{440}{2}} \rightarrow r_{y, \text { sup }}=899,62 \mathrm{~cm}^{3} \\
& r_{y, \text { vig }}=\frac{I_{\text {viga }}}{\ell_{\text {ey,vig }}}=\frac{\frac{19 \cdot 60^{3}}{12}}{728} \rightarrow r_{x, \text { vig }}=469,78 \mathrm{~cm}^{3}
\end{aligned}
$$




\subsubsection{Momentos fletores na ligação - direção y}

A carga na viga V201 (direção y) também tem o valor:

$$
p_{k}=20 \mathrm{kN} / \mathrm{m}
$$

Nessa direção, o esquema estático está representado na figura 8.7. Os cálculos dos momentos fletores na ligação encontram-se indicados na sequência.

Figura 8.7 - Esquema estático da viga V201 (Direção y)

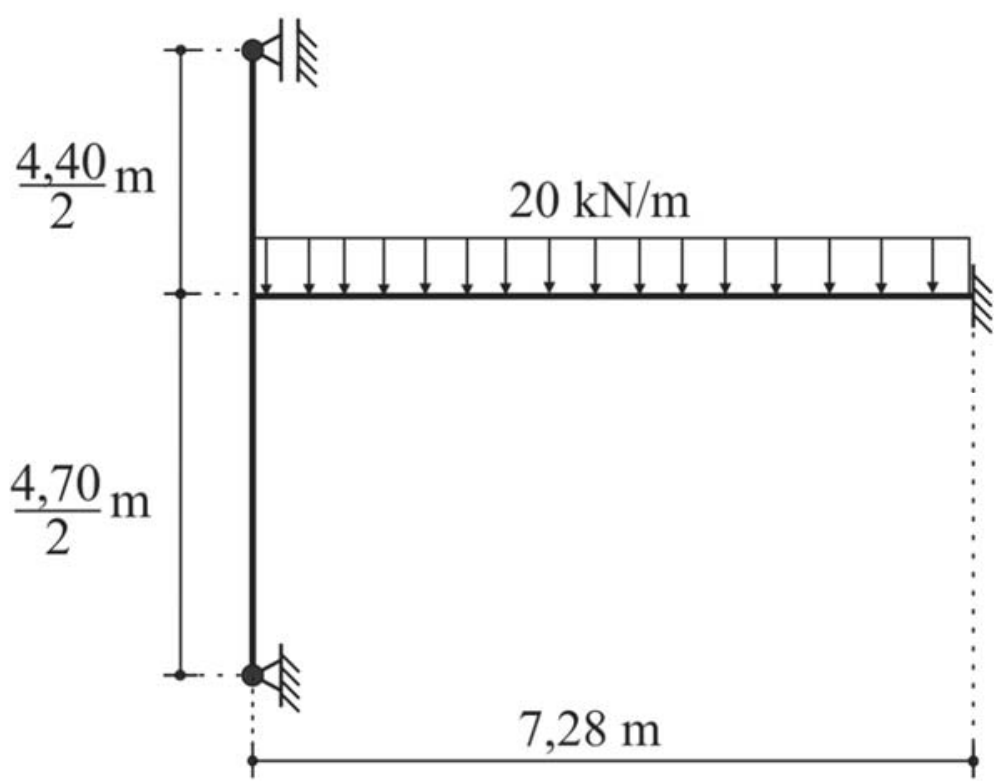

Fonte: Elaborado pelo Autor.

$$
\begin{gathered}
M_{y, \text { eng }}=\frac{p \cdot l^{2}}{12}=\frac{20 \cdot 7,28^{2}}{12} \rightarrow M_{y, \text { eng }}=88,33 \mathrm{kN} / \mathrm{m}^{2} \\
M_{y, \text { inf }}=M_{y, \text { eng }} \cdot \frac{r_{\text {inf }}}{r_{\text {vig }}+r_{\text {inf }}+r_{\text {sup }}}=88,33 \cdot \frac{842,20}{469,78+842,20+899,62} \\
\therefore M_{y, \text { inf }}=33,64 \mathrm{kN} \cdot \mathrm{m} \\
M_{y, \text { sup }}=M_{y, \text { eng }} \cdot \frac{r_{\text {sup }}}{r_{\text {vig }}+r_{\text {inf }}+r_{\text {sup }}}=88,33 \cdot \frac{899,62}{469,78+842,20+899,62}
\end{gathered}
$$

$$
M_{y, v i g}=M_{y, \text { inf }}+M_{y, \text { sup }}=33,64+35,93=69,57 \mathrm{kN} \cdot \mathrm{m}
$$




\subsubsection{Momentos fletores no pilar inferior - direção y}

Para o pilar inferior, tem-se que o momento fletor no topo é igual ao momento fletor inferior do nó, ou seja:

$$
M_{y, \text { topo }}=M_{y, \text { inf }}=33,64 \mathrm{kN} \cdot \mathrm{m}
$$

De modo semelhante, no pilar superior tem-se que o momento fletor na base é igual ao momento fletor superior do nó:

$$
M_{y, \text { base }}=M_{y, \text { sup }}=35,93 \mathrm{kN} \cdot \mathrm{m}
$$

Analogamente à direção $\mathrm{x}$, como neste exemplo será dimensionado somente o tramo inferior do pilar, ou seja, entre o térreo e o primeiro andar tipo, esse momento fletor na base do tramo superior não será considerado.

Portanto, interessa, apenas, o momento fletor:

$$
M_{y, \text { topo }}=33,64 \mathrm{kN} \cdot \mathrm{m}
$$

De modo similar ao da direção $\mathrm{x}$, será admitido que esse tramo inferior é engastado no nível do térreo, consideração que conduz ao momento fletor do topo multiplicado por 0,5 , resultando:

$$
M_{y, \text { base }}=16,82 \mathrm{kN} \cdot \mathrm{m}
$$

Como $M_{\text {topo }}$ e $M_{\text {base }}$ tracionam faces opostas, eles serão considerados com sinais também opostos, de forma que o momento fletor de maior valor absoluto será considerado positivo.

Portanto, neste exemplo, podem-se considerar os valores característicos:

$$
\begin{aligned}
& M_{k y, \text { topo }}=33,64 \mathrm{kN} \cdot \mathrm{m} \\
& M_{k y, \text { base }}=-16,82 \mathrm{kN} \cdot \mathrm{m}
\end{aligned}
$$




\subsection{MOMENTOS FLETORES INICIAIS NO PILAR}

Os momentos fletores iniciais no primeiro lance do pilar $\mathrm{P} 1$, entre o térreo e o primeiro andar tipo, nas duas direções, estão representados na Figura 8.8.

Figura 8.8 - Momentos fletores iniciais (em kN.m) na direção x (da V208) e y (da V201) do pilar P1.
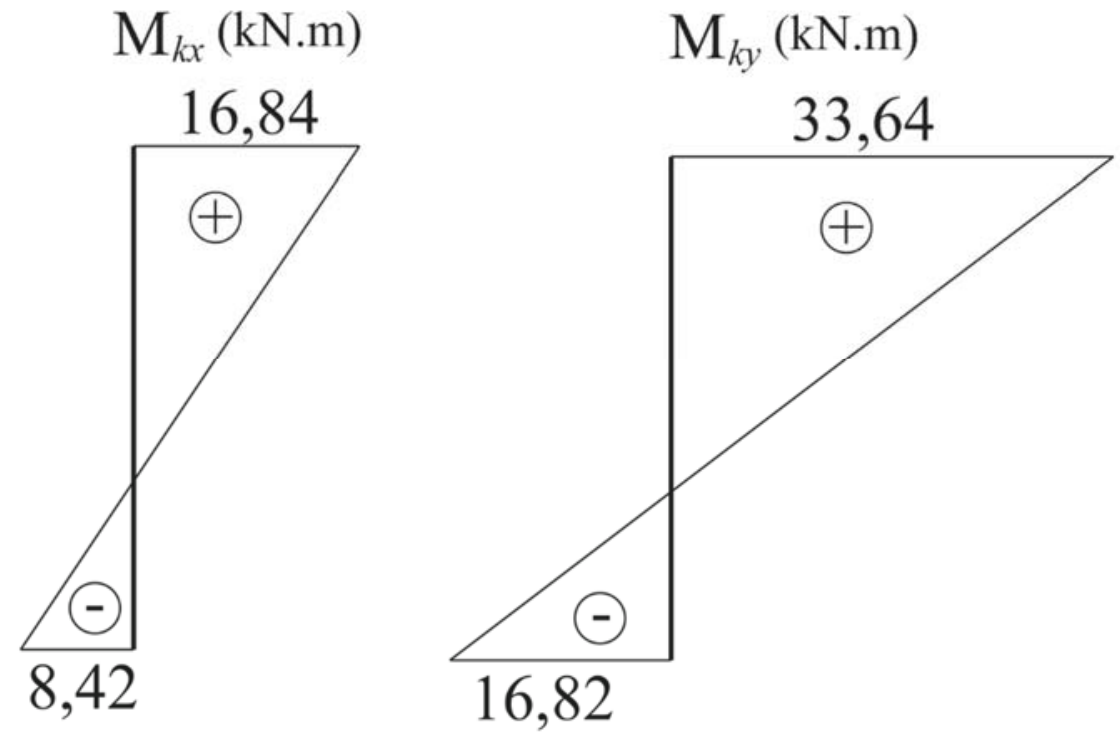

Fonte: Elaborado pelo Autor.

\subsection{MOMENTOS FLETORES NA LIGAÇÃO DE UM PILAR QUALQUER}

Em um nó de extremidade ou de canto de um andar qualquer, salienta-se que no tramo inferior desse nó tem-se:

$$
M_{\text {topo }}=M_{\text {inf }}
$$

De modo semelhante, no tramo superior do nó tem-se:

$$
M_{\text {base }}=M_{\text {sup }}
$$

No caso de pilar de canto, isso vale para as duas direções. 


\subsection{EXCENTRICIDADES INICIAIS}

As excentricidades iniciais são:

$$
\begin{aligned}
& e_{i A x}=\frac{M_{A d x}}{N_{S d}}=\frac{1,4 \cdot 1684}{1203}=1,96 \mathrm{~cm} \\
& e_{i A y}=\frac{M_{A d y}}{N_{S d}}=\frac{1,4 \cdot 3364}{1203}=3,91 \mathrm{~cm}
\end{aligned}
$$

\section{9 ÍNDICES DE ESBELTEZ}

- Direção x

$$
\lambda_{x}=\frac{\ell_{e x} \sqrt{12}}{h_{x}}=\frac{439 \sqrt{12}}{19}=80,0
$$

- Direção y

$$
\lambda_{y}=\frac{\ell_{e y} \sqrt{12}}{h_{y}}=\frac{470 \sqrt{12}}{50}=32,6
$$

\subsection{EXCENTRICIDADE ACIDENTAL VERSUS MOMENTO MÍNIMO}

A ABNT NBR 6118:2014 define um ângulo de inclinação $\theta_{1}$ para modelar os efeitos das imperfeições geométricas locais (item 5.2.2) e permite que esses efeitos possam ser substituídos pela consideração do momento mínimo.

Esse momento fletor é um valor mínimo e não um valor aditivo como a excentricidade acidental gerada por $\theta_{1}$. Assim, têm-se duas vertentes totalmente distintas que se propõem a solucionar o mesmo problema. Por enquanto não há razões que mostram o favorecimento de uma proposta em relação à outra (KIMURA, 2010). 
Dessa forma, o dimensionamento será realizado para as duas propostas separadamente.

\subsection{EXCENTRICIDADE ACIDENTAL}

Deve ser considerada a excentricidade acidental devida à falta de retilineidade do eixo do pilar.

- Direção x

$$
\begin{gathered}
\theta_{1 x}=\frac{1}{100 \sqrt{\ell_{e x}}}=\frac{1}{100 \sqrt{4,39}}=0,0048 \mathrm{rad}>\theta_{1 \min }=\frac{1}{300} \mathrm{rad}=0,0033 \mathrm{rad} \\
e_{a x}=\theta_{1 x} \cdot \frac{\ell_{e x}}{2}=0,0048 \cdot \frac{439}{2}=1,05 \mathrm{~cm}
\end{gathered}
$$

- Direção y:

$$
\begin{gathered}
\theta_{1 y}=\frac{1}{100 \sqrt{\ell_{e y}}}=\frac{1}{100 \sqrt{4,7}}=0,0046 \mathrm{rad}>\theta_{1 \min }=\frac{1}{300} \mathrm{rad}=0,0033 \mathrm{rad} \\
e_{a y}=\theta_{1 y} \cdot \frac{\ell_{e y}}{2}=0,0046 \cdot \frac{470}{2}=1,08 \mathrm{~cm}
\end{gathered}
$$

\subsection{MOMENTO MÍNIMO E EXCENTRICIDADES MÍNIMAS}

A excentricidade não pode ser menor que o valor mínimo. Dessa forma definese uma excentricidade mínima:

- Direção x 


$$
\begin{gathered}
e_{1 x, \min }=0,015+0,03 h_{x}=0,015+0,03 \cdot 0,19=0,0207 \mathrm{~m} \\
\therefore e_{1 x, \operatorname{mí} n}=2,07 \mathrm{~cm}>e_{i A x}=1,96 \mathrm{~cm}
\end{gathered}
$$

- Direção y

$$
\begin{gathered}
e_{1 y, \text { min }}=0,015+0,03 \mathrm{~h}_{\mathrm{y}}=0,015+0,03 \cdot 0,5=0,03 \mathrm{~m} \\
\therefore e_{1 y, \text { mín }}=3 \mathrm{~cm}<e_{i A y}=3,91 \mathrm{~cm}
\end{gathered}
$$

Os momentos mínimos resultam:

$$
\begin{aligned}
& M_{1 d x, \text { min }}=N_{d} \cdot e_{1 x, \text { mín }}=1203 \cdot 0,0207=24,90 \mathrm{kN} . \mathrm{m} \\
& M_{1 d y, \text { min }}=N_{d} \cdot e_{1 y, \text { mín }}=1203 \cdot 0,03=36,09 \mathrm{kN} . \mathrm{m}
\end{aligned}
$$

\subsection{VERIFICAÇÃO DA DISPENSA DOS EFEITOS DE $2^{\mathrm{a}}$ ORDEM}

- Direção x

Para pilares biapoiados ou em balanço com o momento fletor de $1^{\text {a }}$ ordem no extremo do pilar $M_{A d x}=1,4 \cdot 16,84=23,58 \mathrm{kN} . \mathrm{m}<M_{1 d x, \min }=24,90 \mathrm{kN} \cdot \mathrm{m}$ :

$$
\alpha_{b x}=1,0
$$

Assim, o índice de esbeltez limite é calculado por:

$$
\lambda_{1 x}=\frac{25+\frac{12,5 e_{i A x}}{\mathrm{~h}_{\mathrm{x}}}}{\alpha_{b x}}=\frac{25+\frac{12,5 \cdot 1,96}{19}}{1,0}=26,3 \geq 35
$$

Resulta:

$$
\lambda_{1 x}=35<\lambda_{\mathrm{x}}=80,0
$$

Portanto, devem ser considerados os efeitos de $2^{\mathrm{a}}$ ordem. 
- Direção y

Para pilares biapoiados sem cargas transversais, e sendo os momentos fletores de $1^{\mathrm{a}}$ ordem nos extremos do pilar $M_{A d y}=1,4 \cdot 33,64=47,10 \mathrm{kN} \cdot \mathrm{m}>M_{1 d y, \text { min }}=$ $36,09 \mathrm{kN} . \mathrm{m}$ e com $M_{B d y}=1,4 \cdot(-16,82)=-23,55 \mathrm{kN} . \mathrm{m}$ :

$$
\alpha_{b}=0,60+0,40 \frac{M_{B d}}{M_{A d}} \rightarrow \alpha_{b y}=0,6+0,4 \cdot \frac{(-23,55)}{47,10} \rightarrow \alpha_{b y}=0,4
$$

Mas

$$
0,4 \leq \alpha_{b} \leq 1,0
$$

Dessa forma

$$
\alpha_{b y}=0,4
$$

Assim, o índice de esbeltez limite é calculado por:

$$
\lambda_{1 y}=\frac{25+\frac{12,5 e_{i A y}}{\mathrm{~h}_{\mathrm{y}}}}{\alpha_{b y}}=\frac{25+\frac{12,5 \cdot 3,91}{50}}{0,4}=64,9 \geq 35
$$

Resulta:

$$
\lambda_{1 y}=64,9>\lambda_{\mathrm{y}}=32,6
$$

Portanto, os efeitos de $2^{\mathrm{a}}$ ordem podem ser desprezados.

\subsection{MÉTODO DO PILAR-PADRÃO COM CURVATURA APROXIMADA}

O momento fletor total máximo no pilar $\left(M_{d, t o t}\right)$, que abrange o momento fletor de $1^{\mathrm{a}}$ ordem e o de $2^{\mathrm{a}}$ ordem, é calculado pela expressão:

$$
M_{d, t o t}=\alpha_{b} \cdot M_{1 d, A}+N_{d} \cdot \frac{\ell_{\mathrm{e}}^{2}}{10} \cdot \frac{1}{r} \geq M_{1 d, A}
$$


- Direção x

$h_{x}=0,19 m$ (Dimensão da seção na direção considerada);

$N_{d}=1203 \mathrm{kN}$;

$A_{c}=0,19 \cdot 0,5=0,095 \mathrm{~m}^{2}=950 \mathrm{~cm}^{2}$;

$v=\frac{N_{S d}}{A_{c} \cdot f_{c d}}=\frac{1203}{950 \cdot 2,5 / 1,4}=0,709$;

$\alpha_{b x}=1,0$;

$M_{1 d, A x}=23,58 \mathrm{kN} . \mathrm{m}$;

$\ell_{\mathrm{ex}}=4,39 \mathrm{~m}$ (Comprimento equivalente do pilar na direção analisada).

$$
\begin{gathered}
\frac{1}{r}=\frac{0,005}{h(v+0,5)}=\frac{0,005}{0,19 \cdot(0,709+0,5)}=0,0218 \leq \frac{0,005}{h}=\frac{0,005}{0,19}=0,026 \\
M_{d, t o t, x}=1,0 \cdot 23,58+1203 \cdot \frac{4,39^{2}}{10} \cdot 0,0218=74,12 \mathrm{kN} \cdot \mathrm{m} \\
M_{d, t o t, x}=74,12 \mathrm{kN} . \mathrm{m} \geq M_{1 d, A}=1,4 \cdot 16,84=23,58 \mathrm{kN} . \mathrm{m}
\end{gathered}
$$

Para determinação das envoltórias solicitantes, calcula-se o momento mínimo com $2^{\mathrm{a}}$ ordem $\left(M_{d, t o t, \min }\right)$, para a direção x:

$$
M_{d, t o t, m i ́ n}=\alpha_{b} \cdot M_{1 d, m i ́ n}+N_{d} \cdot \frac{\ell_{\mathrm{e}}^{2}}{10} \cdot \frac{1}{r} \geq M_{1 d, \text { mín }}
$$

$1 / r=0,0218$ (calculado anteriormente);

$N_{d}=1203 k N$ (Força normal de cálculo);

$\alpha_{b x}=1,0$

$M_{1 d x, \min }=24,90 \mathrm{kN} . \mathrm{m}$ (momento mínimo);

$\ell_{\mathrm{ex}}=4,39 \mathrm{~m}$ (Comprimento equivalente do pilar na direção analisada).

$$
\begin{gathered}
M_{d, t o t, \text { min }}=1,0 \cdot 24,90+1203 \cdot \frac{4,39^{2}}{10} \cdot 0,0218=74,63 \mathrm{kN} . \mathrm{m} \\
M_{d, t o t, \text { mín }}=74,63 \mathrm{kN} . \mathrm{m} \geq M_{1 d x, \text { mín }}=24,90 \mathrm{kN} . \mathrm{m}
\end{gathered}
$$


- Direção y

Os efeitos de $2^{a}$ ordem na direção y não são computados, já que $\lambda_{1 y}>\lambda_{y}$. Portanto, não é necessário o cálculo dos efeitos de 2aㅡ ordem, o que significa que pode ser adotado, para o momento fletor total $\left(M_{d, t o t}\right)$, o momento fletor de 1 a ordem $\left(M_{1 d, A y}\right)$, e para o momento total mínimo $\left(M_{d, t o t, m i ́ n}\right)$, o momento mínimo $\left(M_{1 d y, m i ́ n}\right)$.

\subsubsection{Pré-dimensionamento}

No pré-dimensionamento serão avaliadas duas situações possivelmente críticas, que ocorrem na seção intermediária. A primeira, com atuação do momento fletor considerando efeito de $2^{a}$ ordem na direção x e momento mínimo na direção y. A segunda, com momento mínimo com $2^{\mathrm{a}}$ ordem na direção $\mathrm{x}$.

No primeiro caso, $M_{d, t o t, x x}=74,12 \mathrm{kN}$. $m$ é o momento fletor total obtido com o método da curvatura aproximada na direção x e $M_{d, t o t, y y}=36,09 \mathrm{kN}$. $\mathrm{m}$ é o momento mínimo na direção y, essa situação está presente na figura 8.9. Com esses momentos fletores, calcula-se a armadura. Serão usados os ábacos para flexão oblíqua de Pinheiro et. al. (2014). 
Figura 8.9 - Pré-dimensionamento (1 ${ }^{\mathrm{a}}$ situação)

\section{1ํㅗ Situação}

Seção Transversal

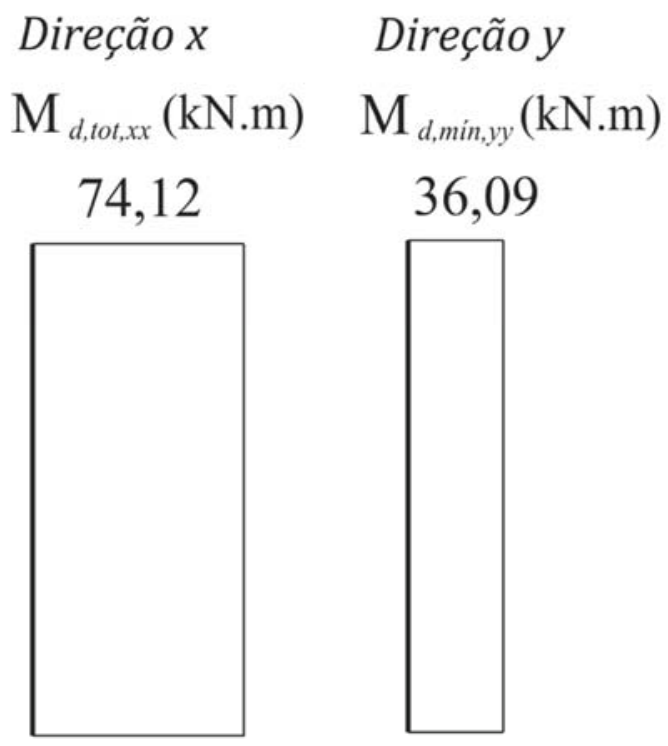

Fonte: Elaborado pelo Autor.

Para escolha do ábaco, d' será calculado para cobrimento $c=3,0 \mathrm{~cm}$ (classe de agressividade II), $\phi_{l}=20 \mathrm{~mm}=2,0 \mathrm{~cm}$ e $\phi_{t}=6,3 \mathrm{~mm}=0,63 \mathrm{~cm}$, diâmetros que foram adotados para este exemplo. Resultam:

$$
\begin{gathered}
d^{\prime}=c+\frac{\phi_{l}}{2}+\phi_{t}=3,0+\frac{2,0}{2}+0,63=4,63 \mathrm{~cm} \\
\frac{d_{x}^{\prime}}{h_{x}}=\frac{4,63}{19}=0,24 \cong 0,25 \\
\frac{d_{y}^{\prime}}{h_{y}}=\frac{4,63}{50}=0,09 \cong 0,1
\end{gathered}
$$

Os adimensionais para uso do ábaco são (concreto C25):

$$
v=\frac{N_{S d}}{A_{c} \cdot f_{c d}}=\frac{1203}{19 \cdot 50 \cdot 2,5 / 1,4}=0,709
$$




$$
\begin{gathered}
\mu_{x}=\frac{v \cdot e_{x}}{h_{x}}=\frac{v \cdot \frac{M_{d, t o t, x x}}{N_{d}}}{h_{x}}=\frac{0,709 \cdot \frac{7412}{1203}}{19}=0,23 \\
\mu_{y}=\frac{v \cdot e_{y}}{h_{y}}=\frac{v \cdot \frac{M_{d, t o t, y y}}{N_{d}}}{h_{y}}=\frac{0,709 \cdot \frac{3609}{1203}}{50}=0,04
\end{gathered}
$$

Nas direções x e y adotaram-se os valores de $d^{\prime} / h$ a favor da segurança, ou seja, os de maior valor em cada direção. Porém, também, podem-se usar ábacos com dois valores de $d^{\prime} / h$, para fazer interpolação.

Os ábacos utilizados (PINHEIRO et al., 2014) foram o 4A (figura 8.10) e o 4B (figura 8.11) com o arranjo 1 (com $d_{x}^{\prime} / h_{x}=0,25$ e $\left.d_{y}^{\prime} / h_{y}=0,1\right)$. Como $v=0,709 \cong$ 0,7 , será feita uma interpolação entre $v=0,6$ e $v=0,8$. Dessa forma, obtêm-se as taxas mecânicas de armadura. 
Figura 8.10 - Ábaco 4A $(v=0,6)$

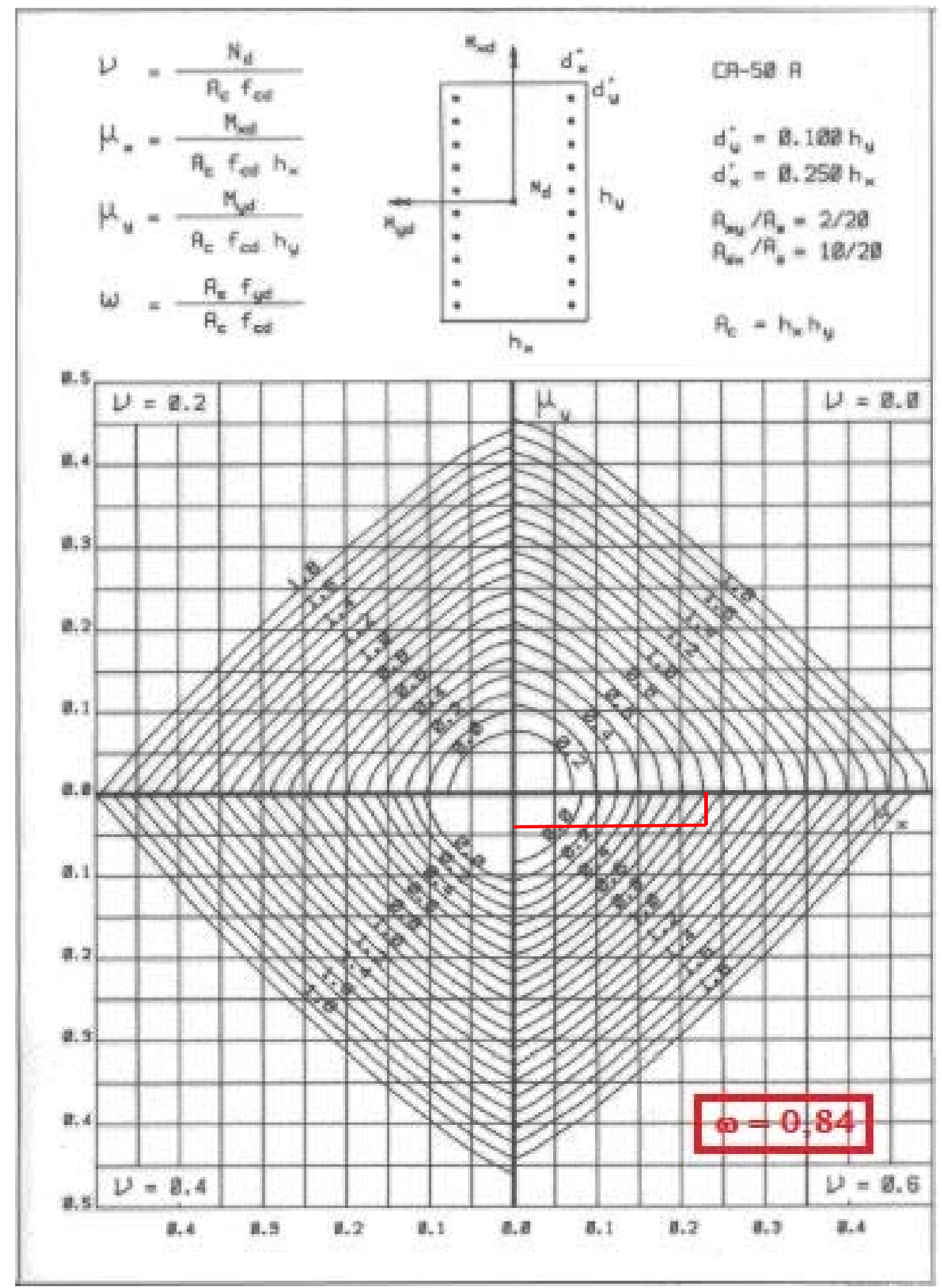

Fonte: PINHEIRO et al., 2014, p. 22.

$$
v=0,6 \rightarrow \omega=0,84
$$


Figura 8.11 - Ábaco 4B $(v=0,8)$

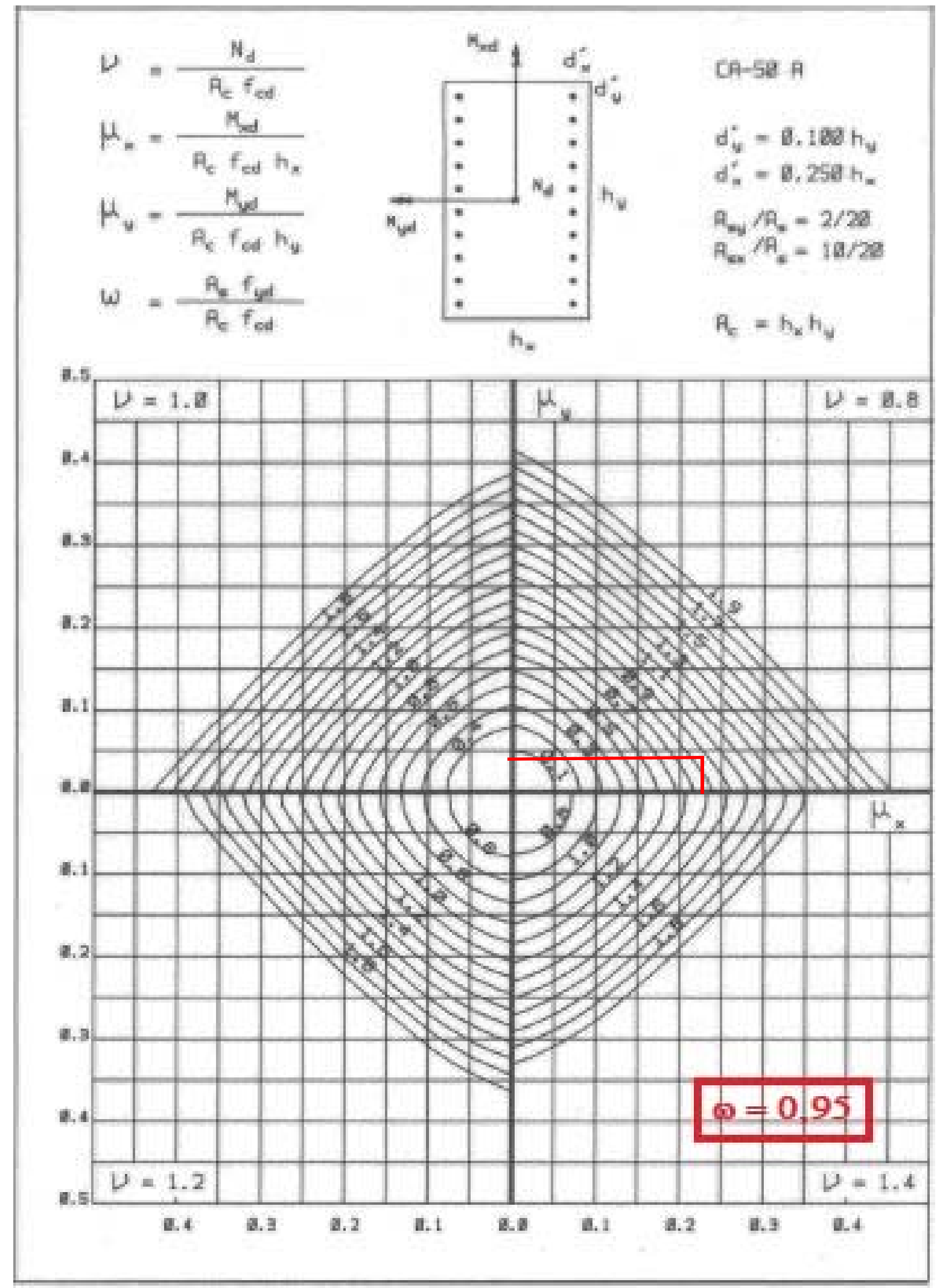

Fonte: PINHEIRO et al., 2014, p. 23. 
Assim, por interpolação (média aritmética dos dois valores):

$$
v \cong 0,7 \rightarrow \omega=0,895
$$

No segundo caso, $M_{d, t o t, \min , x x}=74,63 \mathrm{kN} . \mathrm{m}$ é o momento fletor total obtido com o método da curvatura aproximada e momento mínimo na direção $\mathrm{x}$, essa situação está presente na figura 8.12. Com esse momento fletor total, calcula-se a armadura. Serão usados os ábacos para flexão composta normal de Venturini (1987).

Figura 8.12 - Pré-dimensionamento ( $2^{\text {a }}$ Situação)

\section{$2^{a}$ Situação}

\section{Seção Transversal}

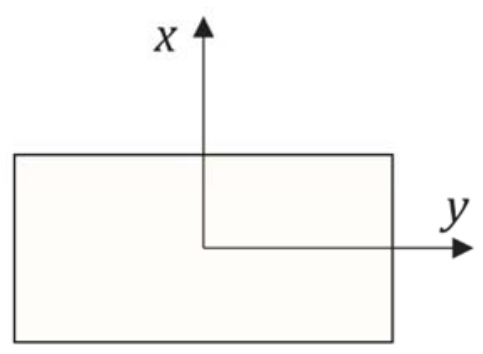

Direção $x$

$\mathrm{M}_{\text {d,tot,min, } x x}$ (kN.m)

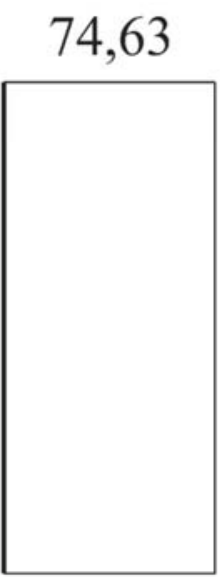

Fonte: Elaborado pelo Autor.

Para escolha do ábaco, d' será calculado para cobrimento $c=3,0 \mathrm{~cm}$ (classe de agressividade II), $\phi_{l}=20 \mathrm{~mm}=2,0 \mathrm{~cm}$ e $\phi_{t}=6,3 \mathrm{~mm}=0,63 \mathrm{~cm}$, diâmetros que foram adotados para este exemplo. Resultam:

$$
\begin{gathered}
d^{\prime}=c+\frac{\phi_{l}}{2}+\phi_{t}=3,0+\frac{2,0}{2}+0,63=4,63 \mathrm{~cm} \\
\frac{d^{\prime}}{h_{x}}=\frac{4,63}{19}=0,24 \cong 0,25
\end{gathered}
$$

Os adimensionais para uso do ábaco são (concreto C25): 


$$
\begin{gathered}
v=\frac{N_{S d}}{A_{c} \cdot f_{c d}}=\frac{1203}{19 \cdot 50 \cdot 2,5 / 1,4}=0,709 \\
\mu_{x}=\frac{v \cdot e_{x}}{h_{x}}=\frac{v \cdot \frac{M_{d, t o t, x}}{N_{d}}}{h_{x}}=\frac{0,709 \cdot \frac{7463}{1203}}{19}=0,23
\end{gathered}
$$

O ábaco utilizado (VENTURINI, 1987) foi o A-5, figura $8.13\left(\right.$ com $d_{x}^{\prime} / h_{x}=0,25$ ). Dessa forma, obtém-se a taxa mecânica de armadura: 
Figura 8.13 - Ábaco A-5

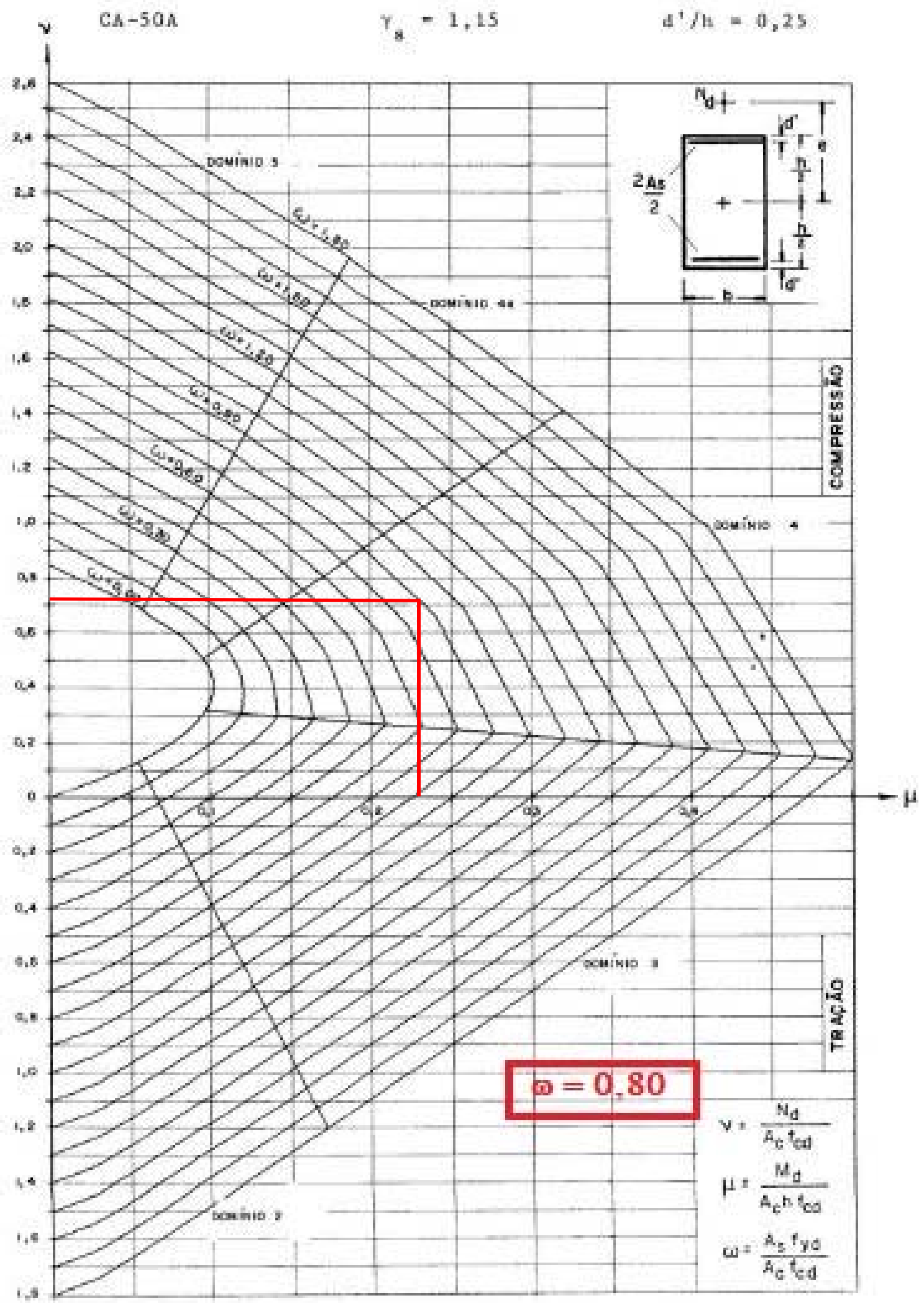

Fonte: VENTURINI, 1987, p. 44. 
Portanto, a área de aço resultante do pré-dimensionamento é definida pelo primeiro caso, resultando:

$$
A_{s}=\frac{\omega \cdot A_{c} \cdot f_{c d}}{f_{y d}}=\frac{0,895 \cdot 19 \cdot 50 \cdot \frac{2,5}{1,4}}{\frac{50}{1,15}}=34,92 \mathrm{~cm}^{2}
$$

A área de aço deve ser maior que a mínima:

$$
A_{s, \min }=\frac{0,15 \cdot N_{S d}}{f_{y d}}=\frac{0,15 \cdot 1203}{50 / 1,15}=4,15 \mathrm{~cm}^{2}>0,004 . A_{c}=3,8 \mathrm{~cm}^{2}
$$

Portanto, a área de aço necessária $\left(34,92 \mathrm{~cm}^{2}\right)$ é maior que a mínima $(4,15$ $\left.\mathrm{cm}^{2}\right)$.

A área de aço deve ser menor que a máxima:

$$
A_{s, m a ́ x}=0,04 A_{c}=0,04 \cdot 19 \cdot 50=38 \mathrm{~cm}^{2}
$$

Portanto, a área de aço necessária $\left(34,92 \mathrm{~cm}^{2}\right)$ é menor que a máxima (38 $\left.\mathrm{cm}^{2}\right)$.

Adotam-se 12 barras de $20 \mathrm{~mm}$, com uma área efetiva de $37,70 \mathrm{~cm}^{2}$ e taxa de armadura $\left(A_{s, \text { efetiva }} / A_{c}\right)$ igual a $4 \%$. Essa armadura atende os requisitos de armadura mínima e máxima.

Esse valor de armadura difere a do ábaco utilizado (ábaco de 20 barras de armadura, figuras 8.10 e 8.11). Deve-se verificar se os esforços adimensionais $\left(v, \mu_{x}\right.$ e $\mu_{y}$ ) também são válidos para o ábaco de 12 barras. Porém, como trata-se de um pré-dimensionamento, essa etapa será suprimida do trabalho.

A armadura adotada apresenta seis linhas de armadura distribuídas na altura $h_{y}$ como demonstrado na figura 8.14. 
Figura 8.14 - Seção pré-definida

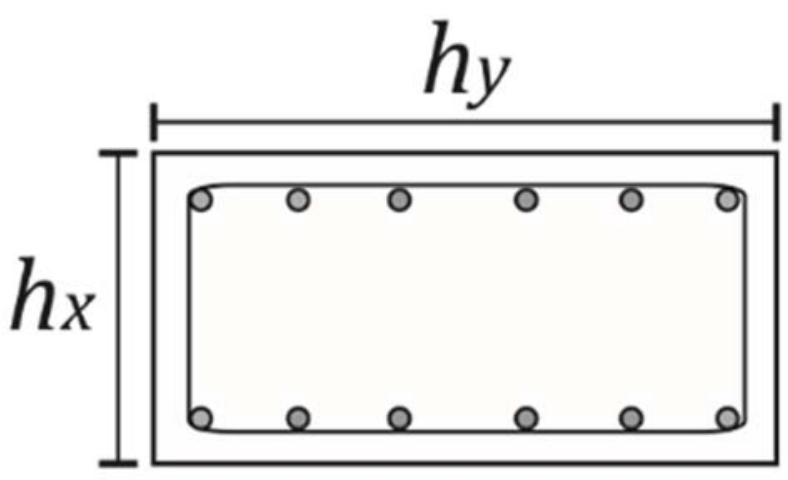

Fonte: Elaborado pelo Autor.

Deve-se verificar se a seção pré-definida atende aos requisitos de espaçamento mínimo e máximo das barras longitudinais. Assim, calculando-se o espaçamento das barras na direção de $h_{x}$ (direção x), têm-se:

$$
a_{x}=h_{x}-2 \cdot d^{\prime} \rightarrow a_{x}=19-2 \cdot 4,63=9,74 \mathrm{~cm}
$$

E na direção de $h_{y}$ (direção y):

$$
a_{y}=\frac{h_{y}-2 \cdot d^{\prime}}{5} \rightarrow a_{y}=\frac{50-2 \cdot 4,63}{5}=8,15 \mathrm{~cm}
$$

Para o espaçamento mínimo, $a_{x}$ e $a_{y}$ devem ser iguais ou superiores a (o agregado graúdo considerado é a brita 2 , com $\phi_{\max }=25 \mathrm{~mm}=2,5 \mathrm{~cm}$ ):

$-2 \mathrm{~cm}$;

- diâmetro da barra: $\phi_{l}=20 \mathrm{~mm}=2 \mathrm{~cm}$;

- 1,2 vez a dimensão máxima característica do agregado graúdo: $1,2 \cdot \phi_{\max }=1,2 \cdot 2,5 \mathrm{~cm}=3 \mathrm{~cm}$.

Considerando o maior valor $(3 \mathrm{~cm})$ para se obter a distância mínima entre eixos das barras deve-se somar $\phi_{l}=2 \mathrm{~cm}$, resultando $5 \mathrm{~cm}$.

Portanto os espaçamentos $a_{x}=9,74 \mathrm{~cm}$ e $a_{y}=8,15 \mathrm{~cm}$ atendem aos requisitos de espaçamento mínimo. 
Para o espaçamento máximo, $a_{x}$ e $a_{y}$ devem ser menores ou iguais a duas vezes a menor dimensão da seção no trecho considerado, sem exceder $40 \mathrm{~cm}$ :

$$
-2 \cdot h_{x}<40 \mathrm{~cm} \rightarrow 2 \cdot 19=38 \mathrm{~cm}<40 \mathrm{~cm} \text {. }
$$

Portanto os espaçamentos $a_{x}=9,74 \mathrm{~cm}$ e $a_{y}=8,15 \mathrm{~cm}$ atendem também aos requisitos de espaçamento máximo.

\subsubsection{Envoltórias}

Conhecendo a armadura, é possível obter os momentos fletores resistentes de cálculo segundo cada um dos eixos em flexão composta normal $\left(M_{R d, x x}\right.$ e $\left.M_{R d, y y}\right)$.

Reforça-se o fato de que o vetor momento fletor resistente de um eixo é perpendicular a ele. Porém, para a construção das envoltórias resistentes, o valor correspondente do momento fletor resistente será computado na direção da flexão (coincidente com o eixo).

Para a determinação desses momentos fletores pode-se proceder de duas formas: uma é com auxílio de ábacos, determinando-se os momentos fletores resistentes analisando a distribuição da armadura em cada eixo; a outra maneira é através do diagrama momento fletor - força normal - curvatura da seção em relação a cada eixo.

Inicialmente serão determinados os momentos fletores resistentes utilizando os ábacos de flexão composta normal. Assim, o arranjo de armadura escolhido referente a cada eixo está indicado na figura 8.15: 
Figura 8.15 - Arranjo de armadura escolhido
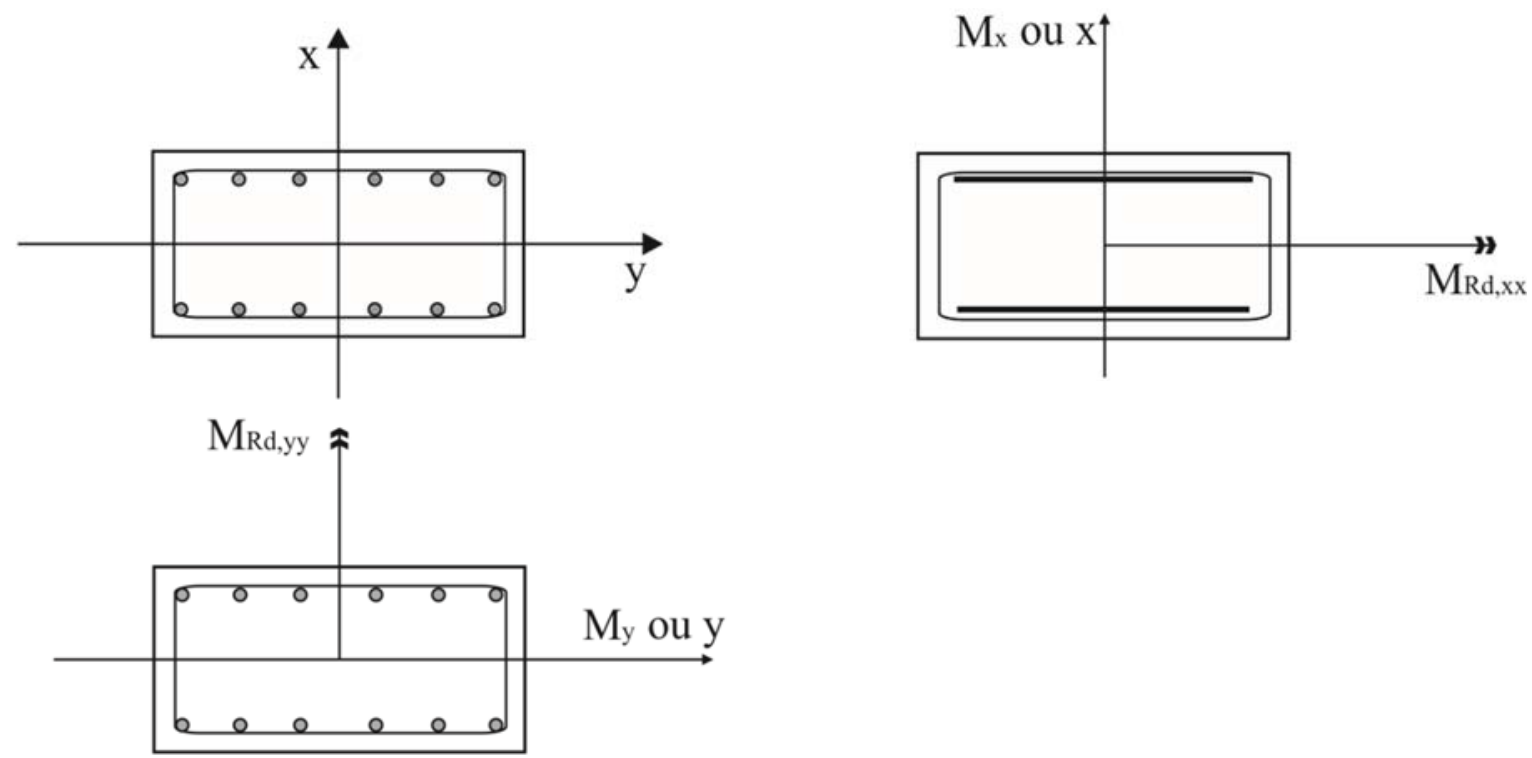

Fonte: Elaborado pelo Autor.

Para obtenção dos momentos fletores resistentes na flexão composta normal, deve-se efetuar o caminho oposto ao do pré-dimensionamento. Assim, inicialmente calcula-se a taxa mecânica de armadura:

$$
\omega=\frac{A_{s} \cdot f_{y d}}{A_{c} \cdot f_{c d}}=\frac{37,70 \cdot \frac{50}{1,15}}{19 \cdot 50 \cdot \frac{2,5}{1,4}}=0,97
$$

Como o valor da normal adimensional $v$ permanece o mesmo $(v=0,709)$, é possível extrair o momento fletor resistente adimensional equivalente. Assim, para a direção X, o ábaco utilizado (VENTURINI, 1987) foi o A-5, figura 8.16 (com $\left.d_{x}^{\prime} / h_{x}=0,25\right)$, já que a distribuição de armadura desse ábaco é condizente com a figura 8.15 (eixo $x)$. 
Figura 8.16 - Ábaco A-5

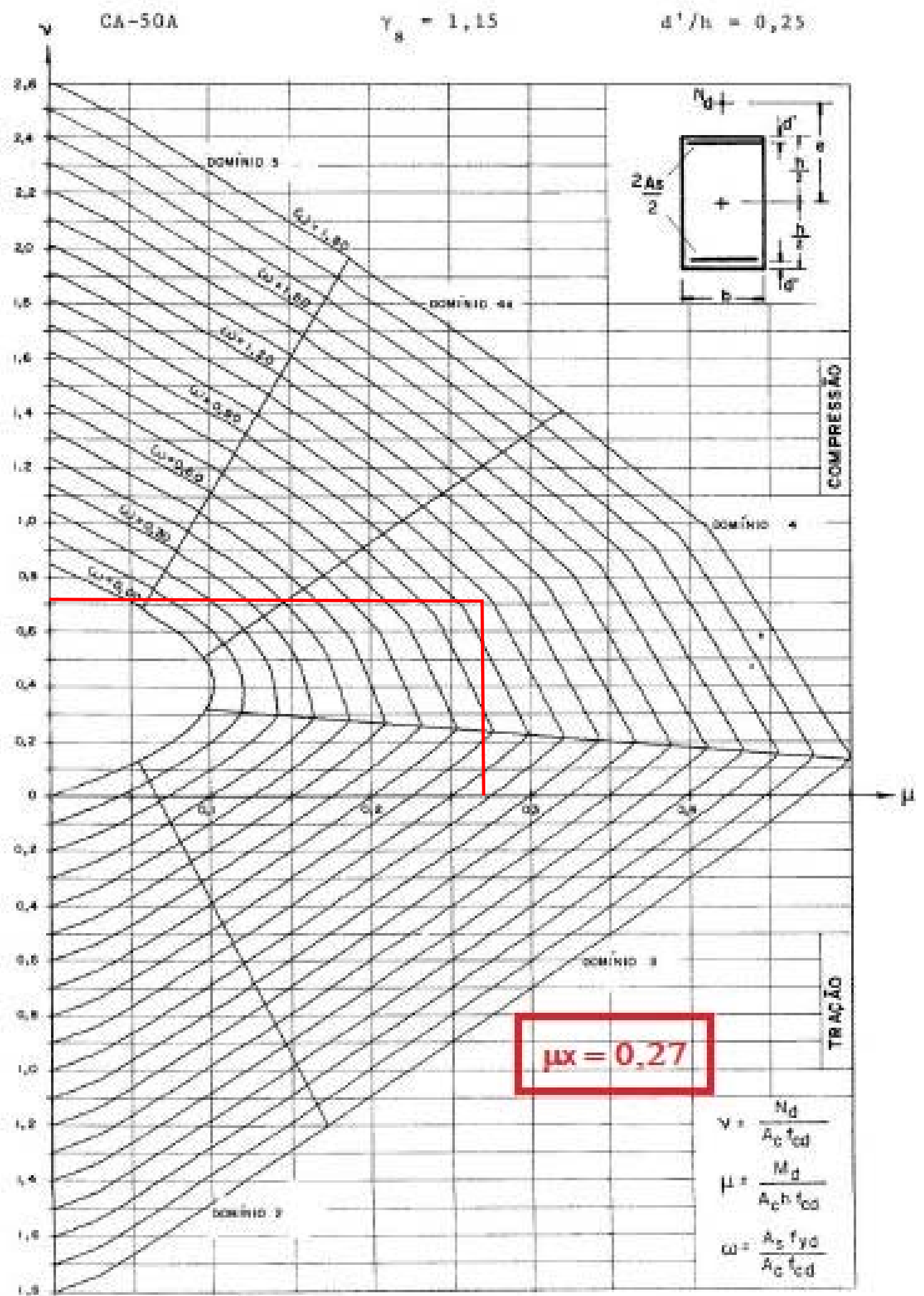

Fonte: VENTURINI, 1987, p. 44.

$$
\mu_{x}=0,27
$$


Mas

$$
\begin{gathered}
M_{R d, x x}=A_{c} \cdot h \cdot f_{c d} \cdot \mu_{x}=19 \cdot 50 \cdot 19 \cdot \frac{2,5}{1,4} \cdot 0,27=8702,68 \mathrm{kN} . \mathrm{cm} \\
\therefore M_{R d, x x}=87,03 \mathrm{kN} . \mathrm{m}
\end{gathered}
$$

Para a direção y o ábaco utilizado (VENTURINI, 1987) foi o A-18, figura 8.17 (com $\left.d_{y}^{\prime} / h_{y}=0,10\right)$, já que a distribuição de armadura desse ábaco é condizente com a figura 8.15 (eixo y). 
Figura 8.17 - Ábaco A-18

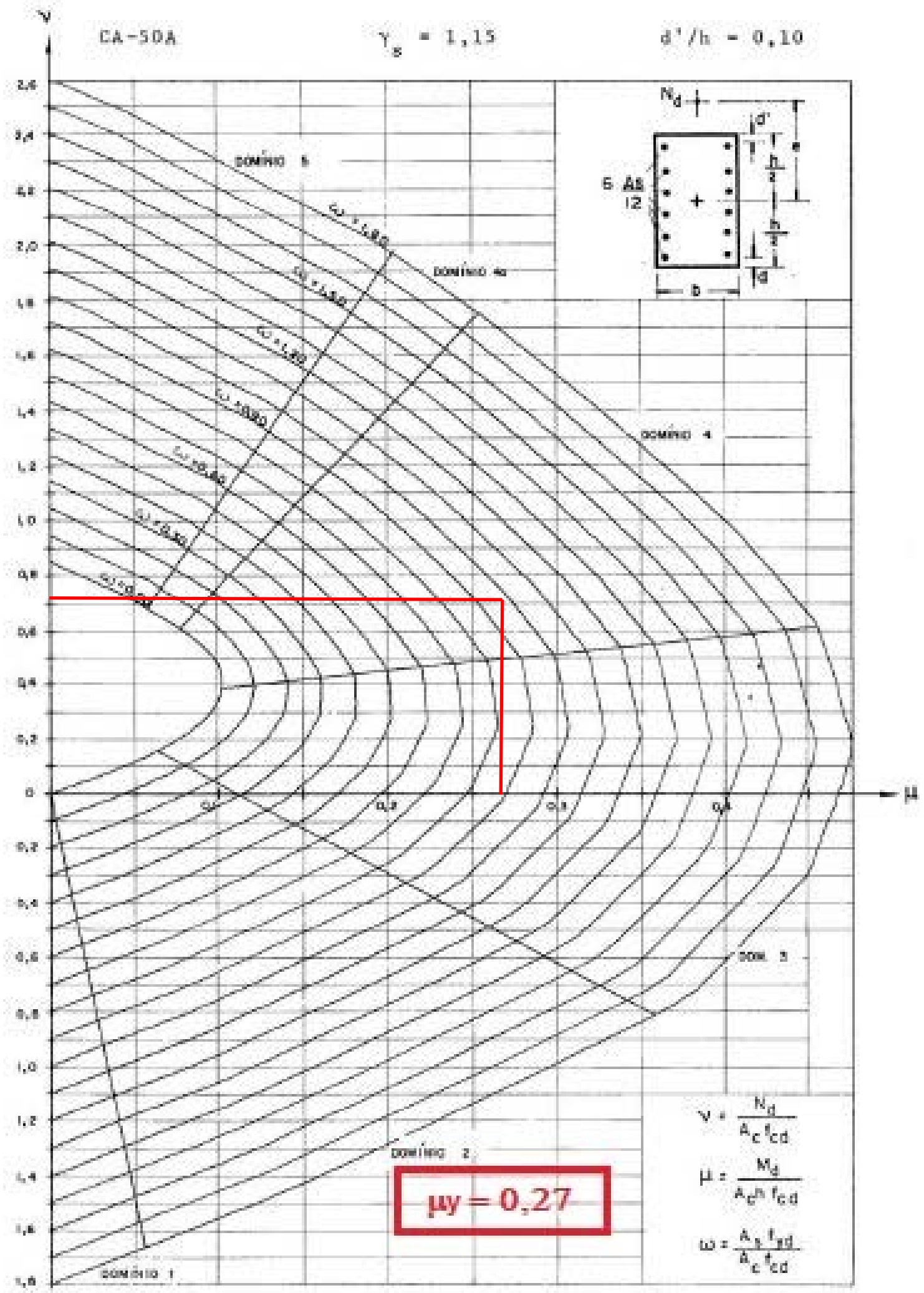

Fonte: VENTURINI, 1987, p. 57.

$$
\mu_{y}=0,27
$$


Mas

$$
\begin{gathered}
M_{R d, y y}=A_{c} \cdot h \cdot f_{c d} \cdot \mu_{x}=19 \cdot 50 \cdot 50 \cdot \frac{2,5}{1,4} \cdot 0,27=22901,79 \mathrm{kN} . \mathrm{cm} \\
\therefore M_{R d, y y}=229,02 \mathrm{kN} . \mathrm{m}
\end{gathered}
$$

O cálculo do momento fletor resistente por meio de ábacos não é o mais indicado, já que há imprecisão na leitura dos resultados. Assim, utilizando o equacionamento e o algoritmo presente no apêndice $A$, é possível traçar o diagrama momento fletor - força normal - curvatura para cada eixo de flexão.

Para a direção x utilizou-se a distribuição de armadura condizente com a figura 8.15 (eixo x), de forma que cada linha de armadura apresente $A_{s} / 2=18,85 \mathrm{~cm}^{2}$.

Figura 8.18 - Diagrama momento fletor - força normal - curvatura (eixo x)

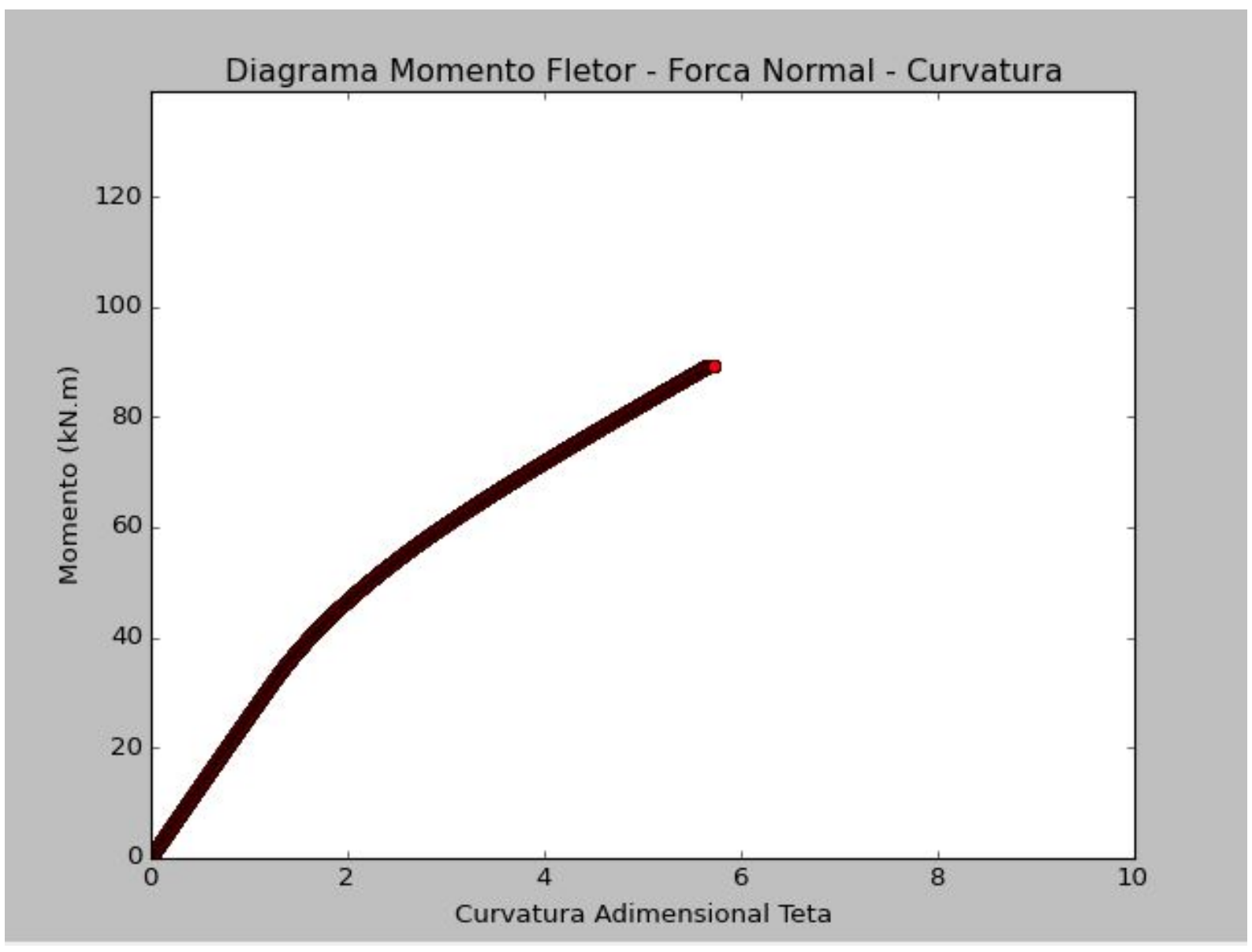

Fonte: Elaborado pelo Autor. 
Como resultado do programa determinou-se com precisão o momento fletor resistente no eixo x (figura 8.18), cujo valor é:

$$
M_{R d, x x}=89,28 k N . m
$$

O momento fletor resistente na direção x obtido pelo ábaco foi de $87,03 \mathrm{kN}$.m (equação 8.105), comparando este valor com o obtido pelo diagrama momento fletor - força normal - curvatura, obtém-se uma diferença de 2,6\%.

Para a direção y utilizou-se a distribuição de armadura condizente com a figura 8.15 (eixo y), de forma que cada linha de armadura apresente $A_{s} / 6=6,28 \mathrm{~cm}^{2}$.

Figura 8.19 - Diagrama momento fletor - força normal - curvatura (eixo y)

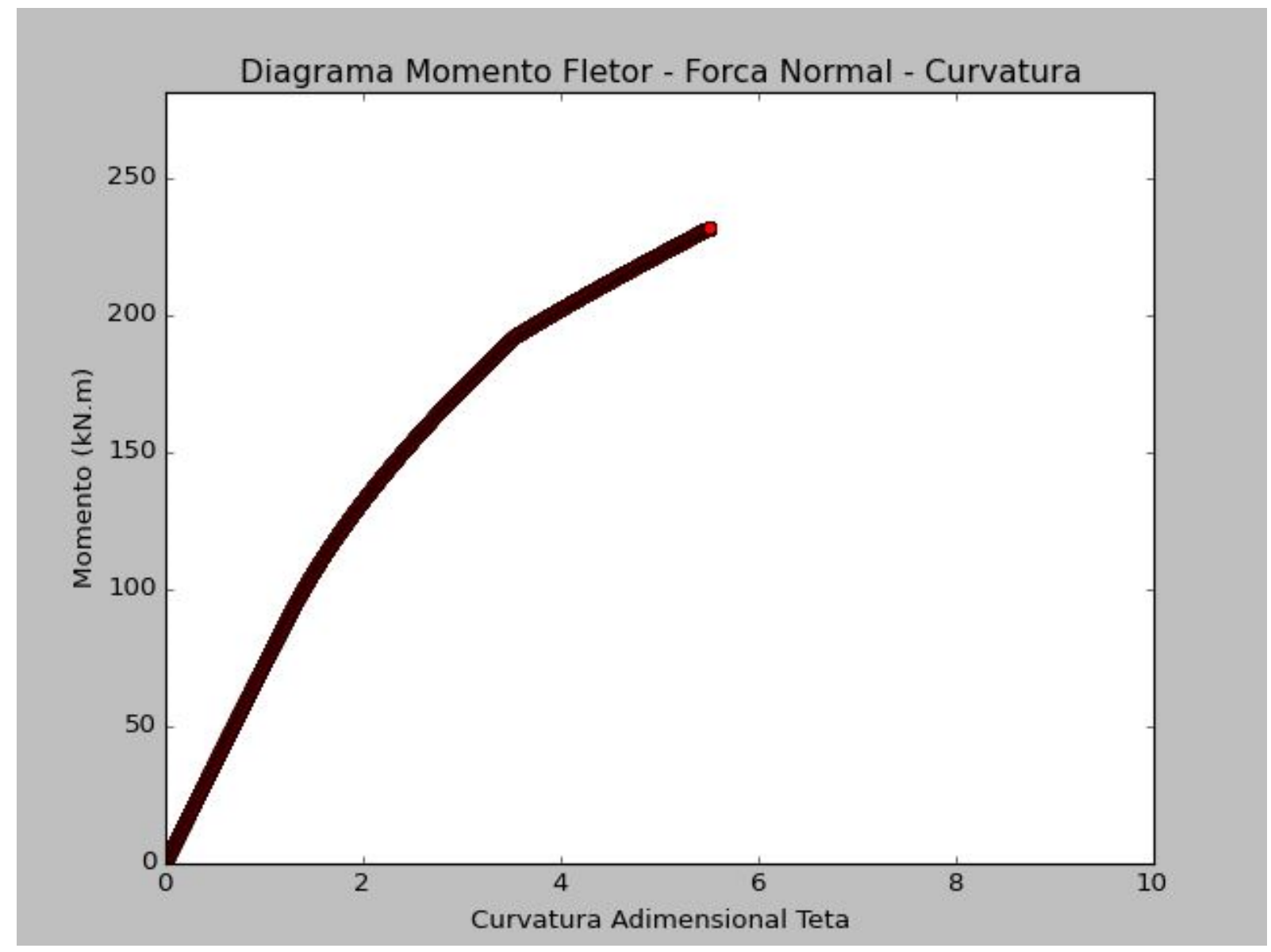

Fonte: Elaborado pelo Autor.

Como resultado do programa determinou-se com precisão o momento fletor resistente no eixo y (Figura 8.19) cujo valor é de: 


$$
M_{R d, y y}=231,63 \mathrm{kN} . \mathrm{m}
$$

O momento fletor resistente na direção y obtido pelo ábaco foi de $229,02 \mathrm{kN}$.m (equação 8.108), comparando este valor com o obtido pelo diagrama momento fletor - força normal - curvatura, obtém-se uma diferença de 1,1\%.

Os valores de momentos fletores resistentes obtidos pelos ábacos, neste exemplo, são uma boa aproximação dos obtidos por métodos mais refinados (diagrama momento fletor - força normal - curvatura).

Com esses valores, a envoltória resistente da seção com 12 barras de $20 \mathrm{~mm}$ é dada pela expressão:

$$
\left(\frac{M_{R d, x}}{89,28}\right)^{1,2}+\left(\frac{M_{R d, y}}{231,63}\right)^{1,2}=1
$$

As envoltórias de momento mínimo e de momento mínimo com $2^{\mathrm{a}}$ ordem são dadas, respectivamente, pelas equações indicadas a seguir:

$$
\begin{aligned}
& \left(\frac{M_{1 d, \text { mín }, x}}{M_{1 d, \text { mín, } x x}}\right)^{2}+\left(\frac{M_{1 d, \text { min }, y}}{M_{1 d, \text { mín,yy }}}\right)^{2}=1 \rightarrow\left(\frac{M_{d, t o t, x}}{24,90}\right)^{2}+\left(\frac{M_{d, t o t, y}}{36,09}\right)^{2}=1 \\
& \left(\frac{M_{d, m i ́ n, t o t, x}}{M_{d, m i ́ n, t o t, x x}}\right)^{2}+\left(\frac{M_{d, m i ́ n, t o t, y}}{M_{d, m i ́ n, t o t, y y}}\right)^{2}=1 \rightarrow\left(\frac{M_{d, t o t, x}}{74,63}\right)^{2}+\left(\frac{M_{d, t o t, y}}{36,09}\right)^{2}=1
\end{aligned}
$$

Para traçar as envoltórias, basta apenas a determinação de alguns pontos das curvas. Assim, será demonstrado como foi traçada a envoltória resistente, de forma que o traçado das demais envoltórias seja análogo.

Inicialmente deve-se determinar, como na tabela 8.1, alguns valores de $M_{R d, x x}$, de forma que os valores estejam compreendidos no intervalo $[0 ; 89,28]$. Nessa tabela, foram considerados quatro pontos intermediários: 


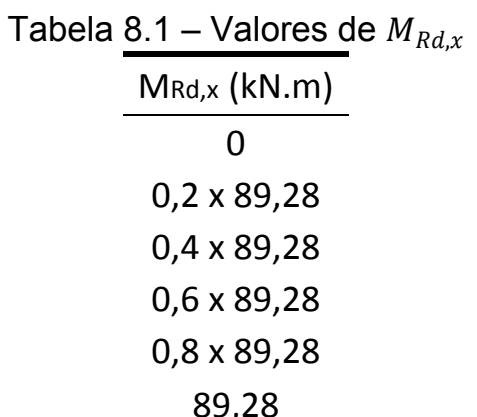

Fonte: Elaborado pelo Autor.

Calculando os valores, resultam os indicados na tabela 8.2:

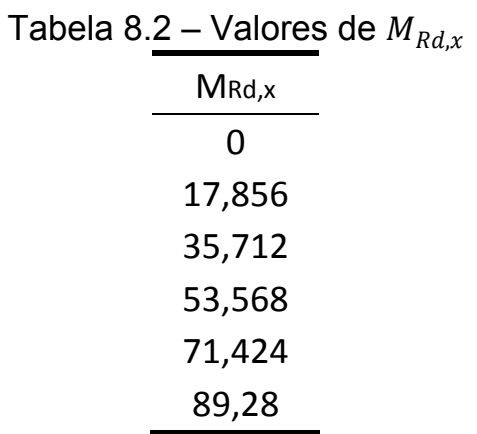

Fonte: Elaborado pelo Autor.

Para o cálculo de $M_{R d, y}$, basta isolá-lo na expressão da envoltória resistente (8.111) em função do valor de $M_{R d, x}$ :

$$
M_{R d, y}=\left[1-\left(\frac{M_{R d, x}}{89,28}\right)^{1,2}\right]^{1 / 1,2} \cdot 231,63
$$

Como exemplo, toma-se $M_{R d, x}=17,856 k N . m$ :

$$
M_{R d, y}=\left[1-\left(\frac{17,856}{89,28}\right)^{1,2}\right]^{1 / 1,2} \cdot 231,63 \rightarrow M_{R d, y}=203,291 \mathrm{kN} . \mathrm{m}
$$

Calculando os valores $M_{R d, y}$, serão obtidos os indicados na tabela 8.3: 


\begin{tabular}{c|c} 
Tabela $8.3-$ Valores de $M_{R d, x}$ \\
\cline { 2 - 3 } MRd,x & MRd,y $M_{R d, y}$ \\
\hline 0 & 231,63 \\
17,856 & 203,291 \\
35,712 & 165,28 \\
53,568 & 120,892 \\
71,424 & 69,272 \\
89,28 & 0 \\
\hline
\end{tabular}

Plotando-se esses valores obtém-se a envoltória indicada na figura 8.20:

Figura 8.20 - Envoltória resistente parcial

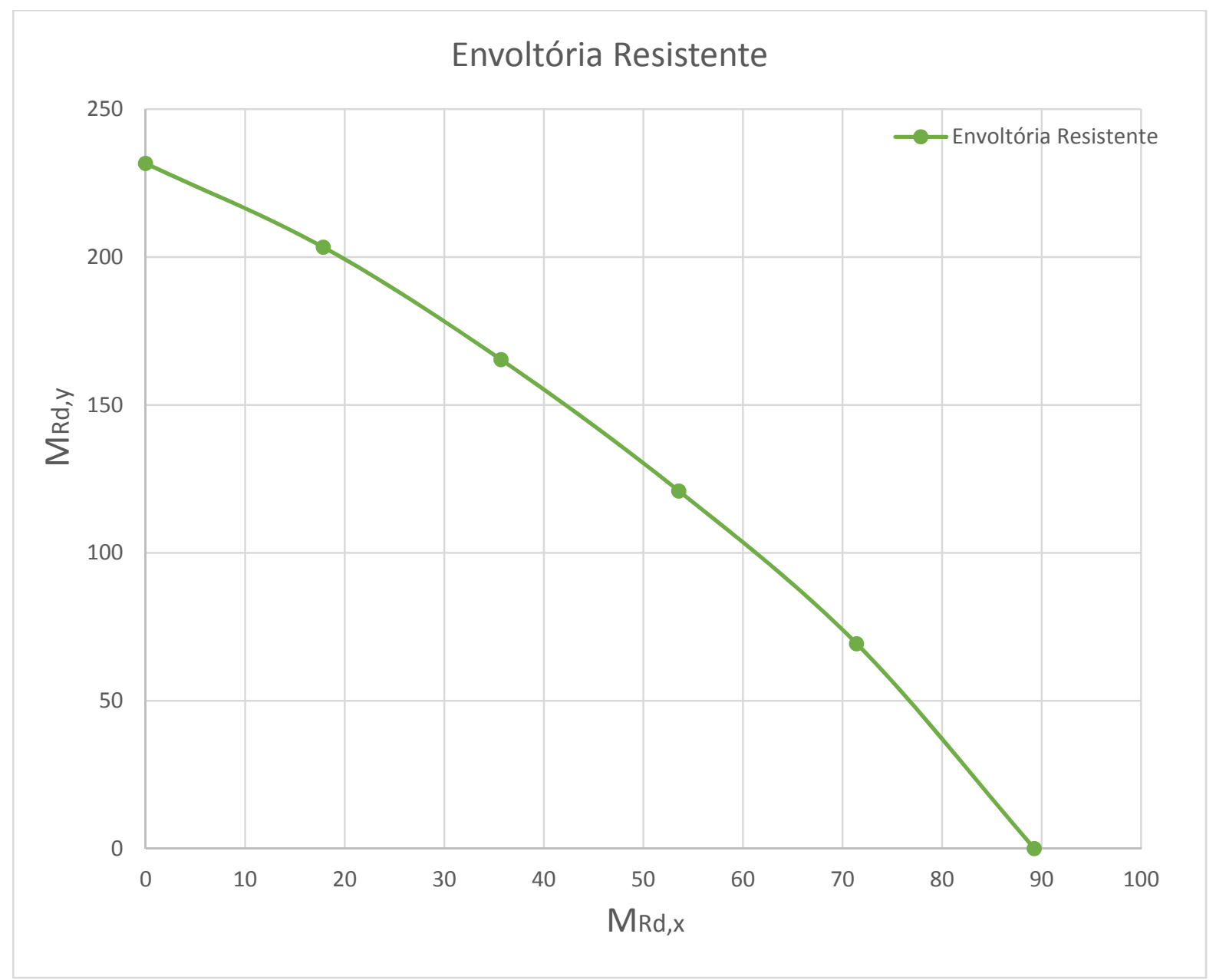

Fonte: Elaborado pelo Autor.

Para obter a envoltória resistente completa, basta rebater os valores simétricos aos eixos $M_{R d, x}$ e $M_{R d, y}$. Assim, resulta a envoltória resistente representada na Figura 8.21: 
Figura 8.21 - Envoltória resistente completa

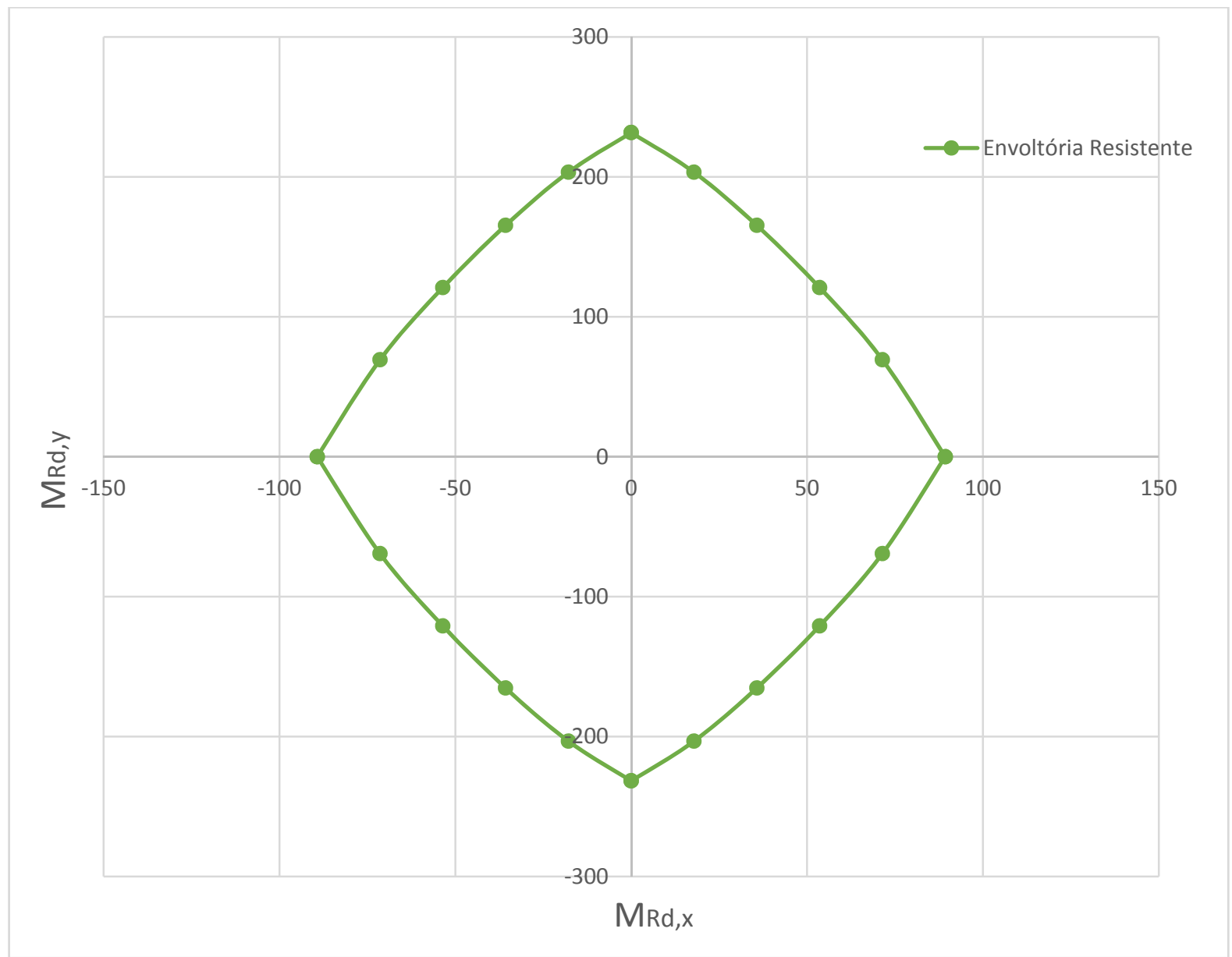

Fonte: Elaborado pelo Autor.

Dessa forma, obtém-se a envoltória resistente, a envoltória mínima e a envoltória mínima com $2^{a}$ ordem (figura 8.22). Também estão indicados os pontos referentes aos momentos fletores solicitantes nas seções de topo, base e intermediária do pilar, cujas coordenadas estão representadas na Tabela 8.4.

Os eixos $M_{R d, x}$ e $M_{R d, y}$ serão substituídos por $M_{x}$ e $M_{y}$ com intuito de generalizar os momentos fletores, já que serão inseridos valores de momentos fletores solicitantes e resistentes.

Destaca-se que, como é possível dispensar os efeitos de segunda ordem na direção y, o cálculo do momento fletor na seção intermediária deve ser conforme prescrito na expressão 8.116:

$$
M_{y, \text { int }}=\alpha_{b y} \cdot M_{1 d, A y}=0,4 \cdot 47,10=18,84 \mathrm{kN} \cdot \mathrm{m}
$$


Porém, como o momento fletor calculado é menor que o momento mínimo em y $\left(M_{1 d y \text {,min }}=36,09 k N . m\right)$, considera-se para a seção intermediária na direção y o valor do momento mínimo.

Tabela 8.4 - Momentos fletores solicitantes no pilar P01

\begin{tabular}{ccc}
\hline Seção & $\mathrm{M}_{\mathrm{x}, \text { tot }}$ & $\mathrm{M}_{\mathrm{y}, \text { tot }}$ \\
& $(\mathrm{kN} . \mathrm{m})$ & $(\mathrm{kN} . \mathrm{m})$ \\
\hline Topo & 23,58 & 47,10 \\
Base & $-11,79$ & $-23,55$ \\
Intermediária & 74,12 & 36,09 \\
\hline
\end{tabular}

Fonte: Elaborado pelo Autor.

Figura 8.22 - Envoltória resistente, envoltórias mínimas e solicitações no pilar P01

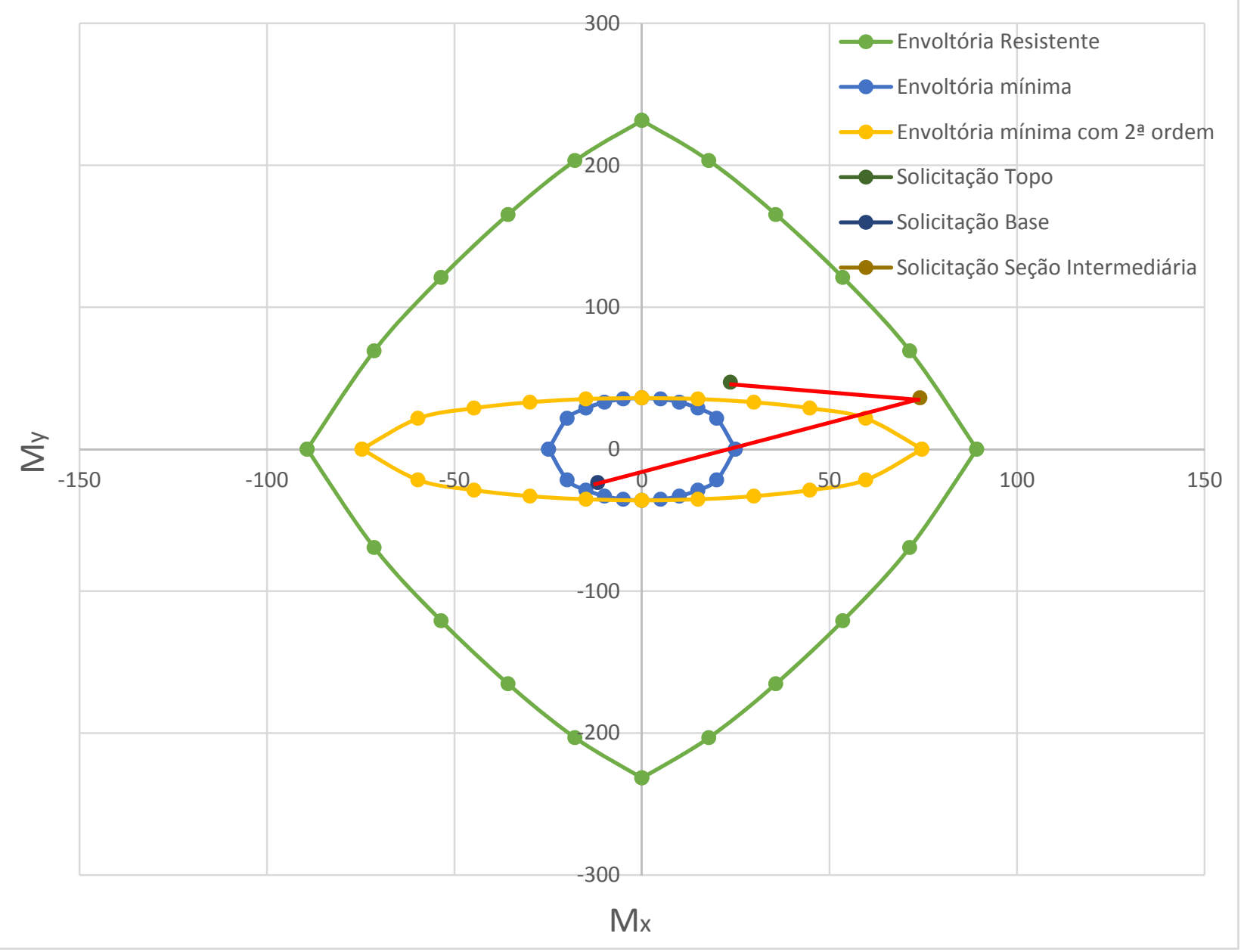

Fonte: Elaborado pelo Autor. 
Analisando a Figura 8.22 verifica-se que o ponto de solicitação da seção intermediária é o crítico (está mais próximo da envoltória resistente). Assim, para verificar a segurança, pode-se, também, fazer o cálculo analítico da segurança:

$$
\begin{aligned}
& \left(\frac{M_{S d, x}}{M_{R d, x x}}\right)^{\alpha}+\left(\frac{M_{S d, y}}{M_{R d, y y}}\right)^{\alpha} \leq 1 \\
& \left(\frac{M_{S d, x}}{65,50}\right)^{1,2}+\left(\frac{M_{S d, y}}{182,16}\right)^{1,2} \leq 1 \\
& \left(\frac{74,12}{89,28}\right)^{1,2}+\left(\frac{36,09}{231,63}\right)^{1,2}=0,907 \leq 1
\end{aligned}
$$

O fato de o ponto de solicitação da seção intermediária estar próximo da envoltória resistente indica que o pré-dimensionamento conduziu a um bom resultado.

Portanto, como a envoltória resistente ultrapassa os momentos fletores solicitantes nas seções críticas e também as envoltórias de momento mínimo e de momento mínimo com $2^{\mathrm{a}}$ ordem, a armadura da seção está verificada.

\subsubsection{Verificação da excentricidade acidental}

No item 8.14.2, as imperfeições geométricas locais foram verificadas pelo fato de as envoltórias mínimas de $1^{\mathrm{a}}$ e $2^{\mathrm{a}}$ ordem serem superadas por uma envoltória resistente.

No caso da excentricidade acidental, não há os conceitos de envoltórias mínimas e de momento mínimo. Assim, a consideração das imperfeições geométricas locais é feita por meio da adição de uma excentricidade acidental às excentricidades solicitantes na seção intermediária do pilar.

Destaca-se que a ABNT NBR 6118:2014 não apresenta as diretrizes para a computação da excentricidade acidental, assim, neste trabalho, será efetuado uma sugestão de como essas excentricidades devem ser consideradas no dimensionamento. 
Dessa forma, utilizando os itens 8.11 e 8.14 , têm-se:

- Direção $x$

$e_{a x}=1,05 \mathrm{~cm}=0,0105 \mathrm{~m}$;

$M_{d, t o t, x}=74,12 \mathrm{kN} . \mathrm{m}$

$N_{d}=1203 k N$;

$M_{x, \text { tot, int }}=M_{d, \text { tot }, x}+N_{d} \cdot e_{a x}=74,12+1203 \cdot 0,0105=86,75 \mathrm{kN} . \mathrm{m}$

- Direção y

$e_{a y}=1,08 \mathrm{~cm}=0,0108 \mathrm{~m}$;

$M_{d, t o t, i n t}=\alpha_{b y} \cdot M_{1 d, A y}=0,4 \cdot 47,10=18,84 \mathrm{kN} . \mathrm{m} ;$

$N_{d}=1203 k N$

$M_{y, \text { tot,int }}=M_{d, \text { tot,int }}+N_{d} \cdot e_{a y}=18,84+1203 \cdot 0,0108=31,83 \mathrm{kN} . \mathrm{m}$

Assim, resultam os momentos fletores solicitantes indicados na tabela 8.5:

Tabela 8.5 - Momentos fletores solicitantes no pilar P01

\begin{tabular}{ccc}
\hline Seção & $M_{\mathrm{x}, \text { tot }}$ & $\mathrm{M}_{\mathrm{y}, \text { tot }}$ \\
& $(\mathrm{kN} . \mathrm{m})$ & $(\mathrm{kN} . \mathrm{m})$ \\
\hline Topo & 23,58 & 47,10 \\
Base & $-11,79$ & $-23,55$ \\
Intermediária & 86,75 & 31,83 \\
\hline
\end{tabular}

Fonte: Elaborado pelo Autor.

Utilizando a armadura pré-dimensionada anteriormente, ou seja, 12 barras de $20 \mathrm{~mm}$, tem-se para a envoltória resistente a expressão:

$$
\left(\frac{M_{R d, x}}{89,28}\right)^{1,2}+\left(\frac{M_{R d, y}}{231,63}\right)^{1,2}=1
$$

Plotando os pontos de solicitações e da envoltória resistente, obtém-se os resultados indicados na figura 8.23 : 
Figura 8.23 - Solicitações do pilar P01 (excentricidade acidental)

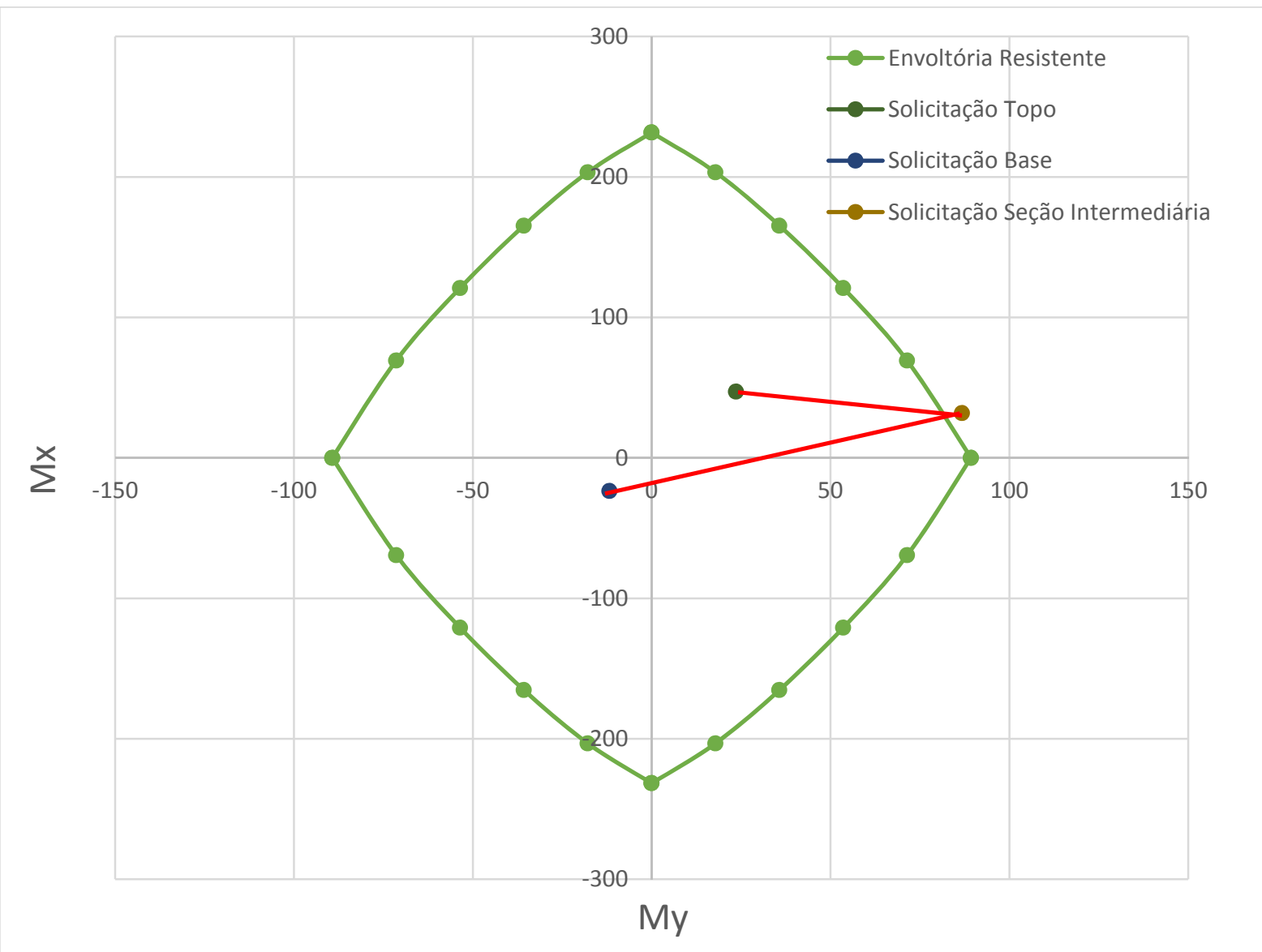

Fonte: Elaborado pelo Autor.

Verifica-se que o ponto de solicitação da seção intermediária não está dentro da região delimitada pela envoltória resistente. Isso ocorre devido ao prédimensionamento ser realizado com as solicitações de momento mínimo (item 7.6.1 deste texto). Porém, para evitar novo pré-dimensionamento da armadura longitudinal, serão efetuadas mudanças na armadura pré-dimensionada.

Assim, inicialmente opta-se por aumentar as bitolas das armaduras longitudinais para que a verificação seja atendida.

Portanto, determinam-se os parâmetros da nova armadura: $c=3,0 \mathrm{~cm}$ (classe de agressividade II), $\phi_{l}=22 \mathrm{~mm}$ e $\phi_{t}=6,3 \mathrm{~mm}$.

Agindo de forma análoga ao que foi feito no item anterior, tem-se que para a direção x utilizou-se a distribuição de armadura condizente com a figura 8.15 (eixo x), 
de forma que cada linha de armadura apresente $A_{s} / 2=22,81 \mathrm{~cm}^{2}$ (já que houve aumento da bitola da armadura).

Figura 8.24 - Diagrama momento fletor - força normal - curvatura (eixo x)

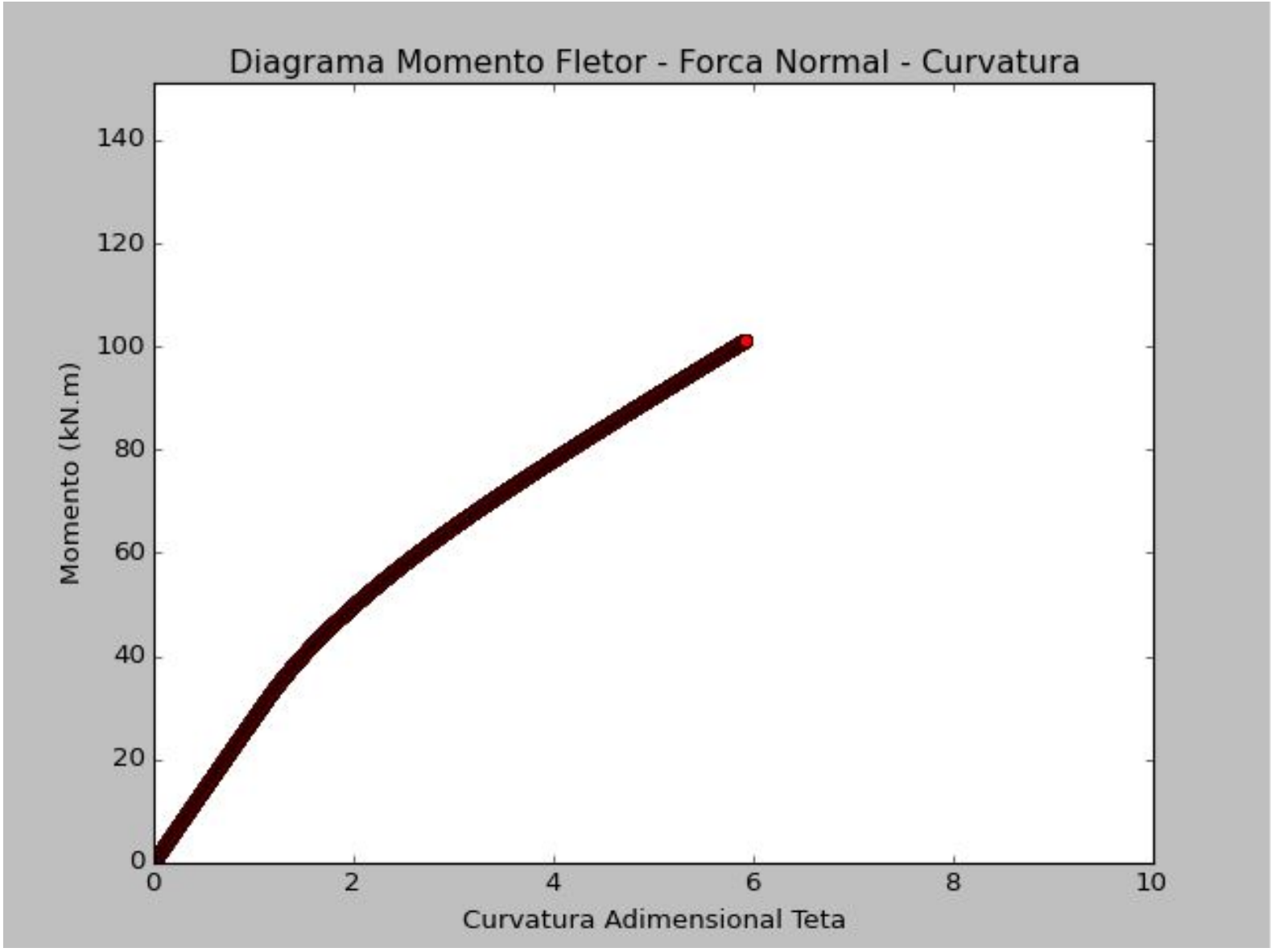

Fonte: Elaborado pelo Autor.

Como resultado do programa determinou-se com precisão o momento fletor resistente no eixo x (figura 8.24) cujo valor é de:

$$
M_{R d, x x}=101,32 \mathrm{kN} . \mathrm{m}
$$

Para a direção y utilizou-se a distribuição de armadura condizente com a figura 8.15 (eixo y), de forma que cada linha de armadura apresente $A_{s} / 6=7,60 \mathrm{~cm}^{2}$. 
Figura 8.25 - Diagrama momento fletor - força normal - curvatura (eixo y)

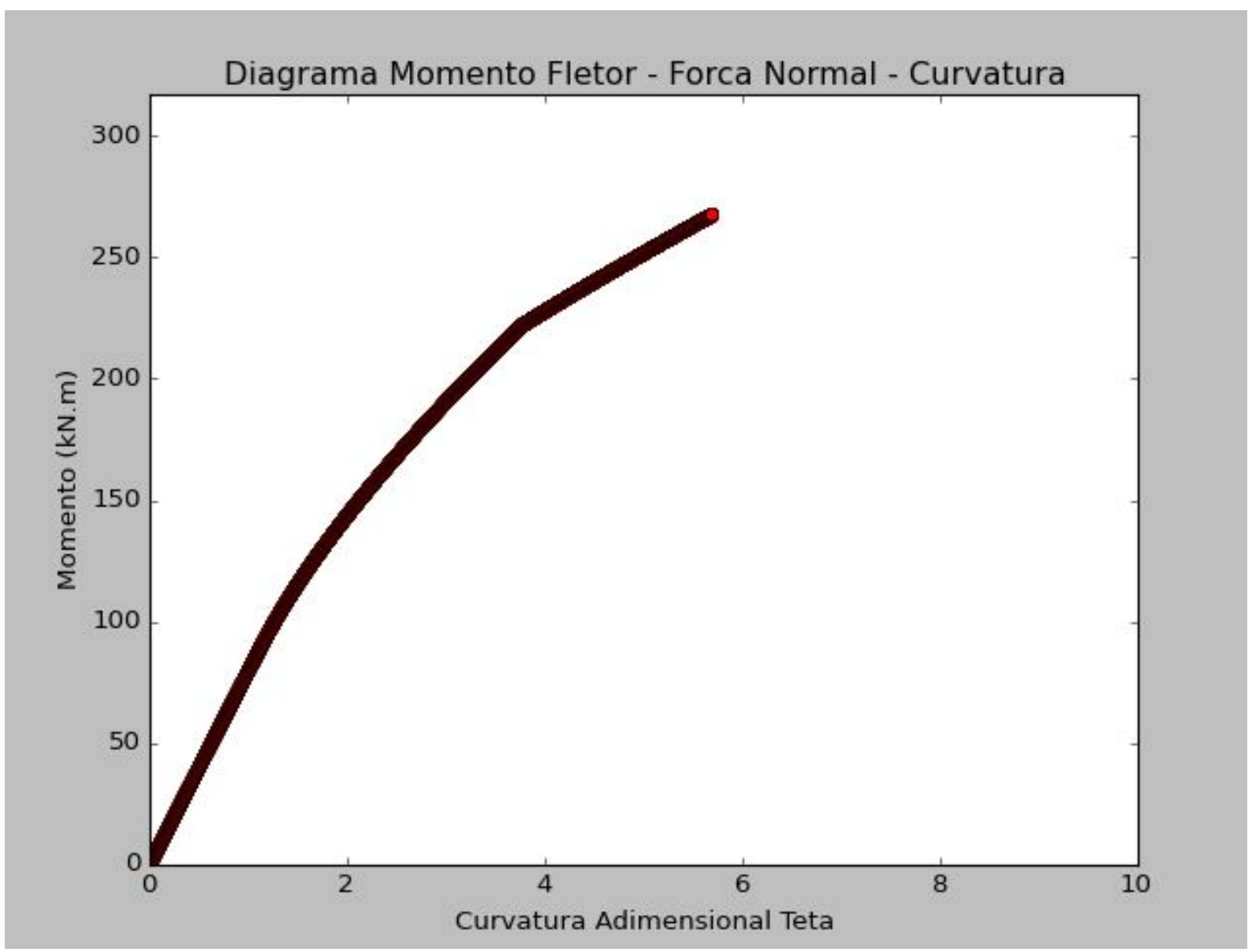

Fonte: Elaborado pelo Autor.

Como resultado do programa determinou-se com precisão o momento fletor resistente no eixo y (figura 8.25) cujo valor é de:

$$
M_{R d, y y}=267,85 \mathrm{kN} . \mathrm{m}
$$

Assim a nova expressão da envoltória resistente é dada por:

$$
\left(\frac{M_{R d, x}}{101,32}\right)^{1,2}+\left(\frac{M_{R d, y}}{267,85}\right)^{1,2}=1
$$

Plotando novamente os pontos de solicitação na nova envoltória resistente, obtêm-se os resultados indicados na figura 8.26. 
Figura 8.26 - Solicitações do pilar P01 (excentricidade acidental)

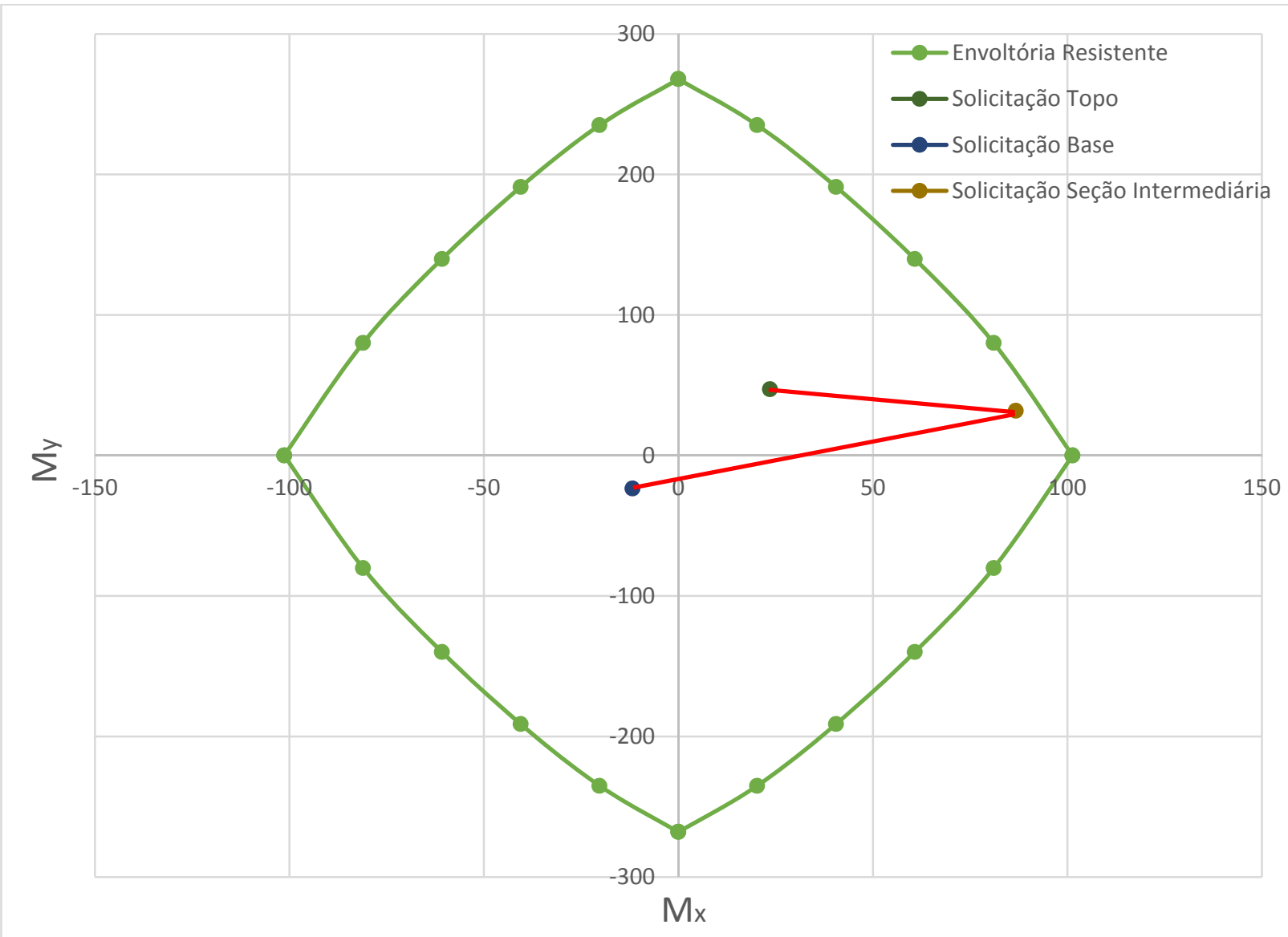

Fonte: Elaborado pelo Autor.

Nessa figura, nota-se que o ponto de solicitação na seção intermediária fica próximo da envoltória resistente. A verificação da segurança também pode ser feita por meio do cálculo analítico:

$$
\begin{aligned}
& \left(\frac{M_{S d, x}}{M_{R d, x x}}\right)^{\alpha}+\left(\frac{M_{S d, y}}{M_{R d, y y}}\right)^{\alpha} \leq 1 \\
& \left(\frac{M_{S d, x}}{101,32}\right)^{1,2}+\left(\frac{M_{S d, y}}{267,85}\right)^{1,2} \leq 1 \\
& \left(\frac{86,75}{101,32}\right)^{1,2}+\left(\frac{31,83}{267,85}\right)^{1,2}=0,908 \leq 1
\end{aligned}
$$

Portanto, como a envoltória resistente ultrapassa os momentos fletores solicitantes nas seções críticas, a armadura da seção está verificada. 


\subsection{MÉTODO DO PILAR-PADRÃO COM RIGIDEZ $\kappa$ APROXIMADA}

Este processo aproximado recai na formulação direta dada a seguir, que possibilita o cálculo do momento fletor fletor total sem necessidade de iterações:

$$
a \cdot M_{d, t o t}^{2}+b \cdot M_{d, t o t}+c=0
$$

- Direção x

$h_{x}=0,19 m$ : altura da seção na direção considerada;

$N_{S d}=1203 \mathrm{kN}$ : força normal de cálculo;

$\alpha_{b x}=1,0$

$M_{1 d, A x}=23,58 \mathrm{kN} . \mathrm{m}$;

$\ell_{\mathrm{ex}}=4,39 \mathrm{~m}$ : comprimento equivalente do pilar na direção analisada.

$$
\begin{gathered}
a=5 \cdot h=5 \cdot 0,19=0,95 \\
b=h^{2} \cdot N_{S d}-\frac{N_{S d} \cdot \ell_{e}^{2}}{320}-5 \cdot h \cdot \alpha_{b} \cdot M_{1 d, A} \\
\therefore b=0,19^{2} \cdot 1203-1203 \cdot \frac{4,39^{2}}{320}-5 \cdot 0,19 \cdot 1,0 \cdot 23,58=-51,42 \\
c=-N_{S d} \cdot h^{2} \cdot \alpha_{b} \cdot M_{1 d, A}=-1203 \cdot 0,19^{2} \cdot 1,0 \cdot 23,58=-1024,04
\end{gathered}
$$

Obtém-se $M_{d, t o t}$ resolvendo a expressão do segundo grau:

$$
\begin{gathered}
a \cdot M_{d, t o t}^{2}+b \cdot M_{d, t o t}+c=0 \\
M_{d, t o t}=\frac{-b+\sqrt{b^{2}-4 . a . c}}{2 a} \\
\therefore M_{d, t o t}=\frac{51,42+\sqrt{(-51,42)^{2}-4 \cdot 0,95 \cdot(-1024,04)}}{2 \cdot 0,95} \\
\therefore M_{d, t o t, x}=69,61 \mathrm{kN} . \mathrm{m}>M_{1 d, A x}=1,4 \cdot 16,84=23,58 \mathrm{kN} . \mathrm{m}
\end{gathered}
$$


Para determinação das envoltórias solicitantes calcula-se o momento mínimo com segunda ordem $\left(M_{d, t o t, \min }\right)$ :

$h_{x}=0,19 m:$ altura da seção na direção considerada;

$N_{S d}=1203 k N$ : força normal de cálculo;

$\alpha_{b x}=1,0$

$M_{1 d x, \min }=24,90 \mathrm{kN} . \mathrm{m}$ : momento mínimo;

$\ell_{\mathrm{ex}}=4,39 \mathrm{~m}$ : comprimento equivalente do pilar na direção analisada.

$$
\begin{gathered}
a=5 \cdot h=5 \cdot 0,19=0,95 \\
b=h^{2} \cdot N_{S d}-\frac{N_{S d} \cdot \ell_{e}^{2}}{320}-5 \cdot h \cdot \alpha_{b} \cdot M_{1 d, \text { mín }} \\
\therefore b=0,19^{2} \cdot 1203-1203 \cdot \frac{4,39^{2}}{320}-5 \cdot 0,19 \cdot 1,0 \cdot 24,90=-52,68 \\
c=-N_{S d} \cdot h^{2} \cdot \alpha_{b} \cdot M_{1 d, A}=-1203 \cdot 0,19^{2} \cdot 1,0 \cdot 24,90=-1081,36
\end{gathered}
$$

Obtém-se $M_{d, t o t, m i n}$ resolvendo a expressão do segundo grau:

$$
\begin{gathered}
M_{d, \text { tot,mín }}=\frac{-b+\sqrt{b^{2}-4 \cdot a \cdot c}}{2 a} \\
\therefore M_{d, t o t, \text { mín }}=\frac{52,68+\sqrt{(-52,68)^{2}-4 \cdot 0,95 \cdot(-1081,36)}}{2 \cdot 0,95} \\
\therefore M_{d, t o t, \text { mín }}=71,40 \mathrm{kN} . \mathrm{m}>M_{1 \mathrm{~d} x, \text { min }}=24,90 \mathrm{kN} . \mathrm{m}
\end{gathered}
$$

\section{- Direção y}

Os efeitos de $2^{\mathrm{a}}$ ordem na direção y não são computados, já que $\lambda_{1 y}>\lambda_{\mathrm{y}}$. Portanto, não é necessário o cálculo dos efeitos de 2a ordem, o que significa que pode ser adotado, para o momento fletor total $\left(M_{d, t o t}\right)$, o momento fletor de 1 a ordem $\left(M_{1 d, A}\right)$, e para o momento total mínimo $\left(M_{d, t o t, m i ́ n}\right)$, o momento mínimo $\left(M_{1 d, m i ́ n}\right)$. 


\subsubsection{Pré-dimensionamento}

No pré-dimensionamento serão avaliadas duas situações possivelmente críticas, que ocorrem na seção intermediária. A primeira, com atuação do momento fletor considerando efeito de $2^{\mathrm{a}}$ ordem na direção x e momento mínimo na direção y. A segunda, com momento mínimo com $2^{a}$ ordem na direção $x$.

No primeiro caso, $M_{d, t o t, x x}=69,61 \mathrm{kN} . \mathrm{m}$ é o momento fletor total obtido com o método da rigidez $\kappa$ aproximada na direção x e $M_{d, t o t, y y}=36,09 k N$. $m$ é o momento mínimo na direção y, essa situação está presente na figura 8.27. Com esses momentos fletores, calcula-se a armadura. Serão usados os ábacos para flexão oblíqua de Pinheiro et. al. (2014).

Figura 8.27 - Pré-dimensionamento ( $1^{\text {a }}$ situação $)$

\section{1a Situação}

\section{Seção Transversal}

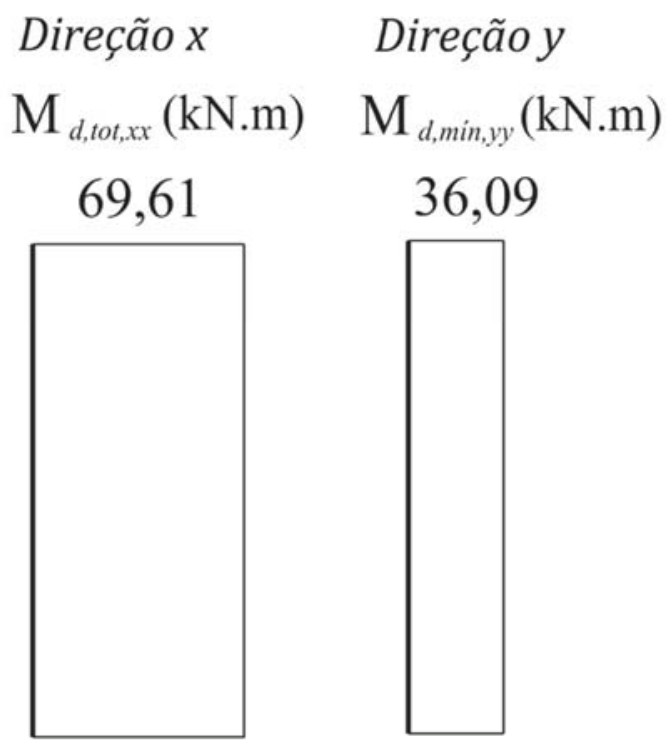

Fonte: Elaborado pelo Autor.

Para escolha do ábaco, d' será calculado para cobrimento $c=3,0 \mathrm{~cm}$ (classe de agressividade II), $\phi_{l}=20 \mathrm{~mm}=2,0 \mathrm{~cm}$ e $\phi_{t}=6,3 \mathrm{~mm}=0,63 \mathrm{~cm}$, diâmetros que foram adotados para este exemplo. Resultam:

$$
d^{\prime}=c+\frac{\phi_{l}}{2}+\phi_{t}=3,0+\frac{2,0}{2}+0,63=4,63 \mathrm{~cm}
$$




$$
\begin{aligned}
& \frac{d_{x}^{\prime}}{h_{x}}=\frac{4,63}{19}=0,23 \cong 0,25 \\
& \frac{d_{y}^{\prime}}{h_{y}}=\frac{4,63}{50}=0,09 \cong 0,1
\end{aligned}
$$

Os adimensionais para uso do ábaco são (concreto C25):

$$
\begin{gathered}
v=\frac{N_{S d}}{A_{c} \cdot f_{c d}}=\frac{1203}{19 \cdot 50 \cdot 2,5 / 1,4}=0,709 \\
\mu_{x}=\frac{v \cdot e_{x}}{h_{x}}=\frac{v \cdot \frac{M_{d, t o t, x}}{N_{d}}}{h_{x}}=\frac{0,709 \cdot \frac{6961}{1203}}{19}=0,22 \\
\mu_{y}=\frac{v \cdot e_{y}}{h_{y}}=\frac{v \cdot \frac{M_{d, t o t, y}}{N_{d}}}{h_{y}}=\frac{0,709 \cdot \frac{3609}{1203}}{50}=0,04
\end{gathered}
$$

Nas direções x e y adotaram-se valores de $d^{\prime} / h$ a favor da segurança, ou seja, os de maior valor. Porém, também, podem-se usar ábacos com dois valores de $d^{\prime} / h$ e fazer interpolação.

Os ábacos utilizados (PINHEIRO et al., 2014) foram o 4A e o 4B, com o arranjo $1\left(d_{x}^{\prime} / h_{x}=0,25\right.$ e $\left.d_{y}^{\prime} / h_{y}=0,1\right)$. Como $v=0,709 \cong 0,7$, será feita uma interpolação entre $v=0,6$ e $v=0,8$ (figuras 8.28 e 8.29). Dessa forma, obtém-se a taxa mecânica de armadura: 
Figura 8.28 - Ábaco 4A $(v=0,6)$

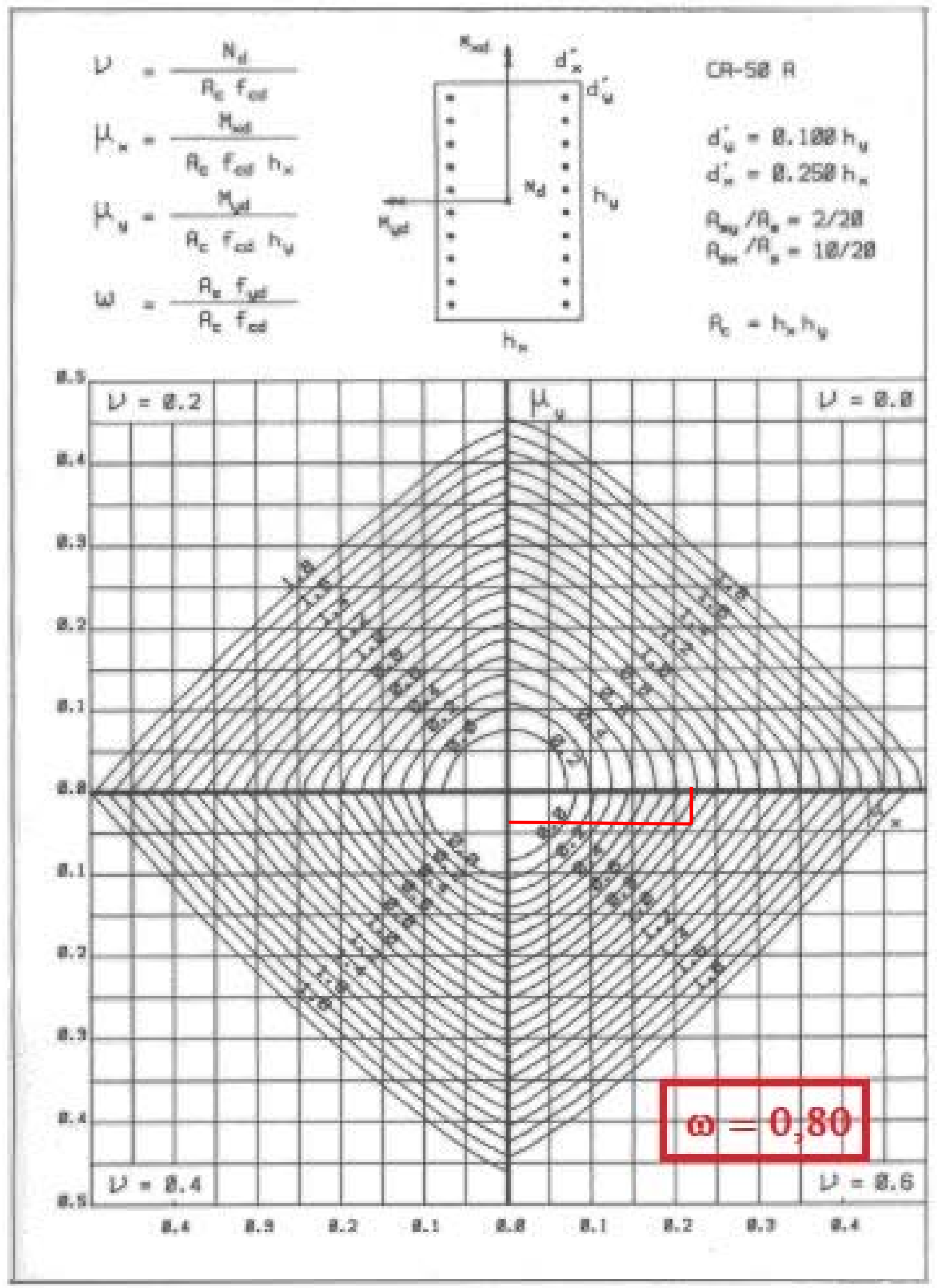

Fonte: PINHEIRO et al., 2014, p. 22.

$$
v=0,6 \rightarrow \omega=0,80
$$


Figura 8.29 - Ábaco 4B
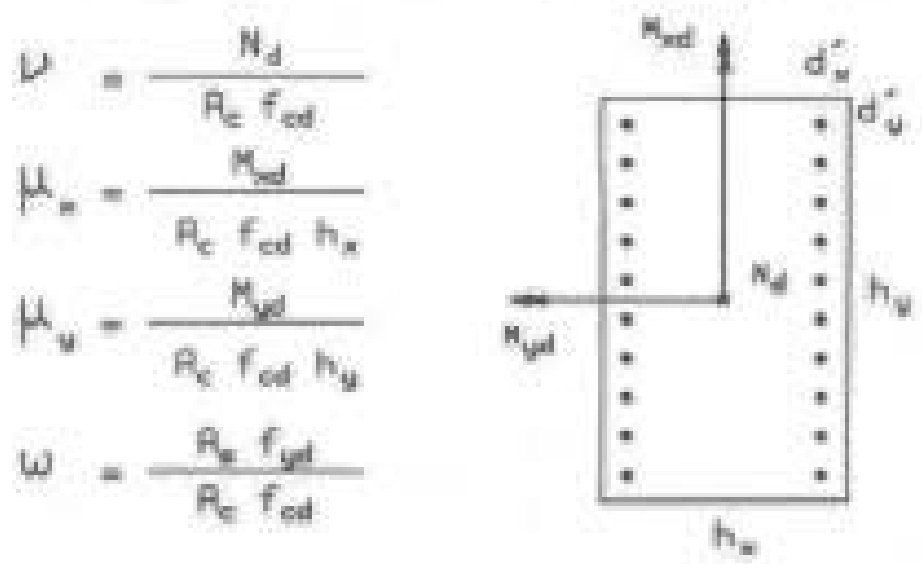

сค-5B म

$d_{i}^{*}-0.18 d h_{u}$ $d^{t},-0.259 h_{m}$

$A_{4} / A_{3}=2 / 22$

$\mathrm{A}_{\mathrm{s}} / \mathrm{A}_{\mathrm{s}}=1 \mathrm{~g} / 2$

$A_{c}=h_{k} h_{y}$

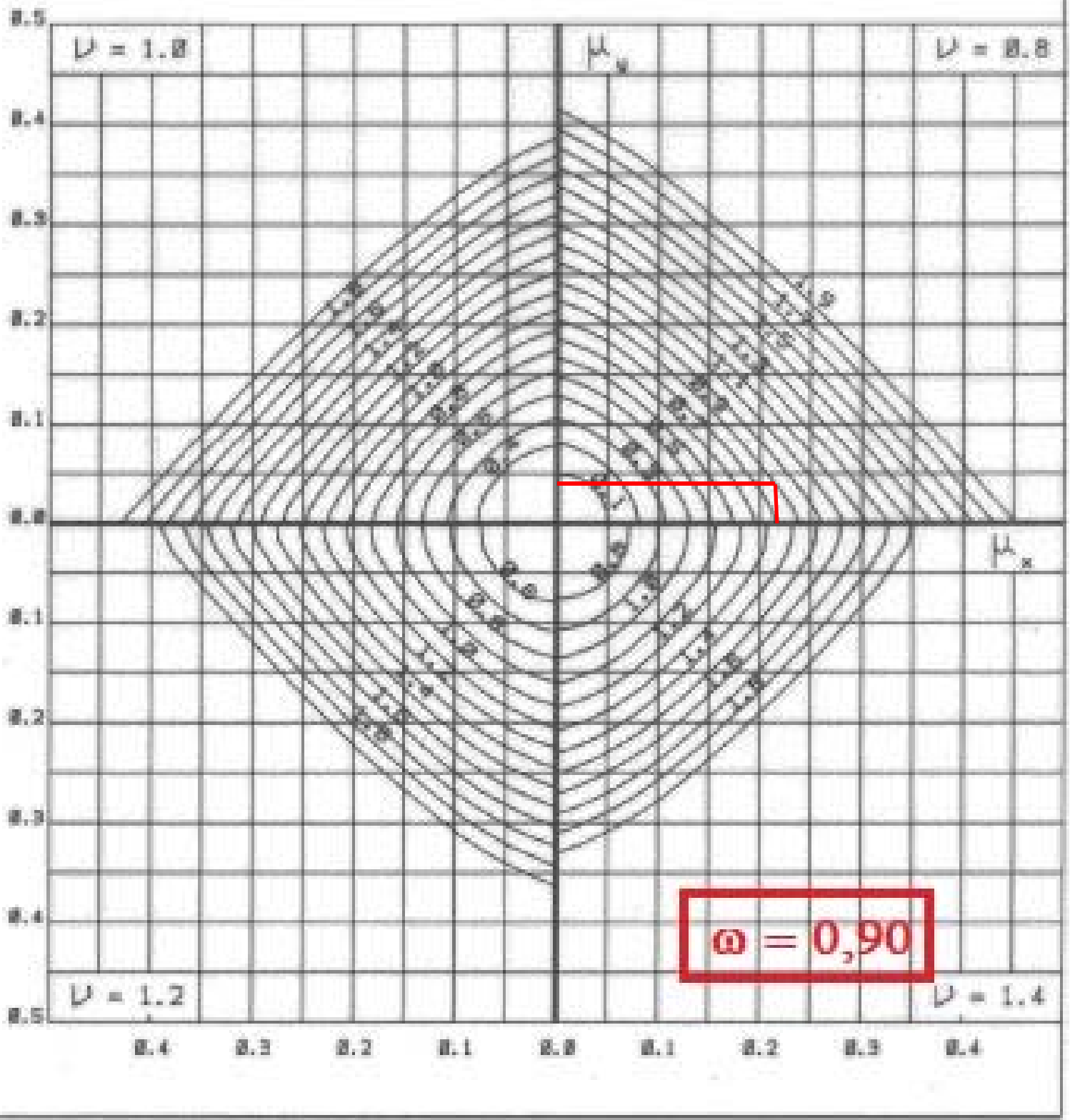

Fonte: PINHEIRO et al., 2014, p. 23.

$$
v=0,8 \rightarrow \omega=0,90
$$


Assim, por interpolação (média aritmética dos dois valores):

$$
v \cong 0,7 \rightarrow \omega=0,85
$$

No segundo caso, $M_{d, t o t, \min , x x}=71,40 \mathrm{kN}$.m é o momento fletor total obtido com o método da rigidez aproximada sobre o momento mínimo na direção $x$, essa situação está presente na figura 8.30. Com esse momento fletor, calcula-se a armadura. Serão usados os ábacos para flexão normal de Venturini (1987).

Figura 8.30 - Pré-dimensionamento (2a situação)

\section{2a Situação}

Seção Transversal

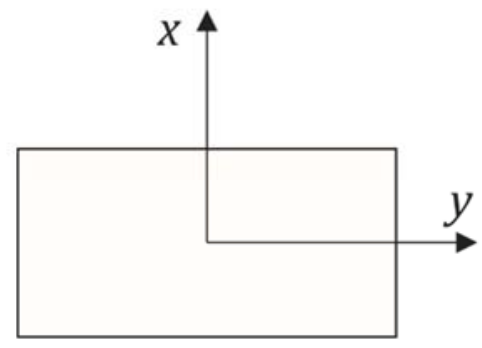

Direção $x$

$\mathrm{M}_{d, t o t, \min , x x}(\mathrm{kN} . \mathrm{m})$

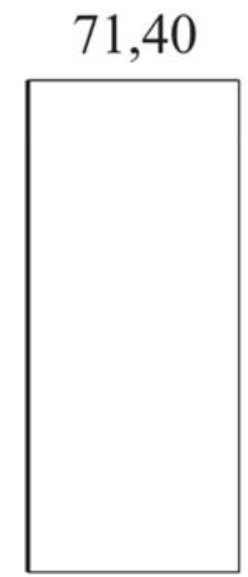

Fonte: Elaborado pelo Autor.

Para escolha do ábaco, d' será calculado para cobrimento $c=3,0 \mathrm{~cm}$ (classe de agressividade II), $\phi_{l}=20 \mathrm{~mm}=2,0 \mathrm{~cm}$ e $\phi_{t}=6,3 \mathrm{~mm}=0,63 \mathrm{~cm}$, diâmetros que foram adotados para este exemplo. Resultam:

$$
\begin{gathered}
d^{\prime}=c+\frac{\phi_{l}}{2}+\phi_{t}=3,0+\frac{2,0}{2}+0,63=4,63 \mathrm{~cm} \\
\frac{d_{x}^{\prime}}{h_{x}}=\frac{4,63}{19}=0,23 \cong 0,25
\end{gathered}
$$

Os adimensionais para uso do ábaco são (concreto C25): 


$$
\begin{gathered}
v=\frac{N_{S d}}{A_{c} \cdot f_{c d}}=\frac{1203}{19 \cdot 50 \cdot 2,5 / 1,4}=0,709 \\
\mu_{x}=\frac{v \cdot e_{x}}{h_{x}}=\frac{v \cdot \frac{M_{d, t o t, x}}{N_{d}}}{h_{x}}=\frac{0,709 \cdot \frac{7140}{1203}}{19}=0,22
\end{gathered}
$$

O ábaco utilizado (VENTURINI, 1987) foi o A-5 (com $\left.d_{x}^{\prime} / h_{x}=0,25\right)$. Dessa forma, obtém-se a taxa mecânica de armadura (figura 8.31): 
Figura 8.31 - Ábaco A-5

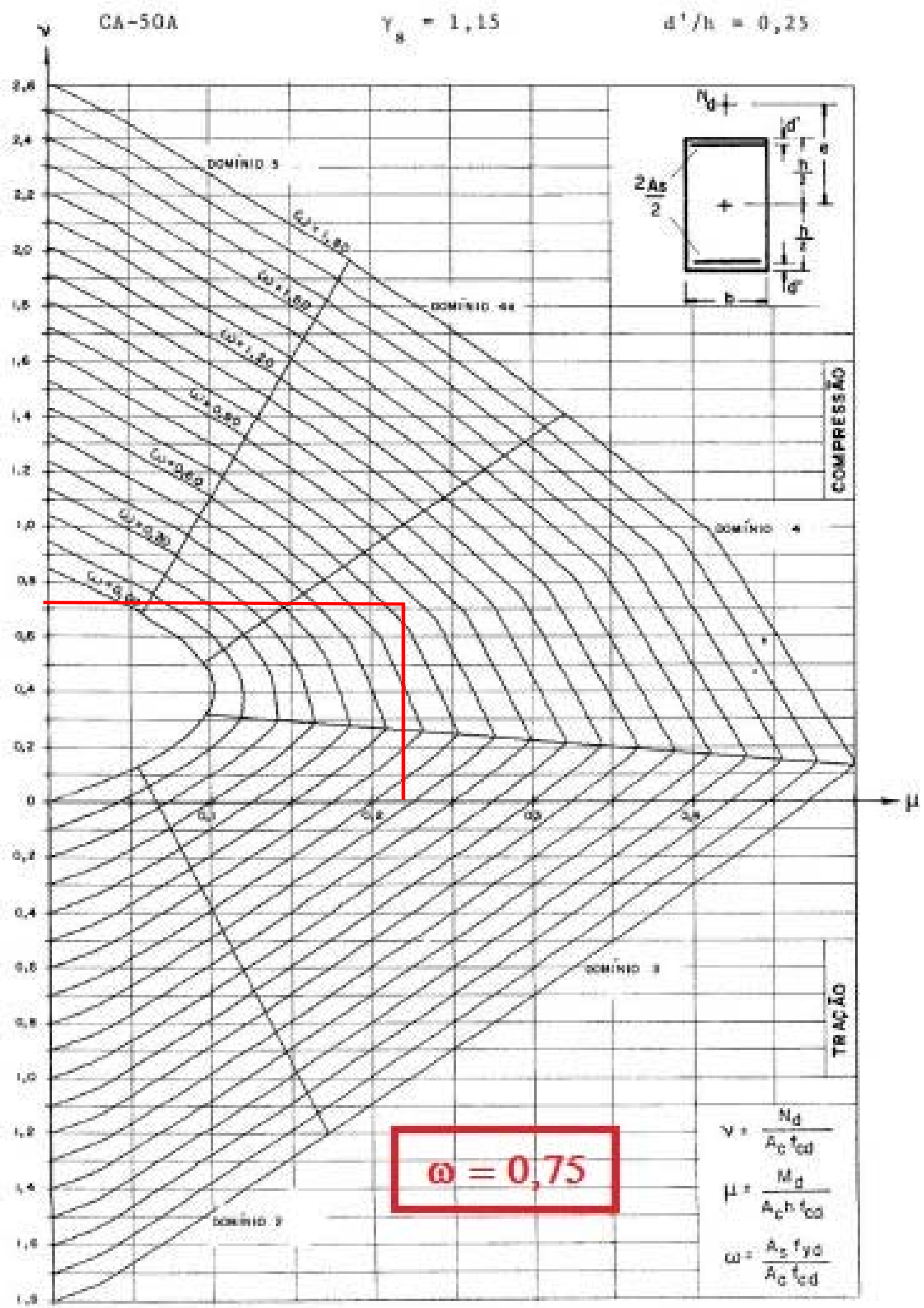

Fonte: VENTURINI, 1987, p. 50. 
Portanto, a área de aço resultante do pré-dimensionamento é definida pelo primeiro caso, resultando:

$$
A_{s}=\frac{\omega \cdot A_{c} \cdot f_{c d}}{f_{y d}}=\frac{0,85 \cdot 19 \cdot 50 \cdot \frac{2,5}{1,4}}{\frac{50}{1,15}}=33,16 \mathrm{~cm}^{2}
$$

A área de aço deve ser maior que a mínima:

$$
A_{s, \min }=\frac{0,15 \cdot N_{S d}}{f_{y d}}=\frac{0,15 \cdot 1203}{50 / 1,15}=4,15 \mathrm{~cm}^{2}>0,004 \cdot A_{c}=3,8 \mathrm{~cm}^{2}
$$

Portanto, a área de aço necessária $\left(33,16 \mathrm{~cm}^{2}\right)$ é maior que a mínima $\left(4,15 \mathrm{~cm}^{2}\right)$.

A área de aço deve ser menor que a máxima:

$$
A_{s, m a ́ x}=0,04 A_{c}=0,04 \cdot 19 \cdot 50=38 \mathrm{~cm}^{2}
$$

Portanto, a área de aço necessária $\left(33,16 \mathrm{~cm}^{2}\right)$ é menor que a máxima $\left(38 \mathrm{~cm}^{2}\right)$.

Adotam-se 12 barras de $20 \mathrm{~mm}$, com uma área efetiva de $37,70 \mathrm{~cm}^{2}$ e taxa de armadura $\left(A_{s, \text { efetiva }} / A_{c}\right)$ igual a $3,97 \%$.

Como no item 8.14.1 o valor de armadura obtido difere a do ábaco utilizado (ábaco de 20 barras de armadura, figuras 8.28 e 8.29). Deve-se verificar se os esforços adimensionais $\left(v, \mu_{x}\right.$ e $\left.\mu_{y}\right)$ também são válidos para o ábaco de 12 barras. Porém, como trata-se de um pré-dimensionamento, essa etapa será suprimida do trabalho.

Devido à configuração dos ábacos de dimensionamento, deve ser adotada armadura bilateral simétrica.

Neste caso, a armadura obtida é a mesma do método do pilar-padrão com curvatura aproximada. Portanto, as condições de espaçamento máximo e mínimo já foram verificadas (item 8.14.1). 


\subsubsection{Envoltórias}

Conhecendo a armadura é possível obter os momentos fletores resistentes de cálculo segundo cada um dos eixos, ou seja, para flexão composta normal $\left(M_{R d, x x} \mathrm{e}\right.$ $\left.M_{R d, y y}\right)$.

Reforça-se o fato de que o vetor momento fletor resistente de um eixo é perpendicular a ele. Porém, para a construção das envoltórias resistentes, o valor correspondente do momento fletor resistente será computado na direção da flexão (coincidente com o eixo).

O arranjo de armadura escolhido referente a cada eixo está indicado na figura 8.32.

Figura 8.32 - Arranjo de armadura escolhido
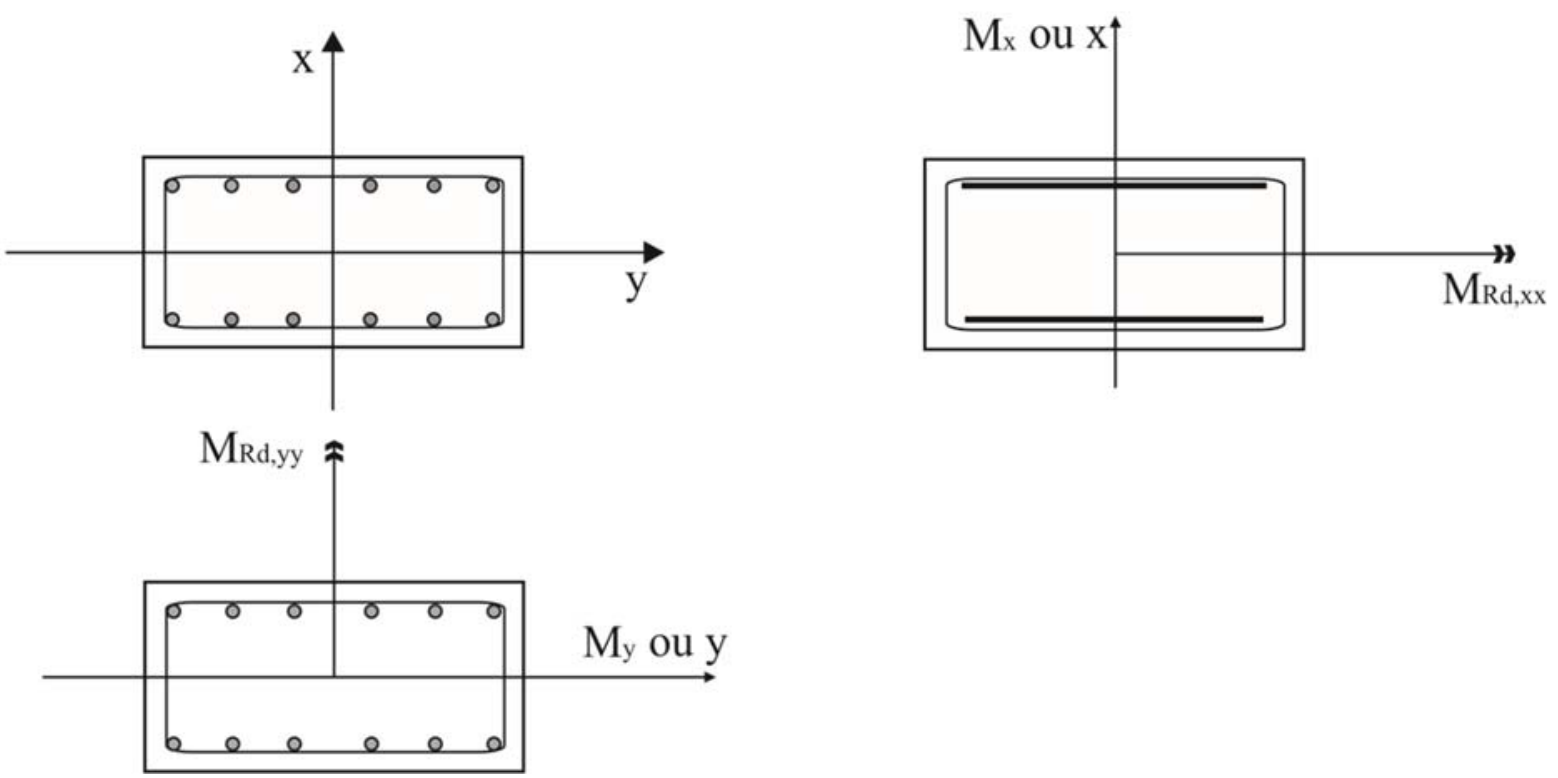

Fonte: Elaborado pelo Autor.

Como o cálculo dos momentos fletores resistentes utilizando ábacos leva a imprecisão visual, serão utilizados os diagramas momento fletor - força normal curvatura correspondentes à distribuição de armadura relativa a cada eixo (figuras 8.33 e 8.34$)$.

Para a direção x utilizou-se a distribuição de armadura condizente com a figura 8.32 (eixo x), de forma que cada linha de armadura apresente $A_{s} / 2=18,85 \mathrm{~cm}^{2}$. 
Figura 8.33 - Diagrama momento fletor - força normal - curvatura (eixo x)

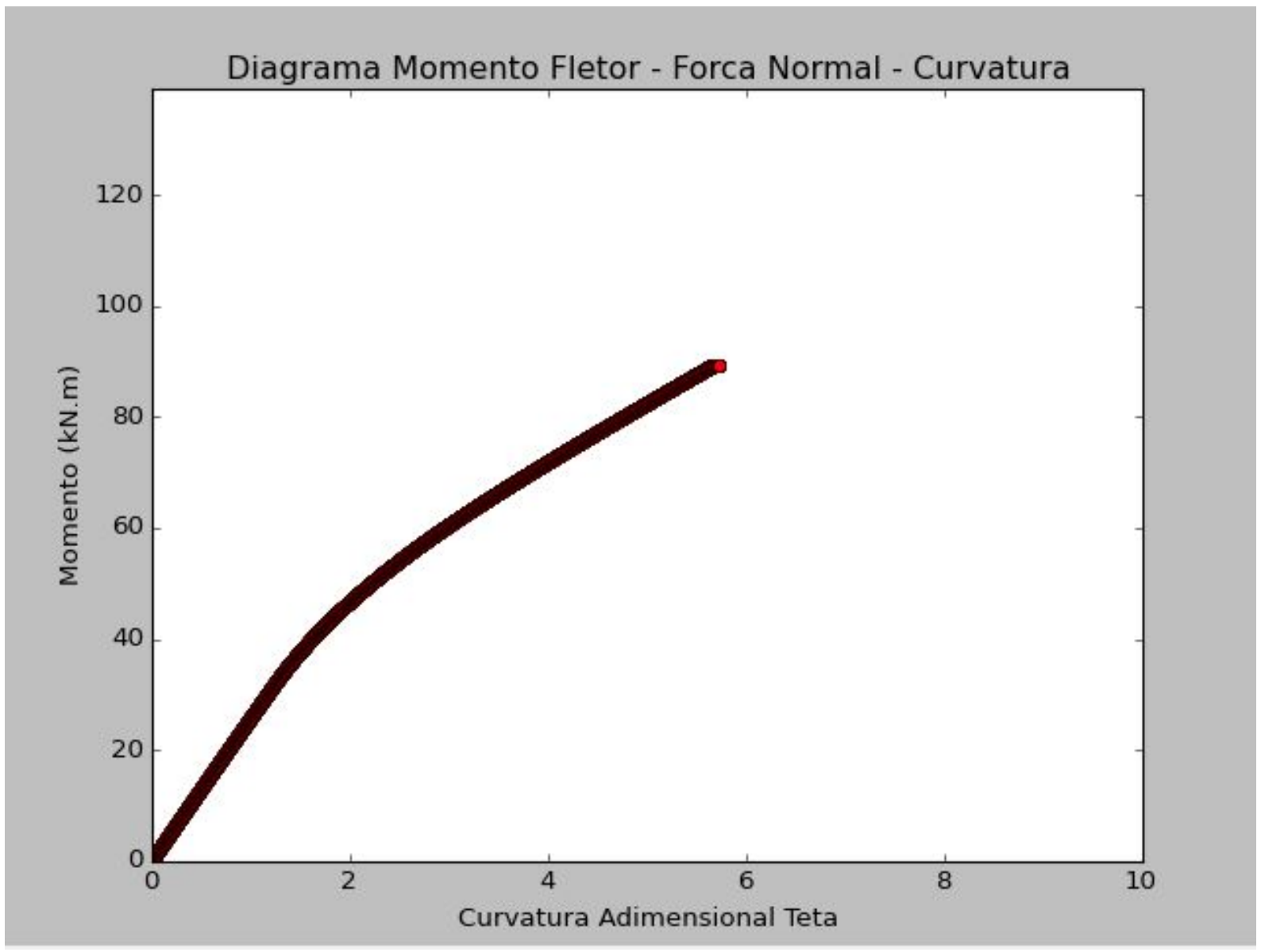

Fonte: Elaborado pelo Autor.

Como resultado do programa determinou-se com precisão o momento fletor resistente no eixo $x$, cujo valor é:

$$
M_{R d, x x}=89,28 \mathrm{kN} \cdot \mathrm{m}
$$

Para a direção y utilizou-se a distribuição de armadura condizente com a figura 8.32 (eixo y), de forma que cada linha de armadura apresente $A_{s} / 6=6,28 \mathrm{~cm}^{2}$. 
Figura 8.34 - Diagrama momento fletor - força normal - curvatura (eixo y)

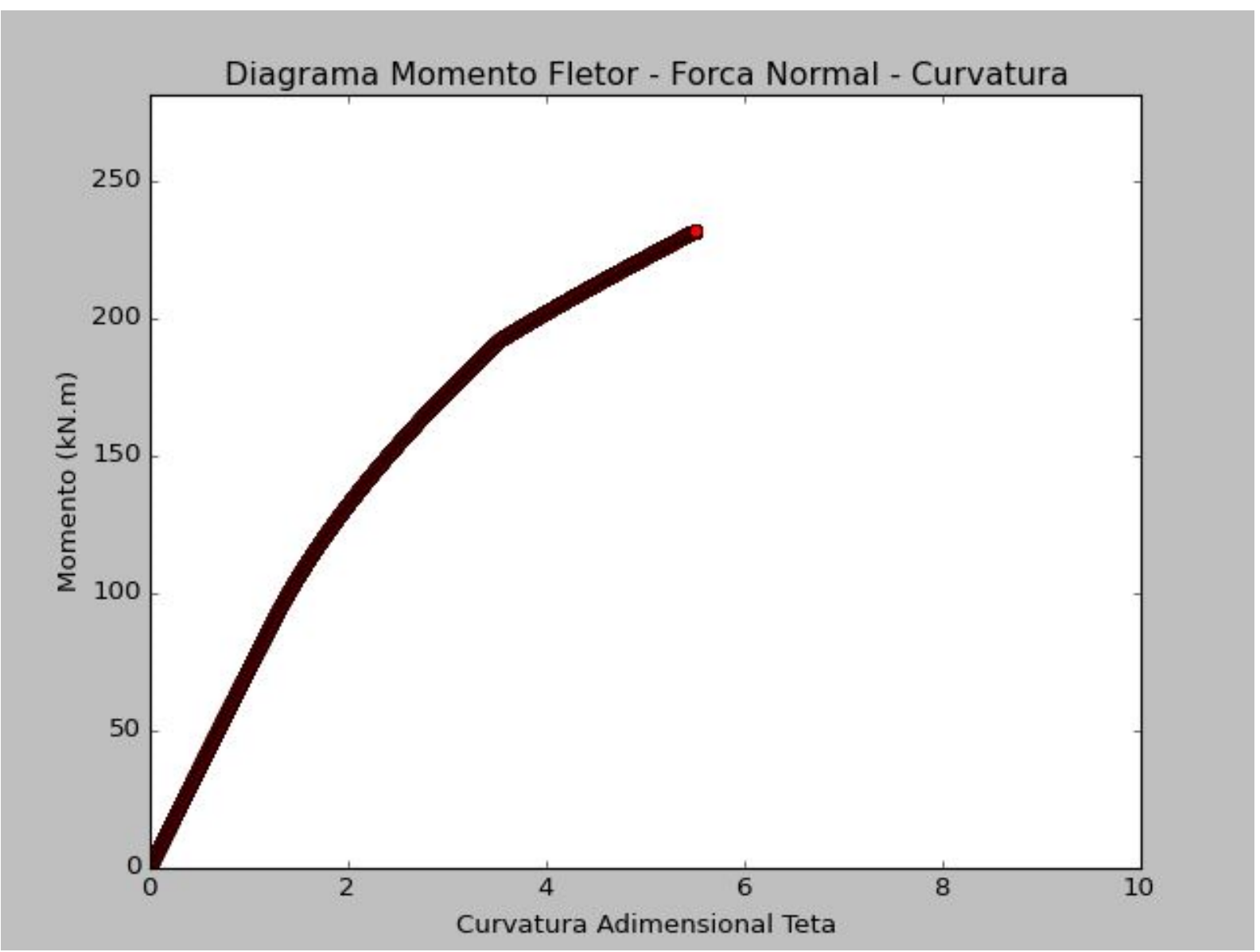

Fonte: Elaborado pelo Autor.

Como resultado do programa determinou-se com precisão o momento fletor resistente no eixo y, cujo valor é:

$$
M_{R d, y y}=231,63 \mathrm{kN} . \mathrm{m}
$$

Com esses valores, a envoltória resistente da seção com 12 barras de $20 \mathrm{~mm}$ é dada pela expressão:

$$
\left(\frac{M_{R d, x}}{89,28}\right)^{1,2}+\left(\frac{M_{R d, y}}{231,63}\right)^{1,2}=1
$$

As envoltórias de momento mínimo e de momento mínimo com $2^{\mathrm{a}}$ ordem são dadas pelas equações a seguir, respectivamente: 


$$
\begin{gathered}
\left(\frac{M_{1 d, m i n, x}}{M_{1 d, m i n}, x x}\right)^{2}+\left(\frac{M_{1 d, m i n, y}}{M_{1 d, m i n, y y}}\right)^{2}=1 \rightarrow\left(\frac{M_{d, t o t, x}}{24,90}\right)^{2}+\left(\frac{M_{d, t o t, y}}{36,09}\right)^{2}=1 \\
\left(\frac{M_{d, m i n, t o t, x}}{M_{d, m i n, t o t, x x}}\right)^{2}+\left(\frac{M_{d, \text { min }, t o t, y}}{M_{d, m i n, t o t, y y}}\right)^{2}=1 \rightarrow\left(\frac{M_{d, t o t, x}}{71,40}\right)^{2}+\left(\frac{M_{d, t o t, y}}{36,09}\right)^{2}=1
\end{gathered}
$$

Dessa forma, traçaram-se: a envoltória resistente, a envoltória mínima e a envoltória mínima com $2^{\mathrm{a}}$ ordem (figura 8.35). Também estão indicados os pontos referentes aos momentos fletores solicitantes nas seções de topo, base e intermediária do pilar, cujas coordenadas estão representadas na Tabela 8.6.

Tabela 8.6 - Momentos fletores solicitantes no pilar P01

\begin{tabular}{ccc}
\hline Seção & $\mathrm{M}_{\mathrm{x}, \text { tot }}$ & $\begin{array}{c}\mathrm{M}_{\mathrm{y}, \text { tot }} \\
(\mathrm{kN} . \mathrm{m})\end{array}$ \\
& 23,58 & 47,10 \\
\hline Topo & $-11,79$ & $-23,55$ \\
Base & 69,61 & 36,09 \\
\hline Intermediária &
\end{tabular}

Fonte: Elaborado pelo Autor. 
Figura 8.35 - Envoltória resistente, envoltórias mínimas e solicitações do pilar P01

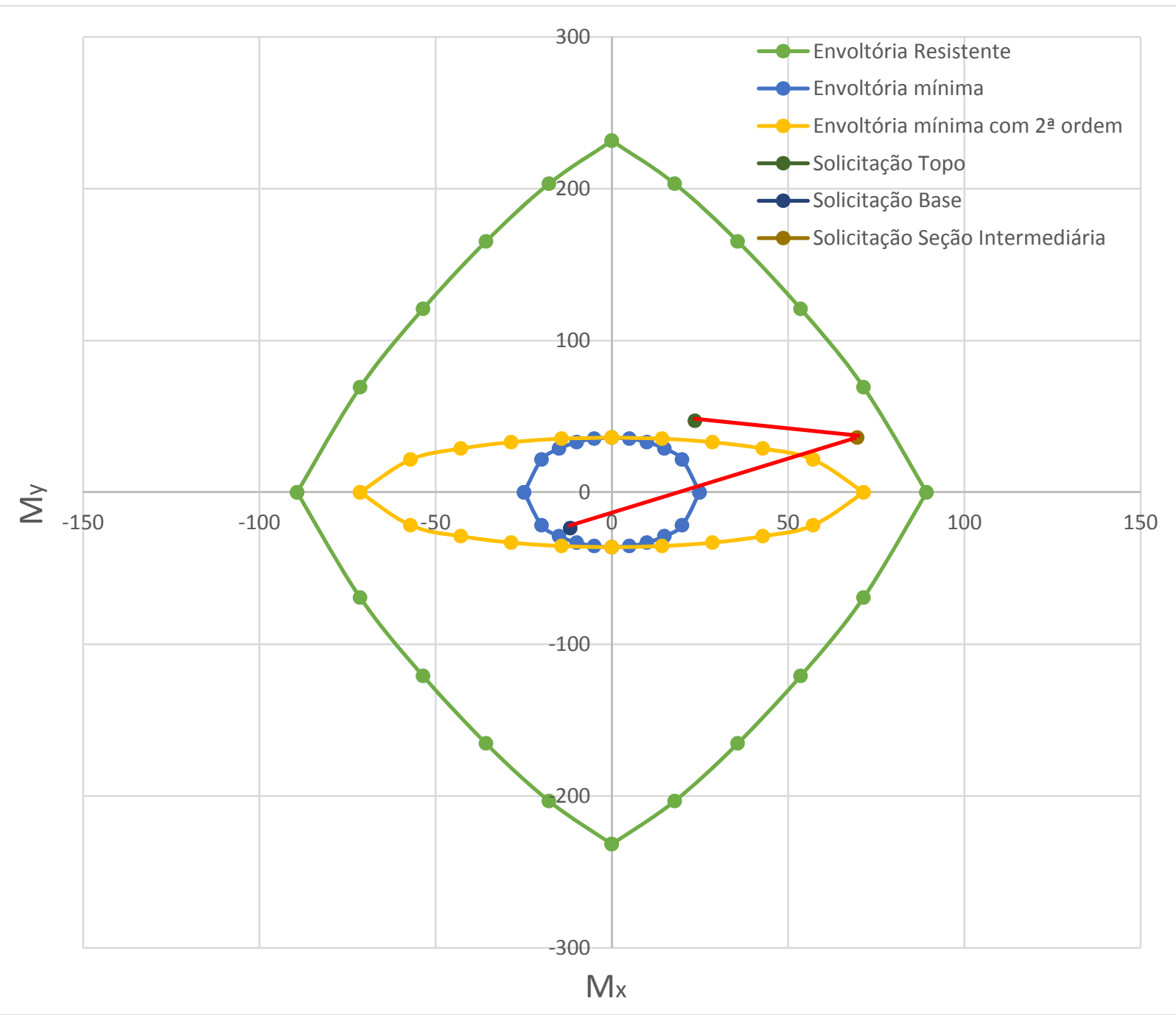

Fonte: Elaborado pelo Autor.

Analisando a figura 8.35 verifica-se que o ponto de solicitação da seção intermediária é o crítico (está mais próximo da envoltória resistente). Assim, para verificar a segurança, pode-se realizar o cálculo analítico, como é indicado a seguir.

$$
\begin{aligned}
& \left(\frac{M_{S d, x}}{M_{R d, x x}}\right)^{\alpha}+\left(\frac{M_{S d, y}}{M_{R d, y y}}\right)^{\alpha} \leq 1 \\
& \left(\frac{M_{R d, x}}{89,28}\right)^{1,2}+\left(\frac{M_{R d, y}}{231,63}\right)^{1,2} \leq 1 \\
& \left(\frac{69,61}{89,28}\right)^{1,2}+\left(\frac{36,09}{231,63}\right)^{1,2}=0,849 \leq 1
\end{aligned}
$$


Como a envoltória resistente ultrapassa os momentos fletores solicitantes nas seções críticas e também as envoltórias de momento mínimo e de momento mínimo com $2^{\mathrm{a}}$ ordem, a armadura da seção está verificada.

Percebe-se que o método do pilar-padrão com rigidez $\kappa$ aproximada gera resultados mais precisos se comparado com o método do pilar-padrão com curvatura aproximada, já que, com a mesma solicitação e a mesma armadura, a verificação de envoltória de um leva a resultado $(0,849)$ que é inferior ao do outro $(0,907)$.

\subsubsection{Verificação da excentricidade acidental}

No caso da excentricidade acidental, não há os conceitos de envoltórias mínimas e de momento mínimo. Assim, a consideração das imperfeições geométricas locais é feita com a adição de uma excentricidade acidental às excentricidades solicitantes na seção intermediária do pilar.

Novamente destaca-se que a ABNT NBR 6118:2014 não apresenta as diretrizes para a computação da excentricidade acidental. Assim, neste trabalho, será efetuado uma sugestão de como essas excentricidades devem ser consideradas no dimensionamento.

Dessa forma, utilizando os itens 8.11 e 8.14 , têm-se os resultados indicados a seguir.

- Direção x

$e_{a x}=1,05 \mathrm{~cm}=0,0105 \mathrm{~m}$;

$M_{d, t o t, x}=69,61 \mathrm{kN} . \mathrm{m}$;

$N_{d}=1203 \mathrm{kN}$

$M_{x, \text { tot,int }}=M_{d, t o t, x}+N_{d} \cdot e_{a x}=69,61+1203 \cdot 0,0105=82,24 k N . m$ 
- Direção y

$e_{a y}=1,08 \mathrm{~cm}=0,0108 \mathrm{~m}$;

$M_{d, t o t, i n t}=\alpha_{b y} \cdot M_{1 d, A y}=0,4 \cdot 47,10=18,84 k N . m$

$N_{d}=1203 \mathrm{kN}$

$M_{y, \text { tot,int }}=M_{d, \text { tot,int }}+N_{d} \cdot e_{a y}=18,84+1203 \cdot 0,0108=31,83 \mathrm{kN} \cdot \mathrm{m}$

Assim, os momentos fletores solicitantes no pilar são indicados na Tabela 8.7:

Tabela 8.7 - Momentos fletores solicitantes no pilar P01

\begin{tabular}{ccc}
\hline Seção & $\mathrm{M}_{\mathrm{x}, \text { tot }}$ & $\mathrm{M}_{\mathrm{y}, \text { tot }}$ \\
& $(\mathrm{kN} \cdot \mathrm{m})$ & $(\mathrm{kN} . \mathrm{m})$ \\
\hline Topo & 23,58 & 47,10 \\
Base & $-11,79$ & $-23,55$ \\
Intermediária & 82,28 & 31,83 \\
\hline
\end{tabular}

Fonte: Elaborado pelo Autor.

Utilizando a armadura pré-dimensionada anteriormente, ou seja, 12 barras de $20 \mathrm{~mm}$, tem-se para a envoltória resistente a expressão:

$$
\left(\frac{M_{R d, x}}{89,28}\right)^{1,2}+\left(\frac{M_{R d, y}}{231,63}\right)^{1,2}=1
$$

Os pontos de solicitações e a envoltória resistente estão indicados na figura 8.36: 
Figura 8.36 - Solicitações do pilar P01 (excentricidade acidental)

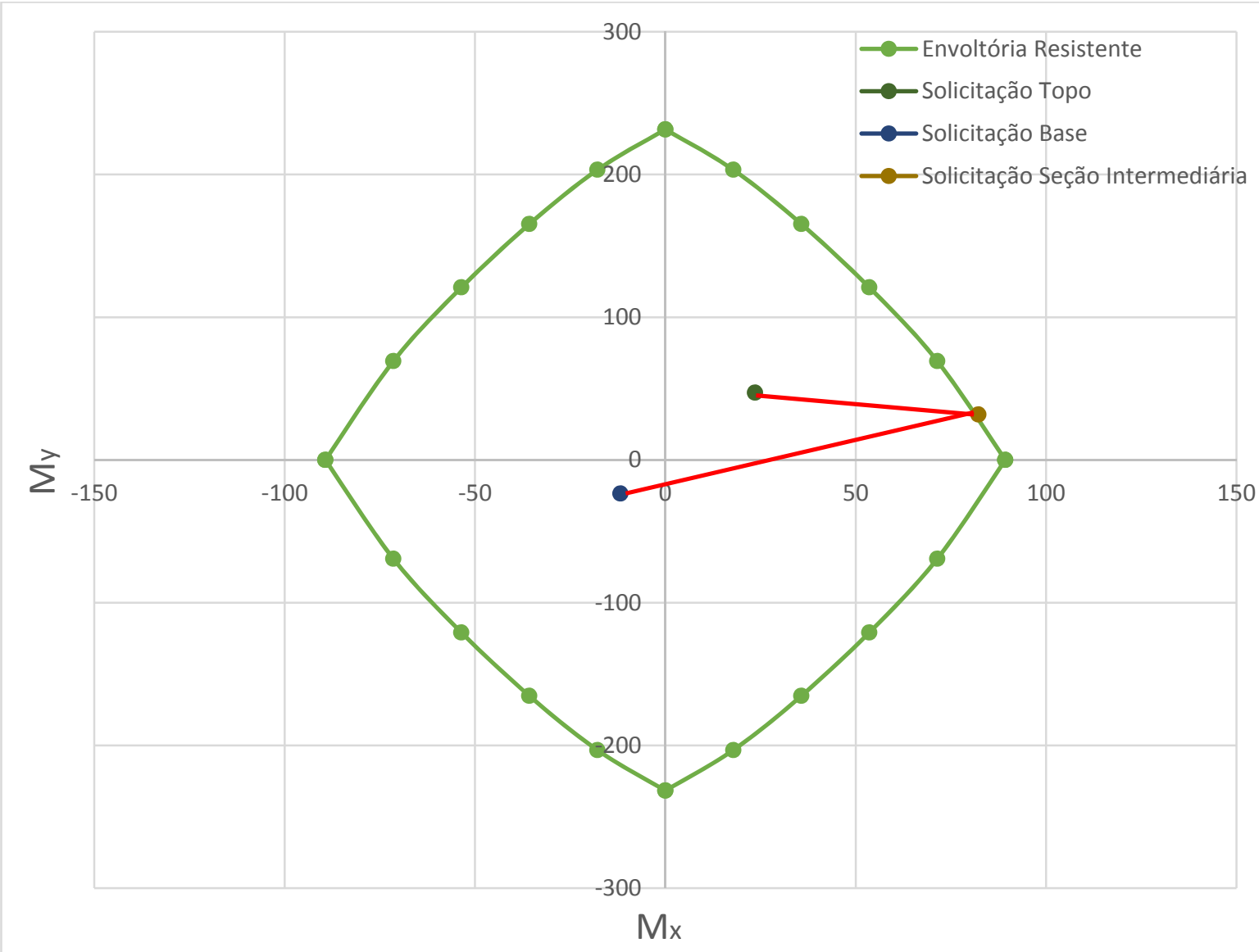

Fonte: Elaborado pelo Autor.

Como o ponto de solicitação intermediária tangencia a envoltória resistente, verifica-se a segurança por meio do cálculo analítico:

$$
\begin{aligned}
& \left(\frac{M_{S d, x}}{M_{R d, x x}}\right)^{\alpha}+\left(\frac{M_{S d, y}}{M_{R d, y y}}\right)^{\alpha} \leq 1 \\
& \left(\frac{M_{S d, x}}{89,28}\right)^{1,2}+\left(\frac{M_{S d, y}}{231,63}\right)^{1,2} \leq 1 \\
& \left(\frac{82,24}{89,28}\right)^{1,2}+\left(\frac{31,83}{231,63}\right)^{1,2}=0,998 \leq 1
\end{aligned}
$$

Portanto, como a envoltória resistente ultrapassa os momentos fletores solicitantes nas seções críticas, a armadura da seção está verificada. 


\subsection{MÉTODO DO PILAR-PADRÃO ACOPLADO A DIAGRAMAS MOMENTO FLETOR - FORÇA NORMAL - CURVATURA}

Em oposição aos dois métodos anteriores (método do pilar-padrão com curvatura aproximada e método do pilar-padrão com rigidez $\kappa$ aproximada), o método do pilar-padrão acoplado a diagramas momento fletor - força normal - curvatura é de verificação.

Assim, é necessária uma armadura pré-selecionada para obter os momentos fletores de segunda ordem que ocorrem na seção intermediária do pilar.

Portanto, o pré-dimensionamento da seção é efetuado por um dos métodos aproximados dos itens anteriores e o dimensionamento é feito por tentativas. A armadura utilizada será de 12 barras de $20 \mathrm{~mm}$, determinada anteriormente.

- Direção x

Com a distribuição da armadura na direção $\mathrm{x}$ indicada na figura 8.37 (duas linhas de barras com $A_{s} / 2=18,85 \mathrm{~cm}^{2}$ ), determina-se o diagrama momento fletor força normal - curvatura relativo à figura 8.38 .

Figura 8.37 - Distribuição da armadura na direção x
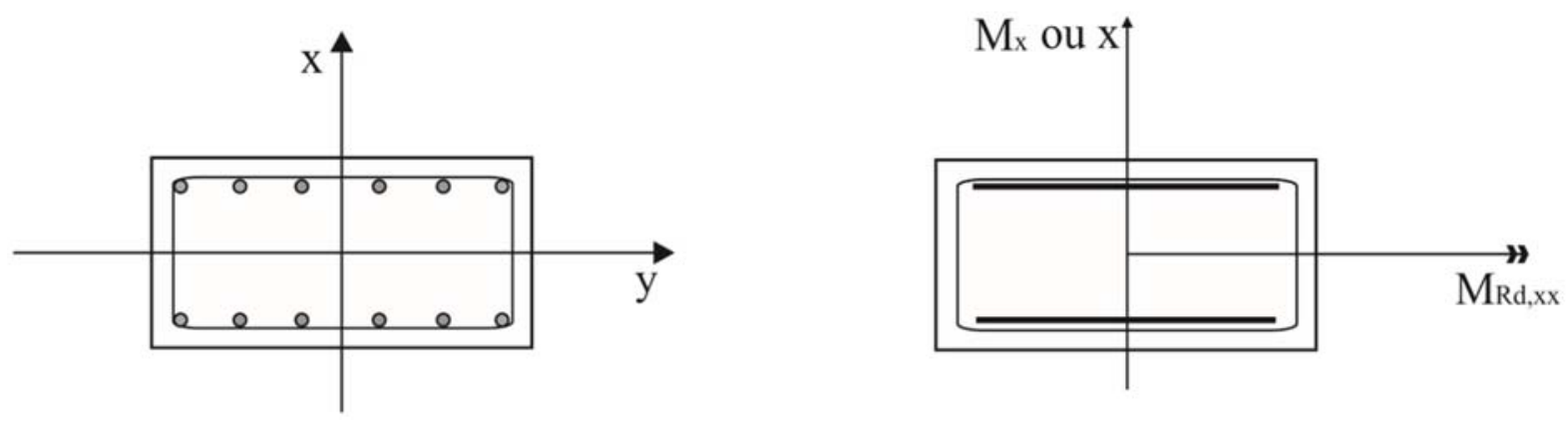

Fonte: Elaborado pelo Autor. 
Figura 8.38 - Diagrama momento fletor - força normal - curvatura (eixo x)

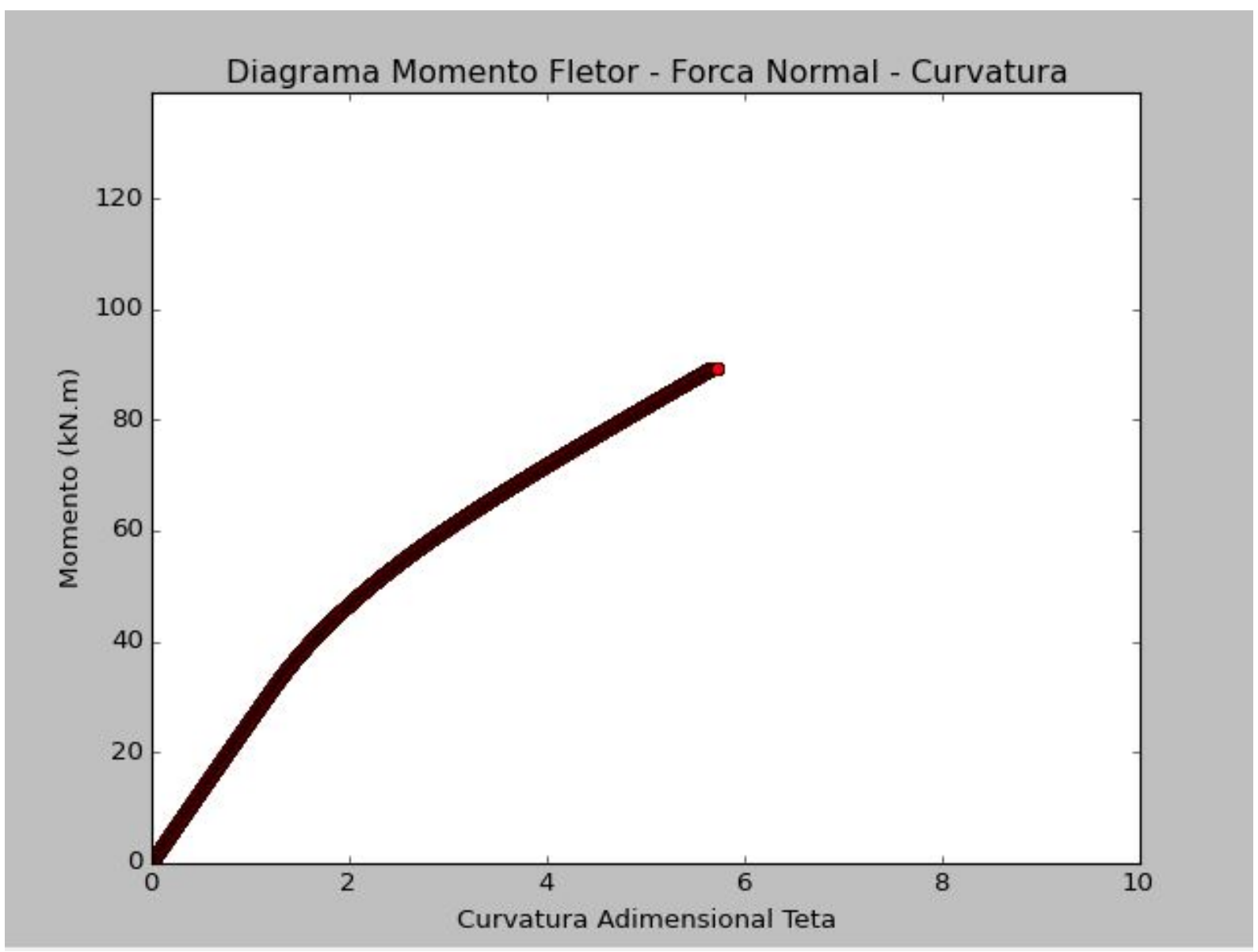

Fonte: Elaborado pelo Autor.

Em seguida deve-se construir uma nova curva, obtida com $1,10 \cdot f_{c d}$ e $N_{R d} / \gamma_{f 3}$. Com essa curva é efetuada a linearização, com a determinação da reta que liga a origem ao ponto correspondente ao momento fletor resistente dividido por $\gamma_{f 3}$ $\left(M_{R d} / \gamma_{f 3}\right)$. 
Figura 8.39 - Linearização do diagrama momento fletor - força normal - curvatura (eixo x)

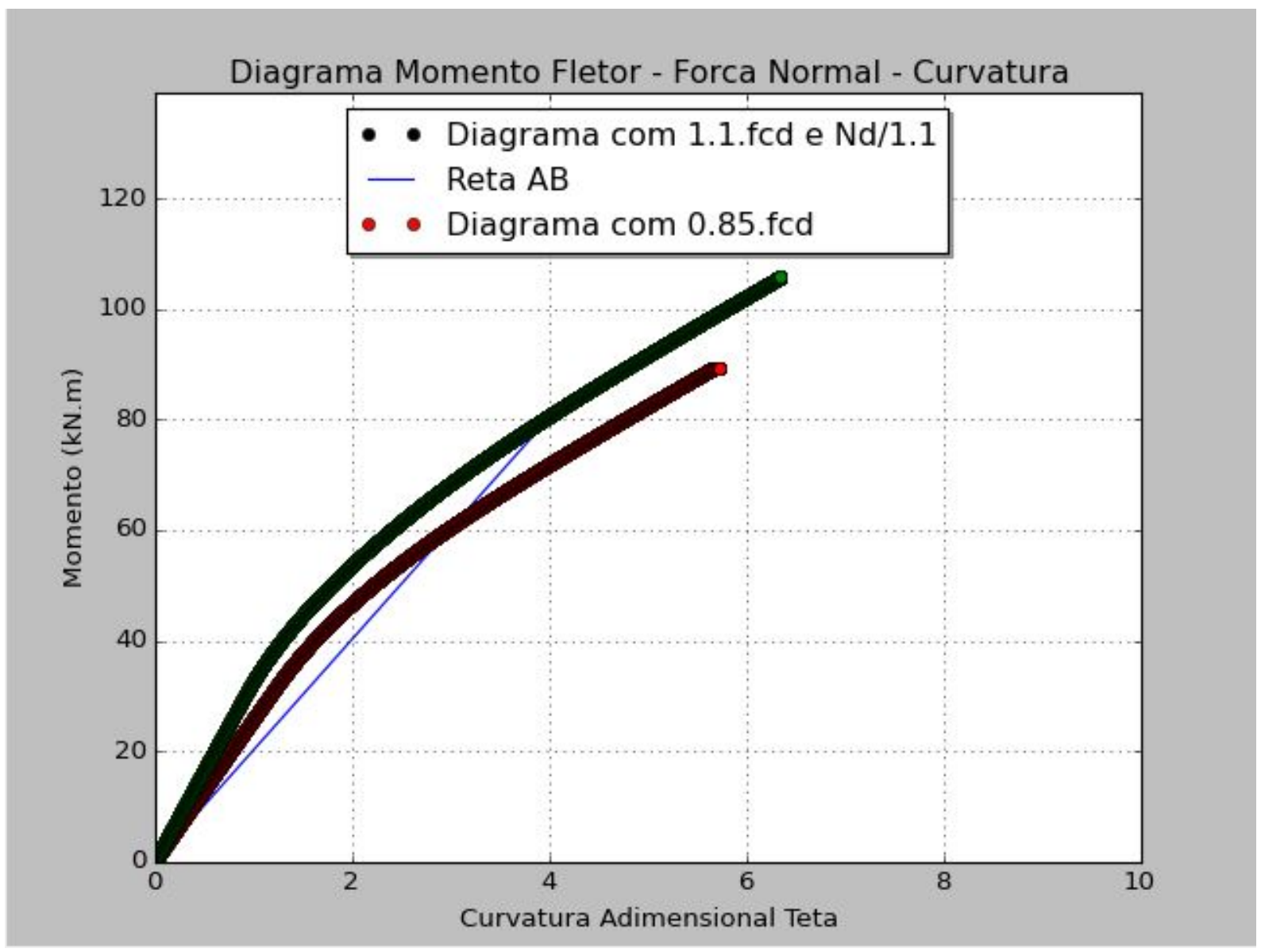

Fonte: Elaborado pelo Autor.

Como resultado do programa, obteve-se o parâmetro $E I_{s e c}$ relativo à tangente da reta $A B$ :

$$
E I_{s e c}=\frac{M_{R d} / \gamma_{f 3}}{1 / r_{c s}}=3808,75 \mathrm{kN} \cdot \mathrm{m}^{2}
$$

A forma adimensional da rigidez secante é dada pela expressão 8.177:

$$
\kappa_{s e c}=\frac{E I_{s e c}}{b \cdot h^{3} \cdot f_{c d}}=\frac{M_{R d} / \gamma_{f 3}}{1 / r_{c s}} \cdot \frac{1}{b \cdot h^{3} \cdot f_{c d}}
$$

$h=h_{x}=19 \mathrm{~cm}=0,19 \mathrm{~m}$ é a altura da seção na direção analisada;

$b=h_{y}=50 \mathrm{~cm}=0,50 \mathrm{~m}$ é a largura da seção na direção analisada; 


$$
\begin{aligned}
& f_{c d}=\frac{2,5}{1,4}=1,785714 \mathrm{kN} / \mathrm{cm}^{2}=17857,14 \mathrm{kN} / \mathrm{m}^{2} . \\
& \kappa_{\text {sec }}=\frac{E I_{\text {sec }}}{b \cdot h^{3} \cdot f_{c d}}=\frac{3808,75}{0,5 \cdot 0,19^{3} \cdot 17857,14}=62,19
\end{aligned}
$$

O parâmetro $\kappa_{\text {sec }}$ representa as características da seção, sendo utilizado para calcular o momento fletor total de uma seção crítica em análise, e sua expressão quando utilizado o parâmetro $\gamma_{f 3}=1,1$ é dada por:

$$
M_{S d, t o t}=\frac{\alpha_{b} \cdot M_{1 d, A}}{1-\frac{\lambda^{2}}{120 \cdot 1,1 \cdot \kappa_{s e c} / v}} \geq M_{1 d, A}
$$

Dessa forma, pode-se obter o momento fletor solicitante total na seção intermediária do lance do pilar com:

$$
\begin{aligned}
& \alpha_{b x}=1,0 \\
& M_{1 d, A}=1,4 \cdot 16,84=23,58 \mathrm{kN} \cdot \mathrm{m} \\
& \lambda_{x}=80,0 \\
& v=\frac{N_{d}}{A_{c} \cdot f_{c d}}=\frac{1203}{19 \cdot 50 \cdot \frac{2,5}{1,4}}=0,709 . \\
& M_{S d, t o t}=\frac{1,0 \cdot 23,58}{1-\frac{80,0^{2}}{120 \cdot 1,1 \cdot 62,19 / 0,709}}=52,72 \mathrm{kN} \cdot \mathrm{m} \geq M_{1 d, A}=23,58 \mathrm{kN} . \mathrm{m} \\
& \therefore M_{d, t o t, x}=52,72 \mathrm{kN} . \mathrm{m}
\end{aligned}
$$

Para determinação das envoltórias solicitantes calcula-se o momento mínimo com segunda ordem $\left(M_{d, t o t, \min }\right)$ :

$$
\begin{aligned}
& \alpha_{b x}=0,4 ; \\
& M_{1 d x, \min }=24,90 \mathrm{kN} . \mathrm{m} \text { (momento mínimo); } \\
& \lambda_{x}=80,0 ;
\end{aligned}
$$




$$
\begin{aligned}
& v=\frac{N_{d}}{A_{c} \cdot f_{c d}}=\frac{1203}{19 \cdot 50 \cdot \frac{., 5}{1,4}}=0,709 . \\
& M_{S d, \text { tot,min }}=\frac{1,0 \cdot 24,90}{1-\frac{80,0^{2}}{120 \cdot 1,1 \cdot 62,19 / 0,709}}=55,67 \mathrm{kN} \cdot \mathrm{m} \geq M_{1 d x, \text { min }} \\
& M_{S d, \text { tot,min }} \geq M_{1 d x, \text { min }}=24,90 \mathrm{kN} . \mathrm{m} \therefore M_{S d, \text { tot,min }}=55,67 \mathrm{kN} . \mathrm{m}
\end{aligned}
$$

- Direção y

Os efeitos de $2^{a}$ ordem na direção y não são computados, já que $\lambda_{1 y}>\lambda_{y}$. Portanto, não é necessário o cálculo dos efeitos de 2 a ordem, o que significa que pode ser adotado, para o momento fletor total $\left(M_{d, t o t}\right)$, o momento fletor de 1 a ordem $\left(M_{1 d, A}\right)$, e para o momento total mínimo $\left(M_{d, t o t, m i ́ n}\right)$, o momento mínimo $\left(M_{1 d, m i ́ n}\right)$.

\subsubsection{Envoltórias}

Do item 8.15.2, cuja armadura analisada é de 12 barras de $20 \mathrm{~mm}$, retira-se a expressão da envoltória resistente:

$$
\left(\frac{M_{R d, x}}{89,28}\right)^{1,2}+\left(\frac{M_{R d, y}}{231,63}\right)^{1,2}=1
$$

As envoltórias de momento mínimo e de momento mínimo com $2^{\mathrm{a}}$ ordem são dadas pelas equações a seguir, respectivamente:

$$
\begin{aligned}
& \left(\frac{M_{1 d, \min n, x}}{M_{1, \text { mín }, x x}}\right)^{2}+\left(\frac{M_{1 d, \text { mín }, y}}{M_{1, \text { mín,yy }}}\right)^{2}=1 \rightarrow\left(\frac{M_{d, t o t, x}}{24,90}\right)^{2}+\left(\frac{M_{d, t o t, y}}{36,09}\right)^{2}=1 \\
& \left(\frac{M_{d, m i n, t o t, x}}{M_{d, m i n, t o t, x x}}\right)^{2}+\left(\frac{M_{d, m i n, t o t, y}}{M_{d, m i ́ n, t o t, y y}}\right)^{2}=1 \rightarrow\left(\frac{M_{d, t o t, x}}{55,67}\right)^{2}+\left(\frac{M_{d, t o t, y}}{36,09}\right)^{2}=1
\end{aligned}
$$

Dessa forma, traçou-se a envoltória resistente e a envoltória mínima. Também estão indicados os pontos referentes aos momentos fletores solicitantes nas seções 
de topo, base e intermediária do pilar, cujas coordenadas estão representadas na Tabela 8.8.

Tabela 8.8 - Momentos fletores solicitantes no pilar P01

\begin{tabular}{ccc}
\hline Seção & $M_{\text {x,tot }}$ & $M_{\mathrm{y}, \text { tot }}$ \\
& $(\mathrm{kN} . \mathrm{m})$ & $(\mathrm{kN} . \mathrm{m})$ \\
\hline Topo & 23,58 & 47,10 \\
Base & $-11,79$ & $-23,55$ \\
Intermediária & 52,72 & 36,09 \\
\hline
\end{tabular}

Fonte: Elaborado pelo Autor.

Figura 8.40 - Envoltória resistente, envoltórias mínimas e solicitações do pilar P01

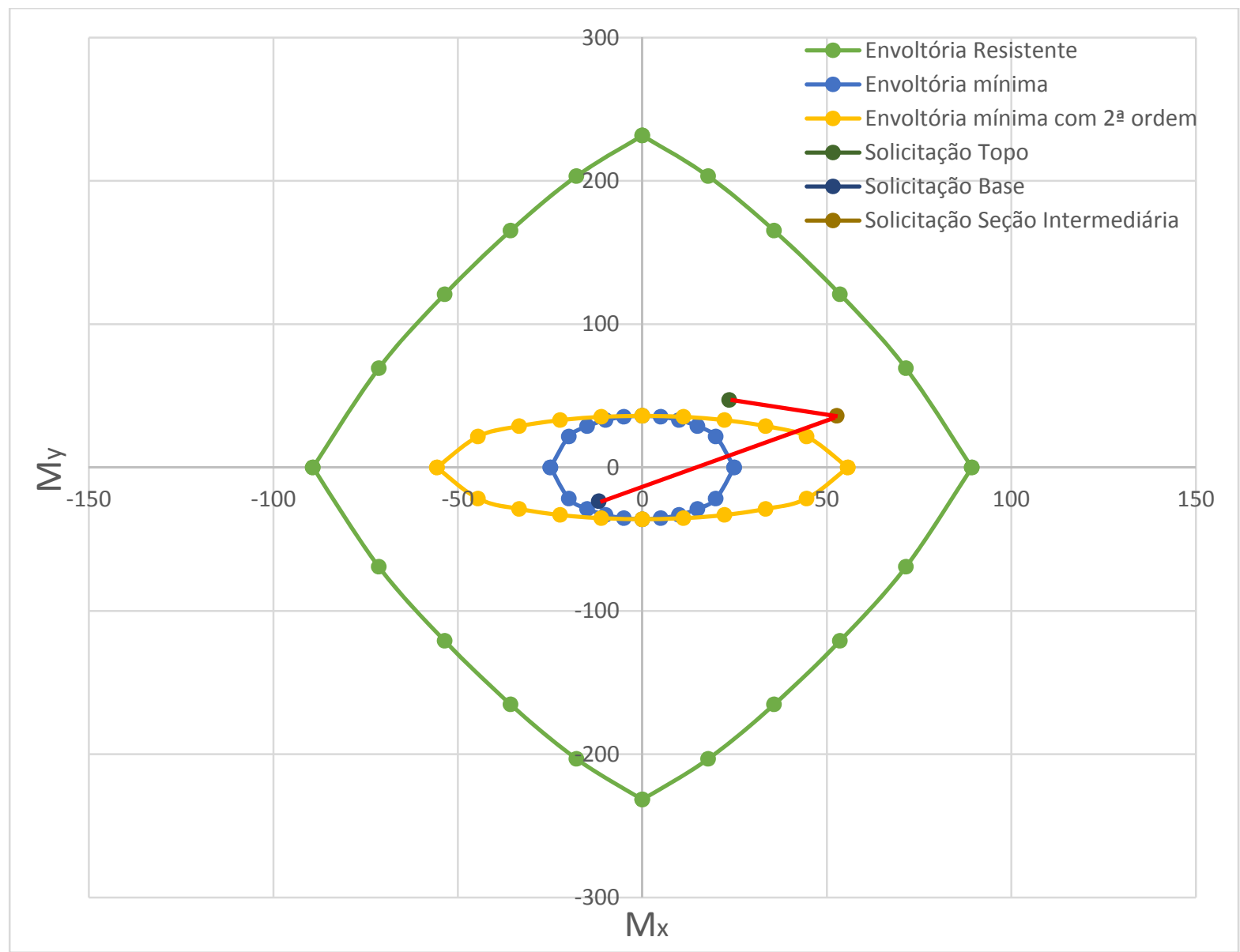

Fonte: Elaborado pelo Autor.

Percebe-se que o ponto de solicitação crítica (solicitação da seção intermediária) está inserido na envoltória resistente e, portanto, a armadura foi verificada. 
Porém, percebe-se que a seção está superdimensionada, já que o ponto crítico está longe da envoltória resistente.

Portanto será adotada uma nova armadura, com 10 barras de $20 \mathrm{~mm}\left(A_{s}=\right.$ $31,42 \mathrm{~cm}^{2}$ ) e será verificado se o dimensionamento torna-se mais eficaz.

\subsubsection{Nova armadura (dez barras de $20 \mathrm{~mm}$ )}

Para a nova armadura adotada têm-se cinco linhas de armadura distribuídas na altura $h_{y}$, como indicado na figura 8.41 .

Figura 8.41 - Seção pré-definida

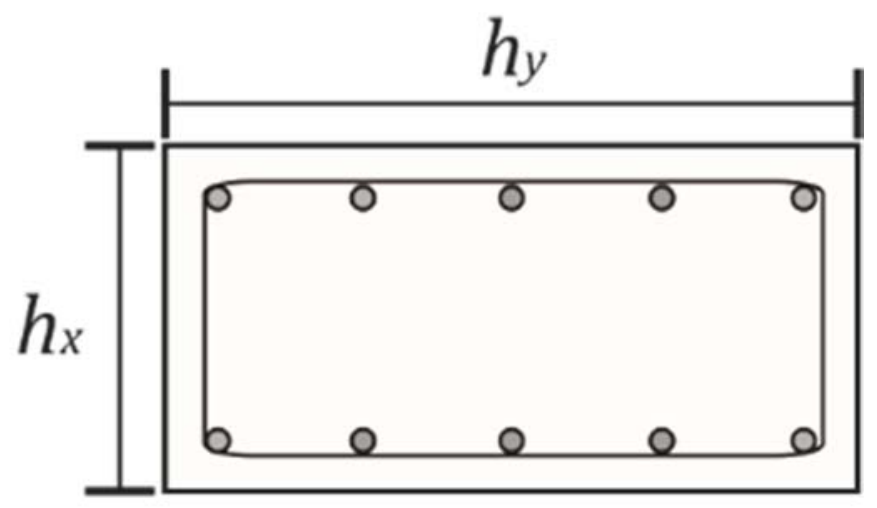

Fonte: Elaborado pelo Autor.

Deve-se verificar se a seção adotada atende aos requisitos de espaçamentos mínimo e máximo das barras longitudinais. Assim, calculando-se o espaçamento das barras na direção de $h_{x}$ (direção x), têm-se:

$$
a_{x}=h_{x}-2 \cdot d^{\prime} \rightarrow a_{x}=19-2 \cdot 4,63=9,74 \mathrm{~cm}
$$

E na direção de $h_{y}$ (direção y):

$$
a_{y}=\frac{h_{y}-2 \cdot d^{\prime}}{4} \rightarrow a_{y}=\frac{50-2 \cdot 4,63}{4}=10,185 \mathrm{~cm}
$$

Para o espaçamento mínimo, $a_{x}$ e $a_{y}$ devem ser iguais ou superiores a (o agregado graúdo considerado é a brita 2 , com $\phi_{\max }=25 \mathrm{~mm}=2,5 \mathrm{~cm}$ ): 
$-2 \mathrm{~cm}$

- diâmetro da barra: $\phi_{l}=20 \mathrm{~mm}=2 \mathrm{~cm}$;

- 1,2 vez a dimensão máxima característica do agregado graúdo: $1,2 \cdot \phi_{\max }=1,2 \cdot 2,5 \mathrm{~cm}=3 \mathrm{~cm}$.

Considerando o maior valor ( $3 \mathrm{~cm}$ ), para se obter a distância mínima entre eixos das barras deve-se somar $\phi_{l}=2 \mathrm{~cm}$, resultando $5 \mathrm{~cm}$.

Portanto os espaçamentos $a_{x}=9,74 \mathrm{~cm}$ e $a_{y}=10,185 \mathrm{~cm}$ atendem aos requisitos de espaçamento mínimo.

Para o espaçamento máximo, $a_{x}$ e $a_{y}$ devem ser menores ou iguais a duas vezes a menor dimensão da seção no trecho considerado, sem exceder $40 \mathrm{~cm}$ :

$$
-2 \cdot h_{x}<40 \mathrm{~cm} \rightarrow 2 \cdot 19=38 \mathrm{~cm}<40 \mathrm{~cm} .
$$

Portanto os espaçamentos $a_{x}=9,74 \mathrm{~cm}$ e $a_{y}=10,185 \mathrm{~cm}$ atendem também aos requisitos de espaçamento máximo.

\section{- Direção x}

Com a distribuição da armadura na direção $x$ indicada na figura 8.42 (duas linhas de armadura com $A_{s} / 2=15,71 \mathrm{~cm}^{2}$ ), determina-se o diagrama momento fletor - força normal - curvatura relativo à figura 8.43 . 
Figura 8.42 - Distribuição da armadura na direção x da seção
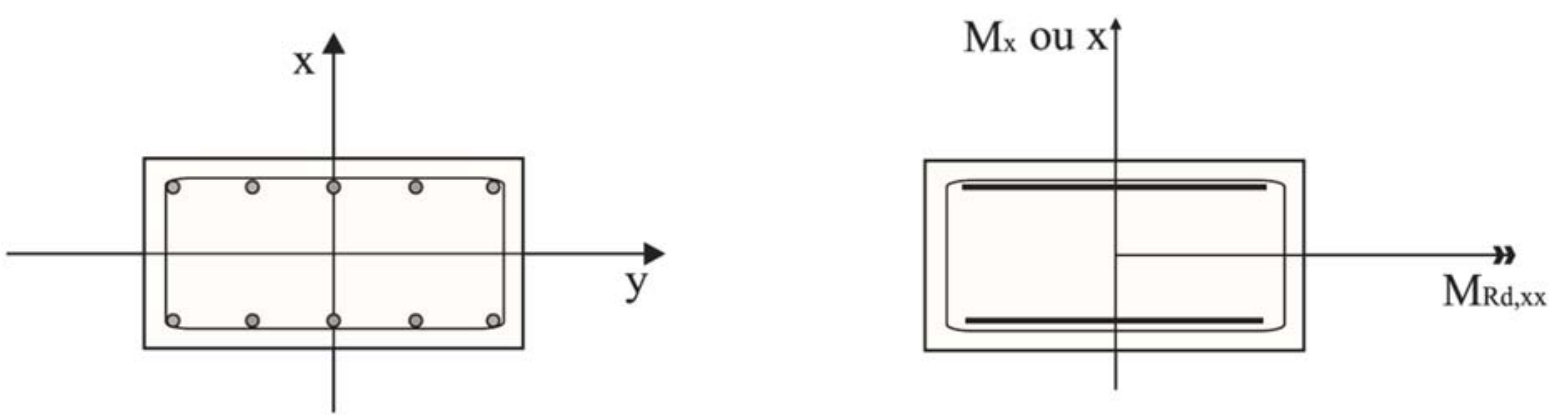

Fonte: Elaborado pelo Autor.

Figura 8.43 - Diagrama momento fletor - força normal - curvatura (eixo x)

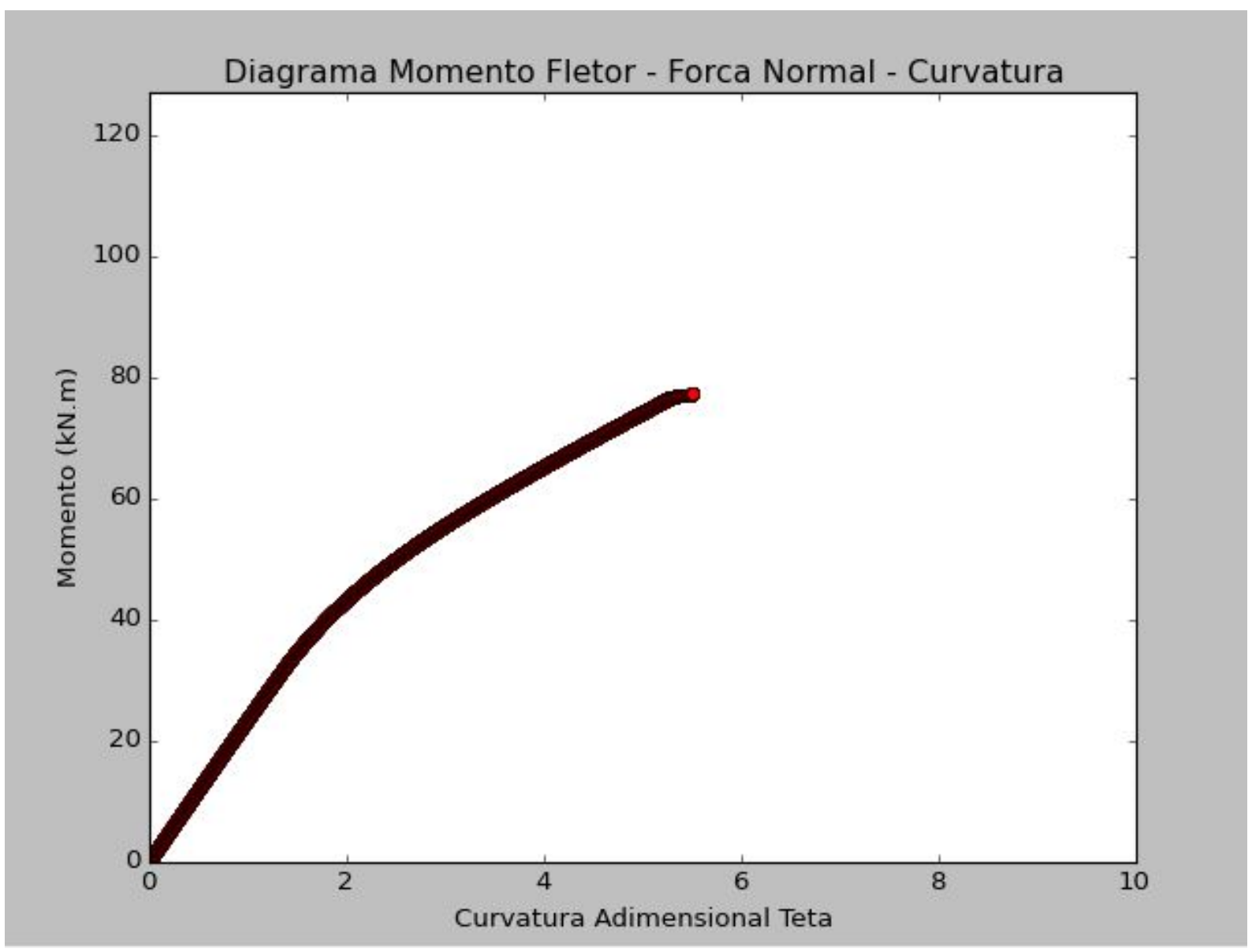

Fonte: Elaborado pelo Autor.

Determinou-se com precisão o momento fletor resistente no eixo $\mathrm{x}$, cujo valor é:

$$
M_{R d, x x}=77,24 k N . m
$$


Em seguida deve-se construir uma nova curva, obtida com $1,10 \cdot f_{c d}$ e $N_{R d} / \gamma_{f 3}$. Com essa curva é efetuada a linearização com a determinação da reta que liga a origem ao ponto correspondente ao momento fletor resistente dividido por $\gamma_{f 3}$ $\left(M_{R d} / \gamma_{f 3}\right)$.

Figura 8.44 - Linearização do diagrama momento fletor - força normal - curvatura (eixo x)

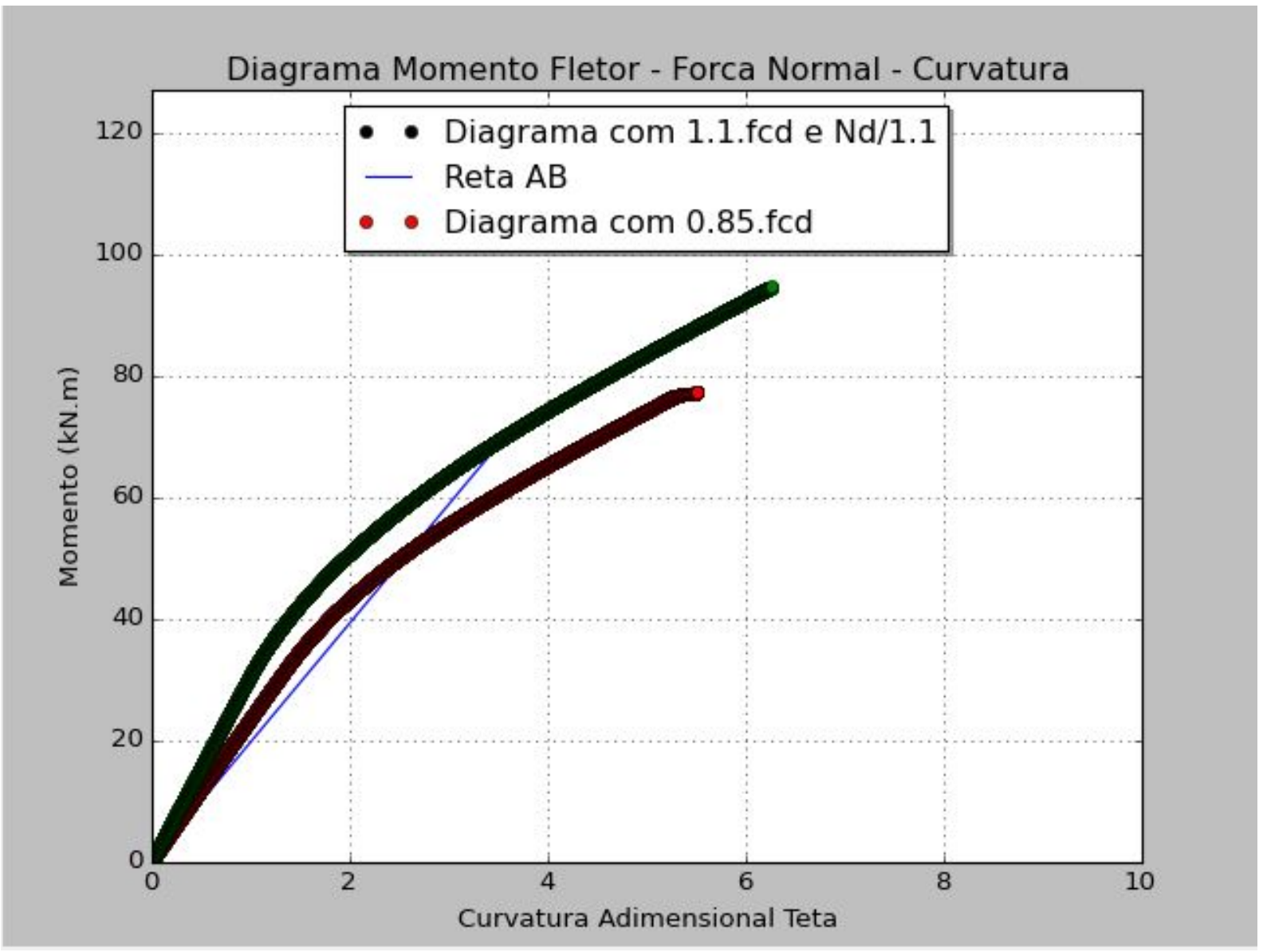

Fonte: Elaborado pelo Autor.

Como resultado do programa, obteve-se o parâmetro $E I_{s e c}$ relativo à tangente da reta $A B$ :

$$
E I_{s e c}=\frac{M_{R d} / \gamma_{f 3}}{1 / r_{c s}}=3716,35 \mathrm{kN} . \mathrm{m}^{2}
$$

A forma adimensional da rigidez secante é dada pela expressão 8.191:

$$
\kappa_{s e c}=\frac{E I_{s e c}}{b \cdot h^{3} \cdot f_{c d}}=\frac{M_{R d} / \gamma_{f 3}}{1 / r_{c s}} \cdot \frac{1}{b \cdot h^{3} \cdot f_{c d}}
$$




$$
\begin{gathered}
h=h_{x}=19 \mathrm{~cm}=0,19 \mathrm{~m} \text { é a altura da seção na direção analisada; } \\
b=h_{y}=50 \mathrm{~cm}=0,50 \mathrm{~m} \text { é a largura da seção na direção analisada; } \\
f_{c d}=\frac{2,5}{1,4}=1,785714 \mathrm{kN} / \mathrm{cm}^{2}=17857,14 \mathrm{kN} / \mathrm{m}^{2} \\
\kappa_{s e c}=\frac{E I_{s e c}}{b \cdot h^{3} \cdot f_{c d}}=\frac{3716,3464}{0,5 \cdot 0,19^{3} \cdot 17857,14}=60,68
\end{gathered}
$$

O parâmetro $\kappa_{\text {sec }}$ representa as características da seção, sendo utilizado para calcular o momento fletor total de uma seção crítica em análise, e sua expressão quando utilizado o parâmetro $\gamma_{f 3}=1,1$ é dada por:

$$
M_{S d, t o t}=\frac{\alpha_{b} \cdot M_{1 d, A}}{1-\frac{\lambda^{2}}{120 \cdot 1,1 \cdot \kappa_{s e c} / v}} \geq M_{1 d, A}
$$

Dessa forma, pode-se obter o momento fletor solicitante total na seção intermediária do lance do pilar com:

$$
\begin{aligned}
& \alpha_{b x}=1,0 \\
& M_{1 d, A}=1,4 \cdot 16,84=23,58 \mathrm{kN} \cdot \mathrm{m} \\
& \lambda_{x}=80,0 \\
& v=\frac{N_{d}}{A_{c} \cdot f_{c d}}=\frac{1203}{19 \cdot 50 \cdot \frac{2,5}{1,4}}=0,709 . \\
& M_{S d, t o t}=\frac{1,0 \cdot 23,58}{1-\frac{80,0^{2}}{120 \cdot 1,1 \cdot 60,68 / 0,709}}=54,39 \mathrm{kN} \cdot \mathrm{m} \geq M_{1 d, A}=23,58 \mathrm{kN} \cdot \mathrm{m} \\
& \therefore M_{d, t o t, x}=54,39 \mathrm{kN} \cdot \mathrm{m}
\end{aligned}
$$

Para determinação das envoltórias solicitantes calcula-se o momento mínimo com segunda ordem $\left(M_{d, t o t, \min }\right)$ :

$$
\begin{aligned}
& \alpha_{b x}=0,4 ; \\
& M_{1 d x, \min }=24,90 \mathrm{kN} . \mathrm{m} \text { (momento mínimo); }
\end{aligned}
$$




$$
\begin{aligned}
& \lambda_{x}=80,0 \\
& \quad v=\frac{N_{d}}{A_{c} \cdot f_{c d}}=\frac{1203}{19 \cdot 50 \cdot \frac{2,5}{1,4}}=0,709 . \\
& M_{S d, t o t, \text { min }}=\frac{1,0 \cdot 24,90}{1-\frac{80,0^{2}}{120 \cdot 1,1 \cdot 60,68 / 0,709}}=57,44 \mathrm{kN} . \mathrm{m} \geq M_{1 d x, \text { min }} \\
& \quad M_{S d, t o t, \text { min }} \geq M_{1 x, \text { min }}=24,90 \mathrm{kN} . \mathrm{m} \therefore M_{S d, t o t, \text { min }}=57,44 \mathrm{kN} . \mathrm{m}
\end{aligned}
$$

\section{- Direção y}

Os efeitos de $2^{\mathrm{a}}$ ordem na direção y não são computados, já que $\lambda_{1 y}>\lambda_{\mathrm{y}}$. Portanto, não é necessário o cálculo dos efeitos de 2 a ordem, o que significa que pode ser adotado, para o momento fletor total $\left(M_{d, t o t}\right)$, o momento fletor de 1 a $\operatorname{ordem}\left(M_{1 d, A}\right)$, e para o momento total mínimo $\left(M_{d, t o t, m i ́ n}\right)$, o momento mínimo $\left(M_{1 d, m i n}\right)$.

Para a construção da envoltória resistente, deve-se, entretanto, determinar o momento fletor resistente no eixo y. Com a distribuição da armadura na direção y da seção (cinco linhas de armadura com $A_{s} / 5=6,28 \mathrm{~cm}^{2}$ ), indicada na figura 8.45, determina-se o diagrama momento fletor - força normal - curvatura (figura 8.46). 
Figura 8.45 - Distribuição da armadura na direção y
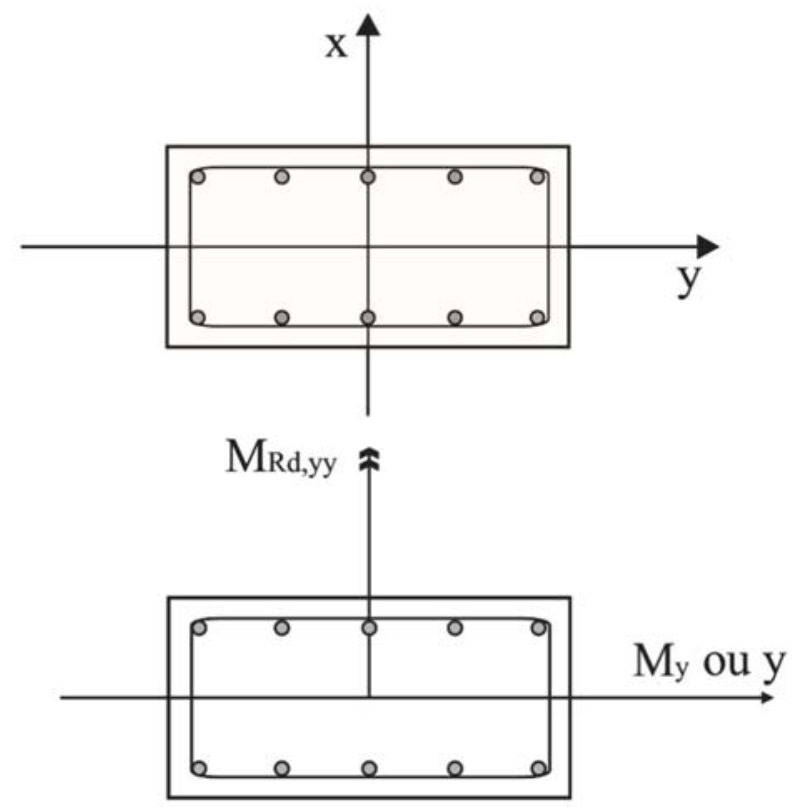

Fonte: Elaborado pelo Autor.

Figura 8.46 - Diagrama momento fletor - força normal - curvatura (eixo y)

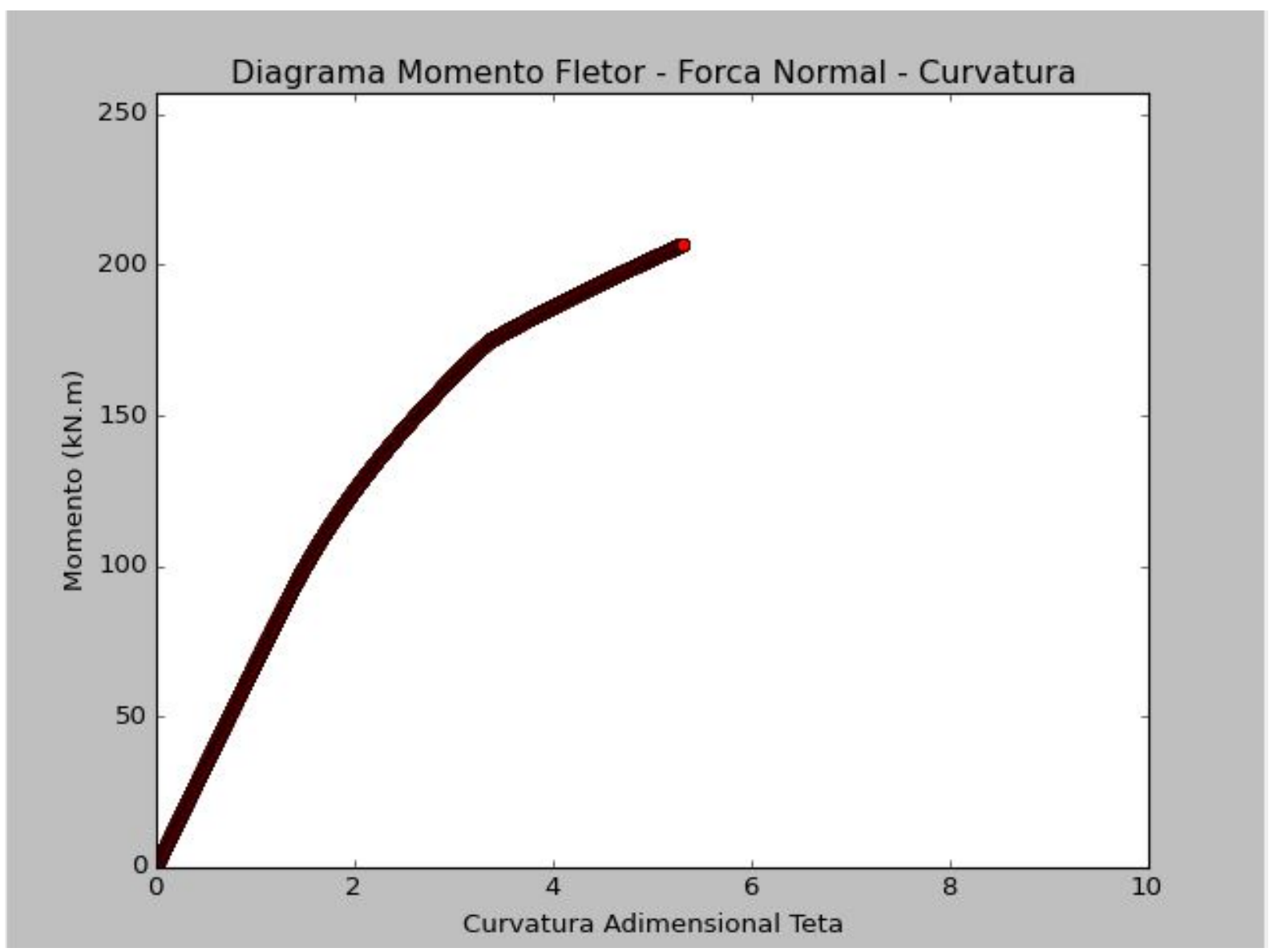

Fonte: Elaborado pelo Autor. 
Determinou-se com precisão o momento fletor resistente no eixo y, cujo valor é:

$$
M_{R d, y y}=207,05 \mathrm{kN} . \mathrm{m}
$$

\subsubsection{Envoltórias}

Com os momentos fletores obtidos, a expressão da envoltória resistente da armadura de dez barras de $20 \mathrm{~mm}$ é:

$$
\left(\frac{M_{R d, x}}{77,24}\right)^{1,2}+\left(\frac{M_{R d, y}}{207,05}\right)^{1,2}=1
$$

As envoltórias de momento mínimo e de momento mínimo com $2^{\mathrm{a}}$ ordem são dadas pelas equações a seguir, respectivamente:

$$
\begin{aligned}
& \left(\frac{M_{1 d, \text { mín }, x}}{M_{1, \text { mín }, x x}}\right)^{2}+\left(\frac{M_{1 d, \text { mín }, y}}{M_{1 d, \text { mín,yy }}}\right)^{2}=1 \rightarrow\left(\frac{M_{d, t o t, x}}{24,90}\right)^{2}+\left(\frac{M_{d, t o t, y}}{36,09}\right)^{2}=1 \\
& \left(\frac{M_{d, m i n, t o t, x}}{M_{d, m i n, t o t, x x}}\right)^{2}+\left(\frac{M_{d, m i n, t o t, y}}{M_{d, m i n, t o t, y y}}\right)^{2}=1 \rightarrow\left(\frac{M_{d, t o t, x}}{57,44}\right)^{2}+\left(\frac{M_{d, t o t, y}}{36,09}\right)^{2}=1
\end{aligned}
$$

Dessa forma, traçou-se a envoltória resistente e a envoltória mínima. Também estão indicados os pontos referentes aos momentos fletores solicitantes nas seções de topo, base e intermediária do pilar, cujas coordenadas estão indicadas na Tabela 8.9 .

Tabela 8.9 - Momentos fletores solicitantes no pilar P01

\begin{tabular}{ccc}
\hline Seção & $\mathrm{M}_{\mathrm{x}, \text { tot }}$ & $\mathrm{M}_{\mathrm{y}, \text { tot }}$ \\
& $(\mathrm{kN} \cdot \mathrm{m})$ & $(\mathrm{kN} . \mathrm{m})$ \\
\hline Topo & 23,58 & 47,10 \\
Base & $-11,79$ & $-23,55$ \\
Intermediária & 54,39 & 36,09 \\
\hline
\end{tabular}

Fonte: Elaborado pelo Autor. 
Figura 8.47 - Envoltória resistente, envoltórias mínimas e solicitações do pilar P01

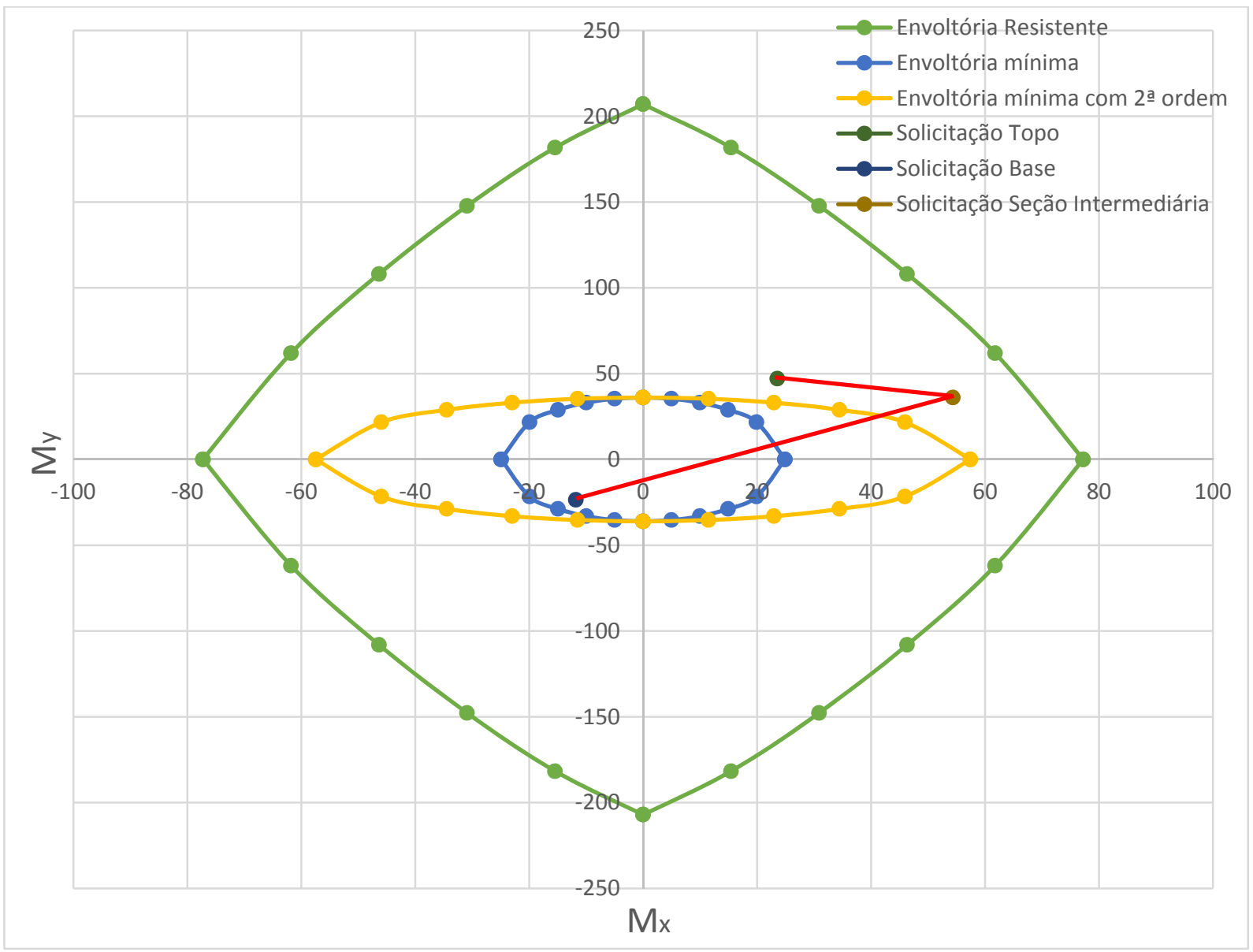

Fonte: Elaborado pelo Autor.

Verificando a segurança por meio do cálculo analítico:

$$
\begin{aligned}
& \left(\frac{M_{S d, x}}{M_{R d, x x}}\right)^{\alpha}+\left(\frac{M_{S d, y}}{M_{R d, y y}}\right)^{\alpha} \leq 1 \\
& \left(\frac{M_{S d, x}}{77,24}\right)^{1,2}+\left(\frac{M_{S d, y}}{207,05}\right)^{1,2} \leq 1 \\
& \left(\frac{54,39}{77,24}\right)^{1,2}+\left(\frac{36,09}{207,05}\right)^{1,2}=0,780 \leq 1
\end{aligned}
$$

Portanto, como a envoltória resistente ultrapassa o momento fletor solicitante da seção crítica (seção intermediária), a armadura da seção está verificada. 
Verifica-se que ainda é possível diminuir a armadura da seção, de forma que o processo de dimensionamento seja iterativo até a busca da armadura que produza esforços próximos da envoltória resistente.

Dessa forma, em busca da armadura que produza o dimensionamento mais eficaz, adotam-se como nova armadura oito barras de $20 \mathrm{~mm}\left(A_{s}=25,13 \mathrm{~cm}^{2}\right)$.

\subsubsection{Nova armadura (oito barras de $20 \mathrm{~mm}$ )}

Para a nova armadura adotada têm-se quatro linhas de armadura distribuídas na altura $h_{y}$ como demonstrado na figura 8.48.

Figura 8.48 - Seção pré-definida

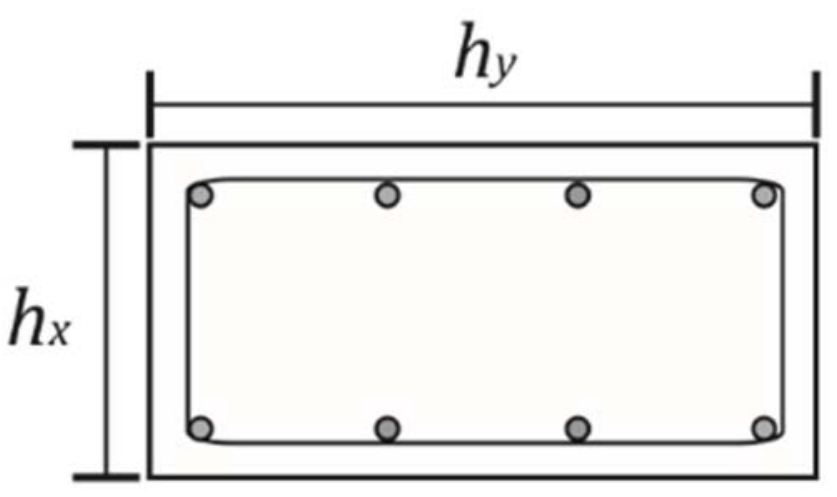

Fonte: Elaborado pelo Autor.

Deve-se verificar se a seção adotada atende aos requisitos de espaçamentos mínimo e máximo das barras longitudinais. Assim, calculando-se o espaçamento das barras na direção de $h_{x}$ (direção x), têm-se:

$$
a_{x}=h_{x}-2 \cdot d^{\prime} \rightarrow a_{x}=19-2 \cdot 4,63=9,74 \mathrm{~cm}
$$

E na direção de $h_{y}$ (direção y):

$$
a_{y}=\frac{h_{y}-2 \cdot d^{\prime}}{3} \rightarrow a_{y}=\frac{50-2 \cdot 4,63}{3}=13,58 \mathrm{~cm}
$$


Para o espaçamento mínimo, $a_{x}$ e $a_{y}$ devem ser iguais ou superiores a (o agregado graúdo considerado é a brita 2, com $\phi_{\max }=25 \mathrm{~mm}=2,5 \mathrm{~cm}$ ):

$-2 \mathrm{~cm}$

- diâmetro da barra: $\phi_{l}=20 \mathrm{~mm}=2 \mathrm{~cm}$;

- 1,2 vez a dimensão máxima característica do agregado graúdo: $1,2 \cdot \phi_{\max }=1,2 \cdot 2,5 \mathrm{~cm}=3 \mathrm{~cm}$.

Considerando o maior valor $(3 \mathrm{~cm})$, para se obter a distância mínima entre eixos das barras deve-se somar $\phi_{l}=2 \mathrm{~cm}$, resultando $5 \mathrm{~cm}$.

Portanto os espaçamentos $a_{x}=9,74 \mathrm{~cm}$ e $a_{y}=13,58 \mathrm{~cm}$ atendem aos requisitos de espaçamento mínimo.

Para o espaçamento máximo, $a_{x}$ e $a_{y}$ devem ser menores ou iguais a duas vezes a menor dimensão da seção no trecho considerado, sem exceder $40 \mathrm{~cm}$ :

$$
-2 \cdot h_{x}<40 \mathrm{~cm} \rightarrow 2 \cdot 19=38 \mathrm{~cm}<40 \mathrm{~cm} .
$$

Portanto os espaçamentos $a_{x}=9,74 \mathrm{~cm}$ e $a_{y}=13,58 \mathrm{~cm}$ atendem também aos requisitos de espaçamento máximo.

\section{- Direção x}

Com a distribuição da armadura na direção x indicada na figura 8.49 (duas linhas de barras com $A_{S} / 2=12,56 \mathrm{~cm}^{2}$ ), determina-se o diagrama momento fletor força normal - curvatura relativo à figura 8.50 . 
Figura 8.49 - Distribuição da armadura na direção x
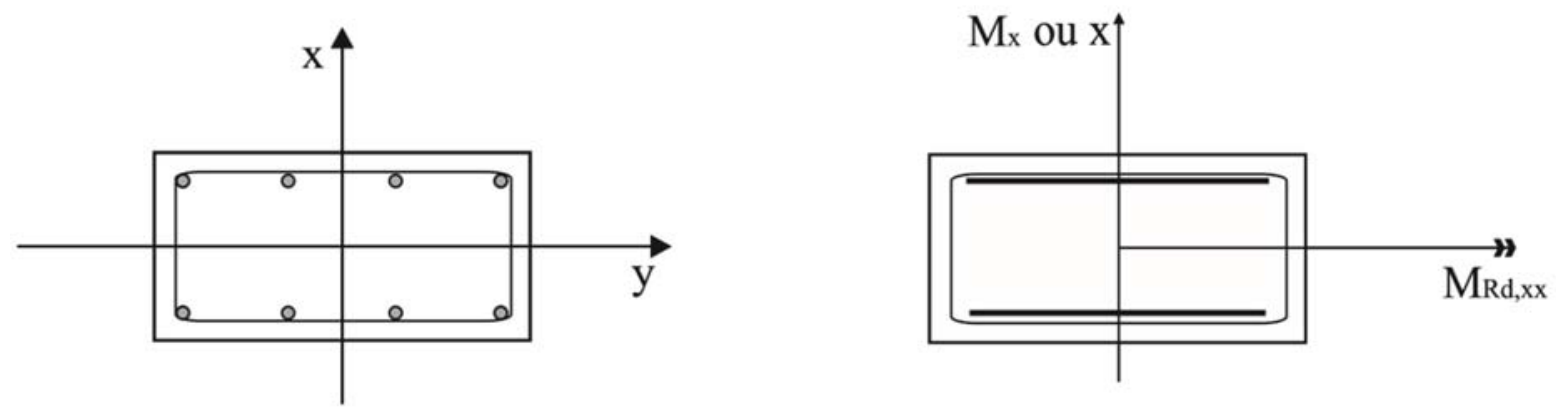

Fonte: Elaborado pelo Autor.

Figura 8.50 - Diagrama momento fletor - força normal - curvatura (eixo x)

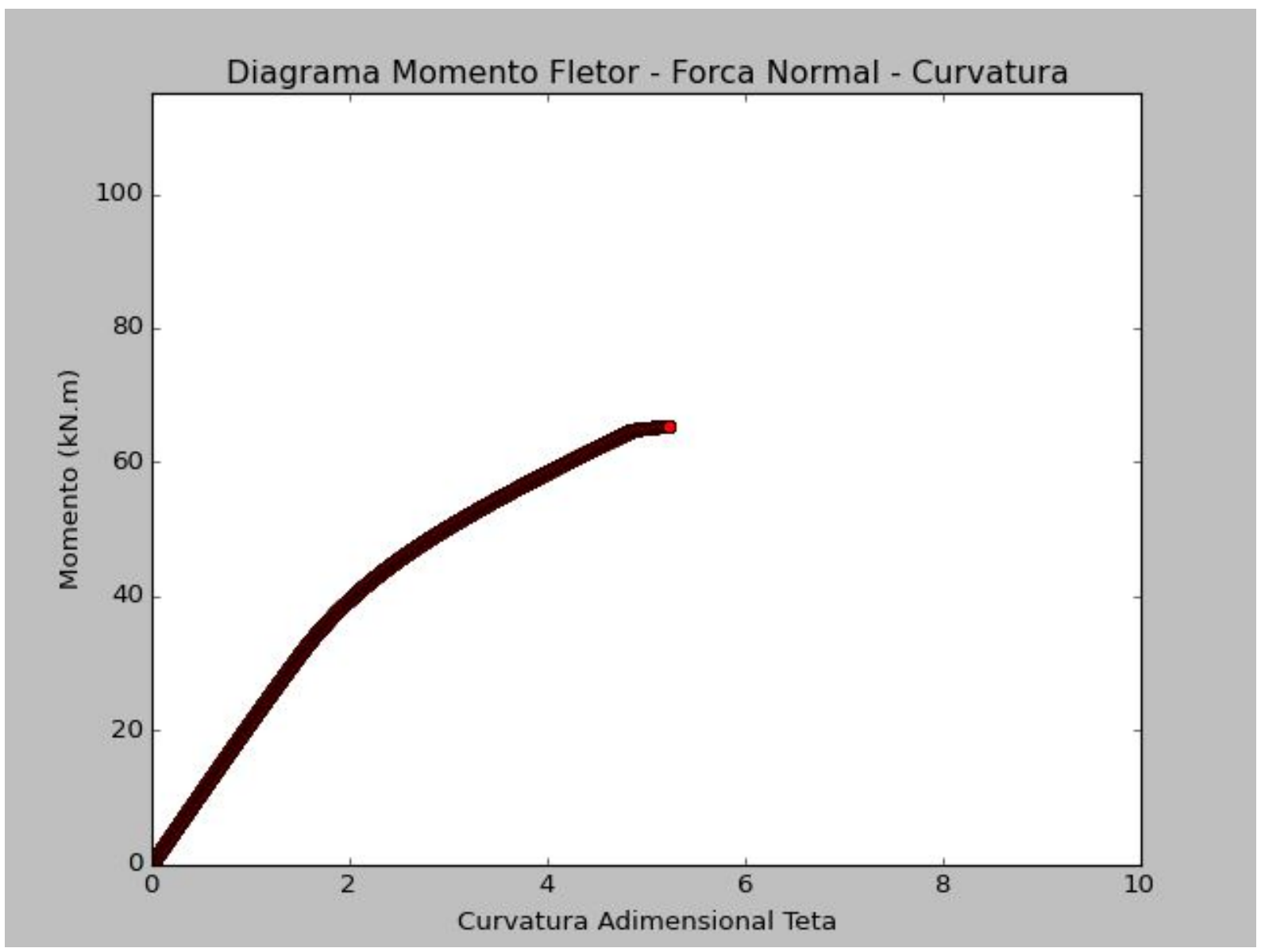

Fonte: Elaborado pelo Autor.

Determinou-se com precisão o momento fletor resistente no eixo $\mathrm{x}$, cujo valor é:

$$
M_{R d, x x}=65,50 k N . m
$$


Em seguida deve-se construir uma nova curva, obtida com $1,10 \cdot f_{c d}$ e $N_{R d} / \gamma_{f 3}$. Com essa curva é efetuada a linearização, com a determinação da reta que liga a origem ao ponto correspondente ao momento fletor resistente dividido por $\gamma_{f 3}$ $\left(M_{R d} / \gamma_{f 3}\right)$.

Figura 8.51 - Linearização do diagrama momento fletor - força normal - curvatura (eixo x)

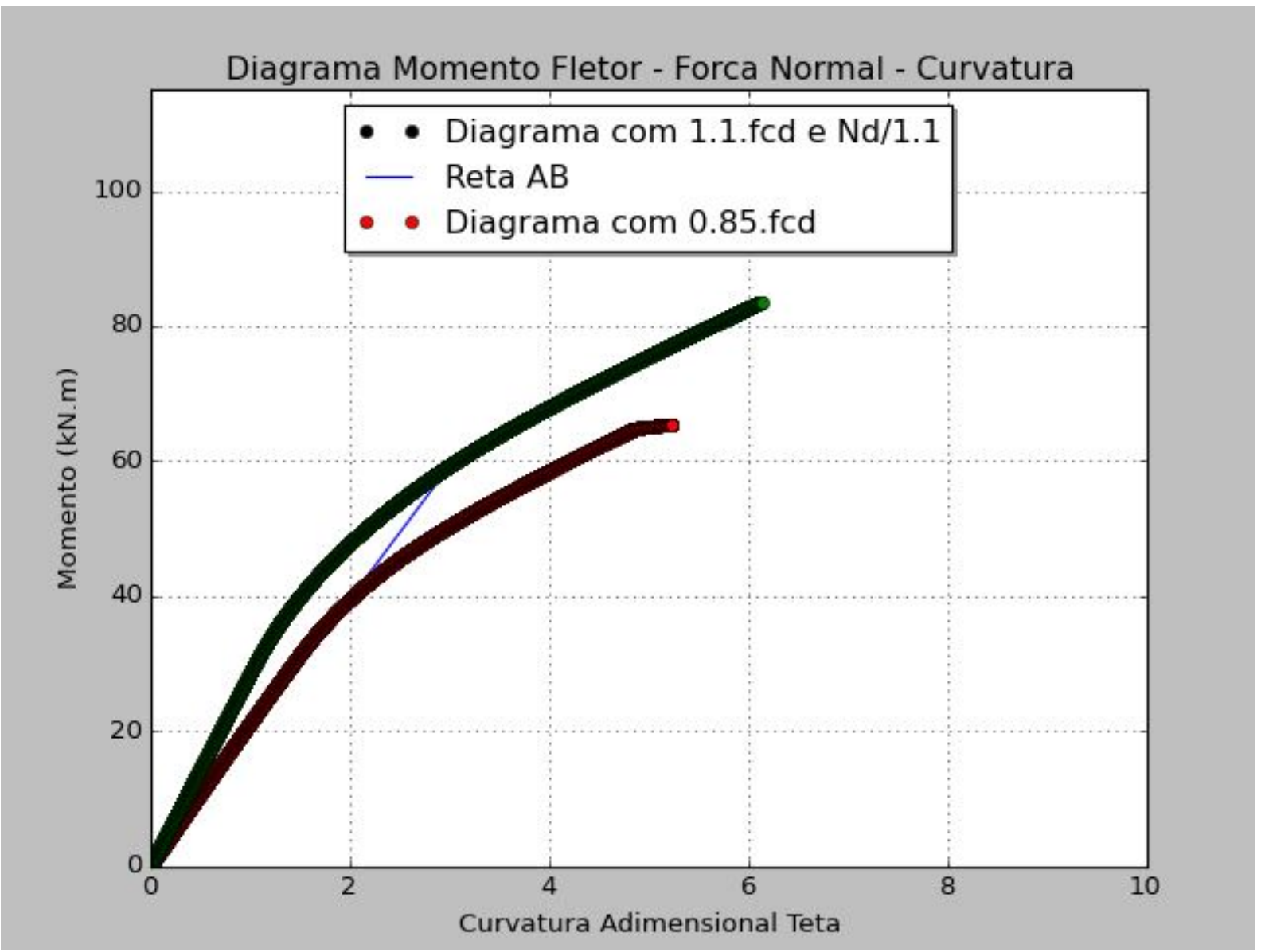

Fonte: Elaborado pelo Autor.

Como resultado do programa, obteve-se o parâmetro $E I_{s e c}$ relativo à tangente da reta $A B$ :

$$
E I_{s e c}=\frac{M_{R d} / \gamma_{f 3}}{1 / r_{c s}}=3742,44 k N . m^{2}
$$

A forma adimensional da rigidez secante é dada pela expressão 8.209:

$$
\kappa_{s e c}=\frac{E I_{s e c}}{b \cdot h^{3} \cdot f_{c d}}=\frac{M_{R d} / \gamma_{f 3}}{1 / r_{c s}} \cdot \frac{1}{b \cdot h^{3} \cdot f_{c d}}
$$


$h=h_{x}=19 \mathrm{~cm}=0,19 \mathrm{~m}$ é a altura da seção na direção analisada;

$b=h_{y}=50 \mathrm{~cm}=0,50 \mathrm{~m}$ é a largura da seção na direção analisada;

$f_{c d}=\frac{2,5}{1,4}=1,785714 \mathrm{kN} / \mathrm{cm}^{2}=17857,14 \mathrm{kN} / \mathrm{m}^{2}$.

$$
\kappa_{s e c}=\frac{E I_{\text {sec }}}{b \cdot h^{3} \cdot f_{c d}}=\frac{3742,4430}{0,5 \cdot 0,19^{3} \cdot 17857,14}=61,11
$$

O parâmetro $\kappa_{\text {sec }}$ representa as características da seção, sendo utilizado para calcular o momento fletor total de uma seção crítica em análise, e sua expressão quando utilizado o parâmetro $\gamma_{f 3}=1,1$ é dada por:

$$
M_{S d, t o t}=\frac{\alpha_{b} \cdot M_{1 d, A}}{1-\frac{\lambda^{2}}{120 \cdot 1,1 \cdot{ }^{\kappa_{s e c} / v}}} \geq M_{1 d, A}
$$

Dessa forma, pode-se obter o momento fletor solicitante total na seção intermediária do lance do pilar com:

$$
\begin{aligned}
& \alpha_{b x}=1,0 ; \\
& M_{1 d, A}=23,58 \mathrm{kN} . \mathrm{m} ; \\
& \lambda_{x}=80,0 ; \\
& v=\frac{N_{d}}{A_{c} \cdot f_{c d}}=\frac{1203}{19 \cdot 50 \cdot \frac{2,5}{1,4}}=0,709 . \\
& M_{S d, t o t}=\frac{1,0 \cdot 23,58}{1-\frac{80,0^{2}}{120 \cdot 1,1 \cdot 61,11 / 0,709}}=53,90 \mathrm{kN} \cdot \mathrm{m} \geq M_{1 d, A}=23,58 \mathrm{kN} \cdot \mathrm{m} \\
& \therefore M_{d, t o t, x}=53,90 \mathrm{kN} \cdot \mathrm{m}
\end{aligned}
$$

Para determinação das envoltórias solicitantes calcula-se o momento mínimo com segunda ordem $\left(M_{d, t o t, \min }\right)$ : 


$$
\begin{aligned}
& \alpha_{b x}=0,4 ; \\
& M_{1 d x, \min }=24,90 \mathrm{kN} . \mathrm{m} \text { (momento mínimo); } \\
& \lambda_{x}=80,0 \text {; } \\
& v=\frac{N_{d}}{A_{c} \cdot f_{c d}}=\frac{1203}{19 \cdot 50 \cdot \frac{2,5}{1,4}}=0,709 \text {. } \\
& M_{S d, t o t, \min }=\frac{1,0 \cdot 24,90}{1-\frac{80,0^{2}}{120 \cdot 1,1 \cdot 61,11 / 0,709}}=56,92 \mathrm{kN} \cdot \mathrm{m} \geq M_{1 d x, \min } \\
& M_{S d, t o t, \min } \geq M_{1 d x, \min }=24,90 \mathrm{kN} . \mathrm{m} \therefore M_{S d, t o t, \min }=56,92 \mathrm{kN} \cdot \mathrm{m}
\end{aligned}
$$

- Direção y

Os efeitos de $2^{a}$ ordem na direção y não são computados, já que $\lambda_{1 y}>\lambda_{y}$. Portanto, não é necessário o cálculo dos efeitos de 2a ordem, o que significa que pode ser adotado, para o momento fletor total $\left(M_{d, t o t}\right)$, o momento fletor de 1 a ordem $\left(M_{1 d, A}\right)$, e para o momento total mínimo $\left(M_{d, t o t, m i ́ n}\right)$, o momento mínimo $\left(M_{1 d, m i ́ n}\right)$.

Entretanto, para a construção da envoltória resistente, deve-se determinar o momento fletor resistente no eixo y. Assim, obtém-se o diagrama momento fletor força normal - curvatura (figura 8.53) referente à distribuição de armadura na direção y (quatro linhas de armadura com $A_{s} / 4=6,28 \mathrm{~cm}^{2}$ ), como indicado na figura 8.52 . 
Figura 8.52 - Distribuição da armadura na direção y
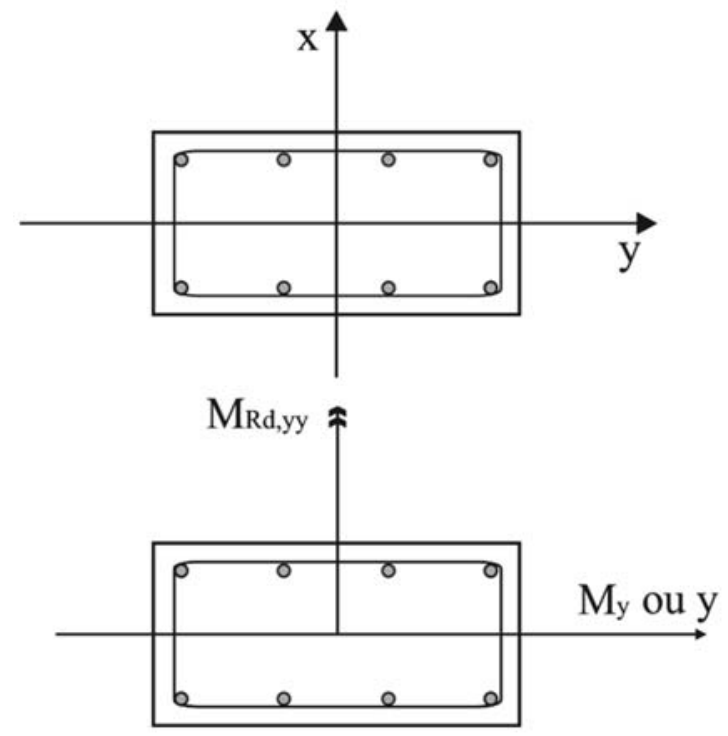

Fonte: Elaborado pelo Autor.

Figura 8.53 - Diagrama momento fletor - força normal - curvatura (eixo y)

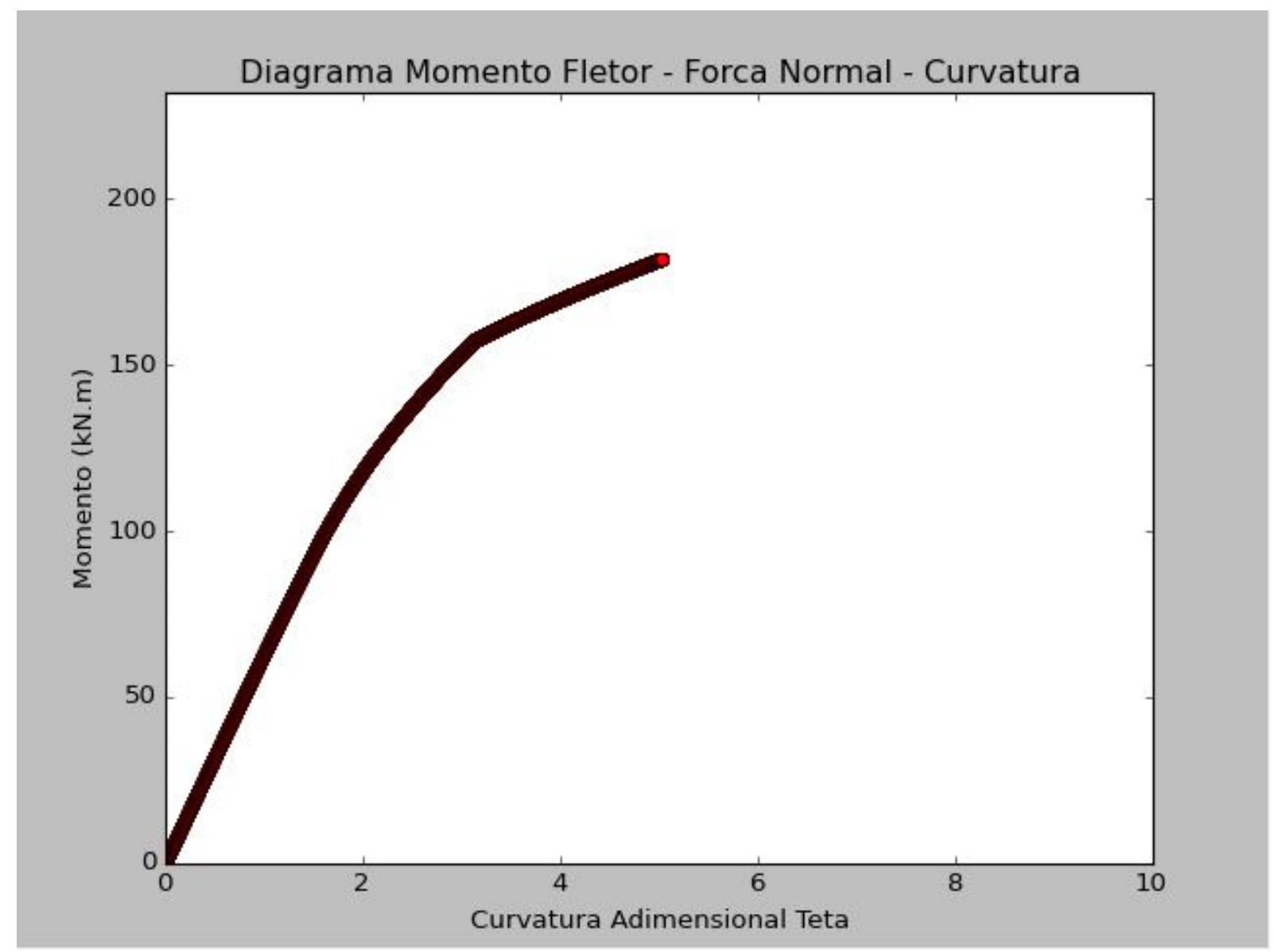

Fonte: Elaborado pelo Autor. 
Determinou-se com precisão o momento fletor resistente no eixo y, cujo valor é:

$$
M_{R d, y y}=182,16 \mathrm{kN} . \mathrm{m}
$$

\subsubsection{Envoltórias}

Com os momentos fletores obtidos, a expressão da envoltória resistente da armadura de oito barras de $20 \mathrm{~mm}$ é:

$$
\left(\frac{M_{R d, x}}{65,50}\right)^{1,2}+\left(\frac{M_{R d, y}}{182,16}\right)^{1,2}=1
$$

As envoltórias de momento mínimo e de momento mínimo com $2^{\mathrm{a}}$ ordem são dadas pelas equações a seguir, respectivamente:

$$
\begin{aligned}
& \left(\frac{M_{1 d, \text { mín }, x}}{M_{1, \text { mín }, x x}}\right)^{2}+\left(\frac{M_{1 d, \text { mín }, y}}{M_{1 d, \text { mín,yy }}}\right)^{2}=1 \rightarrow\left(\frac{M_{d, t o t, x}}{24,90}\right)^{2}+\left(\frac{M_{d, t o t, y}}{36,09}\right)^{2}=1 \\
& \left(\frac{M_{d, m i n, t o t, x}}{M_{d, m i ́ n, t o t, x x}}\right)^{2}+\left(\frac{M_{d, m i ́ n, t o t, y}}{M_{d, m i ́ n, t o t, y y}}\right)^{2}=1 \rightarrow\left(\frac{M_{d, t o t, x}}{56,92}\right)^{2}+\left(\frac{M_{d, t o t, y}}{36,09}\right)^{2}=1
\end{aligned}
$$

Dessa forma, traçou-se a envoltória resistente e a envoltória mínima. Também estão indicados os pontos referentes aos momentos fletores solicitantes nas seções de topo, base e intermediária do pilar, cujas coordenadas estão indicadas na Tabela 8.10 .

Tabela 8.10 - Momentos fletores solicitantes no pilar P01

\begin{tabular}{ccc}
\hline Seção & $\mathrm{M}_{\mathrm{x}, \text { tot }}$ & $\mathrm{M}_{\mathrm{y}, \text { tot }}$ \\
& $(\mathrm{kN} . \mathrm{m})$ & $(\mathrm{kN} . \mathrm{m})$ \\
\hline Topo & 23,58 & 47,10 \\
Base & $-11,79$ & $-23,55$ \\
Intermediária & 53,90 & 36,09 \\
\hline
\end{tabular}

Fonte: Elaborado pelo Autor. 
Figura 8.54 - Envoltória resistente, envoltórias mínimas e solicitações do pilar P01

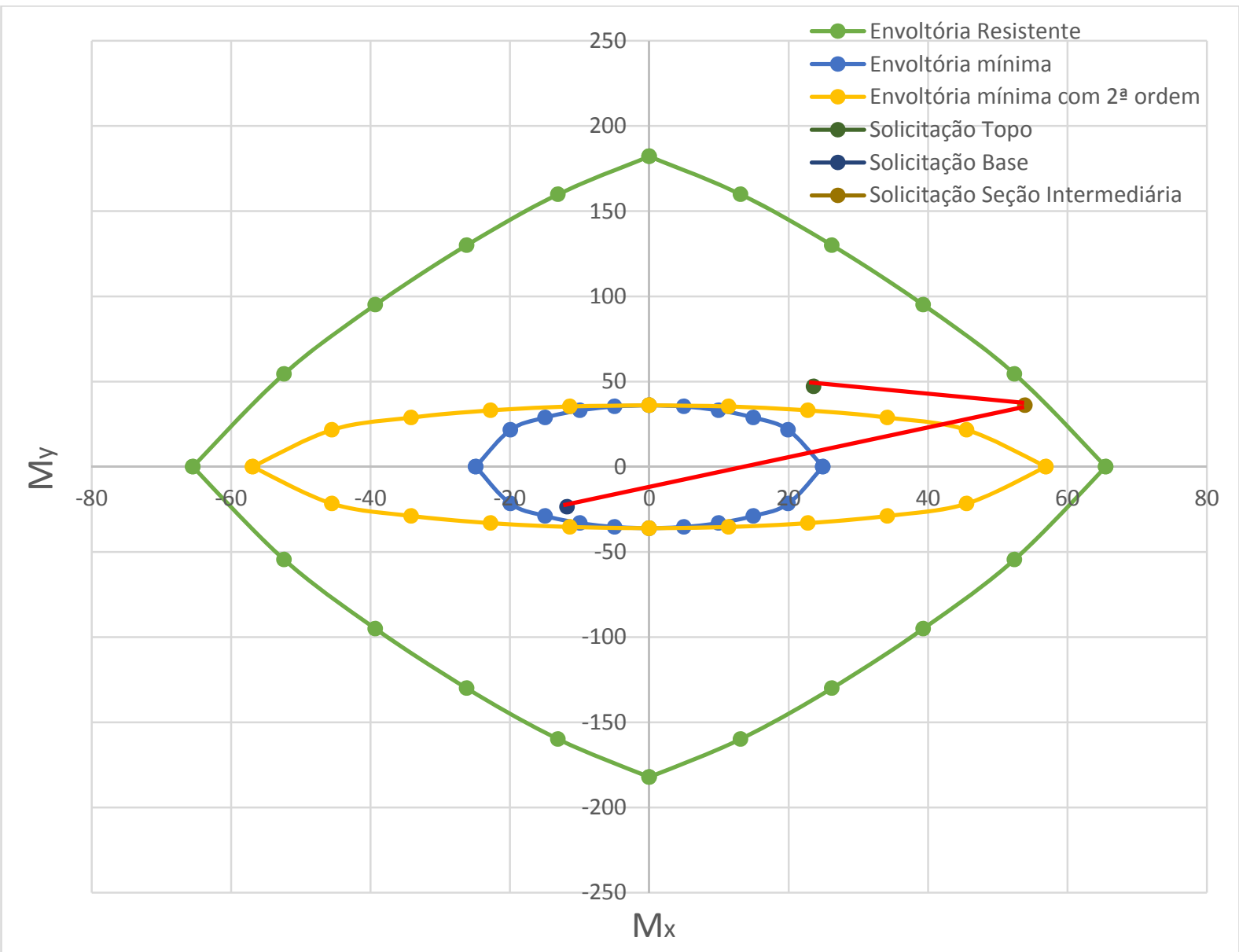

Fonte: Elaborado pelo Autor.

Nessa figura, nota-se que o ponto de solicitação na seção intermediária fica próximo da envoltória resistente. A verificação da segurança também pode ser feita por meio do cálculo analítico:

$$
\begin{aligned}
& \left(\frac{M_{S d, x}}{M_{R d, x x}}\right)^{\alpha}+\left(\frac{M_{S d, y}}{M_{R d, y y}}\right)^{\alpha} \leq 1 \\
& \left(\frac{M_{S d, x}}{65,50}\right)^{1,2}+\left(\frac{M_{S d, y}}{182,16}\right)^{1,2} \leq 1 \\
& \left(\frac{53,90}{65,50}\right)^{1,2}+\left(\frac{36,09}{182,16}\right)^{1,2}=0,935 \leq 1
\end{aligned}
$$


Portanto, como a envoltória resistente ultrapassa os momentos fletores solicitantes nas seções críticas, a armadura da seção está verificada.

\subsubsection{Verificação da excentricidade acidental}

No caso da excentricidade acidental, não há os conceitos de envoltórias mínimas e de momento mínimo. Assim, a consideração das imperfeições geométricas locais é feita com a adição de uma excentricidade acidental às excentricidades solicitantes na seção intermediária do pilar.

Novamente destaca-se que a ABNT NBR 6118:2014 não apresenta as diretrizes para a computação da excentricidade acidental. Assim, neste trabalho, será efetuado uma sugestão de como essas excentricidades devem ser consideradas no dimensionamento.

Para a verificação da excentricidade acidental será utilizada a armadura de dez barras de $20 \mathrm{~mm}$. Dessa forma, utilizando os itens 8.11 e 8.16.3, têm-se:

- Direção x

$e_{a x}=1,05 \mathrm{~cm}=0,0105 \mathrm{~m}$;

$M_{d, t o t, x}=54,39 \mathrm{kN} \cdot \mathrm{m}$;

$N_{d}=1203 k N$;

$M_{x, \text { tot,int }}=M_{d, t o t, x}+N_{d} \cdot e_{a x}=54,39+1203 \cdot 0,0105=67,02 \mathrm{kN} . \mathrm{m}$

- Direção y

$e_{a y}=1,08 \mathrm{~cm}=0,0108 \mathrm{~m}$

$M_{d, t o t, i n t}=\alpha_{b y} \cdot M_{1 d, A y}=0,4 \cdot 47,10=18,84 k N . m$

$N_{d}=1203 k N$

$M_{y, \text { tot,int }}=M_{d, \text { tot,int }}+N_{d} \cdot e_{a y}=18,84+1203 \cdot 0,0108=31,83 \mathrm{kN} \cdot \mathrm{m}$ 
Assim, os momentos fletores solicitantes no pilar são os indicados na Tabela 8.11 .

Tabela 8.11 - Momentos fletores solicitantes no pilar P01

\begin{tabular}{ccc}
\hline Seção & $M_{\text {x,tot }}$ & $M_{\mathrm{y}, \text { tot }}$ \\
& $(\mathrm{kN} . \mathrm{m})$ & $(\mathrm{kN} . \mathrm{m})$ \\
\hline Topo & 23,58 & 47,10 \\
Base & $-11,79$ & $-23,55$ \\
Intermediária & 67,02 & 31,83 \\
\hline
\end{tabular}

Fonte: Elaborado pelo Autor.

Utilizando a armadura de dez barras de $20 \mathrm{~mm}$, tem-se para a envoltória resistente a expressão:

$$
\left(\frac{M_{R d, x}}{77,24}\right)^{1,2}+\left(\frac{M_{R d, y}}{207,05}\right)^{1,2}=1
$$

Plotando os pontos de solicitações e da envoltória resistente tem-se a figura 8.55 . 
Figura 8.55 - Solicitações do pilar P01 (excentricidade acidental)

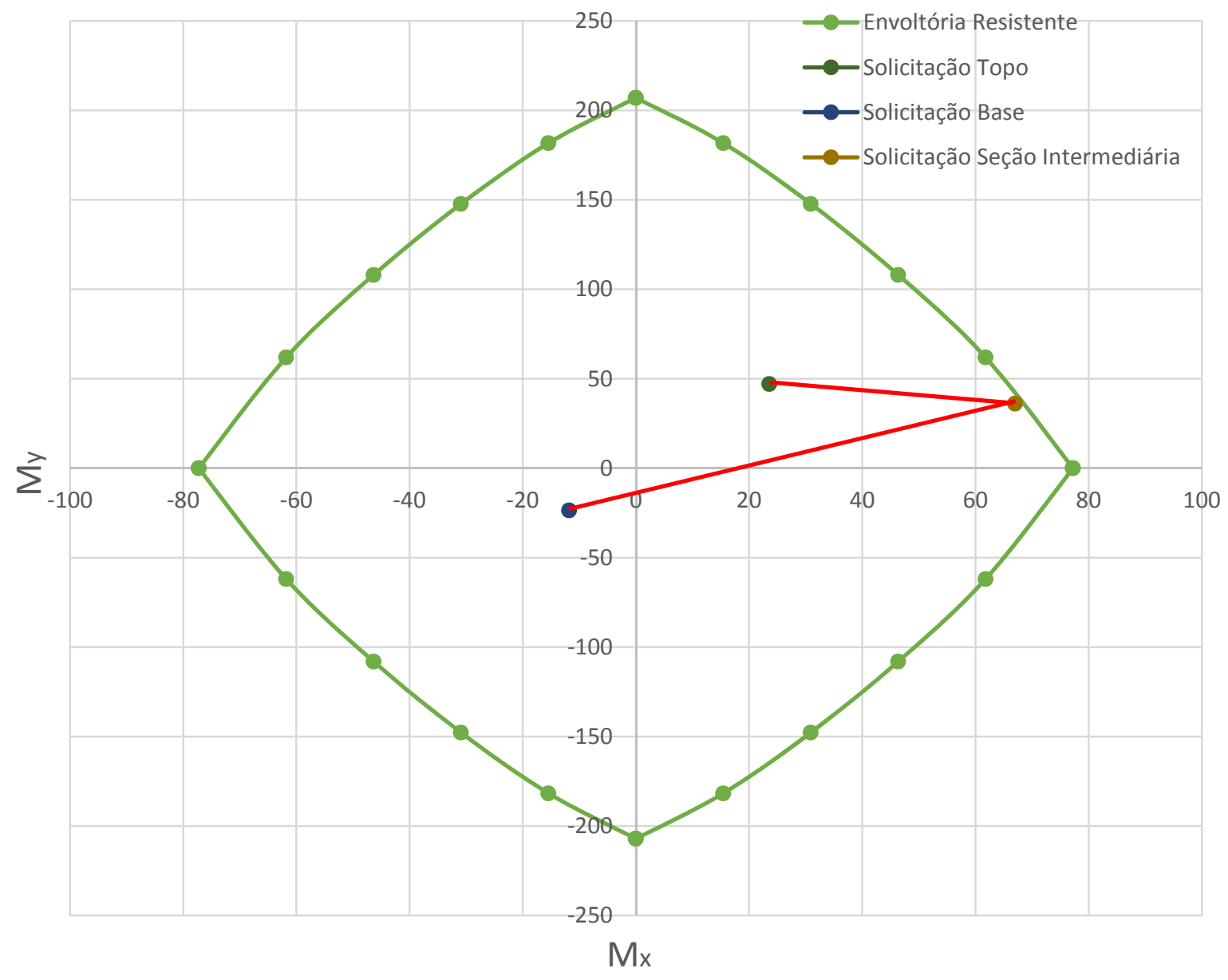

Fonte: Elaborado pelo Autor.

Como o ponto de solicitação intermediária tangencia a envoltória resistente, verifica-se a segurança por meio do cálculo analítico:

$$
\begin{aligned}
& \left(\frac{M_{S d, x}}{M_{R d, x x}}\right)^{\alpha}+\left(\frac{M_{S d, y}}{M_{R d, y y}}\right)^{\alpha} \leq 1 \\
& \left(\frac{M_{S d, x}}{77,24}\right)^{1,2}+\left(\frac{M_{S d, y}}{207,05}\right)^{1,2} \leq 1 \\
& \left(\frac{67,02}{77,24}\right)^{1,2}+\left(\frac{36,09}{207,05}\right)^{1,2}=0,966 \leq 1
\end{aligned}
$$

Portanto, como a envoltória resistente ultrapassa os momentos fletores solicitantes nas seções críticas, a armadura da seção está verificada. 


\subsection{MÉTODO GERAL}

A aplicação do método geral em uma flexão oblíqua é realizada através da análise do pilar nas duas direções separadamente, calculando os efeitos de $2^{\mathrm{a}}$ ordem e das imperfeições geométricas de forma isolada, e depois, ao final, é feita a composição dos esforços obtidos para o dimensionamento das armaduras através das envoltórias resistentes (KIMURA, 2010).

Pode-se dizer, portanto, que será realizada a análise de duas flexões compostas normais, que serão juntadas no final para o dimensionamento.

A utilização do método geral neste exemplo será realizada de maneira separada para as direções x e y, de forma que serão calculadas duas deformadas, uma para cada direção, utilizando para isso o processo de Engesser- Vianello, que utiliza a analogia de Mohr.

Como o processo do pilar-padrão acoplado a diagramas momento fletor - força normal - curvatura, o método geral é de verificação, sendo necessária, portanto, uma armadura pré-definida, para que se possa executar o processo.

A armadura pré-definida será de oito barras de $20 \mathrm{~mm}$, definida no item 8.16.4.

\section{- Direção x}

Para a direção x, o pilar será dividido em cinco elementos:

$$
\Delta x=\frac{\ell_{e x}}{5}=\frac{439}{5}=87,80 \mathrm{~cm}
$$

Com essas divisões, é necessário calcular os pesos elásticos correspondentes ao diagrama de momentos fletores do pilar. Com a teoria da Analogia de Mohr, verifica-se a necessidade da mudança das condições de apoio da viga análoga. Para os pesos elásticos é necessário que se aplique um carregamento de sentido contrário ao do diagrama de momentos fletores do pilar, como indicado na figura 8.56. 
Figura 8.56 - Analogia de Mohr - Pesos elásticos

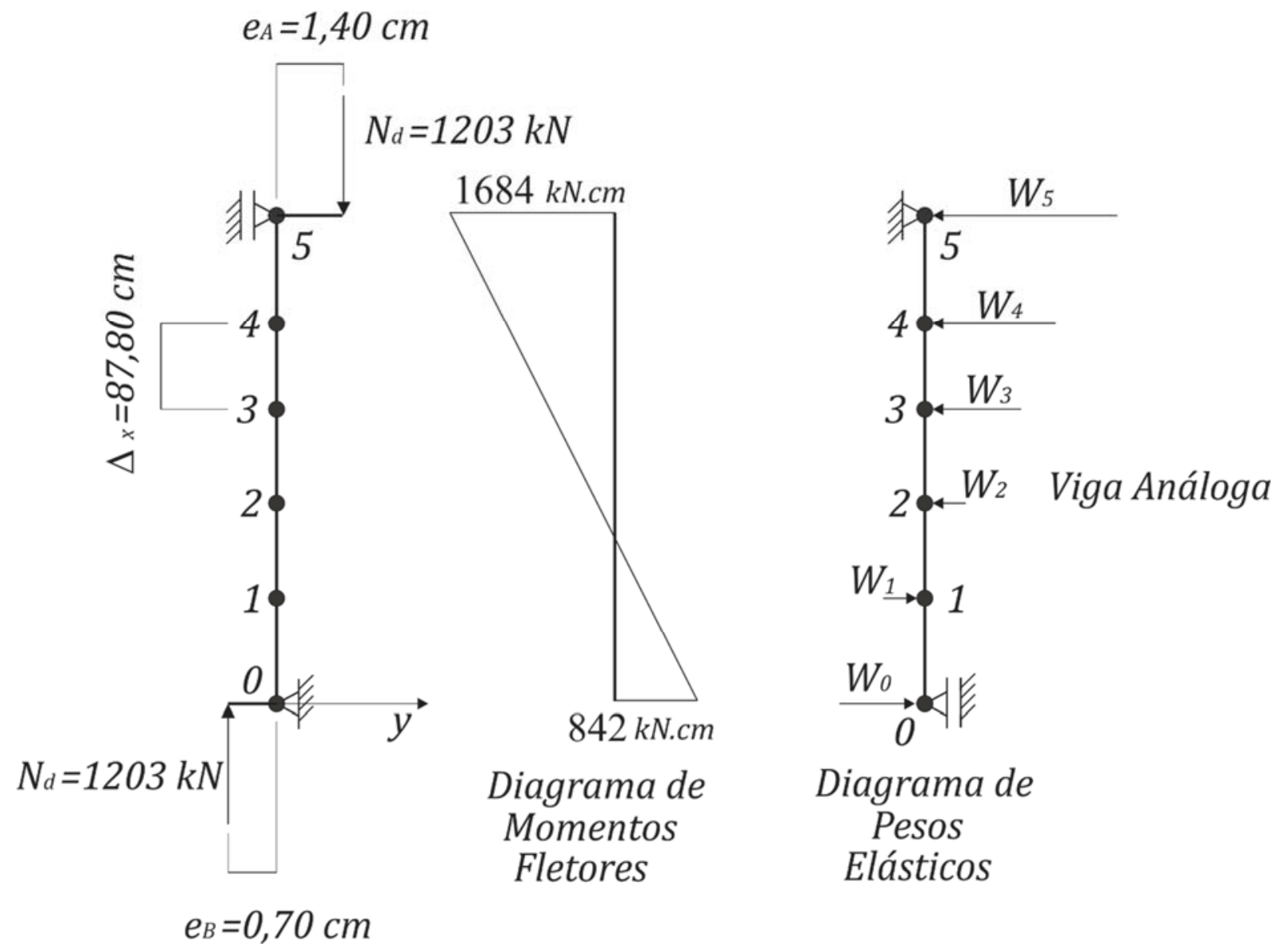

Fonte: Elaborado pelo Autor.

Na primeira iteração, apenas será considerado o momento fletor de $1^{\mathrm{a}}$ ordem. Deve-se, portanto, determinar os momentos fletores de cada seção (obtidos por meio de semelhança de triângulos) e sua respectiva curvatura no diagrama momento fletor - força normal - curvatura, presente na figura 8.57 . Os resultados estão indicados na tabela 8.12. 
Figura 8.57 - Diagrama momento fletor - força normal - curvatura (oito barras de $20 \mathrm{~mm}$ )

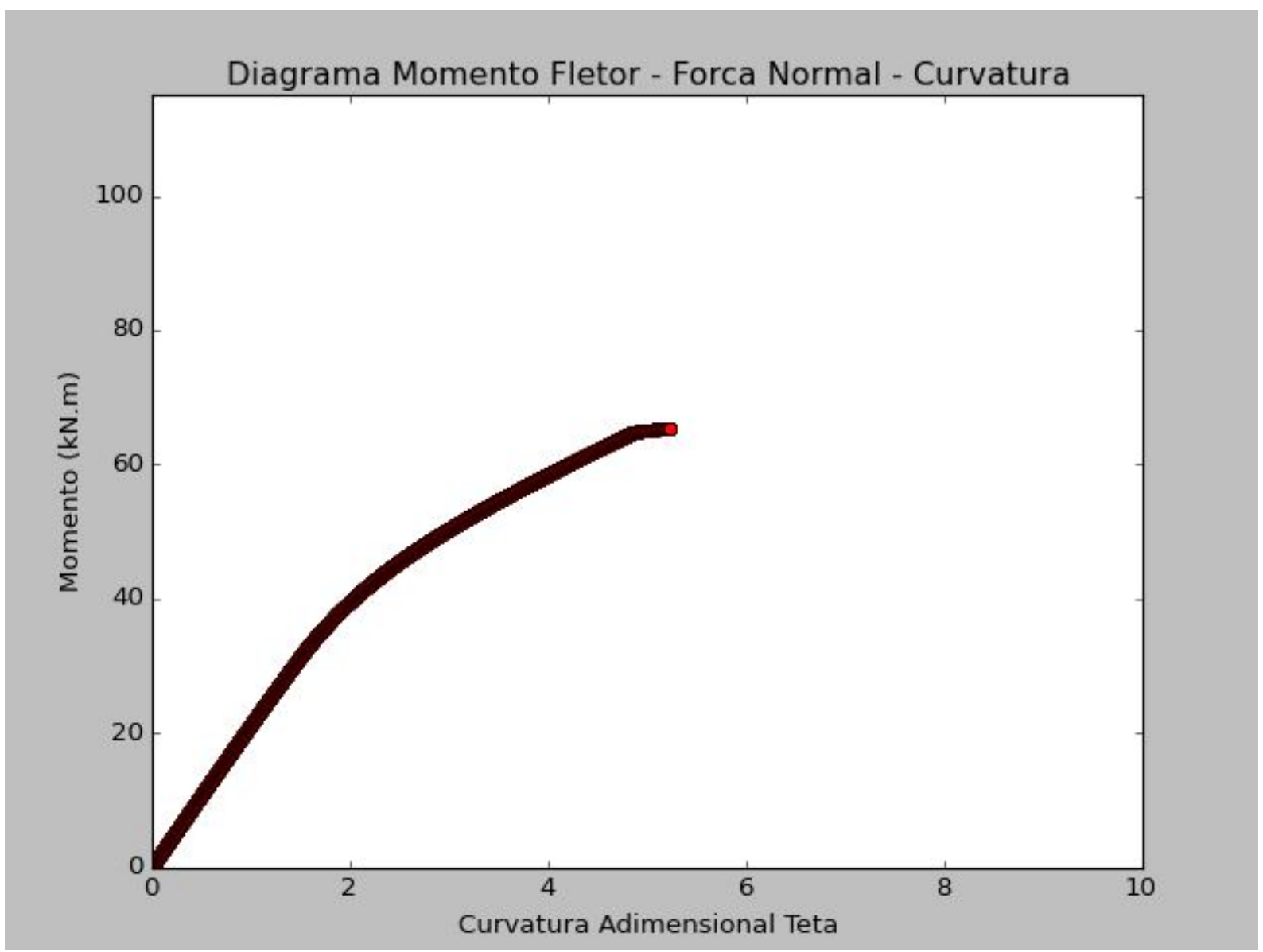

Fonte: Elaborado pelo Autor.

Deve-se transformar a curvatura adimensional em curvatura real:

$$
\frac{1}{r}=\frac{\theta}{1000 \cdot h}
$$


Tabela 8.12 - Subdivisões, momentos fletores e respectivas curvaturas

\begin{tabular}{ccccccc}
\hline Subdivisão & 0 & 1 & 2 & 3 & 4 & 5 \\
\hline $\begin{array}{c}\text { Momento } \\
\text { Fletor (kN.cm) }\end{array}$ & -842 & $-336,79$ & 168,42 & 673,61 & 1178,81 & 1684 \\
$\begin{array}{c}\text { Curvatura } \\
\text { Adimensional }\end{array}$ & 0,394 & 0,158 & 0,079 & 0,315 & 0,553 & 0,792 \\
$\begin{array}{c}\text { Curvatura } \\
(1 / \mathrm{cm})\end{array}$ & 0,02074 & 0,00831 & 0,00416 & 0,01658 & 0,02911 & 0,04168 \\
\hline
\end{tabular}

Fonte: Elaborado pelo Autor.

Com os valores da tabela 8.12 , é possível calcular os valores dos pesos elásticos:

$$
\begin{aligned}
& W_{0} \cdot 10^{3}=\left(\frac{1}{r}\right)_{0} \cdot \frac{\Delta x}{2}=0,02074 \cdot \frac{87,80}{2}=0,91 \\
& W_{1} \cdot 10^{3}=\left(\frac{1}{r}\right)_{1} \cdot \Delta x=0,00831 \cdot 87,80=0,73 \\
& W_{2} \cdot 10^{3}=\left(\frac{1}{r}\right)_{2} \cdot \Delta x=0,00416 \cdot 87,80=0,36 \\
& W_{3} \cdot 10^{3}=\left(\frac{1}{r}\right)_{3} \cdot \Delta x=0,01658 \cdot 87,80=1,46 \\
& W_{4} \cdot 10^{3}=\left(\frac{1}{r}\right)_{4} \cdot \Delta x=0,02911 \cdot 87,80=2,56 \\
& W_{5} \cdot 10^{3}=\left(\frac{1}{r}\right)_{5} \cdot \frac{\Delta x}{2}=0,04168 \cdot \frac{87,80}{2}=1,83
\end{aligned}
$$

Os momentos fletores $M^{\prime}{ }_{i}$ gerados pelo carregamento $W_{i}$ fornecem a deformada $y_{i}$, como indicado na figura 8.58 . Os cálculos estão presentes na tabela 8.13 . 
Tabela 8.13 - Primeira iteração

\begin{tabular}{ccccc}
\hline Seção & $\begin{array}{c}\mathrm{M}_{1} \\
(\mathrm{kN} . \mathrm{cm})\end{array}$ & $1 / \mathrm{r} \times 10^{3}$ & $W_{\mathrm{i} \times 10^{3}}$ & $\mathrm{M}^{\prime} \mathrm{i}=\mathrm{yi}$ \\
\hline 0 & -842 & 0,02074 & 0,91 & 0 \\
1 & $-336,79$ & 0,00831 & 0,73 & 0,0639 \\
2 & 168,42 & 0,00416 & 0,36 & 0,1919 \\
3 & 637,61 & 0,01658 & 1,46 & 0,2883 \\
4 & 1178,81 & 0,02911 & 2,56 & 0,2566 \\
5 & 1684 & 0,04168 & 1,83 & 0 \\
\hline
\end{tabular}

Fonte: Elaborado pelo Autor.

Figura 8.58 - Diagrama de pesos elásticos e deformada correspondente
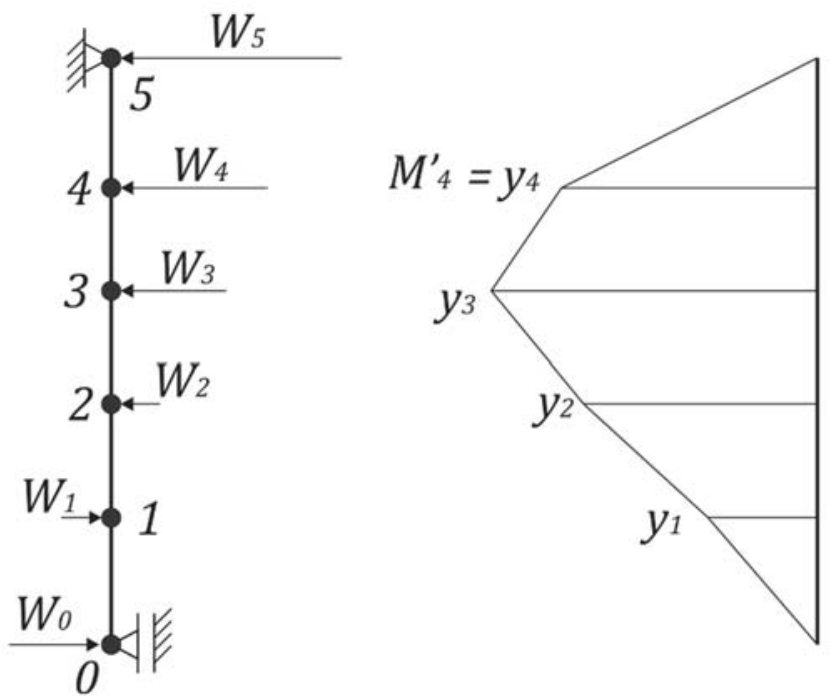

Fonte: Elaborado pelo Autor.

Na segunda iteração surgem os momentos fletores de $2^{\mathrm{a}}$ ordem, ou seja:

$$
M_{2 d}=N_{d} \cdot y_{i}
$$

E, portanto, define-se o momento fletor total:

$$
M_{t d}=M_{1 d}+M_{2 d}
$$

Os cálculos da segunda iteração estão indicados na tabela 8.14. 
Tabela 8.14 - Segunda iteração

\begin{tabular}{ccccccc}
\hline Seção & $\begin{array}{c}M_{1} \\
(k N . c m)\end{array}$ & $M_{2}(k N . c m)$ & $M t(k N . c m)$ & $1 / r \times 10^{3}$ & $W_{i \times 10^{3}}$ & $M^{\prime} i=y i$ \\
\hline 0 & -842 & 0 & -842 & 0,02074 & 0,91 & 0 \\
1 & $-336,79$ & 76,89 & $-259,90$ & 0,006421 & 0,56 & 0,1375 \\
2 & 168,42 & 230,89 & 399,31 & 0,009842 & 0,86 & 0,3244 \\
3 & 637,61 & 346,87 & 984,48 & 0,024263 & 2,13 & 0,4355 \\
4 & 1178,81 & 308,63 & 1487,44 & 0,036789 & 3,23 & 0,3596 \\
5 & 1684 & 0 & 1684 & 0,04168 & 1,83 & 0 \\
\hline
\end{tabular}

Fonte: Elaborado pelo Autor.

Prosseguindo de forma análoga nas demais iterações, procura-se a convergência dos resultados, que é obtida após 12 iterações. Os resultados estão indicados na tabela 8.15 .

Tabela 8.15 - Décima segunda iteração

\begin{tabular}{ccccccc}
\hline Seção & $\begin{array}{c}\mathrm{M} 1 \\
(\mathrm{kN} . \mathrm{cm})\end{array}$ & $\begin{array}{c}\mathrm{M} 2 \\
(\mathrm{kN} . \mathrm{cm})\end{array}$ & $\begin{array}{c}\mathrm{Mt} \\
(\mathrm{kN} . \mathrm{cm})\end{array}$ & $1 / \mathrm{r} \times 10^{3}$ & $\mathrm{~W}_{\mathrm{i} \times 10^{3}}$ & $\mathrm{M}^{\prime} \mathrm{i}=\mathrm{yi}$ \\
\hline 0 & -842 & 0 & -842 & 0,02074 & 0,91 & 0 \\
1 & $-336,79$ & 317,45 & $-19,34$ & 0,000526 & 0,05 & 0,2644 \\
2 & 168,42 & 639,79 & 808,21 & 0,019895 & 1,75 & 0,5328 \\
3 & 637,61 & 778,12 & 1415,73 & 0,035 & 3,07 & 0,6479 \\
4 & 1178,81 & 592,35 & 1771,16 & 0,043895 & 3,85 & 0,4931 \\
5 & 1684 & 0 & 1684 & 0,04168 & 1,83 & 0 \\
\hline
\end{tabular}

Fonte: Elaborado pelo Autor.

- Direção y

Para a direção y, o pilar será dividido em cinco elementos:

$$
\Delta x=\frac{\ell_{e y}}{5}=\frac{470}{5}=94 \mathrm{~cm}
$$

Com essas divisões, é necessário calcular os pesos elásticos correspondentes ao diagrama de momentos fletores do pilar. Com a teoria da Analogia de Mohr, verifica-se a necessidade da mudança das condições de apoio da viga análoga. Para 
os pesos elásticos é necessário que se aplique um carregamento de sentido contrário ao do diagrama de momentos fletores do pilar, como indicado na figura 8.59.

Figura 8.59 - Analogia de Mohr - Pesos elásticos

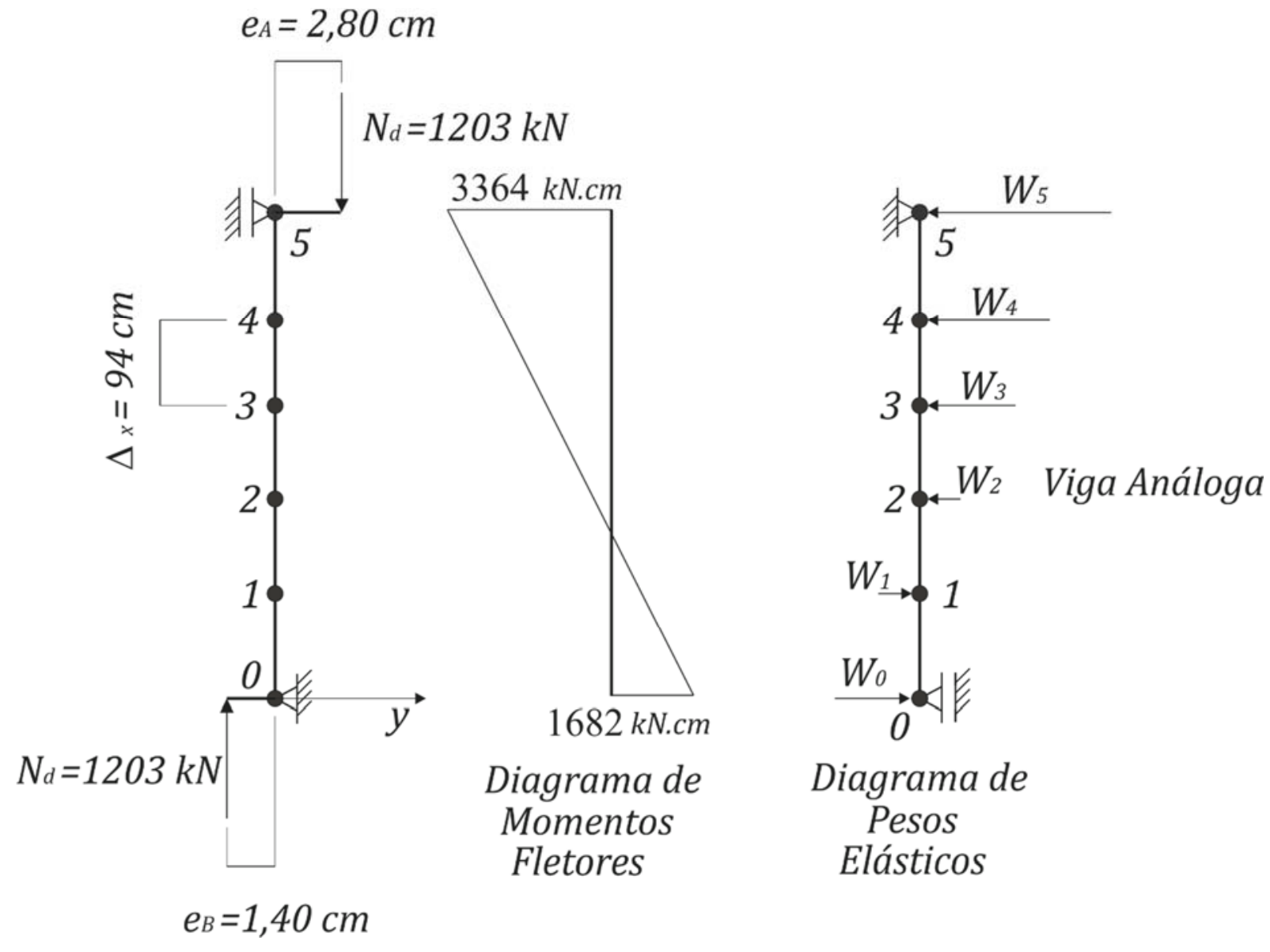

Fonte: Elaborado pelo Autor.

Na primeira iteração, apenas será considerado o momento fletor de $1^{\mathrm{a}}$ ordem. Deve-se, portanto, determinar os momentos fletores de cada seção (obtido por meio de semelhança de triângulos) e sua respectiva curvatura no diagrama momento fletor - força normal - curvatura, presente na figura 8.60. Os resultados estão indicados na tabela 8.16. 
Figura 8.60 - Diagrama momento fletor - força normal - curvatura (oito barras de $20 \mathrm{~mm}$ )

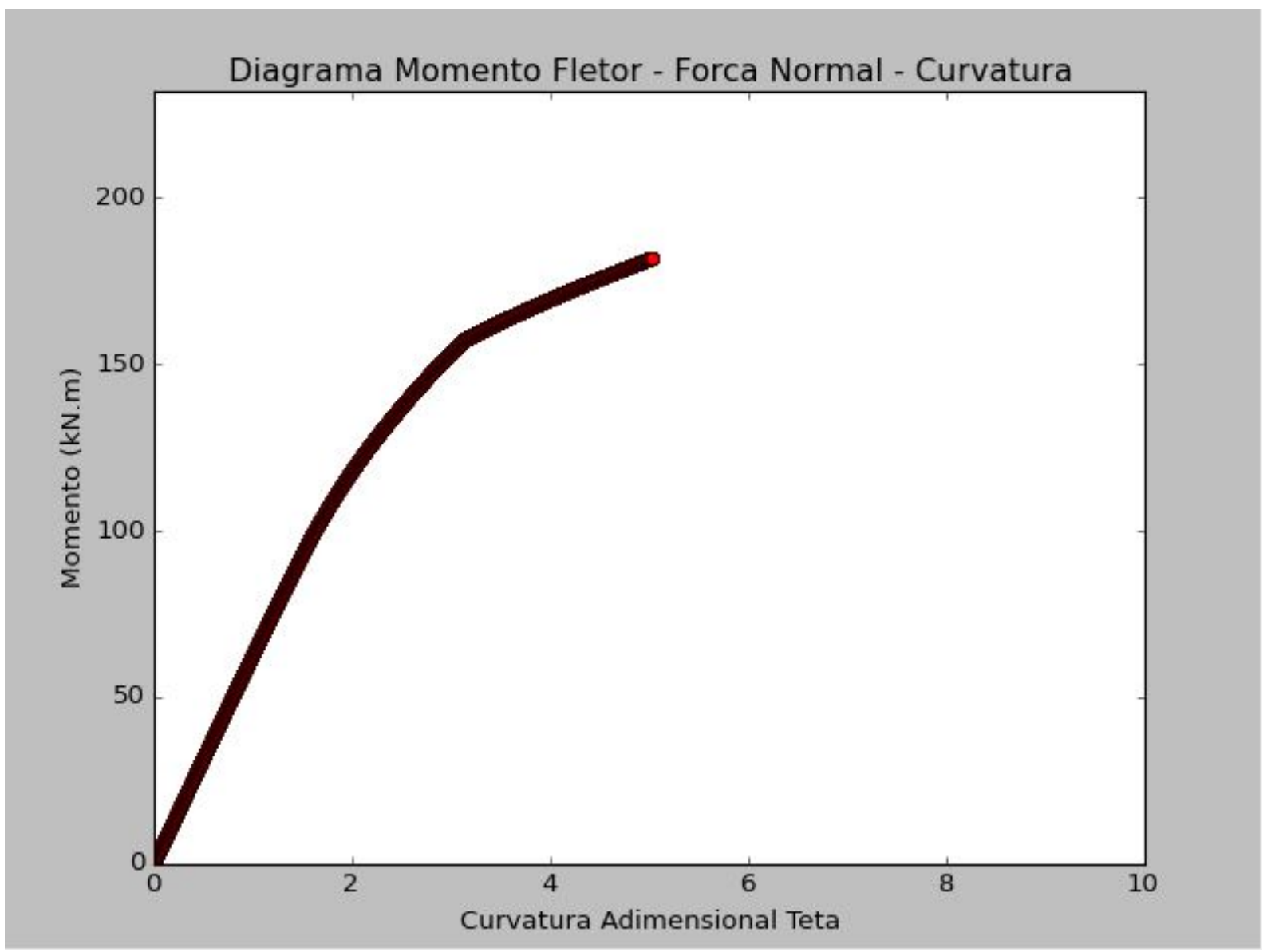

Fonte: Elaborado pelo Autor.

Tabela 8.16 - Subdivisões, momentos fletores e respectivas curvaturas

\begin{tabular}{ccccccc}
\hline Subdivisão & 0 & 1 & 2 & 3 & 4 & 5 \\
\hline $\begin{array}{c}\text { Momento } \\
\text { Fletor (kN.cm) }\end{array}$ & -1682 & $-672,82$ & 336,37 & 1345,58 & 2354,79 & 3364 \\
$\begin{array}{c}\text { Curvatura } \\
\text { Adimensional }\end{array}$ & 0,226 & 0,107 & 0,054 & 0,213 & 0,373 & 0,533 \\
$\begin{array}{c}\text { Curvatura } \\
(1 / \mathrm{cm})\end{array}$ & 0,00452 & 0,00214 & 0,00108 & 0,00426 & 0,00746 & 0,01066 \\
\hline
\end{tabular}

Fonte: Elaborado pelo Autor.

Com os valores da tabela 8.16, é possível calcular os valores dos pesos elásticos: 


$$
\begin{aligned}
& W_{0} \cdot 10^{3}=\left(\frac{1}{r}\right)_{0} \cdot \frac{\Delta x}{2}=0,00452 \cdot \frac{94}{2}=0,21 \\
& W_{1} \cdot 10^{3}=\left(\frac{1}{r}\right)_{1} \cdot \Delta x=0,00214 \cdot 94=0,20 \\
& W_{2} \cdot 10^{3}=\left(\frac{1}{r}\right)_{2} \cdot \Delta x=0,00108 \cdot 94=0,10 \\
& W_{3} \cdot 10^{3}=\left(\frac{1}{r}\right)_{3} \cdot \Delta x=0,00426 \cdot 94=0,40 \\
& W_{4} \cdot 10^{3}=\left(\frac{1}{r}\right)_{4} \cdot \Delta x=0,00746 \cdot 94=0,70 \\
& W_{5} \cdot 10^{3}=\left(\frac{1}{r}\right)_{5} \cdot \frac{\Delta x}{2}=0,01066 \cdot \frac{94}{2}=0,50
\end{aligned}
$$

Os momentos fletores $M^{\prime}{ }_{i}$ gerados pelo carregamento $W_{i}$ fornecem a deformada $y_{i}$. Os cálculos estão presentes na tabela 8.17.

Tabela 8.17 - Primeira iteração

\begin{tabular}{ccccc}
\hline Seção & $\begin{array}{c}\mathrm{M}_{1} \\
(\mathrm{kN} . \mathrm{cm})\end{array}$ & $1 / \mathrm{r} \times 10^{3}$ & $\mathrm{~W}_{\mathrm{i} \times 10^{3}}$ & $\mathrm{M}^{\prime} \mathrm{i}=\mathrm{yi}$ \\
\hline 0 & -1682 & 0,00452 & 0,21 & 0 \\
1 & $-672,82$ & 0,00214 & 0,20 & 0,0188 \\
2 & 336,37 & 0,00108 & 0,10 & 0,0564 \\
3 & 1345,58 & 0,00426 & 0,40 & 0,0846 \\
4 & 2354,79 & 0,00746 & 0,70 & 0,0752 \\
5 & 3364 & 0,01066 & 0,50 & 0 \\
\hline
\end{tabular}

Fonte: Elaborado pelo Autor.

Na segunda iteração surgem os momentos fletores de $2^{\mathrm{a}}$ ordem, ou seja:

$$
M_{2 d}=N_{d} \cdot y_{i}
$$

E, portanto, define-se o momento fletor total:

$$
M_{t d}=M_{1 d}+M_{2 d}
$$


Os cálculos da segunda iteração estão indicados na tabela 8.18.

Tabela 8.18 - Segunda iteração

\begin{tabular}{ccccccc}
\hline Seção & $\begin{array}{c}\mathrm{M}_{1} \\
(\mathrm{kN} . \mathrm{cm})\end{array}$ & $\mathrm{M}_{2}(\mathrm{kN.cm})$ & $\mathrm{Mt}(\mathrm{kN.cm})$ & $1 / \mathrm{r} \times 10^{3}$ & $W_{\mathrm{i} \times 10^{3}}$ & $\mathrm{M}^{\prime} \mathrm{i}=\mathrm{yi}_{\mathrm{i}}$ \\
\hline 0 & -1682 & 0 & -1682 & 0,00532 & 0,25 & 0 \\
1 & $-672,82$ & 22,62 & $-650,20$ & 0,00206 & 0,19 & 0,0206 \\
2 & 336,37 & 67,85 & 404,22 & 0,00128 & 0,12 & 0,0583 \\
3 & 1345,58 & 101,77 & 1447,35 & 0,00458 & 0,43 & 0,0853 \\
4 & 2354,79 & 90,47 & 2445,26 & 0,00774 & 0,73 & 0,0746 \\
5 & 3364 & 0 & 3364 & 0,01066 & 0,50 & 0 \\
\hline
\end{tabular}

Fonte: Elaborado pelo Autor.

Prosseguindo de forma análoga nas demais iterações, procura-se a convergência dos resultados, que é obtida após quatro iterações. Os resultados estão indicados na tabela 8.19.

Tabela 8.19 - Quarta iteração

\begin{tabular}{ccccccc}
\hline Seção & $\begin{array}{c}M_{1} \\
(k N . c m)\end{array}$ & $M_{2}(k N . c m)$ & $M t(k N . c m)$ & $1 / r \times 10^{3}$ & $W_{i} \times 10^{3}$ & $M^{\prime} i=y i$ \\
\hline 0 & -1682 & 0 & -1682 & 0,00532 & 0,25 & 0 \\
1 & $-672,82$ & 24,94 & $-647,88$ & 0,00206 & 0,19 & 0,0207 \\
2 & 336,37 & 70,33 & 406,70 & 0,0013 & 0,12 & 0,0585 \\
3 & 1345,58 & 102,82 & 1448,40 & 0,00458 & 0,43 & 0,0855 \\
4 & 2354,79 & 89,83 & 2444,62 & 0,00774 & 0,73 & 0,0747 \\
5 & 3364 & 0 & 3364 & 0,01066 & 0,50 & 0 \\
\hline
\end{tabular}

Fonte: Elaborado pelo Autor.

A rápida convergência é devida ao fato de que não é necessário computar os efeitos de segunda ordem na direção y $\left(\lambda_{1 y}>\lambda_{y}\right)$, de forma que os momentos fletores de segunda ordem são inexpressivos, e podem ser desprezados. 


\subsubsection{Envoltórias}

Como a armadura pré-selecionada e dimensionada foi de oito barras de $20 \mathrm{~mm}$, do item 8.16.5, a expressão da envoltória resistente é:

$$
\left(\frac{M_{R d, x}}{65,50}\right)^{1,2}+\left(\frac{M_{R d, y}}{182,16}\right)^{1,2}=1
$$

Os valores calculados pela Analogia de Mohr são característicos. A tabela 8.20 apresenta os momentos fletores nas direções $x$ e y com os valores de cálculo.

Tabela 8.20 - Valores de cálculo dos momentos fletores das seções

\begin{tabular}{ccc}
\hline Seção & $M s d, x$ & $M s d, y$ \\
\hline 0 & $-11,79$ & $-23,55$ \\
1 & $-0,27$ & $-9,07$ \\
2 & 11,31 & 5,69 \\
3 & 19,82 & 20,28 \\
4 & 24,80 & 34,22 \\
5 & 23,58 & 47,10 \\
\hline
\end{tabular}

Fonte: Elaborado pelo Autor.

A figura 8.61 apresenta a envoltória resistente e os momentos fletores das seções. 
Figura 8.61 - Envoltória resistente e solicitações das seções

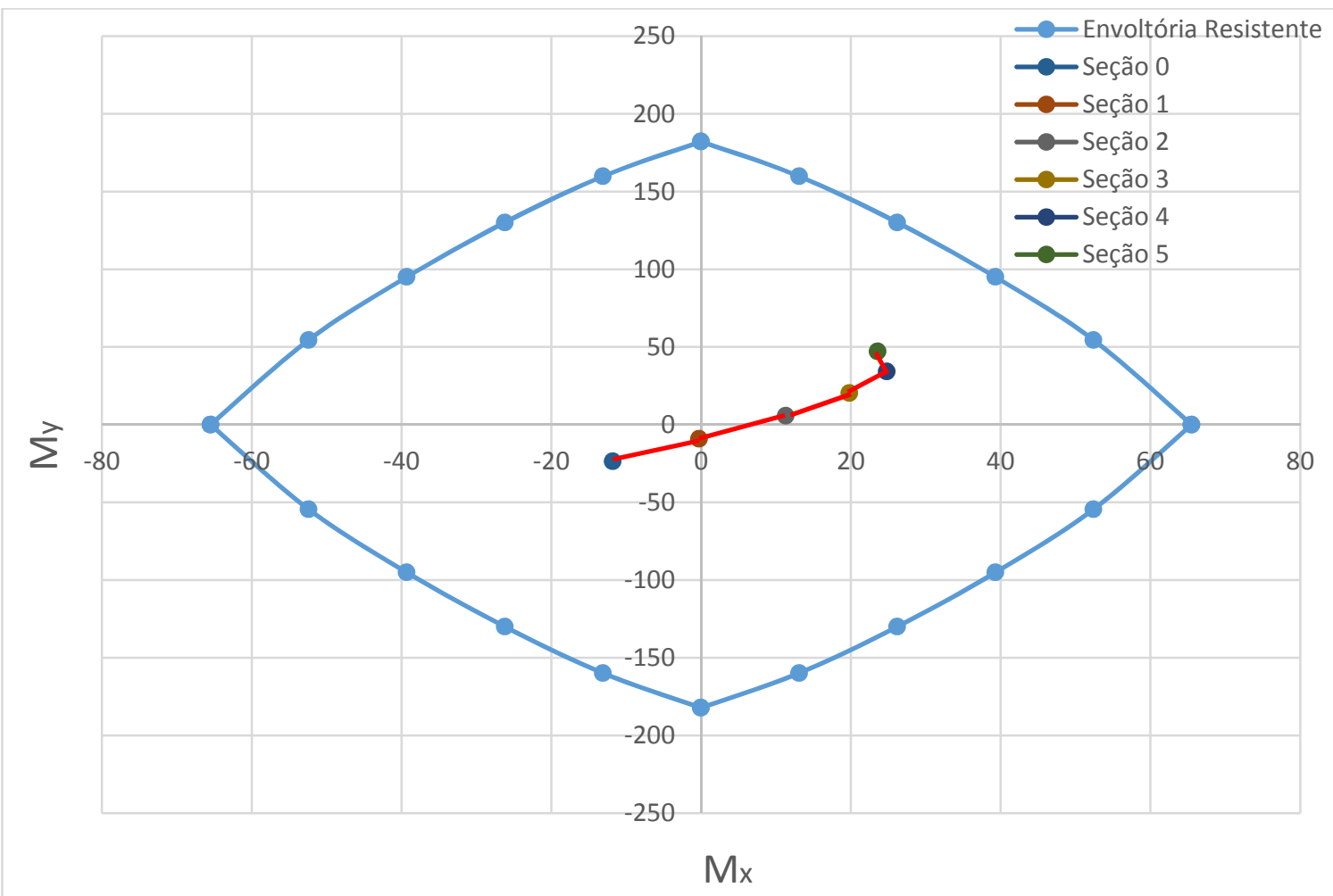

Fonte: Elaborado pelo Autor.

Diferentemente dos métodos anteriores, nos quais era possível computar os efeitos de $2^{\mathrm{a}}$ ordem diretamente no momento mínimo (quando fosse necessário), no método geral a análise é feita seção por seção. Assim, é intuitivo perceber que não há envoltória mínima de $2^{\mathrm{a}}$ ordem, e a consideração do momento mínimo será feita seção por seção.

Pela definição, o momento mínimo é o mínimo valor de momento fletor que deve ser considerado no dimensionamento de uma peça. Dessa forma, quando, na distribuição de momentos fletores da peça, houver momentos fletores menores que o momento mínimo, o momento mínimo é que deverá ser acrescidos dos momentos fletores de $2^{\mathrm{a}}$ ordem, como indicado nas tabelas 8.21 e 8.22 . 
- $\quad$ Direção x

Tabela 8.21 - Consideração do momento mínimo

\begin{tabular}{ccccc}
\hline Seção & M1d,x & M1d,mín,x & $M_{2 d, x}$ & $M s d, x$ \\
\hline 0 & $-11,79$ & $-24,90$ & 0 & $-24,90$ \\
1 & $-4,72$ & $-24,90$ & 4,44 & $-20,46$ \\
2 & 2,36 & 24,90 & 8,96 & 33,86 \\
3 & 8,93 & 24,90 & 10,89 & 35,79 \\
4 & 16,50 & 24,90 & 8,29 & 33,19 \\
5 & 23,58 & 24,90 & 0 & 24,90 \\
\hline
\end{tabular}

Fonte: Elaborado pelo Autor.

- Direção y

Tabela 8.22 - Consideração do momento mínimo

\begin{tabular}{ccccc}
\hline Seção & M1d,y & M1d,mín,y & M2d,y & Msd,y \\
\hline 0 & $-23,55$ & $-36,09$ & 0 & $-36,09$ \\
1 & $-9,42$ & $-36,09$ & 0,35 & $-35,74$ \\
2 & 4,71 & 36,09 & 0,98 & 37,07 \\
3 & 18,84 & 36,09 & 1,44 & 37,53 \\
4 & 32,97 & 36,09 & 1,26 & 37,35 \\
5 & 47,10 & 36,09 & 0 & 47,10 \\
\hline
\end{tabular}

Fonte: Elaborado pelo Autor.

Assim, a tabela 8.20 pode ser reescrita como indicado na tabela 8.23.

Tabela 8.23 - Valores de cálculo dos momentos fletores das seções

\begin{tabular}{ccc}
\hline Seção & Msd, $x$ & $M s d, y$ \\
\hline 0 & $-24,90$ & $-36,09$ \\
1 & $-20,46$ & $-35,74$ \\
2 & 33,86 & 37,07 \\
3 & 35,79 & 37,53 \\
4 & 33,19 & 37,35 \\
5 & 24,90 & 47,10 \\
\hline
\end{tabular}

Fonte: Elaborado pelo Autor.

A envoltória de momento mínimo é dada pela expressão indicada a seguir: 


$$
\left(\frac{M_{1 d, m i n, x}}{M_{1 d, m i n, x x}}\right)^{2}+\left(\frac{M_{1 d, m i n, y}}{M_{1 d, m i n, y y}}\right)^{2}=1 \rightarrow\left(\frac{M_{d, t o t, x}}{24,90}\right)^{2}+\left(\frac{M_{d, t o t, y}}{36,09}\right)^{2}=1
$$

Dessa forma, traçaram-se a envoltória resistente e a envoltória mínima, e indicaram-se os momentos fletores solicitantes nas seções, como pode ser visto na figura 8.62 .

Figura 8.62 - Envoltória resistente, envoltórias mínimas e solicitações do pilar P01

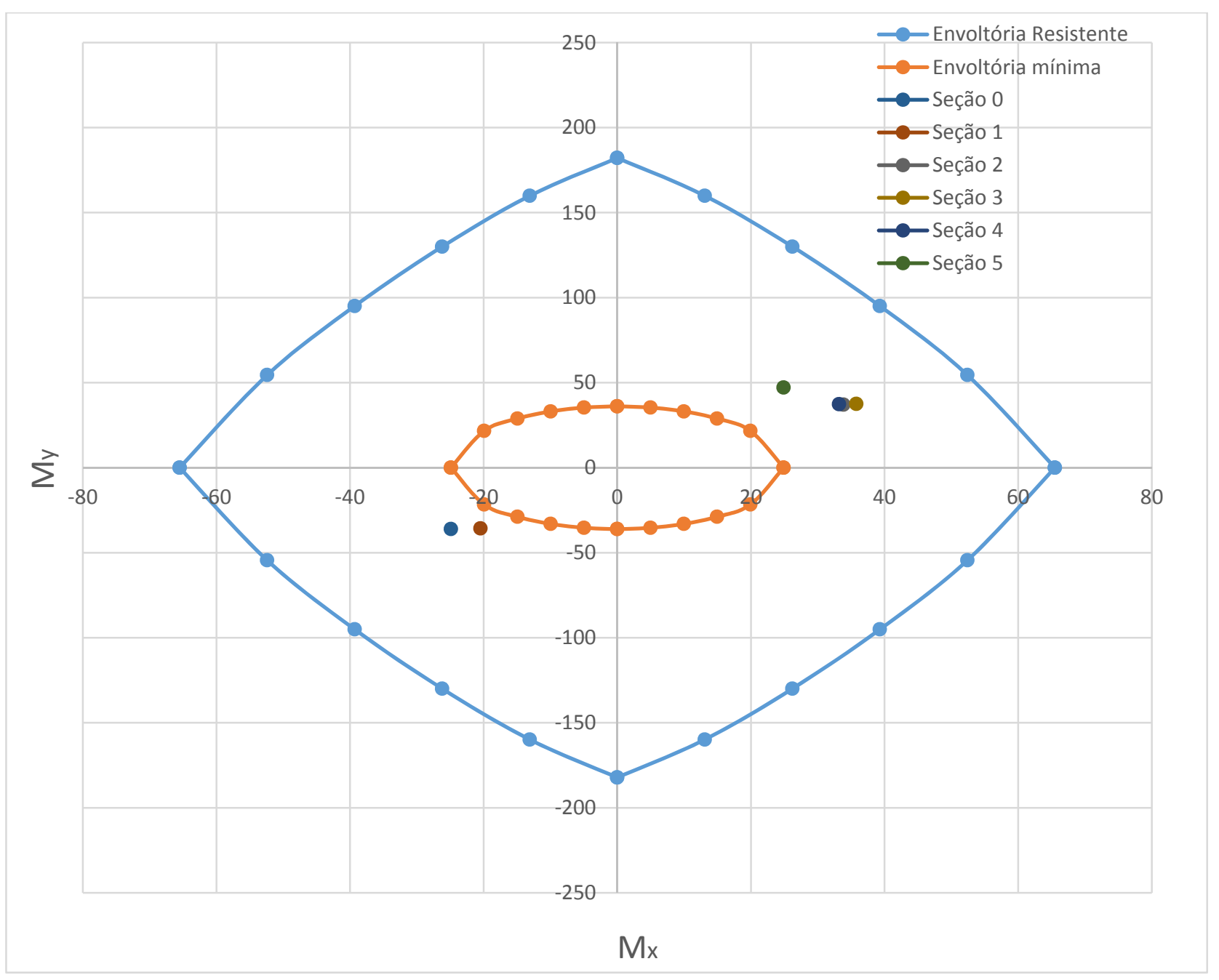

Fonte: Elaborado pelo Autor.

Como todos os pontos de solicitações das seções e a envoltória mínima estão envolvidos pela envoltória resistente, a armadura está verificada. 


\subsubsection{Verificação da excentricidade acidental}

No caso da excentricidade acidental, não há os conceitos de envoltórias mínimas e de momento mínimo. Assim, a consideração das imperfeições geométricas locais é feita por meio da adição de uma excentricidade acidental às excentricidades solicitantes nas seções do pilar.

Novamente destaca-se que a ABNT NBR 6118:2014 não apresenta as diretrizes para a computação da excentricidade acidental. Assim, neste trabalho, será efetuado uma sugestão de como essas excentricidades devem ser consideradas no dimensionamento.

Para a verificação da excentricidade acidental será utilizada a mesma armadura anterior, ou seja, oito barras de $20 \mathrm{~mm}$. Dessa forma, utilizando o item 8.11 têm-se os resultado indicados nas tabelas 8.24 e 8.25 .

- Direção x

$$
e_{a x}=1,05 \mathrm{~cm}=0,0105 \mathrm{~m}
$$

Tabela 8.24 - Consideração da excentricidade acidental

\begin{tabular}{ccccc}
\hline Seção & $M 2 d, x$ & $N d$ & eax & $M s d, x$ \\
\hline 0 & $-11,79$ & 1203 & $-0,0105$ & $-24,42$ \\
1 & $-0,27$ & 1203 & $-0,0105$ & $-12,90$ \\
2 & 11,31 & 1203 & 0,0105 & 23,95 \\
3 & 19,82 & 1203 & 0,0105 & 32,45 \\
4 & 24,80 & 1203 & 0,0105 & 37,43 \\
5 & 23,58 & 1203 & 0,0105 & 36,21 \\
\hline
\end{tabular}

Fonte: Elaborado pelo Autor.

- Direção y

$$
e_{a y}=1,08 \mathrm{~cm}=0,0108 \mathrm{~m}
$$


Tabela 8.25 - Consideração da excentricidade acidental

\begin{tabular}{ccccc}
\hline Seção & $M 2 d, y$ & $N d$ & eay & $M s d, y$ \\
\hline 0 & $-23,55$ & 1203 & $-0,0108$ & $-36,54$ \\
1 & $-9,07$ & 1203 & $-0,0108$ & $-22,06$ \\
2 & 5,69 & 1203 & 0,0108 & 18,69 \\
3 & 20,28 & 1203 & 0,0108 & 33,27 \\
4 & 34,22 & 1203 & 0,0108 & 47,22 \\
5 & 47,10 & 1203 & 0,0108 & 60,09 \\
\hline
\end{tabular}

Fonte: Elaborado pelo Autor.

As solicitações das seções são mostradas na Tabela 8.26.

Tabela 8.26 - Valores de cálculo dos momentos fletores das seções

\begin{tabular}{ccc}
\hline Seção & Msd,x & Msd,y \\
\hline 0 & $-24,42$ & $-36,54$ \\
1 & $-12,90$ & $-22,06$ \\
2 & 23,95 & 18,69 \\
3 & 32,45 & 33,27 \\
4 & 37,43 & 47,22 \\
5 & 36,21 & 60,09 \\
\hline
\end{tabular}

Fonte: Elaborado pelo Autor.

Utilizando a armadura de oito barras de $20 \mathrm{~mm}$, tem-se para a envoltória resistente a expressão:

$$
\left(\frac{M_{R d, x}}{65,50}\right)^{1,2}+\left(\frac{M_{R d, y}}{182,16}\right)^{1,2}=1
$$

Plotando os pontos de solicitações e da envoltória resistente tem-se a figura 8.63. 
Figura 8.63 - Solicitações do pilar P01 (excentricidade acidental)

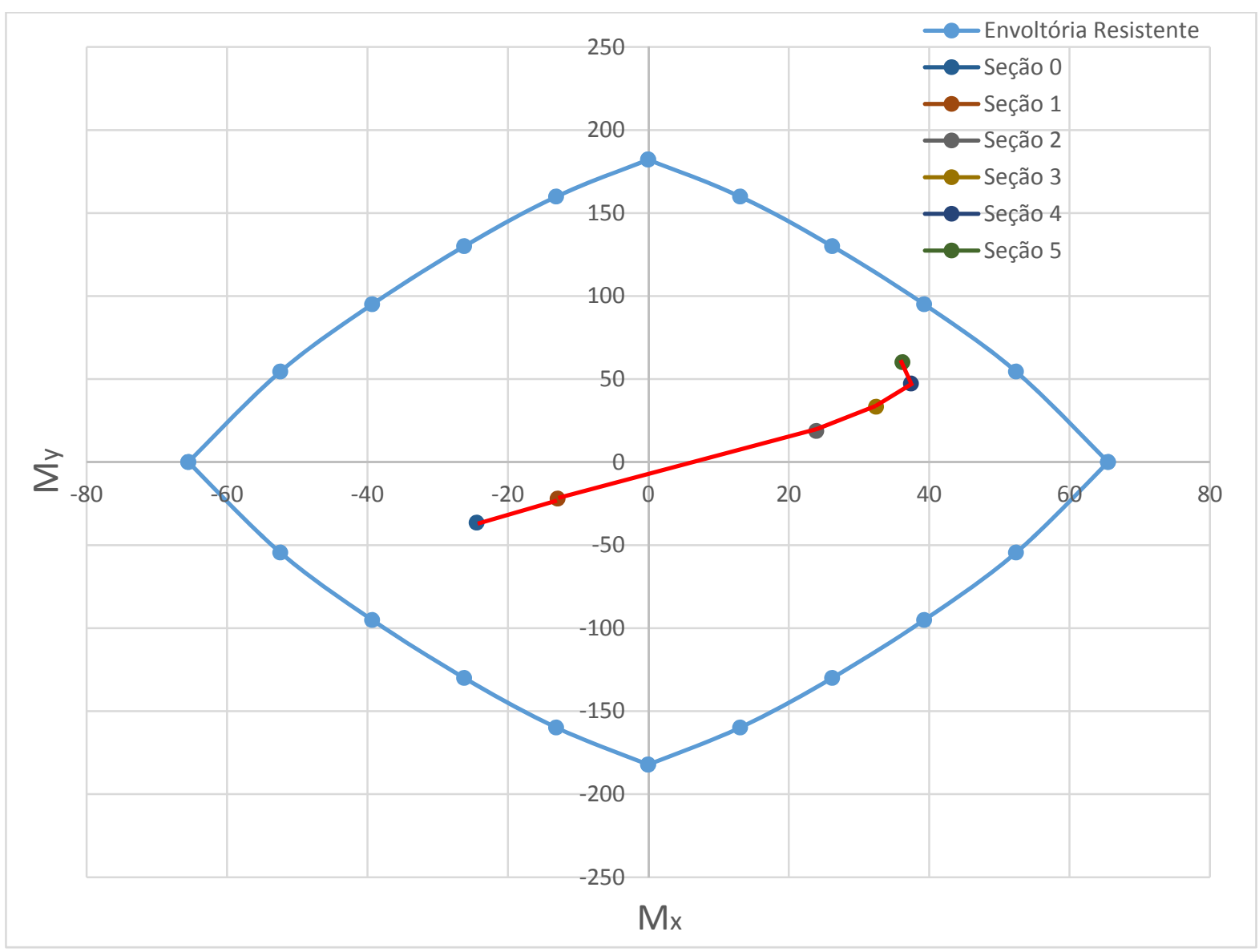

Fonte: Elaborado pelo Autor.

Como o ponto de solicitação da seção 5 está próximo da envoltória resistente, verifica-se a segurança por meio do cálculo analítico:

$$
\begin{aligned}
& \left(\frac{M_{S d, x}}{M_{R d, x x}}\right)^{\alpha}+\left(\frac{M_{S d, y}}{M_{R d, y y}}\right)^{\alpha} \leq 1 \\
& \left(\frac{M_{S d, x}}{65,50}\right)^{1,2}+\left(\frac{M_{S d, y}}{182,16}\right)^{1,2} \leq 1 \\
& \left(\frac{36,21}{65,50}\right)^{1,2}+\left(\frac{60,09}{182,16}\right)^{1,2}=0,755 \leq 1
\end{aligned}
$$

Portanto, como a envoltória resistente ultrapassa os momentos fletores solicitantes em todas as seções do pilar, a armadura da seção está verificada. 
246 | P á g i n a 


\section{Conclusões}

Apresentam-se as conclusões que foram obtidas durante a evolução do trabalho, no que diz respeito aos conceitos e métodos presentes na ABNT NBR 6118:2014.

Inicialmente, foi definido o estado-limite último de instabilidade e verificada a importância do seu estudo. A análise não linear do comportamento do concreto (não linearidade física) aliada com a análise da deformada da estrutura (não linearidade geométrica) definem os tipos de ruína no estado-limite último: esgotamento da capacidade resistente da seção ou a instabilidade do equilíbrio. Verifica-se a necessidade dessa definição nos textos referentes ao estudo de pilares.

No estudo das excentricidades, define-se excentricidade inicial $\left(e_{i}\right)$ como sendo aquela obtida com a relação entre o momento fletor solicitante inicial e a força normal atuante na peça. Essa excentricidade é utilizada para o cálculo da esbeltez limite (item 15.8.2 da ABNT NBR 6118:2014). Porém, a expressão indicada na norma apresenta $e_{1}$, que foi definido neste texto como sendo excentricidade de $1^{\text {a }}$ ordem (soma da excentricidade inicial com a excentricidade acidental), ao invés de $e_{i}$. Assim, recomenda-se cuidado ao utilizar essa expressão da esbeltez limite.

Ainda sobre as excentricidades iniciais, a ABNT NBR 6118:2014 apresenta o processo do modelo clássico de viga contínua para determinação das solicitações iniciais dos pilares. Frisa-se a necessidade de adaptações, já que, nesse processo, pilares de extremidade e intermediários estão submetidos, respectivamente, a uma flexão composta normal e uma compressão centrada. Na realidade, todos os pilares estão submetidos à flexão composta oblíqua, mesmo que os momentos fletores iniciais sejam pequenos.

Em relação às imperfeições geométricas locais, necessita-se de estudo apurado sobre qual vertente é a indicada para a correta modelagem: momento mínimo ou excentricidade acidental, e como a excentricidade acidental deve ser considerada no dimensionamento. Como demonstrado no exemplo de aplicação, verifica-se que, em certos casos, o dimensionamento utilizando a excentricidade acidental produziu resultados maiores se comparados com as envoltórias mínimas geradas com 0 momento mínimo. Porém, como a ABNT NBR 6118:2014 não apresenta diretrizes 
para o uso da excentricidade acidental, foi efetuada uma sugestão de como devem ser computados esses efeitos neste texto, de maneira que possam haver correções futuras realizadas pela norma.

Quanto ao estudo dos efeitos locais de $2^{\mathrm{a}}$ ordem, verifica-se a importância dos diagramas momento fletor - força normal - curvatura, já que as expressões dos métodos aproximados derivam do comportamento ou do estudo da linearização deles, proposta por França (1991). Por isso, apresenta-se, no Apêndice A, o equacionamento e um algoritmo para obtenção desses diagramas.

No texto foram apresentados dois métodos que podem ser utilizados para a determinação da deformada da estrutura para o Método Geral. Verifica-se que, para pilares biapoiados, o Processo de Engesser-Vianello é o mais indicado, e, para pilares engastados na base e livres no topo, o mais indicado é o Processo das Diferenças Finitas. Isso se deve ao fato de a deformada de pilares engastados na base e livres no topo ser simétrica (como demonstrado na figura 7.26, a flecha do ponto 1' é igual à do ponto 1), facilitando o uso do segundo processo.

Foi definida uma nova convenção de eixos e de dimensões da seção, no item 8.1. Acredita-se que com esse novo sistema, as dúvidas sejam sanadas, quanto ao cálculo do momento mínimo (item 11.3.3.4.3) e do momento fletor resistente de pilares, em qualquer posição.

Para o pré-dimensionamento foram propostas duas situações consideradas críticas para o dimensionamento. Como comprovado no exemplo de aplicação, o prédimensionamento foi eficaz para a análise de momento mínimo, porém, é necessário a criação de novas situações críticas para a análise das excentricidades acidentais.

A obtenção dos momentos fletores resistentes da seção por meio de ábacos gera resultados próximos dos obtidos por métodos numéricos (erros da ordem de $5 \%$, gerados pela imprecisão de leitura no ábaco). Porém, para uma análise mais precisa, recomenda-se o uso de outros métodos. Há no texto dois algoritmos para obtenção do momento fletor resistente, um por meio dos diagramas momento fletor - força normal - curvatura (Apêndice A), o outro com o uso da expressão exata dos ábacos de flexão composta normal, construídos por Venturini (1987) (Apêndice B). 
Para o exemplo de aplicação, foi utilizado o modelo clássico de viga contínua para obtenção dos esforços solicitantes iniciais do pilar, para mostrar como é o procedimento. Porém, esse método é discutível para edifícios de vários pavimentos por não considerar ações horizontais, como as do vento. Recomenda-se, portanto, o uso do modelo de pórtico espacial, no qual, é realizada a análise global do edifício.

Os resultados obtidos no exemplo de aplicação estão presentes nas tabelas $9.1,9.2,9.3$ e 9.4 .

Tabela 9.1 - Exemplo de aplicação (momento mínimo)

\begin{tabular}{|c|c|c|c|c|c|}
\hline $\begin{array}{c}\text { Imperfeições } \\
\text { geométricas locais: } \\
\text { momento mínimo }\end{array}$ & $\begin{array}{l}M_{d, t o t, x} \\
(k N . m)\end{array}$ & $\begin{array}{l}M_{d, t o t, y} \\
(k N . m)\end{array}$ & $\begin{array}{l}\text { Armadura } \\
\text { escolhida }\end{array}$ & Seção Crítica & Verificação \\
\hline $\begin{array}{l}\text { Método do pilar- } \\
\text { padrão com } \\
\text { curvatura } \\
\text { aproximada }\end{array}$ & 74,12 & 36,09 & $\begin{array}{c}\text { Doze barras } \\
\text { de } 20 \mathrm{~mm}\end{array}$ & Intermediária & 0,907 \\
\hline $\begin{array}{l}\text { Método do pilar- } \\
\text { padrão com rigidez } \\
\text { "kapa" aproximada }\end{array}$ & 69,61 & 36,09 & $\begin{array}{c}\text { Doze barras } \\
\text { de } 20 \mathrm{~mm}\end{array}$ & Intermediária & 0,849 \\
\hline $\begin{array}{l}\text { Método do pilar- } \\
\text { padrão acoplado a } \\
\text { diagramas } \\
\text { momento fletor - } \\
\text { força normal - } \\
\text { curvatura }\end{array}$ & 53,90 & 36,09 & $\begin{array}{l}\text { Oito barras } \\
\text { de } 20 \mathrm{~mm}\end{array}$ & Intermediária & 0,935 \\
\hline Método Geral & 35,79 & 37,53 & $\begin{array}{l}\text { Oito barras } \\
\text { de } 20 \mathrm{~mm}\end{array}$ & 3 & 0,634 \\
\hline
\end{tabular}

Fonte: Elaborado pelo Autor. 
Tabela 9.2 - Exemplo de aplicação (momento mínimo)

\begin{tabular}{|c|c|c|}
\hline $\begin{array}{l}\text { Imperfeições geométricas } \\
\text { locais: momento mínimo }\end{array}$ & $\begin{array}{l}M_{d, t o t, x} \\
\text { (kN.m) }\end{array}$ & $\begin{array}{l}\text { Redução em } \\
\text { relação ao } \\
\text { anterior (\%) }\end{array}$ \\
\hline $\begin{array}{l}\text { Método do pilar-padrão com } \\
\text { curvatura aproximada }\end{array}$ & 74,12 & - \\
\hline $\begin{array}{l}\text { Método do pilar-padrão com } \\
\text { rigidez "kapa" aproximada }\end{array}$ & 69,61 & $-6,62$ \\
\hline $\begin{array}{l}\text { Método do pilar-padrão } \\
\text { acoplado a diagramas } \\
\text { momento fletor - força normal } \\
\text { - curvatura }\end{array}$ & 53,90 & $-22,57$ \\
\hline Método Geral & 35,79 & $-33,60$ \\
\hline
\end{tabular}

Fonte: Elaborado pelo Autor. 
Tabela 9.3 - Exemplo de aplicação (excentricidade acidental)

\begin{tabular}{|c|c|c|c|c|c|}
\hline $\begin{array}{c}\text { Imperfeições } \\
\text { geométricas locais: } \\
\text { excentricidade } \\
\text { acidental }\end{array}$ & $\begin{array}{l}M_{d, t o t, x} \\
\text { (kN.m) }\end{array}$ & $\begin{array}{l}M_{d, t o t, y} \\
\text { (kN.m) }\end{array}$ & $\begin{array}{l}\text { Armadura } \\
\text { escolhida }\end{array}$ & Seção Crítica & Verificação \\
\hline $\begin{array}{l}\text { Método do pilar- } \\
\text { padrão com } \\
\text { curvatura } \\
\text { aproximada }\end{array}$ & 86,75 & 31,83 & $\begin{array}{l}\text { Doze barras } \\
\text { de } 22 \mathrm{~mm}\end{array}$ & Intermediária & 0,908 \\
\hline $\begin{array}{l}\text { Método do pilar- } \\
\text { padrão com rigidez } \\
\text { "kapa" aproximada }\end{array}$ & 82,24 & 31,83 & $\begin{array}{l}\text { Doze barras } \\
\text { de } 20 \mathrm{~mm}\end{array}$ & Intermediária & 0,998 \\
\hline $\begin{array}{l}\text { Método do pilar- } \\
\text { padrão acoplado a } \\
\text { diagramas } \\
\text { momento fletor - } \\
\text { força normal - } \\
\text { curvatura }\end{array}$ & 67,02 & 31,83 & $\begin{array}{c}\text { Dez barras de } \\
20 \mathrm{~mm}\end{array}$ & Intermediária & 0,966 \\
\hline Método Geral & 36,21 & 60,09 & $\begin{array}{l}\text { Oito barras } \\
\text { de } 20 \mathrm{~mm}\end{array}$ & 5 & 0,755 \\
\hline
\end{tabular}

Fonte: Elaborado pelo Autor. 
Tabela 9.4 - Exemplo de aplicação (excentricidade acidental)

\begin{tabular}{ccc}
\hline $\begin{array}{l}\text { Imperfeições geométricas } \\
\text { locais: excentricidade acidental }\end{array}$ & $\mathrm{M}_{\mathrm{d}, \text { tot, } \mathrm{x}}$ & $\begin{array}{c}\text { Redução em } \\
\text { relação ao } \\
\text { anterior (\%) }\end{array}$ \\
\hline
\end{tabular}

Método do pilar-padrão com curvatura aproximada 86,75

Método do pilar-padrão com rigidez "kapa" aproximada

82,24 $-5,20$

Método do pilar-padrão acoplado a diagramas momento fletor - força normal

67,02 $-18,51$ - curvatura

\section{Método Geral}

Fonte: Elaborado pelo Autor.

Para o exemplo de aplicação, foram considerados os efeitos locais de segunda ordem somente na direção $\mathrm{x}$, devido à considerável esbeltez nessa direção $\left(\lambda_{x}=80,0\right)$. Essa esbeltez é próxima do limite permitido para os métodos aproximados $(\lambda \leq 90)$, de forma que os resultados exagerados dos métodos aproximados (tabelas 9.2 e 9.4) ficam justificados.

É perceptível que os resultados obtidos pela verificação das imperfeições geométricas pela excentricidade acidental, neste exemplo de aplicação, são maiores que os obtidos pela verificação por momento mínimo. Assim, são necessários mais estudos sobre qual modelo deve ser utilizado e como devem ser considerados os efeitos das excentricidades acidentais, já que a NBR 6118:2014 permite o uso de ambos. 
O método aproximado do pilar- padrão com curvatura aproximada, apesar da extrema facilidade de aplicação, foi o que apresentou o pior resultado para a consideração dos efeitos locais de $2^{a}$ ordem. Por ser o primeiro método de cálculo criado para dimensionamento de pilares, não apresenta o refinamento necessário para a análise em $2^{\mathrm{a}}$ ordem.

O método aproximado do pilar-padrão com rigidez $\kappa$ aproximada gerou resultados da ordem de $6 \%$ mais econômicos que o do pilar-padrão com curvatura aproximada. Apesar de se obter a mesma armadura, quando foi utilizado o momento mínimo, a verificação de um $(0,849)$ foi menor que a do outro $(0,907)$, indicando que houve refinamento da formulação. É indicado para o cálculo manual, sem a necessidade de uso computacional, já que apresenta metodologia próxima à do método do pilar-padrão com curvatura aproximada.

Destaca-se que as situações críticas definidas para o pré-dimensionamento são utilizadas apenas nos métodos aproximados. Para o método geral e o método do pilar-padrão acoplado a digramas momento fletor - força normal - curvatura, é necessária armadura pré-definida, pois são métodos de verificação. Assim, recomenda-se o uso das armaduras dimensionadas por um dos métodos aproximados, para posterior refinamento por um dos métodos mais precisos.

O método aproximado do pilar-padrão acoplado a diagramas momento fletor força normal - curvatura apresentou resultados da ordem de $20 \%$ mais econômicos que o método do pilar-padrão com rigidez $\kappa$ aproximada. Esse fato mostra a importância do refinamento da não linearidade física, já que a rigidez $\kappa$ é obtida do diagrama momento fletor - força normal - curvatura da seção pré-definida. $O$ dimensionamento com esse método é iterativo, sendo necessária a construção dos diagramas momento fletor - força normal - curvatura para a análise dos efeitos de $2^{a}$ ordem, sendo, portanto, necessário o uso computacional.

No dimensionamento pelo método do pilar-padrão acoplado a digramas momento fletor - força normal - curvatura, destacam-se alguns fenômenos importantes. Quando houve diminuição da armadura de dez barras de $20 \mathrm{~mm}$ para oito barras de $20 \mathrm{~mm}$, a rigidez secante aumentou de 60,68 para 61,11. Esse resultado causa estranheza ao leitor, pois com a diminuição da armadura houve aumento da rigidez da seção. Porém, o método utiliza a inclinação da reta $A B$ para 
obtenção da rigidez secante. Assim, dependendo do comportamento do diagrama momento fletor - força normal - curvatura, tais resultados podem ser obtidos.

O método geral apresentou os resultados mais econômicos de todos os métodos (da ordem de 40\% mais econômico se comparado com o método do pilarpadrão acoplado a diagrama momento fletor - força normal - curvatura), mostrando a importância do refinamento da não linearidade geométrica. Porém, seu uso é trabalhoso, pois é necessário o diagrama momento fletor - força normal - curvatura da seção, e a subdivisão do pilar em elementos para aplicação dos processos (das diferenças finitas ou de Engesser-Vianello) para obtenção da deformada de segunda ordem. Apesar de ser complexo, é possível verificar em qual seção ocorre o máximo momento fletor total ( $1^{\mathrm{a}}$ ordem $+2^{\mathrm{a}}$ ordem). Verifica-se, também, se existe uma posição de equilíbrio deformada.

Essas foram as questões abordadas neste trabalho. Como sugestão para trabalhos futuros, recomenda-se o estudo apurado das imperfeições geométricas locais, definindo qual modelo deve ser utilizado para o dimensionamento de pilares, e como devem ser considerados os efeitos das excentricidades acidentais. Sugere-se também, a comparação dos resultados teóricos obtidos neste trabalho com resultados experimentais, obtidos em ensaios de laboratório. 


\section{REFERÊNCIAS}

AMARAL, P. T. Análise dos efeitos de $2^{\mathrm{a}}$ ordem em barras comprimidas de concreto armado. 2000. 98 f. Dissertação (Mestrado) - Curso de Engenharia Civil, Departamento de Estruturas, Universidade de São Paulo, São Carlos, 2000. Cap. 7. Disponível em:

$<$ http://web.set.eesc.usp.br/static/data/producao/2000ME_PatriciaTolainedoAmaral.p df>. Acesso em: 29 set. 2015.

ASSOCIAÇÃO BRASILEIRA DE NORMAS TÉCNICAS. NBR 6118:2003 - Projeto de estruturas de concreto - Procedimento. Rio de Janeiro, 2003. 170 p.

ASSOCIAÇÃO BRASILEIRA DE NORMAS TÉCNICAS. NBR 6118:2014 - Projeto de estruturas de concreto - Procedimento. 3. ed. Rio de Janeiro, 2014. 238 p.

ARAÚJO, J. M. Curso de concreto armado. 3. ed. Rio Grande: Dunas, 2010. 330 p.

ARAÚJO, J. M. Dimensionamento de pilares esbeltos de concreto

armado. 1984. 176 f. Dissertação (Mestrado) - Curso de Engenharia Civil, Universidade Federal do Rio Grande do Sul, Porto Alegre, 1985. Disponível em: <http://www.lume.ufrgs.br/handle/10183/1346>. Acesso em: 14 mar. 2016.

ARAÚJO, J. M. Pilares esbeltos de concreto armado Parte 1: Um modelo não linear para análise e dimensionamento. Teoria e Prática na Engenharia Civil, Rio Grande: RS, v.11, n.18, p.81-93, 2011. Disponível em:

<http://www.editoradunas.com.br/revistatpec/Sumario_Numero18.htm>. Acesso em: 14 mar. 2016.

AUFIERI, F. A. Diretrizes para o dimensionamento e detalhamento de pilares em edifícios em concreto armado. 1997. 146 f. Dissertação (Mestrado) - Curso de Engenharia Civil, Departamento de Estruturas, Universidade de São Paulo, São Carlos, 1997. Cap. 11. Disponível em:

<http://web.set.eesc.usp.br/static/data/producao/1997ME_FabioAugustoAufieri.pdf>. Acesso em: 29 set. 2015.

AUFIERO, L. Estabilidade de colunas isostáticas de concreto armado. 1977. 164 f. Dissertação (Mestrado) - Curso de Engenharia Civil, Departamento de Estruturas, Universidade de São Paulo, São Carlos, 1977. Disponível em: <http://web.set.eesc.usp.br/static/data/producao/1977ME_LilianaAufiero_1.pdf>. Acesso em: 29 set. 2015.

BACARJI, E. Análise de estruturas de edifícios: projeto de pilares. 1993. $187 \mathrm{f}$. Dissertação (Mestrado) - Curso de Engenharia Civil, Departamento de Estruturas, Universidade de São Paulo, São Carlos, 1993. Cap. 10. Disponível em: $<$ http://web.set.eesc.usp.br/static/data/producao/1993ME_EdgarBacarji.pdf>. Acesso em: 29 set. 2015. 
CADAMURO JÚNIOR, I. W. Dimensionamento de pilares esbeltos de concreto armado com seção qualquer solicitados por flexão composta oblíqua. 1997. 187 f. Dissertação (Mestrado) - Curso de Engenharia Civil, Universidade de São Paulo, São Carlos, 1997. Cap. 9. Disponível em:

<http://web.set.eesc.usp.br/static/data/producao/1997ME_IsmaelWilsonCadamuroJu nior.pdf>. Acesso em: 19 abr. 2016.

CHAVES, L. E. A. et al. Application of general method for design of concrete columns and encased composite steel and concrete columns. Revista Ibracon de Estruturas e Materiais, [s.I.], v. 8, n. 6, p.755-762, dez. 2015. FapUNIFESP (SciELO). http://dx.doi.org/10.1590/s1983-41952015000600002.

FRANÇA, R. L. S. Contribuição ao estudo dos efeitos de segunda ordem em pilares de concreto armado. 1991. 202 f. Tese (Doutorado) - Curso de Engenharia Civil, Departamento de Engenharia de Estruturas e Fundações, Universidade de São Paulo, São Paulo, 1991.

FRANÇA, R. L. S. Relações momento-curvatura em peças de concreto armado submetidas a flexão oblíqua composta. 1984. 291 f. Dissertação (Mestrado) Curso de Engenharia Civil, Departamento de Engenharia de Estruturas e Fundações, Universidade de São Paulo, São Paulo, 1984. Cap. 11. Disponível em: <http://web.set.eesc.usp.br/static/data/producao/1984ME_RicardoLeopoldoSilvaeFra nca.pdf>. Acesso em: 29 set. 2015.

FUSCO, P. B. Estruturas de concreto: solicitações normais. Rio de Janeiro: Guanabara Dois, 1981. 464 p.

IBRACON (Ed.). Comentários técnicos e exemplos de aplicação da NB-1 NBR 6118:2003 Projeto de estruturas de concreto - Procedimento. São Paulo: Ibracon, 2006. 268 p.

KETTERMANN, A. C. Efeito da deformabilidade dos pilares no estudo do estado-limite último de instabilidade. 2001. 196 f. Dissertação (Mestrado) - Curso de Engenharia Civil, Universidade Federal de Santa Catarina, Florianópolis, 2001. Disponível em: <https://repositorio.ufsc.br/handle/123456789/83285>. Acesso em: 29 set. 2015.

KIMURA, A. E. EE05 - Pilares: Módulo EE05 - Pilares do curso de pós-graduação da FESP. São Paulo: FESP/ABECE/TQS, 2010. 272 p.

LIMA, V. M. S. Palestra proferida no Instituto de Engenharia, São Paulo, 1975. 
MALAKOSKI, J. Pilares esbeltos de concreto armado com seção variável. 1998. 175 f. Dissertação (Mestrado) - Curso de Engenharia Civil, Departamento de Estruturas, Universidade de São Paulo, São Carlos, 1998. Cap. 10. Disponível em: <http://web.set.eesc.usp.br/static/data/producao/1998ME_JoiceMalakoski.pdf>. Acesso em: 29 set. 2015.

MEHTA, P. K.; MONTEIRO, P. J. M. Concreto: Microestrutura, propriedade e materiais. São Paulo: Ibracon, 2008. 674 p. Tradução para o português da terceira edição em inglês.

OLIVEIRA, P. H. A. S. Processo aproximado para consideração da nãolinearidade física de pilares em concreto armado. 2004. 125 f. Dissertação (Mestrado) - Curso de Engenharia Civil, Escola Politécnica, Universidade de São Paulo, São Paulo, 2004. Cap. 7. Disponível em: <http://www.teses.usp.br/teses/disponiveis/3/3144/tde-26092005-220547/pt-br.php>. Acesso em: 19 abr. 2016.

PAULA, J. A. Algoritmos para o estudo de pilares esbeltos de concreto armado solicitados a flexão normal composta. 1988. 191 f. Dissertação (Mestrado) Curso de Engenharia Civil, Departamento de Estruturas, Universidade de São Paulo, São Carlos, 1988. Cap. 8. Disponível em:

<http://www.set.eesc.usp.br/static/media/producao/1988ME_JoelAlvesdePaula.pdf>. Acesso em: 18 abr. 2016.

PINHEIRO, L. M. et al. Bases para cálculo. In: PINHEIRO, L. M. Fundamentos do concreto e projeto de edifícios. São Carlos: Departamento de Engenharia de Estruturas, 2016.

PINHEIRO, L. M.; NASCIMENTO, A. L.; FONTES, F. F. Tabelas Gerais: Tabelas para Dimensionamento de Armaduras. São Carlos: Departamento de Engenharia de São Carlos, 2003. 14 p.

PINTO, R. S.; RAMALHO, M. A. Não linearidade física e geométrica no projeto de edifícios usuais de concreto armado. Cadernos de Engenharia de Estruturas. São Carlos, 2002. 171 - 206 p.

PIRES, S. L. Análise de pilares de concreto armado submetidos à flexão normal composta considerando as não-linearidades física e geométrica. 2006. $100 \mathrm{f}$. Dissertação (Mestrado) - Curso de Engenharia Civil, Universidade Estadual de Campinas, Campinas, 2006. Cap. 8. Disponível em: $<$ http://www.bibliotecadigital.unicamp.br/document/?code $=000782358$ >. Acesso em: 19 abr. 2016. 
RIBEIRO, K. Diagramas para verificação de pilares retangulares em concreto armado submetidos à flexão composta normal. 2011. 308 f. Dissertação (Mestrado) - Curso de Engenharia Civil, Universidade Federal de Santa Catarina, Florianópolis, 2011. Disponível em:

$<$ https://repositorio.ufsc.br/bitstream/handle/123456789/95091/289075.pdf?sequence $=1>$.

Acesso em: 29 set. 2015.

SANTOS, L. M. Cálculo de concreto armado: segundo a nova NB-1 e o CEB. 2. ed. São Paulo: Editora LMS, 1983. 541 p.

SANTOS, L. M. Estado-limite último de instabilidade. M-03/87. São Paulo: Escola Politécnica da Universidade de São Paulo, 1987. 112 p.

SANTOS, L. M. Sub-rotinas básicas do dimensionamento de concreto armado. São Paulo: Editora Thot, 1994. 450 p.

SCADELAI, M. A. Dimensionamento de pilares de acordo com a NBR 6118:2003. 2004. 124 f. Dissertação (Mestrado) - Curso de Engenharia Civil, Departamento de Estruturas, Universidade de São Paulo, São Carlos, 2004. Cap. 9. Disponível em:

<http://web.set.eesc.usp.br/static/data/producao/2004ME_MuriloAlessandroScadelai. pdf>. Acesso em: 29 set. 2015.

SCHIRMBECK, F. R. G. Diagramas momento-curvatura para elementos estruturais de concreto armado submetidos a carregamento monotônico ou cíclico. 1988. 83 f. Dissertação (Mestrado) - Curso de Engenharia Civil, Universidade Federal do Rio Grande do Sul, Porto Alegre, 1988. Disponível em: <http://www.lume.ufrgs.br/handle/10183/1331>. Acesso em: 29 set. 2015.

SOUZA, T. J. M. Considerações sobre os efeitos locais de $\mathbf{2}^{\mathrm{a}}$ ordem. V Simpósio EPUSP sobre estruturas de concreto, São Paulo, 2003.

SÜSSEKIND, J. C. Curso de concreto: Volume II - Concreto Armado. 3. ed. Rio de Janeiro: Editora Globo, 1987. 280 p.

VENTURINI, W. S.; RODRIGUES, R. O. Dimensionamento de peças retangulares de concreto armado solicitadas à flexão reta: Material Bibliográfico utilizado nas disciplinas de concreto armado pelo Departamento de Estruturas da Escola de Engenharia de São Carlos. São Carlos: Departamento de Engenharia de São Carlos, 1987. 131 p.

WIGHT, J. K.; MACGREGOR, J. G. Reinforced Concrete: Mechanics \& Design. 6. ed. New Jersey: Pearson Education, 2012. 1157 p. 


\section{APÊNDICE A}

Neste apêndice apresenta-se a dedução das equações das deformações e das forças resultantes do concreto e do aço em função da curvatura adimensional $\theta$, além do algoritmo para determinação dos diagramas momento fletor - força normal curvatura.

As deduções do equacionamento são conforme Santos (1994) e o algoritmo para a determinação dos diagramas, conforme Ribeiro (2011).

\section{A.1 HIPÓTESES BÁSICAS}

As hipóteses básicas para a determinação do equacionamento e para o desenvolvimento do método para obtenção dos diagramas são as mesmas expostas no item 4 deste trabalho.

\section{A.2 CURVATURA ADIMENSIONAL}

A grandeza curvatura apresenta dimensão: pode ser expressa em $\mathrm{m}^{-1}$, de forma que apresente resultados da ordem de $10^{-5} \mathrm{~m}^{-1}$. É conveniente, portanto, a definição de uma curvatura adimensional (SANTOS, 1994). Assim define-se:

$$
\theta=1000 \cdot h \cdot \frac{1}{r}
$$

Nessa expressão, $h$ é a altura da seção em análise e $r$ o raio de curvatura relativo à direção longitudinal da peça. 


\section{A.3 EQUAÇÕES DE DEFORMAÇÕES EM FUNÇÃO DA CURVATURA}

Aplicando a expressão da curvatura na fibra superior da seção e na fibra da linha neutra, nos dois diagramas genéricos de deformações da figura A.1, conclui-se que:

Figura A.1 - Diagramas genéricos de deformações
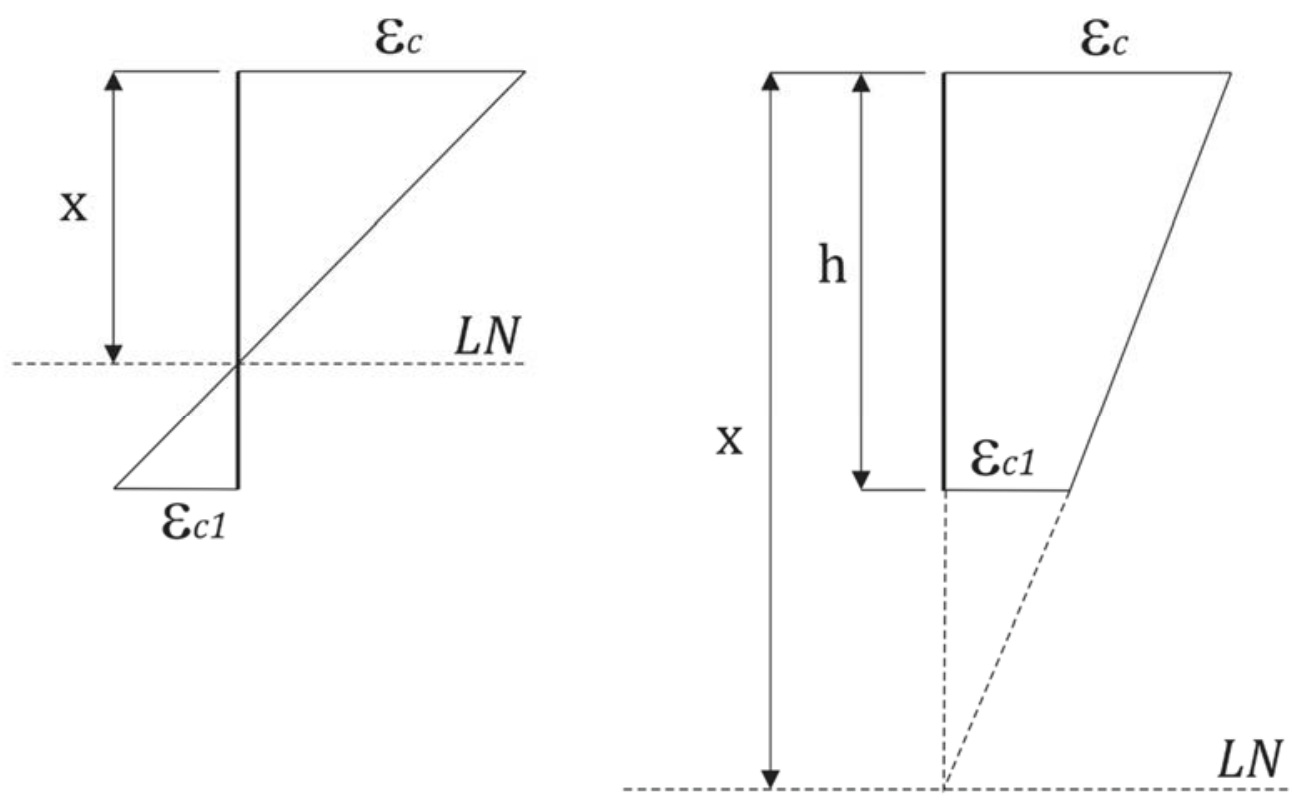

Fonte: Elaborado pelo Autor.

$$
\frac{1}{r}=\frac{\varepsilon_{c}-0}{x}=\frac{\varepsilon_{c}}{x}
$$

E, portanto:

$$
\theta=1000 \cdot h \cdot \frac{\varepsilon_{c}}{x} \rightarrow \varepsilon_{c}=\frac{\theta \cdot x}{1000 \cdot h}
$$

Ou utilizando $\varepsilon_{c}$ em \%:

$$
\varepsilon_{c}=\frac{\theta \cdot x}{h}
$$


Procedendo de forma análoga é possível determinar as demais deformações pertinentes para análise do estado-limite último: fibra superior do concreto, fibra inferior do concreto, armadura das $n$ linhas e na fibra a 3/7 de h (quando o concreto pertencer até a classe C50), lembrando que é prudente tomar, para o cálculo da curvatura, a fibra da linha neutra, pois sua deformação é nula. Assim, tem-se para as deformações as expressões presentes na tabela A.1

Tabela A.1 - Expressões para o cálculo das deformações em função da curvatura

\begin{tabular}{cc}
\hline Deformação & Expressões \\
\hline No concreto (fibra superior) & $\varepsilon_{c}=\frac{\theta \cdot x}{h}$ \\
\hline No concreto (fibra inferior) & $\varepsilon_{c i}=\frac{\theta \cdot(x-h)}{h}$ \\
\hline No aço (armadura qualquer) & $\varepsilon_{S n}=\frac{\theta \cdot\left(x-d_{n}\right)}{h}$ \\
\hline Na fibra a $\frac{3}{7} h$ & $\varepsilon_{\left(\frac{3}{7} h\right)}=\frac{\theta \cdot\left[x-\left(\frac{3}{7} \cdot h\right)\right]}{h}$ \\
\hline
\end{tabular}

Fonte: Elaborado pelo Autor.

\section{A.4 ESTADO-LIMITE ÚLTIMO}

As deformações calculadas devem respeitar o E.L.U. (Estado-limite último) de ruptura. Dessa forma, para concreto até classe C50, é necessário exigir que:
a) $\varepsilon_{c} \leq 3,5 \%$;
b) $\varepsilon_{c i} \leq 3,5 \%$;
c) $\varepsilon_{s n} \leq 10 \%$;
d) $\quad \varepsilon\left(\frac{3}{7} h\right) \leq 2 \%$.

\section{A.5 ESFORÇO RESISTENTE DA ARMADURA}

Para determinação dos esforços resistentes da armadura, é necessário analisar a seção (linhas de armadura) e o diagrama tensão - deformação do aço. Uma das 
hipóteses básicas de dimensionamento é a de que a resistência do concreto à tração seja nula, portanto todo o esforço de tração é absorvido pela armadura de aço. Dessa forma, analisando a figura A.2, que apresenta um diagrama genérico de deformação que pode ocorrer na seção, conclui-se que a força $R_{S}$ é dada por:

Figura A.2 - Diagrama genérico de deformações

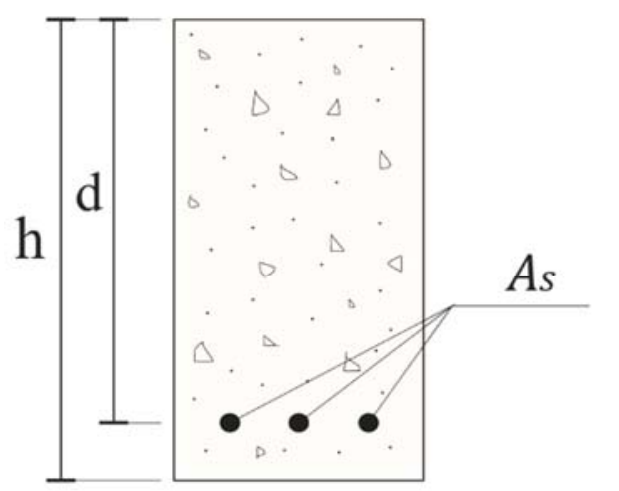

Seção Transversal

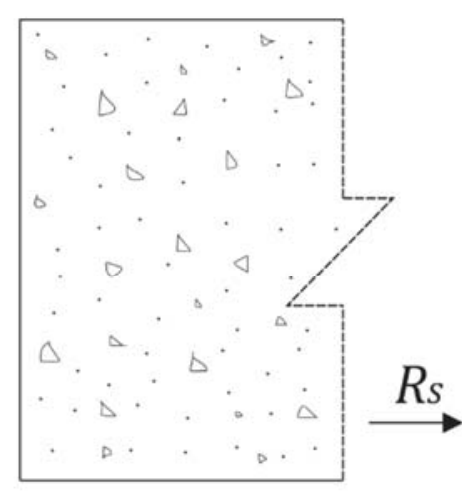

Corte Lateral

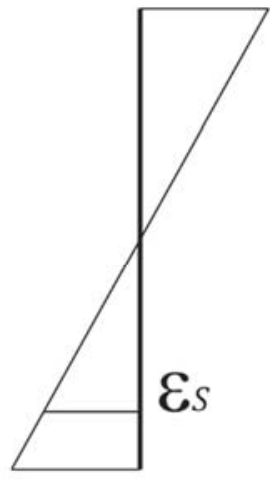

Fonte: Elaborado pelo Autor.

$$
R_{s}=A_{s} \cdot \sigma_{s d}
$$

Para obter o valor $\sigma_{s d}$ é necessário computar a deformação presente na fibra da armadura de aço e, através do diagrama tensão - deformação, extrair a tensão atuante. 
Figura A.3 - Diagramas tensão - deformação para aços de armadura passiva

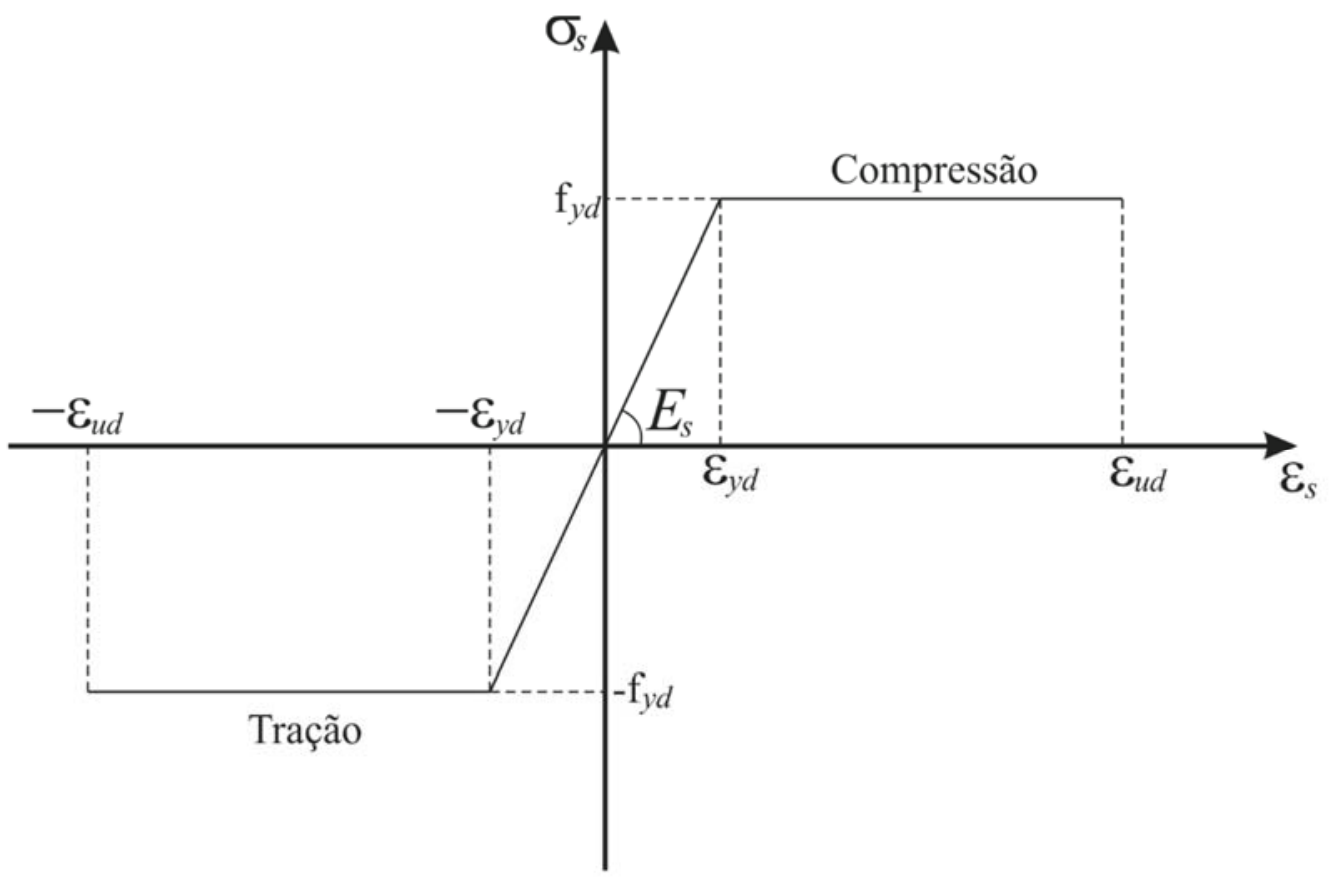

Fonte: Adaptado da ABNT NBR 6118:2014.

Assim, analisando o diagrama tensão - deformação do aço presente na figura A.3, conclui-se que há dois casos possíveis a serem considerados:

- $\quad$ Comportamento linear para $\varepsilon_{s} \leq \varepsilon_{y d}$ :

$$
\sigma_{s d}=f_{y d} \cdot \frac{\varepsilon_{s}}{\varepsilon_{y d}}
$$

- $\quad$ Patamar de escoamento para $\varepsilon_{s}>\varepsilon_{y d}$ :

$$
\sigma_{s d}=f_{y d}
$$

Resumidamente, têm-se, para a armadura de aço, os esforços resistentes presentes na tabela A.2. As seções analisadas apresentarão $n$ linhas de armadura, portanto haverá $n$ esforços resistentes. 
Esforços resistentes da armadura de aço

$$
\left|\varepsilon_{s}\right|>\left|\varepsilon_{y d}\right|
$$

Armadura de Aço

$$
\left|\varepsilon_{s}\right| \leq\left|\varepsilon_{y d}\right|
$$

\section{Expressões}

$$
R_{s}=A_{s} \cdot f_{y d}
$$

$R_{s}=A_{s} \cdot f_{y d} \cdot \frac{\varepsilon_{s}}{\varepsilon_{y d}}$

Fonte: Elaborado pelo Autor.

\section{A.6 ESFORÇO RESISTENTE DO CONCRETO}

Santos (1994) apresenta o equacionamento segundo a NB-1/78, norma vigente na época do lançamento desse livro. O equacionamento é semelhante ao da ABNT NBR 6118:2014 para concretos de classe até C50. Dessa forma, o equacionamento será realizado conforme esse autor propõe.

\section{A.7 DEFORMAÇÃO $\varepsilon_{c}^{\prime}$ NA FIBRA GENÉRICA}

Figura A.4 - Deformação genérica $\varepsilon^{\prime}{ }_{c}$

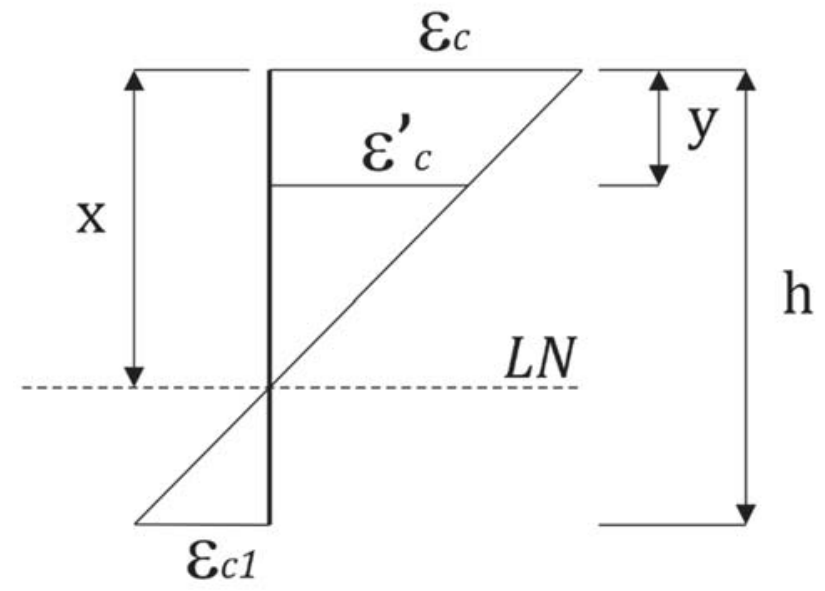

Fonte: Adaptado da ABNT NBR 6118:2014, item 8.3.6.

Da figura A.4, por semelhança de triângulos, conclui-se que: 


$$
\varepsilon_{c}^{\prime}=\varepsilon_{c} \cdot \frac{(x-y)}{x}
$$

De forma que:

- $\quad \varepsilon_{c}=$ Encurtamento máximo (na borda superior);

- $\quad \varepsilon_{c 1}=$ Deformação na borda 1 (borda inferior), que pode ser positivo ou negativo;

- $\quad \varepsilon_{c}^{\prime}=$ Deformação numa fibra genérica, à distância y da borda superior.

\section{A.8 TENSÃO $\sigma_{c}^{\prime}$ NA FIBRA GENÉRICA}

Procedendo de forma análoga à determinação do esforço resistente da armadura de aço, com a deformação presente na fibra genérica de concreto, é possível, através do diagrama tensão - deformação, obter a tensão atuante no concreto.

Figura A.5 - Diagrama tensão - deformação idealizado

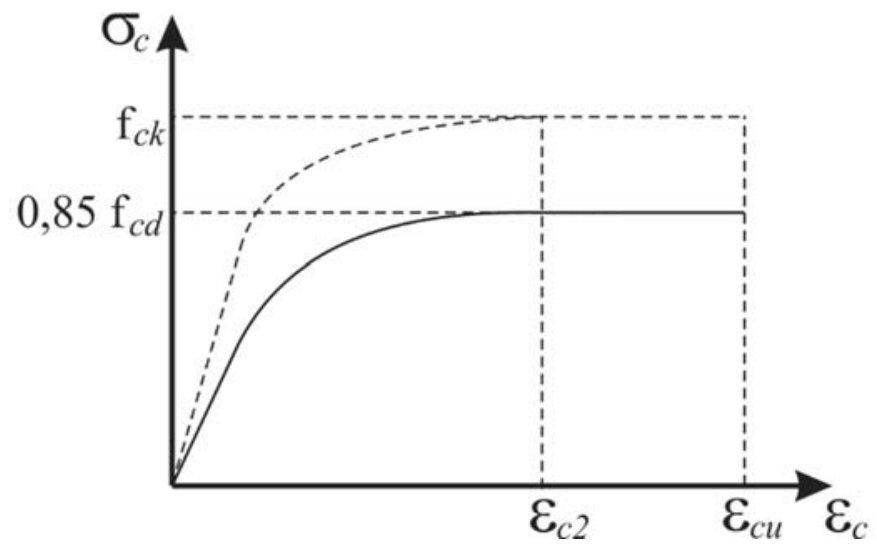

Fonte: Adaptado da ABNT NBR 6118:2014, item 8.2.10.1.

- Para concretos de classe até C50:

$$
\begin{aligned}
& \varepsilon_{c 2}=2,0 \% 0 \\
& \varepsilon_{c u}=3,5 \% 0
\end{aligned}
$$

De acordo com o diagrama da figura A.5 (Concretos de classe até C50): 
- Para $0 \leq \varepsilon_{c}^{\prime} \leq 2 \%$ o

$$
\sigma^{\prime}{ }_{c}=0,85 \cdot f_{c d} \cdot\left[1-\left(1-\frac{\varepsilon_{c}^{\prime}}{2}\right)^{2}\right]=0,85 \cdot f_{c d} \cdot \frac{\varepsilon_{c}^{\prime}}{4} \cdot\left(4-\varepsilon_{c}^{\prime}\right)
$$

- $\quad$ Para $\varepsilon_{c}^{\prime}>2 \%$ o

$$
\sigma_{c}^{\prime}=0,85 \cdot f_{c d}=\frac{0,85 \cdot f_{c k}}{\gamma_{c}}
$$

\section{A.9 ENCURTAMENTO MÍNIMO}

É necessária para dedução das expressões a consideração de um encurtamento mínimo $\varepsilon_{c o}$.

Figura A.6 - Encurtamento mínimo $\varepsilon_{c o}$
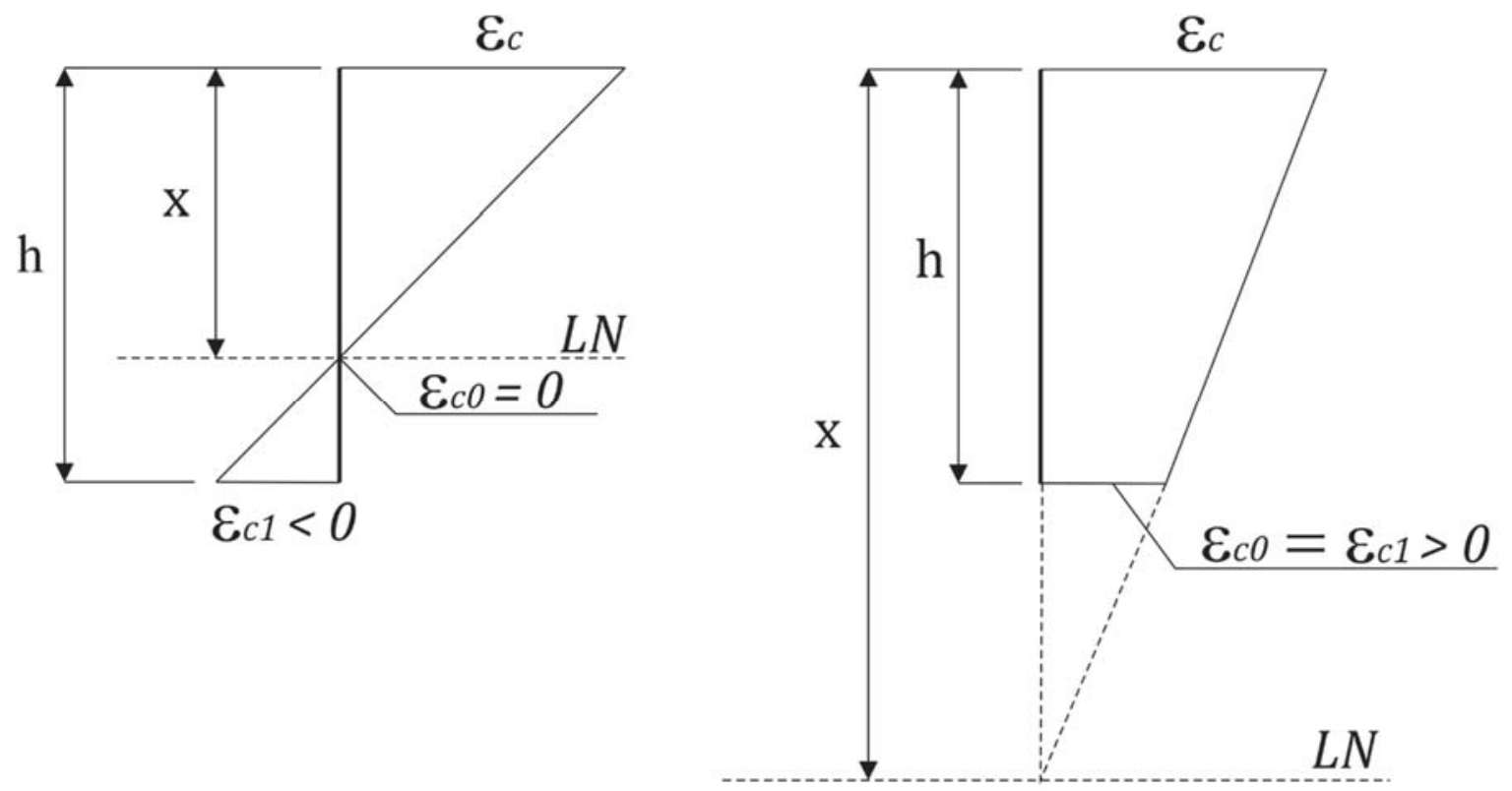

Fonte: Adaptado de SANTOS, 1994, p. 87.

A figura A.6 mostra que:

- $\quad \varepsilon_{c o}=0$ quando $(x \leq h)$

- $\varepsilon_{c o}=\varepsilon_{c 1}=\varepsilon_{c} \cdot \frac{(x-h)}{x}$ quando $(x>h)$ 
Ou seja, $\varepsilon_{c o}$ é nulo quando a linha neutra está dentro da seção, e $\varepsilon_{c o}=\varepsilon_{c 1}$ quando a linha neutra está fora da seção.

\section{A.10 RESULTANTE $R_{c c}$ E BRAÇO DE ALAVANCA $a$}

A resultante de compressão $R_{c c}$ no concreto e sua posição a podem ser determinadas através das integrais definidas pelas equações A.15 e A.16, onde $b$ é a largura da seção no nível $y$, e $d y$ é a largura da área elementar no mesmo nível, conforme demonstrado na figura A.7.

Figura A.7 - Resultante $R_{c c}$ e sua respectiva posição
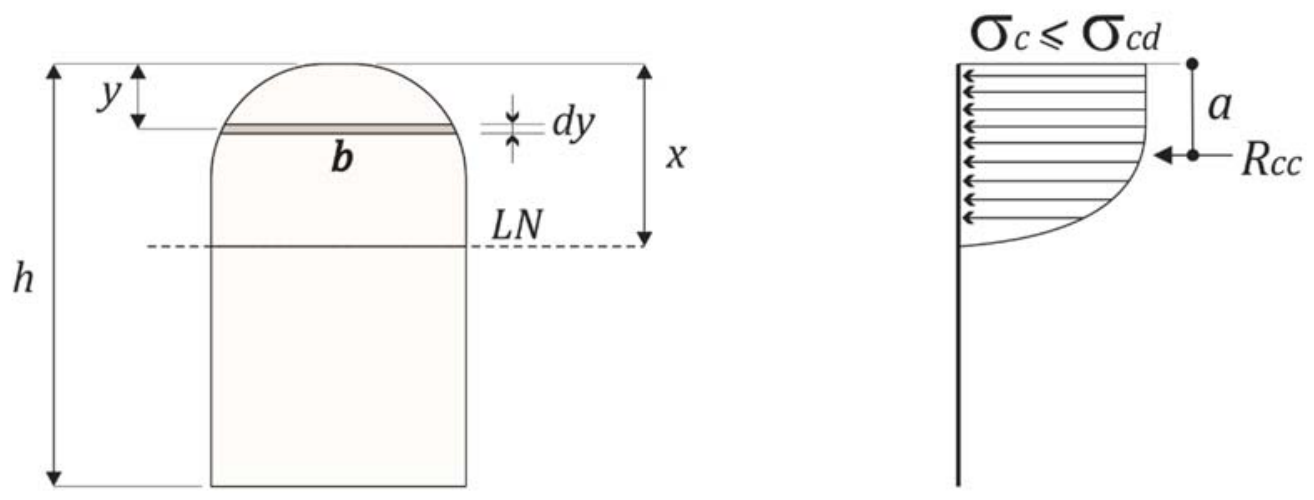

Fonte: Adaptado de SANTOS, 1994, p. 88.

$$
\begin{aligned}
& R_{c c}=\int_{0}^{x} \sigma_{c}^{\prime} \cdot b \cdot d y \quad \text { ou } \quad \int_{0}^{h} \sigma_{c}^{\prime} \cdot b \cdot d y \\
& R_{c c} \cdot a=\int_{0}^{x} \sigma_{c}^{\prime} \cdot b \cdot y \cdot d y \quad \text { ou } \quad \int_{0}^{h} \sigma_{c}^{\prime} \cdot b \cdot y \cdot d y
\end{aligned}
$$

Conforme se trate de $x \leq h$ ou $x>h$, respectivamente. 


\section{A.11 OUTRAS RELAÇÕES}

Conforme definido em A.4:

$$
\varepsilon_{c}=\frac{\theta \cdot x}{h} \rightarrow \frac{x}{h}=\frac{\varepsilon_{c}}{\theta}
$$

Com o emprego da relação A.17, e com a definição de encurtamento mínimo dado por A.13 e A.14, é possível determinar que:

- $\varepsilon_{c o}=0$ para $\varepsilon_{c} \leq \theta$

- $\varepsilon_{c o}=\varepsilon_{c}-\theta$ para $\varepsilon_{c}>\theta$

Isolando y em A.8, e considerando A.17, chega-se a:

$$
y=\frac{h}{\theta} \cdot\left(\varepsilon_{c}-\varepsilon_{c}^{\prime}\right)
$$

Derivando A.20 em relação a $\varepsilon_{c}^{\prime}$, tem-se:

$$
\frac{d y}{d \varepsilon_{c}^{\prime}}=-\frac{h}{\theta} \rightarrow d y=-\frac{h}{\theta} \cdot d \varepsilon_{c}^{\prime}
$$

\section{A.12 DIVISÃO DO ESTUDO EM DOIS CASOS}

Analisando as integrais A.15 e A.16, $\sigma_{c}^{\prime}$ é função de $\varepsilon_{c}^{\prime}, y$ e $d y$ também o são, conforme explicitado em A.20 e A.21. Quanto a $b$, como o trabalho utiliza seções retangulares, o parâmetro é constante em toda seção.

Pode-se então trabalhar com a variável $\varepsilon_{c}^{\prime}$ em substituição à variável $y$, ou seja, integrar de $\varepsilon_{c}$ a $\varepsilon_{c o}$ ao invés de integrar de 0 a $x$ ou de 0 a $h$. Dessa forma o problema fica reduzido a dois casos, conforme explicitado na figura A.8. 
Figura A.8 - Casos a considerar

\section{Caso 1}
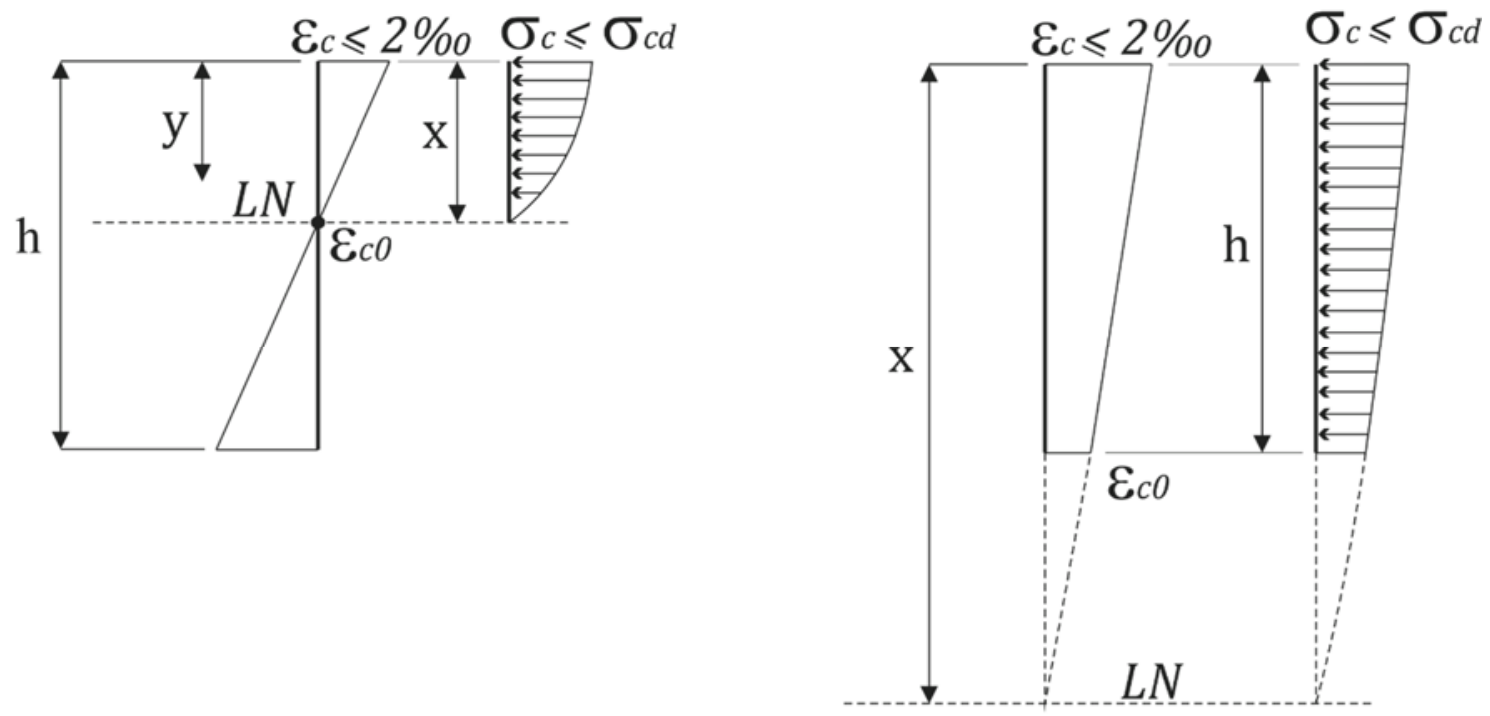

Caso 2
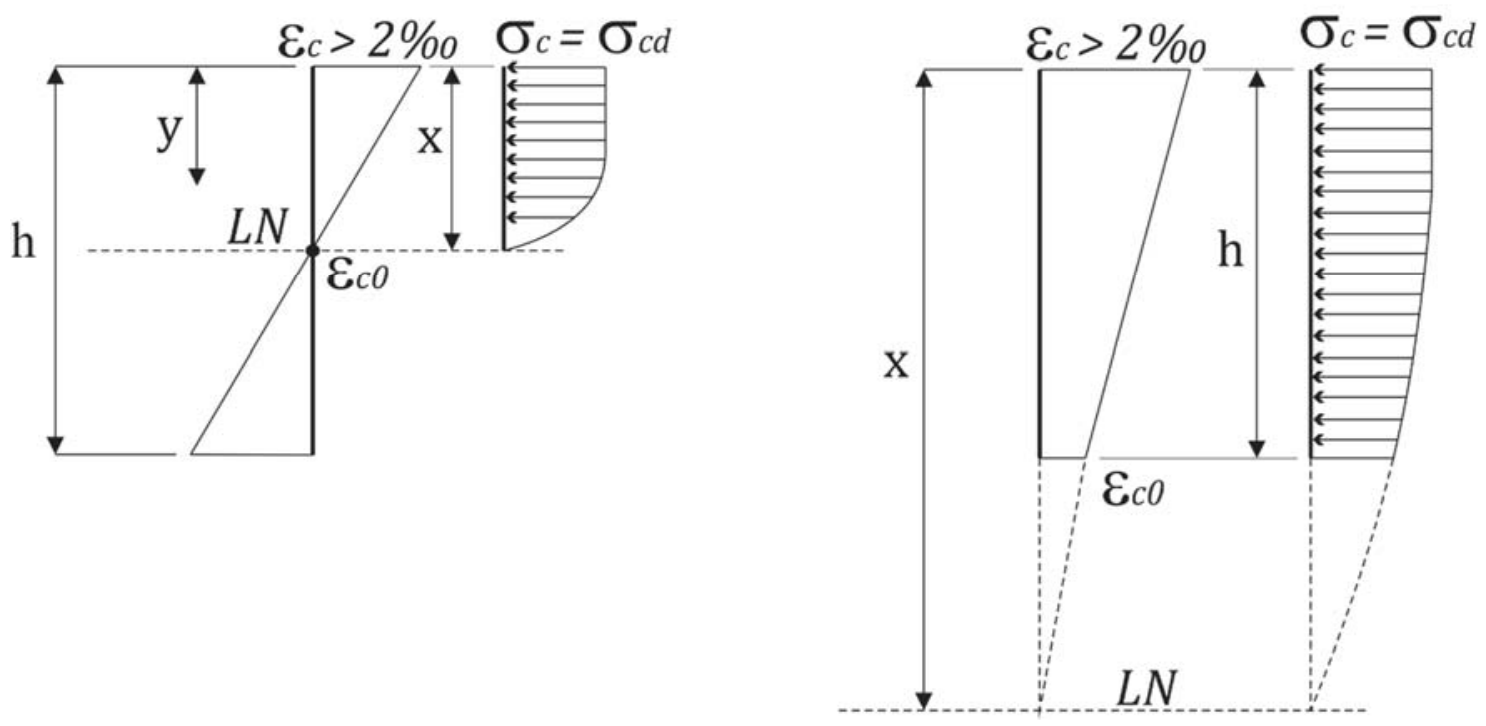

Fonte: Adaptado de SANTOS, 1994, p. 89.

- Caso 1: $\varepsilon_{c} \leq 2 \%$ o

- $\quad$ Caso 2: $\varepsilon_{c}>2 \%$

Naturalmente as expressões de $R_{c c}$ e $a$ conterão $\varepsilon_{c o}$ que valerá zero (quando $x \leq h$ ) ou $\varepsilon_{c}-\theta$ (quando $x>h$ ). 


\section{A.13 SEÇÃO RETANGULAR}

\section{- Caso 1}

Sendo $\varepsilon_{c} \leq 2 \%, \sigma_{c}^{\prime}$ é dado por A.11. Como a seção é retangular, $b$ é constante e $d y$ é dado por A.21. Aplicando A.15 e integrando de $\varepsilon_{c}$ a $\varepsilon_{c o}$, tem-se:

$$
R_{c c}=\int_{\varepsilon_{c}}^{\varepsilon c o} \sigma_{c d} \cdot\left(\varepsilon_{c}^{\prime}-\frac{\varepsilon_{c}^{\prime 2}}{4}\right) \cdot b \cdot\left(-\frac{h}{\theta}\right) d \varepsilon_{c}^{\prime}
$$

De acordo com A.16 e levando em conta A.20 e A.21:

$$
R_{c c} \cdot a=\int_{\varepsilon_{c}}^{\varepsilon c o} \sigma_{c d} \cdot\left(\frac{4 \varepsilon_{c}^{\prime}-\varepsilon_{c}^{\prime 2}}{4}\right) \cdot b \cdot \frac{h}{\theta} \cdot\left(\varepsilon_{c}-\varepsilon_{c}^{\prime}\right)\left(-\frac{h}{\theta}\right) d \varepsilon_{c}^{\prime}
$$

\section{- $\quad$ Caso 2}

Como $\varepsilon_{c}>2 \%$, a integral A.15 será dividida em duas partes: de $\varepsilon_{c}$ a 2 e de 2 a $\varepsilon_{c o}$, com o emprego de A.11 e A.12, respectivamente:

$$
R_{c c}=\int_{\varepsilon_{c}}^{2} \sigma_{c d} \cdot b \cdot\left(-\frac{h}{\theta}\right) d \varepsilon_{c}^{\prime}+\int_{2}^{\varepsilon c o} \sigma_{c d} \cdot\left(\frac{4 \varepsilon_{c}^{\prime}-\varepsilon_{c}^{\prime 2}}{4}\right) \cdot b \cdot\left(-\frac{h}{\theta}\right) d \varepsilon_{c}^{\prime}
$$

E para o cálculo do braço de alavanca:

$$
\begin{array}{r}
R_{c c} \cdot a=\int_{\varepsilon_{c}}^{2} \sigma_{c d} \cdot b \cdot \frac{h}{\theta} \cdot\left(\varepsilon_{c}-\varepsilon_{c}^{\prime}\right) \cdot\left(-\frac{h}{\theta}\right) d \varepsilon_{c}^{\prime} \\
+\int_{2}^{\varepsilon c o} \sigma_{c d} \cdot\left(\frac{4{\varepsilon^{\prime}}_{c}-{\varepsilon_{c}^{\prime}}^{2}}{4}\right) \cdot b \cdot \frac{h}{\theta} \cdot\left(\varepsilon_{c}-\varepsilon_{c}^{\prime}\right) \cdot\left(-\frac{h}{\theta}\right) d \varepsilon_{c}^{\prime}
\end{array}
$$

A tabela A.3 apresenta as integrais desenvolvidas de forma que $\varepsilon_{c o}$ vale zero quando $x \leq h$ e $\varepsilon_{c}-\theta$ quando $x>h$. 
Condições

Expressões

$$
\begin{aligned}
& R_{c c}=\sigma_{c d} \cdot b \cdot x \cdot\left(\frac{\varepsilon_{c}}{2}-\frac{\varepsilon_{c}{ }^{2}}{12}\right) \\
& \varepsilon_{c} \leq 2 \% 0 \\
& x \leq h \\
& a=\frac{x}{4} \cdot \frac{\left(8-\varepsilon_{c}\right)}{\left(6-\varepsilon_{c}\right)} \\
& R_{c c}=\sigma_{c d} b h\left(\varepsilon_{c}+\frac{\varepsilon_{c} \theta}{4}-\frac{\varepsilon_{c}^{2}}{4}-\frac{\theta}{2}-\frac{\theta^{2}}{12}\right) \\
& \varepsilon_{c} \leq 2 \% \\
& x>h \\
& a=\frac{\varepsilon_{c} h}{\theta}-\frac{h\left[\frac{\varepsilon_{c}{ }^{3}}{3}-\frac{\varepsilon_{c}{ }^{4}}{16}-\frac{\left(\varepsilon_{c}-\theta\right)^{3}}{3}+\frac{\left(\varepsilon_{c}-\theta\right)^{4}}{16}\right]}{\theta^{2}\left(\varepsilon_{c}+\frac{\varepsilon_{c} \theta}{4}-\frac{\varepsilon_{c}^{2}}{4}-\frac{\theta}{2}-\frac{\theta^{2}}{12}\right)} \\
& \varepsilon_{c}>2 \% 0 \\
& R_{c c}=\sigma_{c d} b x\left(1-\frac{2}{3 \varepsilon_{c}}\right)
\end{aligned}
$$$$
x \leq h
$$$$
a=x \frac{\left(3 \varepsilon_{c}^{2}-4 \varepsilon_{c}+2\right)}{2 \varepsilon_{c}\left(3 \varepsilon_{c}-2\right)}
$$$$
R_{c c}=\sigma_{c d} b h\left(\frac{12 \varepsilon_{c}-8-\left(\varepsilon_{c}-\theta\right)^{2}\left(6-\varepsilon_{c}+\theta\right)}{12 \theta}\right)
$$

$\varepsilon_{c}>2 \%$

$$
a=\frac{h}{\theta}\left\{\varepsilon_{c}-\frac{\left[24 \varepsilon_{c}^{2}-16-\left(\varepsilon_{c}-\theta\right)^{3}\left(16-3 \varepsilon_{c}+3 \theta\right)\right]}{4\left[12 \varepsilon_{c}-8-\left(\varepsilon_{c}-\theta\right)^{2}\left(6-\varepsilon_{c}+\theta\right)\right]}\right\}
$$

Fonte: RIBEIRO, 2011, p. 61.

\section{A.14 ALGORITMO DE OBTENÇÃO DO DIAGRAMA MOMENTO FLETOR - FORÇA NORMAL - CURVATURA}

A ABNT NBR 6118:2014 não apresenta um algoritmo para o cálculo dos diagramas. É necessária consulta a bibliografia complementar. O algoritmo varia dependendo da obra consultada, mas os passos são basicamente os mesmos. Os 
trabalhos de Fusco (1981), França (1984), Araújo (1984), Süssekind (1987) e Santos (1987) apresentam algoritmos para a determinação dos diagramas, porém, neste trabalho será utilizado o algoritmo proposto por Ribeiro (2011).

Conforme explicitado por Ribeiro (2011), o processo adotado, para uma seção transversal retangular com armadura simétrica disposta em faces opostas, deve ser realizado da seguinte forma:

a) Adota-se para curvatura adimensional $\theta \approx 0$;

b) Arbitra-se a profundidade da linha neutra, representada por $x$, inicialmente $x \approx 0$, e nas etapas seguintes $x=x+\Delta x$;

c) Calculam-se as deformações no concreto $\left(\varepsilon_{c}\right)$, no aço das armaduras $\left(\varepsilon_{s n}\right)$ e na seção transversal $\left(\varepsilon\left(\frac{3}{7} h\right)\right)$ pelas expressões da Tabela A.1;

d) Calculam-se as forças resultantes no concreto $\left(R_{c c}\right)$, pelas expressões da Tabela A.3, e no aço das camadas de armadura $\left(R_{s n}\right)$, pelas expressões da Tabela A.2;

e) Calcula-se o valor do esforço normal atuante na seção, pela expressão:

$$
N_{\text {atuante }}=R_{c c}+R_{s 1}+R_{s 2} \cdots+R_{s n}
$$

f) Verifica-se se $N_{\text {atuante }}=N_{d}$ e, caso contrário, adota-se um novo valor para a profundidade da linha neutra $(x=x+\Delta x)$, e se repetem as fases do processo;

g) Quando a igualdade for verificada $\left(N_{\text {atuante }}=N_{d}\right)$, calcula-se o valor da distância $(a)$ entre a força resultante no concreto e o centroide da seção transversal pelas expressões da Tabela A.3;

h) Determina-se o momento fletor atuante $(M)$ :

$M=R_{s 1} \cdot\left(\frac{h}{2}-d_{1}\right)+R_{s 2} \cdot\left(\frac{h}{2}-d_{2}\right)+\cdots+R_{s n} \cdot\left(\frac{h}{2}-d_{n}\right)+R_{c c} \cdot\left(\frac{h}{2}-a\right)$

i) Repete-se o mesmo processo para os demais valores de $\theta$, fazendo-se $\theta=\theta+\Delta \theta$.

O valor $d_{n}$ é a distância da enésima linha de armadura até o topo da seção, como demonstrado na figura A.9. 
Figura A.9 - Distâncias da armadura até o topo da seção

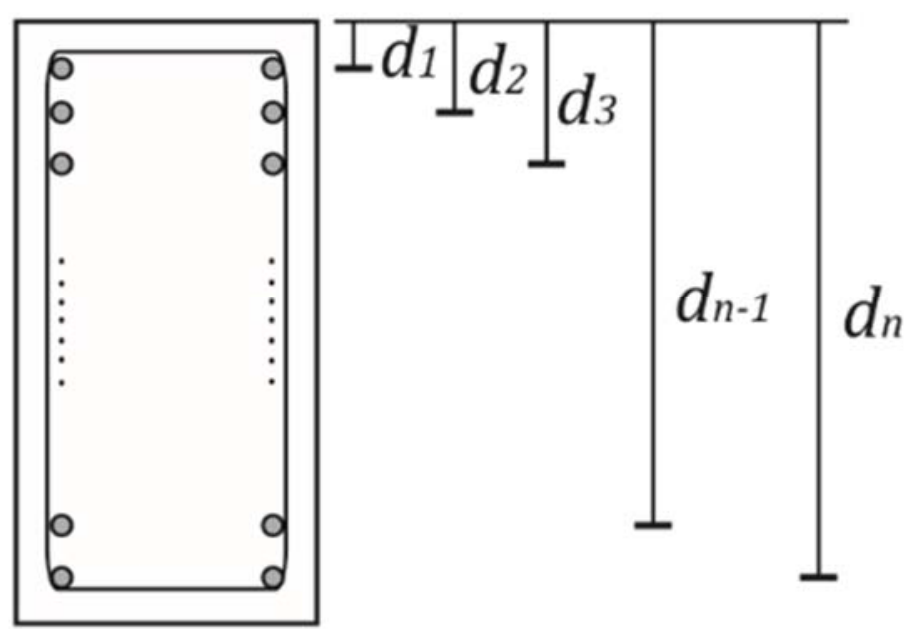

Fonte: Elaborado pelo Autor.

A determinação do diagrama momento fletor - força normal - curvatura é feita por meio de cálculo iterativo. Logo, o cálculo manual é inviável. É necessário, portanto, o uso de programas computacionais. 
274 | P á g i n a 


\section{APÊNDICE B}

No presente apêndice está apresentado o equacionamento e o algoritmo necessário para a geração das curvas $\left(N_{u}, M_{u}\right)$ que serão apresentadas na forma adimensional $(\nu, \mu)$.

Essas curvas são utilizadas no dimensionamento de peças submetidas à flexão composta normal, com a construção de ábacos de dimensionamento, em função do arranjo de armadura e de sua taxa mecânica.

Também será apresentado um algoritmo para obtenção da taxa mecânica de armadura (com disposição pré-definida), sem a necessidade dos ábacos de dimensionamento.

As deduções e o equacionamento são conforme prescrito por Venturini (1987), sendo válidos para concretos de classe até C50.

O item B.4 trata dos valores limites adimensionais para a integração do diagrama tensão-deformação do concreto, e está conforme prescrito por Paula (1988).

\section{B.1 HIPÓTESES BÁSICAS DO ESTADO-LIMITE ÚLTIMO}

Para a determinação do estado-limite último de uma peça é necessária a caracterização de seus materiais constituintes. Dessa forma, para o concreto armado, assume-se que os diagramas tensão - deformação dos materiais concreto e aço sejam conforme prescrito nos itens 3.1 .3 e 3.2.2, respectivamente.

Com relação aos limites para as deformações, tem-se o conceito de domínios de deformações (item 4 deste texto), que apresenta os valores máximos permitidos.

Os domínios de deformações subdividem-se em seis. Porém, existem três valores de deformações considerados limites (para concretos de classe até C50): $-3,5 \%$ e $-2 \%$ para o concreto e $10 \%$ para o aço. Dessa forma, os domínios de deformações podem ser divididos em três regiões bem caracterizadas. 
Assim, a partir dos valores limites (-3,5\%, -2\%o e 10\%0), definem-se as regiões I, II e III indicadas na figura B.1. A região I corresponde ao limite de deformação $10 \%$ no aço e abrange os domínios 1 e 2 . A região II é caracterizada pela deformação $-3,5$ \% no concreto e engloba os domínios 3, 4 e 4a. E a região III é definida pela deformação $-2 \%$ no concreto a $3 / 7 \mathrm{~h}$, coincidindo com o domínio 5 .

Figura B.1 - Regiões de deformações últimas

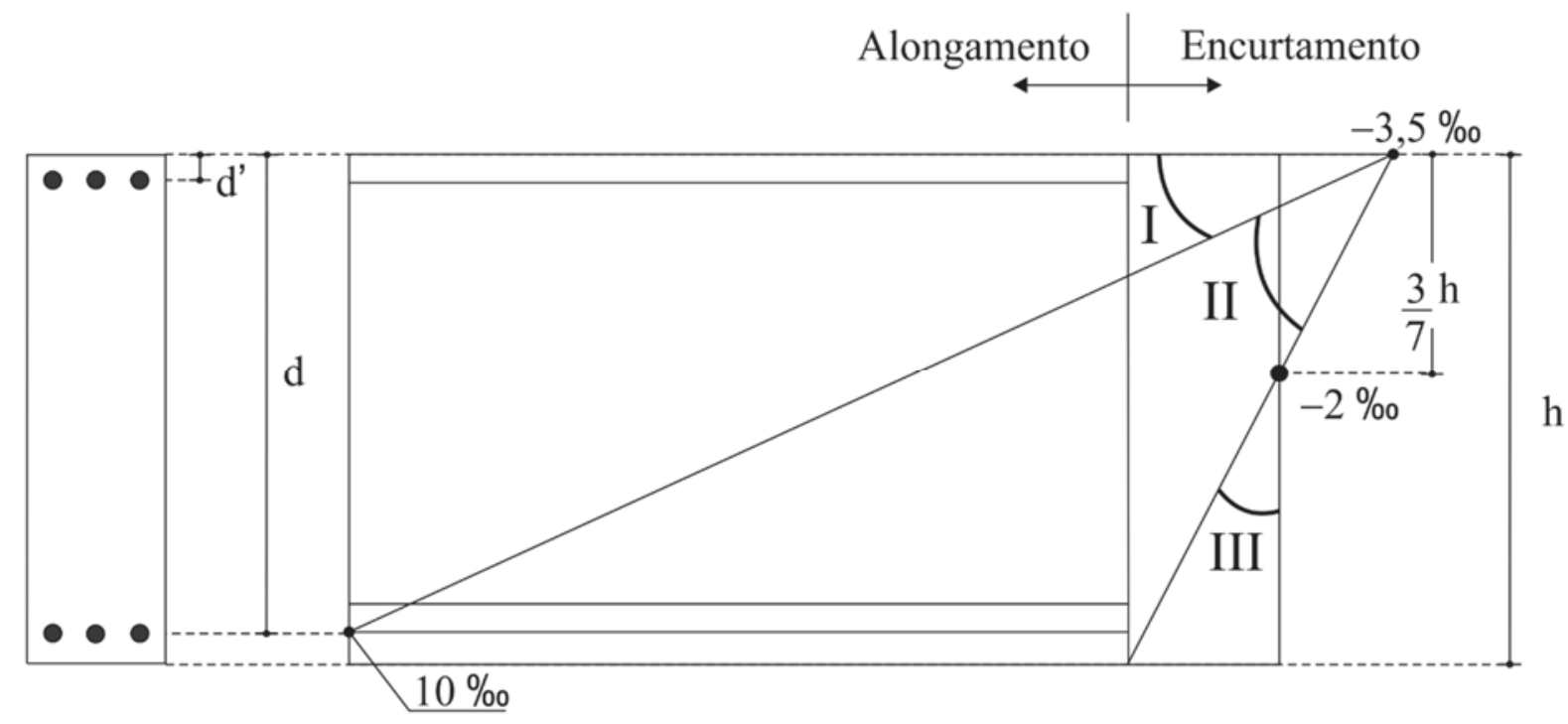

Fonte: Adaptado de VENTURINI, 1987, p. 6.

\section{B.2 COMPATIBILIDADE DE DEFORMAÇÕES}

Admitindo válida a hipótese da conservação da seção plana e considerando que uma das deformações definidas (regiões I, II ou III) seja imposta, as outras deformações da seção podem ser determinadas em função da posição da linha neutra.

\section{B.2.1 Região I}

A região I é caracterizada pela deformação última da armadura tracionada como sendo $\varepsilon_{s u}=10 \% 0=0,01$. Dessa forma, a expressão que relaciona a 
deformação $\varepsilon$ de um ponto genérico distante $y$ do centro geométrico da peça é dada pela expressão B.1, obtida com base na figura B.2.

Figura B.2 - Deformações da região I

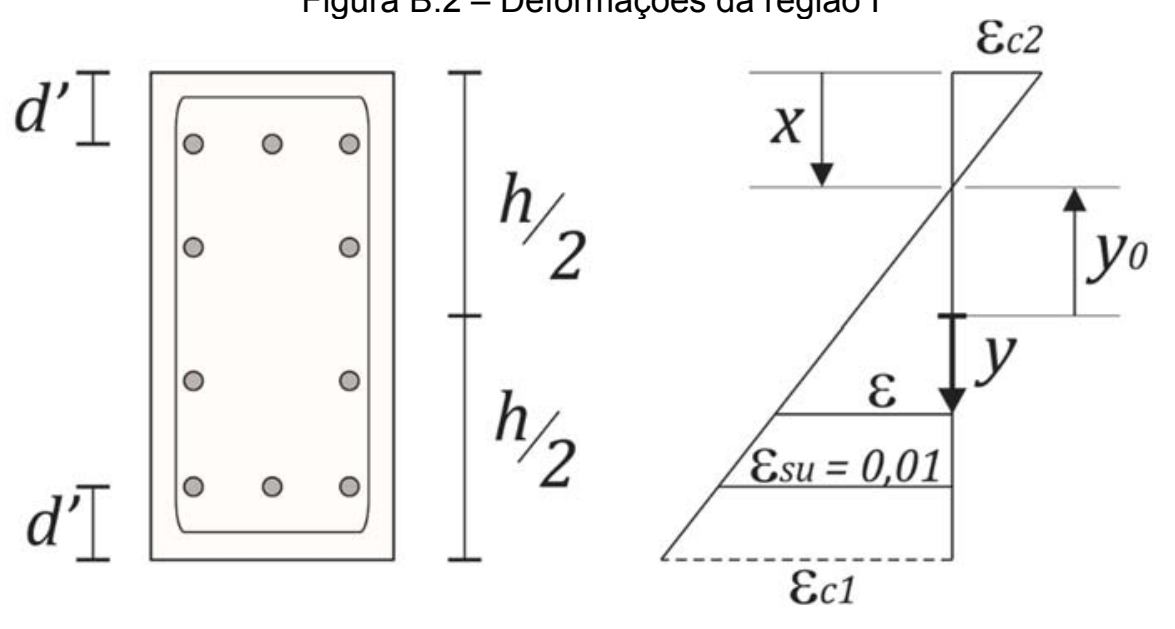

Fonte: Adaptado de VENTURINI, 1987, p. 7.

$$
\frac{\varepsilon}{y-y_{0}}=\frac{\varepsilon_{s u}}{h-d^{\prime}-x}
$$

Analisando a figura B.2, conclui-se que:

$$
x=\frac{h}{2}+y_{0}
$$

Substituindo B.2 em B.1, obtém-se:

$$
\varepsilon=\varepsilon_{s u} \cdot \frac{y-x+\frac{h}{2}}{h-d^{\prime}-x} \quad \rightarrow \quad \varepsilon=\varepsilon_{s u} \cdot \frac{\frac{x}{h}-\frac{y}{h}-\frac{1}{2}}{\frac{x}{h}+\frac{d^{\prime}}{h}-1}
$$

Podem ser adotados os parâmetros adimensionais:

$$
\begin{array}{r}
\beta_{x}^{\prime}=\frac{x}{h} \\
\delta=\frac{d^{\prime}}{h} \\
\beta_{y}=\frac{y}{h}
\end{array}
$$


Substituindo-os na expressão de $\varepsilon$, essa deformação pode ser colocada na forma:

$$
\varepsilon=\varepsilon_{s u} \cdot \frac{\beta_{x}^{\prime}-\left(\beta_{y}+0,5\right)}{\beta_{x}^{\prime}-1+\delta}
$$

A relação B.7 permite o cálculo dos valores das deformações no aço e no concreto para qualquer posição $\left(\beta_{y}\right)$, desde que se conheça a posição da linha neutra $\left(\beta_{x}^{\prime}\right)$.

A deformação $\varepsilon_{c 2}$, que se encontra no ponto mais afastado da seção, com $y=$ $-h / 2$ ou $\beta_{y}=-1 / 2$, deve obedecer aos limites da região I, assim:

$$
\begin{aligned}
& \varepsilon_{c 2} \leq 0,01 \\
& \varepsilon_{c 2} \geq-0,0035
\end{aligned}
$$

Substituindo B.8 em B.7 verifica-se que essa condição implica em dizer que $\beta_{x}^{\prime}$ pertence ao campo real. Introduzindo a desigualdade B.9 em B.7, obtém-se:

$$
0,01 \cdot \frac{\beta_{x}^{\prime}}{\beta_{x}^{\prime}-1+\delta} \geq-0,0035
$$

Simplificando B.10, em termos de $\beta_{x}^{\prime}$ tem-se:

$$
\beta_{x}^{\prime} \leq 0,259 \cdot(1-\delta)
$$

Para valores de $\beta_{x}^{\prime}$ acima do indicado em B.11, as deformações não pertencem mais à região I. Nesses casos, devem-se obter as equações de compatibilidade para a região II ou região III. 


\section{B.2.2 Região II}

A região II é caracterizada pela deformação última do concreto, presente na fibra mais comprimida da peça, como sendo $\varepsilon_{c u 2}=-3,5 \%=-0,0035$. Assim, a expressão de compatibilidade fica definida por B.12, com base na figura B.3.

Figura B.3 - Deformações da região II
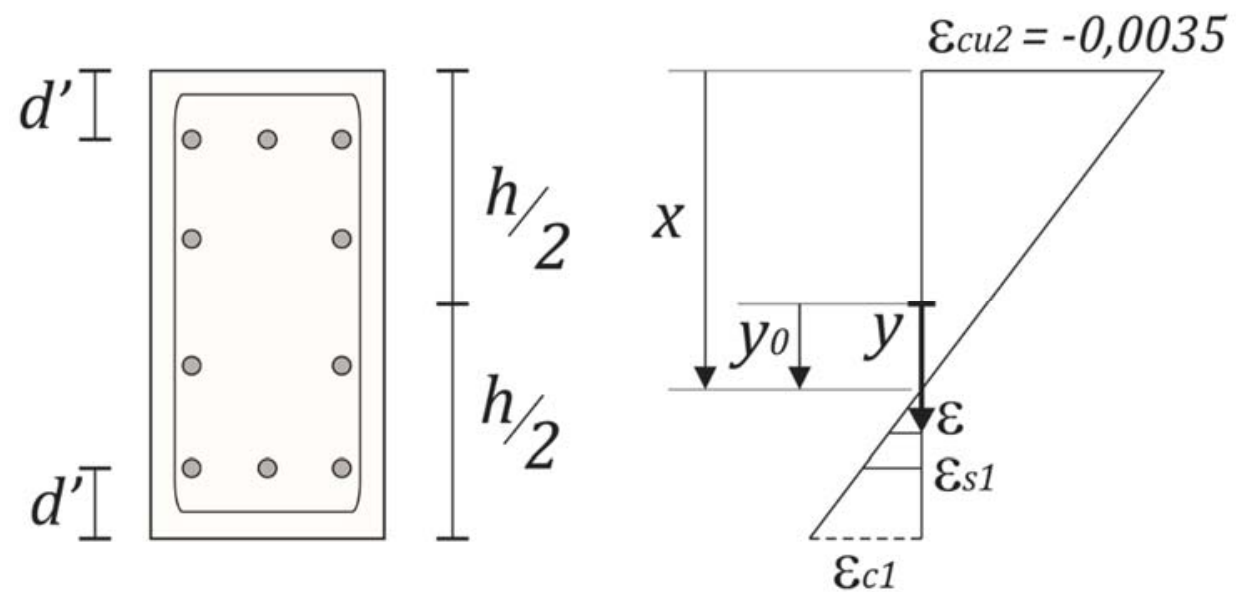

Fonte: Adaptado de VENTURINI, 1987, p. 8.

$$
\frac{\varepsilon}{y-y_{0}}=\frac{-0,0035}{0,5 \cdot h+y_{0}}
$$

Com os valores dados por B.2, B.3 e B.4, substituindo em B.12, obtém-se:

$$
\varepsilon=\varepsilon_{c u 2} \cdot \frac{\beta_{x}^{\prime}-\left(\beta_{y}+0,5\right)}{\beta_{x}^{\prime}}
$$

O valor de $\varepsilon$ deve obedecer aos seguintes limites:

$$
\begin{gathered}
\varepsilon_{s} \leq 0,01 \\
\varepsilon_{c 1} \geq 0
\end{gathered}
$$


Quando a condição B.14 não é atendida, o caso em análise pertence à região I. Caso a condição B.15 não seja atendida, o problema deve ser equacionado com as relações da região III.

Para a condição B.14, tem-se (nesse caso y é a distância do centro geométrico da peça até a linha de armadura):

$$
\beta_{y}=\frac{y}{h} \rightarrow \beta_{y}=\frac{\frac{h}{2}-d^{\prime}}{h} \rightarrow \beta_{y}=0,5-\delta
$$

Para a condição B.14, tem-se (nesse caso y é a distância do centro geométrico da peça até a borda menos comprimida):

$$
\beta_{y}=\frac{y}{h} \rightarrow \beta_{y}=\frac{\frac{h}{2}}{h} \rightarrow \beta_{y}=0,5
$$

Substituindo B.16 e B.17 em B.12, e utilizando as condições B.14 e B.15, obtém-se o seguinte intervalo de variação para $\beta_{x}^{\prime}$ dentro da região II:

$$
0,259 \cdot(1-\delta) \leq \beta_{x}^{\prime} \leq 1
$$

\section{B.2.3 Região III}

Essa região corresponde ao domínio 5. Assim, as deformações ficam em função do valor $\varepsilon_{c u 3}$ fixado para o ponto situado a $3 /{ }_{7} h$ da borda mais comprimida. A figura B.4 mostra o diagrama de deformações para a região III, e a expressão B.19 fornece a deformação para qualquer ponto y da seção, obtida com base na figura B.4. 
Figura B.4 - Deformações da região III
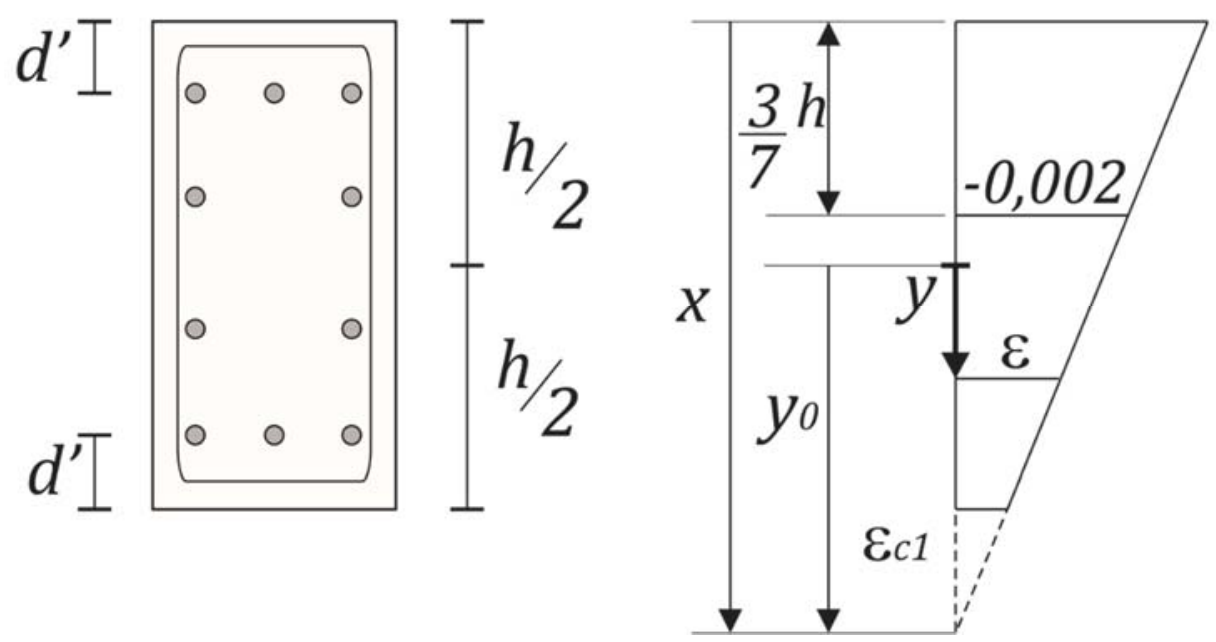

Fonte: Adaptado de VENTURINI, 1987, p. 10.

$$
\varepsilon=-0,002 \cdot \frac{\left(y-y_{0}\right)}{x-\frac{3}{7} \cdot h}
$$

Com os valores dados por B.2, B.3 e B.4, substituindo em B.19, obtém-se:

$$
\varepsilon=-0,002 \cdot \frac{\beta_{x}^{\prime}-\left(\beta_{y}+0,5\right)}{\beta_{x}^{\prime}-\frac{3}{7}}
$$

Para que o estado de deformação da peça pertença à região III, basta que se verifique a condição:

$$
\varepsilon_{c 1} \leq 0
$$

Calculando a deformação $\varepsilon_{c 1}$ na fibra mais tracionada, utilizando B.20 com $y=$ $h / 2$ ou $\beta_{y}=1 / 2$ e impondo a desigualdade B.21, obtém-se o seguinte intervalo para $\beta_{x}^{\prime}$ na região III.

$$
\beta_{x}^{\prime} \geq 1
$$




\section{B.2.3 Expressão única para as três regiões}

As equações B.7, B.13 e B.20 representam as condições de compatibilidade para as três regiões de deformações. Como as três equações correspondem a retas, busca-se uma expressão genérica que expresse por uma única expressão essas condições e que dependa apenas de dois valores característicos da região.

Assim, escolhe-se como parâmetros indicadores da região os valores de deformações última $\varepsilon_{u}$ : 0,01 (Região I), -0,0035 (Região II) e -0,002 (Região III); e uma constante adimensional $\beta_{x 0}^{\prime}$ obtida a partir da distância do ponto do valor último até a borda mais comprimida dividida por $h$. Assim, a seguinte expressão para $\varepsilon$ pode ser escrita:

$$
\varepsilon=\varepsilon_{u} \cdot \frac{\beta_{x}^{\prime}-\left(\beta_{y}+0,5\right)}{\beta_{x}^{\prime}-\beta_{x 0}^{\prime}}
$$

Considerando as três regiões, os valores de $\varepsilon_{u}$ e $\beta_{x 0}^{\prime}$ são:

a) Região l:

$$
\begin{gathered}
\varepsilon_{u}=\varepsilon_{s u}=0,01 \\
\beta_{x 0}^{\prime}=1-\delta
\end{gathered}
$$

b) Região II:

$$
\begin{gathered}
\varepsilon_{u}=\varepsilon_{c u 2}=-0,0035 \\
\beta_{x 0}^{\prime}=0
\end{gathered}
$$

c) Região III:

$$
\begin{gathered}
\varepsilon_{u}=\varepsilon_{c u 3}=-0,002 \\
\beta_{x 0}^{\prime}=3 / 7
\end{gathered}
$$




\section{B.3 EQUAÇÕES DE EQUILÍBRIO - SEÇÃO RETANGULAR}

No item B.2 foram obtidas as equações para o cálculo das deformações em um ponto genérico de uma peça qualquer de concreto armado, a partir dos valores limites definidos pela ABNT NBR 6118:2014 para concretos de classe até C50. Com as deformações, é possível obter as tensões atuantes utilizando para isso os diagramas tensões-deformações dos materiais constituintes da peça (definido nos itens $3.1 .3 \mathrm{e}$ 3.2.2 deste texto). A partir dos valores das tensões, é possível obter os esforços resistentes da seção.

Dessa forma, com base na figura B.5, é possível equacionar:

Figura B.5 - Seção retangular. Tensões, deformações e resultantes

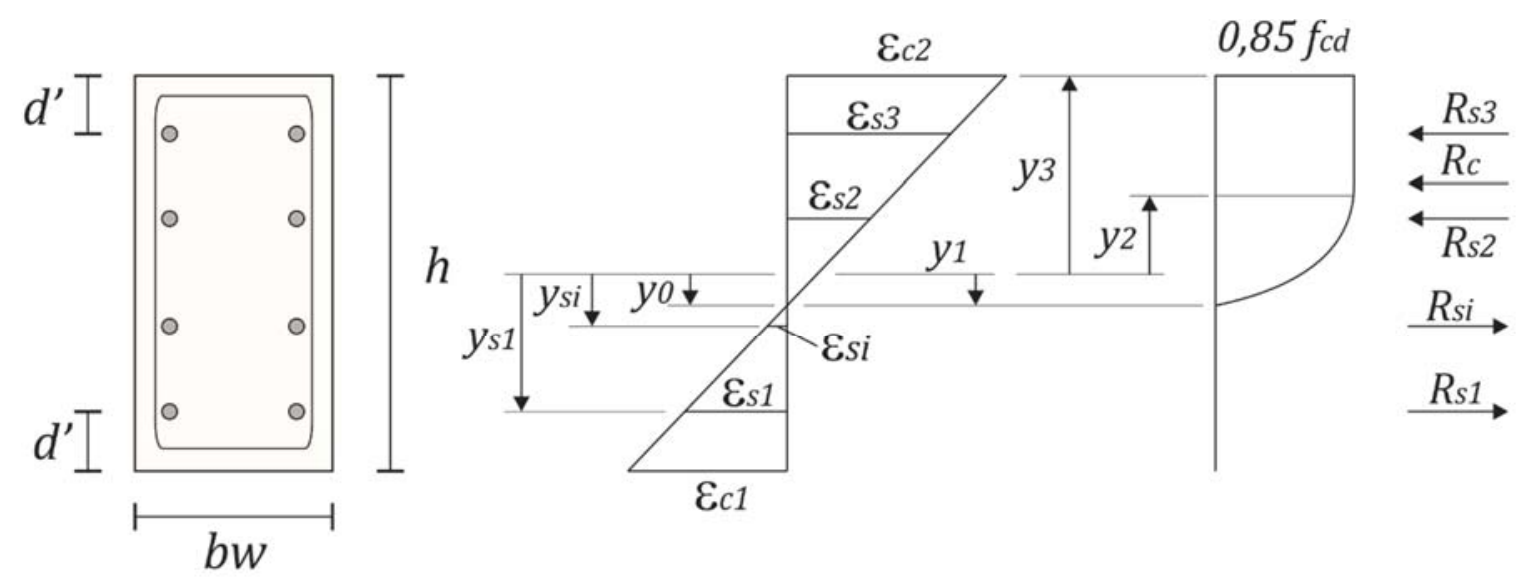

Geometria

Fonte: Adaptado de VENTURINI, 1987, p. 12.

$$
\begin{aligned}
& N_{R}=R_{C}+\sum_{i=1}^{N} R_{s i} \\
& M_{R}=M_{C}+\sum_{i=1}^{N} R_{s i} \cdot y_{s i}
\end{aligned}
$$

De forma que $N$ seja o número de linhas de armadura da seção e $R_{C}$ e $M_{C}$ sejam as resultantes da força e de momento fletor do concreto, respectivamente, e são dadas pelas equações: 


$$
\begin{aligned}
& R_{C}=\int_{A C} \sigma_{c} \cdot d A \\
& M_{C}=\int_{A C} y \cdot \sigma_{c} \cdot d A
\end{aligned}
$$

As resultantes de tensão na armadura são função da tensão $\sigma_{s i}$, e da área de cada barra $A_{s i}$, assim, obtêm-se:

$$
\begin{gathered}
N_{R}=\int_{A C} \sigma_{c} \cdot d A+\sum_{i=1}^{N} \sigma_{s i} \cdot A_{s i} \\
M_{R}=\int_{A C} y \cdot \sigma_{c} \cdot d A+\sum_{i=1}^{N} y_{s i} \cdot \sigma_{s i} \cdot A_{s i}
\end{gathered}
$$

Como a seção é retangular, as integrais de área estão em função da variável $y$, assim B.34 e B.35 ficam dados por:

$$
\begin{gathered}
N_{R}=\int_{-\frac{h}{2}}^{y_{0}} b_{w} \cdot \sigma_{c} \cdot d y+\sum_{i=1}^{N} \sigma_{s i} \cdot A_{s i} \\
M_{R}=\int_{-\frac{h}{2}}^{y_{0}} b_{w} \cdot y \cdot \sigma_{c} \cdot d y+\sum_{i=1}^{N} y_{s i} \cdot \sigma_{s i} \cdot A_{s i}
\end{gathered}
$$

Com as equações B.36 e B.37 é possível obter os esforços resistentes em uma seção de concreto armado com geometria e características dos materiais definidas. As equações estão em função da posição do eixo neutro $y_{0}$ e das tensões $\sigma_{c}$ e $\sigma_{s i}$. Assim, os valores de $N_{R}$ e $M_{R}$ são dependentes da posição deformada a ser imposta, e, portanto podem-se obter pares $\left(N_{R}, M_{R}\right)$ para qualquer posição do eixo neutro.

Percebe-se, portanto, que com as equações B.36 e B.37 é possível traçar as curvas $\left(N_{u}, M_{u}\right)$, porém, é conveniente exprimir essas expressões com valores 
independentes das dimensões da peça $h$ e $b w$ e da tensão de cálculo $f_{c d}$, portanto, essas equações devem ser adimensionalizadas.

\section{B.4 EQUAÇÕES ADIMENSIONAIS}

Antes de definir as equações adimensionais deste item, recomenda-se ao autor rever o item 3.1.3 deste texto, nele estão presentes as equações de tensão do concreto. Como o equacionamento será definido para concretos de classe até C50, obtêm-se as seguintes equações:

$$
\begin{array}{lrl}
\sigma_{c}=-0,85 \cdot f_{c d} & \text { para }-0,002 \geq \varepsilon_{c} \geq-0,0035 \\
\sigma_{c}=850 \cdot f_{c d} \cdot\left[1+250 \cdot \varepsilon_{c}\right] \cdot \varepsilon_{c} & \text { para } 0 \geq \varepsilon_{c} \geq-0,002 \\
\sigma_{c}=0 & \text { para } \varepsilon_{c} \geq 0
\end{array}
$$

O sinal negativo das equações é para caracterizar as tensões e deformações de compressão, de modo que as equações geradas sejam consistentes, evitando-se o uso de casos particulares.

A expressão B.39 difere da expressão 3.4, já que na expressão 3.4 utilizam-se deformações em valores por mil (\%o) e na expressão B.39 empregam-se deformações em valores reais.

A expressão B.40 indica que a resistência do concreto à tração será desprezada no equacionamento.

Analisando a figura 3.1, percebe-se que o concreto apresenta um diagrama de tensões com duas partes bem definidas: uma parte parabólica, e uma parte retangular. Dessa forma, separam-se as integrais B.36 e B.37 em dois termos. Assumindo que o trecho parabólico seja definido entre os valores $y_{1}$ e $y_{2}$ e o trecho retangular seja válido de $y_{2}$ e $y_{3}$, e substituindo o valor de $\sigma_{c}$ conforme B.38, B.39 e B.40, obtêm-se: 


$$
\begin{aligned}
& N_{R}=850 \cdot f_{c d} \cdot b_{w} \cdot \int_{y_{2}}^{y_{1}}\left(1+250 \cdot \varepsilon_{c}\right) \cdot \varepsilon_{c} \cdot d y-0,85 \cdot f_{c d} \cdot b_{w} \cdot\left(y_{2}-y_{3}\right) \\
& +\sum_{i=1}^{N} \sigma_{s i} \cdot A_{s i} \\
& M_{R}=850 \cdot f_{c d} \cdot b_{w} \cdot \int_{y_{2}}^{y_{1}} y \cdot\left(1+250 \cdot \varepsilon_{c}\right) \cdot \varepsilon_{c} \cdot d y-0,425 \cdot f_{c d} \cdot b_{w} \cdot\left(y_{2}{ }^{2}-y_{3}{ }^{2}\right) \\
& +\sum_{i=1}^{N} y_{s i} \cdot \sigma_{s i} \cdot A_{s i}
\end{aligned}
$$

Deve-se observar que os limites $y_{1}, y_{2}$ e $y_{3}$ não devem, em módulo, ser maiores que $h / 2$, de maneira a se ter integração apenas sobre as dimensões reais da peça.

Para colocar as equações em termos adimensionais, necessita-se definir:

$$
\begin{aligned}
& v=\frac{N_{R}}{A_{c} \cdot f_{c d}} \\
& \mu=\frac{M_{R}}{A_{c} \cdot h \cdot f_{c d}}
\end{aligned}
$$

Dividindo as equações B.41 e B.42 por $A_{c} \cdot f_{c d}$ e $A_{c} \cdot h \cdot f_{c d}$ respectivamente, obtêm-se:

$$
\begin{gathered}
v=850 \cdot \int_{\beta_{2}}^{\beta_{1}}\left(1+250 \cdot \varepsilon_{c}\right) \cdot \varepsilon_{c} \cdot d \beta_{y}-0,85 \cdot\left(\beta_{2}-\beta_{3}\right)+\frac{\omega}{f_{y d}} \cdot \sum_{i=1}^{N} \sigma_{s i} \cdot \eta_{s i} \\
\mu=850 \cdot \int_{\beta_{2}}^{\beta_{1}} \beta_{y} \cdot\left(1+250 \cdot \varepsilon_{c}\right) \cdot \varepsilon_{c} \cdot d \beta_{y}-0,425 \cdot\left(\beta_{2}{ }^{2}-\beta_{3}{ }^{2}\right) \\
+\frac{\omega}{f_{y d}} \cdot \sum_{i=1}^{N} \sigma_{s i} \cdot \eta_{s i} \cdot \beta_{s i}
\end{gathered}
$$


A taxa mecânica de armadura $\omega$ é seja dada por:

$$
\omega=\frac{f_{y d} \cdot A_{s}}{f_{c d} \cdot A_{c}}
$$

$\mathrm{E}$ as coordenadas adimensionais das posições das barras $\beta_{s i}$ :

$$
\beta_{s i}=\frac{y_{s i}}{h}
$$

As expressões B.45 e B.46 podem ser transformadas substituindo-se o valor de $\varepsilon_{c}$ pela expressão de compatibilidade B.23, obtendo-se:

$$
\begin{aligned}
& v=850 \cdot \int_{\beta_{2}}^{\beta_{1}}\left(1+250 \cdot \varepsilon_{u} \cdot \frac{\beta_{x}^{\prime}-\left(\beta_{y}+0,5\right)}{\beta_{x}^{\prime}-\beta_{x 0}^{\prime}}\right) \cdot \varepsilon_{u} \cdot \frac{\beta_{x}^{\prime}-\left(\beta_{y}+0,5\right)}{\beta_{x}^{\prime}-\beta_{x 0}^{\prime}} \cdot d \beta_{y} \\
& -0,85 \cdot\left(\beta_{2}-\beta_{3}\right)+\frac{\omega}{f_{y d}} \cdot \sum_{i=1}^{N} \sigma_{s i} \cdot \eta_{s i} \\
& \mu=850 \cdot \int_{\beta_{2}}^{\beta_{1}} \beta_{y} \cdot\left(1+250 \cdot \varepsilon_{u} \cdot \frac{\beta_{x}^{\prime}-\left(\beta_{y}+0,5\right)}{\beta_{x}^{\prime}-\beta_{x 0}^{\prime}}\right) \cdot \varepsilon_{u} \cdot \frac{\beta_{x}^{\prime}-\left(\beta_{y}+0,5\right)}{\beta_{x}^{\prime}-\beta_{x 0}^{\prime}} \cdot d \beta_{y} \\
& -0,425 \cdot\left({\beta_{2}}^{2}-{\beta_{3}}^{2}\right)+\frac{\omega}{f_{y d}} \cdot \sum_{i=1}^{N} \sigma_{s i} \cdot \eta_{s i} \cdot \beta_{s i}
\end{aligned}
$$

Integrando B.49 e B.50 e substituindo os limites $\beta_{1}$ e $\beta_{2}$, obtêm-se:

$$
\begin{gathered}
v=\frac{850 \cdot \varepsilon_{u}}{\beta_{x}^{\prime}-\beta_{x 0}^{\prime}}\left\{\frac{250 \cdot \varepsilon_{u}}{\beta_{x}^{\prime}-\beta_{x 0}^{\prime}}\left[\frac{\left(\beta_{1}^{3}-\beta_{2}^{3}\right)}{3}-\left(\beta_{x}^{\prime}-0,5\right) \cdot\left(\beta_{1}^{2}-\beta_{2}^{2}\right)+\left(\beta_{x}^{\prime}-0,5\right)^{2}\left(\beta_{1}-\beta_{2}\right)\right]\right. \\
\left.\quad-\frac{\left(\beta_{1}^{2}-\beta_{2}^{2}\right)}{2}+\left(\beta_{x}^{\prime}-0,5\right)\left(\beta_{1}-\beta_{2}\right)\right\}-0,85\left(\beta_{2}-\beta_{3}\right) \\
+\frac{\omega}{f_{y d}} \sum_{i=1}^{N} \sigma_{s i} \cdot \eta_{s i}
\end{gathered}
$$




$$
\begin{aligned}
\mu=\frac{850 \cdot \varepsilon_{u}}{\beta_{x}^{\prime}-\beta_{x 0}^{\prime}}\{ & \frac{-\left(\beta_{1}^{3}-\beta_{2}^{3}\right)}{3}+\left(\beta_{x}^{\prime}-0,5\right) \frac{\left(\beta_{1}^{2}-\beta_{2}^{2}\right)}{2} \\
& +\frac{250 \varepsilon_{u}}{\beta_{x}^{\prime}-\beta_{x 0}^{\prime}}\left[-2\left(\beta_{x}^{\prime}-0,5\right) \frac{\left(\beta_{1}^{3}-\beta_{2}^{3}\right)}{3}+\left(\beta_{x}^{\prime}-0,5\right)^{2} \cdot \frac{\left(\beta_{1}^{2}-\beta_{2}^{2}\right)}{2}\right. \\
& \left.\left.+\frac{\left(\beta_{1}{ }^{4}-\beta_{2}{ }^{4}\right)}{4}\right]\right\}-0,425\left(\beta_{2}{ }^{2}-\beta_{3}{ }^{2}\right) \\
& +\frac{\omega}{f_{y d}} \sum_{i=1}^{N} \sigma_{s i} \eta_{s i} \beta_{s i}
\end{aligned}
$$

As equações B.51 e B.52 são expressões que permitem a determinação dos esforços adimensionais em uma seção retangular de concreto armado. As equações são independentes e formam um sistema não linear que resolvido fornece a taxa de armadura $(\omega)$, para uma disposição de barras previamente fixada. Outro parâmetro que também será obtido na resolução desse sistema é a posição da linha neutra $\left(\beta_{x}^{\prime}\right)$ indicando em qual domínio o estado-limite ocorre.

\section{B.5 DEFINIÇÃO DOS VALORES LIMITES ADIMENSIONAIS PARA INTEGRAÇÃO DO DIAGRAMA DE TENSÕES DE COMPRESSÃO NO CONCRETO}

Nas integrais B.41 e B.42, os limites de integração $y_{1}, y_{2}$ e $y_{3}$ representam os valores que definem os trechos do diagrama tensão-deformação do concreto, de forma que o trecho parabólico seja definido entre os valores $y_{1}$ e $y_{2}$ e o trecho retangular seja válido de $y_{2}$ e $y_{3}$.

Quando as equações foram colocadas em forma adimensional, os parâmetros $y_{1}, y_{2}$ e $y_{3}$ transformaram-se em $\beta_{1}, \beta_{2}$ e $\beta_{3}$ (limites adimensionais de integração), sendo:

$$
\begin{aligned}
& \beta_{1}=\frac{y_{1}}{h} \\
& \beta_{2}=\frac{y_{2}}{h}
\end{aligned}
$$




$$
\beta_{3}=\frac{y_{3}}{h}
$$

Logo, percebe-se que esses limites são dependentes da região de deformação (Figura B.1) em que a peça se encontra.

\section{B.5.1 Região I}

A região I é definida para valores de posição da linha neutra conforme dado em B.10, que por comodidade será expresso em B.56 com a inclusão de outro limite:

$$
-\infty \leq \beta_{x}^{\prime} \leq 0,259 \cdot(1-\delta)
$$

Como $\delta\left(d^{\prime} / h\right)$ sempre é positivo e menor que um, conclui-se que para a região I, a posição da linha neutra varie de um valor negativo até o limite $0,259 \cdot(1-\delta)$, que sempre é positivo. Assim, pode-se dividir B.56 em dois intervalos pertinentes para a análise dos valores limites adimensionais:

$$
\begin{gathered}
-\infty \leq \beta_{x}^{\prime} \leq 0 \\
0 \leq \beta_{x}^{\prime} \leq 0,259 \cdot(1-\delta)
\end{gathered}
$$

Para o limite B.57, a posição da linha neutra é sempre negativa (Figura B.6), ou seja, não há compressão na peça. Assim, os valores $y_{1}, y_{2}$ e $y_{3}$, que definem o diagrama tensão-deformação do concreto, estarão presentes em um ponto, que por definição, será o ponto extremo no qual supostamente haveria compressão na peça, ou seja:

$$
y_{1}=y_{2}=y_{3}=-\frac{h}{2}
$$

Portanto, com B.53, B.54 e B.55, para o limite B.57 da região I, têm-se: 


$$
\beta_{1}=\beta_{2}=\beta_{3}=-\frac{1}{2}
$$

\section{Essa situação está presente na figura B.6.}

Figura B.6 - Limites adimensionais para integração do diagrama de tensões no concreto

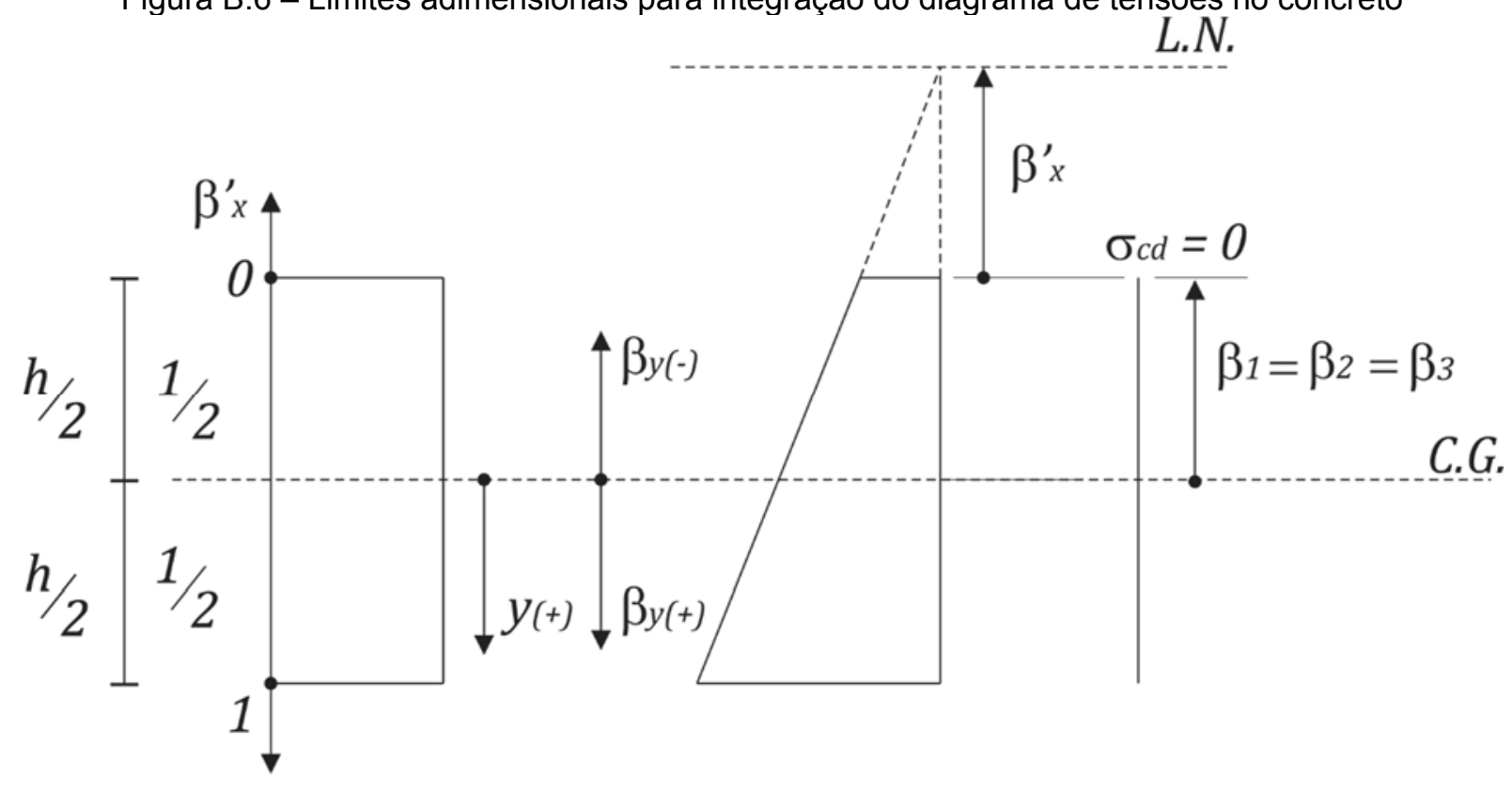

FONTE: Adaptado de PAULA, 1988, p. 60.

Para o limite B.58, a posição da linha neutra se encontra dentro da seção, ou seja, há compressão na peça. Portanto os valores $\beta_{1}$ e $\beta_{2}$ assumirão valores variáveis. Como o valor $\beta_{3}$ representa o início do diagrama retangular de tensões, foi visto na figura B.6 (e nas próximas figuras) que ele sempre assumirá o valor da expressão B.61:

$$
\beta_{3}=-\frac{1}{2}
$$

As tensões de compressão no concreto se distribuem uniformemente até que a fibra, distante $3 / 7$ a partir da borda mais comprimida, alcance a deformação $\varepsilon_{c}=$ -0,002 (PAULA, 1988). Dessa forma, o máximo valor permitido para a ordenada adimensional $\beta_{2}$ (Figura B.7) é de: 


$$
\beta_{2}=\beta_{3}+\frac{3}{7}
$$

Figura B.7 - Limites adimensionais para integração do diagrama de tensões no concreto

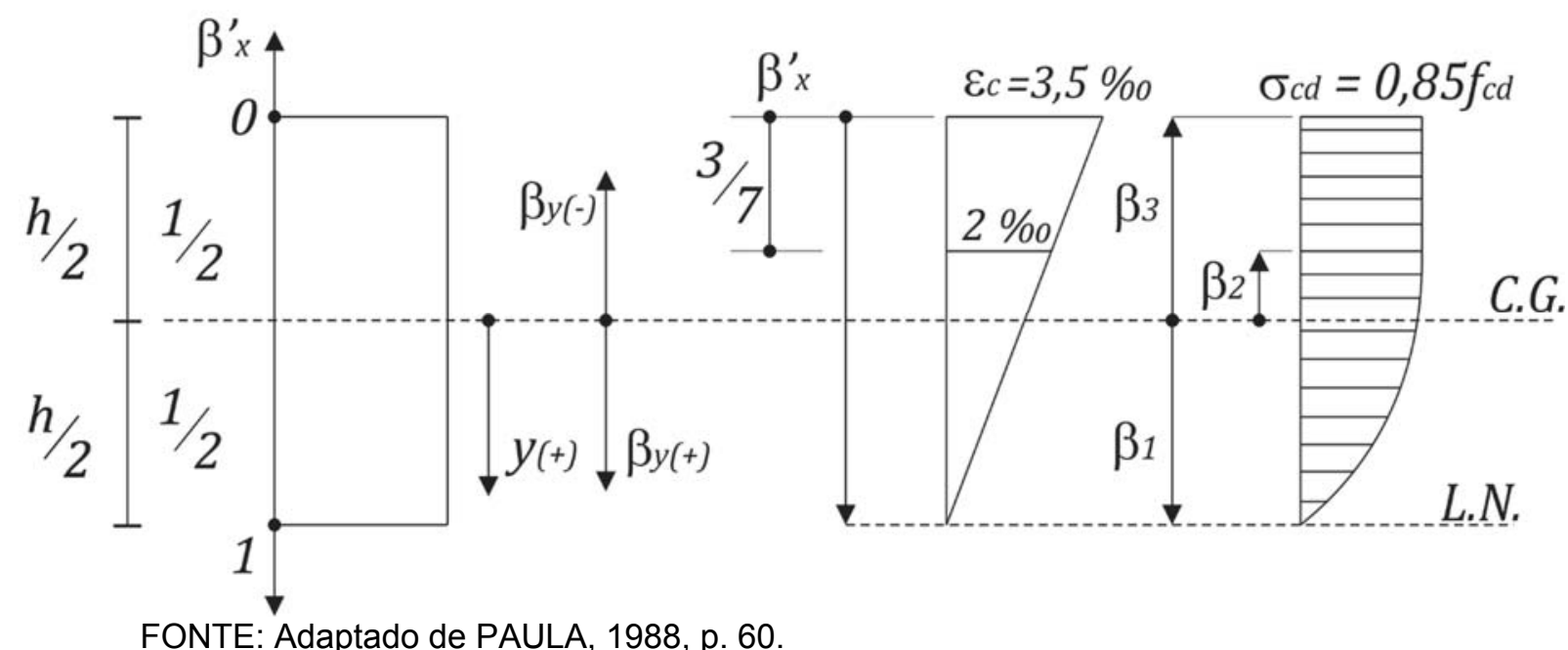

Substituindo a expressão B.61 na expressão B.62, conclui-se que:

$$
\beta_{2}=-\frac{1}{2}+\frac{3}{7} \rightarrow \beta_{2}=-\frac{1}{14}
$$

Como só interessa a integral dentro da seção, pode-se dizer que o valor mínimo permitido para a ordenada adimensional $\beta_{2}$ (Figura B.8), é de:

$$
\beta_{2}=-\frac{1}{2}
$$

Figura B.8 - Limites adimensionais para integração do diagrama de tensões no concreto

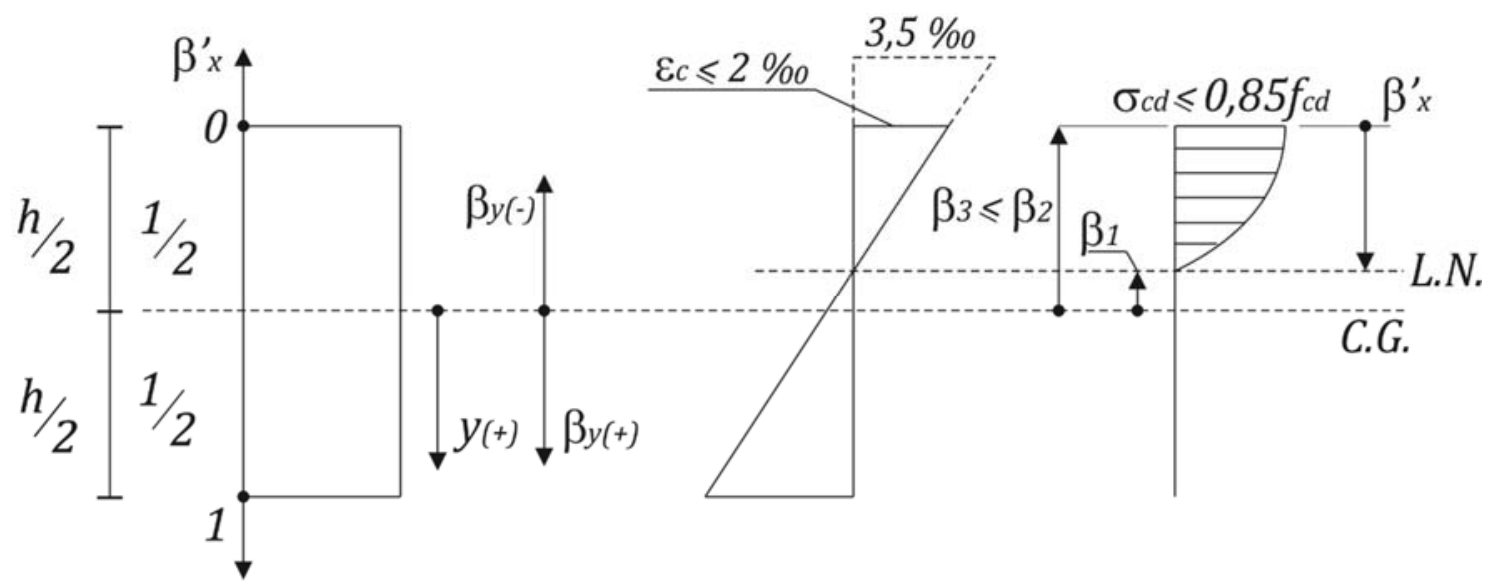

FONTE: Adaptado de PAULA, 1988, p. 60. 
Dessa forma, pode-se dizer que o intervalo de variação da ordenada adimensional $\beta_{2}$ é de:

$$
-\frac{1}{2} \leq \beta_{2} \leq-\frac{1}{14}
$$

Respeitando-se o limite dado por B.65, a expressão de $\beta_{2}$ é dada através da expressão B.23 utilizando o parâmetro B.24 e o parâmetro B.25 e, como $\beta_{2}$ representa a ordenada adimensional que representa a mudança no diagrama tensão-deformação do concreto, deve-se utilizar para $\varepsilon$ a deformação de $-0,002$, correspondente a essa mudança, assim:

$$
\begin{aligned}
& -0,002=0,01 \cdot \frac{\beta_{x}^{\prime}-\left(\beta_{2}+0,5\right)}{\beta_{x}^{\prime}-(1-\delta)} \\
& \therefore \beta_{2}=1,2 \cdot \beta_{x}^{\prime}+0,2 \cdot \delta-0,7
\end{aligned}
$$

Para a ordenada adimensional $\beta_{1}$, que representa o final do diagrama parabólico, analisando as figuras B.6, B.7 e B.8 percebe-se que sua posição coincide com a posição da fibra com deformação nula. Assim, basta impor na expressão B.23, utilizando os parâmetros B.24 e B.25, deformação igual a zero:

$$
\begin{gathered}
0=0,01 \cdot \frac{\beta_{x}^{\prime}-\left(\beta_{1}+0,5\right)}{\beta_{x}^{\prime}-(1-\delta)} \\
\therefore \beta_{1}=\beta_{x}^{\prime}-0,5
\end{gathered}
$$

De forma que, como visto na figura B.6, quando a linha neutra da seção se encontra fora da seção, e a seção esteja inteiramente tracionada, $\beta_{1}$ assume seu valor mínimo dado por:

$$
\beta_{1} \geq-\frac{1}{2}
$$


Porém, quando a seção encontra-se inteiramente comprimida (linha neutra fora da seção, representado na figura B.9), $\beta_{1}$ assume seu valor máximo dado por:

$$
\beta_{1} \leq \frac{1}{2}
$$

Figura B.9 - Limites adimensionais para integração do diagrama de tensões no concreto

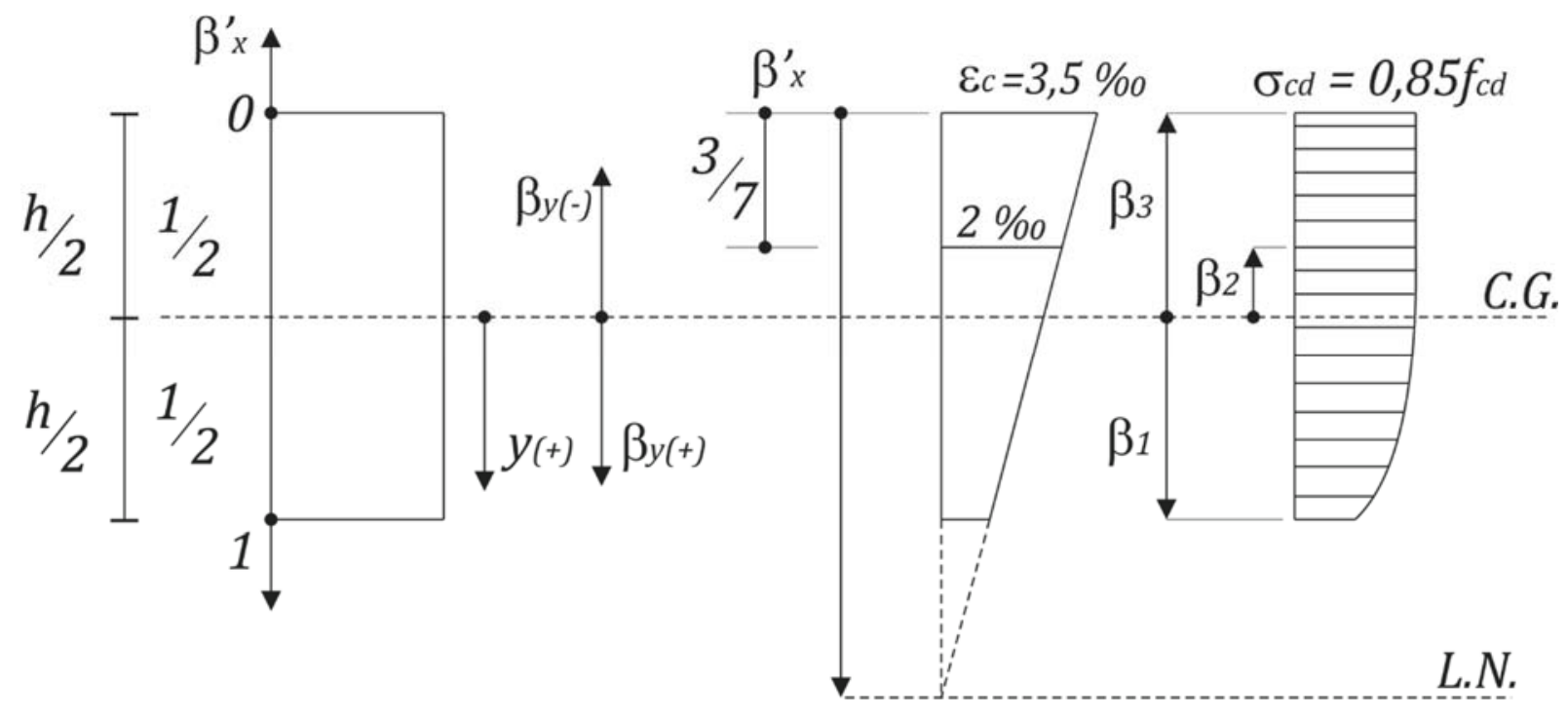

FONTE: Adaptado de PAULA, 1988, p. 62.

Assim, $\beta_{1}$ é dado pela expressão B.67, de forma que se respeite:

$$
-\frac{1}{2} \leq \beta_{1} \leq \frac{1}{2}
$$

\section{B.5.2 Região II}

A região II é definida para valores de posição da linha neutra conforme dado em B.17, que por comodidade será expresso em B.71:

$$
0,259 \cdot(1-\delta) \leq \beta_{x}^{\prime} \leq 1
$$

Com os conceitos dados em B.4.1, pode-se dizer que para a região II: 


$$
\begin{gathered}
\beta_{3}=-\frac{1}{2} \\
\beta_{1}=\beta_{x}^{\prime}-0,5 \\
-\frac{1}{2} \leq \beta_{1} \leq \frac{1}{2}
\end{gathered}
$$

Para obter a ordenada adimensional $\beta_{2}$ referente à região $\mathrm{II}$, basta utilizar a expressão B.23 com os parâmetros B.26 e B.27 e utilizar para $\varepsilon$ a deformação de $-0,002$ :

$$
\begin{gathered}
-0,002=-0,0035 \cdot \frac{\beta_{x}^{\prime}-\left(\beta_{2}+0,5\right)}{\beta_{x}^{\prime}-0} \\
\therefore \beta_{2}=0,42857143 \cdot \beta_{x}^{\prime}-0,5
\end{gathered}
$$

De forma que se respeite:

$$
-\frac{1}{2} \leq \beta_{2} \leq-\frac{1}{14}
$$

\section{B.5.3 Região III}

A região III é definida para valores de posição da linha neutra conforme dado em B.22, que por comodidade será expresso em B.77:

$$
\beta_{x}^{\prime} \geq 1
$$

Com os conceitos dados em B.4.1, pode-se dizer que para a região III:

$$
\begin{gathered}
\beta_{3}=-\frac{1}{2} \\
\beta_{1}=\beta_{x}^{\prime}-0,5
\end{gathered}
$$




$$
-\frac{1}{2} \leq \beta_{1} \leq \frac{1}{2}
$$

Para obter a ordenada adimensional $\beta_{2}$ referente à região III deve-se analisar a figura B.9. Percebe-se que para valores de $\beta_{x}^{\prime} \geq 1$, a ordenada adimensional $\beta_{2}$ é constante e assume o valor de:

$$
\begin{aligned}
& \beta_{2}=\frac{3}{7}-0,5 \\
& \therefore \beta_{2}=-\frac{1}{14}
\end{aligned}
$$

\section{B.6 ALGORITMO PARA A CONSTRUÇÃO DAS CURVAS $\left(v_{u}, \mu_{u}\right)$ (ÁBACOS DE DIMENSIONAMENTO)}

Para a construção das curvas adimensionais $\left(v_{u}, \mu_{u}\right)$ é necessário o conhecimento prévio de alguns parâmetros referente à armadura da seção, tais como: taxa mecânica de armadura $(\omega)$, disposição das barras e tipo de aço.

Basicamente o algoritmo consiste em calcular diversos pares $\left(v_{u}, \mu_{u}\right)$ a partir de valores de $\beta_{x}^{\prime}$ mantendo fixo o valor de $\omega$. Portanto, deve-se proceder:

a) Parâmetros de entrada;

Inicialmente devem-se determinar os parâmetros de entrada da seção em análise para a determinação das curvas:

- $\quad f_{y k}$ é a resistência característica do aço;

- $\quad f_{c k}$ é a resistência característica do concreto a compressão;

- $\quad h$ é a altura da seção transversal;

- $\quad b_{w}$ é a base da seção transversal.

- $\quad \delta$ é o parâmetro relativo à posição da barra longitudinal da seção, e seu cálculo é indicado no próximo item. 
b) Arbitra-se o parâmetro de entrada $\delta$;

O parâmetro $\delta$ é dado por:

$$
\delta=\frac{d^{\prime}}{h}
$$

Porém, para a determinação de $d^{\prime}$ é necessário o conhecimento prévio de alguns dados sobre a armadura. O parâmetro $d^{\prime}$ é a distância do centro de gravidade da armadura longitudinal até a face mais próxima desta, e, portanto, é dado por:

$$
d^{\prime}=c+\phi_{t}+\phi_{l} / 2
$$

Como as curvas $\left(v_{u}, \mu_{u}\right)$ estão em função da taxa mecânica de armadura $\omega$, não se tem conhecimento das bitolas da armadura longitudinal, deve-se, portanto, arbitrar um valor para $\delta$ para a geração das curvas.

c) Calculam-se a posição e as taxas relativas das armaduras;

A posição das armaduras é pré-definida e, para o cálculo das curvas $\left(v_{u}, \mu_{u}\right)$, devem estar presente em sua forma adimensional. Como exemplo considere a figura B.10: 
Figura B.10 - Exemplo de arranjo de armadura

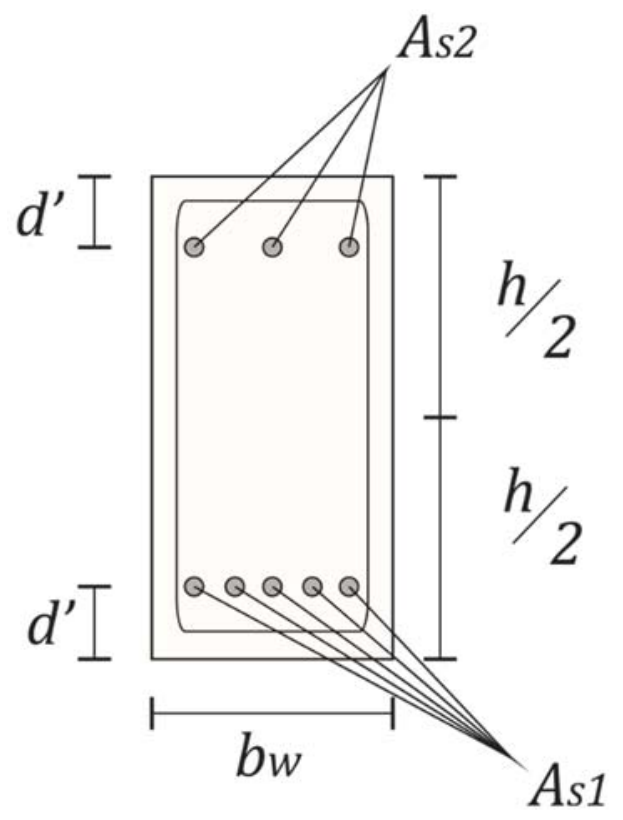

FONTE: Elaborado pelo Autor.

Analisando a figura B.10 é perceptível que a posição das armaduras é dada por:

$$
\begin{aligned}
& \beta_{s 1}=0,5-\delta \\
& \beta_{s 2}=\delta-0,5
\end{aligned}
$$

E as taxas relativas das armaduras são dadas por:

$$
\begin{aligned}
& \eta_{s 1}=\frac{A_{s 1}}{A_{s 1}+A_{s 2}} \\
& \eta_{s 2}=\frac{A_{s 2}}{A_{s 1}+A_{s 2}}
\end{aligned}
$$

Assim, conclui-se que dependendo do arranjo e das taxas relativas de armadura os parâmetros adimensionais de posição e taxa de armadura variarão. 
d) Adota-se para taxa mecânica de armadura $\omega=0$;

e) Arbitra-se a profundidade da linha neutra $\beta_{x}^{\prime}$ e nas etapas seguintes $\beta_{x}^{\prime}=$ $\beta_{x}^{\prime}+\Delta \beta_{x}^{\prime}$

Deve-se arbitrar inicialmente $\beta_{x}^{\prime} \approx-\infty$, porém, para evitar demasiado tempo de processamento, é suficiente arbitrar inicialmente $\beta_{x}^{\prime}=-5$.

f) Determinam-se as ordenadas adimensionais de integração do concreto;

As ordenadas adimensionais de integração do concreto são conforme expresso no item B.4 deste texto. De forma que, dependendo da posição da linha neutra (região I, região II e região III) as ordenadas adimensionais assumam um equacionamento.

g) Determinam-se as tensões atuantes nas armaduras;

As tensões atuantes nas armaduras são dependentes das deformações que estas apresentam. Assim, para a determinação das deformações das armaduras, deve-se utilizar a expressão B.23, com os parâmetros adequadas a cada região, portanto:

- Região I

$$
\varepsilon_{s}=0,01 \cdot \frac{\beta_{x}^{\prime}-\left(\beta_{s}+0,5\right)}{\beta_{x}^{\prime}-(1-\delta)}
$$

- $\quad$ Região II

$$
\varepsilon_{s}=-0,0035 \cdot \frac{\beta_{x}^{\prime}-\left(\beta_{s}+0,5\right)}{\beta_{x}^{\prime}}
$$

- $\quad$ Região III

$$
\varepsilon_{s}=-0,002 \cdot \frac{\beta_{x}^{\prime}-\left(\beta_{s}+0,5\right)}{\beta_{x}^{\prime}-\frac{3}{7}}
$$


$\beta_{s}$ é dado conforme expresso em c).

De forma que:

$$
-0,01 \leq \varepsilon_{s} \leq 0,01
$$

Com as deformações, utilizando o diagrama tensão-deformação do aço, é possível retirar a tensão atuante nas armaduras. Assim:

- Para $\left|\varepsilon_{s}\right| \leq \varepsilon_{y d}$ :

$$
\sigma_{s d}=f_{y d} \cdot \frac{\varepsilon_{s}}{\varepsilon_{y d}}
$$

- $\quad$ Para $\varepsilon_{s}>\varepsilon_{y d}$ :

$$
\sigma_{s d}=f_{y d}
$$

- $\quad$ Para $\varepsilon_{s}<-\varepsilon_{y d}$ :

$$
\sigma_{s d}=-f_{y d}
$$

$\varepsilon_{y d}$ é a deformação de escoamento correspondente ao tipo de aço adotado.

h) Calcula-se o par de esforços resistentes $\left(v_{u}, \mu_{u}\right)$;

Utilizando as equações B.51 e B.52, calcula-se $v_{u}$ e $\mu_{u}$ respectivamente, respeitando os parâmetros definidos para as regiões I, II e III.

i) Repetem-se as fases do processo até $\beta_{x}^{\prime} \approx \infty$;

Sendo suficiente a consideração de $\beta_{x}^{\prime}=15$.

j) Repete-se o mesmo processo (a partir do item e) para os demais valores de $\omega$, fazendo-se $\omega=\omega+\Delta \omega$. 
Nessa fase é possível a determinação de variadas curvas $\left(v_{u}, \mu_{u}\right)$ para várias taxas de armadura $\omega$. Venturini (1987) gera curvas até a taxa mecânica de armadura $\omega=1,80$, sendo o suficiente para a maioria dos casos de dimensionamento devido à restrição de armadura máxima.

\section{B.7 ALGORITMO PARA A DETERMINAÇÃO DA TAXA MECÂNICA DE ARMADURA $\omega$ PARA O DIMENSIONAMENTO}

Para o dimensionamento de uma seção deve-se procurar fazer o par de esforços resistentes ser igual aos valores dos esforços solicitantes adimensionais, garantindo-se o equilíbrio no estado-limite último (VENTURINI, 1987).

Com dados como: força normal adimensional solicitante $\left(v_{s}\right)$, momento fletor adimensional solicitante $\left(\mu_{s}\right)$, disposição das barras e tipo de aço, é possível verificar se o par $\left(v_{s}, \mu_{s}\right)$ é próximo do par $\left(v_{u}, \mu_{u}\right)$, em uma varredura entre as curvas $\left(v_{u}, \mu_{u}\right)$.

Portanto, parece ser possível obter a taxa mecânica de armadura $\omega$ (com certa precisão) sem a necessidade do uso de ábacos de dimensionamento ou construção das curvas $\left(v_{u}, \mu_{u}\right)$. Assim, deve-se proceder:

a) Parâmetros de entrada;

Inicialmente devem-se determinar os parâmetros de entrada da seção em análise:

- $\quad f_{y k}$ é a resistência característica do aço;

- $\mu_{s}$ é o esforço momento fletor solicitante adimensional a que a peça está submetida;

- $\quad v_{s}$ é o esforço normal solicitante a que a peça está submetida;

- $\delta$ é o parâmetro relativo à posição da barra longitudinal da seção. 
b) Arbitra-se o parâmetro de entrada $\delta$;

Assim como explicitado no item B.5 (item b) as curvas $\left(v_{u}, \mu_{u}\right)$ estão em função da taxa mecânica de armadura $\omega$, e, portanto, não se tem conhecimento das bitolas da armadura longitudinal, assim, deve-se arbitrar um valor para $\delta$.

c) Calcula-se a posição e as taxas relativas das armaduras;

Proceder conforme o item B.5 (item c), lembrando que as taxas relativas e a posição das armaduras são dependentes do arranjo pré-definido.

d) Adota-se para taxa mecânica de armadura $\omega=0$;

e) Arbitra-se a profundidade da linha neutra $\beta_{x}^{\prime}$;

Deve-se arbitrar inicialmente $\beta_{x}^{\prime} \approx-\infty$, porém, para evitar demasiado tempo de processamento, é suficiente arbitrar inicialmente $\beta_{x}^{\prime}=-5$.

f) Determinam-se as ordenadas adimensionais de integração do concreto;

g) Determinam-se as tensões atuantes nas armaduras;

h) Calcula-se o par de esforços resistentes $\left(v_{u}, \mu_{u}\right)$;

i) Verifica-se se $v_{u} \cong v_{s}$ e $\mu_{u} \cong \mu_{s}$;

A verificação se os esforços resistentes são próximos dos esforços solicitantes deve ser feita mediante uma tolerância pré-definida. Dessa forma, indica-se como condição de parada do laço (iniciado no item e) a expressão B.95:

$$
1-\left|\frac{v_{u}}{v_{s}}\right|<0,001 \text { e } 1-\left|\frac{\mu_{u}}{\mu_{s}}\right|<0,001
$$

Assim, caso as duas condições de B.95 sejam atendidas, o laço iniciado no item e pode ser finalizado. 
j) Caso $v_{u} \neq v_{s}$ e $\mu_{u} \neq \mu_{s}$, adotar $\beta_{x}^{\prime}=\beta_{x}^{\prime}+\Delta \beta_{x}^{\prime}$;

Caso não se encontre a condição proposta do item i, o processo deve ser reinicializado a partir do item $\mathrm{f}, \operatorname{com} \beta_{x}^{\prime}=\beta_{x}^{\prime}+\Delta \beta_{x}^{\prime}$.

k) Caso $\beta_{x}^{\prime} \approx \infty$, repete-se o mesmo processo, para os demais valores de $\omega$, fazendo-se $\omega=\omega+\Delta \omega$;

Nessa fase é suficiente dizer que se $\beta_{x}^{\prime}=15$, o processo deve ser inicializado a partir do item e, com uma nova taxa mecânica de armadura $\omega=\omega+\Delta \omega$.

I) Caso $v_{u} \cong v_{s}$ e $\mu_{u} \cong \mu_{s}$ seja atendido obter a taxa mecânica de armadura $\omega$ correspondente.

Após o fim do laço, obtido no item $i$, deve-se retirar a taxa mecânica de armadura $\omega$ correspondente a essa situação.

Assim, obtém-se a taxa mecânica de armadura $\omega$ sem a necessidade do uso de ábacos de dimensionamento. 


\section{ANEXO A}

No presente anexo estão apresentados os fundamentos e as diretrizes do estado-limite último de instabilidade conforme prescrito por Santos (1987).

\section{A.1 EQUILÍBRIO ESTÁVEL E EQUILÍBRIO INSTÁVEL}

Os conceitos de equilíbrio estável e de equilíbrio instável podem ser mais bem analisados por meio do esquema da figura A.1, na qual pequenas esferas podem ocupar diversas posições em uma superfície irregular. Com uma pequena perturbação no sistema em equilíbrio, será analisado o efeito dessa perturbação, definindo os conceitos de equilíbrio estável e de equilíbrio instável.

Figura A.1 - Posições de equilíbrio

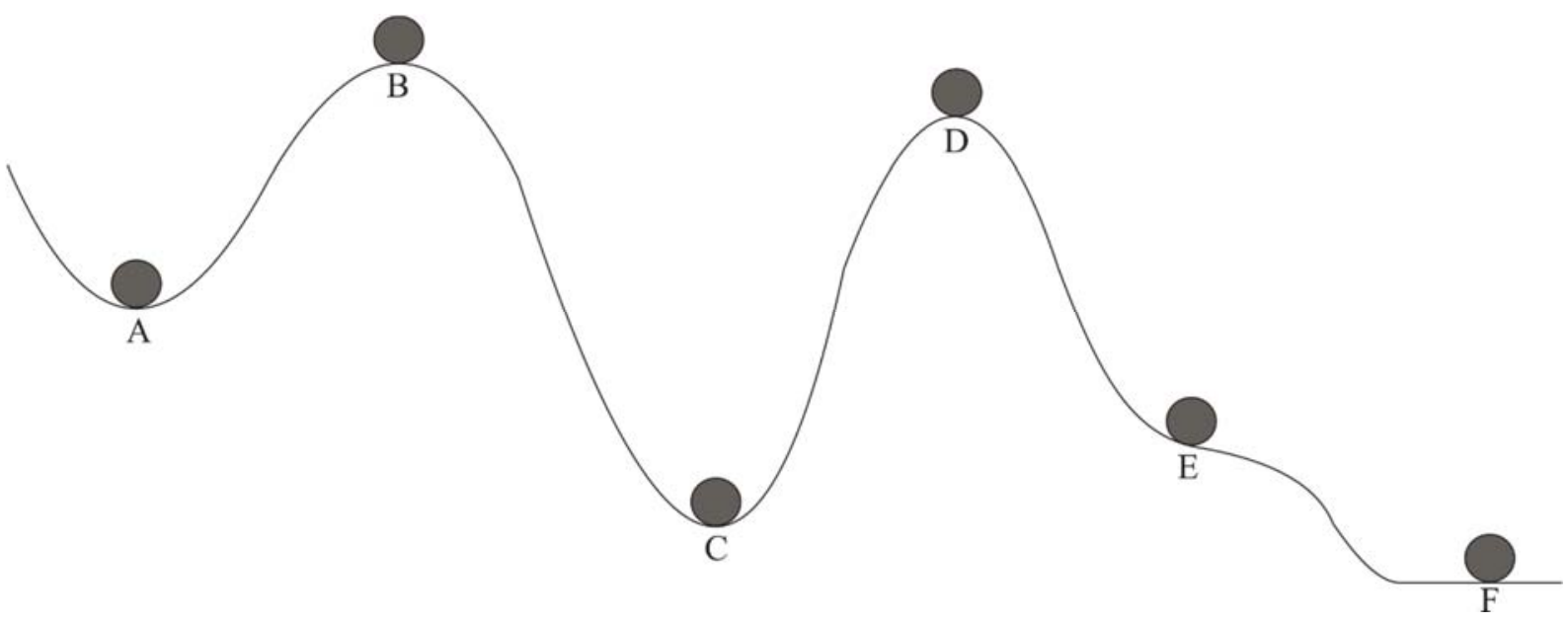

Fonte: Adaptado de SANTOS, 1987, p. 11.

Pela figura A.1 percebe-se que as esferas A e C estão em equilíbrio estável, ou seja, qualquer perturbação, seja ela pela direita ou pela esquerda, faz com que as esferas voltem à posição inicial.

As esferas B e D estão em equilíbrio instável dos dois lados, pois qualquer perturbação que leve essas esferas para a direita ou para a esquerda faz com que o equilíbrio não mais seja na posição inicial. 
A esfera $E$ está em equilíbrio instável de um lado, pois quando a esfera sofre uma perturbação que a leve para a esquerda, a esfera volta para a posição inicial. Porém, quando uma perturbação leva a esfera para a direita, a esfera não volta mais para a posição inicial.

A posição da esfera $\mathrm{F}$ é dita de equilíbrio indiferente, pois ela pode rolar para qualquer um dos dois lados, e cessada a perturbação ela para.

Dessa forma, o equilíbrio estável é estável quando, dada uma pequena perturbação, o corpo tende a voltar à posição inicial. Em contrapartida, o equilíbrio é instável quando isso não ocorre (SANTOS,1987).

\section{A.2 TIPOS DE INSTABILIDADE}

Para conceituar os diversos tipos de instabilidade que podem ocorrer em um pilar, define-se um modelo teórico proposto por Santos (1987, apud LIMA, 1975). Trata-se de um modelo de representação de um pilar por uma barra reta e rígida, de comprimento $l$, livre no topo (com excentricidade e ou sem excentricidade) e articulada na base, com uma mola de constante $K$, como representado na figura A.2. Verifica-se que se a barra indeformável girar de um ângulo $\theta$, a mola sofrerá uma deformação e reagirá com um momento fletor $M_{i}$. Essa reação representa o momento fletor interno ou momento fletor resistente da barra. Verifica-se ainda que a força $F$, quando ocorre a deformação de ângulo $\theta$ da barra, apresenta um momento fletor $M_{e}$, que representa o momento fletor externo devido ao braço a ou ao braço a $+e$.

O material da mola pode ser elástico-linear, ou seja, o momento fletor interno pode ser proporcional à deformação $\theta$, ou elástico-não linear, no qual não há essa proporcionalidade (não linearidade física). Dessa forma, pode ser feita a análise de quatro casos possíveis. Porém, como o foco do trabalho é a flexão composta oblíqua em pilares de concreto armado, será analisada apenas a compressão excêntrica com material elástico-não linear, caso mais próximo dessa solicitação. 
Figura A.2 - Modelo Teórico
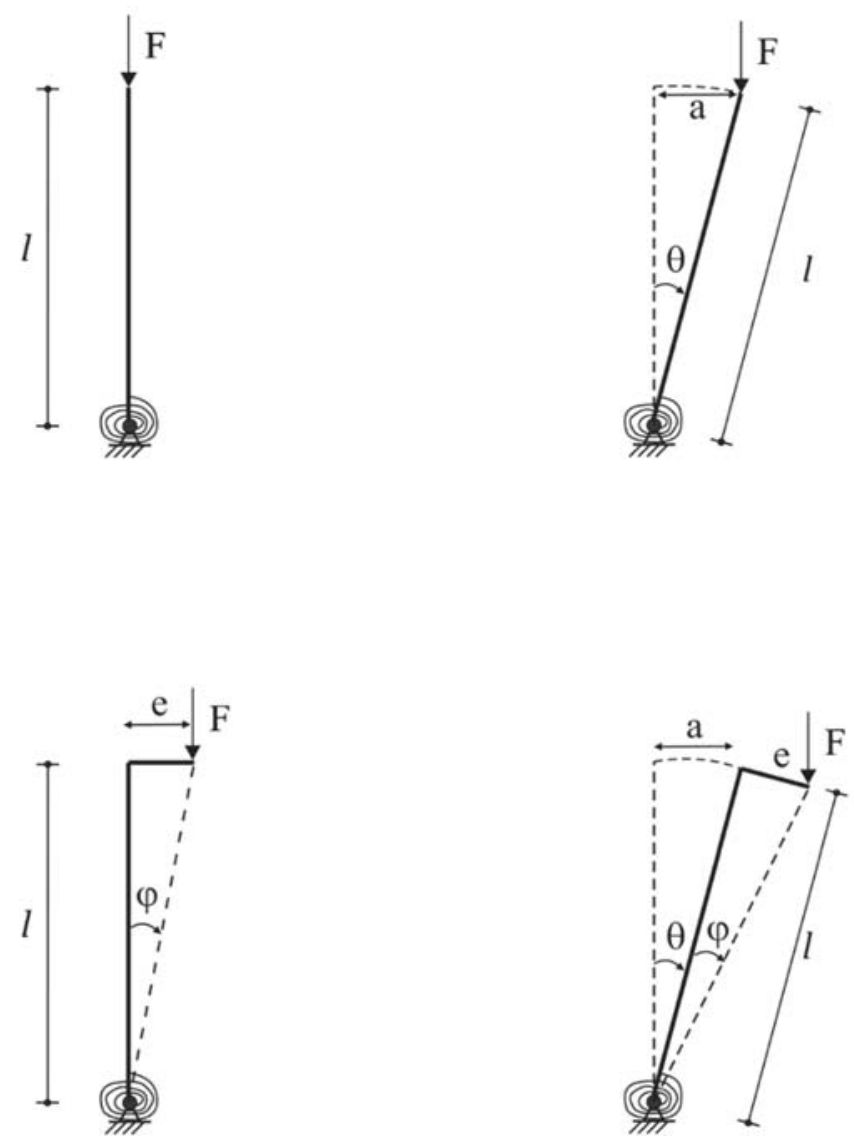

Fonte: Adaptado de SANTOS, 1987, p. 12.

\section{A.3 COMPRESSÃO EXCÊNTRICA E MATERIAL ELÁSTICO-NÃO LINEAR DA MOLA}

As deduções a seguir são indicadas por Santos (1987). O equilíbrio do modelo só será atingido quando houver igualdade entre o momento fletor externo e o momento fletor interno. Dessa forma, analisando a configuração da estrutura deformada presente na figura A.2, conclui-se que o momento fletor externo pode ser dado pela expressão por A.1:

$$
M_{e}=F \cdot(a+e \cdot \cos \theta)
$$

Utilizando a relação trigonométrica, pode-se adotar (Expressão A.2):

$$
a=l \cdot \operatorname{sen} \theta
$$


E, assim, o momento fletor externo fica expresso por:

$$
M_{e}=F \cdot(l \cdot \operatorname{sen} \theta+e \cdot \cos \theta)
$$

Ou ainda por:

$$
M_{e}=F \cdot \sqrt{l^{2}+e^{2}} \cdot \operatorname{sen}(\theta+\varphi)
$$

Em que:

$$
\varphi=\operatorname{arctg} \frac{e}{l}
$$

A condição para que ocorra a compressão excêntrica é a de:

$$
-\frac{\pi}{2}<\varphi<\frac{\pi}{2}
$$

O material da mola é suposto elástico-não linear. Portanto o momento fletor interno não é proporcional à deformação $\theta$, é um caso de não linearidade física. Assim, define-se o momento fletor interno genérico em A.7:

$$
M_{i}=K \cdot \theta \cdot\left(1-\theta^{2}\right)
$$

Analisando a função adotada para o momento fletor interno, verifica-se que ela se anula para $\theta=0$ e para $\theta=1$. Calculando sua derivada obtém-se:

$$
\frac{d M_{i}}{d \theta}=K \cdot\left(1-3 \cdot \theta^{2}\right)
$$

Igualando essa derivada a zero, tem-se o ponto onde ocorre o máximo da função. Resulta:

$$
K \cdot\left(1-3 \cdot \theta^{2}\right)=0 \quad \rightarrow \quad \theta=\frac{\sqrt{3}}{3}
$$


Assim, com as informações obtidas, é possível plotar os gráficos de momento fletor externo e de momento fletor interno. Ambos estão presentes na figura A.3 (sem escala).

Figura A.3 - Gráficos de momento fletor externo e de momento fletor interno
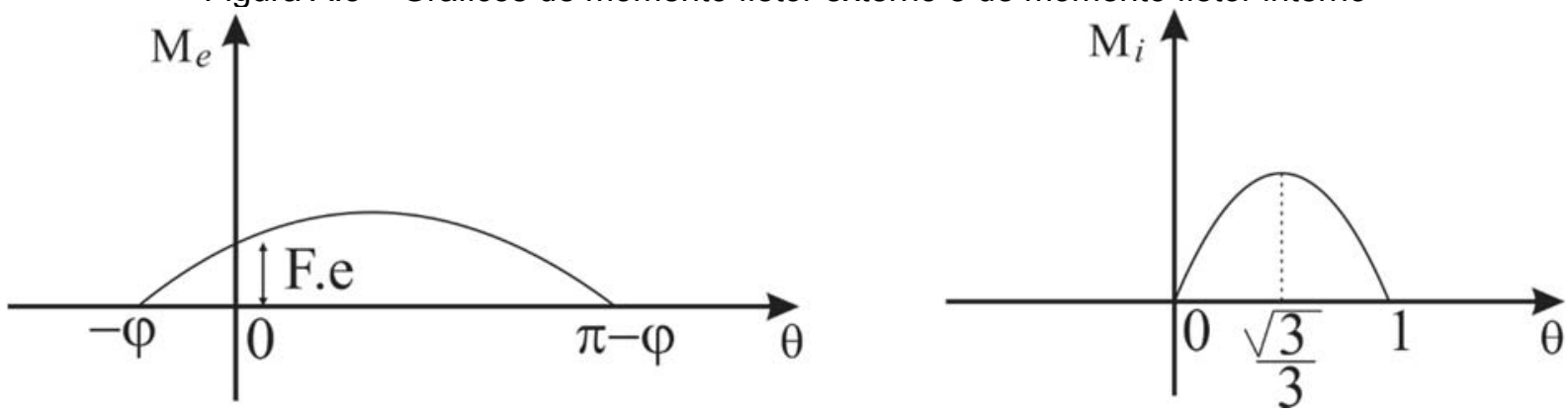

Fonte: Adaptado de SANTOS, 1987, p. 24.

As figuras A.4, A.5 e A.6 representam os três casos possíveis da superposição dos gráficos das funções.

Figura A.4 - Gráficos de momento fletor externo e de momento fletor interno - Primeiro caso

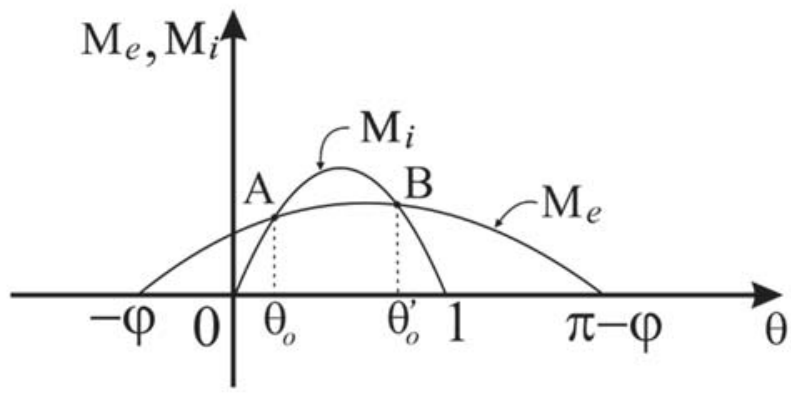

Fonte: Adaptado de SANTOS, 1987, p. 24.

Figura A.5 - Gráficos de momento fletor externo e de momento fletor interno - Segundo caso

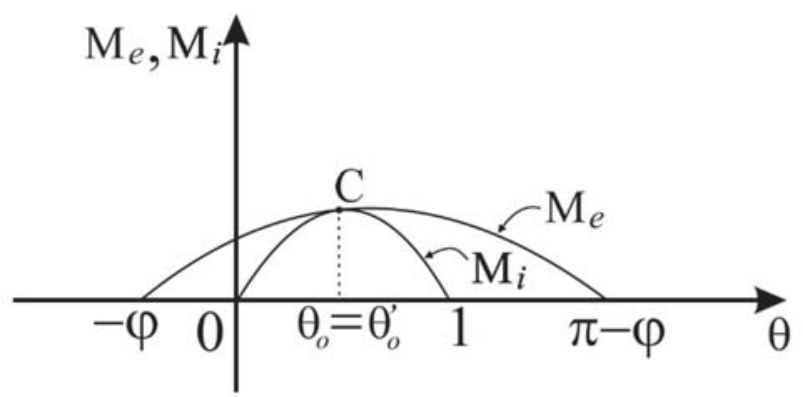

Fonte: Adaptado de SANTOS, 1987, p. 24. 
Figura A.6 - Gráficos de momento fletor externo e de momento fletor interno - Terceiro caso

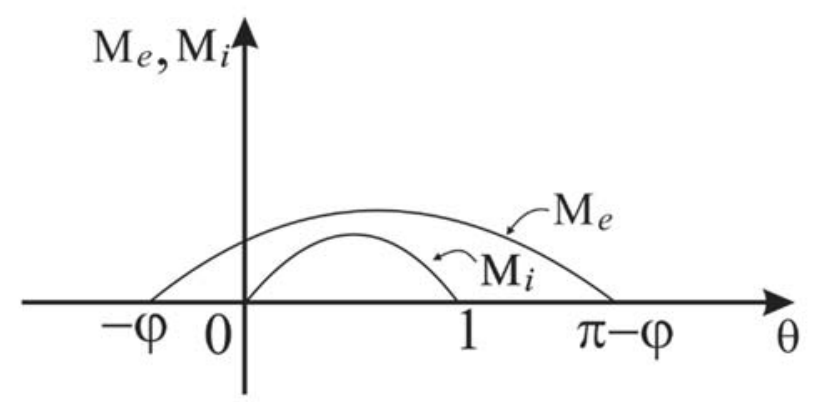

Fonte: Adaptado de SANTOS, 1987, p. 24.

O primeiro caso está representado na figura A.4, no qual se verificam duas configurações de equilíbrio (momento fletor externo igual ao momento fletor interno) indicadas pelos pontos A e B. Lembrar que $\theta$ representa a inclinação do eixo do pilar em relação à posição vertical.

A situação do ponto A configura um equilíbrio estável. Afinal, supondo-se uma perturbação $\theta>0$ e $\theta<\theta_{0}$, o momento fletor externo (Expressão A.1) supera o momento fletor interno (Expressão A.7) fazendo com que a barra tenda a ser derrubada, de forma que o ângulo $\theta$ aumente até que o equilíbrio seja atingindo na posição $A$, pois o esforço da mola (momento fletor interno), que é restaurador (tende a fazer com que a barra volte à vertical), iguala o momento fletor externo, proveniente da força aplicada.

Caso seja efetuada uma perturbação $\theta>0$ e $\theta>\theta_{0}$, o momento fletor interno, que é restaurador, supera o momento fletor externo. Dessa forma, o esforço da mola faz com que o equilíbrio seja alcançado na posição $\theta_{0}$, indicada pelo ponto $\mathrm{A}$.

A situação do ponto $B$ configura um equilíbrio instável, já que, supondo uma perturbação $\theta>0$ e $\theta<\theta^{\prime}{ }_{0}$, o momento fletor interno supera o momento fletor externo até que a mola faça com que o equilíbrio seja atingido na posição $B$, quando $O$ momento fletor externo se iguala ao interno.

Porém, caso seja efetuada uma perturbação $\theta>0$ e $\theta>\theta^{\prime}{ }_{0}$, o momento fletor externo supera o momento fletor interno, e, assim, não há como o sistema voltar à posição de equilíbrio representada pelo ponto $B$. 
O segundo caso está representado na figura A.5, para o qual há apenas uma configuração de equilíbrio, indicada pelo ponto C.

A situação do ponto $C$ configura um equilíbrio instável. Afinal, efetuada uma perturbação $\theta>0$ e $\theta>\theta^{\prime}{ }_{0}=\theta_{0}$, o momento fletor externo supera o momento fletor interno e o sistema não tem a capacidade de voltar à posição de equilíbrio original. $A$ mesma análise vale para o caso em que $\theta>0$ e $\theta<\theta^{\prime}{ }_{0}=\theta_{0}$.

O terceiro caso, representado na figura A.6, configura uma situação na qual não há equilíbrio.

Assim, o primeiro caso é o de interesse, já que é possível alcançar uma posição de equilíbrio estável. Para analisar a situação de equilíbrio do ponto $A$, deve-se igualar as funções de momento fletor externo e de momento fletor interno. Assim:

$$
M_{e}=M_{i} \quad \rightarrow \quad F \cdot \sqrt{l^{2}+e^{2}} \cdot \operatorname{sen}\left(\theta_{0}+\varphi\right)=K \cdot \theta_{0} \cdot\left(1-\theta_{0}^{2}\right)
$$

Rearranjando a expressão, obtém-se:

$$
\frac{F \cdot l}{K}=\frac{l}{\sqrt{l^{2}+e^{2}}} \cdot \frac{\theta_{0} \cdot\left(1-\theta_{0}{ }^{2}\right)}{\operatorname{sen}\left(\theta_{0}+\varphi\right)}
$$

Da expressão A.11, têm-se como parâmetros constantes: $l, K, e$ e $\varphi$. Assim, pode-se determinar uma relação entre as variáveis $F$ e $\theta_{0}$, já que a cada valor de $F$ correspondem duas posições de equilíbrio: $\theta_{0}$ e $\theta^{\prime}{ }_{0}$.

Analisando as figuras A.4 a A.6, verifica-se que a expressão A.11 é uma função de segundo grau em $\theta_{0}$, sendo possíveis as seguintes soluções: dois valores diferentes para $\theta_{0}\left(\theta_{0}\right.$ e $\left.\theta^{\prime}{ }_{0}\right)$, dois valores de igual amplitude para $\theta_{0}\left(\theta_{0}=\theta^{\prime}{ }_{0}\right)$ ou nenhum valor para $\theta_{0}$.

Como a expressão A.11 é implícita, é compreensível que quando se assume um valor para $F \cdot l / K$, pode-se obter valores de $\theta_{0}$ dependentes do valor inicial adotado para este. 
Assim, conforme se varia o parâmetro $F \cdot l / K$, o sistema pode assumir o primeiro caso (Figura A.4) e passar para o segundo caso (Figura A.5), ou ainda assumir terceiro caso (Figura A.6).

Resolvendo numericamente a expressão A.11, pode-se tabelar $F \cdot l / K$ em função de $a / l$, utilizando as relações A.2 e A.5. Serão considerados os três valores da excentricidade $e$ indicados a seguir, com os correspondentes valores de $\varphi$ :

$$
\begin{aligned}
& e=0,2 \cdot l \rightarrow \varphi=\operatorname{arctg}(0,2)=0,1974 \\
& e=0,1 \cdot l \rightarrow \varphi=\operatorname{arctg}(0,1)=0,0997 \\
& e=0,05 \cdot l \rightarrow \varphi=\operatorname{arctg}(0,05)=0,0500
\end{aligned}
$$

a) $e=0,2 \cdot l$ :

Tabela A.5 - Dados referentes a $e=0,2 \cdot l$

\begin{tabular}{c|c|c|c|c}
\hline$F \cdot l / K$ & $\theta_{0}$ & $\theta^{\prime}{ }_{0}$ & $a / l$ & $a^{\prime} / l$ \\
\hline 0,000 & 0,000 & 1,000 & 0,000 & 0,841 \\
0,100 & 0,022 & 0,950 & 0,022 & 0,813 \\
0,200 & 0,050 & 0,893 & 0,050 & 0,779 \\
0,300 & 0,086 & 0,827 & 0,086 & 0,736 \\
0,400 & 0,136 & 0,747 & 0,136 & 0,679 \\
0,500 & 0,213 & 0,638 & 0,211 & 0,596 \\
0,587 & 0,412 & 0,412 & 0,400 & 0,400 \\
\hline
\end{tabular}

Fonte: Elaborado pelo Autor.

b) $e=0,1 \cdot l$ :

Tabela A.6 - Dados referentes a $e=0,1 \cdot l$

\begin{tabular}{c|c|c|c|c}
\hline$F \cdot l / K$ & $\theta_{0}$ & $\theta^{\prime}{ }_{0}$ & $a / l$ & $a^{\prime} / l$ \\
\hline 0,000 & 0,000 & 1,000 & 0,000 & 0,841 \\
0,100 & 0,011 & 0,953 & 0,011 & 0,815 \\
0,200 & 0,025 & 0,901 & 0,025 & 0,784 \\
0,300 & 0,043 & 0,843 & 0,043 & 0,747 \\
0,400 & 0,067 & 0,776 & 0,067 & 0,700 \\
0,500 & 0,101 & 0,696 & 0,101 & 0,641 \\
0,600 & 0,157 & 0,592 & 0,156 & 0,558 \\
0,700 & 0,310 & 0,387 & 0,305 & 0,377 \\
0,703 & 0,348 & 0,348 & 0,341 & 0,341 \\
\hline
\end{tabular}

Fonte: Elaborado pelo Autor. 
c) $\quad e=0,05 \cdot l$ :

Tabela A.7 - Dados referentes a $e=0,05 \cdot l$

\begin{tabular}{c|c|c|c|c}
\hline$F \cdot l / K$ & $\theta_{0}$ & $\theta_{0}^{\prime}$ & $a / l$ & $a^{\prime} / l$ \\
\hline 0,000 & 0,000 & 1,000 & 0,000 & 0,841 \\
0,100 & 0,006 & 0,955 & 0,006 & 0,816 \\
0,200 & 0,013 & 0,905 & 0,012 & 0,787 \\
0,300 & 0,0214 & 0,850 & 0,021 & 0,751 \\
0,400 & 0,0334 & 0,789 & 0,033 & 0,710 \\
0,500 & 0,0502 & 0,718 & 0,050 & 0,658 \\
0,600 & 0,0758 & 0,633 & 0,076 & 0,592 \\
0,700 & 0,121 & 0,523 & 0,121 & 0,499 \\
0,796 & 0,2878 & 0,288 & 0,284 & 0,284 \\
\hline
\end{tabular}

Fonte: Elaborado pelo Autor.

Como previsto, os resultados indicados nas tabelas mostram que para pequenos valores de $F$, há duas soluções: $\theta_{0}$ e $\theta^{\prime}{ }_{0}$ para o equilíbrio. Com o crescimento de $F$ chega-se a um ponto em que $\theta_{0}$ e $\theta^{\prime}{ }_{0}$ coincidem, havendo apenas uma posição de equilíbrio. A partir desse ponto, não se encontra mais solução, ou seja, o equilíbrio torna-se impossível.

Analisando a figura A.4, verifica-se que a solução $\theta_{0}$ gera um equilíbrio estável (análise já efetuada neste mesmo item), e a solução $\theta^{\prime}{ }_{0}$ gera um equilíbrio instável. $A$ solução $\theta_{0}=\theta^{\prime}{ }_{0}$, representada pela figura A.5, gera equilíbrio instável. Com essas informações, é possível plotar o gráfico da figura A.7.

Examinando a figura A.7 pode-se chegar a algumas conclusões: para cada valor de $F$ a barra da figura A.2 assume um valor de $\theta$ correspondente ao equilíbrio estável. Caso a barra não se rompa antes (esgotamento da resistência do material), o carregamento pode atingir um valor limite. A partir desse ponto, o equilíbrio deixa de ser estável e passa a ser instável, ou seja, não é possível atingir o equilíbrio. Tratase, portanto, de um ponto limite. A carga correspondente a esse ponto é chamada de carga crítica. Esse fenômeno é conhecido como "instabilidade na flexão composta" e define o estado-limite último de instabilidade que ocorre em pilares de concreto armado submetido a uma flexão. 
Figura A.7 - Equilíbrio instável e estável para diferentes excentricidades

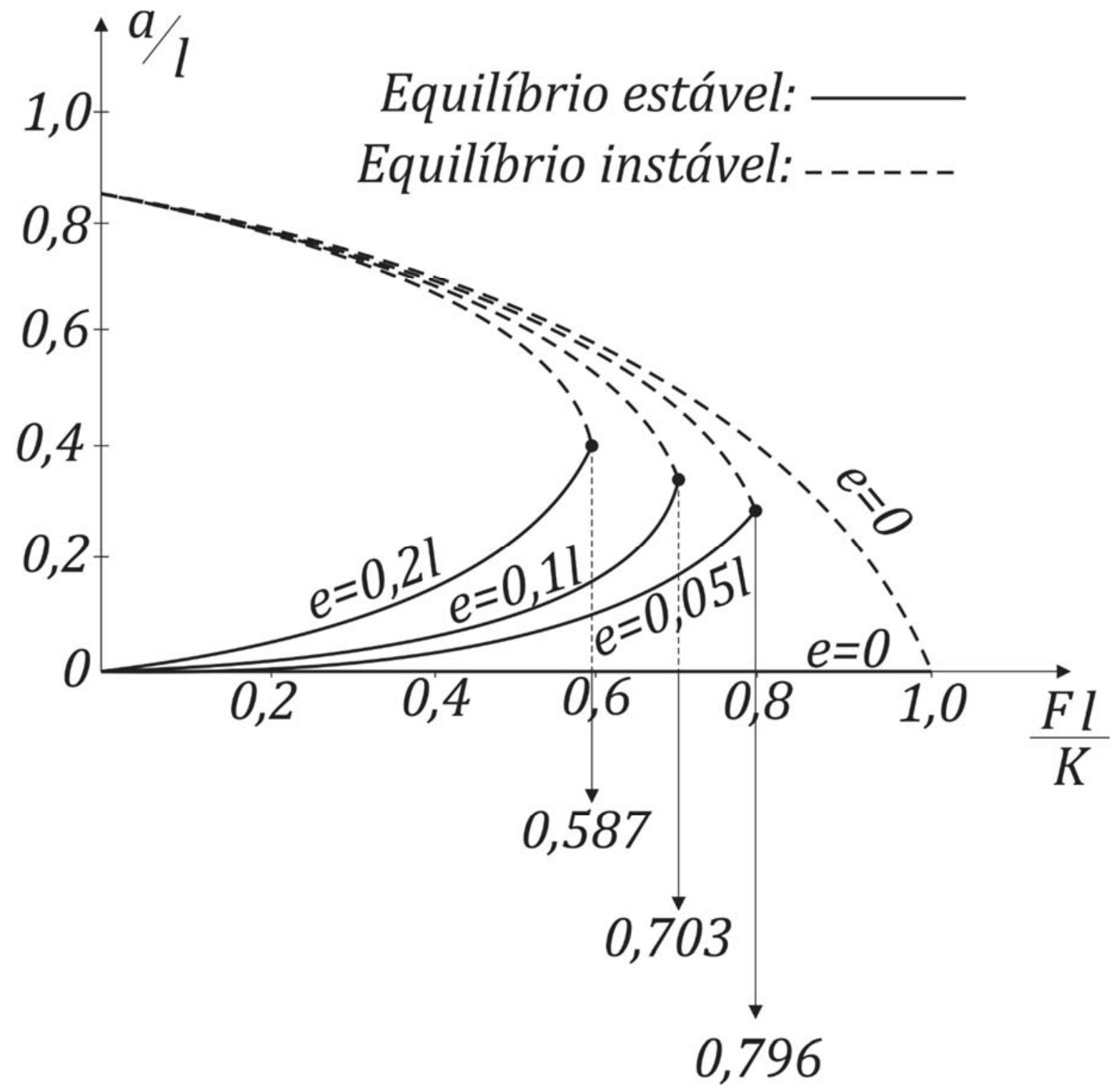

Fonte: Adaptado de SANTOS, 1987, p. 26. 